PNNL-18054

WTP-RPT-167, Rev 0

Prepared for the U.S. Department of Energy under Contract DE-AC05-76RL01830

\title{
Characterization and Leach Testing for PUREX Cladding Waste Sludge (Group 3) and REDOX Cladding Waste Sludge (Group 4) Actual Waste Sample Composites
}

$\begin{array}{llll}\text { LA Snow } & \text { RC Daniel } & \text { LK Jagoda } & \text { RA Peterson } \\ \text { EC Buck } & \text { KE Draper } & \text { ED Jenson } & \text { RG Swoboda } \\ \text { AJ Casella } & \text { MK Edwards } & \text { AE Kozelisky } & \\ \text { JV Crum } & \text { SK Fiskum } & \text { PJ MacFarlan } & \end{array}$

February 2009 


\title{
DISCLAIMER
}

This report was prepared as an account of work sponsored by an agency of the United States Government. Neither the United States Government nor any agency thereof, nor Battelle Memorial Institute, nor any of their employees, makes any warranty, express or implied, or assumes any legal liability or responsibility for the accuracy, completeness, or usefulness of any information, apparatus, product, or process disclosed, or represents that its use would not infringe privately owned rights. Reference herein to any specific commercial product, process, or service by trade name, trademark, manufacturer, or otherwise does not necessarily constitute or imply its endorsement, recommendation, or favoring by the United States Government or any agency thereof, or Battelle Memorial Institute. The views and opinions of authors expressed herein do not necessarily state or reflect those of the United States Government or any agency thereof.

\author{
PACIFIC NORTHWEST NATIONAL LABORATORY \\ operated by \\ BATTELLE \\ for the \\ UNITED STATES DEPARTMENT OF ENERGY \\ under Contract DE-AC05-76RL01830
}

Printed in the United States of America

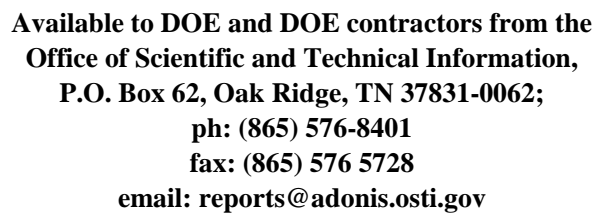

Available to DOE and DOE contractors from the Office of Scientific and Technical Information, P.O. Box 62, Oak Ridge, TN 37831-0062; ph: (865) 576-8401 fax: (865) 5765728

email: reports@adonis.osti.gov

\author{
Available to the public from the National Technical Information Service, \\ U.S. Department of Commerce, 5285 Port Royal Rd., Springfield, VA 22161 \\ ph: (800) 553-6847 \\ fax: (703) 605-6900 \\ email: orders@nits.fedworld.gov \\ online ordering: http://www.ntis.gov/ordering.htm
}




\section{Characterization and Leach Testing for PUREX Cladding Waste Sludge (Group 3) and REDOX Cladding Waste Sludge (Group 4) Actual Waste Sample Composites}

$\begin{array}{llll}\text { LA Snow } & \text { RC Daniel } & \text { LK Jagoda } & \text { RA Peterson } \\ \text { EC Buck } & \text { KE Draper } & \text { ED Jenson } & \text { RG Swoboda } \\ \text { AJ Casella } & \text { MK Edwards } & \text { AE Kozelisky } & \\ \text { JV Crum } & \text { SK Fiskum } & \text { PJ MacFarlan } & \end{array}$

February 2009

Test Specification: 24590-PTF-TSP-RT-06-003, Rev. 1

Work Authorization: 019

Test Plan: TP-RPP-WTP-467, Rev. 1 and TP-RPP-WTP-456, Rev. 0

Test Exceptions: None

R\&T Focus Area: Pretreatment

Service Requisition Number: 24590-QL-SRA-W000-00107, Rev 0

Pacific Northwest National Laboratory

Richland, Washington 99352 


\section{COMPLETENESS OF TESTING}

This report describes the results of work and testing specified by Test Specification 24590-PTF-TSP-RT-06-003, Rev. 1 and Test Plans TP-RPP-WTP-467, Rev. 1 7/31/07 and TP-RPP-WTP-456, Rev. 0 11/29/06. The work and any associated testing followed the quality assurance requirements outlined in the Test Specification/Plan. The descriptions provided in this test report are an accurate account of both the conduct of the work and the data collected. Test plan results are reported. Also reported are any unusual or anomalous occurrences that are different from expected results. The test results and this report have been reviewed and verified.

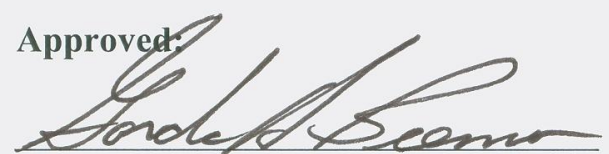

Gordon H. Beeman, Manager WTP R\&T Support Project

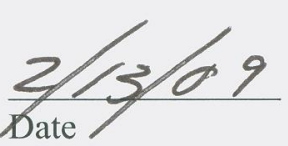




\section{Contents}

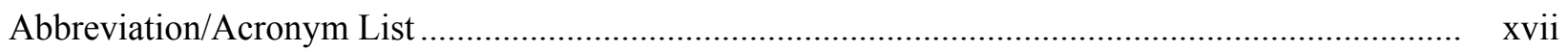

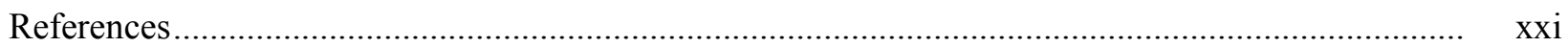

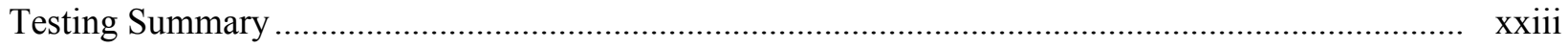

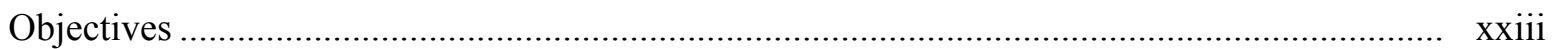

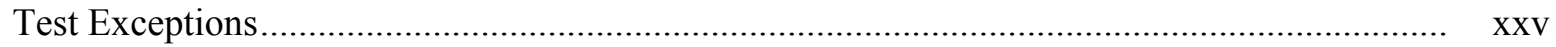

Results and Performance Against Success Criteria ….......................................................... xxv

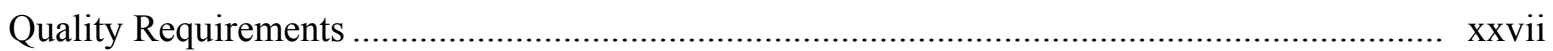

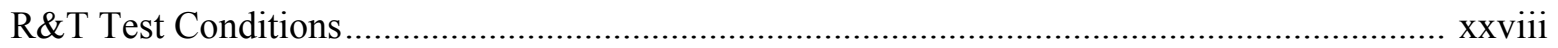

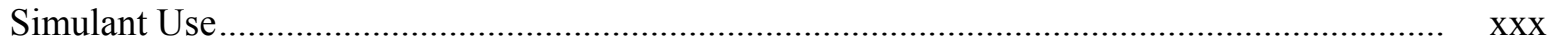

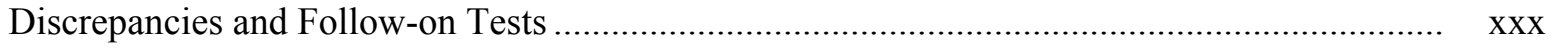

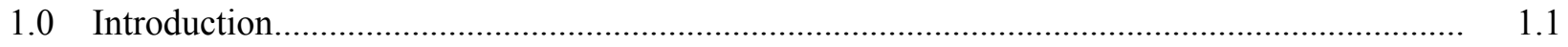

1.1 Tank Waste Pretreatment Operations at the WTP ..................................................... 1.1

1.2 Issues Identified by the External Flowsheet Review Team ............................................. 1.2

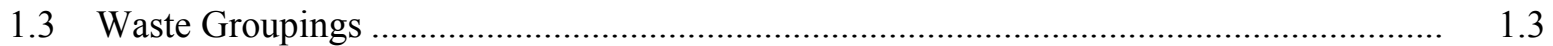

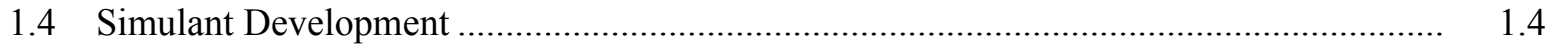

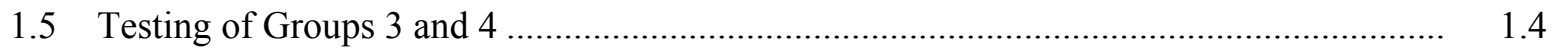

2.0 Test Sample Selection, Compositing, and Homogenization................................................ 2.1

2.1 Group 3 CWP and Group 4 CWR Sample Selection.................................................. 2.1

2.2 Equipment for Group 3 and 4 Sample Homogenization and Sub-Sampling .................... $\quad 2.7$

2.3 Group 3 Sample Homogenization and Sub-Sampling ................................................. 2.8

2.4 Group 4 Sample Homogenization and Sub-sampling.................................................. 2.14

3.0 Group 3 Characterization and Leaching ...................................................................... 3.1

3.1 Group 3 Characterization Experimental ................................................................ 3.1

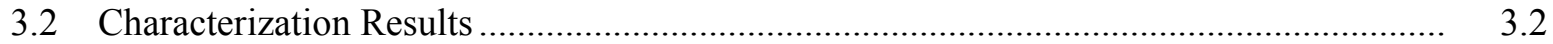

3.2.1 Physical Properties of the Composite Group 3 CWP Slurry ................................... 3.2

3.2.2 Rheology of the Composite Group 3 CWP Slurry ............................................... 3.5

3.2.3 Chemical and Radiochemical Composition of the Group 3 Slurry......................... 3.9

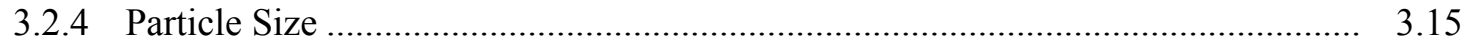

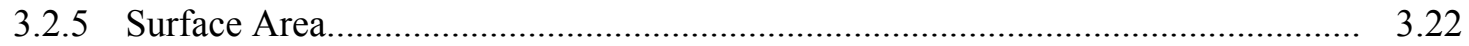

3.2.6 Crystal Form and Habit ......................................................................... 3.22

3.3 Group 3 CWP Sludge Batch Parametric Leaching: Experimental ................................. 3.34

3.3.1 Initial Washing of the Group 3 Solids ........................................................... 3.34

3.3.2 Division of the Washed Group 3 Solids.............................................................. 3.35

3.3.3 Caustic Leaching of the Washed Group 3 Solids ............................................ 3.35

3.3.4 Washing of Caustic Leached Group 3 Solids for Analysis.................................. 3.38

3.4 Group 3 PUREX Cladding Sludge Waste Parametric Caustic-Leaching Test Results ...... 3.39 
3.4.1 Time, Temperature, and Hydroxide Effects on Aluminum Dissolution from the Group 3 Solids ................................................................................. 3.40

3.4.2 Effect of Ionic Strength on Aluminum Dissolution ........................................... 3.44

3.4.3 Anions, Phosphorus, Silicon, Cr, and Iron Leaching Behavior .......................... 3.44

3.4.4 Assessment of Final Leaching Conditions ..................................................... 3.44

3.4.5 Comparison of Initial and Caustic-Leached and Washed-Solids Properties........... 3.45

4.0 Group 4 Characterization and Leaching ............................................................................ 4.1

4.1 Group 4 Characterization Experimental .................................................................. 4.1

4.2 Characterization Results ........................................................................................ 4.2

4.2.1 Physical Properties of the Composite Group 4 CWR Slurry ............................... 4.2

4.2.2 Rheology of the Composite Group 4 CWR Slurry .............................................. 4.5

4.2.3 Chemical and Radiochemical Composition of the Group 4 CWR Slurry............... 4.9

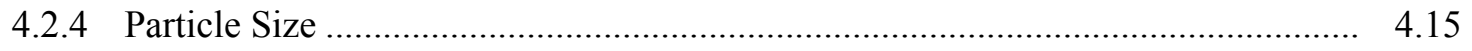

4.2.5 Surface Area............................................................................................... 4.21

4.2.6 Crystal Form and Habit.................................................................................... 4.22

4.3 Group 4 CWR Sludge Batch Parametric Leaching: Experimental .................................. 4.40

4.3.1 Initial Washing of the Group 4 Solids ............................................................. 4.40

4.3.2 Division of the Washed Group 4 Solids................................................................. 4.41

4.3.3 Caustic Leaching of the Washed Group 4 Solids ................................................ 4.41

4.3.4 Washing of Caustic-Leached Group 4 Solids for Analysis ................................. 4.42

4.4 Group 4 CWR Sludge Parametric Caustic-Leaching Test Results .................................. 4.43

4.4.1 Time, Temperature, and Hydroxide Effects on Aluminum Dissolution from the

Group 4 Solids ........................................................................................ 4.43

4.4.2 Effect of Ionic Strength on Aluminum Dissolution .......................................... 4.48

4.4.3 Anions, Phosphorus, Silicon, Cr, and Iron Leaching Behavior ............................. 4.48

4.4.4 Assessment of Final Leaching Conditions ............................................................ 4.49

4.4.5 Comparison of Initial and Caustic-Leached and Washed Solids Properties........... 4.49

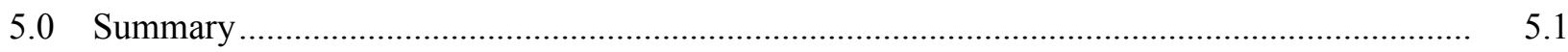

Appendix A Supplemental Information Regarding Sample Selection............................................. A.1

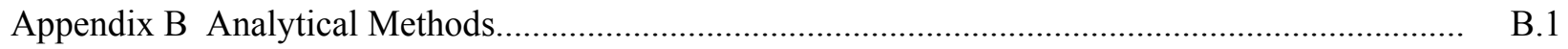

Appendix C Physical Properties Determination and Rheology Methods ........................................ C.1

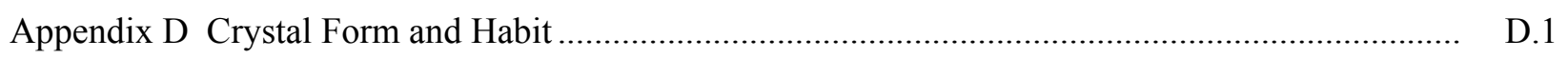

Appendix E Quality Assurance and Quality Control............................................................... E. E.

Appendix F Duplicate Sample Differential Particle Size Plots for the Initial Group 3 Sample ........ F. F

Appendix G Detailed Cumulative PSD for the Initial Group 3 Sample ...................................... G.1

Appendix H Detailed Cumulative PSD for the Caustic Leached Group 3 Sample ......................... H.1

Appendix I Group 3 Analytical Results from Parametric Leaching ............................................ I. I

Appendix J Duplicate Sample Differential Particle Size Plots for the Initial Group 4 Sample ......... J.1

Appendix K Detailed Cumulative PSD for the Initial Group 4 Sample ....................................... K.1 
Appendix L Group 4 Analytical Results from Parametric Leaching.......

L.1 


\section{Figures}

Figure No.

Caption

Page No.

1.1. Schematic Representation of the Key Processes to be Performed in the WTP

2.1. Estimated Tank Waste Composition of Selected Analytes for CWP Sludge Wastes in the Hanford Tank Farm (BBI Source)

2.2. Estimated Tank Waste Composition of Selected Analytes for CWR Sludge Wastes in the Hanford Tank Farm (BBI Source)

2.3. Selection Decision Process for Group 3 and Group 4 Sludge Samples.

2.4. Representative Photographs of As-Received Group 3 Waste Samples .

2.5. Contribution of the Individual Tanks to the Composition of the Group 3 Composite Sample ...

2.6. Group 3 Confirmation of Successful Material Composite Based on Density and Settled Solids

2.7. Representative Photographs of As-Received Group 4 Waste Samples

2.8. Contribution of the Individual Tanks to the Composition of the Group 4 Composite Sample ...

2.9. Group 4 Confirmation of Successful Material Composite Based on Density and Settled Solids

3.1. Composite Group 3 Analysis Scheme....

3.2. Group 3 CWP Solids Settling Test

3.3. Flow Curve (shear stress versus shear rate) for the Group 3 Initial Characterization Slurry Sample TI513-G3-AR-RH1 at $25^{\circ} \mathrm{C}, 40^{\circ} \mathrm{C}$, and $60^{\circ} \mathrm{C}$.

3.4. Chemical Characterization Sample of Group 3 CWP Sludge a) Centrifuged Solids

b) Combined Washed Solids

3.5. Wash Sequence of Group 3 CWP Sludge Supporting Initial Characterization.

3.6. Selected Analyte Phase Distribution for Group 3 CWP Sludge.

3.7. Pre-Sonication Volume Distribution Result for the Primary Group 3 Initial Characterization Sample as a Function of Pump Speed

3.8. Volume-Distribution Result for the Primary Group 3 Initial Characterization Sample as a Function of Sonication

3.9. Post-Sonication Volume Distribution Result for the Primary Group 3 Initial Characterization Sample as a Function of Pump Speed .

3.10. Comparison of Primary and Duplicate Sample Differential Volume PSD of Group 3 Initial Characterization at 3000 RPM before Sonication...

3.11. Comparison of Primary and Duplicate Sample Differential Volume PSD of Group 3 Initial Characterization at 3000 RPM after Sonication.

3.12. XRD Pattern of Washed Group 3 CWP Sludge with Rutile (TiO2) Internal Standard (a) Raw 
Figure No.

Spectral Pattern (b) Background-Subtracted Pattern with Stick-Peak Identification

3.13. Washed Group 3 CWP Sludge Phase Composition (Entrained Supernatant Removed), Best Estimate

3.14. SEM Images of Washed Group 3 CWP Sludge

3.15. SEM Images of Washed Group 3 CWP Sludge

3.16. SEM-EDS Images of Washed Group 3 CWP Sludge

3.17. STEM Images of Washed Group 3 CWP Solids.

3.18. STEM-HAADF Image (Inverted Contrast) and EDS Analyses of Regions of Interest of Washed Group 3 CWP Solids with Cancrinite

3.19. STEM-HAADF Image (Inverted Contrast) and EDS Analyses of Regions of Interest of Washed Group 3 CWP Solids with Gibbsite.

3.20. (a) High Resolution TEM Image of Uranium in Washed Group 3 CWP Solids; (b) Histogram of Contrast across Marked Region on (c) High Resolution Lattice Image of U3O8 Phase

3.21. TEM Image and EDS Analysis of Region of Interest of Iron Particle in Washed Group 3 CWP Solids

3.22. Aluminum Heating Block and Shaker Table Used in Parametric Leaching Tests......

3.23. Washing, Subdivision, and Analysis Scheme for the Group 3 Caustic-Leached Solids.

3.24. Aluminum Concentration and Percent Removed Versus Time at $60 \mathrm{C}$ for Leaching of the Group 3 Washed Solids in 1, 3, and $5 \mathrm{M} \mathrm{NaOH}$

3.25. Aluminum Concentration and Percent Removed Versus Time at 80 C for Leaching of the Group 3 Washed Solids in 1, 3, and $5 \mathrm{M} \mathrm{NaOH}$.

3.26. Aluminum Concentration and Percent Removed Versus Time at $100 \mathrm{C}$ for Leaching of the Group 3 Washed Solids in 1, 3, and $5 \mathrm{M} \mathrm{NaOH}$.

3.27. Aluminum Concentration and Percent Dissolved in $1 \mathrm{M} \mathrm{NaOH}$.....

3.28. Aluminum Concentration and Percent Dissolved in $3 \mathrm{M} \mathrm{NaOH}$

3.29. Aluminum Concentration and Percent Dissolved in $5 \mathrm{M} \mathrm{NaOH}$

3.30. Matrix Effect of $\mathrm{Na}$ Concentration on $\mathrm{Al}$ (Gibbsite) Dissolution in $3 \mathrm{M} \mathrm{NaOH}$ at $80^{\circ} \mathrm{C}$

3.31. Group 3 CWP Sludge Reduction in Solid Mass with Water Washing and Caustic Leaching ....

3.32. Pre-sonication Volume Distribution Result for the Caustic-Leached and Washed Group 3 Solids (sample 585-G3-CL-PSD) as a Function of Pump Speed...

3.33. Volume Distribution Result for the Caustic-Leached and Washed Group 3 Solids Before, During, and After Sonication at 3000 RPM

3.34. Post-Sonication Volume Distribution Result for the Caustic-Leached and Washed Group 3 Solids as a Function of Pump Speed .

3.35. Influence of Caustic-Leaching and Washing on Group 3 (PUREX Cladding Waste Sludge) Waste Solids PSD. 
3.37. XRD Pattern of Caustic-Leached Group 3 CWP Sludge with Rutile (TiO2) Internal Standard (a) Raw Data and (b) Background-Subtracted with Stick-Peak Identification

3.38. SEM Images of Group 3 CWP Sludge Caustic Leached and Washed Solids (a) $20 \mathrm{kV}$, $1500 \times$; (b) $20 \mathrm{kV}, 1500 \times$; (c) $10 \mathrm{kV}, 1500 \times$; (d) $5 \mathrm{kV}, 1250 \times$.

3.39. SEM Image of Group 3 CWP Sludge Caustic Leached and Washed Solids with EDS Spectra (a) SEM Image; (b) EDS Spectra of Spot 1; (c) EDS Spectra of Spot 3; (d) EDS Spectra of Spot 8

3.40. SEM Image of Group 3 CWP Sludge Caustic Leached and Washed Solids with EDS Spectra (a) SEM Image; (b) EDS Spectra of Spot 1; (c) EDS Spectra of Spot 3; (d) EDS Spectra of Spot 4

3.41. (a) TEM-EDS Analysis and (b) Selected Area Electron Diffraction Pattern of Nickel Alloy Particle.

3.42. TEM Image of a Typical Particle Agglomerate Found in the Caustic-Leached Sample ......

3.43. TEM Image of a Large Electron Opaque Iron/Uranium Particle.

3.44. (a) TEM Image, (b) Selected Area Diffraction, and (c) EDS Analysis of an Iron-Rich Phase in the Caustic Leached Group 3 Sample

3.45. (a) TEM Image, (b) EDS Analysis, and (c) Selected Area Diffraction of Uranium Phase in the Caustic Leached Group 3 Sample .

4.1. Composite Group 4 Analysis Scheme.....

4.2. Group 4 CWR Settling Test....

4.3. Flow Curve (shear stress versus shear rate) for the Group 4 Initial Characterization Slurry Sample TI514-G4-AR-RH1 at $25^{\circ} \mathrm{C}$ (initial measurement).

4.4. Chemical Characterization Sample of Group 4 CWR Sludge a) Centrifuged Solids b) Combined Washed Solids

4.5. Wash Sequence of Group 4 CWR Sludge Supporting Initial Characterization .

4.6. Selected Analyte Phase Distribution for Group 4 CWR Sludge

4.7. Pre-S Volume Distribution Result for the Primary Group 4 Initial Characterization Sample as a Function of Pump Speed

4.8. Volume Distribution Result for the Primary Group 4 Initial Characterization Sample as a Function of Sonication

4.9. Post-Sonication Volume Distribution Result for the Primary Group 4 Initial Characterization Sample as a Function of Pump Speed .

4.10. Comparison of Primary and Duplicate Sample Differential Volume PSD of Group 4 Initial Characterization at 3000 RPM before Sonication

4.11. Comparison of Primary and Duplicate Sample Differential Volume PSD of Group 4 Initial Characterization at 3000 RPM after Sonication.

4.12. XRD Pattern of Washed Group 4 CWR Sludge, (a) Raw Diffraction Pattern and (b) Background-Subtracted Diffraction Pattern with Stick-Peak Identification of Gibbsite 
4.13. XRD Pattern of Washed Group 4 CWR Sludge Focusing on Lower-Intensity Lines, Background-Subtracted with Stick-Peak Identification (rutile is the internal standard).

4.14. Washed Group 4 CWR Sludge Phase Composition (entrained supernatant removed), Best Estimate

4.15. SEM Images of Washed Group 4 CWR Sludge, Various Magnifications and Views ......

4.16. SEM Images of Washed Group 4 CWR Sludge

4.17. SEM Images of Washed Group 4 CWR Sludge

4.18. SEM Images with EDS of Washed Group 4 CWR Sludge.....

4.19. SEM Image with EDS of Group 4 CWR with EDS Examination

4.21. (a) STEM-HAADF Image and (b) EDS Analysis of a Gibbsite Particle in Washed Group 4 Solids.

4.22. TEM Image of Particle Agglomerate Showing an Amorphous Iron-Bearing Region, Cancrinite, and a Calcium Uranium Oxide

4.23. (a) High Magnification STEM-HAADF Image and (b) EDS Analysis of Uranium-Bearing Material in the Washed Group 4 Solids.

4.24. TEM Images of Washed Group 4 Solids. (a) Boehmite crystals and a cancrinite particle, (b) EDS of the boehmite phase.

4.25. TEM Image of Large Cancrinite Crystal in the Washed Group 4 Solids.....

4.26. (a) TEM Image of Cancrinite Crystals, (b) Electron Diffraction Pattern, and (c) Rotational Averaged Diffraction Pattern

4.27. (a) STEM-HAADF Image of Washed Group 4 Solids, and (b) EDS Analyses of Washed Group 4 Solids.

4.28. (a) STEM-HAADF Image of an Agglomerate in the Washed Group 4 Solids, (b) EDS Analysis of the Agglomerate

4.29. (a) STEM-HAADF Image of Iron-Silicate Particle in Washed Group 4 Solids, (b) EDS Analysis of the Iron-Silicate Particle.

4.30. Washing, Subdivision, and Analysis Scheme for the Group 4 Caustic-Leached Solids

4.31. Aluminum Concentration and Percent Removed Versus Time at 60 C for Leaching of the Group 4 Washed Solids in 1, 3, and $5 \mathrm{M} \mathrm{NaOH}$.

4.32. Aluminum Concentration and Percent Removed Versus Time at 80 C for Leaching of the Group 4 Washed Solids in 1, 3, and $5 \mathrm{M} \mathrm{NaOH}$

4.33. Aluminum Concentration and Percent Removed Versus Time at $100 \mathrm{C}$ for Leaching of the Group 4 Washed Solids in 1, 3, and $5 \mathrm{M} \mathrm{NaOH}$.

4.34. Aluminum Concentration and Percent Dissolved in $1 \mathrm{M} \mathrm{NaOH}$

4.35. Aluminum Concentration and Percent Dissolved in $3 \mathrm{M} \mathrm{NaOH}$

4.36. Aluminum Concentration and Percent Dissolved in $5 \mathrm{M} \mathrm{NaOH}$ 
Figure No.

Page No.

4.38. Group 4 CWR Sludge Reduction in Solid Mass with Water Washing and Caustic Leaching.... 4.52 


\section{Tables}

Table No.

Caption

Page No.

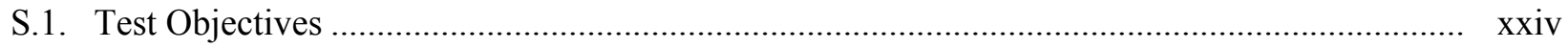

S.2. Results and Performance Against Success Criteria ….......................................................... xxvi

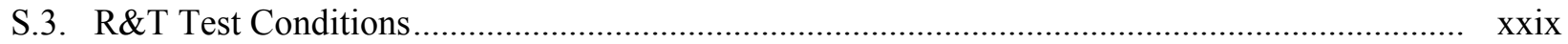

1.1. Projected Distribution of Water-Insoluble Components in the Tank Waste Groupings............. 1.4

2.1. Selection of Group 3 - PUREX Cladding Waste Sludge Tanks............................................. 2.5

2.2. Group 3 Samples and Masses from 222S Archive .......................................................... 2.6

2.3. Selection of REDOX Cladding Waste Sludge Tanks .......................................................... 2.6

2.4. Group 4 Samples and Masses from 222S Archive ........................................................... 2.7

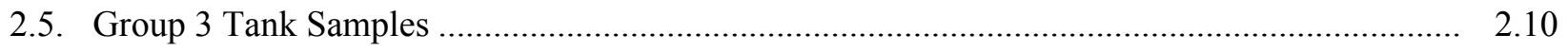

2.6. Group 3 Sub-Composite Samples .................................................................................. 2.11

2.7. Group 3 Final Compositing Stage, Transferring Sub-Composites to 1-Liter Composite Jar ...... 2.11

2.8. Group 3 Sub-Sample Mass Density and Settling Data ......................................................... 2.13

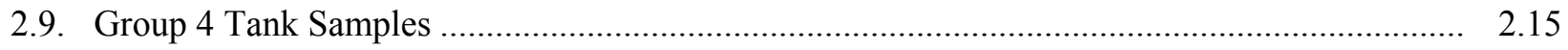

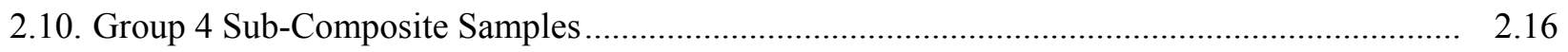

2.11. Final Group 4 Compositing Stage, Transferring Sub-Samples to 1-L Composite Jar................ 2.16

2.12. Group 4 Sub-Sample Mass Density and Settling Data .................................................... 2.18

3.1. Group 3 Characterization Samples ................................................................................

3.2. Physical-Property Measurements of Homogenized Group 3 CWP Slurry ............................... 3.4

3.3. Supplemental Physical Properties from Chemical Characterization Samples ......................... 3.5

3.4. Shear strength of Group 3 Initial Characterization Settled Solids at Ambient Hot-Cell

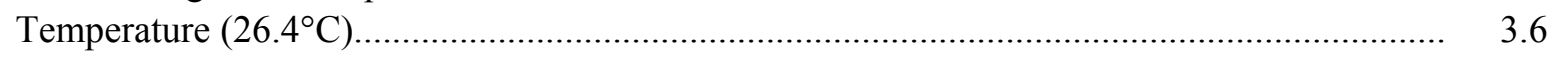

3.5. Results of Fitting Analysis for Rheology Sample TI513-G3-AR-RH1 _................................. 3.9

3.6. Radionuclide Characterization of the Group 3 CWP Sludge ................................................. 3.11

3.7. Chemical Characterization of the Group 3 CWP Sludge ................................................... 3.12

3.8. Phase Distribution of Selected Analytes in Group 3 CWP Sludge ........................................ 3.14

3.9. Particle-Size Analysis Percentile Results of the Primary Group 3 Initial Characterization

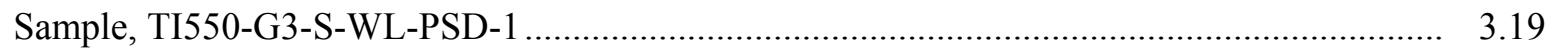

3.10. Particle-Size Analysis Percentile Results of the Duplicate Group 3 Initial Characterization

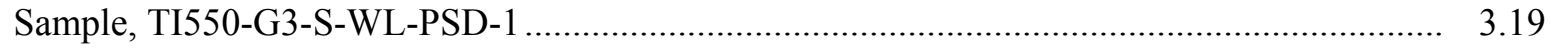

3.11. Absolute Relative Percent Difference between Primary and Duplicate Group 3 Initial Characterization Samples.... 
3.12. Weight Percent of Group 3 CWP Sludge Mineral Phases, Best Estimate ............................... 3.25

3.13. Compositional Analysis of Zirconium Containing Regions (Atomic \%)................................ 3.34

3.14. Group 3 Caustic Leaching Conditions .......................................................................... 3.36

3.15. Group 3 PUREX Cladding Waste Sludge Leaching Final (48 hr) Aqueous Phase Conditions .. 3.45

3.16. Group 3 Solids Wash Solution Composition and Density .................................................... 3.46

3.17. Group 3 PUREX Cladding Waste Sludge Leached Solids Composition and Leach Factors

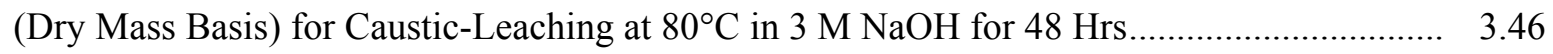

3.18. Group 3 CWP Sludge Aluminum Leach Factors .................................................................. 3.49

3.19. Particle-Size Analysis Percentile Results for the Caustic-Leached and Washed Group 3 Solids (sample 585-G3-CL-PSD).

3.20. Cumulative Undersize Percentiles Showing the Influence of Caustic-Leaching and Washing on the PSD of Group 3 Solids at Measurement Condition 7-3000 RPM, Post-Sonication (3,000 RPM, 75\% Sonication)

3.21. Normalized Weight Percents for Various Analytes Found by EDS of SEM Images for Figure 3.39 and Figure 3.40

3.22. EDS Analysis of Nickel-Iron Phase Shown in Figure 3.41.

3.23. EDS Analysis of Particle Agglomerate Shown in Figure 3.43

3.24. Selected Area Electron Diffraction Results from a Uranium Phase in the Caustic Leached Group 3 Sample.

4.1. Group 4 Characterization Samples

4.2. Physical Property Measurements of Homogenized Group 4 CWR Slurry ......

4.3. Supplemental Physical Properties from Chemical Characterization Samples

4.4. Shear Strength of Group 4 Initial Characterization Settled Solids at Ambient Hot-Cell Temperature (sample TI514-G4-AR-RH1)..

4.5. Results of Fitting Analysis for Group 4 Initial Characterization Sample TI514-G4-AR-RH1 ..

4.6. Radionuclide Characterization of the Group 4 CWR Sludge

4.7. Chemical Characterization of the Group 4 CWR Sludge.....

4.8. Phase Distribution of Selected Analytes in Group 4 CWR Sludge

4.9. Particle-Size Analysis Percentile Results from Primary Group 4 Initial Characterization Sample, TI547-G4-S-WL-PSD-1

4.10. Particle-Size Analysis Percentile Results from Duplicate Group 4 Initial Characterization Sample, TI547-G4-S-WL-PSD-2

4.11. Absolute Relative Percent Difference Between Primary and Duplicate Group 4 Initial Characterization Samples....

4.12. Weight Percent of Group 4 CWR Sludge Mineral Phases, Best Estimate ............................... 4.25

4.13. Results from EDS Analyses of Areas Shown in Figure 4.27 ................................................. 4.39

4.14. Results from EDS Analyses of Agglomerate Shown in Figure 4.28 ...................................... 4.40 
Table No.

Page No.

4.15. Group 4 Caustic-Leaching Conditions ................................................................................... 4.42

4.16. Group 4 REDOX Cladding Waste Sludge Leaching Final (48 hr) Aqueous Phase Conditions . 4.49

4.17. Group 4 Solids Wash Solution Composition and Density

4.18. Group 4 REDOX Cladding Waste Sludge Leached Solids Composition and Leach Factors (Dry Mass Basis) for Caustic-Leaching at $80^{\circ} \mathrm{C}$ in $3 \mathrm{M} \mathrm{NaOH}$ for $48 \mathrm{hrs}$

5.1. Summary of Major Physical Properties and Mineral Phases of Group 3 PUREX Cladding Waste Sludge and Group 4 REDOX Cladding Waste Sludge

5.2. Summary of Elemental Composition of Group 3 CWP Sludge and Group 4 CWR Sludge Slurries

5.3. Composition of Caustic-Leached Group 3 Solids with Leach Factors of Selected Analytes (3 $\mathrm{M} \mathrm{NaOH}, 80^{\circ} \mathrm{C}, 48 \mathrm{~h}$ ).

5.4. Composition of Caustic-Leached Group 4 Solids with Leach Factors of Selected Analytes $\left(3 \mathrm{M} \mathrm{NaOH}, 80^{\circ} \mathrm{C}, 48 \mathrm{~h}\right)$. 



\section{Abbreviation/Acronym List}

\begin{tabular}{|c|c|}
\hline AEA & alpha energy analysis \\
\hline ASO & Analytical Support Organization \\
\hline ASR & Analytical Service Request \\
\hline ATL & Advanced Technologies and Laboratories, International Inc. \\
\hline BBI & Best Basis Inventory \\
\hline BET & (Brunauer, Emmett, and Teller) surface area analysis technique \\
\hline BNI & Bechtel National, Incorporated \\
\hline $\mathrm{BS}$ & blank spike \\
\hline $\mathrm{CCD}$ & charge coupled device \\
\hline $\mathrm{CCN}$ & corporate correspondence number $(\mathrm{BNI})$ \\
\hline CUF & cross-flow ultrafiltration testing system \\
\hline CWP & PUREX cladding waste \\
\hline CWR & REDOX cladding waste \\
\hline DACS & data acquisition collection system \\
\hline DI & deionized \\
\hline DOE & U.S. Department of Energy \\
\hline ED & electron diffraction \\
\hline EDS & energy-dispersive spectroscopy \\
\hline EELS & electron energy-loss spectroscopy \\
\hline EFRT & external flowsheet review team \\
\hline EQL & estimated quantitation limit \\
\hline FTIR & Fourier transform infrared \\
\hline GEA & gamma energy analysis \\
\hline GIF & Gatan Imaging Filter \\
\hline HAADF & High Angle Annular Dark-Field Detector \\
\hline HDPE & high-density polypropylene \\
\hline HLRF & High-Level Radiochemistry Facility \\
\hline HLW & high-level waste \\
\hline HP & hot persulfate \\
\hline $\mathrm{IC}$ & ion chromatography \\
\hline ICDD & International Centre for Diffraction Data \\
\hline ICP-OES & inductively coupled plasma-optical emission spectroscopy \\
\hline ICSD & Inorganic Crystal Structure Database \\
\hline
\end{tabular}


$\mathrm{KOH}$

KPA

LAW

LCS

LEPS

MDL

MRQ

MS

M\&TE

NIST

OES

ORP

PB

PNNL

PSD

PTF

PUREX

QA

QAM

QAPjP

QARD

QC

REDOX

RIR

RPD

RPL

RPP-WTP

RSD

$\mathrm{R} \& \mathrm{~T}$

TIC

TMP

TOC

TRU

SBMS

SEM

STEM potassium hydroxide

kinetic phosphorescence analysis

low activity waste

laboratory control sample

Low-Energy Photon Spectroscopy

minimum detection limit

minimum reportable quantity

matrix spike

measuring and test equipment

National Institute of Science and Technology

optical emission spectroscopy

Office of River Protection

preparation blank

Pacific Northwest National Laboratory

particle-size distribution

Pretreatment Facility

plutonium-uranium extraction

quality assurance

Quality Assurance Manual

quality assurance project plan

Quality Assurance Requirements and Descriptions

quality control

reduction oxidation

relative intensity ratio

relative percent difference

Radiochemical Processing Laboratory

River Protection Project - Waste Treatment Plant Support Project

relative standard deviation

research and technology

total inorganic carbon

transmembrane pressure

total organic carbon

transuranics

Standards Based Management System

scanning electron microscopy

scanning transmission electron microscopy 
TEM/ED

TP

TWINS

UDS

UFP

WCS

WTP

XRD transmission electron microscopy

test plan

Tank-Waste Information Network System

undissolved solids

ultrafiltration process

wet centrifuged solids

Waste Treatment and Immobilization Plant

X-ray diffraction 



\section{References}

Barnes HA, and NQ Dzuy. 2001. "Rotating Vane Rheometry - A Review." Journal of Non-Newtonian Fluid Mechanics 98(1):1-14.

Fiskum SK, EC Buck, RC Daniel, K Draper, MK Edwards, TL Hubler, LK Jagoda, ED Jenson, GJ Lumetta, BK McNamara, RA Peterson, SI Sinkov, and LA Snow. 2008. Characterization and Leach Testing for REDOX Sludge and S-Saltcake Actual Waste Sample Composites. PNNL-17368 (WTP-RPT157), Pacific Northwest National Laboratory, Richland, WA.

Li H, J Addai-Mensah, JC Thomas, and AR Gerson. 2005. "The Influence of Al(III) Supersaturation and $\mathrm{NaOH}$ Concentration on the Rate of Crystallization of $\mathrm{Al}(\mathrm{OH})_{3}$ Precursor Particles From Sodium Aluminate Solutions,” J. Colloid and Interface Science, 286:511-519.

Lumetta, GJ, EC Buck, RC Daniel, K Draper, MK Edwards, SK Fiskum, LK Jagoda, ED Jenson, AE KOzelisky, PJ MacFarlan, RA Peterson, RW Shimskey, SI Sinkov, and LA Snow. 2008.

Characterization, Leaching, and Filtration Testing for Bismuth Phosphate Sludge (Group 1) and Bismuth Phosphate Saltcake (Group 2) Actual Waste Sample Composites. WTP-RPT-166, Pacific Northwest National Laboratory, Richland, WA.

Lumetta GJ. 2007. Review of Caustic Leaching Testing With Hanford Tank Waste Sludges. WTP-RPT151, Pacific Northwest National Laboratory, Richland, WA.

Lumetta GJ and BM Rapko. 1999. "Removal of Chromium from Hanford Tank Sludges." Sep. Sci. Technol. 34:1495-1506.

Lumetta GJ, I Burgeson, MJ Wagner, J Liu, and YL Chen. 1997. Washing and Caustic Leaching of Hanford Tank Sludge: Results of FY1997 Studies. PNNL-11636 Rev 1, Pacific Northwest National Laboratory, Richland, WA.

Meacham JE. 2003. Aluminum Wash and Leach Factors. RPP-11079, Rev 0, CH2MHill Hanford Group, Richland, WA.

Misra, C. 1970. "Solubility of aluminum trihydroxide (hydrargillite) in sodium hydroxide solution." Chem. Ind. 19:619-623.

Malvern Instruments Ltd. 1997. Sample Dispersion and Refractive Index Guide. MAN 0079, Version 3.1, Worcestershire, England.

Rapko BM, GJ Lumetta, JD Vienna, and SK Fiskum. 2005. Oxidative Alkaline Leaching of SX-101 and SY-102 and Its Impact on Immobilized High Level Waste. PNWD-3600 (WTP-RPT-137), BattellePacific Northwest Division, Richland, WA. (WTP Doc. No. 24590-101-TSA-W000-0004-168-00002 Rev 00A.)

Rapko, BM, JGH Geeting, SI Sinkov, and JD Vienna. 2004. Oxidative-Alkaline Leaching of Washed 241-SY-102 and 241-SX-101 Tank Sludges. PNWD-3512 (WTP-RPT-117), Battelle-Pacific Northwest Division, Richland, WA. (WTP Doc. No. 24590-101-TSA-W000-0004-99-00012 Rev 00A.) 
Rapko BM, JD Vienna, SI Sinkov, J Kim, and AJ Cisar. 2002. Alkaline Leaching of Key, Non-

Radioactive Components from Simulants and Hanford Tank Sludge 241-S-110: Results of FY 01 Studies. PNNL-14018, Pacific Northwest National Laboratory, Richland, WA.

Rapko BM. 1998. Oxidative Alkaline Dissolution of Chromium from Hanford Tank Sludges: Results of FY 98 Studies. PNNL-11908, Pacific Northwest National Laboratory, Richland, WA.

Shimskey RW, JM Billing, EC Buck, AJ Casella, JV Crum, RC Daniel, K Draper, MK Edwards, RT Hallen, AE Kozelisky, PJ MacFarlan, RA Peterson, RG Swoboda. 2008. Filtration and Leach Testing for PUREX Cladding Sludge and REDOX Cladding Sludge Actual Waste Sample Composites. WTPRPT-181, Pacific Northwest National Laboratory, Richland, WA.

Shimskey RW, JM Billing, EC Buck, RC Daniel, K Draper, MK Edwards, JGH Geeting, RT Hallen, ED Jenson, AE Kozelisky, PJ MacFarlan, RA Peterson, LA Snow, RG Swoboda. 2008. Filtration and Leach Testing for REDOX Sludge and S-Saltcake Actual Waste Sample Composites. WTP-RPT-172, Pacific Northwest National Laboratory, Richland, WA. 


\section{Testing Summary}

A testing program evaluating actual tank waste was developed in response to Task 4 from the M-12 External Flowsheet Review Team (EFRT) issue response plan. ${ }^{(a)}$ The testing program was subdivided into logical increments. The bulk water-insoluble solid wastes that are anticipated to be delivered to the Waste Treatment and Immobilization Plant (WTP) were identified according to type such that the actual waste testing could be targeted to the relevant categories. Eight broad waste groupings were defined. Samples available from the $222 \mathrm{~S}$ archive were identified and obtained for testing. The actual wastetesting program included homogenizing the samples by group, characterizing the solids and aqueous phases, and performing parametric leaching tests.

Two of the eight defined groups - plutonium-uranium extraction (PUREX) cladding waste sludge (Group 3, or CWP) and reduction-oxidation (REDOX) cladding waste sludge (Group 4, or CWR) - are the subjects of this report. Both the Group 3 and 4 waste composites were anticipated to be high in gibbsite, requiring caustic leaching. Characterization of the composite Group 3 and Group 4 waste samples confirmed them to be high in gibbsite. The focus of the Group 3 and 4 testing was on determining the behavior of gibbsite during caustic leaching. The waste-type definition, archived sample conditions, homogenization activities, characterization (physical, chemical, radioisotope, and crystal habit), and caustic leaching behavior as functions of time, temperature, and hydroxide concentration are discussed in this report. Testing was conducted according to TP-RPP-WTP-467. ${ }^{\text {(b) }}$

\section{Objectives}

The test objectives are summarized in Table S.1 along with a discussion of how the objectives were met. Several objectives (in gray shading lighter than header shading) did not specifically apply to the scope of work described in this report; they will be/were reported in companion reports as indicated in the controlling test plan.

(a) SM Barnes, and R Voke. 2006. "Issue Response Plan for Implementation of External Flowsheet Review Team (EFRT) Recommendations - M12: Undemonstrated Leaching Process.” 24590-WTP-PL-ENG-06-0024 Rev. 0.

(b) SK Fiskum. 2007. Characterization and Small Scale Testing of Hanford Wastes to Support the Development and Demonstration of Leaching and Ultrafiltration Pretreatment Processes. TP-RPP-WTP-467, Rev. 0, 2/2/07 and Rev. 1, 7/31/07. 
Table S.1. Test Objectives

\begin{tabular}{|c|c|c|}
\hline Test Objective & $\begin{array}{c}\text { Objective } \\
\text { Met? (Y/N) }\end{array}$ & Discussion \\
\hline $\begin{array}{l}\text { 1) Determine the physical and chemical } \\
\text { characteristics (summarized in } \\
\text { Section } 6.2 .2 \text { of the test plan) } \\
\text { relevant to leaching and } \\
\text { ultrafiltration behaviors of actual } \\
\text { waste samples required for the } \\
\text { validation of simulants. }\end{array}$ & $\mathrm{Y}$ & $\begin{array}{l}\text { The following characterizations were conducted on } \\
\text { the washed solids for Group } 3 \text { and Group } 4 \text { : } \\
\text { - solids chemical composition } \\
\text { - mineral composition } \\
\text { - particle-size distribution } \\
\text { - crystal habit and morphology } \\
\text { - slurry density } \\
\text { - slurry rheology, flow curve, and shear strength } \\
\text { - settling rate, fraction of settled solids, and } \\
\text { fraction of centrifuged solids. } \\
\text { The results are summarized in Sections } 3 \text { and } 4 \text {. }\end{array}$ \\
\hline $\begin{array}{l}\text { 2) Determine the dissolution rate of } \\
\text { aluminum in the actual waste } \\
\text { samples, present predominantly as } \\
\text { gibbsite, as a function of temperature } \\
\text { and free-hydroxide concentration, } \\
\text { and over a range of sodium } \\
\text { concentrations of interest to the } \\
\text { caustic-leaching process. }\end{array}$ & $\mathrm{Y}$ & $\begin{array}{l}\text { A significant portion of the } \mathrm{Al} \text { in the Group } 3 \text { and } 4 \\
\text { wastes was present in the form of gibbsite. } \\
\text { Parametric leach testing was conducted on small } \\
(\sim 1 \text {-g) aliquots of these wastes to determine the } \\
\text { dissolution rate of gibbsite. Leaching parameters } \\
\text { were varied and included temperature }(60,80 \text {, and } \\
\left.100^{\circ} \mathrm{C}\right) \text {, hydroxide concentration }(1,3 \text {, and } 5 \mathrm{M}) \text {, and } \\
\text { time ( } 0 \text { to } 48 \text { hours). Dissolution kinetics is also } \\
\text { discussed. Results are summarized in Sections } 3.4 \\
\text { and } 4.4 \text {. }\end{array}$ \\
\hline $\begin{array}{l}\text { Determine the dissolution rate of } \\
\text { aluminum in the actual waste } \\
\text { samples, present predominantly as } \\
\text { boehmite, as a function of } \\
\text { temperature, free-hydroxide } \\
\text { concentration, and over a range of } \\
\text { sodium concentrations of interest to } \\
\text { the caustic leaching process. }\end{array}$ & NA & $\begin{array}{l}\text { Neither Group } 3 \text { nor Group } 4 \text { was expected to contain } \\
\text { significant quantities of boehmite, and indeed this was } \\
\text { found to be the case. The boehmite dissolution } \\
\text { parameters were discussed for the parametric testing } \\
\text { of Group } 5 \text { (REDOX Sludge Waste) sample in WTP- } \\
\text { RPT-157 (Fiskum et al. 2008). }\end{array}$ \\
\hline $\begin{array}{l}\text { Determine the dissolution rate of } \\
\text { chromium and the extent of } \\
\text { dissolution of plutonium and other } \\
\text { safety-related constituents ( } \mathrm{U}, \mathrm{Fe} \text {, } \\
\mathrm{Mn}, \mathrm{Ni} \text {, and } \mathrm{Zn} \text { ) in the actual waste } \\
\text { samples as functions of temperature } \\
\text { and over a range of } \mathrm{NaOH} \\
\text { concentrations of interest for } \\
\text { oxidative leaching. (The } \mathrm{NaMnO}_{4} \\
\text { dosage will be predetermined for the } \\
\text { oxidation of the chromium in the } \\
\text { waste solids.) }\end{array}$ & NA & $\begin{array}{l}\text { Oxidative leaching was not an objective of the } \\
\text { Group } 3 \text { and Group } 4 \text { testing because neither of these } \\
\text { was anticipated to be a high-Cr waste. } \\
\text { Initial parametric testing using S-Saltcake waste } \\
\text { (Group 6) for Cr dissolution was summarized in } \\
\text { WTP-RPT-157 (Fiskum et al. 2008). Subsequent } \\
\text { parametric testing using bismuth phosphate saltcake } \\
\text { waste (Group 2) for Cr was also performed as } \\
\text { described in WTP-RPT-166 (Lumetta et al. 2008). } \\
\text { Batch leaching of Cr occurred during the filtration } \\
\text { testing described in report WTP-RPT-172 and } \\
\text { WTP-RPT-166. }\end{array}$ \\
\hline $\begin{array}{l}\text { 5) Determine the dissolution/reaction } \\
\text { rate of phosphates in the actual waste }\end{array}$ & NA & $\begin{array}{l}\text { Neither Group } 3 \text { nor Group } 4 \text { contained significant } \\
\text { amounts of P. }\end{array}$ \\
\hline
\end{tabular}


Table S.1 (Contd)

\begin{tabular}{|c|c|c|}
\hline Test Objective & $\begin{array}{c}\text { Objective } \\
\text { Met? (Y/N) }\end{array}$ & Discussion \\
\hline $\begin{array}{l}\text { samples as a function of temperature } \\
\text { and over a range of } \mathrm{NaOH} \\
\text { concentrations of interest for the } \\
\text { caustic leaching process as well as } \\
\text { the extent of dissolution during post- } \\
\text { leaching wash. }\end{array}$ & & $\begin{array}{l}\text { Initial parametric testing of the bismuth phosphate } \\
\text { sludge (Group 1) and bismuth phosphate saltcake } \\
\text { (Group 2) for phosphate dissolution by caustic } \\
\text { leaching was summarized in WTP-RPT-166 } \\
\text { (Lumetta et al. 2008). } \\
\text { Batch leaching of a blend of the Group } 1 \text { and } 2 \\
\text { wastes was performed during a bench-scale } \\
\text { filtration/leaching test. The leaching results of this } \\
\text { test were also summarized in WPT-RPT-166. }\end{array}$ \\
\hline $\begin{array}{l}\text { 6) Determine ultrafiltration flux before } \\
\text { and after caustic and oxidative } \\
\text { leaching over the operating range of } \\
\text { solids concentrations during the } \\
\text { leaching processes at } 25^{\circ} \mathrm{C} \text { when } \\
\text { sufficient actual waste sample is } \\
\text { available for testing of the filtration } \\
\text { behavior. }\end{array}$ & NA & $\begin{array}{l}\text { Ultrafiltration (CUF) testing was performed on a } \\
\text { blended composite of the Group } 3 \text { and Group } 4 \text { solids. } \\
\text { These results are reported in WPT-RPT-181 } \\
\text { (Shimskey et al. 2008) }\end{array}$ \\
\hline $\begin{array}{l}\text { 7) Scanning electron microscopy } \\
\text { (SEM), transmission electron } \\
\text { microscopy (TEM), energy } \\
\text { dispersive spectroscopy (EDS), and } \\
\text { X-ray diffraction (XRD) will be used } \\
\text { to determine the primary mineral } \\
\text { forms present for Al, Cr, and P and } \\
\text { provide information to enable the } \\
\text { correlation of these mineral forms to } \\
\text { dissolution behavior. }\end{array}$ & $\mathrm{Y}$ & $\begin{array}{l}\text { SEM, TEM, EDS, and XRD were performed on the } \\
\text { washed Group } 3 \text { and Group } 4 \text { solids before caustic } \\
\text { leaching. SEM, TEM, EDS, and XRD were } \\
\text { performed on the washed Group } 3 \text { solids after caustic } \\
\text { leaching. Nearly the entire Group } 4 \text { sample dissolved } \\
\text { during caustic leaching, leaving only enough sample } \\
\text { to do a single fusion and subsequent analysis, so } \\
\text { SEM, TEM, EDS, and XRD were not performed on } \\
\text { the Group } 4 \text { caustic leached sample. } \\
\text { The solids characterization results are distributed } \\
\text { throughout the report at the specific relevant sections. }\end{array}$ \\
\hline
\end{tabular}

\section{Test Exceptions}

No test exceptions applied to this work.

\section{Results and Performance Against Success Criteria}

The test plan delineated several success criteria, which are listed in Table S.2. Selected criteria were relevant to the test scope included in this report; the other criteria that are outside of the reported scope are shaded. 
Table S.2. Results and Performance Against Success Criteria

\begin{tabular}{|c|c|c|}
\hline \multicolumn{2}{|c|}{ List Success Criteria } & \multirow{2}{*}{$\begin{array}{l}\text { Explain How the Tests Did or Did Not } \\
\text { Meet the Success Criteria } \\
\text { Letter report number RPP-WTP-07-705 (GJ Lumetta } \\
\text { and RT Hallen, WTP-RPT-151, Review of Caustic } \\
\text { Leaching Testing With Hanford Tank Waste Sludges), } \\
\text { which addressed this success criterion, was delivered to } \\
\text { BNI-WTP on 1/24/2007. }\end{array}$} \\
\hline & $\begin{array}{l}\text { A summary (letter report format) of the available } \\
\text { information (including published literature) is } \\
\text { provided on the characteristics (both known } \\
\text { characteristics and those needed to be determined) } \\
\text { relevant to leaching and filtration behaviors of the } \\
\text { tank farm waste groupings identified for testing. }\end{array}$ & \\
\hline & $\begin{array}{l}\text { The physical and chemical characteristics for each } \\
\text { of the actual waste-sample composites selected for } \\
\text { testing are provided (including a format in } \\
\text { conformance with the presentation protocols } \\
\text { [24590-WTP-GPG-RTD-001]). The relevant } \\
\text { physical and chemical characteristics are } \\
\text { elaborated in Test Conditions, Section 6.0, of the } \\
\text { test plan. }\end{array}$ & $\begin{array}{l}\text { All physical and chemical characterization testing as } \\
\text { defined in the test plan was completed for the Group } 3 \\
\text { and } 4 \text { initial solids and for the Group } 3 \text { caustic-leached } \\
\text { solids. Nearly all of the Group } 4 \text { solids dissolved during } \\
\text { caustic-leaching, leaving only enough sample to do a } \\
\text { single fusion and subsequent chemical characterization. } \\
\text { For Group } 4 \text {, there was insufficient sample available to } \\
\text { perform physical characterization testing of the caustic- } \\
\text { leached sample. This included extensive chemical } \\
\text { characterization of selected leached solids. The } \\
\text { analytical results for each test group are reported in the } \\
\text { appropriate report sections. }\end{array}$ \\
\hline 3) & $\begin{array}{l}\text { The dissolution rate and the extent of dissolution of } \\
\text { aluminum present predominantly as gibbsite in } \\
\text { actual waste solids are determined as a function of } \\
\text { temperature, free-hydroxide, and sodium } \\
\text { concentrations. The associated uncertainties in test } \\
\text { results are provided. }\end{array}$ & $\begin{array}{l}\text { Dissolution of the gibbsite fraction of the Group } 3 \text { and } 4 \\
\text { washed solids was evaluated by measuring the } \mathrm{Al} \text { in the } \\
\text { leaching solution as a function of time }(0,1,2,4,8,24 \text {, } \\
\text { and } 48 \mathrm{~h} \text { ). The effects of free-hydroxide concentration, } \\
\left.\text { sodium concentration (from adding } 1 \text { and } 5 \mathrm{M} \mathrm{NaNO}_{3}\right) \text {, } \\
\text { and temperature were assessed. Testing was conducted } \\
\text { at three free-hydroxide concentrations }(1,3 \text {, and } 5 \mathrm{M}) \\
\text { and at three temperatures }\left(60,80 \text {, and } 100^{\circ} \mathrm{C}\right) \text {. One test } \\
\left.\text { condition ( } 3 \mathrm{M} \text { free hydroxide at } 80^{\circ} \mathrm{C}\right) \text { for each group } \\
\text { was conducted in triplicate to assess overall test } \\
\text { precision. } \\
\text { The dissolution of the gibbsite fraction of both the } \\
\text { Group } 3 \text { and } 4 \text { solids was rapid, with a steady state } \\
\text { reached in } 1 \text { to } 8 \text { h under all conditions examined. The } \\
\text { steady-state Al concentrations in these experiments } \\
\text { represented nearly } 100 \% \text { Al dissolution. Detailed results } \\
\text { are presented in Sections } 3.0 \text { and } 4.0 \text {. }\end{array}$ \\
\hline 4) & $\begin{array}{l}\text { The dissolution rate and the extent of dissolution of } \\
\text { aluminum present predominantly as boehmite in } \\
\text { actual waste solids are determined as a function of } \\
\text { temperature, free-hydroxide, and sodium } \\
\text { concentrations. The associated uncertainties in test } \\
\text { results are provided. }\end{array}$ & $\begin{array}{l}\text { Not applicable. Neither Group } 3 \text { nor Group } 4 \text { samples } \\
\text { had significant amounts of boehmite. } \\
\text { Parametric testing of the Group } 5 \text { waste for boehmite } \\
\text { dissolution was summarized in WTP-RPT-157. }\end{array}$ \\
\hline 5) & $\begin{array}{l}\text { The dissolution rate and the extent of dissolution of } \\
\text { chromium in the actual waste solids are determined } \\
\text { as a function of temperature and over a range of }\end{array}$ & $\begin{array}{l}\text { Not applicable. Neither Group } 3 \text { nor Group } 4 \text { samples } \\
\text { had significant amounts of Cr. }\end{array}$ \\
\hline
\end{tabular}


Table S.2 (Contd)

\begin{tabular}{|c|c|c|}
\hline \multicolumn{2}{|c|}{ List Success Criteria } & $\begin{array}{l}\text { Explain How the Tests Did or Did Not } \\
\text { Meet the Success Criteria }\end{array}$ \\
\hline & $\begin{array}{l}\mathrm{NaOH} \text { concentrations of interest to oxidative } \\
\text { leaching. The } \mathrm{NaMnO}_{4} \text { dosage will be } \\
\text { predetermined for the oxidation of the chromium in } \\
\text { the waste solids. The associated uncertainties in } \\
\text { the test results are provided. }\end{array}$ & $\begin{array}{l}\text { Parametric testing of the Group } 6 \text { and Group } 2 \text { waste for } \\
\text { Cr dissolution was summarized in WTP-RPT-157 and } \\
\text { WTP-RPT-166. }\end{array}$ \\
\hline 6) & $\begin{array}{l}\text { The dissolution rate and the extent of dissolution of } \\
\text { phosphates in the actual waste solids are } \\
\text { determined as a function of temperature and } \mathrm{NaOH} \\
\text { concentration along with the uncertainty in these } \\
\text { estimates. }\end{array}$ & $\begin{array}{l}\text { Not applicable. Neither Group } 3 \text { nor Group } 4 \text { samples } \\
\text { had significant amounts of phosphate. } \\
\text { Parametric testing of the Group } 1 \text { waste for phosphate } \\
\text { dissolution was summarized in WTP-RPT-166. }\end{array}$ \\
\hline 7) & $\begin{array}{l}\text { The ultrafiltration flux before and after caustic and, } \\
\text { as applicable, oxidative leaching (reconcentration, } \\
\text { if sufficient solids are available) over the operating } \\
\text { range of solids concentrations with the actual waste } \\
\text { samples at } 25^{\circ} \mathrm{C} \text { is defined when available sample } \\
\text { size is adequate for the testing. }\end{array}$ & $\begin{array}{l}\text { Not applicable. Ultrafiltration testing was not conducted } \\
\text { as a part of this report. } \\
\text { CUF testing was performed on a blended composite of } \\
\text { the Group } 3 \text { and Group } 4 \text { solids. These results are } \\
\text { reported in WPT-RPT- } 181 \text {. }\end{array}$ \\
\hline & $\begin{array}{l}\text { Determination of the primary mineral forms } \\
\text { present for } \mathrm{Al}, \mathrm{Cr} \text {, and } \mathrm{P} \text {, and a qualitative } \\
\text { correlation of the dissolution behavior of these } \\
\text { waste elements to the mineral forms identified. }\end{array}$ & $\begin{array}{l}\text { Very little } \mathrm{P} \text { or } \mathrm{Cr} \text { was present in either the Group } 3 \text { or } \\
\text { Group } 4 \text { waste samples (less than } 1 \mathrm{wt} \%) \text {. Analysis by } \\
\text { XRD determined that both the Group } 3 \text { and } 4 \text { solids } \\
\text { were dominated by gibbsite. } \\
\text { In addition to gibbsite, } \mathrm{XRD} \text { determined that the } \\
\mathrm{Group} 3 \text { solids also contained minor amounts of } \\
\mathrm{Fe}_{1.67} \mathrm{H}_{0.99} \mathrm{O}_{3} \text { (hematite), } \\
1.06 \mathrm{Na}_{2} \mathrm{O} \cdot \mathrm{Al}_{2} \mathrm{O}_{3} \cdot 1.60 \mathrm{SiO}_{2} \cdot 1.60 \mathrm{H}_{2} \mathrm{O} \text { (hydroxycancrinite), } \\
\text { and/or } \mathrm{Na}_{8.16}\left(\mathrm{Al}_{6} \mathrm{Si}_{6} \mathrm{O}_{24}\right)\left(\mathrm{NO}_{3}\right)_{2.16}\left(\mathrm{H}_{2} \mathrm{O}\right)_{1.62} \text { (nitrate } \\
\text { cancrinite). } \\
\text { The Group } 4 \text { solids were determined to also contain } \\
\text { minor amounts of sodium aluminum silicate hydrate } \\
\left.\left[\left(\mathrm{Na} \mathrm{N}_{2} \mathrm{O}\right)_{1.31} \mathrm{Al}_{2} \mathrm{O}_{3}(\mathrm{SiO})_{2}\right)_{2.01}\left(\mathrm{H}_{2} \mathrm{O}\right)_{1.65}\right] \text {. Minor } \\
\text { contributions from boehmite }(\mathrm{AlOOH}) \text {, quartz }\left(\mathrm{SiO} \mathrm{O}_{2}\right) \text {, } \\
\text { vaterite }\left(\mathrm{CaCO} \mathrm{O}_{3}\right) \text {, sodium uranium oxide }\left(\mathrm{Na}_{6} \mathrm{U}_{7} \mathrm{O}_{24}\right) \text {, } \\
\text { and lepidocrocite }(\mathrm{FeO} O \mathrm{OH}]) \text { were shown as possibly } \\
\text { present. In these cases, only one diffraction line was } \\
\text { identified; intensities of confirming lines were too low to } \\
\text { detect. }\end{array}$ \\
\hline
\end{tabular}

\section{Quality Requirements}

Pacific Northwest National Laboratory (PNNL) is operated for the U.S. Department of Energy (DOE) by Battelle under Contract DE-AC05-76RL01830. PNNL implements a Quality Assurance Program that is based upon the requirements as defined in DOE Order 414.1C, "Quality Assurance," and 10 CFR 830, "Energy/Nuclear Safety Management," Subpart A-"Quality Assurance Requirements." PNNL has chosen to implement the requirements of DOE Order 414.1C and 10 CFR 830, Subpart A by integrating 
them into the laboratory's management systems and daily operating processes. The procedures necessary to implement the requirements are documented through the laboratory's Standards-Based Management System (SBMS).

PNNL implemented the RPP-WTP quality requirements by performing work in accordance with the River Protection Project - Waste Treatment Plant Support Program (RPP-WTP) Quality Assurance Plan (RPPWTP-QA-001, QAP). Work was performed to the quality requirements of NQA-1-1989 Part I, "Basic and Supplementary Requirements," NQA-2a-1990, Part 2.7, and DOE/RW-0333P, Rev 13, Quality Assurance Requirements and Descriptions (QARD). These quality requirements were implemented through the River Protection Project - Waste Treatment Plant Support Program (RPP-WTP) Quality Assurance Manual (RPP-WTP-QA-003, QAM). The analytical requirements were implemented through RPP-WTP's Statement of Work (RPP-WTP-QA-005) with the Radiochemical Processing Laboratory (RPL) Analytical Service Operations (ASO).

A matrix that cross-references the NQA-1, NQA-2a, and QARD requirements with the procedures for RPP-WTP work was provided in the test plan TP-RPP-WTP-467. It included justification for those requirements not implemented.

Experiments that were not method-specific were performed in accordance with RPP-WTP's procedures QA-RPP-WTP-1101 "Scientific Investigations" and QA-RPP-WTP-1201 "Calibration and Control of Measuring and Testing Equipment" so that sufficient data were taken with properly calibrated measuring and test equipment (M\&TE) to obtain quality results.

RPP-WTP addressed internal verification and validation activities by conducting an independent technical review of the final data report in accordance with RPP-WTP's procedure QA-RPP-WTP-604. This review verified that the reported results were traceable, that inferences and conclusions were soundly based, and the reported work satisfied the Test Plan objectives. This review procedure is part of PNNL's RPP-WTP Quality Assurance Manual.

\section{R\&T Test Conditions}

The R\&T test conditions, as defined in the BNI Test Specification, ${ }^{(a)}$ are summarized in Table S.3.

(a) PS Sundar. Nov. 2006. Characterization and Small Scale Testing of Hanford Wastes to Support the Development and Demonstration of Leaching and Ultrafiltration Pretreatment Processes. 24590-PTF-TSPRT-06-003, Rev. 1. 
Table S.3. R\&T Test Conditions

\begin{tabular}{|l|l||}
\hline List R\&T Test Conditions & Were Test Conditions Followed? \\
\hline $\begin{array}{l}\text { 1) Selection of actual wastes for testing: the waste } \\
\text { samples selected for testing will be from the } \\
\text { groupings identified in the resolution of Issue M4. }\end{array}$ & $\begin{array}{l}\text { Yes. Two of the eight waste groupings identified in } \\
\text { resolution of Issue M4 were tested: Group 3 (CWP } \\
\text { sludge) and Group 4 (CWR sludge). }\end{array}$ \\
\hline $\begin{array}{l}\text { 2) Physical and chemical characterization properties } \\
\text { shall be stated and carried out according to the } \\
\text { guideline document 24590-WTP-GPG-RTD-001. }\end{array}$ & $\begin{array}{l}\text { Yes. Physical characterizations, including specific } \\
\text { gravity (density), settling rate, rheology, volume- } \\
\text { percent settled solids, and volume-percent } \\
\text { centrifuged solids, were determined for both test } \\
\text { groups according to the requirements document. }\end{array}$ \\
$\begin{array}{ll}\text { Chemical characterization was conducted on the } \\
\text { supernatant (water used to dissolve and slurry the } \\
\text { solids into a workable homogenized composite) on } \\
\text { the solids rinsed with three contacts of 1:1 volume } \\
\text { ratios of 0.01 M NaOH and on the rinse solution } \\
\text { composite. }\end{array}$ \\
\hline $\begin{array}{l}\text { 3) Actual determinations of waste leach kinetics } \\
\text { will be carried out in well-mixed conditions. A test } \\
\text { matrix will be forwarded to the research and } \\
\text { technology (R\&T) M12 issue manager for } \\
\text { concurrence before testing. Residual leached and } \\
\text { washed solids will be characterized. }\end{array}$ & $\begin{array}{l}\text { Yes. Test matrices for both the Group 3 and } \\
\text { Group 4 waste samples were forwarded to, and } \\
\text { approved by, the BNI R\&T M12 issue manager. } \\
\text { Actual test conditions are given in Sections 3.0 and } \\
\text { 4.0 and were compliant with the test matrices. }\end{array}$ \\
\hline 4) Testing for filtration behavior will be performed. & $\begin{array}{l}\text { Not applicable. Cross-flow filtration testing was not } \\
\text { performed as a part of the work scope reported here. } \\
\text { Rather, CUF testing was performed on a blended } \\
\text { composite of the Group 3 and Group 4 solids. } \\
\text { These results are reported in WPT-RPT-181. }\end{array}$ \\
\hline
\end{tabular}




\section{Simulant Use}

The testing used actual Hanford tank wastes; simulant usage does not apply.

\section{Discrepancies and Follow-on Tests}

None. 


\subsection{Introduction}

This report is one in a series that defines the characterization and parametric leaching of actual Hanford tank wastes in support of the Hanford Waste Treatment and Immobilization Plant (WTP) pretreatment process development and demonstration. The tests reported here were conducted according to test plan TP-RPP-WTP-467, ${ }^{(a)}$ which was written in response to Bechtel National, Inc. (BNI) Test Specification 24590-PTF-TSP-RT-06-003 Rev. 1. ${ }^{\text {(b) }}$ This report focuses on initial characterization and caustic-leaching testing performed using two composite waste samples representing uranium-plutonium extraction (PUREX) cladding waste sludge and reduction-oxidation (REDOX) cladding waste sludge.

\subsection{Tank Waste Pretreatment Operations at the WTP}

Figure 1.1 provides a schematic illustration of the primary functions to be performed in the WTP. Initially, the low-activity waste (LAW) liquid stream will be removed from the high-level waste (HLW) solids phase by ultrafiltration in the Pretreatment Facility (PTF). The concentrated HLW solids will be pretreated with caustic and, in some cases, oxidative leaching processes to dissolve and remove materials (aluminum, chromium, phosphates, and sulfates) that would otherwise limit HLW loading in the immobilized waste glass. The current plant design calls for the pretreatment leaching processes to be carried out in the ultrafiltration feed vessels. The function of caustic leaching is to solubilize the aluminum, phosphorus, and sulfur in the HLW solids, thereby removing these components from the HLW vitrification feed. The function of oxidative leaching is to oxidize the chromium [from $\mathrm{Cr}$ (III) to $\mathrm{Cr}(\mathrm{VI})$ ] with a sodium permanganate $\left(\mathrm{NaMnO}_{4}\right)$ solution, so that the $\mathrm{Cr}$ can be routed to the LAW stream. The HLW solids will be re-concentrated after each leaching and washing operation in the ultrafilter.

The current design of the PTF was based on aluminum dissolution results from earlier small, bench-scale, caustic leaching tests that were supplied to BNI by the U.S. Department of Energy's (DOE's) Office of River Protection (ORP). Only a limited number of small bench-scale oxidative leaching tests using two selected actual waste tank samples (SX-101 and SY-102) with the preferred oxidant $\mathrm{NaMnO}_{4}$ were carried out to estimate the oxidant dosage and the efficacy of the oxidative leaching process (Rapko et al. 2004; Rapko et al. 2005), but a number of previous studies demonstrated the technical feasibility of the oxidative leaching process (Rapko 1998; Lumetta and Rapko 1999; Rapko and Vienna 2002; Rapko et al. 2002). The testing with actual radioactive wastes has been generally limited to small-scale testing (typically 1 to $10 \mathrm{~g}$ ) because of limited sample availability and personnel safety associated with sample handling.

(a) SK Fiskum, TP-RPP-WTP-467, Rev. 0, 2/2/07 and Rev. 1 7/31/07, Characterization and Small Scale Testing of Hanford Wastes to Support the Development and Demonstration of Leaching and Ultrafiltration Pretreatment Processes.

(b) PS Sundar. 2006. 24590-PTF-TSP-RT-06-003 Rev. 1, Characterization and Small Scale Testing of Hanford Wastes to Support the Development and Demonstration of Leaching and Ultrafiltration Pretreatment Processes. 


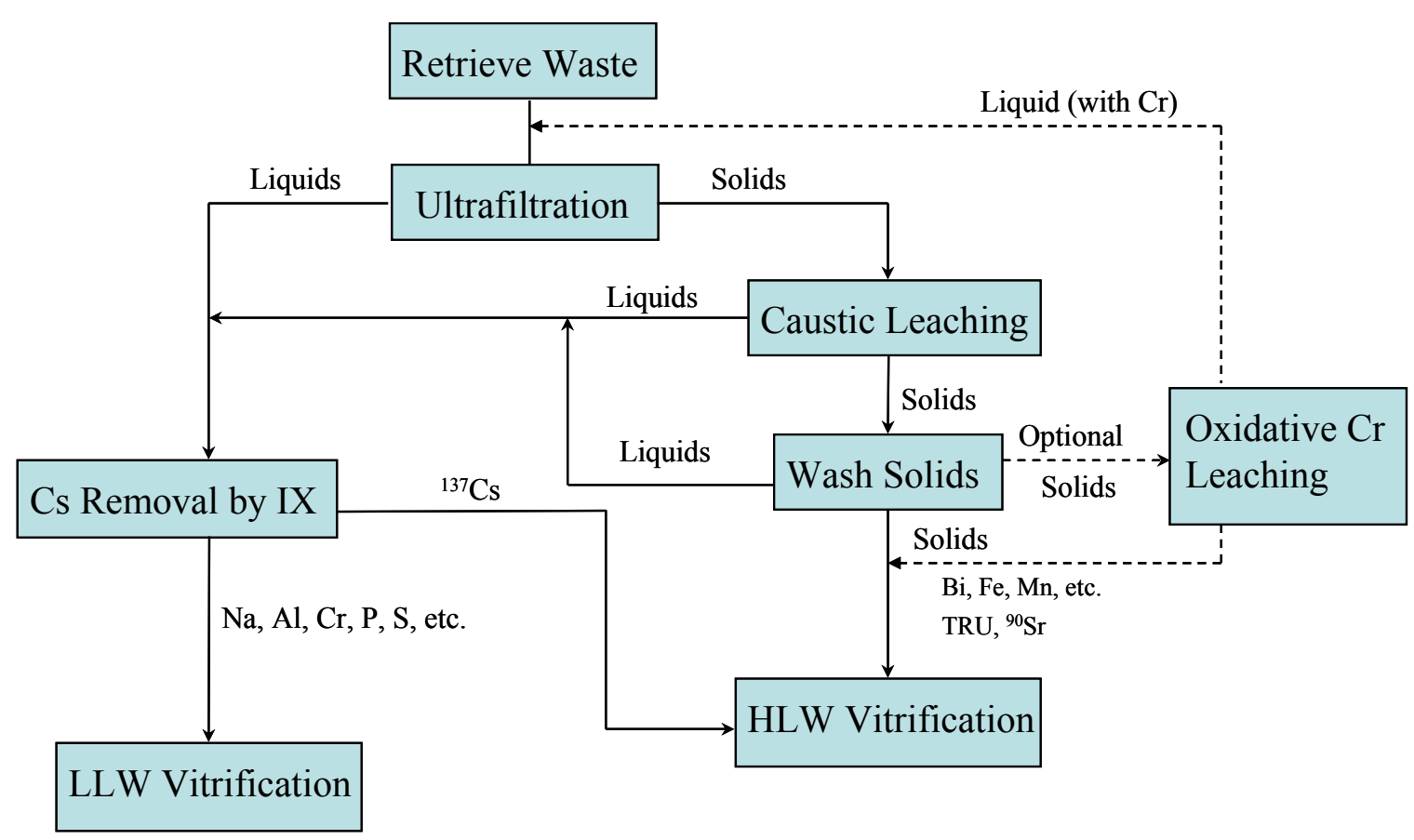

Figure 1.1. Schematic Representation of the Key Processes to be Performed in the WTP (Note: This is for illustrative purposes only; it is not meant to be a comprehensive view of the functions performed within the WTP.)

\subsection{Issues Identified by the External Flowsheet Review Team}

A team of foremost experts from industry, national laboratories, and universities (referred to as the External Flowsheet Review Team or EFRT) was assembled by BNI in October of 2005 to conduct an indepth review of the process flowsheet supporting the design of the WTP. The EFRT identified several issues from the critical review of the process flowsheet, ${ }^{(\mathrm{a}, \mathrm{b})}$ including

- Issue M4: The WTP has not demonstrated that its design is sufficiently flexible to reliably process all of the Hanford tank farm wastes at the design throughputs.

- Issue M12: Neither the caustic leaching nor the oxidative leaching process has been demonstrated at greater than bench scale. The small-scale experiments are capable of defining the leaching chemistry. However, they are limited in their capability to predict the effectiveness of these processes without a scale-up demonstration.

- Issue M13: For wastes requiring leaching, a combination of inadequate filter flux and area will likely limit throughput to the HLW or LAW vitrification facilities.

(a) WTP Doc. No. 24590-WTP-PL-ENG-06-0008, Rev 0, "Hanford Waste Treatment and Immobilization Plant (WTP) Project Response Plan for Resolution of Issues Identified by the Comprehensive Review of the WTP Flowsheet and Throughput." L Lucas, March 2006.

(b) WTP Project Doc. No. CCN 132846 "Comprehensive Review of the Hanford Waste Treatment Plant Flowsheet and Throughput - Assessment Conducted by an Independent Team of External Experts." March 2006, chartered by the Hanford Waste Treatment and Immobilization Plant Project at the Direction of the U.S. Department of Energy, Office of Environmental Management, Washington DC. 
The work scope defined in the TP-RPP-WTP-467 represented the initial actual waste-testing part of Task 4 from the M-12 EFRT issue response plan. ${ }^{\text {(a) }}$ The actual tank waste testing was interfaced with responses developed to resolve EFRT Issue M4. In this case, a family of waste groupings representing the behavior of $\sim 75 \%$ of the tank-farm inventory was developed to assist in designing subsequent tests that will assess the adequacy of the overall flowsheet design in treating the tank-farm wastes. These waste groupings were the basis for selecting actual wastes for the current scope of testing.

Additional EFRT-defined issues were identified that likely will also benefit from the actual waste testing reported herein, including:

- Issue M1: Piping that transports slurries will plug unless it is properly designed to minimize this risk. This design approach has not been followed consistently, which will lead to frequent shutdowns due to line plugging.

- Issue M2: Large, dense particles will accelerate erosive wear in mixing vessels. The effects of such particles on vessel life must be re-evaluated.

- Issue M3: Issues were identified related to mixing-system designs that will result in insufficient mixing and/or extended mixing times. These issues include a design basis that discounts the effects of large particles and of rapidly settling Newtonian slurries. There is also insufficient testing of the selected designs.

- Issue M6: Many of the process operating limits have not been defined. Further testing is required to define process limits for WTP unit operations. Without this more complete understanding of each process, it will be difficult or impossible to define a practical operating range for each unit operation.

\subsection{Waste Groupings}

The available information regarding tank history and tank waste characterization was analyzed. This analysis revealed eight groupings of waste tanks that represent $\sim 75 \%$ of the inventory of those components that are most significant with respect to leaching in the WTP; i.e., Al, Cr, phosphate, and sulfate (Fiskum et al. 2008). Table 1.1 summarizes the eight waste groups along with the estimated water-insoluble fractions (with respect to the entire tank farm inventory) of selected components contained in each one. To support the actual waste testing, samples were obtained from the archives at the Hanford 222S Laboratory. Composites of these archived samples were made to obtain the most representative samples of each group as practical. The details of the sample selection for Groups 3 and 4 are provided in Section 2.0.

(a) SM Barnes, and R Voke, September 2006, 24590-WTP-PL-ENG-06-0024 Rev. 0, "Issue Response Plan for Implementation of External Flowsheet Review Team (EFRT) Recommendations - M12: Undemonstrated Leaching Process." 
Table 1.1. Projected Distribution of Water-Insoluble Components in the Tank Waste Groupings (Fiskum et al. 2008)

\begin{tabular}{|c|c|c|c|c|c|c|c|c|}
\hline Group ID & Type & $\begin{array}{c}\text { Al } \\
(\%)\end{array}$ & $\begin{array}{l}\mathrm{Cr} \\
(\%)\end{array}$ & $\begin{array}{l}F \\
(\%)\end{array}$ & $\begin{array}{c}\mathrm{Fe} \\
(\%)\end{array}$ & $\begin{array}{c}\text { Oxalate } \\
(\%)\end{array}$ & $\begin{array}{c}\text { Phosphate } \\
\text { (\%) }\end{array}$ & $\begin{array}{c}\text { Sulfate } \\
(\%)\end{array}$ \\
\hline 1 & Bi Phosphate sludge & 4 & 4 & 22 & 22 & 0.5 & 36 & 7 \\
\hline 2 & $\begin{array}{l}\text { Bi Phosphate saltcake } \\
(\mathrm{BY}, \mathrm{T})\end{array}$ & 13 & 18 & 24 & 8 & 37 & 23 & 42 \\
\hline 3 & $\begin{array}{l}\text { CWP, PUREX Cladding } \\
\text { Waste sludge }\end{array}$ & 17 & 1 & 1.3 & 5 & 1 & 2 & 0.4 \\
\hline 4 & $\begin{array}{l}\text { CWR, REDOX Cladding } \\
\text { Waste sludge }\end{array}$ & 10 & 1 & $<0.1$ & 1 & 0.4 & 0.1 & $<0.1$ \\
\hline 5 & REDOX sludge & 29 & 6 & 0.1 & 4 & 3 & 1 & 0.4 \\
\hline 6 & S - Saltcake (S) & 8 & 46 & 0.6 & 4 & 27 & 4 & 14 \\
\hline 7 & TBP Waste sludge & 1 & 0.4 & 0.5 & 7 & 0.1 & 17 & 3 \\
\hline 8 & FeCN Waste sludge & 1 & 1 & 0.4 & 7 & 1 & 6 & 1 \\
\hline & Balance & 17 & 24 & 51 & 41 & 30 & 10 & 32 \\
\hline \multicolumn{9}{|c|}{$\begin{array}{l}\text { Note: The component values were round } \\
\text { CWP = PUREX cladding waste } \\
\text { CWR = REDOX cladding waste } \\
\text { FeCN = ferrocyanide } \\
\text { PUREX = plutonium uranium extraction } \\
\text { REDOX = reduction oxidation } \\
\text { TBP = tributyl phosphate }\end{array}$} \\
\hline
\end{tabular}

\subsection{Simulant Development}

BNI plans to carry out process development and scale-up testing to demonstrate the design effectiveness of both the caustic- and the oxidative-leaching processes over the entire applicable range of Hanford tank farm wastes. ${ }^{\text {(a) }}$ Scale-up testing will require substantial volumes of feed. Therefore, the development of simulants that mimic the chemical, leaching, and ultrafiltration behaviors over the range observed for actual waste groups is necessary to the process development and demonstration. The characterization and leaching performance data obtained from the actual waste testing will serve as benchmarks for defining the simulant characteristics and behaviors and as a basis for revising the parameters used in evaluating WTP process performance using the appropriate process models.

\subsection{Testing of Groups 3 and 4}

The characterization and parametric leaching of two of the eight defined groups-PUREX cladding waste (CWP) sludge (Group 3) and REDOX cladding waste (CWR) sludge (Group 4) - are the subject of this report. For both of these groups, the solids consist of $>85 \%$ gibbsite. The Group 3 and 4 testing was focused on caustic dissolution of the gibbsite phase (Table 1.1) to better characterize the leaching chemistry of gibbsite as found in actual tank waste. The parametric caustic-leaching tests performed on

(a) WTP Doc. No. 24590-WTP-PL-ENG-06-0008, Rev 0, "Hanford Waste Treatment and Immobilization Plant (WTP) Project Response Plan for Resolution of Issues Identified by the Comprehensive Review of the WTP Flowsheet and Throughput." L Lucas, March 2006. 
these two groups of waste will serve to increase the understanding of how these waste types behave in the bench-scale pretreatment processes.

The waste-type definition, sample identification, archived sample conditions, and homogenization activities are discussed in this report. The caustic leaching experiments and results are described for the Group 3 and Group 4 solids. The physical, chemical, radioisotope, and crystal morphology characterization in the waste before and after leach processing are also discussed.

The results from these tests will refine the knowledge base of the tank waste chemical and mineralogical characteristics. Parametric leach testing will provide the leaching kinetics of gibbsite to support followon leach and filtration testing with simulants. 


\subsection{Test Sample Selection, Compositing, and Homogenization}

This section describes the rationale for selecting PUREX cladding waste (CWP) sludge (Group 3) and REDOX cladding waste (CWR) sludge (Group 4) test materials from the Hanford tank waste sample archive located in the $222 \mathrm{~S}$ building at the Hanford Site. Retrieval of new sample materials from the tanks was deemed to be prohibitively expensive and time intensive and therefore was not considered. Also described are the sample compositing and homogenization activities.

\subsection{Group 3 CWP and Group 4 CWR Sample Selection}

CWP sludge with a predominant gibbsite component was targeted for testing to support the Group 3 gibbsite leaching studies. The Tank-Waste Information Network System (TWINS) database ${ }^{(a)}$ was queried to identify the tanks containing $>50 \%$ CWP. These tank wastes were queried in the Best Basis Inventory $(\mathrm{BBI})^{(\mathrm{a})}$ for the major inorganic components (Al, $\mathrm{Bi}, \mathrm{Cr}, \mathrm{Fe}, \mathrm{Na}, \mathrm{Si}, \mathrm{U}, \mathrm{Zr}$, and phosphate) in the solid and sludge phases. Figure 2.1 shows the relative mass distributions of these analytes for the Group 3 sample. Note that major elemental and anionic contributions from $\mathrm{Na}$, nitrate, nitrite, and oxalate were excluded from the data in Figure 2.1.

The $222 \mathrm{~S}$ archive sample inventory ${ }^{(\mathrm{b})}$ was searched for sludge samples from the tanks identified as containing $>50 \% \mathrm{CWP}$. The samples were then cross-referenced to the TWINS database to determine if analytical data from the specific samples were available; samples identified as containing $>70 \mathrm{mg} \mathrm{Al}$ per g sludge (wet mass basis) were carried forward in the selection process. Of these samples, those with $<5 \mathrm{~g}$ of material were omitted. The final list of samples was submitted to $\mathrm{CH} 2 \mathrm{MHill}$ personnel ${ }^{(\mathrm{c})}$ to confirm that 1) the samples represent the CWP stream based on the tank strata, core segment, and corresponding characterization results and 2) the samples were not held for other activities and could be released from the archive.

CWR sludge with a predominant gibbsite component was targeted for testing to support the Group 4 gibbsite leaching studies. Selection was carried out in the same manner as for the Group 3 samples, except that tanks containing $>50 \%$ CWR were identified, and samples identified as containing $>100 \mathrm{mg}$ Al per g sludge (wet mass basis) were carried forward in the selection process. Figure 2.2 shows the relative mass distributions of selected analytes for the Group 4 sample.

The decision process flowchart for selecting tank waste samples from the sample archive is summarized in Figure 2.3.

(a) The TWINS database and the BBI are DOE-owned resources.

(b) Personal communication of the inventory database, file "Vials May 18," provided from P Brackenbury, Bechtel, June 2006.

(c) Dave Place and Bruce Higley, Process Engineers, Process Analysis Organization, CH2MHill. 


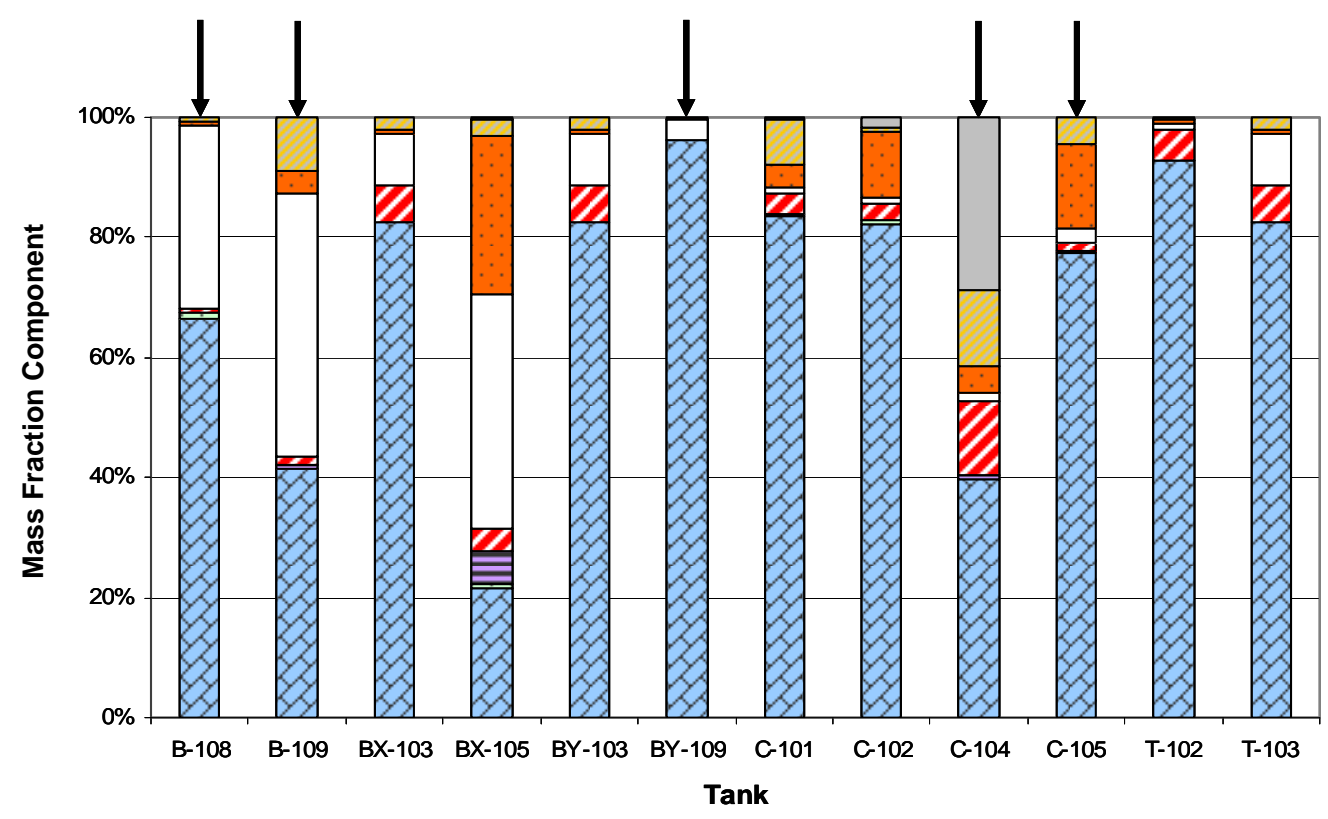

$\square \mathrm{Al} \quad \square \mathrm{Bi} \quad$ 算 $\quad \square \mathrm{Fe} \quad \square \mathrm{PO} 4 \quad \square \mathrm{Si} \quad \square$ UTOTAL $\quad \square \mathrm{Zr}$

Figure 2.1. Estimated Tank Waste Composition of Selected Analytes for CWP Sludge Wastes in the Hanford Tank Farm (BBI Source). Note: arrows point to the tanks actually used to prepare the Group 3 composite. The major elemental and anionic contributions from $\mathrm{Na}$, nitrate, nitrite, and oxalate were excluded from the data. 


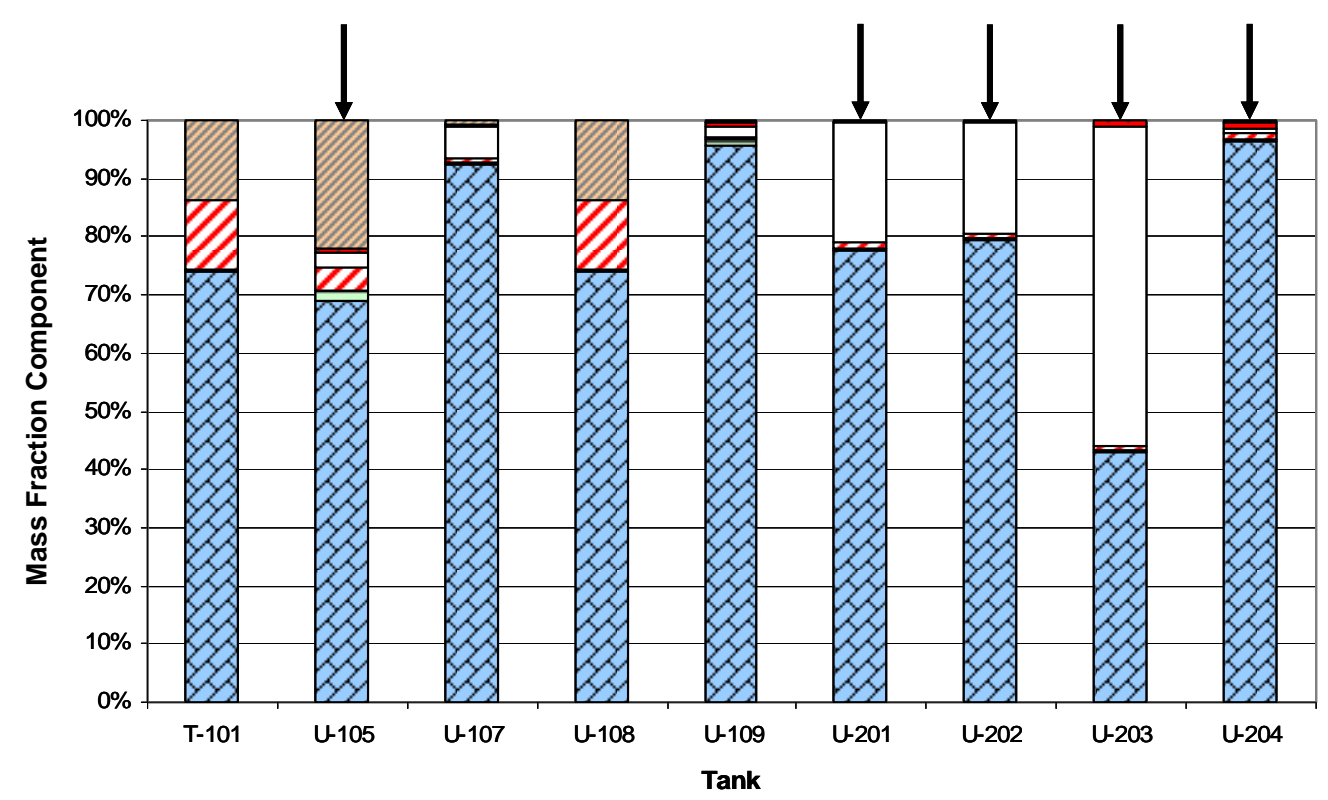

\begin{tabular}{|c|c|c|c|c|c|c|c|}
\hline 曰 Al & $\square \mathrm{Bi}$ & 目 $\mathrm{Cr}$ & $\square \mathrm{Fe}$ & $\square$ PO4 & $\square \mathrm{Si}$ & ■ UTOTAL & $\square \mathrm{Zr}$ \\
\hline
\end{tabular}

Figure 2.2. Estimated Tank Waste Composition of Selected Analytes for CWR Sludge Wastes in the Hanford Tank Farm (BBI Source). Note: arrows point to the tanks actually used to prepare the Group 4 composite. The major elemental and anionic contributions from $\mathrm{Na}$, nitrate, nitrite, and oxalate were excluded from the data. 
Identify Tank Waste Samples from TWINS

(CWP for Group 3, CWR for Group 4)

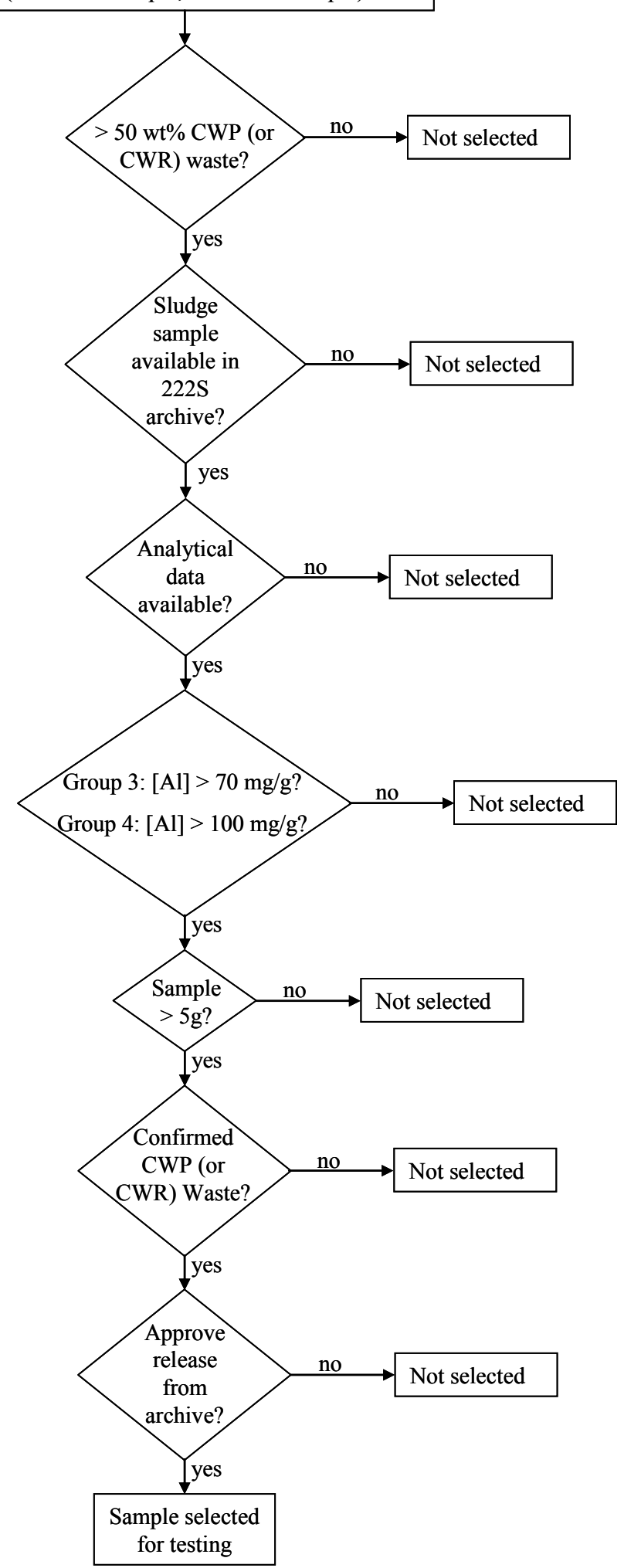

Figure 2.3. Selection Decision Process for Group 3 and Group 4 Sludge Samples 
Table 2.1 summarizes the tank sources evaluated for Group 3 and shows whether the tank met or failed the selection criteria. Samples highlighted in bold in the table were those determined to meet all of the selection criteria.

Table 2.1. Selection of Group 3-PUREX Cladding Waste Sludge Tanks

\begin{tabular}{|c|c|c|c|c|c|}
\hline \multirow[b]{2}{*}{ Tank } & \multirow[b]{2}{*}{$\begin{array}{c}\text { CWP Sludge } \\
\text { kL }\end{array}$} & \multirow[b]{2}{*}{$\begin{array}{c}\text { Total Sludge, } \\
\text { kL }\end{array}$} & \multirow[b]{2}{*}{$\begin{array}{l}\text { Fraction CWP } \\
\text { Sludge }\end{array}$} & \multicolumn{2}{|c|}{ 222S Archive } \\
\hline & & & & $\begin{array}{c}\text { Available } \\
\text { Samples }\end{array}$ & $\begin{array}{c}\text { Analytical } \\
\text { Results }\end{array}$ \\
\hline B-108 & 104 & 104 & 1 & yes & yes \\
\hline B-109 & 189 & 189 & 1 & yes & yes \\
\hline $\mathrm{BX}-103^{(\mathrm{a})}$ & 214 & 235 & 0.91 & yes & no \\
\hline $\mathrm{BX}-105^{(\mathrm{a})}$ & 96 & 160 & 0.60 & yes & no \\
\hline $\mathrm{BY}-103^{(\mathrm{a})}$ & 34 & 34 & 1 & yes & no \\
\hline BY-109 & 89 & 89 & 1 & yes & yes \\
\hline $\mathrm{C}-101^{(\mathrm{b})}$ & 208 & 333 & 0.62 & no & yes \\
\hline $\mathrm{C}-102^{\text {(a) }}$ & 980 & 1196 & 0.82 & yes & no \\
\hline C-103 & 101 & 101 & 1 & yes & yes \\
\hline C-104 & 555 & 980 & 0.57 & yes & yes \\
\hline C-105 & 450 & 500 & 0.9 & yes & yes \\
\hline $\mathrm{T}-102^{(\mathrm{b})}$ & 64 & 72 & 0.89 & no & yes \\
\hline $\mathrm{T}-103^{(\mathrm{b})}$ & 64 & 87 & 0.74 & no & yes \\
\hline \multicolumn{6}{|c|}{$\begin{array}{l}\text { (a) Characterization data were not available in TWINS. } \\
\text { (b) Sludge samples not available at } 222 \mathrm{~S} \text { based on inven }\end{array}$} \\
\hline
\end{tabular}

Table 2.2 summarizes the individual samples (sample date, tank ID, sample core, and segment) from the archive that met the selection criteria. These samples had been in storage at $222 \mathrm{~S}$ for $\sim 5$ to 12 years. The long storage time could potentially cause the sample characteristics to be altered relative to the asretrieved sample condition through aging and drying. However, as stated previously, obtaining fresh core samples from the Hanford waste tanks was outside the scope of the project budget and schedule. Also shown in Table 2.2 are the anticipated aluminum concentrations (wet sample basis) and the mass assumed available based on the archive inventory in $\sim 2002$. A total of $0.90 \mathrm{~kg}$ of PUREX cladding sludge was assumed to be available and sufficient for the complete testing scope. However, several samples were not available. Based on changes to the samples used (e.g., before sub-sampling) and the gross and tare weights provided along with the samples, this lowered the expected value of CWP sludge to $0.574 \mathrm{~kg}$.

Table 2.3 summarizes the tank sources evaluated for Group 4 and shows whether the tank met or failed the selection criteria. Samples highlighted in bold in the table were those determined to meet all of the selection criteria. 
Table 2.2. Group 3 Samples and Masses from 222S Archive

\begin{tabular}{|c|c|c|c|c|c|c||}
\hline $\begin{array}{c}\text { Tank } \\
\text { Sampling } \\
\text { Date }\end{array}$ & Jar \# & Tank & Core & Segment & $\begin{array}{c}\text { Estimated } \\
\text { Al, mg/g }\end{array}$ & $\begin{array}{c}\text { Net Sample } \\
\text { Weight (g) }\end{array}$ \\
\hline $4 / 10 / 1995$ & 19798 & C-105 & 72 & 3 & 219 & 53.72 \\
\hline $4 / 4 / 1996$ & 9765 & C-105 & 72 & 3 & 219 & 32 \\
\hline $9 / 15 / 1996$ & 11356 & C-104 & 162 & 4 & 215 & 19.9 \\
\hline $9 / 4 / 1996$ & 11244 & C-104 & 165 & 6 & 197 & 21.9 \\
\hline $9 / 16 / 1996$ & 11366 & C-104 & 165 & 6 & 197 & 31.9 \\
\hline $9 / 16 / 1996$ & 11245 & C-104 & 165 & 6 & 197 & 7 \\
\hline $7 / 1 / 1997$ & 13043 & BY-109 & 203 & 7 & 197 & 55 \\
\hline $7 / 1 / 1997$ & 13044 & BY-109 & 203 & 7 & 197 & 101.6 \\
\hline $1 / 21 / 2002$ & 19098 & BY-109 & 203 & 7 & 197 & 121.2 \\
\hline $2 / 4 / 2002$ & 19134 & BY-109 & 203 & 7 & 197 & 17.5 \\
\hline $3 / 6 / 1995$ & 6440 & C-103 & 66 & 4 & 192 & 18.84 \\
\hline $10 / 18 / 1996$ & 11505 & B-108 & 173 & 1 & 98.9 & 12.06 \\
\hline $10 / 18 / 1996$ & 11506 & B-108 & 173 & 1 & 98.9 & 53.95 \\
\hline $10 / 17 / 1996$ & 11507 & B-108 & 173 & Comp & 79.2 & 22.4 \\
\hline $9 / 17 / 1996$ & 11486 & B-109 & 169 & 2 & 104 & 59.3 \\
\hline \multicolumn{7}{|l|}{} \\
\hline $\begin{array}{l}\text { (a) Sample date is defined in TWINS database. } \\
\text { (b) Wet mass basis, as defined in TWINS database. }\end{array}$ \\
\hline
\end{tabular}

Table 2.3. Selection of REDOX Cladding Waste Sludge Tanks

\begin{tabular}{|c|c|c|c|c|c|}
\hline \multirow[b]{2}{*}{ Tank } & \multirow[b]{2}{*}{$\begin{array}{c}\text { CWR Sludge } \\
\text { kL }\end{array}$} & \multirow[b]{2}{*}{$\begin{array}{c}\text { Total Sludge, } \\
\text { kL }\end{array}$} & \multirow[b]{2}{*}{$\begin{array}{c}\text { Fraction CWR } \\
\text { Sludge }\end{array}$} & \multicolumn{2}{|c|}{ 222S Archive } \\
\hline & & & & $\begin{array}{l}\text { Available } \\
\text { Samples }\end{array}$ & $\begin{array}{l}\text { Identified as } \\
\text { Sludge }\end{array}$ \\
\hline $241-\mathrm{T}-101^{(\mathrm{a})}$ & 140 & 140 & 1 & no & yes \\
\hline 241-U-105 & 121 & 121 & 1 & yes & yes \\
\hline $241-\mathrm{U}-107^{(\mathrm{b})}$ & 57 & 57 & 1 & yes & no \\
\hline $241-\mathrm{U}-108^{(\mathrm{b})}$ & 110 & 110 & 1 & yes & no \\
\hline 241-U-204 & 7 & 7 & 1 & yes & yes \\
\hline $241-U-109^{(b)}$ & 103 & 103 & 1 & yes & no \\
\hline 241-U-201 & 11 & 11 & 1 & yes & yes \\
\hline 241-U-202 & 10 & 10 & 1 & yes & yes \\
\hline 241-U-203 & 9 & 9 & 1 & yes & yes \\
\hline \multicolumn{6}{|c|}{$\begin{array}{l}\text { (a) Samples not available at } 222 \mathrm{~S} \text { based on inventory. } \\
\text { (b) TWINS lists samples as "saltcake" or "mix saltcake/sludge," i.e., not sludge. }\end{array}$} \\
\hline
\end{tabular}

Table 2.4 summarizes the individual samples (sample date, tank ID, sample core, and segment) from the archive that met the selection criteria. These samples had also been in storage at 222-S for $\sim 5$ to 12 years. A total of $0.66 \mathrm{~kg}$ of CWR sludge was assumed to be available and sufficient for the complete testing scope. However, one sample was not available. Based on changes to the samples used and the gross and 
tare weights provided along with the samples, this lowered the expected value of CWR sludge to $0.622 \mathrm{~kg}$.

Table 2.4. Group 4 Samples and Masses from $222 \mathrm{~S}$ Archive

\begin{tabular}{|c|c|c|c|c|c|c|}
\hline $\begin{array}{c}\text { Tank } \\
\text { Sampling } \\
\text { Date }^{(a)}\end{array}$ & Jar \# & Tank & Core & Segment & $\begin{array}{l}\text { Estimated } \\
\text { Al, mg/g }\end{array}$ & $\begin{array}{l}\text { Net Sample } \\
\text { Weight (g) }\end{array}$ \\
\hline $4 / 6 / 1995$ & 6916 & U-202 & 78 & 1 & 309 & 75.16 \\
\hline $4 / 6 / 1995$ & 6911 & U-202 & 78 & 1 & 309 & 73.53 \\
\hline $11 / 19 / 1998$ & 15011 & U-202 & 78 & 1 & 309 & 28.8 \\
\hline $9 / 17 / 1997$ & 13486 & U-202 & 78 & 1 & 309 & 12.4 \\
\hline $8 / 7 / 2002$ & 19169 & U-202 & 78 & Comp & 309 & 31.6 \\
\hline $4 / 6 / 1995$ & 6882 & U-201 & 70 & 2 & 250 & 32.1 \\
\hline $8 / 8 / 2002$ & 19154 & U-201 & 70 & Comp & 250 & 25.6 \\
\hline 9/26/1997 & 13462 & U-201 & 74 & 1 & 250 & 31.4 \\
\hline $11 / 19 / 1998$ & 15020 & U-204 & 82 & 1 & 229 & 32.9 \\
\hline $7 / 30 / 2002$ & 19476 & U-203 & 80 & 1 & 212 & 31.5 \\
\hline $8 / 18 / 1999$ & 16961 & U-105 & 136 & $9 \mathrm{~A}$ & 165 & 120.9 \\
\hline 4/5/1996 & 9711 & U-105 & 136 & $9 \mathrm{~A}$ & 165 & 79.29 \\
\hline 4/3/1996 & 9702 & U-105 & 136 & 9A & 165 & 11.97 \\
\hline 9/8/1997 & 13072 & U-204 & 81 & 1 & 148 & 65.09 \\
\hline \multicolumn{5}{|c|}{ (9) Sample date is defined in TWINS datahoce } & Sum & 652 \\
\hline
\end{tabular}

\subsection{Equipment for Group 3 and 4 Sample Homogenization and Sub- Sampling}

Because of the small number of samples available for Group 3 CWP sludge waste and Group 4 CWR sludge waste, a different method for compositing and homogenization had to be developed than was used for the other waste groupings. It was desirable to achieve uniform mixing, including breaking up agglomerates and dried clumps that may have formed due to dehydration during the archival storage period. Furthermore, it was desired to mix the samples without affecting the original particle-size distribution of the material. Several methods were tried and discarded because of the potential for sample loss or the potential to alter the fundamental particle-size structure of the original material. The method that showed the most promise was using stainless steel ball bearings with hand agitation of the jar.

Kaolin and Bentonite clay simulants of varying yield strengths and levels of hydration were used to determine the level of mixing achievable in 220-, 500- and 1000-mL jars with the use of stainless steel ball bearings. These clays were chosen for two reasons. First, they have distinctly different colors, allowing for a visual determination of effectiveness of the mixing. Second, these clays each have a different affinity for water and therefore do not necessarily combine uniformly without problems.

It was determined that the best mixing occurred with a minimum of five stainless steel ball bearings, and 5 to 10 was optimal. It was also determined that homogeneity was usually reached after 10 to 15 minutes of mixing. A minimum mixing time of 20 minutes was adopted for the test instructions. 
Safety-coated glass bottles were used for all compositing of tank wastes for this work to make sure that if the jar were to crack or break, the testing-material loss would be minimized. No bottles broke during this work. Poly bottles $(1 \mathrm{~L})$, tared and filled with DI water, were taken into the hot cell. This was the source of all water used for rinsing and rehydrating the samples. Steel scrapers and rubber spatulas were fitted for use in HLRF with the manipulators. Stainless steel strainers were modified and used to remove the ball bearings after compositing and to verify that no large agglomerates or foreign materials (such as rocks) were in the samples.

\subsection{Group 3 Sample Homogenization and Sub-Sampling}

The 15 Group 3 CWR sludge samples were shipped from the Hanford 222S laboratory to PNNL. Masses for these archived samples were provided by Advanced Technologies and Laboratories International (ATL) in the shipping letter report. Many of the samples had dried out during the time spent in archived storage. Photographs, as-received weights, and detailed sample descriptions were all recorded in TI-RPPWTP-513. The samples' appearance and color ranged from white dry solids, to gray pastes, to tan sludge. The supernatant liquid was yellow on the samples that still had standing liquid. Figure 2.4 shows some representative photographs of the as-received samples.


Figure 2.4. Representative Photographs of As-Received Group 3 Waste Samples

The Group 3 sample material fell into the following general categories:

- Dry powdery sample

- Dry solid sample; usually added water to soak sample so it could be broken up and removed from the jar for compositing.

- Semi-solid; usually sample was added to composite without soaking sample with water first.

- Clearly visible supernatant liquid in jar with sludge.

- Samples with previous lid fragments that needed to be removed.

The 15 individual sample jars for Group 3 consisted of samples from six tanks (B-108, B-109, C-103, C-104, C-105, and BY-109). The materials from the six tanks each went through a stepwise compositing 
process, where samples from each tank were homogenized in sub-composite jars. Since these samples represent the last remaining sources of this tank waste without retrieving another core, it was determined that small archive samples of the composited waste from each tank should be taken for potential analysis at a later date. After the archive samples were removed, the sub-composites were combined into a 1-L jar and homogenized. Table 2.5 lists the individual samples from each tank, along with gross mass (expected and found), the mass of the empty container, and the net mass of waste transferred to the sub-composite jars.

Table 2.5 shows each of the samples from the six tanks. The B-109 and C-103 wastes each consisted of one sample, so no sub-compositing was necessary. The C-105 waste consisted of two samples, approximately $64.5 \mathrm{~g}$ of expected combined mass. C-105 tank samples were initially composited as dry material because the white solids transferred quantitatively from the sample jars to the corresponding subcomposite jar without the need of water. The B-108 waste consisted of three samples, approximately $74.8 \mathrm{~g}$ of expected combined mass. These samples were combined and homogenized in a $500-\mathrm{mL}$ jar. The C-104 waste consisted of four samples, approximately $66.8 \mathrm{~g}$ of expected combined mass. These samples were combined and homogenized in a $220-\mathrm{mL}$ jar. The BY-109 waste consisted of four samples, approximately $292.5 \mathrm{~g}$ of expected combined mass. These samples were combined and homogenized in a 500-mL jar.

For the wet samples from Tanks B-108, C-104, and BY-109, solids were removed from the sample jars by a process of scraping and rinsing with DI water using a squirt bottle. In this fashion, nearly all residues were removed from the sample jars. There may have been some loss of water due to evaporation that would be increased by air flow and temperature inside the hot cell, which is usually 28 to $35^{\circ} \mathrm{C}$.

The sub-composite slurries from each tank were allowed to hydrate overnight. Then stainless steels balls ( 5 to 10 in number) were added to each sub-composite jar, and the samples were mixed by tumbling until visually homogeneous or a minimum of 20 minutes. After this, an archive sample was removed from each of the six sub-composite samples by pipette with the tip removed to make sure that larger particles were not excluded. 
Table 2.5. Group 3 Tank Samples

\begin{tabular}{|c|c|c|c|c|c|}
\hline $\begin{array}{l}\text { Hanford } \\
\text { Tank ID }\end{array}$ & 222-S ID & $\begin{array}{c}\text { 222S Expected } \\
\text { Gross } \\
\text { Mass (g) }\end{array}$ & $\begin{array}{l}\text { PNNL As- } \\
\text { found } \\
\text { Gross } \\
\text { Mass (g) }\end{array}$ & $\begin{array}{c}\text { PNNL Empty } \\
\text { Container } \\
\text { Mass (g) }\end{array}$ & $\begin{array}{c}\text { PNNL Mass } \\
\text { Transferred } \\
\text { (g) }\end{array}$ \\
\hline C-103 & 6440 & 41.2 & 41.795 & 26.919 & 14.876 \\
\hline B-109 & 11486 & 147.1 & 151.828 & 94.078 & 57.750 \\
\hline C-105 & 9765 & 116.0 & 122.165 & 80.54 & 41.625 \\
\hline C-105 & 19798 & None & 118.03 & 85.58 & 32.45 \\
\hline \multicolumn{5}{|c|}{ C-105 Sub total net weight $=$} & 74.08 \\
\hline B-108 & 11505 & 100.0 & 105.08 & 94.336 & 10.74 \\
\hline B-108 & 11506 & 140.2 & 144.613 & 93.715 & 50.90 \\
\hline B-108 & 11507 & 98.8 & 104.243 & 94.606 & 9.64 \\
\hline \multicolumn{5}{|c|}{ B-108 Sub total net weight $=$} & 71.28 \\
\hline C-104 & 11244 & 107.5 & 113.37 & 95.585 & 17.78 \\
\hline $\mathrm{C}-104$ & 11245 & 99.9 & 102.548 & 93.468 & 9.08 \\
\hline C-104 & 11356 & 109.3 & 114.31 & 95.672 & 18.64 \\
\hline C-104 & 11366 & 104.2 & 107.558 & 92.371 & 15.19 \\
\hline \multicolumn{5}{|c|}{ C-104 Sub total net weight $=$} & 60.69 \\
\hline BY-109 & 13043 & 144 & 143.50 & 94.092 & 49.41 \\
\hline BY-109 & 13044 & 185.8 & 187.529 & 95.191 & 92.34 \\
\hline BY-109 & 19098 & 203.6 & 200.749 & 90.568 & 110.18 \\
\hline BY-109 & 19134 & 101.9 & 107.115 & 91.593 & 15.52 \\
\hline \multicolumn{5}{|c|}{ BY-109 Sub total net weight $=$} & 267.45 \\
\hline
\end{tabular}

After all of the recoverable sample materials were transferred to the larger sub-composite jars, the empty sample jars were reweighed after the residual water from the rinsing process had evaporated. These values were used to calculate sample recovery and actual amount of sample added to each sub-composite jar. A few jars had significant differences between the expected gross mass and the as-found gross mass. These larger differences are probably due to loss of water from the sample over time during storage at $222 \mathrm{~S}$ and/or sample loss in shipping. The jar lids tend to become brittle in the radiological environment over time, so some of these likely cracked, and the water evaporated. Some tare masses were based on jars with blue lids; lids had been replaced with green lids for shipping. The mass difference associated with the change in lids is $\sim 4.6 \mathrm{~g}$, and this was taken into account for the applicable samples. New lids were placed on the jars before shipping.

Following removal of the archive samples, the remaining sample equivalent weights of the six tank subcomposites were determined as shown in Table 2.6. 
Table 2.6. Group 3 Sub-Composite Samples

\begin{tabular}{|c|c|c|c|c|c|c||}
\hline & $\begin{array}{c}\text { Mass } \\
\text { Transferred } \\
\text { from original } \\
\text { bottles (g) }\end{array}$ & $\begin{array}{c}\text { Archive } \\
\text { Sample } \\
\text { Mass (g) }\end{array}$ & $\begin{array}{c}\text { Loss in } \\
\text { Transfer to } \\
\text { Final (g) }\end{array}$ & $\begin{array}{c}\text { Mass of } \\
\text { original } \\
\text { sample } \\
\text { Transferred } \\
\text { (g) }\end{array}$ & $\begin{array}{c}\text { Mass Water } \\
\text { added (g) }\end{array}$ & $\begin{array}{c}\text { Total Mass } \\
\text { Slurry (g) }\end{array}$ \\
\hline C-103 & 14.88 & 0.817 & 0.0 & 14.06 & none & 14.06 \\
\hline B-109 & 57.75 & 3.66 & 0.0 & 54.09 & none & 54.09 \\
\hline $\begin{array}{c}\text { TI-513-C105- } \\
\text { Comp }\end{array}$ & 74.08 & 1.99 & -0.12 & 72.09 & none & 72.09 \\
\hline $\begin{array}{c}\text { TI-513-B108- } \\
\text { Comp }\end{array}$ & 71.28 & 9.26 & 4.63 & 57.39 & 152 & 209.39 \\
\hline $\begin{array}{c}\text { TI-513- } \\
\text { BY109-Comp }\end{array}$ & 267.50 & 5.69 & 2.67 & 259.14 & 189 & 448.14 \\
\hline $\begin{array}{c}\text { TI-513-C104- } \\
\text { Comp }\end{array}$ & 60.69 & 5.16 & 3.06 & 52.47 & 97 & 149.47 \\
\hline \multicolumn{1}{|l|}{} & & $\begin{array}{c}\text { Total Tank } \\
\text { Slurry } \\
\text { Material } \\
\text { Transferred: }\end{array}$ & 509.23 & $\begin{array}{c}\text { Total } \\
\text { Composite } \\
\text { Slurry } \\
\text { Material } \\
\text { Transferred: }\end{array}$ & \\
\hline
\end{tabular}

The total mass of the Group 3 sample material provided by 222S was expected to be $574.2 \mathrm{~g}$, and the PNNL net adjusted weight recovered was $535.8 \mathrm{~g}$ for the combined tanks (including the archive sample masses), for an adjusted recovery of $93 \%$. Half of the final tank composite based on the mass balance was made up of BY-109 tank wastes as can be seen in Figure 2.5. The sub-composite samples indicated in Table 2.6 were transferred with water rinsing as needed and combined into a 1-L final composite jar, TI-513-AR-J1. During this process, the sub-composite samples were passed though a stainless steel strainer to remove the stainless steel balls used for the previous mixing and to make sure that no large aggregates or large pieces of foreign material, like rocks, would remain in the sample. After all samples had been added to the final composite jar and all equipment (spatula, sieve, and mashing tool) had been rinsed free of sample, the sieve screen was removed. Total sample mass, settled solids density, and slurry density were measured after 1 and 11 days. The results are given in Table 2.7.

Table 2.7. Group 3 Final Compositing Stage, Transferring Sub-Composites to 1-Liter Composite Jar

\begin{tabular}{|c|c|c|c|c|c|}
\hline $\begin{array}{c}\text { 1-Liter Comosite } \\
\text { Jar ID }\end{array}$ & $\begin{array}{c}\text { Sample } \\
\text { Net Wt, g }\end{array}$ & $\begin{array}{c}\text { Total Slurry } \\
\text { Volume, mL }\end{array}$ & $\begin{array}{c}\text { Settled } \\
\text { Solids } \\
\text { Volume, mL }\end{array}$ & $\begin{array}{c}\text { Gross Slurry } \\
\text { Density, } \\
\text { g/mL }\end{array}$ & $\begin{array}{c}\text { \% Settled } \\
\text { Solids }\end{array}$ \\
\hline & & & After 1 Day: & \\
\hline TI-513-G3-AR-J1 & 1021.95 & 750 & 295 & 1.36 & 39.3 \\
\hline & & & After 11 Days: & 35.1 \\
\hline TI-513-G3-AR-J1 & 1016.81 & 740 & 260 & 1.37 & \multicolumn{5}{|l}{} \\
\hline
\end{tabular}




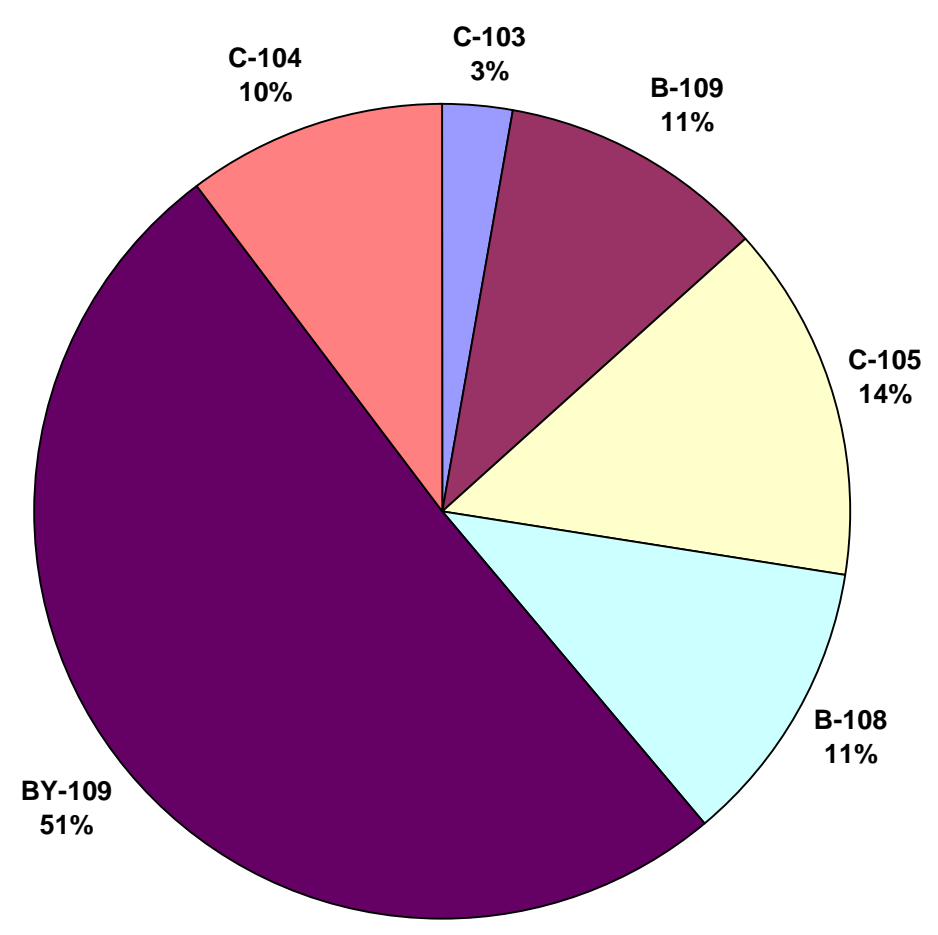

Figure 2.5. Contribution of the Individual Tanks to the Composition of the Group 3 Composite Sample

The testing material contained solids that settled quickly. Therefore, it was determined that the final composite jar would be mixed with an overhead mixer for an hour. A mechanical stirrer with a stainless steel impeller was lowered into the 1-L bottle, and the material was mixed thoroughly. The temperature in the hot cell was $29^{\circ} \mathrm{C}$ at the start of mixing. The goal of this step was to homogenize the sample using as little force as possible. Speed was slowly increased until the solids were mobilized.

The Group 3 final composite was mixed for $1 \mathrm{~h}$ before commencement of sub-sampling. Subsamples were taken with the mixer still operating to achieve representative sub-sampling. The consistency of the Group 3 composite was viscous, and the sample was dark in color. The sub-samples were removed in a specific order to pre-determined target volumes. Pre-weighed and labeled jars and centrifuge tubes were staged in collection vessels in the order provided in Table 2.8. The remaining sample in the final composite was determined, and this was included in the following homogenization acceptance chart. 
Table 2.8. Group 3 Sub-Sample Mass Density and Settling Data

\begin{tabular}{||l|c|c|c|c|c|c||}
\hline $\begin{array}{c}\text { Sample ID in Order } \\
\text { of Collection }\end{array}$ & $\begin{array}{c}\text { Target } \\
\text { Collection } \\
\text { Volume }\end{array}$ & $\begin{array}{c}\text { Sample Net } \\
\text { Wt, g }\end{array}$ & $\begin{array}{c}\text { Total Slurry } \\
\text { Volume, mL }\end{array}$ & $\begin{array}{c}\text { Settled } \\
\text { Solids } \\
\text { Volume, mL }\end{array}$ & $\begin{array}{c}\text { Gross } \\
\text { Slurry } \\
\text { Density, } \\
\text { g/mL }\end{array}$ & $\begin{array}{c}\text { \% Settled } \\
\text { Solids }\end{array}$ \\
\hline TI-513-G3-AR-J1-I & na & 1016.810 & 740 & 260 & 1.37 & 35.1 \\
\hline TI-513-G3-AR-S1 & $8-10 \mathrm{~mL}$ & 9.399 & 6.90 & 2.65 & 1.36 & 38.4 \\
\hline TI-513-G3-AR-S2 & $8-10 \mathrm{~mL}$ & 10.842 & 8.05 & 3.05 & 1.35 & 37.9 \\
\hline TI-513-G3-AR-S3 & $8-10 \mathrm{~mL}$ & 8.036 & 5.95 & 2.10 & 1.35 & 35.3 \\
\hline TI-513-G3-AR-RH1 & $70 \mathrm{~mL}$ & 167.310 & 120 & 40 & 1.39 & 33.3 \\
\hline TI-513-G3-AR-C1 & $10-15 \mathrm{~mL}$ & 33.892 & 24.5 & 8.50 & 1.38 & 34.7 \\
\hline TI-513-G3-AR-C2 & $10-15 \mathrm{~mL}$ & 34.610 & 25.0 & 8.75 & 1.38 & 35.0 \\
\hline TI-513-G3-AR-J1-R & na & 737.600 & 535 & 205 & 1.38 & 38.3 \\
\hline
\end{tabular}

For compositing to be considered successful, the sample density and settled-solids-data standard deviation had to be less than $\pm 5 \%$, and there had to be no statistically significant trend in settled solids and density variation due to the order in which the subsamples were removed. Figure 2.6 shows that the Group 3 composting and sub-sampling successfully met these criteria.

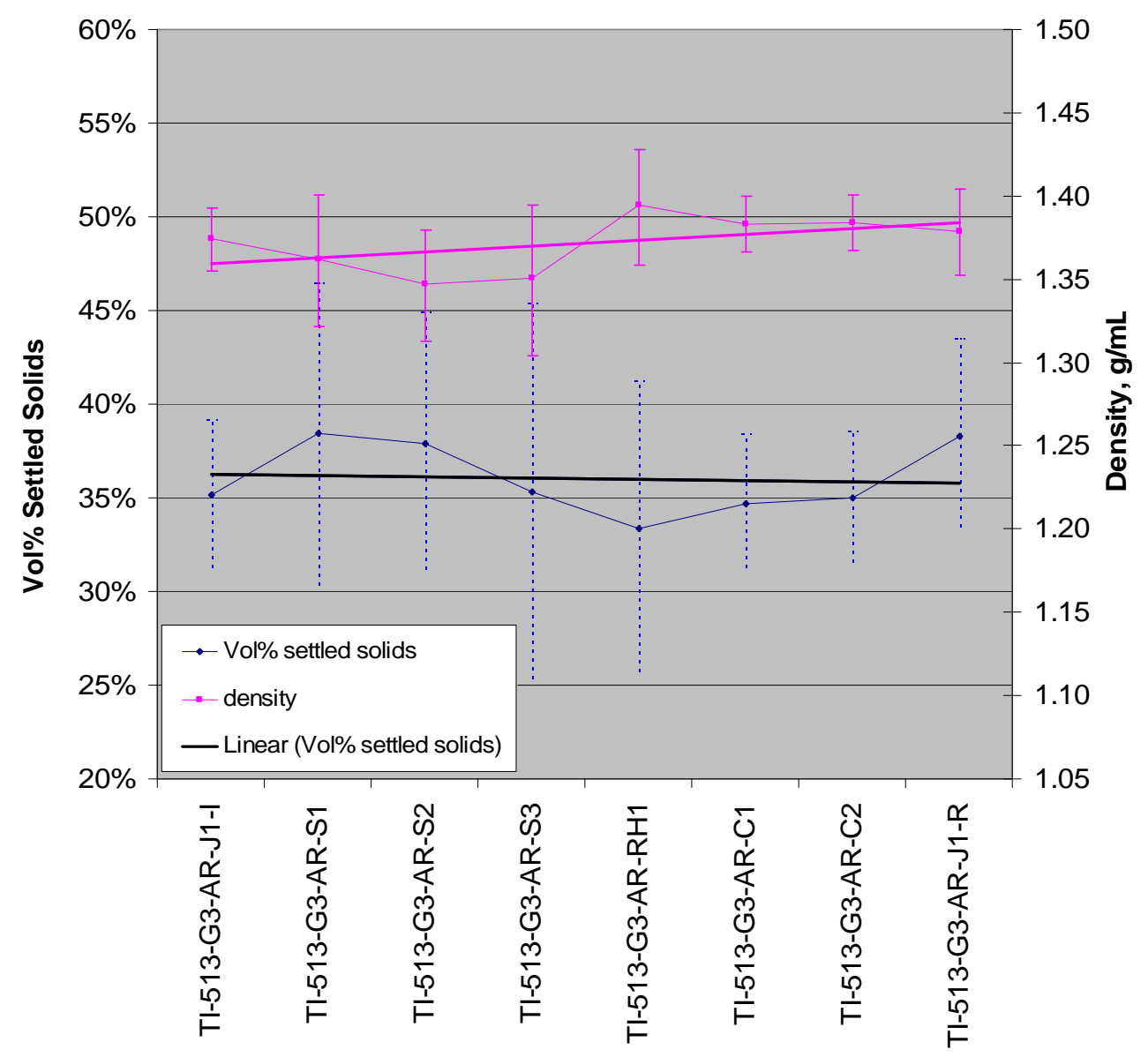

Figure 2.6. Group 3 Confirmation of Successful Material Composite Based on Density and Settled Solids 


\subsection{Group 4 Sample Homogenization and Sub-sampling}

The 14 Group 4 CWR sludge samples were shipped from the Hanford 222S laboratory to PNNL. Masses for these archived samples were provided by ATL in the shipping letter report. Many of the samples had dried out during the time spent in archived storage. Photographs, as-received weights, and detailed sample descriptions were all recorded in TI-RPP-WTP-514. The samples' appearance and color ranged from white dry powders, to gray solids, to dark tar-like sludge. The supernatant liquid was yellow on the samples that still had standing liquid. Figure 2.7 shows some representative photographs of the asreceived samples.
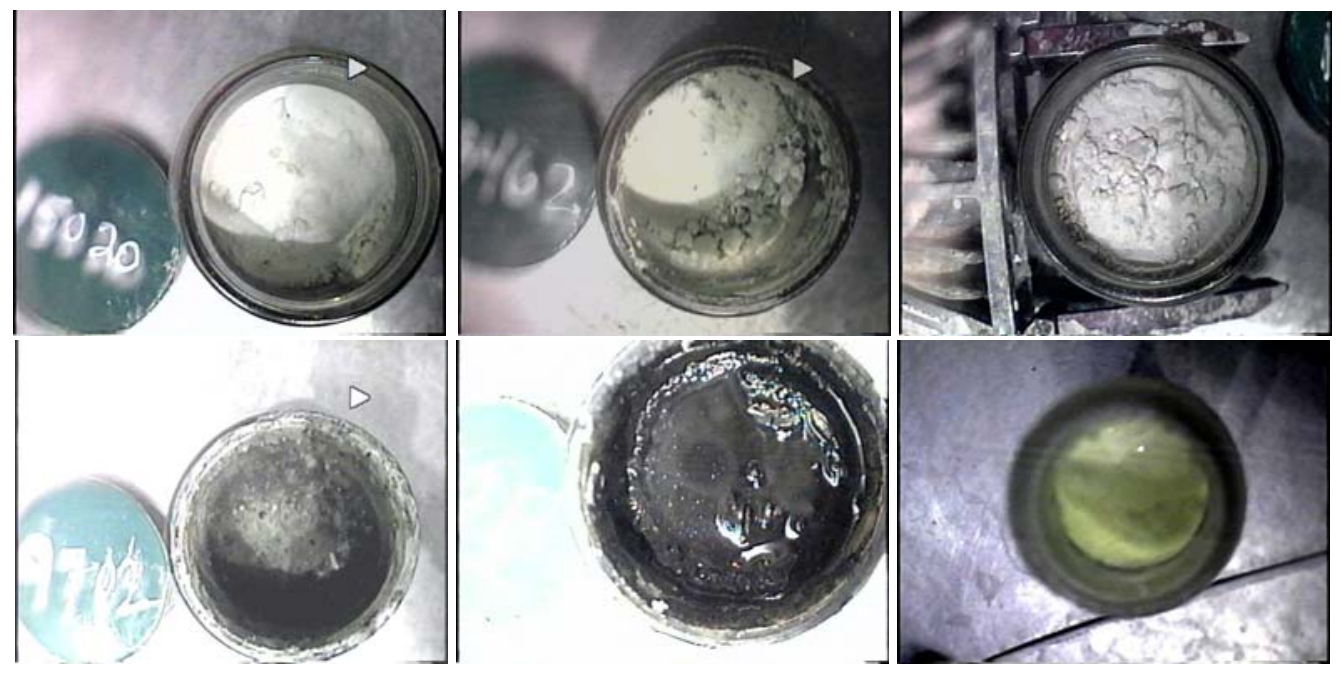

Figure 2.7. Representative Photographs of As-Received Group 4 Waste Samples

The Group 4 sample material fell into the following general categories:

- Dry powdery sample

- Dry solid sample; usually added water to soak sample so it could be broken up and removed from the jar for compositing.

- Semi-solid; usually sample was added to composite without soaking sample with water first.

- Clearly visible supernatant liquid in jar with sludge.

The 14 individual sample jars for Group 4 consisted of samples from five tanks (U-105, U-201, U-202, U-203, and U-204). These samples were treated in the same manner as the Group 3 samples, with a stepwise compositing process and removal of small archive samples. Table 2.9 lists the individual samples from each tank, along with gross mass (expected and found), the mass of the empty container, and the net mass of waste transferred to the sub-composite jars.

The U-203 waste consisted of one sample. The U-105 waste consisted of three samples, approximately $215.9 \mathrm{~g}$ of expected combined mass. These samples were combined and homogenized in a $500-\mathrm{mL}$ jar. The U-201 waste consisted of three samples, approximately $76.9 \mathrm{~g}$ of expected combined mass. These samples were combined and homogenized in a $220-\mathrm{mL}$ jar. The U-202 waste consisted of five samples, approximately $206 \mathrm{~g}$ of expected combined mass. These samples were combined and homogenized in a 
500-mL jar. The U-204 waste consisted of two samples, approximately $97.7 \mathrm{~g}$ of expected combined mass. These samples were combined and homogenized in a $220-\mathrm{mL}$ jar.

The wet samples from tanks U-105, U-201, U-202, and U-204 were transferred to the sub-composite jars and homogenized in the same manner as was discussed for the Group 3 samples. An archive sample was removed from each of the five sub-composite samples by pipette with the tip removed to make sure that larger particles were not excluded.

Table 2.9. Group 4 Tank Samples

\begin{tabular}{|c|c|c|c|c|c||}
\hline $\begin{array}{c}\text { Hanford } \\
\text { Tank ID }\end{array}$ & 222-S ID & $\begin{array}{c}\text { 222S Expected } \\
\text { Gross } \\
\text { Mass (g) }\end{array}$ & $\begin{array}{c}\text { PNNL As- } \\
\text { found } \\
\text { Gross } \\
\text { Mass (g) }\end{array}$ & $\begin{array}{c}\text { PNNL Empty } \\
\text { Container } \\
\text { Mass (g) }\end{array}$ & $\begin{array}{c}\text { PNNL Mass } \\
\text { Transferred } \\
\text { (g) }\end{array}$ \\
\hline U-203 & 19476 & 111.8 & 117.98 & 90.72 & 27.26 \\
\hline U-105 & 9702 & 102.2 & 101.49 & 92.27 & 9.22 \\
\hline U-105 & 9711 & 169.9 & 168.42 & 92.42 & 76.00 \\
\hline U-105 & 16961 & 205.8 & 205.38 & 93.67 & 111.71 \\
\hline \multicolumn{7}{|c|}{ U-105 Sub total net weight = } & 196.93 \\
\hline U-201 & 6882 & 52.6 & 53.03 & 25.4 & 27.63 \\
\hline U-201 & 13462 & 111.2 & 116.42 & 89.41 & 27.01 \\
\hline U-201 & 19154 & 146.5 & 154.94 & 131.77 & 23.17 \\
\hline \multicolumn{7}{|c|}{ U-201 Sub total net weight = } & 77.8 \\
\hline U-202 & 6911 & 87.4 & 85.85 & 30.0 & 55.85 \\
\hline U-202 & 6916 & 97.4 & 96.69 & 30.0 & 66.69 \\
\hline U-202 & 13486 & 102.7 & 102.93 & 90.72 & 12.21 \\
\hline U-202 & 15011 & 111.8 & 114.56 & 91.13 & 23.43 \\
\hline U-202 & 19169 & 153.2 & 161.83 & 131.76 & 30.07 \\
\hline \multicolumn{7}{|c|}{ U-202 Sub total net weight = } & 188.3 \\
\hline U-204 & 13072 & 152.6 & 158.13 & 93.05 & 65.08 \\
\hline U-204 & 15020 & 118.9 & 125.03 & 92.50 & 32.53 \\
\hline \hline
\end{tabular}

After all of the recoverable sample materials were transferred to the larger sub-composite jars, the empty sample jars were reweighed after the residual water from the rinsing process had evaporated. These values were used to calculate sample recovery and actual amount of sample added to each sub-composite jar. As discussed for the Group 3 samples, a few jars had significant differences between the expected gross mass and the as-found gross mass. The same reasons discussed for the Group 3 samples apply to the Group 4 samples. Following removal of the archive samples, the remaining sample equivalent weights of five tank sub-composites were determined as shown in Table 2.10. 
Table 2.10. Group 4 Sub-Composite Samples

\begin{tabular}{|c|c|c|c|c|c|c|}
\hline Sub-Comp \# & $\begin{array}{c}\text { Mass } \\
\text { Transferred } \\
\text { from original } \\
\text { bottles (g) }\end{array}$ & $\begin{array}{c}\text { Archive } \\
\text { Sample } \\
\text { Mass (g) }\end{array}$ & $\begin{array}{c}\text { Loss in } \\
\text { Transfer to } \\
\text { Final (g) }\end{array}$ & 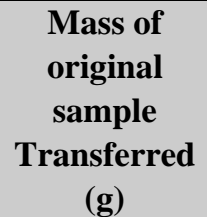 & $\begin{array}{c}\text { Mass Water } \\
\text { added (g) }\end{array}$ & $\begin{array}{l}\text { Total Mass } \\
\text { Slurry (g) }\end{array}$ \\
\hline U-203 & 27.26 & 3.02 & 0.0 & 24.24 & none & 24.24 \\
\hline $\begin{array}{l}\text { TI-514-U- } \\
\text { 105-Comp }\end{array}$ & 196.93 & 4.05 & 1.20 & 191.68 & 94.0 & 285.68 \\
\hline $\begin{array}{l}\text { TI-514-U- } \\
\text { 201-Comp }\end{array}$ & 77.8 & 1.77 & 0.99 & 75.04 & none & 75.04 \\
\hline $\begin{array}{l}\text { TI-514-U- } \\
\text { 202-Comp }\end{array}$ & 188.3 & 2.11 & 0.82 & 185.37 & none & 185.37 \\
\hline $\begin{array}{l}\text { TI-514-U- } \\
\text { 204-Comp }\end{array}$ & 97.6 & 1.91 & 0.0 & 95.69 & none & 95.69 \\
\hline & & & $\begin{array}{l}\text { Total Tank } \\
\text { Slurry } \\
\text { Material } \\
\text { Transferred: }\end{array}$ & 572.02 & $\begin{array}{c}\text { Total } \\
\text { Composite } \\
\text { Slurry } \\
\text { Material } \\
\text { Transferred: }\end{array}$ & 666.02 \\
\hline
\end{tabular}

The total mass of the Group 4 sample material obtained from 222S was expected to be $600.6 \mathrm{~g}$, and the PNNL net adjusted weight recovered was $584.88 \mathrm{~g}$ for the combined tanks (including the archive sample masses) for an adjusted recovery of $97 \%$. Over half of the final tank composite based on the mass balance was made up of U-202 and U-105 tank wastes as can be seen in Figure 2.8.

The sub-composite samples indicated in Table 2.10 were transferred with water rinsing as needed and combined into a 1-L final composite jar, TI-514-AR-J1. During this process, the sub-composite samples were passed though a stainless steel strainer to remove the stainless steel balls used for the previous mixing and to make sure that no large aggregates or large pieces of foreign material, like rocks, would remain in the sample. After all samples had been added to the final composite jar and all equipment (spatula, sieve, and mashing tool) had been rinsed free of sample, the sieve screen was removed. The total sample mass, settled solids density, and slurry density were measured after $2 \mathrm{~h}$ and 4 days. The results are given in Table 2.11.

Table 2.11. Final Group 4 Compositing Stage, Transferring Sub-Samples to 1-L Composite Jar

\begin{tabular}{|c|c|c|c|c|c|}
\hline $\begin{array}{c}\text { 1-Liter } \\
\text { Composite Jar } \\
\text { ID } \\
\end{array}$ & $\begin{array}{c}\text { Sample } \\
\text { Net } W t, g \\
\end{array}$ & $\begin{array}{l}\text { Total Slurry } \\
\text { Volume, mL }\end{array}$ & $\begin{array}{c}\text { Settled } \\
\text { Solids } \\
\text { Volume, } \mathbf{m L} \\
\end{array}$ & $\begin{array}{c}\text { Gross Slurry } \\
\text { Density, } \\
\text { g/mL } \\
\end{array}$ & $\begin{array}{c}\% \text { Settled } \\
\text { Solids } \\
\end{array}$ \\
\hline & \multicolumn{5}{|c|}{ After 2 Hours: } \\
\hline TI-514-G3-AR-J1 & 1055.14 & 800 & 220 & 1.32 & 27.5 \\
\hline & \multicolumn{5}{|c|}{ After 4 Days: } \\
\hline TI-514-G3-AR-J1 & 1055.14 & 785 & 295 & 1.34 & 37.6 \\
\hline
\end{tabular}




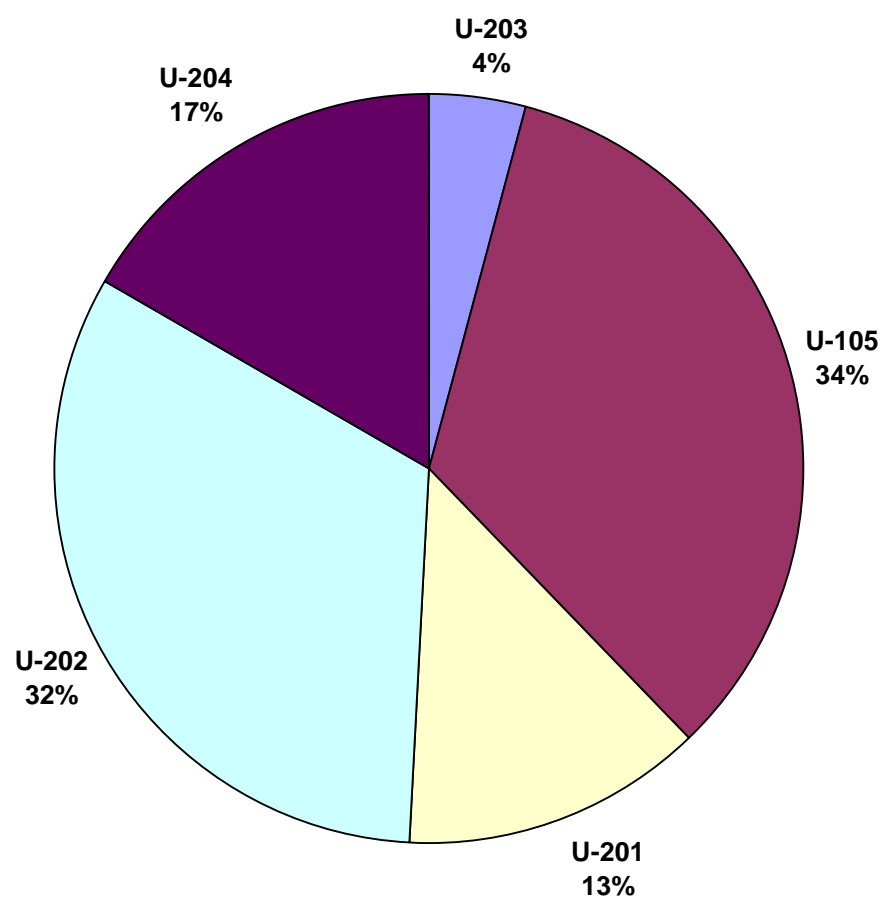

Figure 2.8. Contribution of the Individual Tanks to the Composition of the Group 4 Composite Sample

The Group 4 final composite jar was mixed with an overhead mixer for an hour. A mechanical stirrer with a stainless steel impeller was lowered into the 1-L bottle, and the material was mixed thoroughly. The temperature in the hot cell was $29^{\circ} \mathrm{C}$ at the start of mixing. The goal of this step was to homogenize the sample using as little force as possible. Speed was slowly increased until the solids were mobilized.

The Group 4 final composite sample was mixed for $1 \mathrm{~h}$ before beginning sub-sampling. Subsamples were taken with the mixer still operating to achieve representative sub-sampling. The consistency of the Group 4 composite was viscous, and the sample was dark in color. The sub-samples were removed in a specific order to pre-determined target volumes. Pre-weighed and labeled jars and centrifuge tubes were staged in collection vessels in the order provided in Table 2.12. The remaining sample in the final composite was determined, and this was included in the following homogenization acceptance chart. 
Table 2.12. Group 4 Sub-Sample Mass Density and Settling Data

\begin{tabular}{|l|c|c|c|c|c|c||}
\hline $\begin{array}{c}\text { Sample ID in Order } \\
\text { of Collection }\end{array}$ & $\begin{array}{c}\text { Target } \\
\text { Collection } \\
\text { Volume }\end{array}$ & $\begin{array}{c}\text { Sample Net } \\
\text { Wt, g }\end{array}$ & $\begin{array}{c}\text { Total Slurry } \\
\text { Volume, } \mathbf{~ m L}\end{array}$ & $\begin{array}{c}\text { Settled } \\
\text { Solids } \\
\text { Volume, } \mathbf{m L}\end{array}$ & $\begin{array}{c}\text { Gross } \\
\text { Slurry } \\
\text { Density, } \\
\text { g/mL }\end{array}$ & $\begin{array}{c}\text { Settled } \\
\text { Solids }\end{array}$ \\
\hline TI514-G4-AR-J1 & na & 1055.140 & 785 & 295 & 1.34 & 37.6 \\
\hline TI514-G4-AR-S1 & $8-10 \mathrm{~mL}$ & 13.938 & 10.2 & 3.85 & 1.37 & 37.7 \\
\hline TI514-G4-AR-S2 & $8-10 \mathrm{~mL}$ & 12.760 & 9.9 & 3.60 & 1.29 & 36.4 \\
\hline TI514-G4-AR-S3 & $8-10 \mathrm{~mL}$ & 13.429 & 10.0 & 3.6 & 1.34 & 36.0 \\
\hline TI514-G4-AR-RH1 & $70 \mathrm{~mL}$ & 116.283 & 88 & 33 & 1.32 & 37.5 \\
\hline TI514-G4-AR-C1 & $10-15 \mathrm{~mL}$ & 18.874 & 13.75 & 4.9 & 1.37 & 35.6 \\
\hline TI514-G4-AR-C2 & $10-15 \mathrm{~mL}$ & 16.378 & 12.5 & 4.5 & 1.31 & 36.0 \\
\hline TI514-G4-AR-J1 & na & 847.650 & 620 & 240 & 1.37 & 38.7 \\
\hline \hline
\end{tabular}

For compositing to be considered successful, the sample density and settled-solids-data standard deviation had to be less than $\pm 5 \%$, and there had to be no statistically significant trend in settled solids and density variation due to the order in removing the subsamples. Figure 2.9 shows that the Group 4 compositing and sub-sampling successfully met these criteria. 


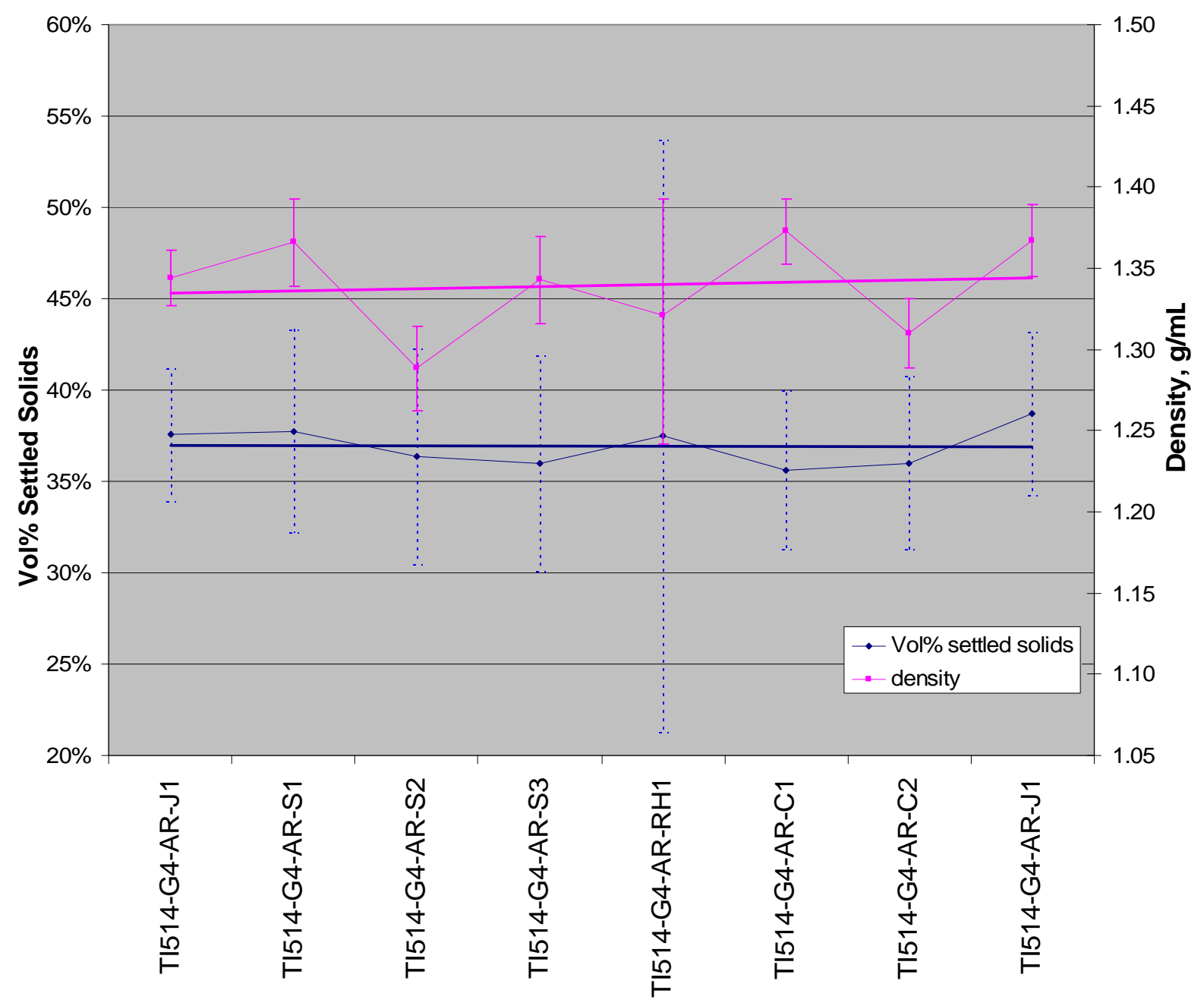

Figure 2.9. Group 4 Confirmation of Successful Material Composite Based on Density and Settled Solids 


\subsection{Group 3 Characterization and Leaching}

This section reports and discusses the characterization activities, analytical results, parametric leach testing, and leaching results for the Group 3 PUREX Cladding Waste (CWP) sludge slurry composite.

\subsection{Group 3 Characterization Experimental}

This section reports and discusses the initial characterization results for the Group 3 CWP sludge slurry composite, supernatant, and washed solids. Table 3.1 lists the Group 3 characterization samples that were taken during the homogenization and sample splitting activities described in Section 2. Figure 3.1 ${ }^{\text {(a) }}$ summarizes the sample processing performed to characterize the Group 3 sample.

The supernatant results represent the equilibrated aqueous phase in contact with the solids; the solids characterization results were obtained after washing with $0.01 \mathrm{M} \mathrm{NaOH}$. Solids washing was considered crucial to better understand the nature of the solids, free of complications associated with supernatant entrainment.

Table 3.1. Group 3 Characterization Samples

\begin{tabular}{|l|l|c|c|}
\hline Sample ID & Characterization Activity & $\begin{array}{c}\text { Slurry } \\
\text { Volume, mL }\end{array}$ & $\begin{array}{c}\text { Slurry } \\
\text { Mass, g }\end{array}$ \\
\hline TI-513-G3-AR-S1 & Physical Properties & 6.90 & 9.399 \\
\hline TI-513-G3-AR-S2 & Physical Properties & 8.05 & 10.842 \\
\hline TI-513-G3-AR-S3 & Physical Properties & 5.95 & 8.036 \\
\hline TI-513-G3-AR-C1 & $\begin{array}{l}\text { Chemical characterization } \\
\text { and crystal habit }\end{array}$ & 24.5 & 33.892 \\
\hline TI-513-G3-AR-C2 & $\begin{array}{l}\text { Chemical characterization } \\
\text { and crystal habit }\end{array}$ & 25.0 & 34.610 \\
\hline TI-513-G3-AR-RH1 & Rheology & 120 & 167.310 \\
\hline
\end{tabular}

(a) The physical property testing was conducted according to TI-RPP-WTP-513, Group 3 - PUREX Cladding Sludge Hanford Tank Waste Sample Compositing, Homogenization, and Sub-Division, R. Swoboda, 10/17/07; the solids washing and sample handling was conducted according to TI-RPP-WTP-550, Initial Characterization of Group 3 Tank Waste: PUREX Cladding Waste Sludge, S Fiskum, 10/19/07. 


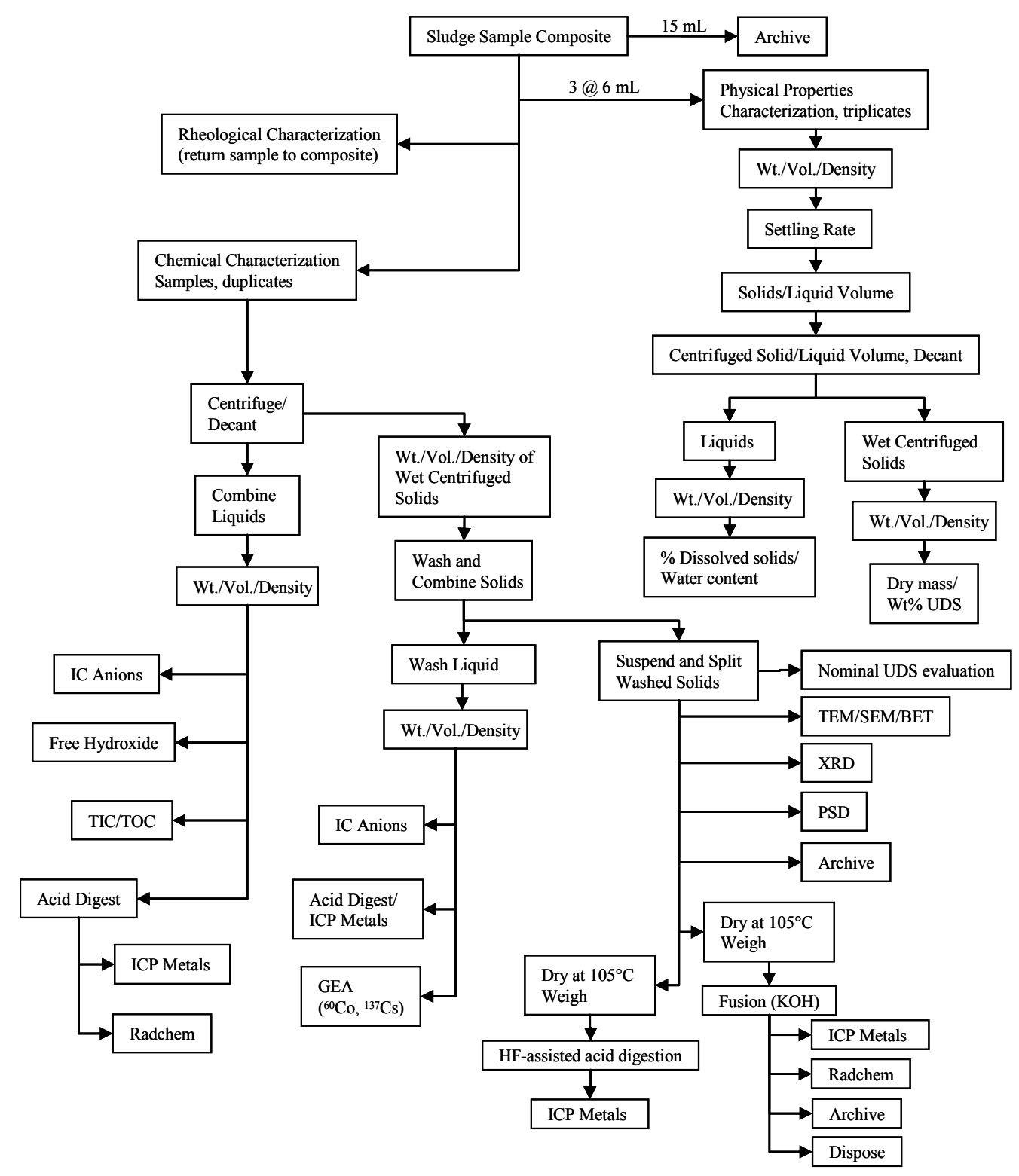

Figure 3.1. Composite Group 3 Analysis Scheme

\subsection{Characterization Results}

\subsubsection{Physical Properties of the Composite Group 3 CWP Slurry}

All physical characterization methods discussed here are described in Appendices B and C. The settling curves of the triplicate samples of Group 3 composited solids are shown in Figure 3.2. Results are shown in two ways: 1) volume percent settled solids as a function of time and 2) height of settled solids as a function of time. Settling proceeded rapidly and was essentially complete after $1 \mathrm{hr}$. 
a)

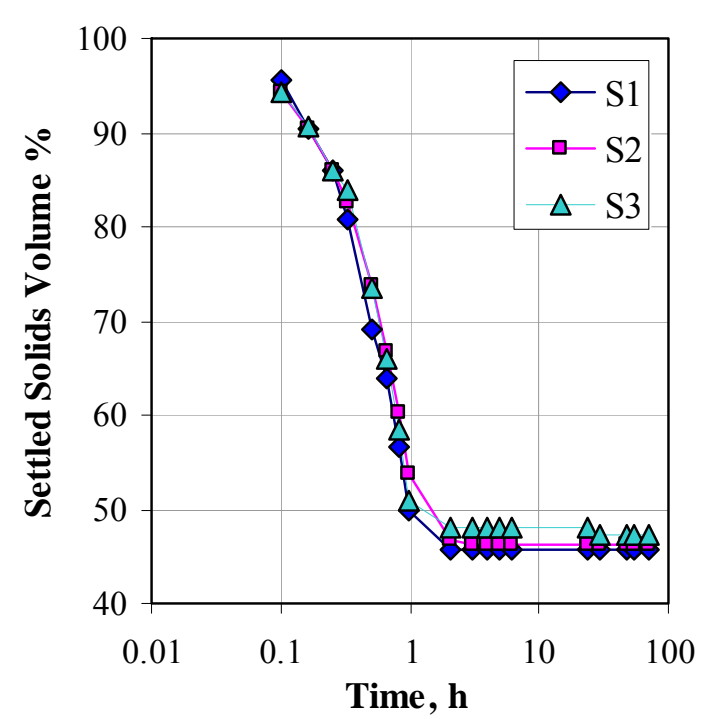

b)

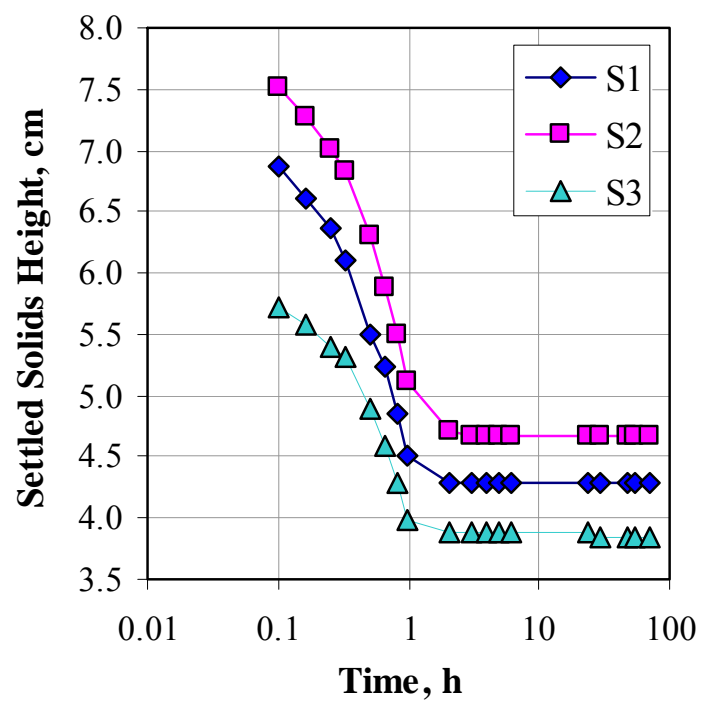

Figure 3.2. Group 3 CWP Solids Settling Test

Physical-property results for the CWP Group 3 sludge are summarized in Table 3.2 along with the propagated $1-\sigma$ errors, averages, and relative standard deviations. Good precision was obtained for the sample set. Density and vol\% values associated with this testing were limited to 2 significant figures because of the small sample size $(<10 \mathrm{~mL})$ and volume measure uncertainty in the graduated centrifuge tubes and cylinders $(\sim 0.2 \mathrm{~mL})$; the third significant figure is shown for indication only. Supernatant density was also determined to more significant figures as part of the chemical analysis processing.

The two $25-\mathrm{mL}$ samples taken for chemical characterization were evaluated for density, $\mathrm{wt} \%$, and vol $\%$ centrifuged solids as part of the initial phase separation, providing supplemental physical-property results. Results are summarized in Table 3.3. In this case, the $\mathrm{wt} \%$ and vol $\%$ wet centrifuged solids were significantly less than the values observed with the physical-property testing samples (AR-S1, -S2, and -S3) whereas the wet centrifuged solids densities were higher than observed from the physical-property testing. The differences associated with these parameters suggest that the solids may have packed more densely in the characterization samples. Even though the centrifuging conditions were the same in each case $(1 \mathrm{~h}$ at $1000 \mathrm{G})$, the sample size and aspect ratio of the centrifuged solids were significantly different and may have contributed to the observed difference. 
Table 3.2. Physical-Property Measurements of Homogenized Group 3 CWP Slurry

\begin{tabular}{|c|c|c|c|c|c|c|}
\hline Description & AR-S1 & AR-S2 & AR-S3 & $\begin{array}{l}\text { Nominal } \\
1 \sigma \text { error }\end{array}$ & Avg. & $\operatorname{RSD}^{(\mathrm{a})}(\%)$ \\
\hline \multicolumn{7}{|c|}{ Bulk Sample } \\
\hline Sample Size (mL) & 6.5 & 7.4 & 5.0 & 0.2 & na & na \\
\hline Sample Size (g) & 9.338 & 10.642 & 7.566 & 0.003 & na & na \\
\hline Density $(\mathrm{g} / \mathrm{mL})^{(\mathrm{b})}$ & 1.44 & 1.44 & 1.51 & 0.04 & 1.46 & 3.0 \\
\hline Total Solids (wt $\%$ ) & 40.9 & 42.3 & 42.8 & 0.04 & 42.0 & 2.4 \\
\hline Total Undissolved Solids (wt\%) & 27.9 & 29.2 & 29.3 & 0.03 & 28.8 & 2.7 \\
\hline Settling Rate $(\mathrm{cm} / \mathrm{h})$ & 2.60 & 2.65 & 1.94 & NA & 2.40 & 17 \\
\hline \multicolumn{7}{|c|}{ Settled Solids } \\
\hline Density $(\mathrm{g} / \mathrm{mL})^{(\mathrm{b})}$ & 1.53 & 1.62 & 1.72 & 0.09 & 1.62 & 5.7 \\
\hline $\mathrm{Vol}^{\left({ }^{(\mathrm{b})}\right.}$ & 46.3 & 47.4 & 47.2 & 2.6 & 46.9 & 1.2 \\
\hline $\mathrm{Wt} \%$ & 51.2 & 56.3 & 57.4 & 3.6 & 55 & 3.3 \\
\hline Total Undissolved Solids (wt\%) & 51.8 & 50.0 & 47.3 & 3.5 & 49.7 & 4.6 \\
\hline \multicolumn{7}{|c|}{ Wet Centrifuged Solids } \\
\hline Density $(\mathrm{g} / \mathrm{mL})^{(\mathrm{b})}$ & 1.75 & 1.71 & 1.66 & 0.15 & 1.71 & 2.9 \\
\hline $\mathrm{Vol}^{(\mathrm{b})}$ & 36.9 & 39.2 & 42.0 & 3.3 & 39.4 & 6.5 \\
\hline $\mathrm{Wt} \%$ & 46.5 & 48.4 & 48.5 & 0.034 & 47.8 & 2.3 \\
\hline Total Undissolved Solids (wt $\%$ ) & 62.8 & 57.5 & 52.4 & 5.2 & 57.6 & 9.0 \\
\hline Total Solids (wt\%) & 67.0 & 67.5 & 67.7 & 0.06 & 67.4 & 0.5 \\
\hline \multicolumn{7}{|c|}{ Supernatant } \\
\hline Density $(\mathrm{g} / \mathrm{mL})^{(\mathrm{b})}$ & 1.26 & 1.16 & 1.15 & 0.03 & 1.19 & 5.3 \\
\hline Total Dissolved Solids (wt\%) & 17.4 & 17.9 & 18.5 & 0.06 & 17.9 & 2.9 \\
\hline Water Content $(\mathrm{g} / \mathrm{g})$ & 0.826 & 0.821 & 0.815 & 0.001 & 0.821 & 0.6 \\
\hline
\end{tabular}


Table 3.3. Supplemental Physical Properties from Chemical Characterization Samples

\begin{tabular}{|c|c|c|c|c|c|c|}
\hline Description & AR-C1 & AR-C2 & $\begin{array}{l}\text { Nominal } \\
1 \sigma \text { error }\end{array}$ & Avg. & $\begin{array}{c}\mathrm{RPD}^{(\mathbf{a})} \\
(\%)\end{array}$ & $\begin{array}{l}\text { Comparison to } \\
\text { Table } 3.2 \\
\text { Results }\end{array}$ \\
\hline Sample Size $(\mathrm{mL})$ & 24.5 & 25.0 & 1 & na & na & na \\
\hline Sample Size (g) & 33.461 & 34.329 & 0.004 & na & na & na \\
\hline Bulk Density $(\mathrm{g} / \mathrm{mL})^{(\mathrm{b})}$ & 1.37 & 1.37 & 0.056 & 1.37 & 0 & $-6.2 \%$ \\
\hline $\begin{array}{l}\text { Wet Centrifuged Solids } \\
\text { Density }(\mathrm{g} / \mathrm{mL})^{(\mathrm{b})}\end{array}$ & 1.96 & 1.98 & 0.13 & 1.97 & 0.94 & $+15 \%$ \\
\hline Vol\% Centrifuged Solids ${ }^{(b)}$ & 29.8 & 30.0 & 2.4 & 29.9 & 0.68 & $-24 \%$ \\
\hline $\mathrm{Wt} \%$ Centrifuged Solids & 42.79 & 43.25 & 0.12 & 43.0 & 1.1 & $-10 \%$ \\
\hline Supernatant Density $(\mathrm{g} / \mathrm{mL})$ & \multicolumn{2}{|c|}{1.158} & 0.002 & na & na & $-3 \%$ \\
\hline \multicolumn{7}{|c|}{$\begin{array}{l}\text { (a) RPD = relative percent difference } \\
\text { (b) The density and vol\% values are only valid to two significant figures since the volume measures were } \\
\text { determined to two significant figures; the third significant figure is provided for indication only. } \\
\text { Bolded values indicate differences exceeding the uncertainties. }\end{array}$} \\
\hline
\end{tabular}

\subsubsection{Rheology of the Composite Group 3 CWP Slurry}

Two samples were employed for shear-strength and flow-curve testing of waste Group 3. Flow-curve testing used slurry sample TI513-G3-AR-RH1; shear strength used slurry sample TI513-G3-AR-J1. Both samples were derived from homogenizing tank wastes associated with the processing of Group 3. Flowcurve and shear-strength analyses produced the following reportable data for the Group 3 initial characterization sample:

- a single measurement of settled solids shear strength after settling for 72 hours

- flow-curve data for Group 3 slurries at $25^{\circ} \mathrm{C}, 40^{\circ} \mathrm{C}$, and $60^{\circ} \mathrm{C}$

- best-fit Newtonian viscosities at $25^{\circ} \mathrm{C}, 40^{\circ} \mathrm{C}$, and $60^{\circ} \mathrm{C}$.

The waste slurry and settled solids samples were tested "as-is"; no sample treatment was performed before analysis with exception of the mechanical agitation required to disperse the waste solids in Group 3 slurry sample jars TI513-G3-AR-RH1 and TI513-G3-AR-J1.

\subsubsection{Shear Strength}

Shear strength was measured as described in Appendix C, section C.2.1. A single measurement of shear strength was made on settled solids in sample jar TI513-G3-AR-J1. Before shear-strength testing, settled slurry solids were dispersed uniformly by vigorously shaking the jar on a vortex mixer. The dispersion was then allowed to settle for 72 hours. After this period of time, the shear strength of the settled solids was measured.

The volume of settled solids in the test jar as it was provided for shear-strength measurement was limited, and it was not possible to fully immerse the vane tool without contacting the bottom of the sample jar. After 72 hours of settling, the settled solids only provided approximately $10 \mathrm{~mm}$ of height of settled solids for testing. To avoid contact with the floor of the sample jar, only $8 \mathrm{~mm}$ of the total $16 \mathrm{~mm}$ of vane 
immersion depth was achieved. Because of limited immersion, the shear-strength result reported herein is not independent of container geometry. In addition, the inability to fully immerse the vane into the solids lowers the vane-solids contact area during testing, yielding lower stress measurements than would be observed for a fully immersed vane. No attempt was made to correct for lowered contact area during analysis. However, it must be recognized that because only half vane immersion is achieved ( $8 \mathrm{~mm}$ out of $16 \mathrm{~mm}$ ), the shear strength reported herein is likely half of what it would have been for a fully immersed vane.

The result for Group 3 initial characterization shear-strength testing is shown in Table 3.4. The single measurement for sample TI513-G3-AR-J1 settled solids at 72 hours of settling time indicates a shear strength of $700 \mathrm{~Pa}$ at half-vane immersion. Correcting this value for particle immersion yields a rough estimate of $1500 \mathrm{~Pa}$ for the actual shear strength of this sample.

Table 3.4. Shear strength of Group 3 Initial Characterization Settled Solids at Ambient Hot-Cell Temperature $\left(26.4^{\circ} \mathrm{C}\right)$

\begin{tabular}{||l|c|c||}
\hline Test Sample & Settling Time & Shear Strength [Pa] \\
\hline TI513-G3-AR-J1 & 72 hours & $700 \mathrm{~Pa}^{(\mathrm{a})}$ \\
\hline (a) Value corresponds to test where only half vane immersion is achieved. \\
Actually, the shear strength is likely on the order of $1500 \mathrm{~Pa}$. \\
\hline
\end{tabular}

\subsubsection{Flow Curve}

Flow-curve testing was performed as described in Appendix C, section C.2.2. Flow-curve testing for slurry sample TI513-G3-AR-RH1 was performed at $25^{\circ} \mathrm{C}, 40^{\circ} \mathrm{C}$, and $60^{\circ} \mathrm{C}$. Two measurements (an initial and replicate) were performed at $25^{\circ} \mathrm{C}$ to assess reproducibility. Immediately before flow-curve testing, the solids in jar TI513-G3-AR-RH1 were dispersed uniformly by vigorously shaking the jar with the remote manipulator. After shaking, a sub-sample of the slurry was transferred to the rheometer measuring cup. Visual inspection of the slurry during and after transfer found no immediately observable solids settling.

Each flow-curve analysis was performed over a 15-minute period, split into three 5-minute intervals. Over the first 5 minutes, the shear rate was smoothly increased from zero to $1000 \mathrm{~s}^{-1}$. For the second 5 minutes, the shear rate was held constant at $1000 \mathrm{~s}^{-1}$. For the final 5 -minutes, the shear rate was smoothly reduced back to zero. During this time, the resisting torque and rotational rate were continuously recorded. Each flow-curve measurement was preceded by a 3-minute shearing step intended to break the sample structure and to verify that the rotor was properly centered.

After the flow-curve measurement was complete, visual inspection of the cup contents found a significant layer ( 1 to $2 \mathrm{~mm}$ thick) of settled solids. It is likely that solids settling influenced rheology measurements. The consequence of solids settling would be lowered solids concentration in the suspending phase (especially of large aggregates), which would yield a weaker fluid rheology (i.e., lowered yield stress and consistency).

Figure 3.3 shows the results of flow-curve testing for the Group 3 initial characterization slurry sample, TI513-G3-AR-RH1. The flow behavior is Newtonian with a zero yield stress. Although some of the 
curves show a finite offset of $\sim 0.2 \mathrm{~Pa}$, this falls below the instrument's yield sensitivity of $0.5 \mathrm{~Pa}$ and, as such, is not significantly different than zero. Flow-curve data show a linear stress response over shear rates from zero up to 400 or $500 \mathrm{~s}^{-1}$. At higher shear rates (generally $400 \mathrm{~s}^{-1}$ and above), flow-curve data show an increase in the slope of the stress response curve. This increase is likely a result of Taylor vortex formation onset (i.e., unstable/turbulent flow), which renders the effected data unusable.

Rotational viscometry operates under the assumption of laminar flow. Because most rotational viscometers employ small gap sizes $(\sim 1 \mathrm{~mm})$ and because most tests fluids are non-Newtonian or are Newtonian with high viscosity (i.e., greater than $10 \mathrm{cP}$ ), flow conditions within the gap are typically laminar. However, turbulent flow conditions will be realized during flow-curve measurement for low viscosity fluids. For example, flow-curve measurements of water (which has a viscosity of $1 \mathrm{cP}$ ) in the MV1-measurement-cup system show a transition from laminar to turbulent flow around $200 \mathrm{~s}^{-1}$. This transition point scales approximately with viscosity, such that transition points for higher viscosity fluids can be predicted simply by multiplying $200 \mathrm{~s}^{-1}$ by the ratio of the current viscosity to that of water. Thus, 5-cP fluids should have a transition point around $1000 \mathrm{~s}^{-1}$, which is the measurement limit for the flow curves discussed herein. As such, laminar-to-turbulent flow transitions should not be observed for fluids with viscosities greater than $5 \mathrm{cP}$.

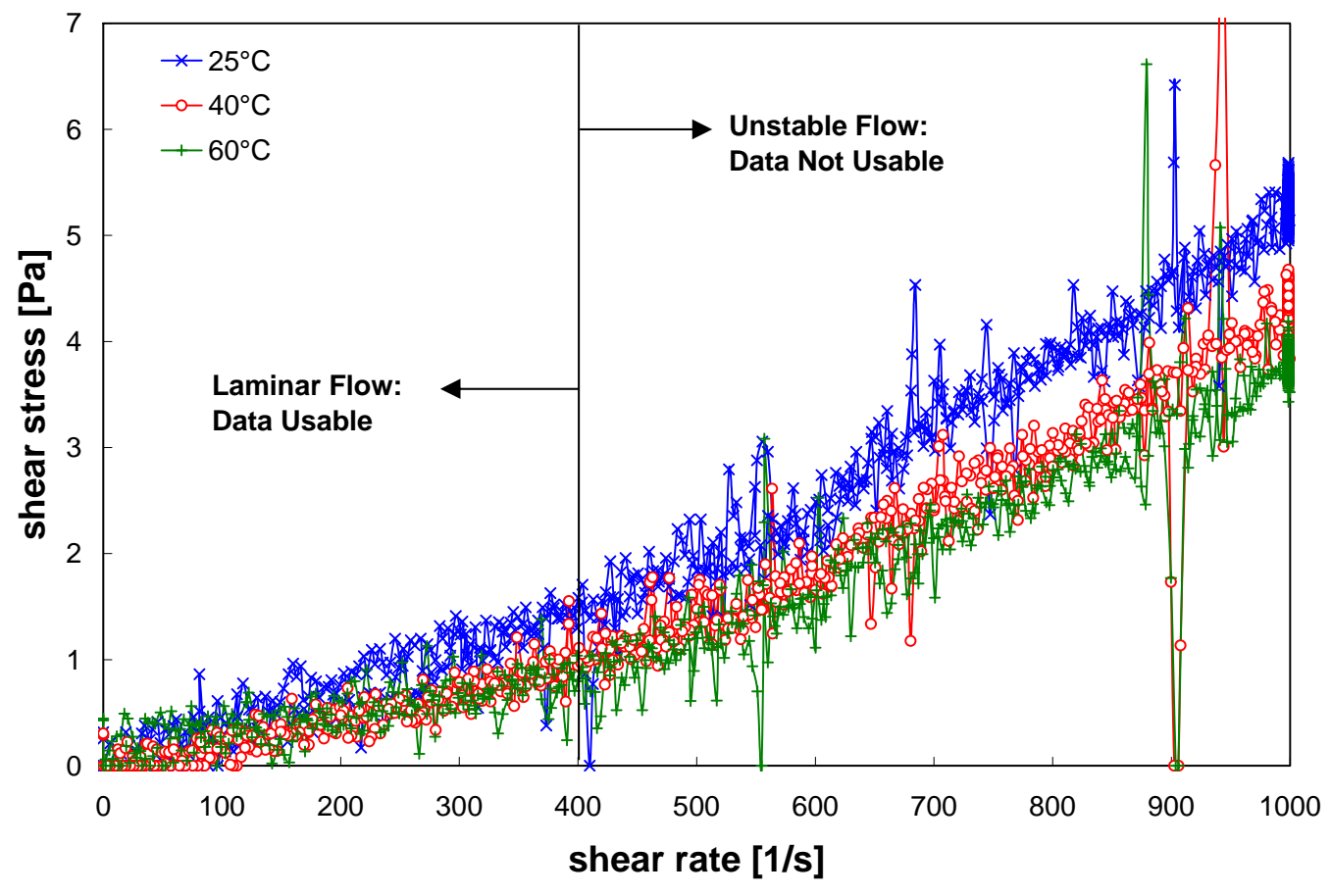

Figure 3.3. Flow Curve (shear stress versus shear rate) for the Group 3 Initial Characterization Slurry Sample TI513-G3-AR-RH1 at $25^{\circ} \mathrm{C}, 40^{\circ} \mathrm{C}$, and $60^{\circ} \mathrm{C}$. Note: the second repeat measurement for $25^{\circ} \mathrm{C}$ is shown here because it is the closest to the $40^{\circ}$ and $60^{\circ} \mathrm{C}$ measurements in time.

Turbulent flow dissipates more energy than laminar flow. As a result, more force is required to maintain constant rotation of the measurement systems in turbulent flow. This is observed in flow-curve measurements as an increase in the slope of the shear-stress versus shear-rate curve (like observed in 
Figure 3.3). This increase is not predictable and cannot be analyzed to extract the actual viscosity of the test fluid. Thus, any flow-curve data beyond the transition point is usually discarded.

The flow curves shown in Figure 3.3 are relatively free of hysteresis. Specifically, the up- and downramp data generally agree with the instrument limits of accuracy $(\sim 0.5 \mathrm{~Pa})$. Any difference can easily be attributed to rotor inertial effects. The lack of hysteresis suggests that shearing or settling of the sample does not significantly affect the measurements. It should be noted that lack of hysteresis does not necessarily mean that these effects are absent because any changes could have occurred during the shearing step or before the sample was analyzed. As stated before, significant settled solids were observed on the bottom of the measuring cup after the measurement was completed. It is likely that these solids settled out before the measurement took place. The effect of settling on the measurement results reported herein is that viscosities regressed from the flow curve may be lower than for the fully dispersed slurry. Unfortunately, without additional information on how slurry rheology acts as a function of solids concentration, it is difficult to evaluate how large a decrease in slurry viscosity occurs as a result of settling.

Analysis of the flow-curve data is affected by the small (but statistically insignificant) stress offset and the formation of Taylor vortices. Given the $\pm 0.2 \mathrm{~Pa}$ typical stress variation in measurement data, the best description of the current flow behavior that can be concluded based on the current measurement data is Newtonian. As such, Newtonian viscosity was derived for each flow-curve measurement. However, the analysis employed a Bingham-Plastic fitting model to account for the small but finite stress offset. Here, Newtonian viscosity is equated with the Bingham consistency index (i.e., Bingham-Plastic slope). Next, data believed to be influenced by Taylor vortex formation are excluded from the fits. The shear rate range for all fits is limited to between 0 and $400 \mathrm{~s}^{-1}$. Finally, rotor inertial effects and measurement noise sometimes caused down-ramp stress data to fall below zero. Less-than-zero stress measurements are reported as zero by the RheoWin software, which can result in fit bias. Both the replicate $25^{\circ} \mathrm{C}$ and $40^{\circ} \mathrm{C}$ down-ramp flow-curve measurements were impacted significantly by less than zero stress correction by the RheoWin software. To correct for this, the fitting analysis for the replicate $25^{\circ} \mathrm{C}$ and $40^{\circ} \mathrm{C}$ measurements was limited to the up-ramp data.

In addition to determining Newtonian viscosity from the flow curve, secondary viscosities are derived from the constant rotation (shearing) step performed before each measurement. Here, the apparent viscosity is averaged over the period of constant rotation at $470 \mathrm{~s}^{-1}$; i.e., taken from data obtained at the rotor speed (200 RPM) used in the constant rotation step performed before the flow curve measurements. It should be noted that the rate of rotation during these measurements fell in the range where Taylor vortex formation was observed. As such, viscosity determinations from constant rotation should be approached with caution because they may be biased to higher values as a result of flow turbulence.

Table 3.5 summarizes the best-fit Newtonian viscosity for flow-curve data for sample TI513-G3-ARRH1. The results indicate a Newtonian viscosity that generally falls between 1.7 and $3.6 \mathrm{cP}$, depending on temperatures. An increased temperature yields a decrease in the slurry viscosity, likely as a result of a decrease in suspending phase viscosity. The viscosities determined by flow-curve fitting analysis and by constant-rotation analysis typically agree within the standard deviation of the measurements (i.e., the error associated with each constant rotation measurement). The exception to this is the measurement at $60^{\circ} \mathrm{C}$. Here, the constant rotation viscosity is significantly higher than that determined from the flow curve. It should be noted that since the $60^{\circ} \mathrm{C}$ measurement corresponds to the lowest viscosity, the transition point 
from laminar to turbulent flow will also occur at the lowest shear rate for this temperature. As such, the deviation between constant rotation and flow-curve fit viscosities at this temperature is likely a result of turbulent flow biasing the constant rotation measurement to higher viscosity.

Table 3.5. Results of Fitting Analysis for Rheology Sample TI513-G3-AR-RH1. Unless specified otherwise, flow-curve viscosities are determined by fitting both up- and down-ramp data. The error listed for the constant rotation fits corresponds to the standard deviation associated with each measurement.

\begin{tabular}{|c|c|c|c|c|c|}
\hline Model & $\begin{array}{c}\text { Temperature } \\
{\left[{ }^{\circ} \mathrm{C}\right]}\end{array}$ & Range & $\begin{array}{l}\text { Viscosity } \\
\text { [MPA·S] }\end{array}$ & Error & $\mathbf{R}$ \\
\hline \multirow{4}{*}{$\begin{array}{c}\text { Newtonian } \\
\text { (Flow Curve) }\end{array}$} & $25(1$ of 2$)$ & $0-400 \mathrm{~s}^{-1}$ & 3.2 & $\mathrm{n} / \mathrm{a}$ & 0.92 \\
\hline & $25(2$ of 2$)$ & $0-400 \mathrm{~s}^{-1}$ (a) & 3.4 & $\mathrm{n} / \mathrm{a}$ & 0.95 \\
\hline & 40 & $0-400 \mathrm{~s}^{-1(a)}$ & 2.3 & $\mathrm{n} / \mathrm{a}$ & 0.92 \\
\hline & 60 & $0-400 \mathrm{~s}^{-1}$ & 1.7 & $\mathrm{n} / \mathrm{a}$ & 0.76 \\
\hline \multirow{4}{*}{$\begin{array}{l}\text { Constant Rotation } \\
\quad\left(\text { At } 470 \mathrm{~s}^{-1}\right)\end{array}$} & 25 (1 of 2$)$ & $\mathrm{n} / \mathrm{a}$ & 3.2 & 0.2 & $\mathrm{n} / \mathrm{a}$ \\
\hline & $25(2$ of 2$)$ & $\mathrm{n} / \mathrm{a}$ & 3.6 & 0.3 & $\mathrm{n} / \mathrm{a}$ \\
\hline & 40 & $\mathrm{n} / \mathrm{a}$ & 2.2 & 0.7 & $\mathrm{n} / \mathrm{a}$ \\
\hline & 60 & $\mathrm{n} / \mathrm{a}$ & $2.2^{(b)}$ & 0.2 & $\mathrm{n} / \mathrm{a}$ \\
\hline
\end{tabular}

For the current measurement, measurement noise and the low slurry viscosity $(<5 \mathrm{cP})$ makes determination of apparent viscosity at a shear rate of $33 \mathrm{~s}^{-1}$ difficult and subject to significant error. In terms of calculated apparent viscosities, the Newtonian results reported in Table 3.5 represent the apparent viscosity over the entire range of shear and should provide a reasonable estimation of the apparent viscosity at $33 \mathrm{~s}^{-1}$. Thus, the determination of apparent viscosity from measurement data is forgone in favor for the results in Table 3.5.

In summary, flow-curve analysis for the Group 3 Initial Characterization slurry sample, TI513-G3-ARRH1, suggests Newtonian rheology. Regression analysis of the flow-curve data finds a slurry viscosity ranging from 3.4 to $3.6 \mathrm{cP}$ at $25^{\circ} \mathrm{C}$ and $\sim 1.7 \mathrm{cP}$ at $60^{\circ} \mathrm{C}$. As indicated by the results, an increased slurry temperature yields lower slurry viscosity, likely as a result of lowering the suspending phase viscosity. The flow-curve data are relatively free of hysteresis, which suggests that settling and/or shearing effects are minimal or occur before flow-curve measurement.

\subsubsection{Chemical and Radiochemical Composition of the Group 3 Slurry}

One of the two characterization samples is shown in Figure 3.4a following centrifuging. The gray centrifuged solids appeared generally uniform top to bottom; the supernatant was pale yellow, most likely because of the presence of chromate ion. The supernatant density was determined to be $1.16 \pm 0.002$ $\mathrm{g} / \mathrm{mL}\left(\mathrm{T}=25^{\circ} \mathrm{C}\right)$ based on the average masses of four $1-\mathrm{mL}$ volume deliveries. This value agrees with that obtained during the physical-property testing procedure (density $=1.19 \pm 0.03 \mathrm{~g} / \mathrm{mL}$ ) within the experimental uncertainty. 
a)

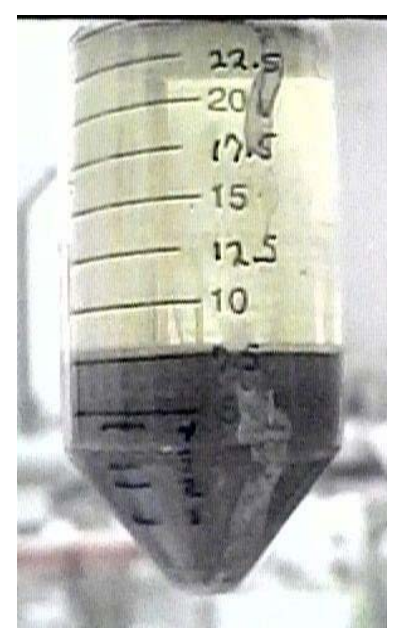

b)

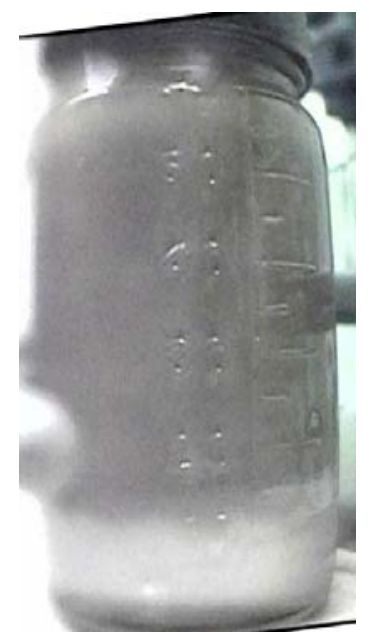

Figure 3.4. Chemical Characterization Sample of Group 3 CWP Sludge a) Centrifuged Solids b) Combined Washed Solids

The specific washing scheme for the CWP sludge is provided in Figure 3.5. With each successive washing step, the centrifuged solids (CS) packing was more easily disturbed during the course of supernatant removal with the transfer pipette. The hydroxide concentration in the final wash solution was $\sim 0.01 \mathrm{M}$. The CS volumes were estimated based on the centrifuge-tube graduations. No measurable change in the centrifuged solids volume occurred during the washing process. A photograph of the washed solids is shown in Figure 3.4b; the white solids settled readily whereas gray solids remained suspended. The solids suspension was attributed to the low ionic strength or relatively low $\mathrm{pH}$ of the final aqueous phase.

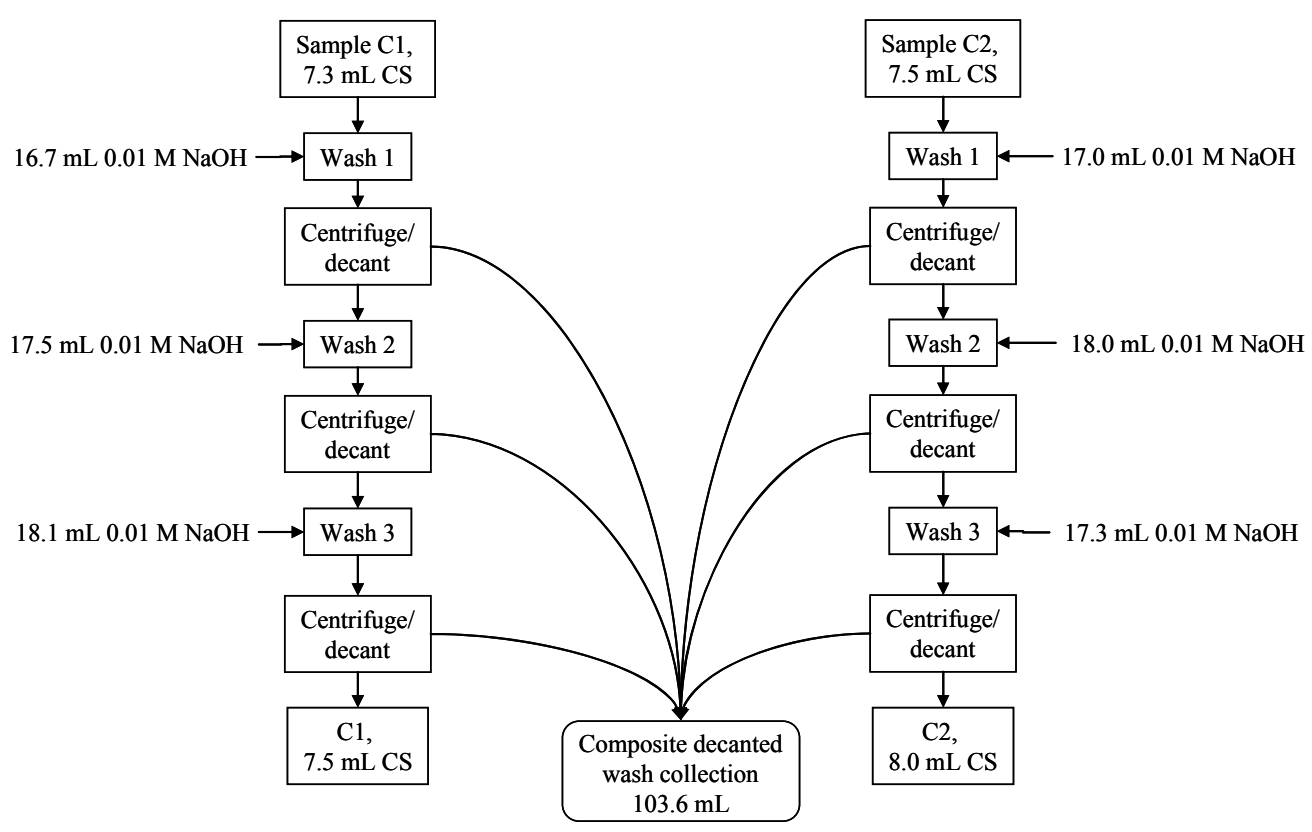

Figure 3.5. Wash Sequence of Group 3 CWP Sludge Supporting Initial Characterization 
The average radioanalytical results for the supernatant, composited wash solution, and washed solids are provided in Table 3.6 along with the applicable relative percent differences (RPD, measure of precision) between duplicates. The concentration of the gross-beta results and the sum of beta emitters, ${ }^{137} \mathrm{Cs}$ and ${ }^{90} \mathrm{Sr}$ (in secular equilibrium with ${ }^{90} \mathrm{Y}$ ), were essentially equivalent (ratio close to 1.0 ). The reasonably good agreement between these values indicated that no other major source of beta activity was present. Similarly, the gross alpha activity was reasonably close to the sum of the alpha emitters $\left({ }^{238} \mathrm{Pu},{ }^{239+240} \mathrm{Pu}\right.$, and detected ${ }^{241} \mathrm{Am}$ ), indicating that no other significant source of alpha activity was present.

Table 3.6. Radionuclide Characterization of the Group 3 CWP Sludge

\begin{tabular}{|c|c|c|c|c|c|c|}
\hline \multirow{3}{*}{$\begin{array}{l}\text { Sample ID> } \\
\text { Analyte } \\
\end{array}$} & \multirow{2}{*}{\multicolumn{2}{|c|}{$\begin{array}{c}\text { Supernatant } \\
08-00826 \\
\end{array}$}} & \multirow{2}{*}{\multicolumn{2}{|c|}{$\begin{array}{c}\text { Wash composite } \\
08-00827^{(\mathbf{b})} \\
\end{array}$}} & \multirow{2}{*}{\multicolumn{2}{|c|}{$\begin{array}{c}\text { Washed solids }^{(a)} \\
08-00828 \\
\end{array}$}} \\
\hline & & & & & & \\
\hline & $\mu \mathrm{Ci} / \mathrm{mL}$ & RPD & $\mu \mathrm{Ci} / \mathrm{mL}$ & RPD & $\mu \mathrm{Ci} / \mathrm{g}$ & RPD \\
\hline${ }^{137} \mathrm{Cs}$ & $3.84 \mathrm{E}+1$ & 0.52 & $2.71 \mathrm{E}+0$ & \multirow{12}{*}{ na } & $5.36 \mathrm{E}+1$ & 0.9 \\
\hline${ }^{60} \mathrm{Co}$ & $1.01 \mathrm{E}-3$ & 2.5 & $7.01 \mathrm{E}-5$ & & $4.80 \mathrm{E}-2$ & 4.4 \\
\hline${ }^{241} \mathrm{Am}$ & $<6.0 \mathrm{E}-3$ & na & $<3$. E-4 & & $1.00 \mathrm{E}+0$ & 3.4 \\
\hline${ }^{238} \mathrm{Pu}$ & $2.69 \mathrm{E}-4$ & 16 & $\mathrm{n} / \mathrm{a}$ & & $1.04 \mathrm{E}-1$ & 11 \\
\hline${ }^{239+240} \mathrm{Pu}$ & $1.87 \mathrm{E}-3$ & 13 & $\mathrm{n} / \mathrm{a}$ & & $9.39 \mathrm{E}-1$ & 6.8 \\
\hline Gross alpha & $1.69 \mathrm{E}-3$ & 5 & $\mathrm{n} / \mathrm{a}$ & & $2.03 \mathrm{E}+0$ & 6.4 \\
\hline Gross beta & $3.34 \mathrm{E}+1$ & 14 & $\mathrm{n} / \mathrm{a}$ & & $5.78 \mathrm{E}+2$ & 1.0 \\
\hline${ }^{90} \mathrm{Sr}$ & $3.84 \mathrm{E}-2$ & 15 & $\mathrm{n} / \mathrm{a}$ & & $2.77 \mathrm{E}+2$ & 8.7 \\
\hline Alpha sum & $2.14 \mathrm{E}-3$ & 13 & $\mathrm{n} / \mathrm{a}$ & & $2.05 \mathrm{E}+0$ & 2.0 \\
\hline$\alpha$ gross/sum & 0.79 & na & $\mathrm{n} / \mathrm{a}$ & & 0.99 & \\
\hline Beta sum & $3.85 \mathrm{E}+1$ & 0.55 & $\mathrm{n} / \mathrm{a}$ & & $6.08 \mathrm{E}+2$ & 8.0 \\
\hline$\beta$ gross/sum & 0.87 & na & $\mathrm{n} / \mathrm{a}$ & & 0.95 & \\
\hline \multicolumn{7}{|l|}{ Opportunistic } \\
\hline${ }^{154} \mathrm{Eu}$ & $<4$.E-4 & na & $<3 . \mathrm{E}-5$ & na & $2.87 \mathrm{E}-1$ & 8.7 \\
\hline${ }^{155} \mathrm{Eu}$ & $<6 . \mathrm{E}-3$ & na & $<4$.E-4 & na & $1.16 \mathrm{E}-1$ & 3.4 \\
\hline $\begin{array}{l}\text { (a) Analyte c } \\
\text { (b) This samp } \\
\text { Notes: } \\
\text { Analytical Serv } \\
\text { Reference date } \\
\text { na= not applic }\end{array}$ & $\begin{array}{l}\text { entrations are } \\
\text { was not requir } \\
\text { Request } 7874 \\
\text { all radionucli } \\
\text {; } / \mathrm{a}=\text { not an }\end{array}$ & $\begin{array}{l}\text { oulated o } \\
\text { o be run }\end{array}$ & $\begin{array}{l}\text { a dry-mass ba } \\
\text { duplicate; th }\end{array}$ & re, an F & vas not calc & ted. \\
\hline
\end{tabular}

The chemical compositions of the Group 3 CWP supernatant, composite wash solution, and washed solids are provided in Table 3.7. Results for both solids preparation methods (fusion and HF-assisted acid digestion) are shown. Overall good agreement between the solids preparation and analysis methods was shown except in the case of $\mathrm{Zn}$ where the methods resulted in $\sim 2 \times$ difference. The LCS Si recovery for the fusion method was low ( $41 \%$ recovery); thus, the sample Si concentration should be considered a lower bound. 
Table 3.7. Chemical Characterization of the Group 3 CWP Sludge

\begin{tabular}{|c|c|c|c|c|c|c|c|c|c|c|}
\hline & \multicolumn{3}{|c|}{ Supernatant } & \multicolumn{3}{|c|}{ Wash composite } & \multicolumn{4}{|c|}{ Washed solids $^{(a)}$} \\
\hline Sample ID> & \multicolumn{3}{|c|}{ 08-00826 } & \multicolumn{3}{|c|}{ 08-00827 ${ }^{(\mathbf{b})}$} & \multicolumn{4}{|c|}{ 08-00828 } \\
\hline & & & & & & & Fusion & & Acid D & gest \\
\hline Analyte & $\mu \mathrm{g} / \mathrm{mL}$ & $\mathbf{M}$ & RPD & $\mu \mathrm{g} / \mathrm{mL}$ & $\mathbf{M}$ & RPD & $\mu \mathrm{g} / \mathrm{g}$ & RPD & $\mu \mathrm{g} / \mathrm{g}$ & RPD \\
\hline $\mathrm{Al}$ & 2,035 & $7.54 \mathrm{E}-2$ & 0.5 & 136 & $5.04 \mathrm{E}-3$ & \multirow{17}{*}{ na } & 297,500 & 2.4 & 325,500 & 0.92 \\
\hline $\mathrm{B}$ & {$[6.15]$} & [5.7E-4] & {$[102]$} & $<0.11$ & $<1.1 \mathrm{E}-5$ & & $<27$ & na & na & na \\
\hline $\mathrm{Bi}$ & $<3.61$ & $<1.7 \mathrm{E}-5$ & na & $<0.71$ & $<3.4 \mathrm{E}-6$ & & [730] & {$[0]$} & 785 & 3.6 \\
\hline $\mathrm{Cd}$ & $<0.50$ & $<4.4 \mathrm{E}-6$ & na & $<0.08$ & $<7.2 \mathrm{E}-7$ & & [24] & {$[0]$} & 47.1 & 2.3 \\
\hline $\mathrm{Cr}$ & 261 & $5.01 \mathrm{E}-3$ & 1.2 & 17.7 & 3.40E-4 & & 314 & 0.6 & 333 & 1.2 \\
\hline $\mathrm{Fe}$ & {$[1.35]$} & {$[2.4 \mathrm{E}-5]$} & [22] & {$[0.40]$} & [7.2E-6] & & 14,000 & 1.4 & 15,550 & 0.64 \\
\hline K & 1,055 & $2.70 \mathrm{E}-2$ & 0.9 & 68.1 & $1.74 \mathrm{E}-3$ & & na & na & [83] & [67] \\
\hline $\mathrm{Mn}$ & {$[0.37]$} & [6.7E-6] & {$[145]$} & {$[0.027]$} & [4.9E-7] & & $1,009^{(\mathrm{c})}$ & 4.3 & 1,035 & 1.0 \\
\hline $\mathrm{Na}$ & 73,700 & $3.21 \mathrm{E}+0$ & 1.1 & 11,000 & $4.78 \mathrm{E}-1$ & & {$[14,500]$} & [7] & 15,150 & 0.66 \\
\hline $\mathrm{Ni}$ & 3.27 & $5.57 \mathrm{E}-5$ & 19.6 & {$[0.14]$} & {$[2.4 \mathrm{E}-6]$} & & na & na & 1,515 & 0.66 \\
\hline $\mathrm{P}$ & 1,545 & $4.99 \mathrm{E}-2$ & 0.6 & 2,100 & $6.78 \mathrm{E}-2$ & & [620] & [42] & 1,230 & 6.50 \\
\hline $\mathrm{S}$ & 7,260 & $2.26 \mathrm{E}-1$ & 0.3 & 470 & $1.47 \mathrm{E}-2$ & & $<554$ & na & [110] & {$[0]$} \\
\hline $\mathrm{Si}$ & {$[3.80]$} & [1.4E-4] & [147] & 2.27 & $8.08 \mathrm{E}-5$ & & $8,980^{(\mathrm{d})}$ & 2.0 & na & na \\
\hline $\mathrm{Sr}$ & {$[0.043]$} & [4.9E-7] & [79] & {$[0.005]$} & {$[5.8 \mathrm{E}-8]$} & & 83.6 & 5 & 105 & 0.0 \\
\hline $\mathrm{U}$ & [17] & [7.1E-5] & [59] & [2.7] & [1.1E-5] & & 12,750 & 0.8 & 13,900 & 1.4 \\
\hline $\mathrm{Zn}$ & {$[1.35]$} & [2.1E-5] & [7] & 1.03 & $1.58 \mathrm{E}-5$ & & 184 & 3.8 & 192 & 5.2 \\
\hline $\mathrm{Zr}$ & $<0.13$ & $<1.5 \mathrm{E}-6$ & na & $<0.026$ & $<2.9 \mathrm{E}-7$ & & 4,810 & 7.9 & 8,250 & 0.0 \\
\hline U KPA & \multicolumn{6}{|c|}{$\mathrm{n} / \mathrm{a}$} & 9,755 & 2.6 & -- & -- \\
\hline nitrite & 19,150 & 4.16E-1 & 0.52 & 1,225 & $2.66 \mathrm{E}-2$ & 0.82 & \multirow{8}{*}{\multicolumn{4}{|c|}{$\mathrm{n} / \mathrm{a}$}} \\
\hline nitrate & 46,850 & $7.56 \mathrm{E}-1$ & 0.64 & 3,085 & $4.98 \mathrm{E}-2$ & 1.0 & & & & \\
\hline phosphate & 3,605 & $3.80 \mathrm{E}-2$ & 1.9 & 6,355 & $6.69 \mathrm{E}-2$ & 1.4 & & & & \\
\hline sulfate & 20,450 & 2.13E-1 & 0.49 & 1,365 & $1.42 \mathrm{E}-2$ & 0.73 & & & & \\
\hline oxalate & 2,970 & $3.38 \mathrm{E}-2$ & 0.67 & 1,565 & $1.78 \mathrm{E}-2$ & 0.64 & & & & \\
\hline free hydroxide & 5,270 & $3.10 \mathrm{E}-1$ & 0.00 & & & & & & & \\
\hline TOC as $\mathrm{C}$ & 1,805 & $1.504 \mathrm{E}-1$ & 0.55 & & & & & & & \\
\hline TIC as $\mathrm{C}$ & 4,455 & $3.713 \mathrm{E}-1$ & 2.9 & & & & & & & \\
\hline \multicolumn{11}{|l|}{ Opportunistic } \\
\hline fluoride & 4,155 & $2.19 \mathrm{E}-1$ & 0.24 & 904 & $4.76 \mathrm{E}-2$ & 0.22 & \multirow{2}{*}{\multicolumn{4}{|c|}{$\mathrm{n} / \mathrm{a}$}} \\
\hline chloride & 925 & $2.61 \mathrm{E}-2$ & 3.0 & 60 & $1.69 \mathrm{E}-3$ & 0.17 & & & & \\
\hline $\mathrm{Ag}$ & $<0.25$ & $<2.3 \mathrm{E}-6$ & na & {$[0.098]$} & [9.1E-7] & & {$[16]$} & [38] & {$[9.05]$} & [21] \\
\hline As & $<6.19$ & $<8.3 \mathrm{E}-5$ & na & {$[1.7]$} & {$[2.3 \mathrm{E}-5]$} & & $<192$ & na & $<32$ & na \\
\hline $\mathrm{Ba}$ & {$[0.43]$} & [3.1E-6] & [97] & 0.086 & $6.23 \mathrm{E}-7$ & & 82.5 & 4 & 118 & 3.4 \\
\hline $\mathrm{Be}$ & 0.113 & $1.25 \mathrm{E}-5$ & 46. & {$[0.002]$} & {$[2.7 \mathrm{E}-7]$} & na & 2.71 & 18 & 2.97 & 6.4 \\
\hline $\mathrm{Ca}$ & {$[4.6]$} & [1.1E-4] & {$[48]$} & {$[1.1]$} & {$[2.7 \mathrm{E}-5]$} & & $<3,810$ & na & 1,210 & 0.0 \\
\hline $\mathrm{Ce}$ & $<1.20$ & $<8.6 \mathrm{E}-6$ & na & $<0.24$ & $<1.7 \mathrm{E}-6$ & & {$[62]$} & [61] & 100 & 8.4 \\
\hline Co & {$[0.71]$} & [1.2E-5] & na & $<0.057$ & $<9.7 \mathrm{E}-7$ & & $<12$ & na & {$[16]$} & [13] \\
\hline $\mathrm{Cu}$ & 1.88 & $2.96 \mathrm{E}-5$ & 18 & {$[0.22]$} & {$[3.5 \mathrm{E}-6]$} & & 147 & 15 & 127 & 3.1 \\
\hline
\end{tabular}


Table 3.7 (Contd)

\begin{tabular}{|c|c|c|c|c|c|c|c|c|c|c|}
\hline & \multicolumn{3}{|c|}{ Supernatant } & \multicolumn{3}{|c|}{ Wash composite } & \multicolumn{4}{|c|}{ Washed solids } \\
\hline $\begin{array}{l}\text { Sample } \\
\text { ID > }\end{array}$ & \multicolumn{3}{|c|}{ 07-00365 } & \multicolumn{3}{|c|}{ 07-00366 } & \multicolumn{4}{|c|}{ 07-00367 } \\
\hline \multirow[b]{2}{*}{ Analyte } & \multirow[b]{2}{*}{$\mu \mathrm{g} / \mathrm{mL}$} & \multirow[b]{2}{*}{$\mathbf{M}$} & \multirow[b]{2}{*}{ RPD } & \multirow[b]{2}{*}{$\mu \mathrm{g} / \mathrm{mL}$} & \multirow[b]{2}{*}{$\mathbf{M}$} & \multirow[b]{2}{*}{ RPD } & \multicolumn{2}{|c|}{ Fusion } & \multicolumn{2}{|c|}{ Acid Digest } \\
\hline & & & & & & & $\mu \mathrm{g} / \mathrm{g}$ & RPD & $\mu \mathrm{g} / \mathrm{g}$ & RPD \\
\hline Dy & $<0.35$ & $<2.1 \mathrm{E}-6$ & na & $<0.069$ & $<4.2 \mathrm{E}-7$ & \multirow{22}{*}{ na } & $<10$ & na & $<2.1$ & na \\
\hline $\mathrm{Eu}$ & {$[0.12]$} & [7.7E-7] & [109] & {$[0.016]$} & [1.1E-7] & & [4.19] & [139] & {$[1.36]$} & {$[65]$} \\
\hline $\mathrm{La}$ & $<0.42$ & $<3.0 \mathrm{E}-6$ & na & $<0.067$ & $<4.8 \mathrm{E}-7$ & & {$[40]$} & {$[40]$} & 86.8 & 1.7 \\
\hline $\mathrm{Li}$ & 1.87 & $2.69 \mathrm{E}-4$ & 1.6 & 0.722 & $1.04 \mathrm{E}-4$ & & [42] & {$[12]$} & 43.0 & 3.0 \\
\hline $\mathrm{Mg}$ & $<2.46$ & $<1.0 \mathrm{E}-4$ & na & $<0.033$ & $<1.4 \mathrm{E}-6$ & & 205 & 2 & 288 & 0.7 \\
\hline Mo & 16.2 & $1.68 \mathrm{E}-4$ & 3.1 & {$[0.96]$} & [1.0E-5] & & $<25$ & na & [9] & [95] \\
\hline $\mathrm{Nd}$ & $<0.98$ & $<6.8 \mathrm{E}-6$ & na & $<0.13$ & $<8.9 \mathrm{E}-7$ & & [49] & {$[52]$} & 102 & 1.0 \\
\hline $\mathrm{Pb}$ & $<3.86$ & $<1.9 \mathrm{E}-5$ & na & $<0.76$ & $<3.7 \mathrm{E}-6$ & & [915] & {$[12]$} & 1,240 & 0.0 \\
\hline $\mathrm{Pd}$ & {$[1.18]$} & [1.1E-5] & [71] & {$[0.15]$} & [1.4E-6] & & [25] & [19] & $<4.6$ & na \\
\hline $\mathrm{Rh}$ & {$[2.25]$} & [2.2E-5] & [22] & $<0.29$ & $<2.8 \mathrm{E}-6$ & & $<45$ & na & [11] & {$[38]$} \\
\hline $\mathrm{Ru}$ & {$[3.65]$} & [3.6E-5] & [19] & $<0.202$ & $<2.0 \mathrm{E}-6$ & & [76] & {$[21]$} & [52] & [6] \\
\hline $\mathrm{Sb}$ & $<2.41$ & $<2.0 \mathrm{E}-5$ & na & $<0.48$ & $<3.9 \mathrm{E}-6$ & & $<107$ & na & $<15$ & na \\
\hline $\mathrm{Se}$ & [22] & [2.7E-4] & [14] & {$[3.8]$} & [4.8E-5] & & $<410$ & na & $<51$ & na \\
\hline $\mathrm{Sn}$ & {$[6.6]$} & [5.6E-5] & [39] & $<0.64$ & $<5.4 \mathrm{E}-6$ & & $<87$ & na & [30] & [13] \\
\hline $\mathrm{Ta}$ & $<2.05$ & $<1.1 \mathrm{E}-5$ & na & $<0.40$ & $<2.2 \mathrm{E}-6$ & & $<69$ & na & $<12$ & na \\
\hline $\mathrm{Te}$ & $<3.13$ & $<2.5 \mathrm{E}-5$ & na & $<0.62$ & $<4.9 \mathrm{E}-6$ & & {$[105]$} & {$[28]$} & [44] & [25] \\
\hline Th & [3.95] & [1.7E-5] & [53] & {$[0.24]$} & [1.0E-6] & & {$[170]$} & [35] & 444 & 1.1 \\
\hline $\mathrm{Ti}$ & $<0.319$ & $<6.7 \mathrm{E}-6$ & na & $<0.010$ & $<2.1 \mathrm{E}-7$ & & 113 & 4 & 106 & 1.9 \\
\hline $\mathrm{Tl}$ & $<4.58$ & $<2.2 \mathrm{E}-5$ & na & $<0.90$ & $<4.4 \mathrm{E}-6$ & & $<104$ & na & [43] & [70] \\
\hline V & 1.12 & $2.19 \mathrm{E}-5$ & 19 & 3.59 & $7.05 \mathrm{E}-5$ & & $<11$ & na & 10.8 & 5.6 \\
\hline $\mathrm{W}$ & 38.0 & $2.06 \mathrm{E}-4$ & 2.4 & [2.9] & [1.6E-5] & & $<73$ & na & [69] & [7] \\
\hline $\mathrm{Y}$ & $<0.039$ & $<4.3 \mathrm{E}-7$ & na & $<0.008$ & $<8.6 \mathrm{E}-8$ & & {$[9.4]$} & {$[6]$} & 14.3 & 1.4 \\
\hline \multicolumn{11}{|c|}{$\begin{array}{l}\text { (b) This sample was not required to be run in duplicate; therefore, an RPD was not calculated. } \\
\text { (c) The fusion blank Mn concentration was } 14 \% \text { of the sample concentration, exceeding the } 5 \% \text { threshold. Since the } \\
\text { sample result agreed with the results from the acid digestion, no re-preparation was required. }\end{array}$} \\
\hline \multicolumn{11}{|c|}{$\begin{array}{l}\text { (d) The Si LCS recovered low at } 41 \% \text {, indicating that the result might be biased low. } \\
\text { Notes: }\end{array}$} \\
\hline \multicolumn{11}{|c|}{ Analytical Service Request 8078 . } \\
\hline \multicolumn{11}{|c|}{$\begin{array}{l}\text { Analyte uncertainties were typically within } \pm 15 \% \text {; results in brackets indicate that the analyte } \\
\text { concentrations were greater than the minimum detection limit (MDL) and less than the estimated } \\
\text { quantitation limit (EQL), and uncertainties were }>15 \% \text {. }\end{array}$} \\
\hline \multicolumn{11}{|c|}{$\begin{array}{l}\text { Opportunistic analytes are reported for information only; QC requirements did not apply to these } \\
\text { analytes. } \\
\text { na }=\text { not applicable, sample was not analyzed in duplicate or the analyte was }<\mathrm{MDL} \text {. } \\
\mathrm{n} / \mathrm{a}=\text { not analyzed, analysis was not required. }\end{array}$} \\
\hline
\end{tabular}

The washed water-insoluble solids were $\sim 30 \mathrm{wt} \% \mathrm{Al}$ with $\sim 1.5 \mathrm{wt} \%$ each of $\mathrm{Na}, \mathrm{Fe}$, and $\mathrm{U}$ (dry mass basis). The supernatant was primarily sodium salts (nitrate, nitrite, sulfate, hydroxide, carbonate, and fluoride). The anionic and cationic charge balance was evaluated for the supernatant, resulting in a $2.2 \%$ 
difference, well within analytical uncertainties. The wash solution was generally a dilution of the supernatant except in the case of $\mathrm{P}$ and phosphate, which were significantly higher in the wash solution. This indicated that water-soluble phosphate solids were still present in the unwashed solids phase.

Water wash factors for each component were calculated from the mass distribution in the combined supernatant and wash solutions relative to the total analyte mass according to Equation 3.1.

$$
F_{i}=\frac{S_{i}+W_{i}}{S_{i}+W_{i}+U D S_{i}}
$$

where $\quad F_{i}=$ analyte fraction removed during washing

$\mathrm{S}_{\mathrm{i}}=$ analyte mass in supernatant fraction

$\mathrm{W}_{\mathrm{i}}=$ analyte mass in combined wash solution

$\mathrm{UDS}_{\mathrm{i}}=$ analyte mass in the undissolved solids.

The fractional distributions of selected analytes in the supernatant, wash, and solids phases are shown in Table 3.8 and Figure 3.6. A large portion ( $>90 \%$ ) of the $\mathrm{Na}, \mathrm{P}$, and $\mathrm{S}$ partitioned to the aqueous phase. About $29 \%$ of the $\mathrm{Cr}$ remained in the solids phase. The Al remained primarily in the solids phase. The water-wash factors obtained from the current testing were compared with the weighted mean of the waterwash factors obtained from the TWINS database. The weighting factors were calculated from the relative masses of tank wastes that were used to create the composite. With the exception of Al, the experimentally observed wash factors were somewhat greater than those reported in TWINS. The Al wash factor was significantly less than the TWINS value. The specific sample selection process confounded direct cross comparison of these water-wash factors with those in the TWINS database. Samples high in Al were selected for testing, and these did not necessarily represent the tank composite.

Table 3.8. Phase Distribution of Selected Analytes in Group 3 CWP Sludge

\begin{tabular}{|c|c|c|c|c|c|}
\hline Analyte & $\begin{array}{c}\text { Supernatant } \\
\text { wt } \%\end{array}$ & $\begin{array}{c}\text { Wash Solution } \\
\text { wt } \%\end{array}$ & $\begin{array}{c}\text { Water-Wash } \\
\text { Factor } \\
\text { wt } \% \\
\end{array}$ & $\begin{array}{c}\text { TWINS Water- } \\
\text { Wash Factor }^{(a)} \\
\text { wt } \% \\
\end{array}$ & $\begin{array}{l}\text { Solids } \\
\text { wt } \%\end{array}$ \\
\hline $\mathrm{Cr}$ & 61.1 & 9.3 & 70.4 & 47 & 29.6 \\
\hline $\mathrm{Al}$ & 1.6 & 0.2 & 1.9 & 18 & 98.1 \\
\hline $\mathrm{Na}$ & 70.8 & 23.6 & 94.4 & 79 & 5.6 \\
\hline $\mathrm{P}$ & 23.0 & 69.9 & 92.9 & $82^{(\mathrm{b})}$ & 7.1 \\
\hline $\mathrm{S}$ & 86.9 & 12.6 & [99.5] & $95^{(\mathrm{c})}$ & {$[0.5]$} \\
\hline \multicolumn{6}{|c|}{$\begin{array}{l}\text { (a) The water-wash factor represents the weighted mean of the five represented } \\
\text { TWINS database. The C- } 103 \text { tank waste was not incorporated since all was } \\
\text { was only } \sim 2 \mathrm{wt} \% \text { of the total composite mass. } \\
\text { (b) TWINS reported a phosphate water-wash factor. } \\
\text { (c) Reported in TWINS as sulfate; sulfur water wash factor was not available. } \\
\text { TWINS report date was } 6 / 2 / 08 \text {. } \\
\text { Results in brackets indicate that the analyte concentrations were }>\text { MDL }\end{array}$} \\
\hline
\end{tabular}




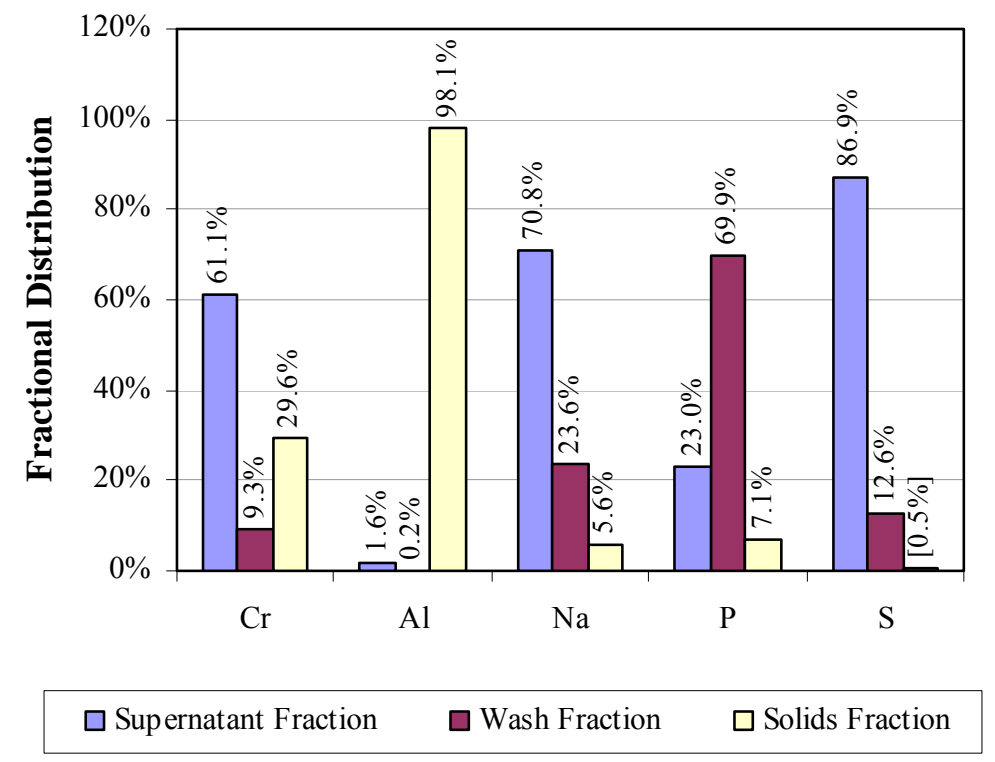

Figure 3.6. Selected Analyte Phase Distribution for Group 3 CWP Sludge

\subsubsection{Particle Size}

Particle size was measured as described in Appendix C, section C.3.1 on a Mastersizer 2000 (Malvern Instruments, Inc., Southborough, MA 01772 USA). Figure 3.7 through Figure 3.9 and Table 3.9 and Table 3.10 present the results of Group 3 initial characterization particle-size analysis as a function of test conditions. Figure 3.7 through Figure 3.9 show the differential volume population distribution for the primary Group 3 initial characterization sample and allow a qualitative examination of the PSD behavior with respect to pump speed and sonication. Table 3.9 is a summary of the measured oversize diameter percentiles (by volume/weight) for the primary sample, TI550-G3-S-WL-PSD-1. Table 3.10 presents the same results for the duplicate sample, TI550-G3-S-WL-PSD-2. Both tables present cumulative oversize diameters corresponding to the $10^{\text {th }}, 50^{\text {th }}$, and $90^{\text {th }}$ volume/weight percentiles, hereafter referred to as $d(10), d(50)$, and $d(90)$, respectively. These tables will be used to quantitatively examine reproducibility and changes in particle size.

Figure 3.7 shows the PSD for the primary Group 3 initial characterization sample as a function of pump speed before sonication. The distribution of particles ranges from 0.2 to $40 \mu \mathrm{m}$, with the exception of the 4000-RPM condition where the range extends to $200 \mu \mathrm{m}$. The peak maxima are between 11 and $15 \mu \mathrm{m}$, and all three conditions are continuous and uni-modal, although there is a weak shoulder near $2 \mu \mathrm{m}$. Distribution changes with respect to the flow rate are minor with the exception of the appearance of a larger shoulder population spanning 30 to $200 \mu \mathrm{m}$ at 4000 RPM. This is expected as higher pump speeds are capable of suspending larger particles and particle aggregates. Particle sizes appear to be stable with respect to flow because they are not sheared apart at higher pump speeds. 


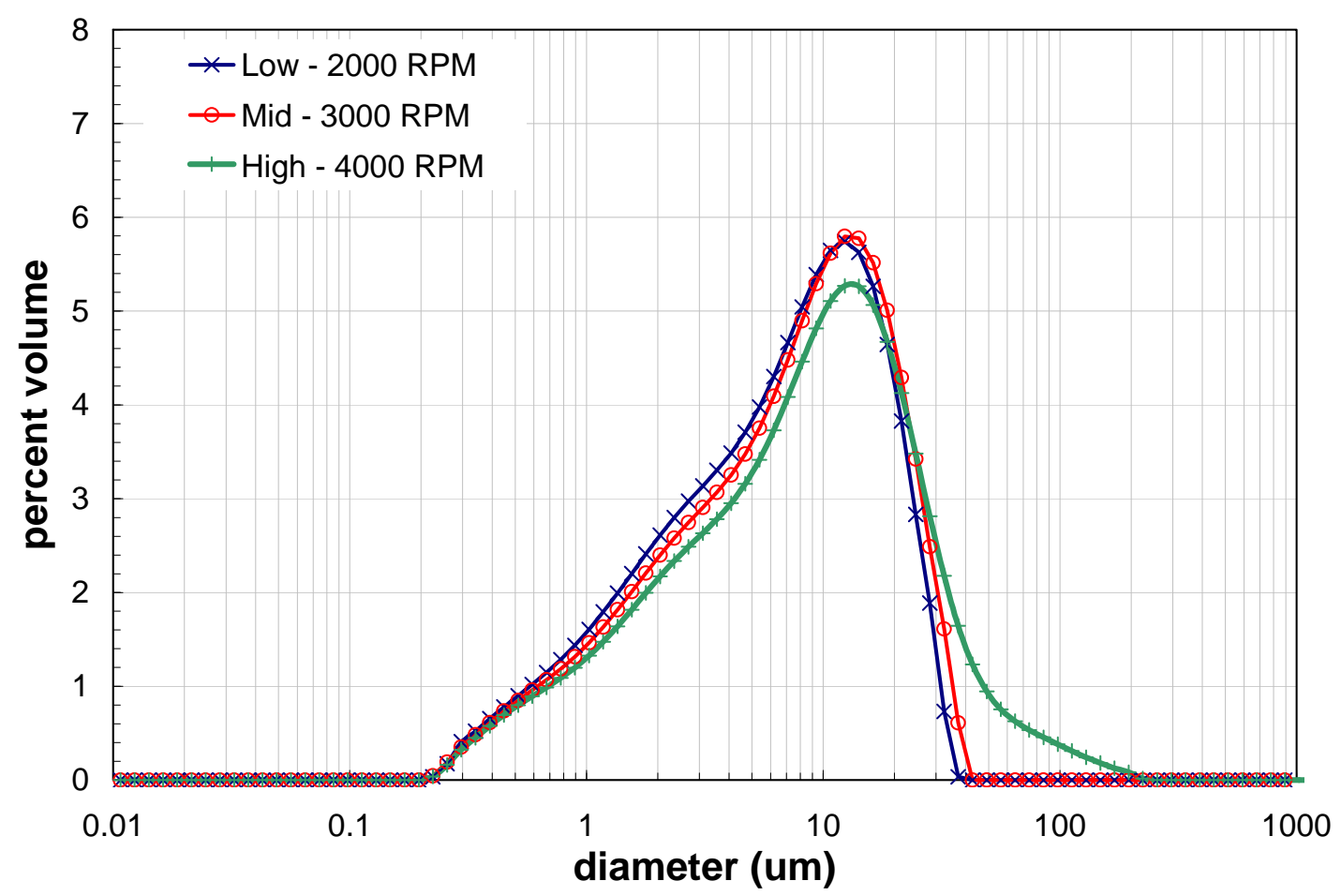

Figure 3.7. Pre-Sonication Volume Distribution Result for the Primary Group 3 Initial Characterization Sample as a Function of Pump Speed

Figure 3.8 shows the PSD as a function of sonication. This figure indicates that sonication shifts the entire particle population to smaller diameters and increases the central ( 8 to $9 \mu \mathrm{m})$ population of particles, probably as a result of particle aggregate disruption. Disruption is evidenced by a decreased fraction of 12- to $40-\mu \mathrm{m}$ particles and an increased fraction of $0.2-$ to $12-\mu \mathrm{m}$ particles. After-sonication results show that although aggregates larger than $14 \mu \mathrm{m}$ do not reform within the time scale of the measurement, there may be some tendency of smaller particles to recombine. This results in an increase in the relative population of 5 - to $10-\mu \mathrm{m}$ particles. 


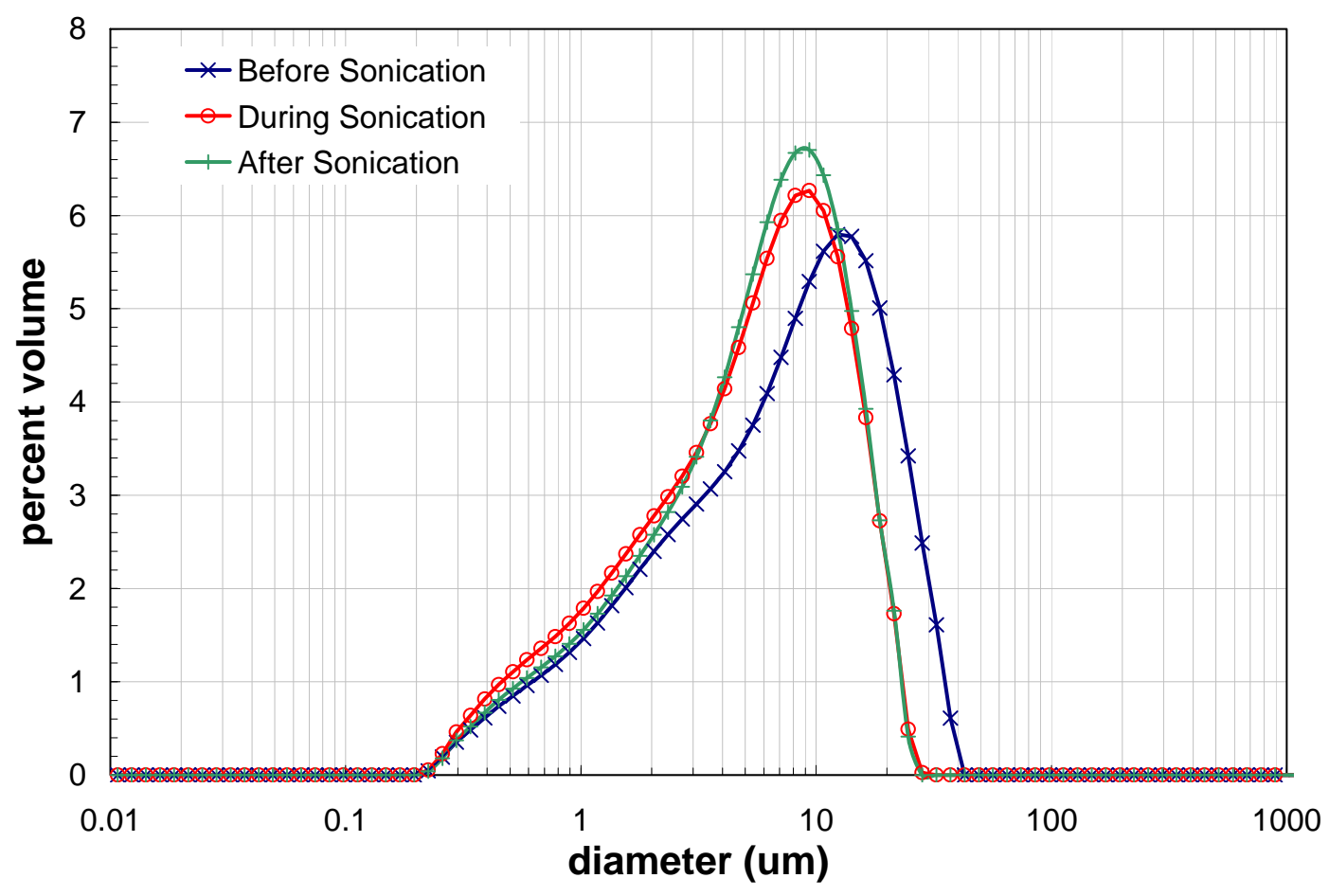

Figure 3.8. Volume-Distribution Result for the Primary Group 3 Initial Characterization Sample as a Function of Sonication. Note: the during-sonication condition corresponds to measurement condition 6: 3,000 RPM, 75\% Sonication.

Figure 3.9 shows the primary Group 3 initial characterization PSD as a function of pump speed after the waste dispersion has been sonicated. Here, changes in pump speed do not appear to significantly change the distribution. Based on this observation, it can be concluded that the particles are still stable with respect to mechanical (shear-induced) break-up, even after sonication. Changes as a result of sonication appear permanent as aggregate recovery does not occur over the duration of the PSD measurement. 


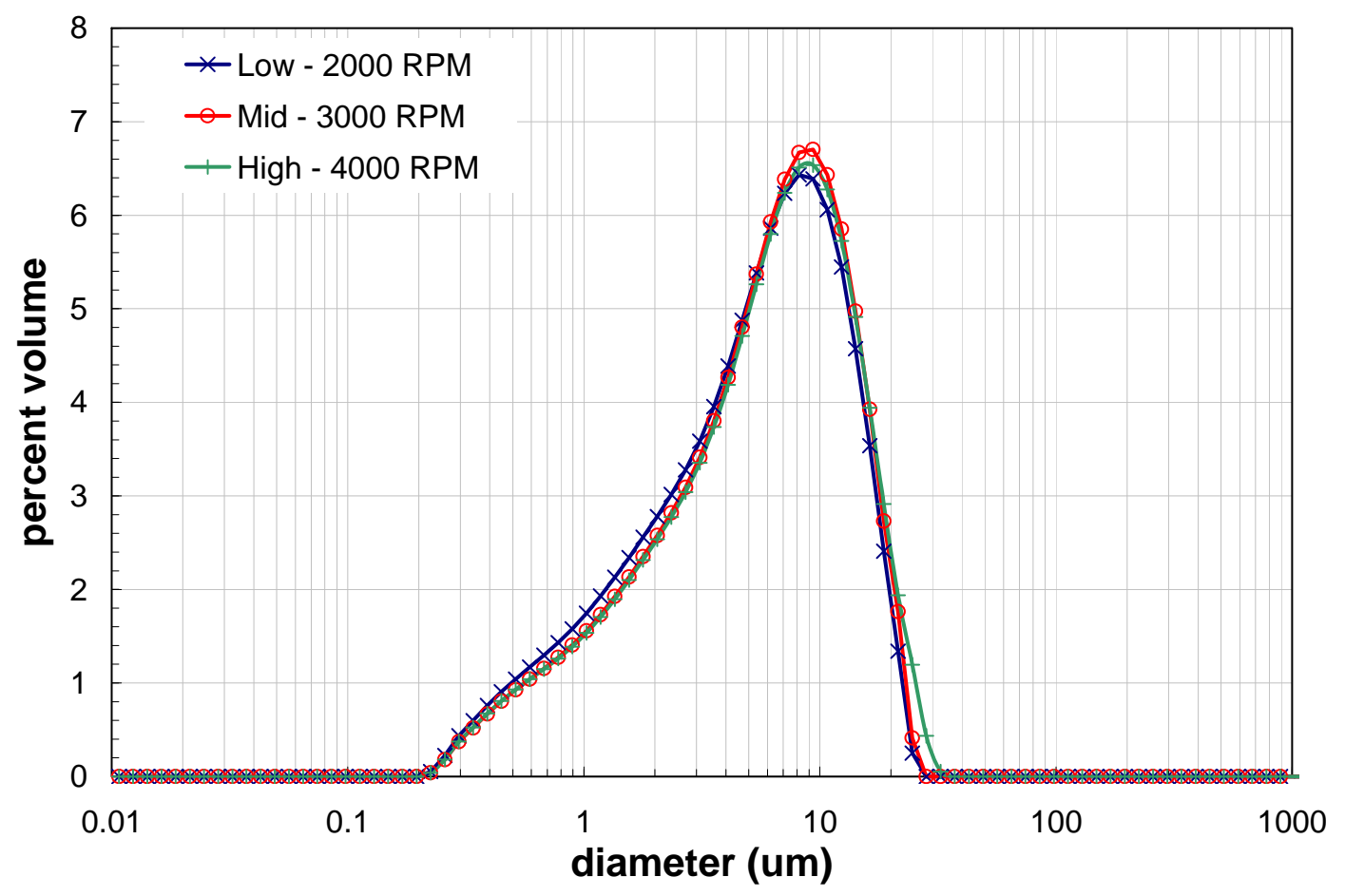

Figure 3.9. Post-Sonication Volume Distribution Result for the Primary Group 3 Initial Characterization Sample as a Function of Pump Speed

Table 3.9 and Table 3.10 show select cumulative oversize percentiles for the primary and duplicate Group 3 particle dispersions. Using the primary results as a reference, the behavior of Group 3 initial characterization particle size as a function of pump speed and sonication can be quantitatively evaluated. Specifically, the following observations can be made:

- In general, the $\mathrm{d}(10)$ falls between 0.96 and $1.3 \mu \mathrm{m}$, the $\mathrm{d}(50)$ between 5.5 and $8.8 \mu \mathrm{m}$, and the $\mathrm{d}(90)$ between 14 and $30 \mu \mathrm{m}$

- The listed diameter percentiles appear to be slightly sensitive to changes in pump speed before sonication. Increases in flow appear to influence increases in the mean diameter [i.e., the $\mathrm{d}(50)$ ]. For example, a decrease in pump speed from 4000 and 2000 RPM before sonication decreases the particle diameter from 8.8 to $6.9 \mu \mathrm{m}$. This is a decrease of $22 \%$, which is above the instrument limit of accuracy $(10 \%)$ and therefore is significant and not merely random noise or measurement error.

- Sonication of the Group 3 solids dispersion decreases particle size. The PSD results at 3000 RPM indicate that sonication lowers the mean particle size from 7.7 to $6.0 \mu \mathrm{m}$. This represents a decrease of $22 \%$ in the mean particle size and is significant relative to the measurement accuracy $(10 \%)$.

- After sonication, the diameter percentiles appear to be less sensitive to changes in the pump speed. The mean diameter varies between 5.5 and $6.1 \mu \mathrm{m}$, which is a difference of $9.8 \%$, and it is difficult to determine the significance. 
Table 3.9. Particle-Size Analysis Percentile Results of the Primary Group 3 Initial Characterization Sample, TI550-G3-S-WL-PSD-1

\begin{tabular}{||c|c|c|c|c|c||}
\hline $\begin{array}{c}\text { Measurement } \\
\text { Condition }\end{array}$ & Pump Speed & Sonication & $\begin{array}{c}\mathbf{d}(\mathbf{1 0}) \\
{[\boldsymbol{\mu m}]}\end{array}$ & $\begin{array}{c}\mathbf{d}(\mathbf{5 0}) \\
{[\boldsymbol{\mu m}]}\end{array}$ & $\begin{array}{c}\mathbf{d}(\mathbf{9 0}) \\
{[\boldsymbol{\mu m}]}\end{array}$ \\
\hline 1 & 3000 & pre-sonic & 1.2 & 7.7 & 22 \\
\hline 2 & 4000 & pre-sonic & 1.3 & 8.8 & 30 \\
\hline 3 & 2000 & pre-sonic & 1.1 & 6.9 & 20 \\
\hline 4 & 3000 & $25 \%$ & 0.97 & 6.3 & 18 \\
\hline 5 & 3000 & $50 \%$ & 0.97 & 6.0 & 16 \\
\hline 6 & 3000 & $75 \%$ & 0.96 & 5.6 & 15 \\
\hline 7 & 3000 & post-sonic & 1.1 & 6.0 & 15 \\
\hline 8 & 4000 & post-sonic & 1.1 & 6.1 & 15 \\
\hline 9 & 2000 & post-sonic & 1.0 & 5.5 & 14 \\
\hline
\end{tabular}

Table 3.10. Particle-Size Analysis Percentile Results of the Duplicate Group 3 Initial Characterization Sample, TI550-G3-S-WL-PSD-1

\begin{tabular}{||c|c|c|c|c|c||}
\hline $\begin{array}{c}\text { Measurement } \\
\text { Condition }\end{array}$ & Pump Speed & Sonication & $\begin{array}{c}\mathbf{d}(\mathbf{1 0}) \\
{[\boldsymbol{\mu m}]}\end{array}$ & $\begin{array}{c}\mathbf{d}(\mathbf{5 0}) \\
{[\boldsymbol{\mu m}]}\end{array}$ & $\begin{array}{c}\mathbf{d}(\mathbf{9 0}) \\
{[\boldsymbol{\mu m}]}\end{array}$ \\
\hline 1 & 3000 & pre-sonic & 1.0 & 6.0 & 17 \\
\hline 2 & 4000 & pre-sonic & 1.1 & 6.3 & 20 \\
\hline 3 & 2000 & pre-sonic & 1.0 & 5.8 & 16 \\
\hline 4 & 3000 & $25 \%$ & 1.0 & 5.7 & 16 \\
\hline 5 & 3000 & $50 \%$ & 1.0 & 5.5 & 14 \\
\hline 6 & 3000 & $75 \%$ & 1.0 & 5.2 & 13 \\
\hline 7 & 3000 & post-sonic & 1.0 & 5.1 & 13 \\
\hline 8 & 4000 & post-sonic & 1.0 & 5.1 & 13 \\
\hline 9 & 2000 & post-sonic & 1.0 & 5.1 & 13 \\
\hline
\end{tabular}

The behavior of the duplicate sample PSD with respect to pump speed and sonication is similar to that of the primary sample. However, the PSD of the duplicate sample favors consistently smaller diameters than that of the primary at equivalent measurement conditions. Table 3.11 shows the absolute relative percent difference between the $\mathrm{d}(10), \mathrm{d}(50)$, and $\mathrm{d}(90)$ values determined for the primary and duplicate Group 3 initial characterization samples. Here, the absolute relative percent difference is determined using equation 3.2 .

$$
R P D=\left|\frac{d_{d}(n)-d_{p}(n)}{d_{p}(n)}\right|
$$

where $d_{p}(n)$ and $d_{d}(n)$ are the primary and duplicate cumulative oversize diameters corresponding to the $n^{\text {th }}$ percentile. The listed RPDs indicate that there is a slight difference between samples. 
Table 3.11. Absolute Relative Percent Difference between Primary and Duplicate Group 3 Initial Characterization Samples

\begin{tabular}{|c|c|c|c|c|c||}
\hline \multirow{2}{*}{$\begin{array}{c}\text { Measurement } \\
\text { Condition }\end{array}$} & \multirow{2}{*}{ Pump Speed } & \multirow{2}{*}{ Sonication } & \multicolumn{3}{|c|}{ Absolute RPD } \\
\cline { 4 - 6 } & & $\mathbf{d}(\mathbf{1 0})$ & $\mathbf{d}(\mathbf{5 0 )}$ & $\mathbf{d}(\mathbf{9 0})$ \\
\hline 1 & 3000 & pre-sonic & $11 \%$ & $21 \%$ & $20 \%$ \\
\hline 2 & 4000 & pre-sonic & $15 \%$ & $28 \%$ & $34 \%$ \\
\hline 3 & 2000 & pre-sonic & $5.8 \%$ & $16 \%$ & $16 \%$ \\
\hline 4 & 3000 & $25 \%$ & $5.8 \%$ & $8.8 \%$ & $13 \%$ \\
\hline 5 & 3000 & $50 \%$ & $5.5 \%$ & $8.0 \%$ & $12 \%$ \\
\hline 6 & 3000 & $75 \%$ & $5.3 \%$ & $6.9 \%$ & $9.5 \%$ \\
\hline 7 & 3000 & post-sonic & $9.2 \%$ & $15 \%$ & $14 \%$ \\
\hline 8 & 4000 & post-sonic & $9.9 \%$ & $17 \%$ & $17 \%$ \\
\hline 9 & 2000 & post-sonic & $0.80 \%$ & $9.0 \%$ & $11 \%$ \\
\hline
\end{tabular}

For particle-size measurements on the Malvern Mastersizer 2000, RPDs of up to $10 \%$ are generally expected, given the accuracy of the instrument. The results for Group 3 initial characterization samples show RPDs that range from 0.80 to $34 \%$, depending on the measurement condition and percentile examined. Based on the large number of RPDs greater than $10 \%$ in Table 3.11, it is likely that there is a significant size difference in the solids species in the primary and duplicate samples. The largest RPDs are observed in the pre-sonication measurement conditions, indicating that sonication eliminates some size differences between the samples. Since, during sonication, the measurements lie close to or below $10 \%$, the size differences between the primary and the duplicate sample may be largely influenced by agglomeration.

Figure 3.10 and Figure 3.11 show how the differences in the primary and duplicate PSDs described in the preceding paragraphs manifest in the differential volume distributions. Figure 3.10 compares the primary and duplicate PSDs at 3000 RPM before sonication. With respect to the pre-sonication comparison, both distributions show similar trends in population with peaks centered between 9 to $15 \mu \mathrm{m}$ and spanning 0.2 to $40 \mu \mathrm{m}$. The main difference is that the primary sample has a significantly increased population of 10 to $40 \mu \mathrm{m}$. This causes the larger percentiles observed in Table 3.9 (relative to those in Table 3.10) and $>10 \%$ RPDs in Table 3.11 . 


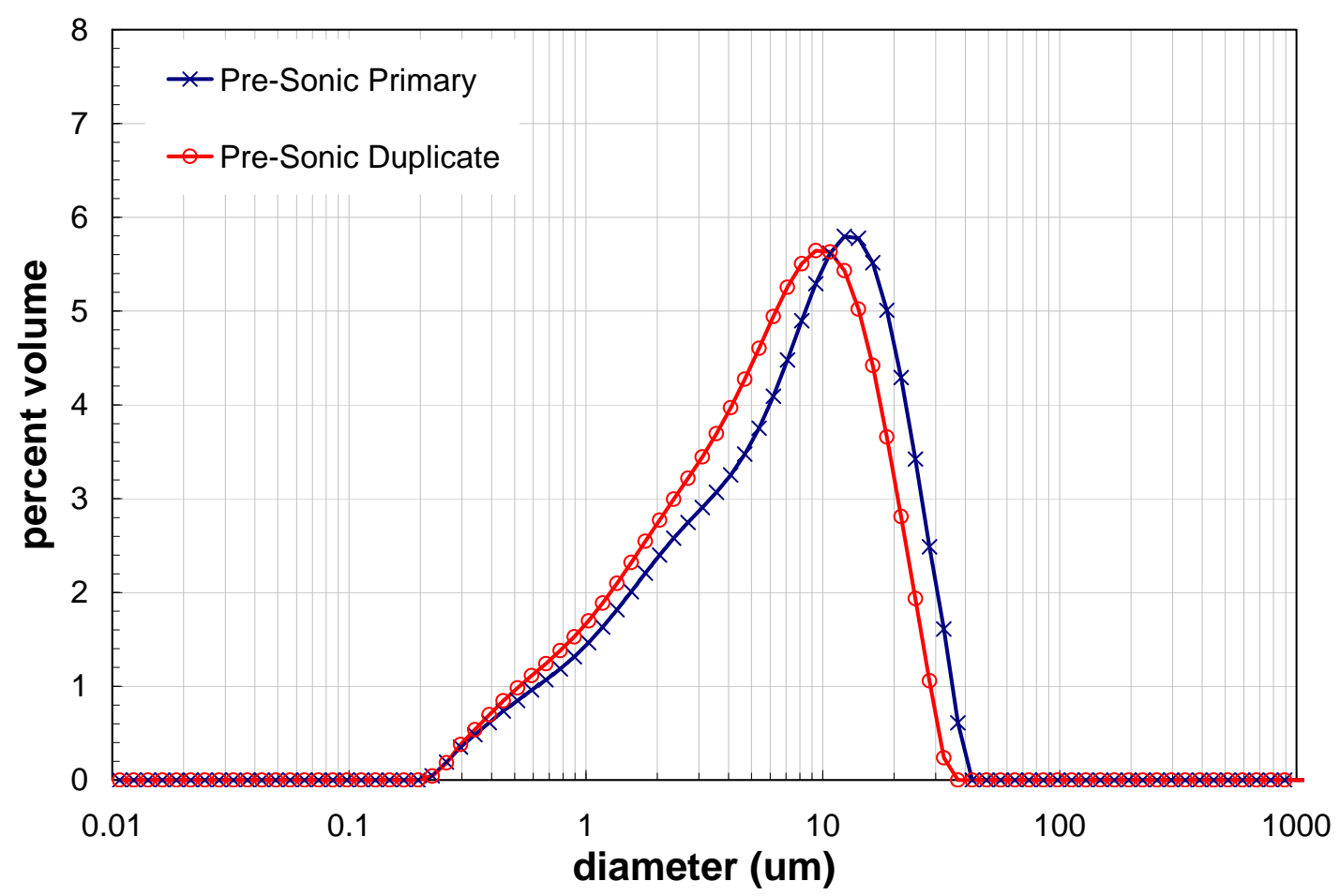

Figure 3.10. Comparison of Primary and Duplicate Sample Differential Volume PSD of Group 3 Initial Characterization at 3000 RPM before Sonication

Figure 3.11 compares primary and duplicate distributions after sonication. Overall, the primary and duplicate distributions show a uni-modal particle size spanning 0.2 to $30 \mu \mathrm{m}$ with the peak centered around 7 to $10 \mu \mathrm{m}$. After-sonication results show that the increased particle size observed in the primary sample before sonication is maintained after sonication. The difference between the primary and duplicate distributions after sonication appears less than before sonication (an observation confirmed by the results in Table 3.11). This supports the earlier assertion that the difference between samples may be in their state of particle aggregation. 


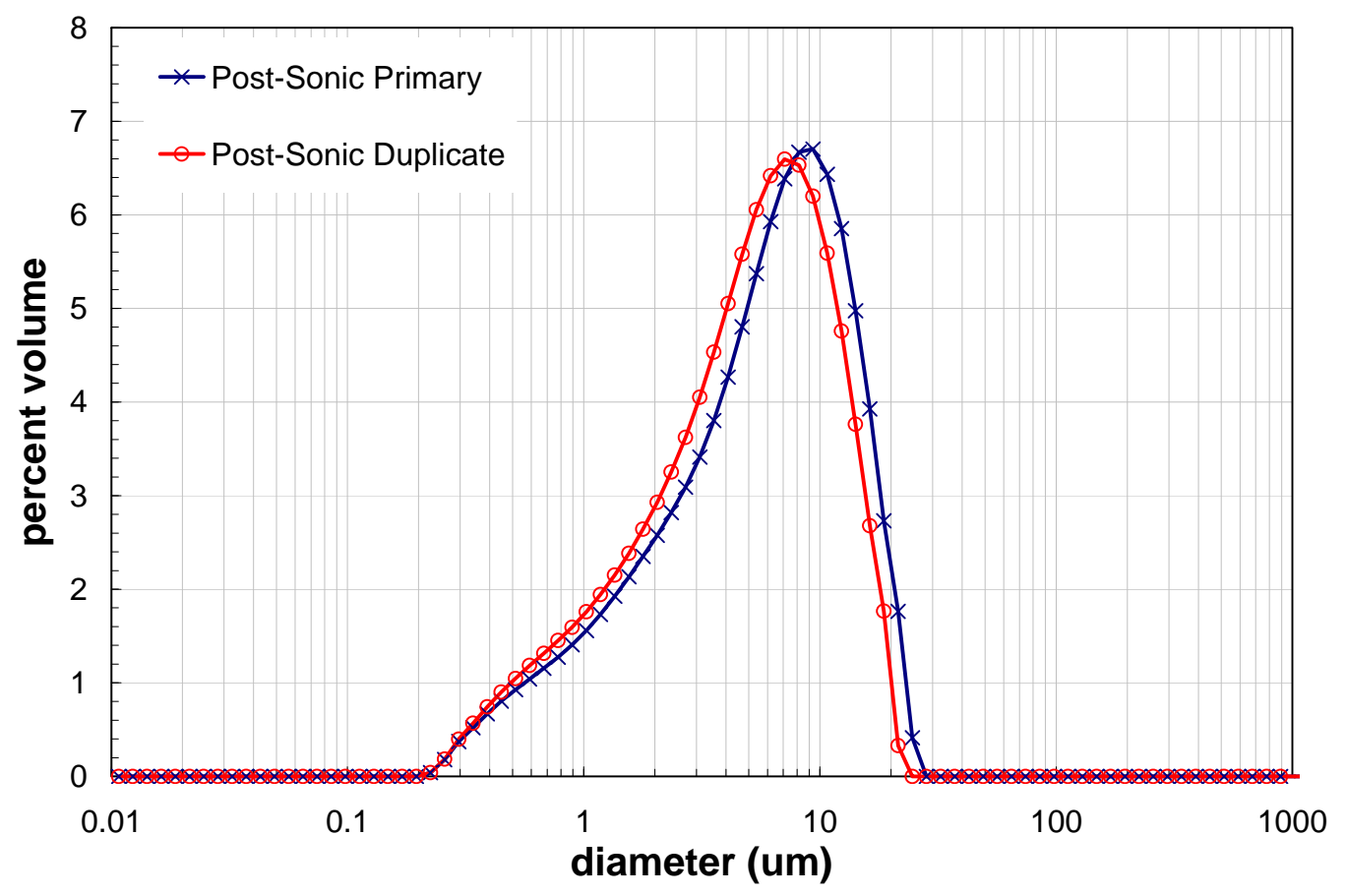

Figure 3.11. Comparison of Primary and Duplicate Sample Differential Volume PSD of Group 3 Initial Characterization at 3000 RPM after Sonication

In summary, the particle-size analysis of the initial characterization Group 3 (PUREX Cladding Waste Sludge) yielded a broad uni-modal PSD with a peak centered between 11 to $15 \mu \mathrm{m}$ and a range from 0.2 to $40 \mu \mathrm{m}$. The range extends to $200 \mu \mathrm{m}$ at the high flow rate, indicating the presence of some larger difficult-to-suspend particles or agglomerates. Sonication shifts the range to 0.2 to $20 \mu \mathrm{m}$, suggesting that some of the larger particles may be agglomerates that were disrupted during sonication. The agglomerate disruption due to sonication appeared stable during the time of the measurement.

\subsubsection{Surface Area}

Surface area was measured as discussed in Appendix C, section C.3.2. Duplicate samples $(0.26 \mathrm{~g}$ and $0.31 \mathrm{~g}$ ) tested for surface area resulted in 4.0 and $4.4 \mathrm{~m}^{2} / \mathrm{g}$, averaging $4.2 \mathrm{~m}^{2} / \mathrm{g}$ with a relative percent difference of $\pm 5 \%$.

\subsubsection{Crystal Form and Habit}

The raw and background-subtracted XRD patterns for the washed Group 3 solids are provided in Figure 3.12. The XRD pattern was dominated by $\mathrm{Al}(\mathrm{OH})_{3}$ (gibbsite, crystal density $2.441 \mathrm{~g} / \mathrm{cm}^{3}$, JADE Version 8.0). Phases that were present in minor amounts were $\mathrm{Fe}_{1.67} \mathrm{H}_{0.99} \mathrm{O}_{3}$ (hematite, crystal density $4.672 \mathrm{~g} / \mathrm{cm}^{3}$, JADE Version 8.0), $1.06 \mathrm{Na}_{2} \mathrm{O} \cdot \mathrm{Al}_{2} \mathrm{O}_{3} \cdot 1.60 \mathrm{SiO}_{2} \cdot 1.60 \mathrm{H}_{2} \mathrm{O}$ (hydroxycancrinite), and/or $\mathrm{Na}_{8.16}\left(\mathrm{Al}_{6} \mathrm{Si}_{6} \mathrm{O}_{24}\right)\left(\mathrm{NO}_{3}\right)_{2.16}\left(\mathrm{H}_{2} \mathrm{O}\right)_{1.62}$ (nitrate cancrinite, crystal density $2.451 \mathrm{~g} / \mathrm{cm}^{3}$, JADE Version 8.0 ). Hydroxycancrinite and nitrate cancrinite have nearly identical diffraction patterns and cannot be distinguished from these data. Phases possibly present, but which could not be confirmed, were $\mathrm{Na}\left(\left(\mathrm{UO}_{2}\right) \mathrm{O}\right)(\mathrm{OH}) \cdot \mathrm{H}_{2} \mathrm{O}$ (clarkeite, crystal density $7.168 \mathrm{~g} / \mathrm{cm}^{3}$, JADE Version 8.0$)$ and $\mathrm{UO}_{3} \cdot \mathrm{H}_{2} \mathrm{O}($ uranium oxide hydrate, crystal density $6.766 \mathrm{~g} / \mathrm{cm}^{3}$, JADE Version 8.0). The clarkeite peak was quite 
broad $\left(1.02^{\circ}\right.$ full width half-max $2-\theta$ at the $14.82^{\circ}$ line $)$, and confirming lines were very weak and overridden by other phases. The $\mathrm{UO}_{3} \cdot \mathrm{H}_{2} \mathrm{O}$ had only one observed line at $17.6^{\circ} 2-\theta$; confirming lines were too low in intensity to detect. The generally low background in the raw spectral pattern indicated that the sample was highly crystalline, i.e., minimal amorphous structure was present.

The XRD results were consistent with the chemical analysis. Chemical analysis showed a large amount of $\mathrm{Al}$ was present with minor amounts of $\mathrm{Fe}, \mathrm{Si}, \mathrm{U}$, and $\mathrm{Na}$. The approximate mass percent of the chemical phases in the Group 3 washed solids was determined by evaluating the identified crystalline species in conjunction with the elemental concentrations. Table 3.12 summarizes the best estimate of the mass percent of phases in the washed solids. Phases were listed as "observed" if recognized in the XRD pattern. The nitrate cancrinite and hydoxycancrinite phases could not be distinguished by XRD; therefore, these are listed together. The clarkeite and uranium oxide hydrate are listed together since their presence was estimated as "possible" by XRD, U was identified in the chemical analysis, and the wt\% was equivalent regardless of the phase assignment. Other miscellaneous metals were found by chemical analysis, but phase assignments could not be made; the combined mass totaled $0.9 \mathrm{wt} \%$. The entrainedsalts component was determined from the calculated dilution of entrained supernatant in the wet centrifuged solids; because of the extended washing, entrainment was reduced to a trace $0.1 \mathrm{wt} \%$.

A close examination of Table 3.12 shows that only three phases were identified that contain Al. For simplicity, phase calculations were assessed using nitrate cancrinite (setting the hydroxycancrinite to 0 $\mathrm{wt} \%$ ) and Clarkeite (setting the uranium oxide hydrate to $0 \mathrm{wt} \%$ ). The total amount of nitrate cancrinite was bounded by the total quantity of Si measured by chemical analysis. The Al not bound in the cancrinite was assigned to gibbsite. (Note, however, that the Si concentration could be biased low. If the total $\mathrm{Na}$ concentration is instead considered as bounding the nitrate cancrinite concentration, the calculated nitrate cancrinite phase component would increase to $7.8 \mathrm{wt} \%$, and the gibbsite phase would decrease slightly to $86 \mathrm{wt} \%$.) All Fe measured in the chemical analysis was assigned to the identified phase, hematite. Other phases of Fe may be present at $<0.1 \mathrm{wt} \%$, which would slightly reduce the hematite mass fraction. A fraction of the total Na present (identified through chemical analysis) could not be accounted for from the identified components (cancrinite, clarkeite, and entrainment); the unidentified fraction represented $0.4 \mathrm{wt} \%$ of the dry washed solids.

The mineral phase ratios calculated from the weight $\%$ values presented in Table 3.12 were compared to the phase ratios determined from the XRD data with JADE interpretation as a means to check the proposed composition. The phase ratios were in reasonable agreement. The JADE software evaluation resulted in a cancrinite:gibbsite ratio of $\sim 0.031$ (0.062 calculated value from Table 3.12) and a hematite:gibbsite ratio of $\sim 0.031$ ( 0.043 calculated value from Table 3.12). Therefore, the overall phase assignment is a reasonable assessment. 
a)

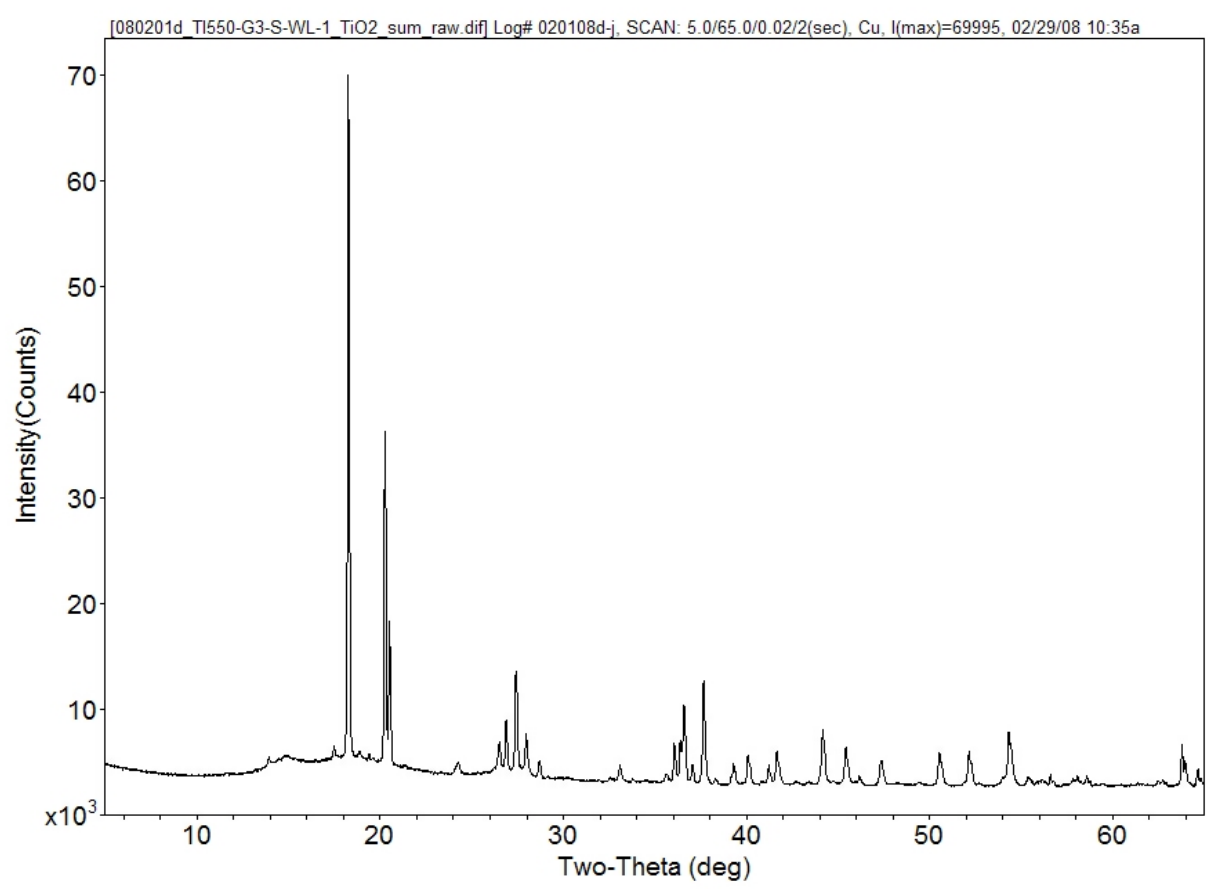

b)

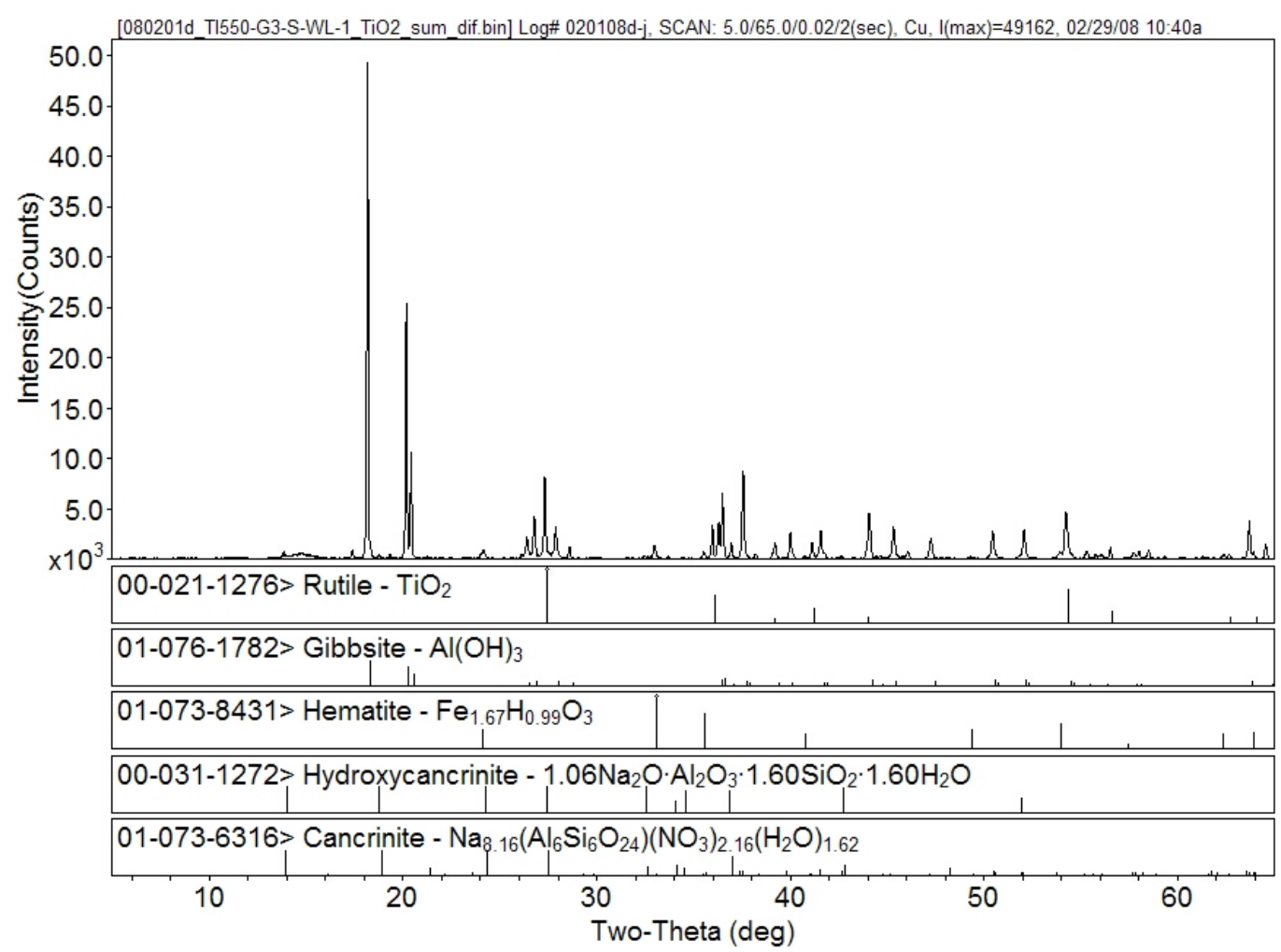

Figure 3.12. XRD Pattern of Washed Group 3 CWP Sludge with Rutile $\left(\mathrm{TiO}_{2}\right)$ Internal Standard (a) Raw Spectral Pattern (b) Background-Subtracted Pattern with Stick-Figure Peak Identification 
Table 3.12. Weight Percent of Group 3 CWP Sludge Mineral Phases, Best Estimate

\begin{tabular}{|c|c|c|c|}
\hline Crystalline Phase & Chemical Structure & Weight \% & Basis $^{(a)}$ \\
\hline Gibbsite & $\mathrm{Al}(\mathrm{OH})_{3}$ & 87.6 & Observed \\
\hline Hematite & $\mathrm{Fe}_{1.67} \mathrm{H}_{0.99} \mathrm{O}_{3}$ & 3.8 & $\begin{array}{l}\text { Observed, } \\
\text { Chem. } \\
\text { analysis }\end{array}$ \\
\hline $\begin{array}{l}\text { Nitrate Cancrinite and/or } \\
\text { Hydroxycancrinite }\end{array}$ & $\begin{array}{l}\mathrm{Na}_{8.16}\left(\mathrm{Al}_{6} \mathrm{Si}_{6} \mathrm{O}_{24}\right)\left(\mathrm{NO}_{3}\right)_{2.16}\left(\mathrm{H}_{2} \mathrm{O}\right)_{1.62}, \\
1.06 \mathrm{Na}_{2} \mathrm{O} \cdot \mathrm{Al}_{2} \mathrm{O}_{3} \cdot 1.60 \mathrm{SiO}_{2} \cdot 1.60 \mathrm{H}_{2} \mathrm{O}\end{array}$ & $\sim 5.5$ & Observed \\
\hline $\begin{array}{l}\text { Clarkeite and/or } \\
\text { uranium oxide hydrate }\end{array}$ & $\begin{array}{l}\mathrm{Na}\left(\left(\mathrm{UO}_{2}\right) \mathrm{O}\right)(\mathrm{OH}) \cdot \mathrm{H}_{2} \mathrm{O} \\
\mathrm{UO}_{3} \cdot \mathrm{H}_{2} \mathrm{O}\end{array}$ & 0.25 & $\begin{array}{l}\text { Possible, } \\
\text { Chem. } \\
\text { analysis }\end{array}$ \\
\hline $\begin{array}{l}\text { Unknown, below detection, } \\
\text { and/or amorphous }\end{array}$ & $\mathrm{Bi}, \mathrm{Ca}, \mathrm{Cr}, \mathrm{Mn}, \mathrm{Ni}, \mathrm{Pb}, \mathrm{Sr}, \mathrm{Zn}, \mathrm{Zr}$ & 0.9 & $\begin{array}{l}\text { Chem. } \\
\text { analysis }\end{array}$ \\
\hline Unaccounted sodium & $\mathrm{Na}$ & 0.4 & Calculated \\
\hline $\begin{array}{l}\text { Entrained } \mathrm{Na} \text { salts from } \\
\text { supernatant }\end{array}$ & various & 0.1 & Calculated \\
\hline Assumed counter ions & oxides, hydroxides, etc. & 1.5 & Balance \\
\hline \multicolumn{2}{|l|}{ Sum } & 100 & \\
\hline \multicolumn{4}{|c|}{$\begin{array}{l}\text { (a) Observed indicates that the characteristic crystal diffraction pattern of the identified } \\
\text { crystalline phase was observed in the sample XRD pattern. } \\
\text { Possible indicates that only one line of the characteristic crystal diffraction pattern was } \\
\text { observed, and its intensity was only slightly above background. Intensities of confirming } \\
\text { lines were too low to detect; therefore, the assigned crystalline phase should be considered } \\
\text { with caution. } \\
\text { Chemical analysis indicates that the } \mathrm{wt} \% \text { is an upper bound based on the chemical analysis } \\
\text { and } 100 \% \text { assignment of the elemental concentration to the phase assignment (see text for } \\
\text { discussion). } \\
\text { Calculated indicates that the wt } \% \text { was calculated after correcting for various processing steps } \\
\text { such as dilutions, chemical analysis, and phase assignment/distribution (see text for } \\
\text { discussion). } \\
\text { Weight } \% \text { values are calculated based on the concentrations of analytes as measured by ICP. }\end{array}$} \\
\hline
\end{tabular}

Figure 3.13 shows the phase ratio breakdown after correcting for the entrained supernatant salts from the composition. Gibbsite comprised $87.6 \mathrm{wt} \%$ of the mass fraction of well-washed solids. Thus, as intended, the Group 3 waste sludge sample was clearly dominated by gibbsite and $\sim 97 \mathrm{wt} \%$ of the $\mathrm{Al}$ in Group 3 sample was in the form of gibbsite. 


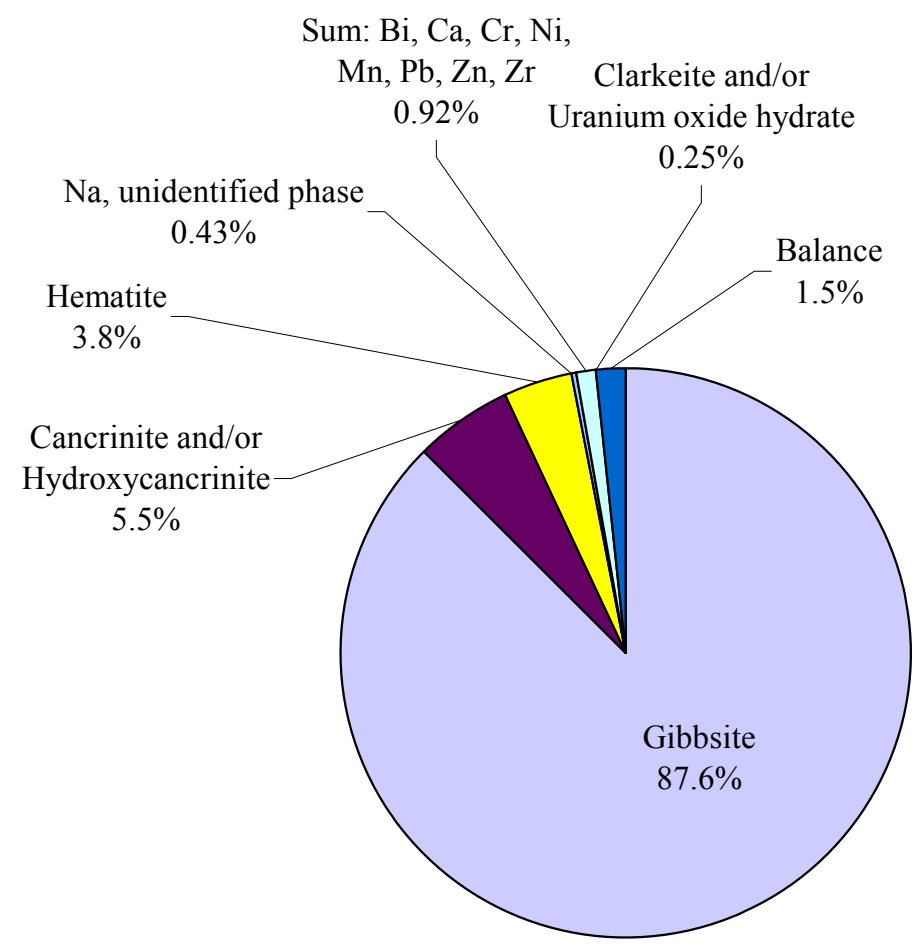

Figure 3.13. Washed Group 3 CWP Sludge Phase Composition (Entrained Supernatant Removed), Best Estimate

Several SEM images of the washed solids are shown in Figure 3.14 and Figure 3.15. The typical gibbsite structures are seen as thick hexagonal platelets and rods. Cubic rods can be seen along with lepispheric (i.e., appearing like balls of twine) structures typical of cancrinite. Larger conchoidal structures were visible in Figure 3.15, but the composition was not defined. 

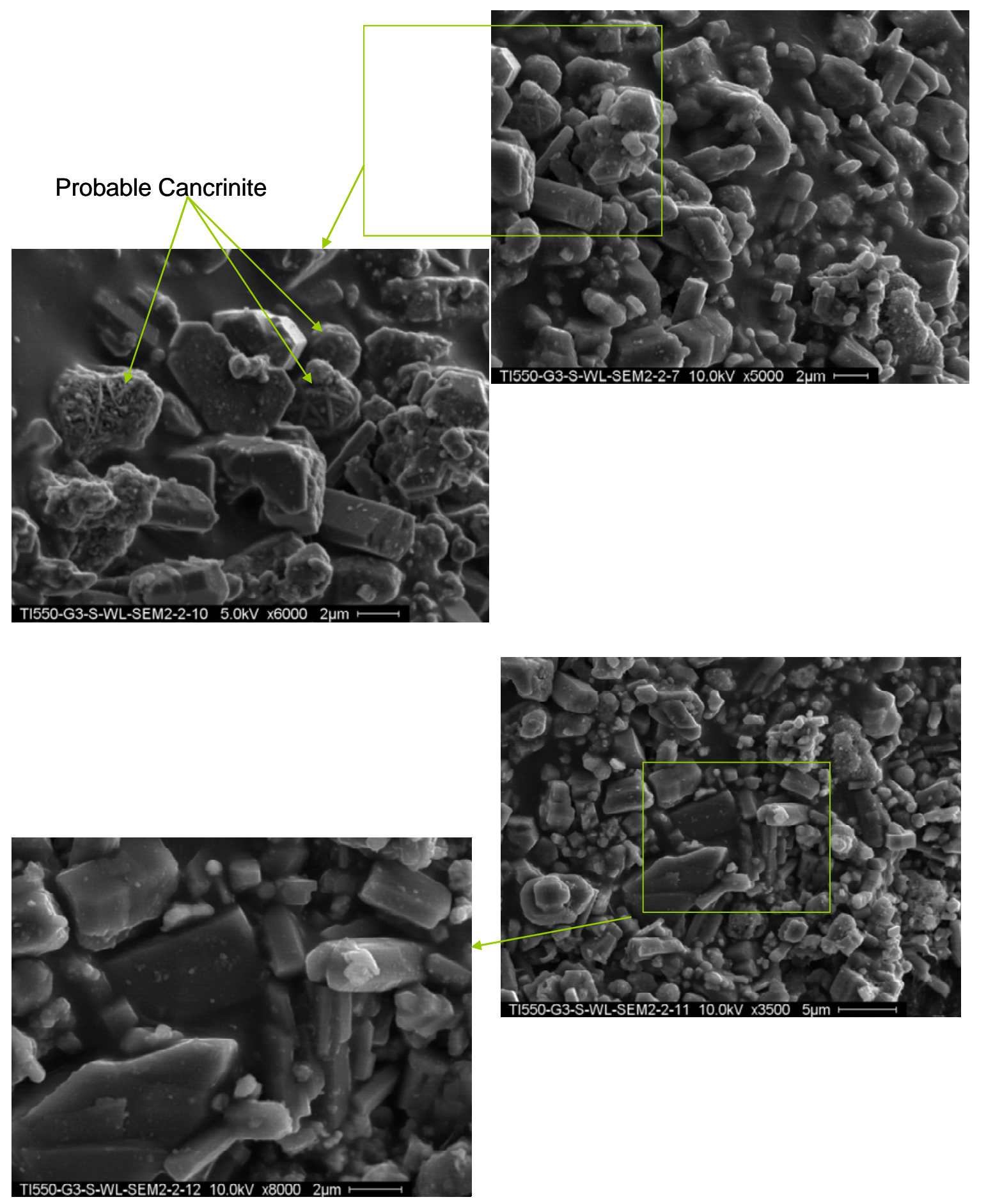

Figure 3.14. SEM Images of Washed Group 3 CWP Sludge 


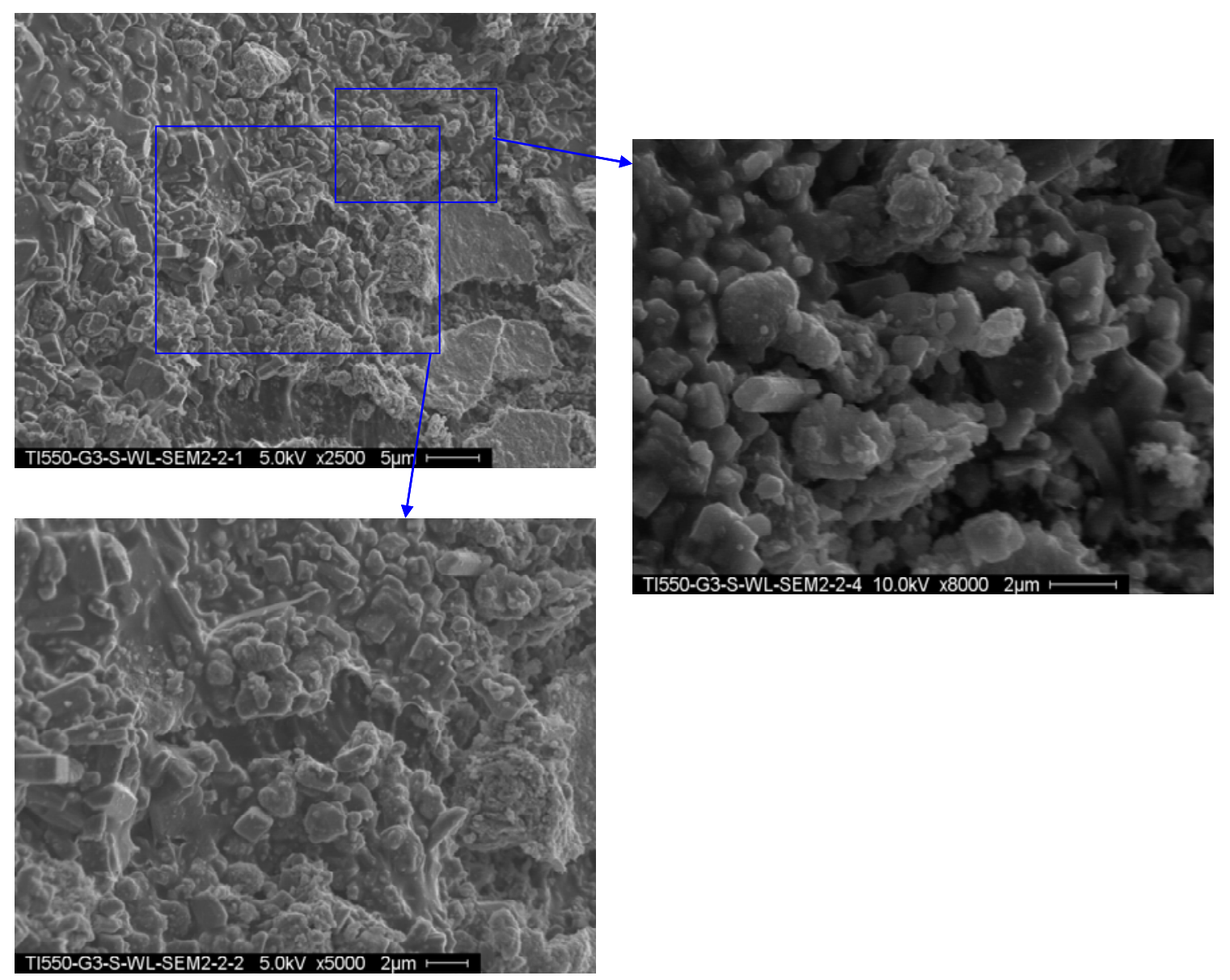

Figure 3.15. SEM Images of Washed Group 3 CWP Sludge

Additional SEM images with EDS evaluation are shown in Figure 3.16. Consistent with the chemical and XRD evaluation, the matrix is dominated by $\mathrm{Al}$ and $\mathrm{O}$, with smaller quantities of $\mathrm{Fe}, \mathrm{Na}$, and $\mathrm{Si}$. The sample was sputtered with carbon in preparation for SEM analysis. It is not clear if the $\mathrm{C}$ is from the sample (e.g., as a carbonate or oxalate) or associated with the coating. 

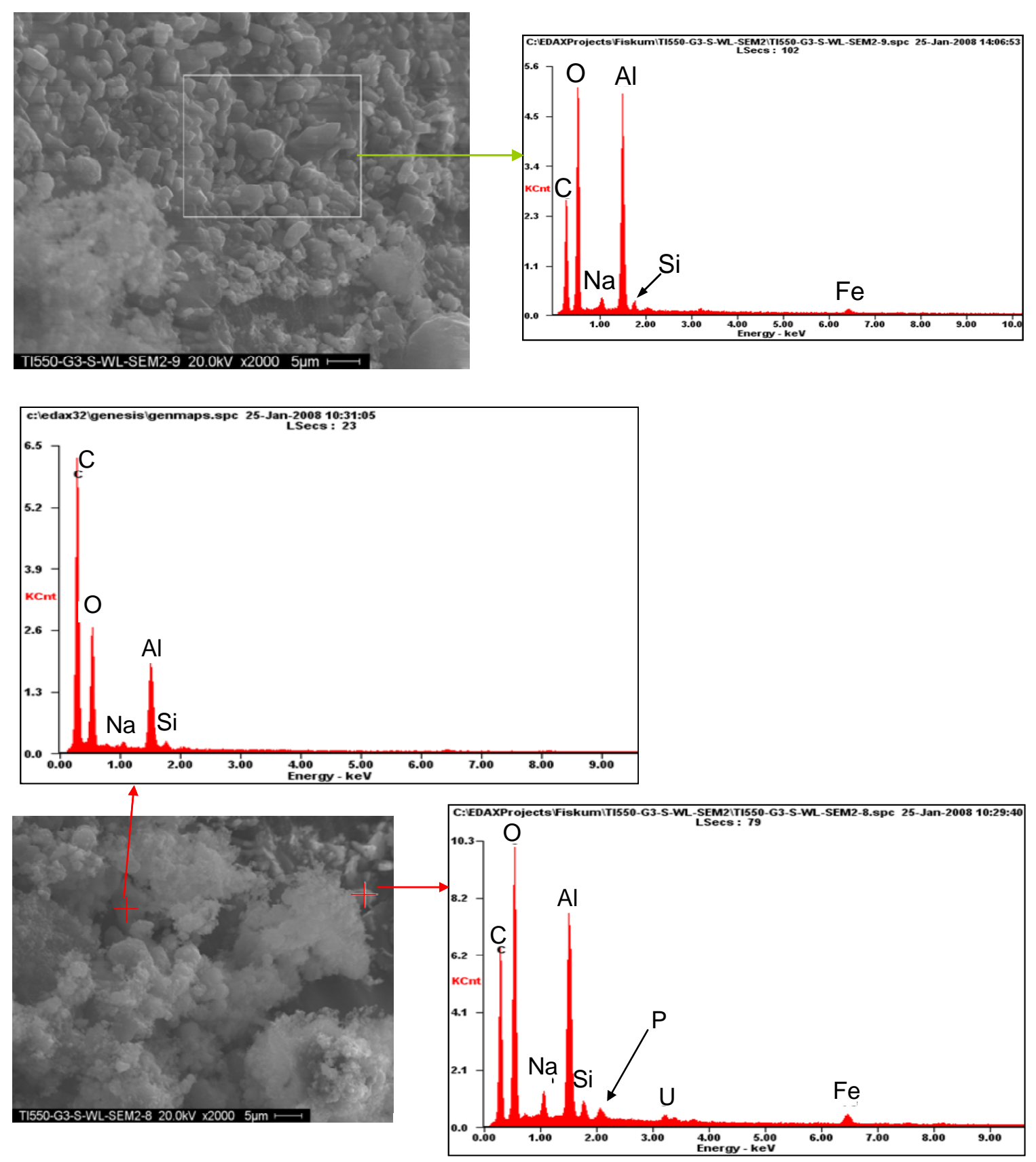

Figure 3.16. SEM-EDS Images of Washed Group 3 CWP Sludge

Figure 3.17 shows representative TEM images of the washed Group 3 CWP solids. Several gibbsite particles, each several micrometers in length, are visible. High-surface-area agglomerate phases are also shown. In Figure 3.17a, aluminosilicate, iron-rich, and uranium phases are also visible as agglomerates. 
(a)

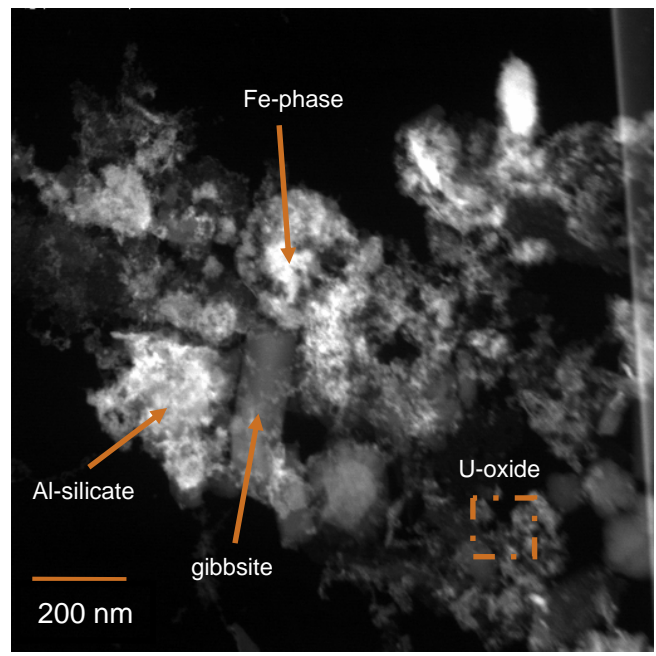

(c)

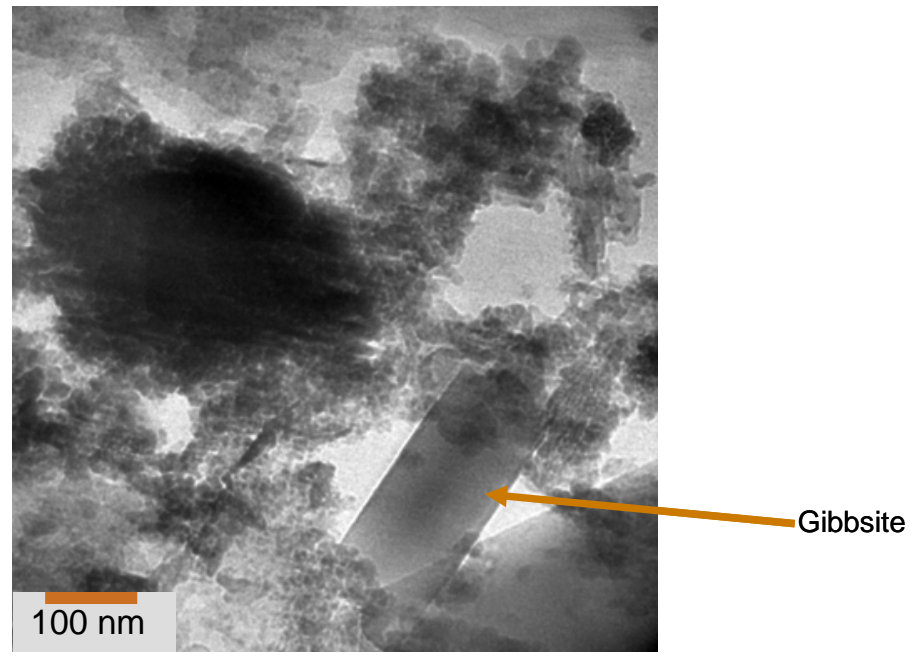

(b)

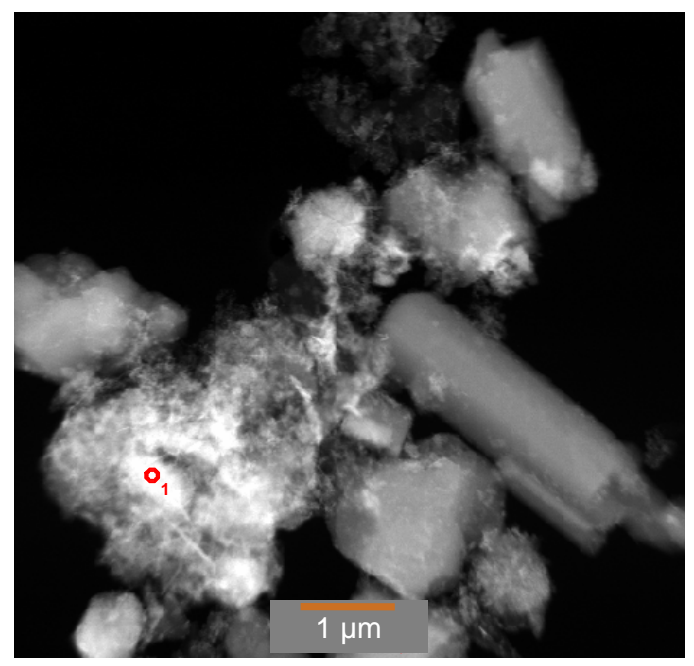

Figure 3.17. STEM Images of Washed Group 3 CWP Solids. (a) HAADF image showing four phases; (b) HAADF image showing several gibbsite particles; (c) Medium magnification TEM image showing gibbsite particle surrounded by high-surface-area material.

The STEM-HAADF images in Figure 3.18 and Figure 3.19 show highly heterogeneous particle agglomerates. In Figure 3.18, an aluminum-rich area is visible, as well as two areas rich in uranium, and a cancrinite particle. In Figure 3.19, gibbsite, zirconium-rich, and uranium oxide particles are shown. The gibbsite particle is several micrometers in size. 
(a)

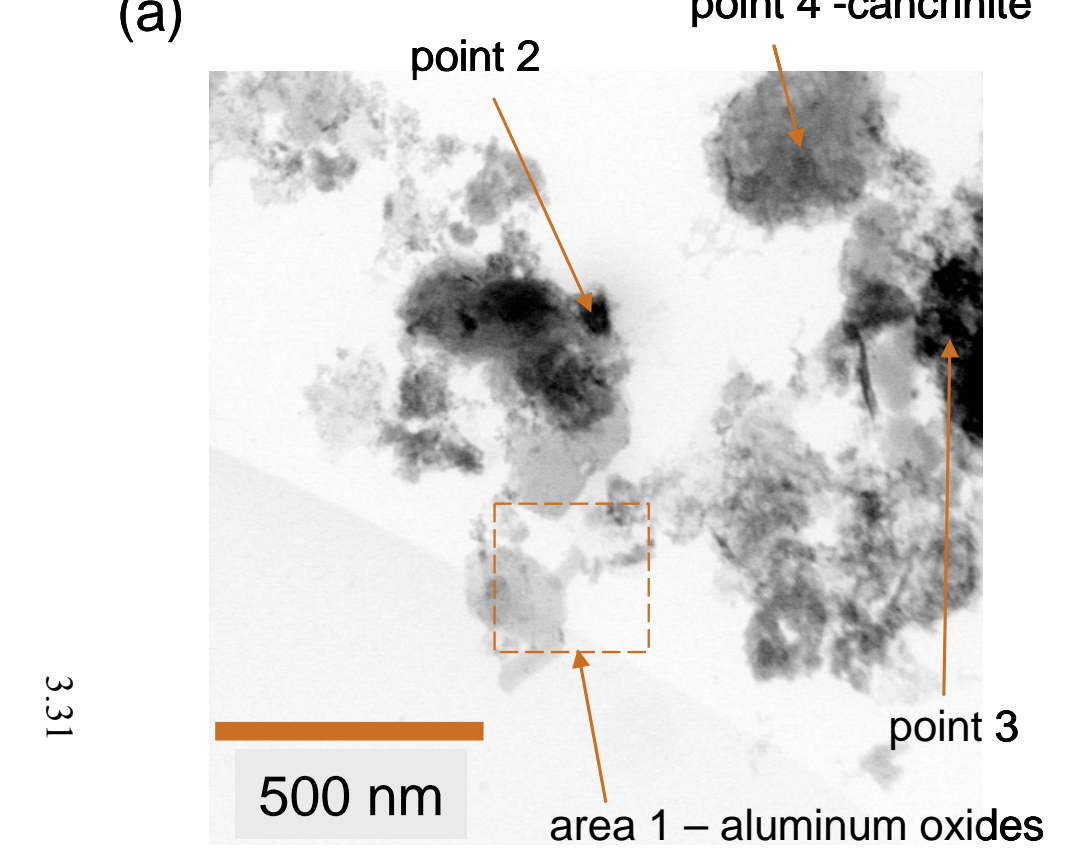

(b)

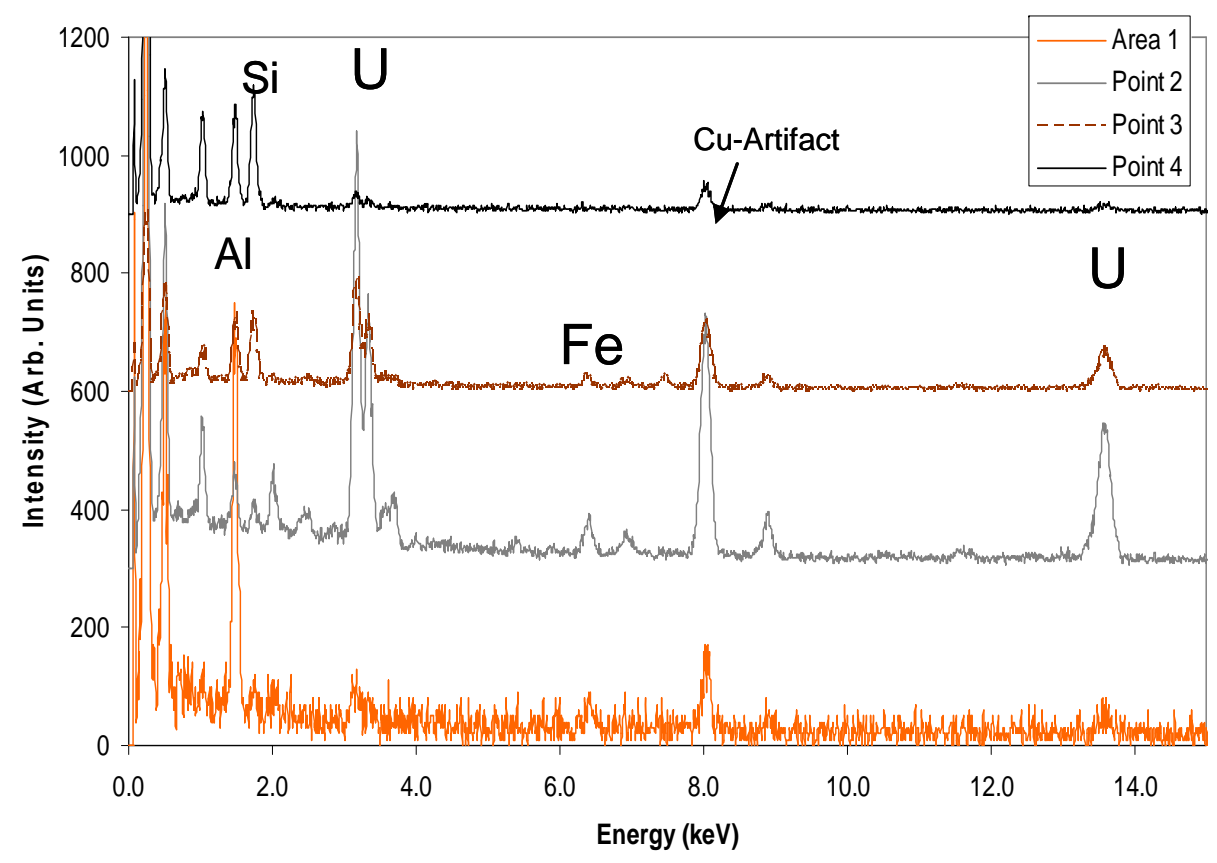

Figure 3.18. STEM-HAADF Image (Inverted Contrast) and EDS Analyses of Regions of Interest of Washed Group 3 CWP Solids with Cancrinite 

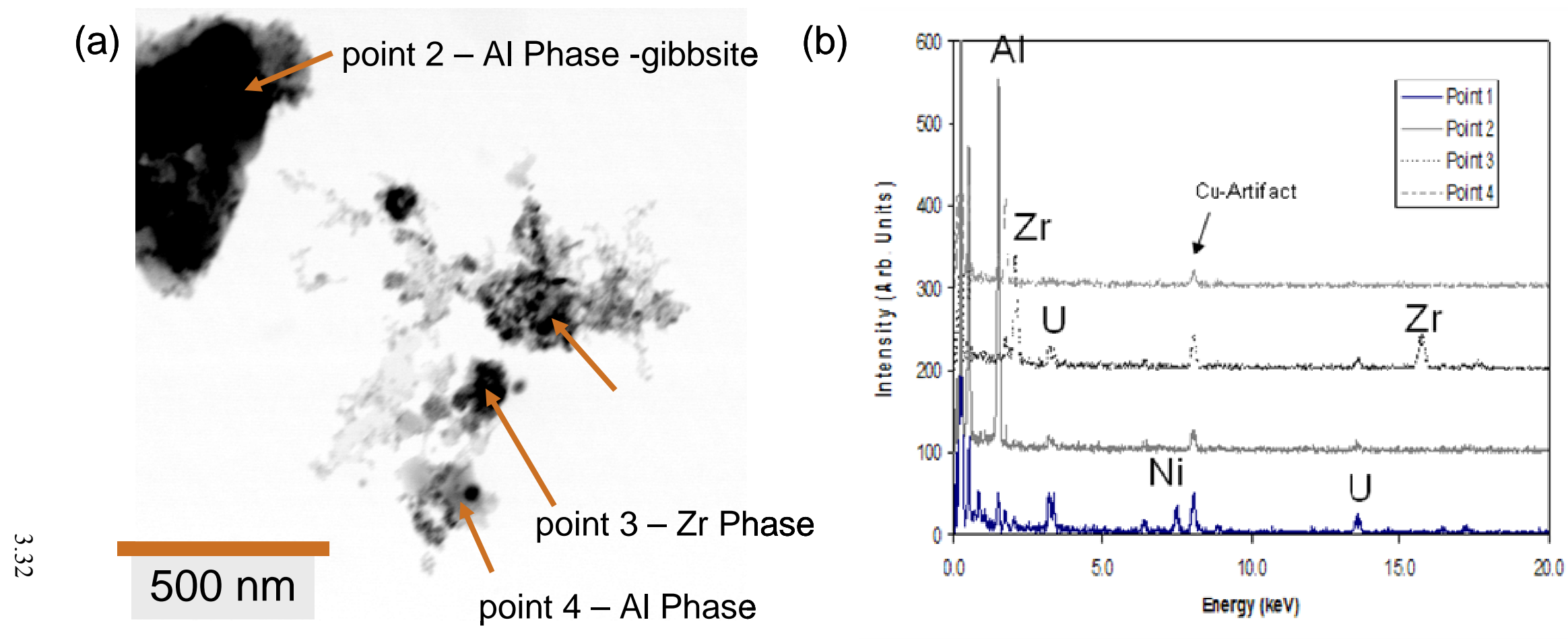

Figure 3.19. STEM-HAADF Image (Inverted Contrast) and EDS Analyses of Regions of Interest of Washed Group 3 CWP Solids with Gibbsite 
Several different types of phases were observed in the Group 3 washed solids. The uranium phases were extremely small, having diameters of 5 to $20 \mathrm{~nm}$. The lattice fringes visible in the high-resolution images of the uranium phases in Figure 3.20a demonstrate the fine crystalline nature of the uranium particles. The Fourier transform of the lattice image in Figure 3.20a (bottom right) was used to look at the angles between planes. An angle of $\sim 60^{\circ}$ was obtained. In $\alpha-\mathrm{U}_{3} \mathrm{O}_{8}$, the interplanar angle between $\mathrm{d}_{(130)}(3.43 \AA)$ and $\mathrm{d}_{(200)}(3.36 \AA)$ is $59.3^{\circ}$. The histogram shown in Figure $3.20 \mathrm{~b}$ shows the average image contrast across the region of interest shown in Figure 3.20c. The red circles represent atomic positions in the structure. The histogram was obtained from an enlarged region from the high-resolution image. The vertical axis represents contrast with the peaks and valleys corresponding to lattice planes. The number and distance was used to calculate an average d-spacing of $0.46 \pm 0.05 \mathrm{~nm}$. This is not diagnostic for a particular uranium phase; however, the spacing is in agreement with $\alpha-\mathrm{U}_{3} \mathrm{O}_{8} \cdot \mathrm{U}_{3} \mathrm{O}_{8}$ was previously reported by Lumetta et al. (1997) in S-104 and S-101 tank sludge.

(a)

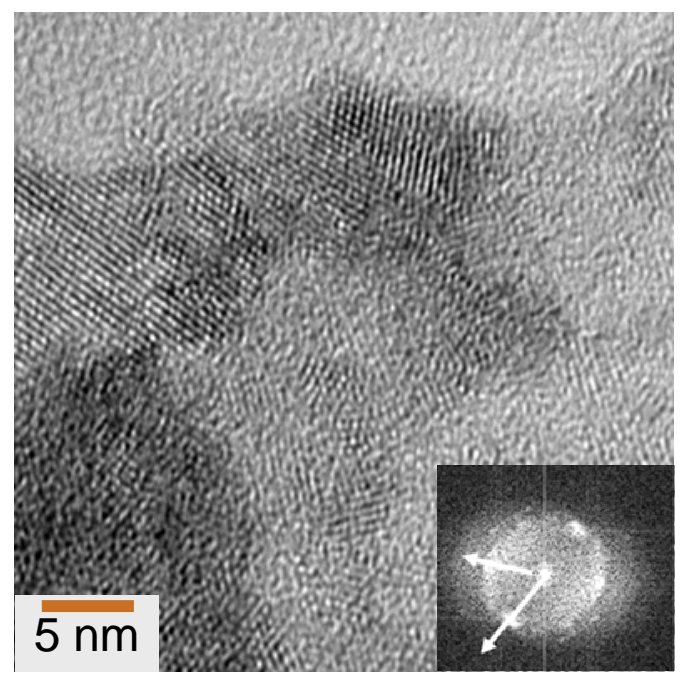

(b)

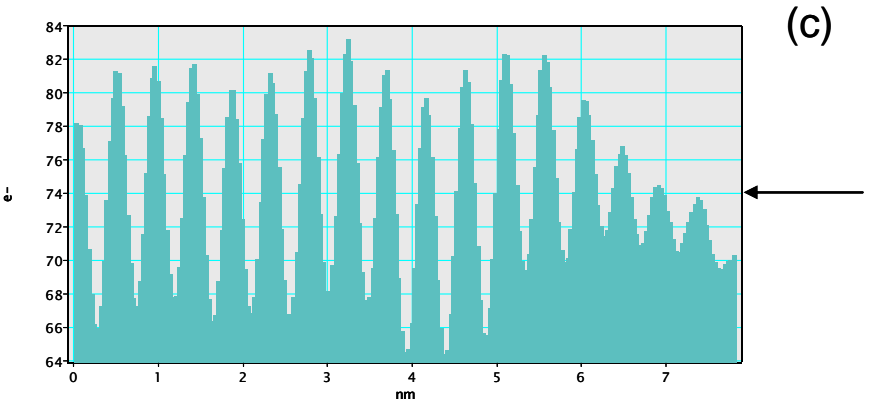

$0.46 \mathrm{~nm}$ spacing



Figure 3.20. (a) High Resolution TEM Image of Uranium in Washed Group 3 CWP Solids;

(b) Histogram of Contrast across Marked Region on (c) High Resolution Lattice Image of $\mathrm{U}_{3} \mathrm{O}_{8}$ Phase 
In Figure 3.21, a crystalline iron oxide particle, possibly hematite, is visible. The particle is just under 1 micrometer in length. Small amounts of zirconium were found in the sample, most often associated with uranium and iron. Table 3.13 gives examples of analyzed zirconium-bearing regions. The EDS compositional analysis indicates that there is a variable quantity of $\mathrm{Zr}$ to $\mathrm{U}$ in the analyzed particles. This indicates that two phases are most likely present.

(a)

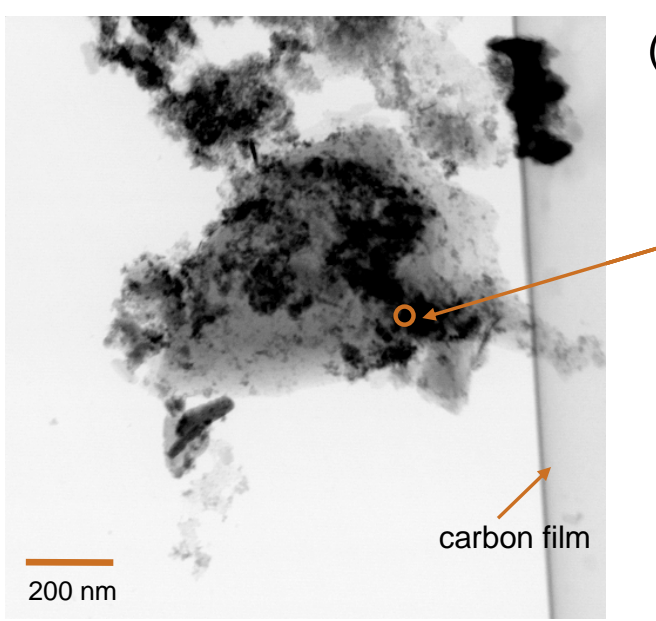

(b)

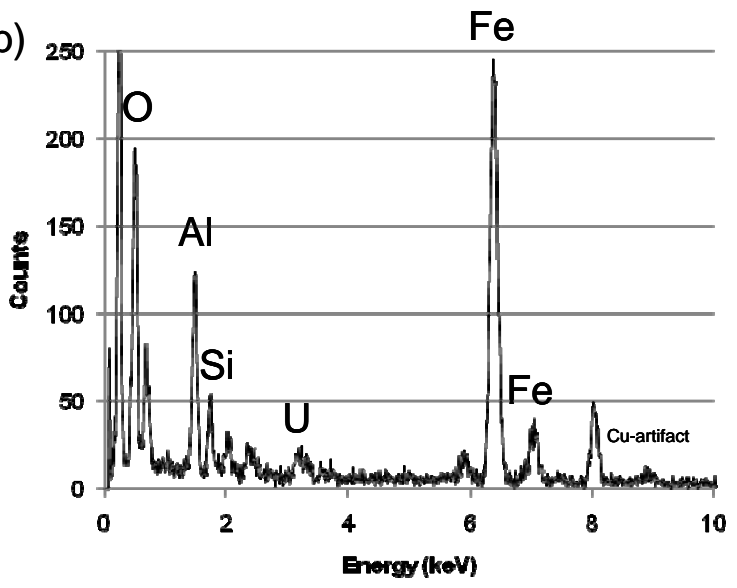

Figure 3.21. TEM Image and EDS Analysis of Region of Interest of Iron Particle in Washed Group 3 CWP Solids

Table 3.13. Compositional Analysis of Zirconium Containing Regions (Atomic \%)

\begin{tabular}{|c|c|c|c|}
\hline Element & Region 1 & Region 2 & Region 3 \\
\hline $\mathrm{Na}$ & 6.6 & 5.9 & 10.2 \\
\hline $\mathrm{Fe}$ & 24.1 & 53.5 & 41.4 \\
\hline $\mathrm{Zr}$ & 6.0 & 3.9 & 2.5 \\
\hline $\mathrm{U}$ & 34.3 & 49.0 & 56.1 \\
\hline
\end{tabular}

\subsection{Group 3 CWP Sludge Batch Parametric Leaching: Experimental}

Parametric caustic leaching tests were performed on the Group 3 PUREX cladding waste sludge sample to determine the behavior of gibbsite during leaching at different conditions. The composite Group 3 sample material was rinsed with $0.01 \mathrm{M} \mathrm{NaOH}$, subdivided, and subjected to a parametric test matrix for caustic leach testing as discussed in the following sections.

\subsubsection{Initial Washing of the Group 3 Solids}

The Group 3 composite sample was mixed with an overhead stirrer fitted with a bladed stainless steel impeller. A 49.0-g aliquot was removed with a large transfer pipette and transferred to a $200-\mathrm{mL}$ centrifuge bottle. At a concentration of $0.27 \mathrm{~g}$ dry water-insoluble solids per gram of slurry, the $49-\mathrm{g}$ slurry contained $13.2 \mathrm{~g}$ of water-insoluble solids. The slurry aliquot was centrifuged at $\sim 2500 \mathrm{RPM}$ $(1200 \mathrm{G})$ for $15 \mathrm{~min}$, and then the supernatant was removed. The volume of centrifuged solids was estimated to be $\sim 15 \mathrm{~mL}$ based on volume graduations on the sample bottle. Approximately $45 \mathrm{~mL}$ 
( $3 \times$ the centrifuged solids volume) of $0.01 \mathrm{M} \mathrm{NaOH}$ was added to wash the solids. The slurry was placed on a vortex mixer to loosen the solids and then shaken for 15 minutes on a shaker table. The slurry was centrifuged at $\sim 1200 \mathrm{G}$ for $30 \mathrm{~min}$, and then the supernatant was removed. The longer centrifuging time was used because the liquid looked pale brown in the bottle, although it appeared clear when pouring it out of the bottle. The washing steps were repeated twice for a total of three washes. The third wash was centrifuged for 20 minutes. The liquid was very faintly brown when it was poured off of the solids, suggesting suspension of some fines under these conditions.

\subsubsection{Division of the Washed Group 3 Solids}

To conduct a successful sample subdivision, the washed centrifuged solids needed to be thinned. DI water $(74.6 \mathrm{~mL})$ was added to the solids, resulting in slurry containing $13.2 \mathrm{~g}$ solids in $103.8 \mathrm{~g}$ of slurry, equivalent to $12.7 \mathrm{wt} \%$ undissolved solids (UDS). This was later measured more precisely in the fumehood to be $14.1 \mathrm{wt} \%$ UDS.

An overhead mixer equipped with a 3-bladed stainless steel impeller was used to homogenize the thinned slurry. Thirteen $\sim 7.1$-g slurry samples were transferred to $125-\mathrm{mL}$ high-density polyethylene (HDPE) bottles with a large disposable polyethylene pipette. Each sample contained $\sim 1 \mathrm{~g}$ UDS. The samples were removed from the hot cell for follow-on processing at the fume hood workstation.

One additional sample (585-G3-WL-Solids) containing approximately $2.2 \mathrm{~g}$ of slurry (equivalent to 0.28 g dry solids) was transferred to a 60-mL HDPE bottle. A portion of this sample was submitted for a potassium hydroxide $(\mathrm{KOH})$ fusion and the following subsequent analyses: inductively coupled plasmaoptical emission spectroscopy (ICP-OES) metals, gamma energy analysis (GEA), Pu, total alpha, total beta, ${ }^{90} \mathrm{Sr}$, and U by kinetic phosphorescence analysis (KPA). These analyses were performed to establish the starting composition of the washed solids.

\subsubsection{Caustic Leaching of the Washed Group 3 Solids}

The leaching test matrix for each of the 13 samples is summarized in Table 3.14. The test matrix evaluated the effects of free-hydroxide concentration ( 1 to $5 \mathrm{M} \mathrm{NaOH})$, temperature $\left(60\right.$ to $\left.100^{\circ} \mathrm{C}\right)$, and sodium nitrate concentration ( 1 to $5 \mathrm{M} \mathrm{NaNO}_{3}$ ) on gibbsite leaching kinetics. The test matrix was proposed and approved by BNI. Copies of the request and concurrence letters can be found in Appendix M. 
Table 3.14. Group 3 Caustic Leaching Conditions

\begin{tabular}{|c|c|c|c|c|c|c|c|}
\hline \multirow[b]{2}{*}{ Bottle ID } & \multicolumn{2}{|c|}{ Free OH, $\mathrm{M}$} & \multicolumn{2}{|c|}{ Na, M } & \multicolumn{2}{|c|}{$\mathrm{NO}_{3}^{-}, \mathrm{M}$} & \multirow{2}{*}{$\begin{array}{c}\text { Temperature } \\
{ }^{\circ} \mathbf{C}^{(\mathrm{c})} \\
\end{array}$} \\
\hline & Target & Measured $^{(a)}$ & Target & Measured $^{(a)}$ & Target & Measured $^{(b)}$ & \\
\hline G3-60-1 & 1 & 0.95 & 1 & 1.09 & NA & NA & 60 \\
\hline G3-60-3 & 3 & 3.03 & 3 & 3.22 & NA & NA & 60 \\
\hline G3-60-5 & 5 & 5.15 & 5 & 5.27 & NA & NA & 60 \\
\hline G3-80-1 & 1 & 0.93 & 1 & 1.06 & NA & NA & 80 \\
\hline G3-80-3a & 3 & 3.01 & 3 & 3.21 & NA & NA & 80 \\
\hline G3-80-3b & 3 & 3.17 & 3 & 3.21 & NA & NA & 80 \\
\hline G3-80-3c & 3 & 2.93 & 3 & 3.07 & $\mathrm{NA}$ & NA & 80 \\
\hline G3-80-1N-3 & 3 & 2.88 & 4 & 3.95 & 1 & 1.05 & 80 \\
\hline G3-80-5N-3 & 3 & 2.80 & 8 & 8.04 & 5 & 5.33 & 80 \\
\hline G3-80-5 & 5 & 4.93 & 5 & 4.87 & NA & NA & 80 \\
\hline G3-100-1 & 1 & 0.94 & 1 & 1.09 & NA & NA & 100 \\
\hline G3-100-3 & 3 & 3.12 & 3 & 3.44 & NA & NA & 100 \\
\hline G3-100-5 & 5 & 5.23 & 5 & 5.61 & NA & NA & 100 \\
\hline $\begin{array}{l}\text { (a) The mea } \\
\text { (b) The mea } \\
\text { (c) The temp } \\
\text { Note: All analy } \\
\text { Analytical Ser }\end{array}$ & $\begin{array}{l}\text { red analyt } \\
\text { red } \mathrm{NO}_{3}^{-} \text {- } \\
\text { rature unc } \\
\text { concentr } \\
\text { ce Reques }\end{array}$ & $\begin{array}{l}\text { concentrations } r \\
\text { ncentrations are } \\
\text { tainty was } \pm 2.5^{\circ} \\
\text { ons were measu } \\
\text { ASR): } 8094\end{array}$ & $\begin{array}{l}\text { present the } \\
\text { an average } \\
\text { ed at ambi }\end{array}$ & $\begin{array}{l}\text { oncentration ob } \\
\text { f seven measu } \\
\text { t }\left(\sim 21^{\circ} \mathrm{C}\right) \text { temp }\end{array}$ & $\begin{array}{l}\text { ined after } \\
\text { ements ov } \\
\text { rature. }\end{array}$ & $\begin{array}{l}\text { 48-h contact tim } \\
r \text { the entire sam }\end{array}$ & pling period. \\
\hline
\end{tabular}

The $\mathrm{NaOH}$ concentration in each leaching mixture was adjusted to support the test matrix. Sodium hydroxide $(19 \mathrm{M})$ was added to each aliquot of the washed solids slurry in the following amounts: $5.3 \mathrm{~mL}$ to yield $1 \mathrm{M} \mathrm{NaOH}, 15.8 \mathrm{~mL}$ to yield $3 \mathrm{M} \mathrm{NaOH}$, and $26.3 \mathrm{~mL}$ to yield $5 \mathrm{M} \mathrm{NaOH}$. Sodium nitrate $(7 \mathrm{M})$ was added to two of the samples in the following amounts: $14.3 \mathrm{~mL}$ to yield $1 \mathrm{M} \mathrm{NaNO}_{3}$ and $71.4 \mathrm{~mL}$ to yield $5 \mathrm{M} \mathrm{NaNO}_{3}$. The leaching mixtures were then diluted to a final volume of $100 \mathrm{~mL}$ (with an estimated uncertainty of $2 \mathrm{~mL}$ ) with DI water. (The $100-\mathrm{mL}$ volume had been pre-marked on each sample bottle.) The contact time with the concentrated $\mathrm{NaOH}$ was brief $(<5 \mathrm{~min})$. The sample bottles were weighed after each addition of reagents $\left(\mathrm{NaOH}\right.$, water, and $\left.\mathrm{NaNO}_{3}\right)$. Each leaching vessel was closed with a cap equipped with a tube condenser. The condenser was used to eliminate pressurization and minimize water loss, while at the same time minimizing the spread of contamination.

The sample slurries were transferred to a temperature-controlled shaker table. The temperature was controlled with an aluminum heating block (J-KEM Scientific, Inc.) equipped with a Type T thermocouple. The heating block was supported on a J-KEM BTS-3500 digital bench-top shaker (Figure 3.22). The shaking speed was digitally controlled to $200 \mathrm{rpm}$; based on visual inspection, the solids were well suspended in solution. The samples were grouped according to the leaching temperature, and one group was leach-tested at a time. The heating block was pre-heated to the appropriate temperature before leach testing. 


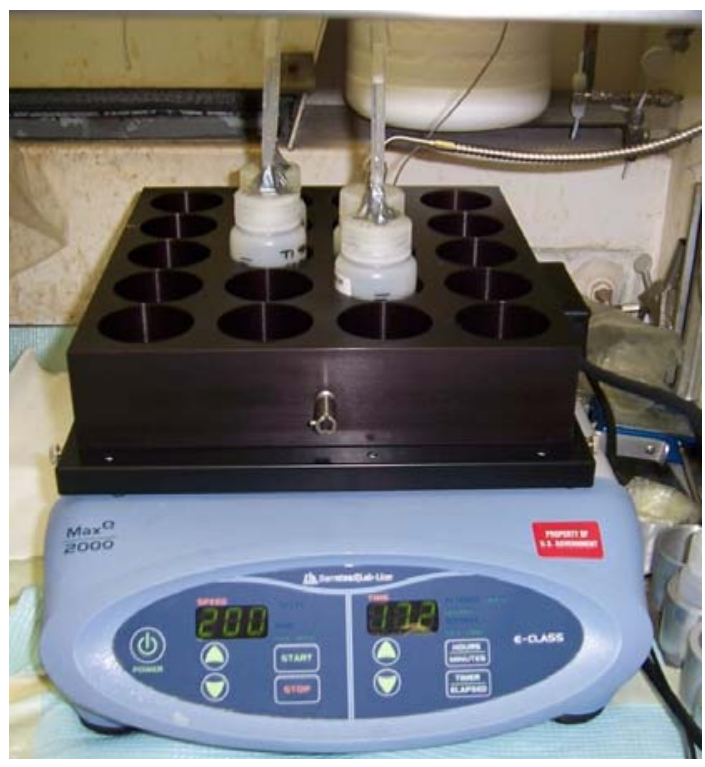

Figure 3.22. Aluminum Heating Block and Shaker Table Used in Parametric Leaching Tests

The leaching mixtures were shaken at temperature for 48 hours, and solution samples were withdrawn at 0 (taken before insertion into heating block), 1, 2, 4, 8, 24, and 48 hours. At each sampling time, the shaker was stopped, and the solids were allowed to settle for $\sim 5$ to $10 \mathrm{~min}$, resulting in sufficient clarification of the aqueous portion to support sampling without removing any solids. Approximately $1.5-\mathrm{mL}$ of the clarified leachate solution was withdrawn with a transfer pipette and filtered through a $0.45-\mu \mathrm{m}$ pore size nylon syringe filter; the syringe filter and the syringe had been pre-heated in an oven to the sample temperature $\left(60,80\right.$, or $\left.100^{\circ} \mathrm{C}\right)$ before filtering in an effort to minimize temperature changes impacting the sample. One $0.5-\mathrm{mL}$ sample of filtered solution was acidified with $15 \mathrm{~mL}$ of $0.3 \mathrm{M} \mathrm{HNO}_{3}$ for analysis by ICP-OES; another $0.5-\mathrm{mL}$ sample of filtered solution was added to $2.5 \mathrm{~mL}$ of $1 \times 10^{-4} \mathrm{M}$ $\mathrm{NaOH}$ for analysis by ion chromatography. The remaining filtered solution was returned to the leaching vessel, and the leaching process was continued. The new liquid level was marked after each sample was taken. Evaporation was minimal during the course of the experiment, but when evaporation was observed, DI water was added to restore the volume to the previously marked liquid level. After 48 hours, additional leachate samples were taken to determine the free-hydroxide ion concentration and gamma-emitting isotopes by GEA.

After the final samples were taken at temperature, the slurries were removed from the mixing/heating block and cooled to ambient $\left(\sim 22^{\circ} \mathrm{C}\right)$ temperature. The slurries were centrifuged, and the leachate was decanted. $^{(b)}$

The equilibrium concentration values for free hydroxide, sodium, and nitrate are shown in Table 3.14 and were based on results from the samples taken at 48 hours.

(b) The contact dose rates of the leached solids were too high to safely conduct transfer to volume-graduated centrifuge tubes to assess the volume of centrifuged solids. 


\subsubsection{Washing of Caustic Leached Group 3 Solids for Analysis}

The solids from the triplicate samples (G3-80-3a, $-3 \mathrm{~b}$, and $-3 \mathrm{c}$, leached at $80^{\circ} \mathrm{C}$ in $3 \mathrm{M} \mathrm{NaOH}$, and each consisting of $\sim 1 \mathrm{~g}$ centrifuged slurry) were prepared for characterization as shown in Figure 3.23. One of the solids samples was slurried in $\sim 15 \mathrm{~mL}$ of $0.01 \mathrm{M} \mathrm{NaOH}$ and divided between the remaining two solids samples. The leaching bottle was then rinsed with $10 \mathrm{~mL}$ of $0.01 \mathrm{M} \mathrm{NaOH}$, and the wash was split between the remaining two solids samples. The solids were mixed on a shaker table for 15 minutes. The slurry was centrifuged for $5 \mathrm{~min}$ and the supernatant removed. Dilute sodium hydroxide solution (0.01 $\mathrm{M} ; 15 \mathrm{~mL}$ ) was added to the solids, the compacted solids were broken up with a disposable pipette, and the slurry was mixed on a shaker table for 15 minutes. The slurry was centrifuged for 5 min and the supernatant removed. The wash steps were repeated once more for a total of three washes. Additional $\mathrm{NaOH}$ was used to move the solids from one of the bottles in order to combine all solids in one bottle. The sample was centrifuged for $5 \mathrm{~min}$ and the supernatant removed. After the final wash, the solids were slurried in $\sim 2 \mathrm{~mL}$ of DI water and sub-divided for analysis by particle-size distribution (PSD), X-ray diffraction (XRD), transmission electron microscopy (TEM), scanning electron microscopy (SEM), and a $\mathrm{KOH}$ fusion with subsequent analysis for ICP-OES metals, GEA, Pu, total alpha, total beta, ${ }^{90} \mathrm{Sr}$, and $\mathrm{U}$ by KPA. There was not enough material remaining to submit for a surface area measurement by the Brunauer, Emmett, and Teller (BET) method. 




Figure 3.23. Washing, Subdivision, and Analysis Scheme for the Group 3 Caustic-Leached Solids. Note that for sample G3-CL-BET, not enough material was available to perform the BET analysis.

\subsection{Group 3 PUREX Cladding Sludge Waste Parametric Caustic- Leaching Test Results}

The Al component in the Group 3 waste was nearly pure gibbsite. The parametric leach testing of this waste sample was directed toward understanding gibbsite dissolution in the actual tank waste to understand and subsequently match the dissolution properties to a simulant material. The parametric leaching results and residual solids composition are discussed in the following sections. Data for the figures in this section can be found in Appendix I. 


\subsubsection{Time, Temperature, and Hydroxide Effects on Aluminum Dissolution from the Group 3 Solids}

The rate and extent of Al removal from the washed Group 3 solids were investigated as a function of time, temperature, and free-hydroxide concentration. Based on the total Al concentration in the washed Group 3 solids ( $301 \mathrm{mg} / \mathrm{g}$ - free of residual supernatant), the complete dissolution of $\mathrm{Al}$ in the $100 \mathrm{~mL}$ of leaching solution would result in a concentration of $3.0 \mathrm{mg} \mathrm{Al} / \mathrm{mL}$ or $0.112 \mathrm{M}$.

The aluminum leaching data at 60,80 , and $100^{\circ} \mathrm{C}$ at varying free-hydroxide concentrations are plotted in Figure 3.24 through Figure 3.26, respectively. A measure of experimental precision is shown by the triplicate tests conducted at $3 \mathrm{M}$ free hydroxide and at $80^{\circ} \mathrm{C}$ in Figure 3.25. The scatter in the data was within the analytical characterization uncertainty of $\pm 15 \%$.

In all cases except 1 and $3 \mathrm{M} \mathrm{NaOH}$ at $60^{\circ} \mathrm{C}$, the $\mathrm{Al}$ dissolution was rapid and complete. It is not clear why $100 \%$ dissolution was not reached in 1 and $3 \mathrm{M} \mathrm{NaOH}$, as the conditions used were slightly below the solubility limit for gibbsite at $60^{\circ} \mathrm{C}$ in $1 \mathrm{M} \mathrm{NaOH}$ of $0.19 \mathrm{M}$ as calculated from the empirical model developed by Misra (1970) and referenced by Li et al. (2005) and far below the solubility limit at $60^{\circ} \mathrm{C}$ in $3 \mathrm{M} \mathrm{NaOH}$ of $0.7 \mathrm{M}$. All the tests performed at $100^{\circ} \mathrm{C}$ reached completion within the first 2 hours, and at $80^{\circ} \mathrm{C}$, the reaction appears to have reached completion between 4 and 8 hours. At $60^{\circ} \mathrm{C}$, the reaction appears to take up to 48 hours to reach steady state in $1 \mathrm{M} \mathrm{NaOH}$ and between 8 and 24 hours in $3 \mathrm{M}$ $\mathrm{NaOH}$. At 80 and $100^{\circ} \mathrm{C}$, there was very little increase in dissolution with increasing $\mathrm{NaOH}$ concentration, with nearly complete $\mathrm{Al}$ dissolution at all $\mathrm{NaOH}$ concentrations examined.

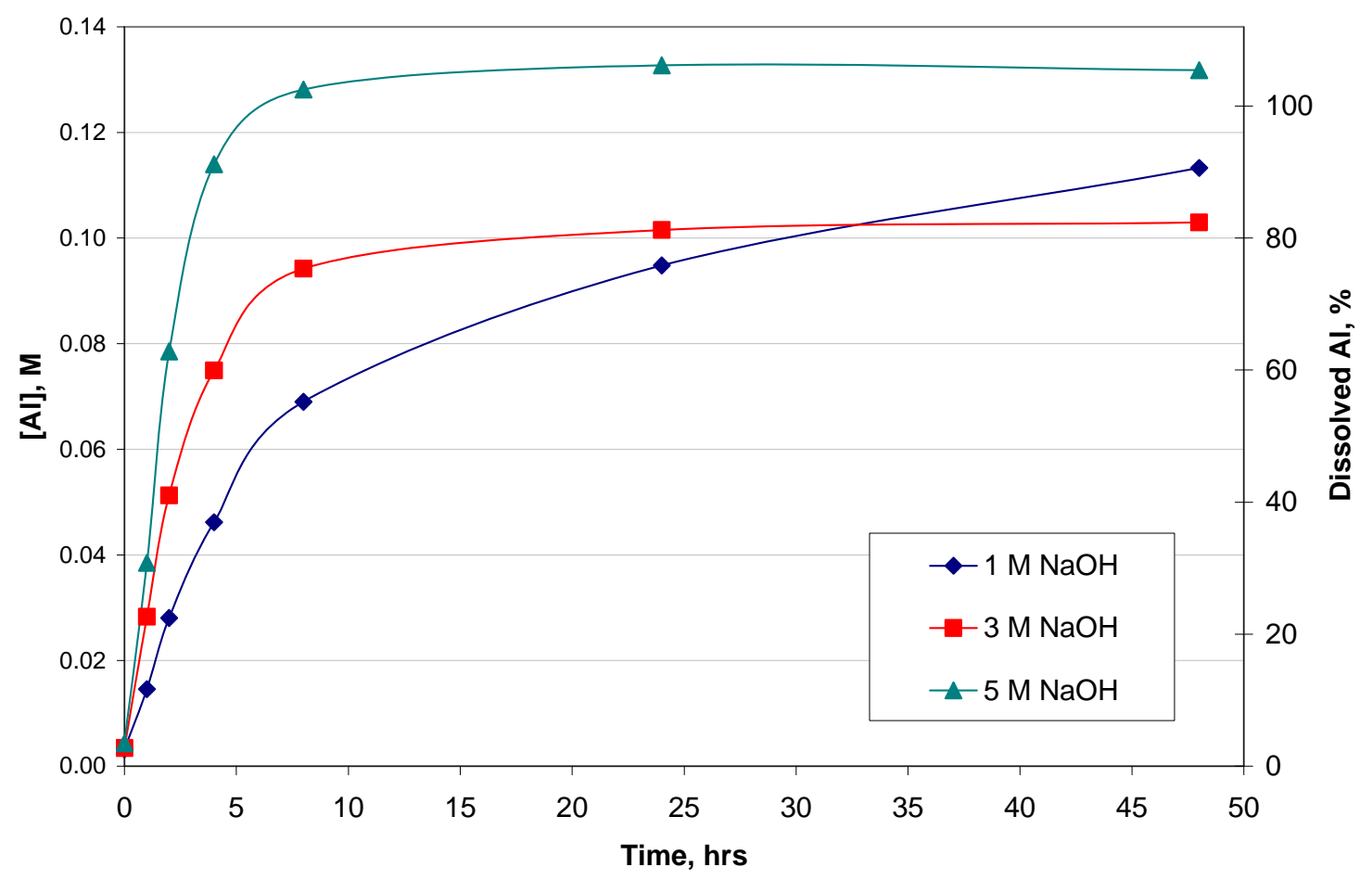

Figure 3.24. Aluminum Concentration and Percent Removed Versus Time at $60^{\circ} \mathrm{C}$ for Leaching of the Group 3 Washed Solids in 1, 3, and $5 \mathrm{M} \mathrm{NaOH}$ 




Figure 3.25. Aluminum Concentration and Percent Removed Versus Time at $80^{\circ} \mathrm{C}$ for Leaching of the Group 3 Washed Solids in 1, 3, and $5 \mathrm{M} \mathrm{NaOH}$.

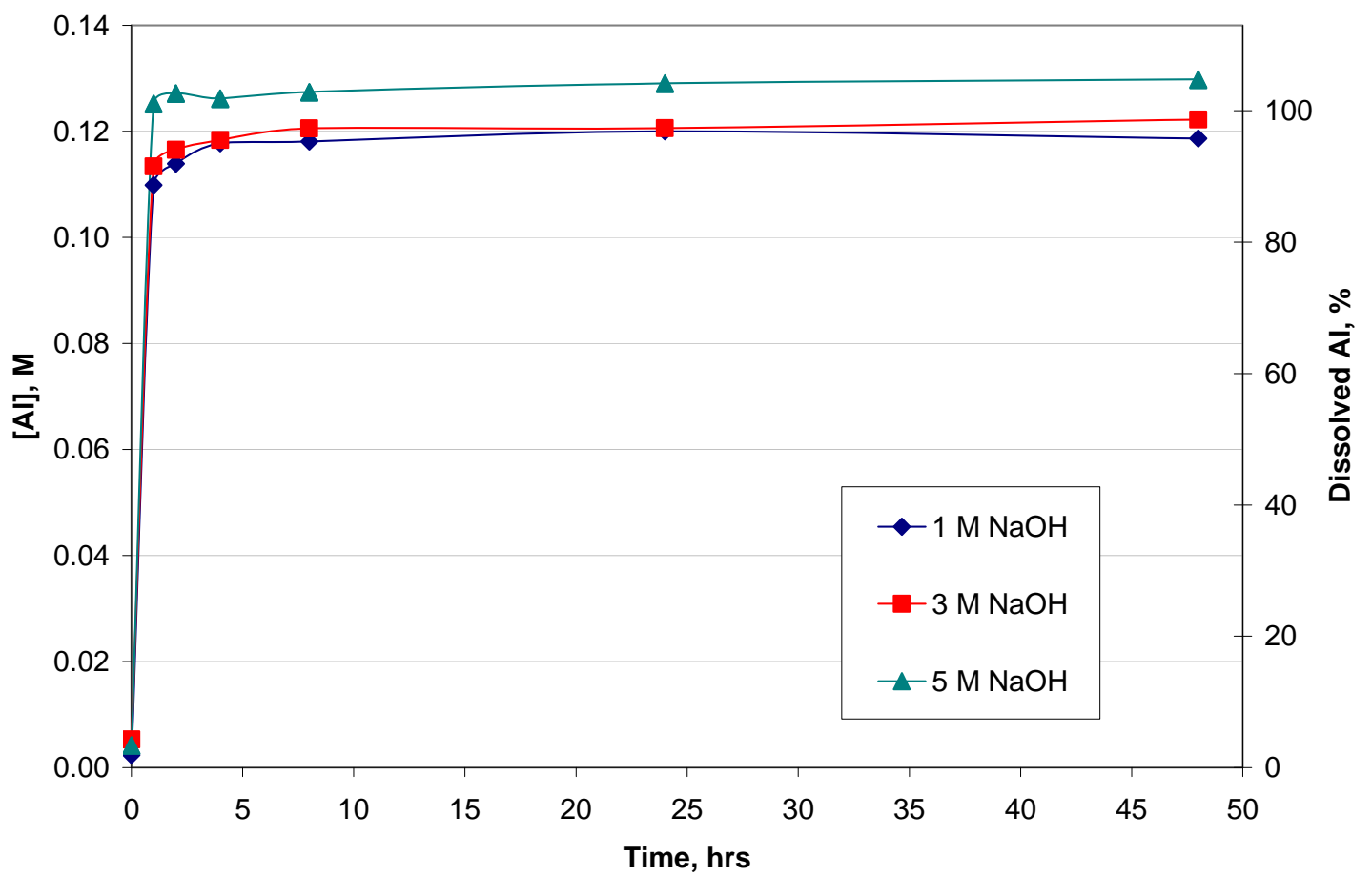

Figure 3.26. Aluminum Concentration and Percent Removed Versus Time at $100^{\circ} \mathrm{C}$ for Leaching of the Group 3 Washed Solids in 1, 3, and $5 \mathrm{M} \mathrm{NaOH}$ 
The same data are re-plotted in Figure 3.27 through Figure 3.29 to show the effect of temperature at constant free-hydroxide concentrations of 1,3 , and $5 \mathrm{M} \mathrm{NaOH}$, respectively. In 1 and $3 \mathrm{M} \mathrm{NaOH}$, the temperature had a small effect on the gibbsite dissolution rate, with the reaction at $60^{\circ} \mathrm{C}$ taking longer than the reaction at 80 and $100^{\circ} \mathrm{C}$. Rapid $\mathrm{Al}$ removal was observed at 80 and $100^{\circ} \mathrm{C}$ for all cases, with essentially complete removal being achieved after 4 hours in 1 and $3 \mathrm{M} \mathrm{NaOH}$ and after 1 hour in $5 \mathrm{M}$ $\mathrm{NaOH}$. At 48 -h and $1 \mathrm{M}$ free hydroxide, leaching at 60 to $100^{\circ} \mathrm{C}$ resulted in $\sim 91$ to $100 \mathrm{wt} \% \mathrm{Al}$ removal, although the reaction at $60^{\circ} \mathrm{C}$ was much slower than at 80 and $100^{\circ} \mathrm{C}$. In $3 \mathrm{M}$ free hydroxide, leaching at $60^{\circ} \mathrm{C}$ was faster than in $1 \mathrm{M}$ free hydroxide, reaching its steady-state value between 8 and 24 hours. In 5 $\mathrm{M}$ free hydroxide, leaching at $60^{\circ} \mathrm{C}$ reached the same value of $\mathrm{Al}$ removed after only 8 hours.



Figure 3.27. Aluminum Concentration and Percent Dissolved in $1 \mathrm{M} \mathrm{NaOH}$ 


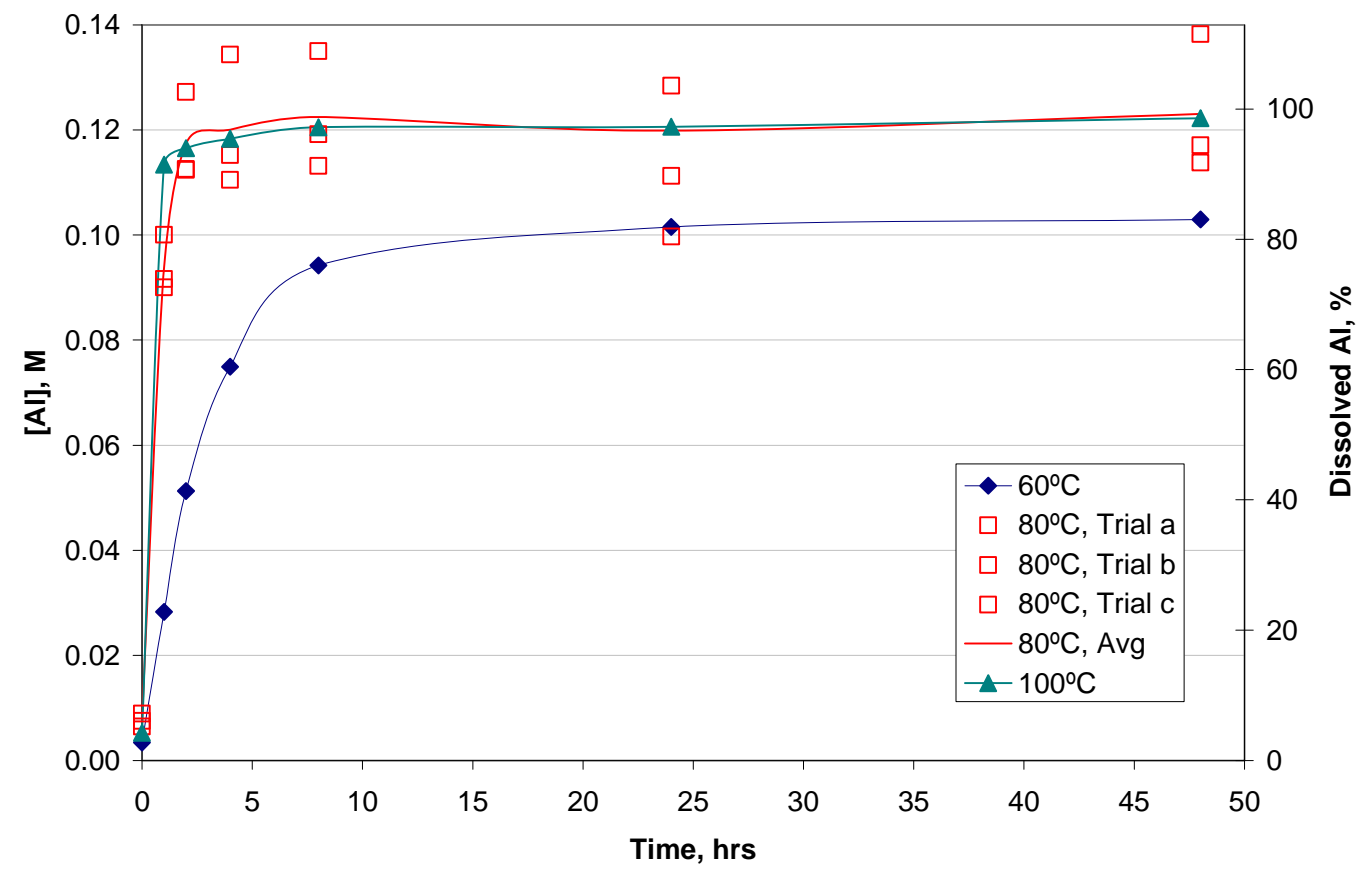

Figure 3.28. Aluminum Concentration and Percent Dissolved in $3 \mathrm{M} \mathrm{NaOH}$

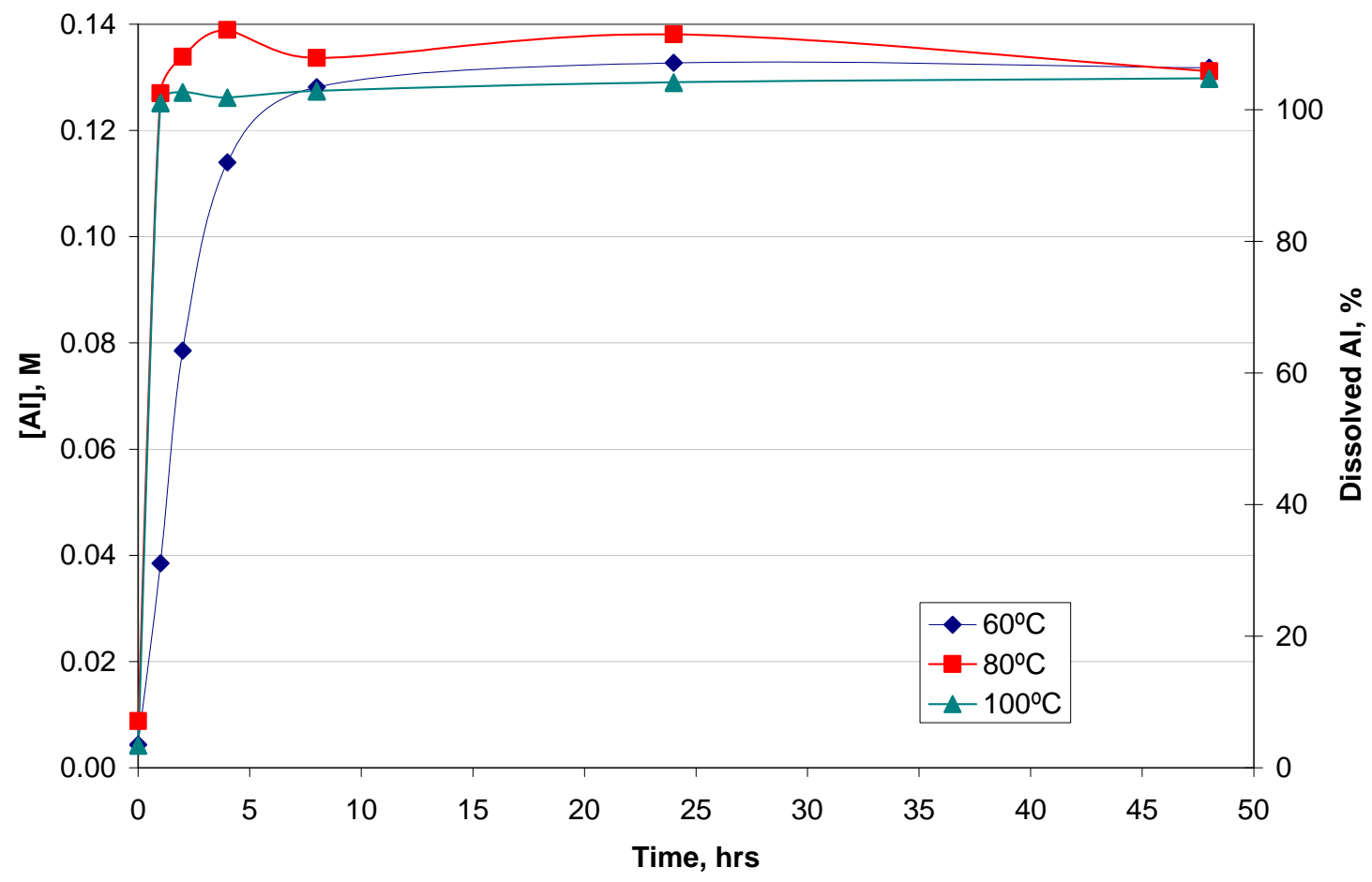

Figure 3.29. Aluminum Concentration and Percent Dissolved in $5 \mathrm{M} \mathrm{NaOH}$ 


\subsubsection{Effect of Ionic Strength on Aluminum Dissolution}

The effect of ionic strength on the $\mathrm{Al}$ dissolution behavior was assessed by increasing the $\mathrm{NaNO}_{3}$ concentration during leaching of the Group 3 solids in $3 \mathrm{M} \mathrm{NaOH}$ at $80^{\circ} \mathrm{C}$. The total $\mathrm{Na}$ concentrations were increased to $4 \mathrm{M}$ by adding $1 \mathrm{M} \mathrm{NaNO}_{3}$ and to $8 \mathrm{M}$ by adding $5 \mathrm{M} \mathrm{NaNO}_{3}$. Figure 3.30 summarizes the results. In the figure, the results from triplicate tests conducted in $3 \mathrm{M} \mathrm{Na}$ (i.e., no added $\mathrm{NaNO}_{3}$ ) are also included. Within the experimental uncertainty, no clear effect of changing $\mathrm{Na}$ molarity on the rate of Al dissolution was evident.

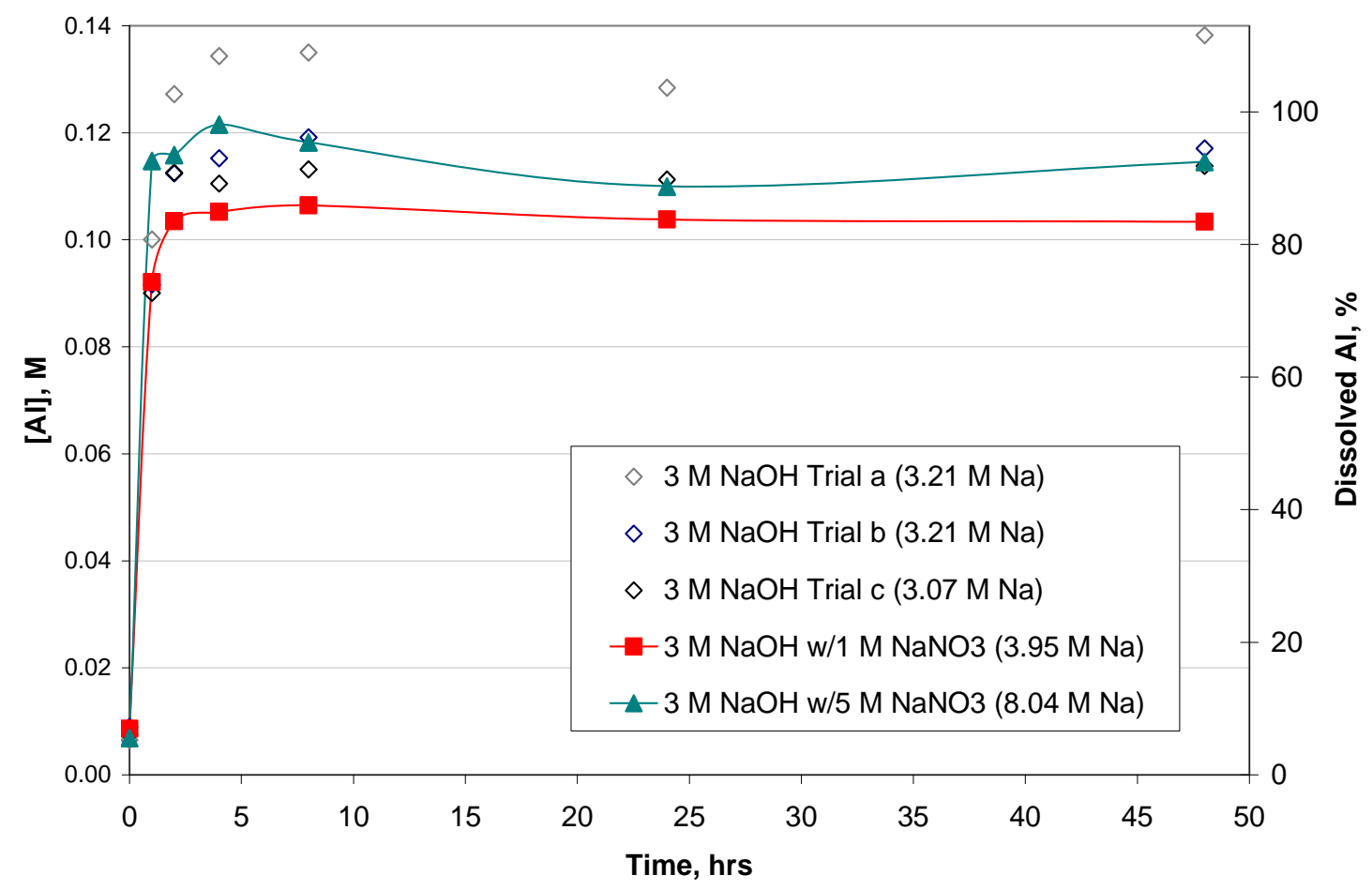

Figure 3.30. Matrix Effect of $\mathrm{Na}$ Concentration on $\mathrm{Al}$ (Gibbsite) Dissolution in $3 \mathrm{M} \mathrm{NaOH}$ at $80^{\circ} \mathbf{C}$. Note: The data point for $3 \mathrm{M} \mathrm{NaOH}$; Trial $\mathrm{b}$ is not plotted because the value was suspect.

\subsubsection{Anions, Phosphorus, Silicon, $\mathrm{Cr}$, and Iron Leaching Behavior}

The concentrations of $\mathrm{Cr}, \mathrm{Fe}, \mathrm{P}$, and $\mathrm{Si}$ were measured by ICP-OES. The anionic compositions were also assessed at each sampling period. The $\mathrm{Cr}$ concentrations were generally below the estimated sample quantitation limit (EQL) - but appear to generally increase with increasing contact time. The $\mathrm{Fe}$ and $\mathrm{Si}$ data were generally above the EQL while the $\mathrm{P}$ and anions were generally below the EQL. The Fe, Si, P, and anion concentrations in the leachate did not significantly change during the leach testing. The results are summarized in Appendix I.

\subsubsection{Assessment of Final Leaching Conditions}

A summary of the final (48-h) leaching solution chemistry and physical parameters is shown in Table 3.15. The final free-hydroxide and sodium concentrations were at the targeted values within the uncertainty of the analytical methods $( \pm 15 \%)$. The calculated percentage of aluminum that was removed 
at each leaching condition is also shown. Appendix I provides a compilation of the concentrations of all analytes, including $\mathrm{Al}, \mathrm{Cr}, \mathrm{Fe}, \mathrm{Na}, \mathrm{P}, \mathrm{Si}$, fluoride, nitrite, nitrate, phosphate, and sulfate in the final leaching solutions. The GEA results for ${ }^{60} \mathrm{Co}$ and ${ }^{241} \mathrm{Am}$ were $<\mathrm{MDL}$; the GEA results are also provided in Appendix I.

Table 3.15. Group 3 PUREX Cladding Waste Sludge Leaching Final ( 48 hr) Aqueous Phase Conditions

\begin{tabular}{|c|c|c|c|c|c|c|}
\hline Temp., ${ }^{\circ} \mathrm{C}$ & $\begin{array}{c}\text { Density, } \\
\text { g/mL }\end{array}$ & $\begin{array}{c}\text { Free OH, } \\
\text { M }\end{array}$ & $\mathrm{NO}_{3}, \mathrm{M}$ & Na, $\mathrm{M}$ & Al, $\mathbf{M}$ & $\begin{array}{c}\text { Wt \% Al } \\
\text { Removed }^{(b)}\end{array}$ \\
\hline 60 & 1.05 & 0.95 & NA & 1.09 & 0.113 & 91 \\
\hline 60 & 1.13 & 3.03 & NA & 3.22 & 0.103 & 83 \\
\hline 60 & 1.20 & 5.15 & NA & 5.27 & 0.132 & 106 \\
\hline 80 & 1.05 & 0.93 & NA & 1.06 & 0.129 & 104 \\
\hline 80 trial a & 1.13 & 3.01 & NA & 3.21 & 0.138 & 99 \\
\hline 80 trial b & 1.13 & 3.17 & NA & 3.21 & 0.117 & 99 \\
\hline 80 trial c & 1.13 & 2.93 & NA & 3.07 & 0.114 & 99 \\
\hline 80 with $1 \mathrm{M} \mathrm{NaNO}_{3}$ & 1.17 & 2.88 & $1.05^{(\mathrm{a})}$ & 3.95 & 0.103 & 83 \\
\hline 80 with $5 \mathrm{M} \mathrm{NaNO}_{3}$ & 1.38 & 2.80 & $5.33^{(\mathrm{a})}$ & 8.04 & 0.115 & 92 \\
\hline 80 & 1.20 & 4.93 & NA & 4.87 & 0.131 & 106 \\
\hline 100 & 1.05 & 0.94 & NA & 1.09 & 0.119 & 96 \\
\hline 100 & 1.13 & 3.12 & NA & 3.44 & 0.122 & 99 \\
\hline 100 & 1.20 & 5.23 & NA & 5.61 & 0.130 & 105 \\
\hline \multicolumn{7}{|c|}{$\begin{array}{l}\text { (a) Average of seven measurements over the entire sampling period. } \\
\text { (b) Values greater than } 100 \% \text { can be interpreted as essentially } 100 \% \mathrm{Al} \text { removal. } \\
\text { Analytical Service Request (ASR) } 8094\end{array}$} \\
\hline
\end{tabular}

\subsubsection{Comparison of Initial and Caustic-Leached and Washed-Solids Properties}

The Group 3 solids that had been caustic leached at $80^{\circ} \mathrm{C}$ in $3 \mathrm{M} \mathrm{NaOH}$ for $48 \mathrm{hrs}$ were combined and washed in preparation for analysis. The wash solution composition and the washed solids chemical, radiochemical, particle size, and crystal habit are discussed.

\subsubsection{Leached-Solids Wash Solution}

After the third washing of the caustic-leached Group 3 solids, the wet centrifuged solids mass was $0.52 \mathrm{~g}$. The densities of the three sequential wash solutions were $1.018 \mathrm{~g} / \mathrm{mL}, 1.002 \mathrm{~g} / \mathrm{mL}$, and $0.999 \mathrm{~g} / \mathrm{mL}$, respectively. The composite wash-solution ( $94.7 \mathrm{~mL}$ volume) density, ICP metals, and anion composition are shown in Table 3.16. The concentrations of all analytes in the composite wash-solution are given in Appendix I.

The analysis of the wash solution by ICP for metal content indicated the presence of primarily $\mathrm{Na}, \mathrm{Al}$, and $\mathrm{Si}$. There was no evidence of additional dissolution of these species during the washing process. 
Table 3.16. Group 3 Solids Wash Solution Composition and Density

\begin{tabular}{|c|c|c|c|c|c||}
\hline \hline Analyte & $\mu \mathrm{g} / \mathbf{m L}$ & Analyte & $\mu \mathrm{g} / \mathbf{m L}$ & Density Measurement & $\mathbf{g} / \mathbf{m L}$ \\
\hline $\mathrm{Al}$ & 111.1 & $\mathrm{Si}$ & 5.48 & Density & 1.007 \\
\hline $\mathrm{Cr}$ & $<0.05$ & nitrate & {$[4.40]$} & & \\
\cline { 1 - 4 } $\mathrm{Na}$ & 2,553 & phosphate & $<0.60$ & & \\
\cline { 1 - 3 } $\mathrm{P}$ & $<1.52$ & sulfate & $<0.75$ & & \\
\hline
\end{tabular}

\subsubsection{Chemical and Radiochemical Composition}

The initial composition of washed solids (before caustic leaching) is provided in Table 3.17 along with selected results from the initial characterization study. The solids composition after leaching in $3 \mathrm{M}$ $\mathrm{NaOH}$ at $80^{\circ} \mathrm{C}$ for 48 hours and washing is also shown in Table 3.17. Both the initial solids for characterization and the "before leaching" material had been extensively washed, i.e., little or no salt entrainment was expected (except for $\mathrm{NaOH}$ from the washing liquid). The composition of the initial characterization sample was generally consistent with that for the "before leaching" material.

Table 3.17. Group 3 PUREX Cladding Waste Sludge Leached Solids Composition and Leach Factors (Dry Mass Basis) for Caustic-Leaching at $80^{\circ} \mathrm{C}$ in $3 \mathrm{M} \mathrm{NaOH}$ for $48 \mathrm{Hrs}$

\begin{tabular}{|c|c|c|c|c|}
\hline Analyte & $\begin{array}{c}\text { Avg. Initial } \\
\text { Charac. } \\
\mu g / g \\
\text { (ASR 7874) }\end{array}$ & $\begin{array}{c}\text { Avg. Before } \\
\text { Leaching, } \\
\mu g / g \\
\text { (ASR 8094) }\end{array}$ & $\begin{array}{c}\text { Avg. After } \\
\text { Leaching, } \\
\mu g / g \\
\text { (ASR 8094) }\end{array}$ & $\begin{array}{c}\text { Observed } \\
\text { Leach } \\
\text { Factor }\end{array}$ \\
\hline $\mathrm{Al}$ & 297,500 & 299,500 & 27,100 & 0.99 \\
\hline B & $<27$ & [18] & [68] & -- \\
\hline $\mathrm{Bi}$ & [730] & [847] & 10,400 & 0 \\
\hline $\mathrm{Cd}$ & [24] & [74] & 472 & -- \\
\hline $\mathrm{Cr}$ & 314 & 366 & 1,630 & 0.61 \\
\hline $\mathrm{Fe}$ & 14,000 & 17,750 & 166,000 & 0 \\
\hline $\mathrm{K}$ & na & na & na & na \\
\hline $\mathrm{Mn}$ & $1,009^{(a)}$ & 1,200 & 12,200 & 0 \\
\hline $\mathrm{Na}$ & {$[14,500]$} & {$[13,000]$} & {$[43,000]$} & -- \\
\hline $\mathrm{Ni}$ & na & na & na & na \\
\hline $\mathrm{P}$ & [620] & [225] & {$[2,900]$} & -- \\
\hline $\mathrm{S}$ & $<554$ & $<738$ & $<1256$ & -- \\
\hline $\mathrm{Si}$ & $8,980^{(b)}$ & 13,050 & 33,300 & 0.78 \\
\hline $\mathrm{Sr}$ & 84 & 78 & 1,300 & 0 \\
\hline $\mathrm{U}$ & 12,750 & 15,550 & 213,000 & 0 \\
\hline $\mathrm{Zn}$ & 184 & [110] & 568 & -- \\
\hline $\mathrm{Zr}$ & 4,810 & 2,285 & 144,000 & 0 \\
\hline \multirow[t]{2}{*}{ U KPA } & 9,755 & 14,482 & 209613 & 0 \\
\hline & $\mu \mathrm{Ci} / \mathrm{g}$ & $\mu \mathrm{Ci} / \mathrm{g}$ & $\mu \mathrm{Ci} / \mathrm{g}$ & \\
\hline${ }^{60} \mathrm{Co}$ & 0.048 & $5.23 \mathrm{E}-02$ & 0.544 & 0 \\
\hline${ }^{90} \mathrm{Sr}$ & 277 & 294 & 3808 & 0 \\
\hline${ }^{137} \mathrm{Cs}$ & 53.6 & $6.11 \mathrm{E}+01$ & 88.1 & 0.88 \\
\hline
\end{tabular}


Table 3.17 (contd)

\begin{tabular}{|c|c|c|c|c|}
\hline Analyte & $\begin{array}{c}\text { Avg. Initial } \\
\text { Charac. } \\
\mu g / g \\
\text { (ASR 7874) }\end{array}$ & $\begin{array}{c}\text { Avg. Before } \\
\text { Leaching, } \\
\mu g / g \\
\text { (ASR 8094) }\end{array}$ & $\begin{array}{l}\text { Avg. After } \\
\text { Leaching, } \\
\mu g / g \\
\text { (ASR 8094) }\end{array}$ & $\begin{array}{l}\text { Observed } \\
\text { Leach } \\
\text { Factor }\end{array}$ \\
\hline${ }^{154} \mathrm{Eu}$ & 0.287 & 3.94E-01 & 3.90 & 0.14 \\
\hline${ }^{155} \mathrm{Eu}$ & 0.116 & $1.49 \mathrm{E}-01$ & 1.51 & 0 \\
\hline${ }^{238} \mathrm{Pu}$ & $1.04 \mathrm{E}-1$ & $1.26 \mathrm{E}-01$ & 1.57 & 0 \\
\hline${ }^{239+240} \mathrm{Pu}$ & 0.939 & 1.23 & 13.9 & 0 \\
\hline${ }^{241} \mathrm{Am}$ & 1.00 & 1.23 & 12.37 & 0 \\
\hline total alpha & 2.03 & 2.54 & 27.6 & 0.06 \\
\hline total beta & 578 & 622 & 7986 & 0 \\
\hline \multicolumn{5}{|l|}{ Opportunistic } \\
\hline $\mathrm{Ag}$ & [16] & [16] & [35] & -- \\
\hline As & $<192$ & $<87.2$ & $<306$ & -- \\
\hline $\mathrm{Ba}$ & 82.5 & 46 & 1,460 & 0 \\
\hline $\mathrm{Be}$ & 2.71 & 5.65 & 6.50 & 0.90 \\
\hline $\mathrm{Ca}$ & $<3,810$ & $<2,460$ & {$[17,000]$} & -- \\
\hline $\mathrm{Ce}$ & [62] & [29] & 1,050 & -- \\
\hline Co & $<12$ & [31] & [180] & -- \\
\hline $\mathrm{Cu}$ & 147 & 195 & 677 & 0.70 \\
\hline Dy & $<10$ & $<6.49$ & $<22.8$ & -- \\
\hline $\mathrm{Eu}$ & [4.19] & {$[.92]$} & [11] & -- \\
\hline $\mathrm{La}$ & {$[40]$} & $<17.0$ & 973 & -- \\
\hline $\mathrm{Li}$ & [42] & {$[38]$} & [57] & -- \\
\hline $\mathrm{Mg}$ & 205 & [264] & 3,360 & -- \\
\hline Mo & $<25$ & [16] & $<56.5$ & -- \\
\hline $\mathrm{Nd}$ & [49] & [27] & 1,090 & -- \\
\hline $\mathrm{Pb}$ & [915] & {$[1,425]$} & 8,350 & -- \\
\hline $\mathrm{Pd}$ & [25] & $<14.3$ & $<50.2$ & -- \\
\hline $\mathrm{Rh}$ & $<45$ & $<29.1$ & $<102$ & -- \\
\hline $\mathrm{Ru}$ & [76] & [62] & 691 & -- \\
\hline $\mathrm{Sb}$ & $<107$ & $<69.3$ & $<243$ & -- \\
\hline $\mathrm{Se}$ & $<410$ & $<246$ & $<863$ & -- \\
\hline Sn & $<87$ & $<55.9$ & [350] & -- \\
\hline $\mathrm{Ta}$ & $<69$ & $<44.7$ & $<157$ & -- \\
\hline $\mathrm{Te}$ & [105] & {$[58]$} & [220] & -- \\
\hline Th & {$[170]$} & [94] & 5,410 & -- \\
\hline $\mathrm{Ti}$ & 113 & 119 & 1,430 & 0 \\
\hline $\mathrm{Tl}$ & $<104$ & $<71.8$ & $<235$ & -- \\
\hline $\mathrm{V}$ & $<11$ & $<12.0$ & {$[27]$} & -- \\
\hline $\mathrm{W}$ & $<73$ & [47] & [610] & -- \\
\hline $\mathrm{Y}$ & {$[9.4]$} & [10] & 160 & -- \\
\hline
\end{tabular}

(a) The fusion blank Mn concentration was $14 \%$ of the sample concentration, exceeding the 5\% threshold. Since the sample result agreed with the results from the acid digestion, no re-preparation was required.

(b) The Si LCS recovered low at 41\%, indicating that the result might be biased low. 
Because the maximum $\mathrm{Al}$ concentration projected to be in the caustic leachate solutions (based on the $\mathrm{Al}$ in the initial solids) was up to $27 \%$ less than that found in the final $3 \mathrm{M} \mathrm{NaOH}$ leachate solutions, three methods of determining the percent leached were performed. Method 1 used the concentration of each analyte experimentally determined in the initial solids and the concentration of the analytes determined in the final leachate solutions. Method 2 used the concentration of the analytes in the final leachate solutions and the concentration in the final leached solids. Method 3 used the concentrations in the initial and final solids and the "concentration factor" method (Lumetta et al. 2008).

For the first method, the total amount (on a dry-solids basis) of solids that went into each sample was determined based on the measurement of the UDS in the sample slurry and the mass of slurry added to each leaching bottle. The mass of solids in each leaching bottle was multiplied by the concentration of each component in the initial solids to determine the total mass (in $\mu \mathrm{g}$ ) of the individual component in each sample $\left(\mathrm{W}_{\mathrm{IS}}\right)$. The total mass of each component in the final leachate solution $\left(\mathrm{W}_{\mathrm{L}}\right)$ was calculated by multiplying the concentration of the components $(\mu \mathrm{g} / \mathrm{mL})$ determined to be in solution at $48 \mathrm{~h}$ by $100 \mathrm{~mL}$ (the total volume of leaching solution). The leach factor was then taken as the mass of each component in the leachate solution at $48 \mathrm{hrs}$ divided by the mass of that component in the initial sample (Equation 3.3).

$$
L F_{1}=\left(\frac{W_{L}}{W_{I S}}\right)
$$

For the second method, the mass of residual solids in each of the three samples treated at $80^{\circ} \mathrm{C}$ in $3 \mathrm{M}$ $\mathrm{NaOH}$ was first determined. These three solids samples were combined, washed, and then slurried in water. A sample of this slurry was dried to determine the wt $\%$ UDS. The total mass of solids was determined from the slurry mass and $w t \%$ UDS. This number was then divided by three to obtain the average mass of dried solids in each of the three samples of leached solids. This mass was then multiplied by the concentration of each component in the final solids to determine the mass (in $\mu \mathrm{g}$ ) of the component in each leached sample. The leach factor was then calculated by dividing the mass of the component in the leachate solution $\left(\mathrm{W}_{\mathrm{L}}\right)$ by the total mass of the component in each sample, calculated from the mass of each in the final solids and leachate solution (sum of $\mathrm{W}_{\mathrm{L}}$ and weight in the final samples $\left[\mathrm{W}_{\mathrm{FS}}\right]$ ) as shown in Equation 3.4.

$$
L F_{\text {triplicate_samples }}=\left(\frac{W_{L}}{W_{L}+W_{F S}}\right)
$$

As is done with the "concentration factor" method (i.e., method 3), the average leach factor from the three samples was calculated. The average of the concentration of each component in the final leachates from the triplicate runs was divided by the average leach factor of the triplicate samples to obtain an average corrected concentration (CC) that corresponds to the concentration that would be obtained if $100 \%$ of the sample had dissolved. The weight of each component in the leachate solutions is divided by the average corrected concentration to determine the leach factors as shown in Equation 3.5.

$$
L F_{2}=\left(\frac{W_{L}}{C C}\right)
$$


The third method is the same that was previously reported in Fiskum et al. (2008). The analysis of the leachate solutions showed that $\mathrm{Fe}, \mathrm{Mn}, \mathrm{U},{ }^{60} \mathrm{Co},{ }^{155} \mathrm{Eu},{ }^{241} \mathrm{Am},{ }^{90} \mathrm{Sr},{ }^{239+240} \mathrm{Pu}$, and ${ }^{238} \mathrm{Pu}$ were not dissolved by caustic leaching. The relative concentration factor (CF) of these analytes averaged 11.55 in the final leached solids, based on the ratio of the analyte concentrations after leaching to the analyte concentrations before leaching. This term was used to determine the specific analyte leach factors according to Equation 3.6:

$$
L F_{3}=1-\left(\frac{C_{L}}{C_{W} \times 11.55}\right)
$$

where $\mathrm{LF}_{3}$ is the caustic-leach factor, $\mathrm{C}_{\mathrm{L}}$ is the leached analyte concentration, and $\mathrm{C}_{\mathrm{W}}$ is the washed analyte concentration.

Results from all three methods are given in Table 3.18. Reasonably good agreement is seen between all three methods. All values of percent leached plotted in this section and shown in Table 3.15 and Table 3.17 were calculated using method three, the "concentration factor" method.

Table 3.18. Group 3 CWP Sludge Aluminum Leach Factors

\begin{tabular}{|c|c|c|c|c|c|}
\hline & $\begin{array}{l}\text { Free } \\
\text { OH, }\end{array}$ & & $\begin{array}{c}\text { Fraction Removed } \\
\text { Based on initial } \\
\text { solids/leachate } \\
\text { solution }\end{array}$ & $\begin{array}{c}\text { Fraction Removed } \\
\text { Based on final } \\
\text { solids/leachate } \\
\text { solution }\end{array}$ & $\begin{array}{c}\text { Fraction Removed } \\
\text { Based on initial/final } \\
\text { solids } \\
\text { (“concentration } \\
\text { factor" method) }\end{array}$ \\
\hline Temp., ${ }^{\circ} \mathrm{C}$ & M & $\mathrm{Na}, \mathrm{M}$ & Al & $\overline{\mathrm{Al}}$ & $\overline{A l}$ \\
\hline 60 & 0.95 & 1.09 & 0.98 & 0.91 & 0.91 \\
\hline 60 & 3.03 & 3.22 & 0.94 & 0.83 & 1.03 \\
\hline 60 & 5.15 & 5.27 & 1.16 & 1.06 & 0.91 \\
\hline 80 & 0.93 & 1.06 & 1.15 & 1.04 & 1.04 \\
\hline 80 trial a & 3.01 & 3.21 & 1.27 & 0.99 & 1.11 \\
\hline 80 trial b & 3.17 & 3.21 & 1.06 & 0.99 & 0.94 \\
\hline 80 trial $\mathrm{c}$ & 2.93 & 3.07 & 1.02 & 0.99 & 0.92 \\
\hline 80 with $1 \mathrm{M} \mathrm{NaNO}_{3}$ & 2.88 & 3.95 & 0.94 & 0.83 & 0.83 \\
\hline 80 with $5 \mathrm{M} \mathrm{NaNO}_{3}$ & 2.80 & 8.04 & 1.02 & 0.92 & 0.92 \\
\hline 80 & 4.93 & 4.87 & 1.18 & 1.06 & 1.06 \\
\hline 100 & 0.94 & 1.09 & 1.07 & 0.96 & 0.96 \\
\hline 100 & 3.12 & 3.44 & 1.10 & 0.99 & 0.99 \\
\hline 100 & 5.23 & 5.61 & 1.16 & 1.05 & 1.05 \\
\hline
\end{tabular}

Notably, extended (48-hr) leach times did not mobilize U, Sr, Mn, or Pu to the aqueous phase. Consistent with previous leaching tests with Hanford sludge solids, a significant fraction (88\%) of the ${ }^{137} \mathrm{Cs}$ was dissolved and would be routed to the LAW pretreatment facility. 
Approximately $84 \%$ of the mass dissolved with a 48-hr leach time. As shown in Figure 3.31, in this case, iron and uranium were the predominant residual metals, and uranium would be expected to become the limiting component of the HLW glass loading.

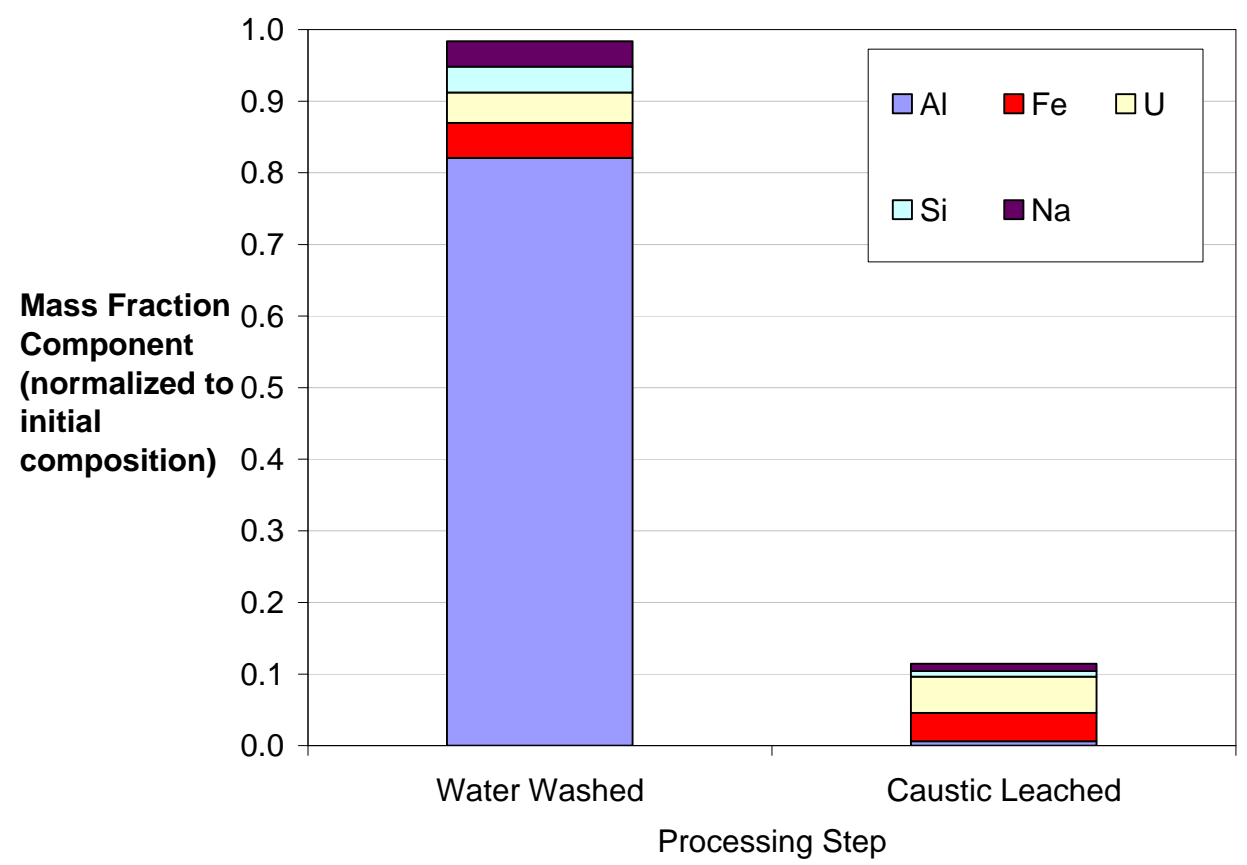

Figure 3.31. Group 3 CWP Sludge Reduction in Solid Mass with Water Washing and Caustic Leaching

\subsubsection{Particle-Size Distribution}

PSD measurements were performed on a sample of the caustic-leached solids (sample ID 585-G3-CLPSD). Table 3.19 shows selected cumulative undersize percentiles for this sample. Here, the $\mathrm{d}(10)$ ranges from 0.53 to $1.2 \mu \mathrm{m}$, the $\mathrm{d}(50)$ ranges from 2.4 to $11 \mu \mathrm{m}$, and the $\mathrm{d}(90)$ ranges from 33 to $125 \mu \mathrm{m}$.

The listed diameter percentiles appear to be slightly sensitive to changes in pump speed, both before and after sonication. Increases in flow rate appear to influence increases in the mean diameter [i.e., the d(50)]. For a decrease from 3000 to 2000 RPM before sonication, the mean particle diameter decreases from 11 to $9.5 \mu \mathrm{m}$. This is a decrease of $\sim 14 \%$ and is close to, but above, the limit of significance $(10 \%)$. Sonication of the caustic-leached and washed Group 3 solids dispersion greatly decreases particle size. The PSD results at 3000 RPM indicate that sonication lowers the mean particle diameter [i.e., the $\mathrm{d}(50)$ ] from 11 to $2.4 \mu \mathrm{m}$. This represents a decrease of $\sim 78 \%$ in the mean particle size and is significant relative to the measurement accuracy $(10 \%)$.

The particle-size analysis of caustic-leached and washed Group 3 solids indicates a multimodal distribution with a range of 0.2 to $200 \mu \mathrm{m}$. Particles appear to be highly susceptible to agglomeration, which can be disrupted through sonication. Recovery of agglomerates and settling appear to heavily influence the distribution after sonication. 
Table 3.19. Particle-Size Analysis Percentile Results for the Caustic-Leached and Washed Group 3 Solids (sample 585-G3-CL-PSD)

\begin{tabular}{||c|c|c|c|c|c||}
\hline $\begin{array}{c}\text { Measurement } \\
\text { Condition }\end{array}$ & Pump Speed & Sonication & $\begin{array}{c}\mathbf{d}(\mathbf{1 0}) \\
{[\boldsymbol{\mu m}]}\end{array}$ & $\begin{array}{c}\mathbf{d}(\mathbf{5 0}) \\
{[\boldsymbol{\mu m}]}\end{array}$ & $\begin{array}{c}\mathbf{d}(\mathbf{9 0}) \\
{[\boldsymbol{\mu m}]}\end{array}$ \\
\hline 1 & 3000 & pre-sonic & 1.1 & 11 & 90 \\
\hline 2 & 4000 & pre-sonic & 1.2 & 9.7 & 125 \\
\hline 3 & 2000 & pre-sonic & 1.1 & 9.5 & 84 \\
\hline 4 & 3000 & $25 \%$ & 0.92 & 11 & 74 \\
\hline 5 & 3000 & $50 \%$ & 0.71 & 7.8 & 69 \\
\hline 6 & 3000 & $75 \%$ & 0.57 & 2.7 & 59 \\
\hline 7 & 3000 & post-sonic & 0.54 & 2.4 & 60 \\
\hline 8 & 4000 & post-sonic & 0.57 & 3.2 & 124 \\
\hline 9 & 2000 & post-sonic & 0.53 & 2.4 & 33 \\
\hline \multicolumn{7}{|l|}{ Note: \% sonication values represent \% total displacement amplitudes. } \\
\hline
\end{tabular}

Figure 3.32 shows the PSD in the caustic-leached and washed Group 3 solids as a function of pump speed before sonication. The particle distributions at 2000 and 3000 RPM are broad, ranging from 0.2 to $300 \mu \mathrm{m}$ with a primary peak around 13 to $17 \mu \mathrm{m}$ and a secondary peak around 100 to $120 \mu \mathrm{m}$. The particle distributions at 3000 RPM also show a third peak around $2 \mu \mathrm{m}$, which is evident at $2000 \mathrm{RPM}$ only as a shoulder. At 4000 RPM, the particle-size range extends from 0.2 to over $2000 \mu \mathrm{m}$ (with $2000 \mu \mathrm{m}$ being the upper limit of the particle measurement). This high-flow-rate condition is tri-modal with a broad primary peak between 6 and $17 \mu \mathrm{m}$, a secondary peak around $95 \mu \mathrm{m}$, and a third peak between 1300 and $1500 \mu \mathrm{m}$. This 1300 - to $1500-\mu \mathrm{m}$ peak is most likely an artifact of background measurement noise with the high pump speed. This artifact is seen on occasion with the Malvern Mastersizer 2000 because the 1000- to $2000-\mu \mathrm{m}$ range corresponds to the highest laser intensity variations. Occasionally, this noise is higher than average and can be mistaken as a real signal by the analysis routine.

Figure 3.33 shows changes that occur in the distribution of particles as a result of applying sonication. Before sonication, a distinct tri-modal distribution exists ranging from 0.2 to $300 \mu \mathrm{m}$. During and after sonication, a split is observed in the distribution with a uni-modal peak over the range of 0.2 to $6 \mu \mathrm{m}$ and a bi-modal peak over the range of 7 to $200 \mu \mathrm{m}$. One possible explanation of this result is sonic-induced disruption of the 4- to $10-\mu \mathrm{m}$ particles. The data suggest the existence of large (10- to $200-\mu \mathrm{m})$ particles or agglomerates that are not easily disrupted under the influence of ultrasound. The change in distribution appears to remain stable after sonication during the duration of the PSD measurement. 


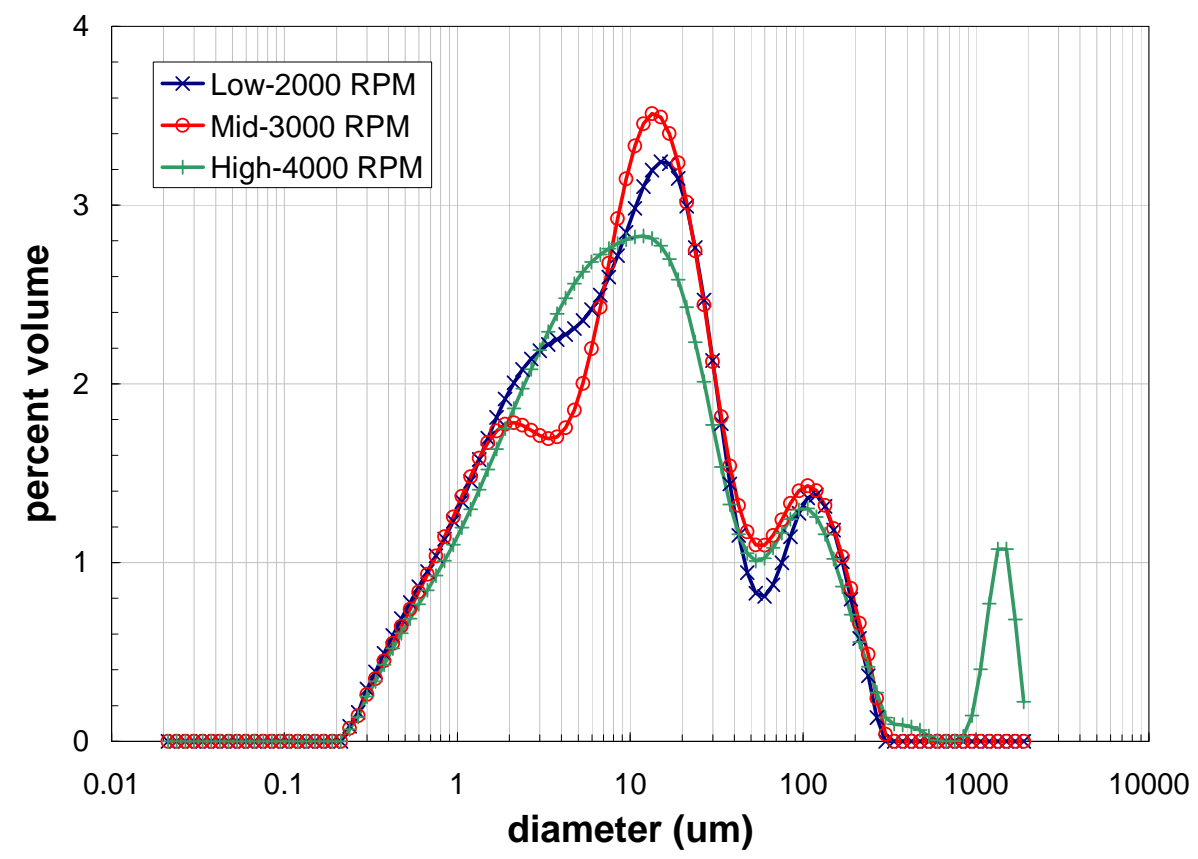

Figure 3.32. Pre-sonication Volume Distribution Result for the Caustic-Leached and Washed Group 3 Solids (sample 585-G3-CL-PSD) as a Function of Pump Speed



Figure 3.33. Volume Distribution Result for the Caustic-Leached and Washed Group 3 Solids Before, During, and After Sonication at 3000 RPM. Note: the during-sonication condition corresponds to measurement condition 6 (3000 RPM, 75\% Sonication). 
Figure 3.34 shows the post-sonication PSD behavior of the caustic-leached and washed Group 3 solids as a function of analyzer pump speed. Here, changes in pump speed significantly influence the distribution. At all pump speeds, the PSDs ranged from 0.2 to $200 \mu \mathrm{m}$. As observed in the pre-sonication measurements, at $4000 \mathrm{RPM}$, a peak exists at $1000 \mu \mathrm{m}$, which is most likely an artifact of background noise, as previously described. Three peaks exist in all conditions with maxima around 2, 11, and 100 $\mu \mathrm{m}$. There were also two valleys present in the distributions with minima around 7 and $50 \mu \mathrm{m}$. From condition 7 to 8 (in Table 3.19), with an increase in pump speed from 3000 to 4000 RPM, there is a recovery of the 5- $\mu \mathrm{m}$ valley, which may cause the corresponding relative decrease in the peaks. The settling of larger particles and/or agglomerates, or a recombination of $<2-\mu \mathrm{m}$ particles to form aggregates may factor into this effect. With the decrease in pump speed from 4000 to $2000 \mathrm{RPM}$, continued particle settling of approximately $50-\mu \mathrm{m}$ particles and aggregate recovery may account for relative increased peak maxima.

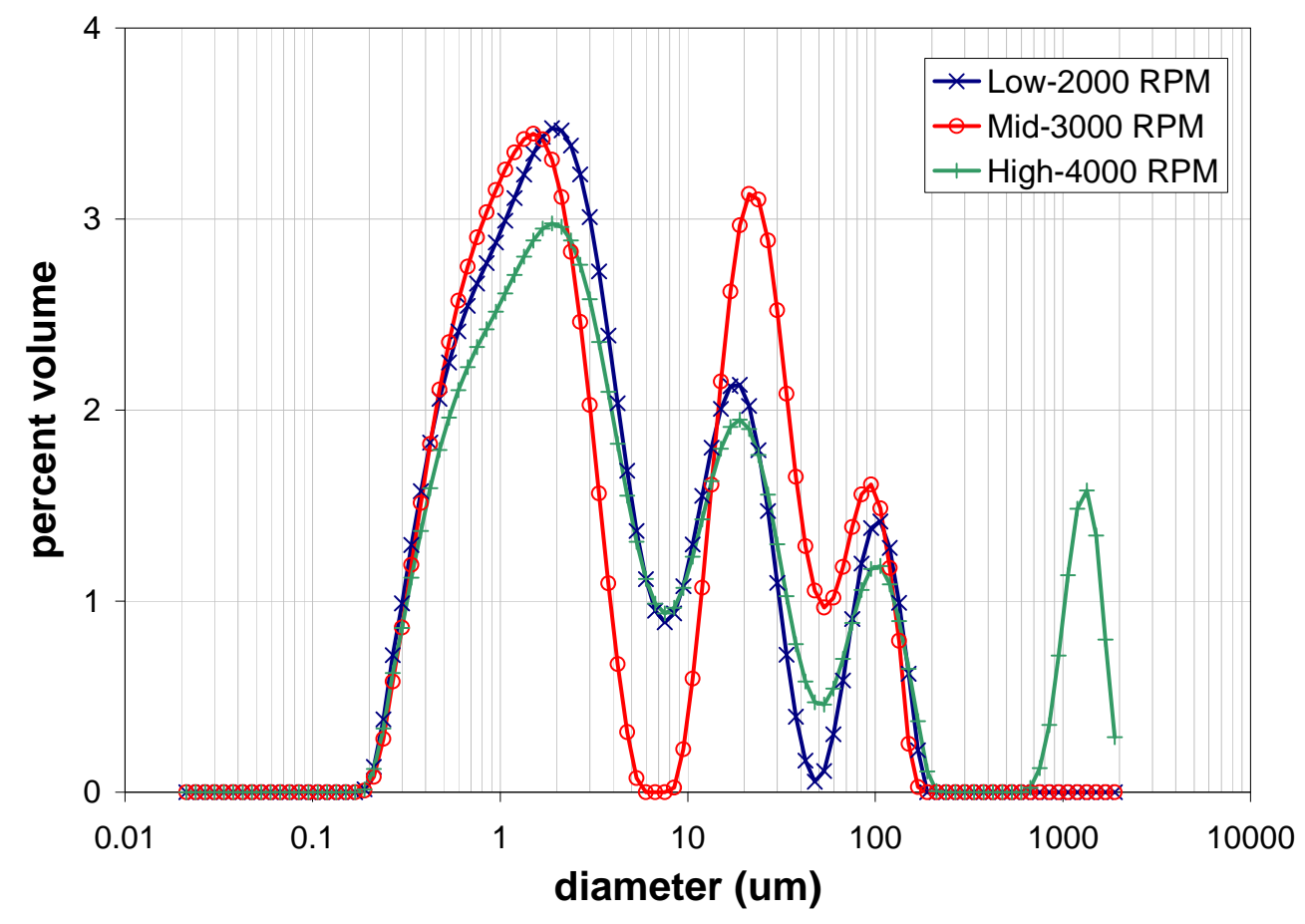

Figure 3.34. Post-Sonication Volume Distribution Result for the Caustic-Leached and Washed Group 3 Solids as a Function of Pump Speed

The influence of caustic leaching and washing on the Group 3 particles can be evaluated by comparing the PSD for the source material (i.e., that for initial characterization sample TI550-G3-S-WL-PSD) to the caustic-leached and washed Group 3 Parametric PSD sample (585-G3-CL-PSD). The PSD measurement for the primary initial characterization samples is used for this comparison.

Caution must be used when directly comparing PSDs, as these PSDs include both primary particles and particle aggregates. The structure of the aggregate fractions depends on 1) physical conditions such as the analyzer pump speed and sonication state and 2) chemical conditions such as particle interaction potentials and sample history. 
One expected outcome of caustic leaching is a decrease in particle size as a result of solid dissolution. However, removal of leachable solid species may reveal the size distribution of particles only minimally represented in the initial sample. In addition, changes in the dominant particle surface chemistry can yield increased particle agglomeration, which in turn results in increases in the apparent particle size. In addition to chemical effects, the mechanical force needed to pump the dispersion can also shear particle aggregates (as well as influence the volume of aggregates suspended). As such, the apparent PSD of a material may also vary with pump speed.

In an attempt to mitigate these issues, the process PSDs reported above will be compared by comparing PSDs at two measurement conditions. Comparisons will be made at measurement condition 1 (3000 RPM, before sonication) and 7 (3000 RPM, after sonication). Condition 7 allows for comparison of the same pump speed after agglomerate disruption.

Table 3.20 and Figure 3.35 and Figure 3.36 indicate the changes that occur to the Group 3 solids PSD as a result of the caustic-leaching and washing operations. Figure 3.35 shows that before sonication, caustic leaching and washing reduces the number of particles around $13 \mu \mathrm{m}$ while increasing those around $100 \mu \mathrm{m}$. Figure 3.36 shows that post-sonication, caustic leaching, and washing reduces the fraction contribution of particles around $9 \mu \mathrm{m}$ while increasing the fraction contribution of the 0.2 to $2 \mu \mathrm{m}$ and 11 to $170 \mu \mathrm{m}$. The reduction in the primary peak population (at 13 and $9 \mu \mathrm{m}$ before and after sonication, respectively) is likely a result of either dissolution of material off of the particle surface or agglomerate breakage. This reduction results in a relative increase in population for larger particles $(>30 \mu \mathrm{m})$ before sonication, and both smaller particles $(<2 \mu \mathrm{m})$ and larger particles $(>10 \mu \mathrm{m})$ post-sonication. The relative increase in smaller particles may be a result of the surface dissolution of the primary peak particles, or smaller particles may be relatively more abundant because the peak particles are reduced (i.e., less other species in solution). The relative increase of larger particles may possibly result from agglomeration due to particle flocculates that form in the caustic-leached solids as a result of changed surface chemistry. Such a particle agglomerate as seen by TEM is shown in Figure 3.42 (figure callout out of sequence). Alternatively, the large reduction in the solids mass achieved through gibbsite dissolution might reveal the presence of larger particles that were not evident in the initial sample because of their relatively low abundance.

Table 3.20. Cumulative Undersize Percentiles Showing the Influence of Caustic-Leaching and Washing on the PSD of Group 3 Solids at Measurement Condition 7-3000 RPM, Post-Sonication (3,000 RPM, 75\% Sonication)

\begin{tabular}{||l|c|c|c||}
\hline \multicolumn{1}{|c|}{ Sample } & $\begin{array}{c}\mathbf{d}(\mathbf{1 0}) \\
{[\boldsymbol{\mu m}]}\end{array}$ & $\begin{array}{c}\mathbf{d}(\mathbf{5 0}) \\
{[\boldsymbol{\mu m}]}\end{array}$ & $\begin{array}{c}\mathbf{d}(\mathbf{9 0}) \\
{[\boldsymbol{\mu m}]}\end{array}$ \\
\hline Group 3 Initial Characterization (TI550-G3-S-WL-PSD-1) & 1.1 & 6.0 & 15 \\
\hline Group 3 Caustic-Leached and Washed (TI585-G3-CL-PSD) & 0.54 & 2.4 & 60 \\
\hline
\end{tabular}




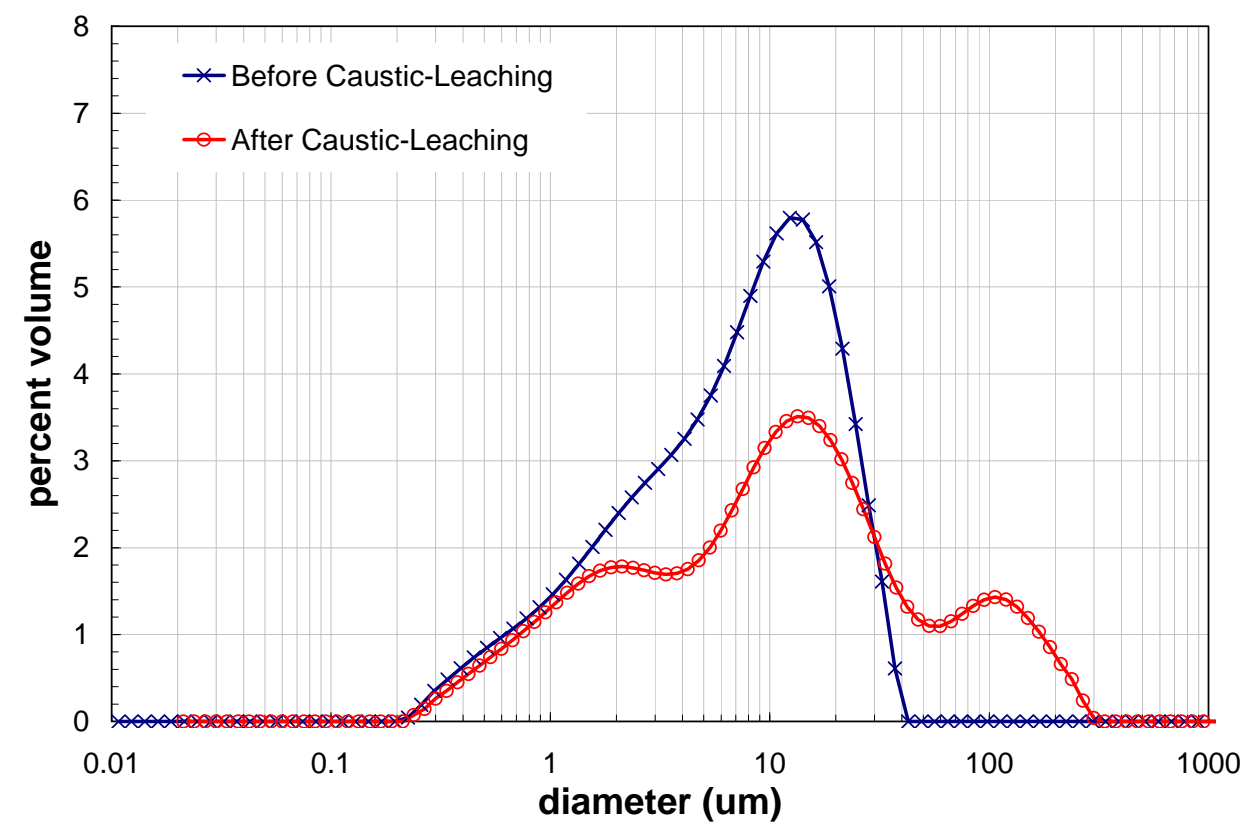

Figure 3.35. Influence of Caustic-Leaching and Washing on Group 3 (PUREX Cladding Waste Sludge) Waste Solids PSD. All PSDs were taken at measurement condition 1 (3000 RPM, Before Sonication).

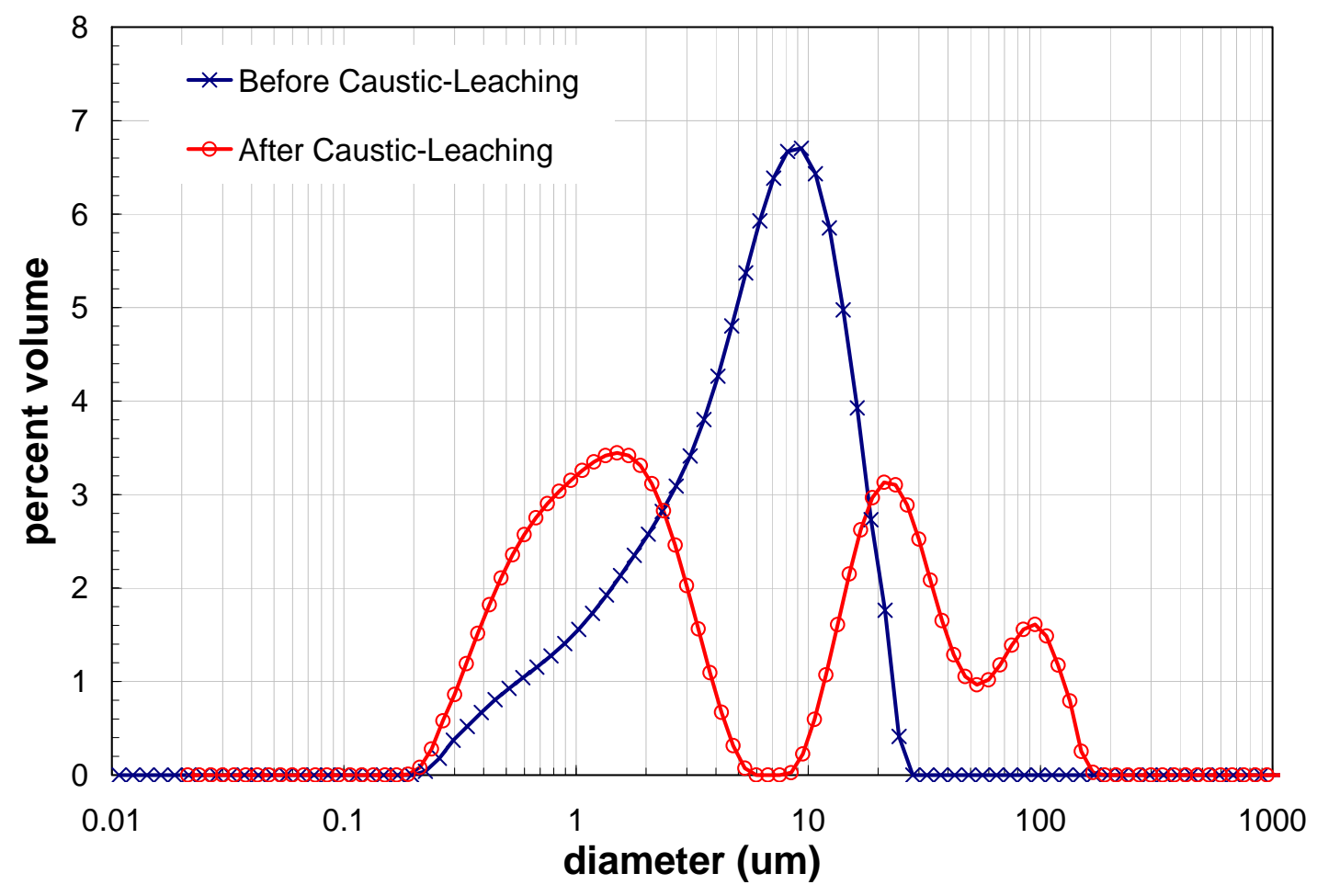

Figure 3.36. Influence of Caustic-Leaching and Washing on Group 3 (PUREX Cladding Waste Sludge) Waste Solids PSD. All PSDs were taken at measurement condition 7 (3000 RPM, After Sonication). 


\subsubsection{Crystal Form and Habit}

The following sections summarize the mineral-phase evaluation of the leached and washed solids.

\subsection{XRD}

The XRD pattern of the leached and washed solids (sample ID 585-G3-CL-XRD) is provided in Figure 3.37a; the background-subtracted XRD pattern with stick-figure phase identification is shown in Figure 3.37b.

Rutile, $\mathrm{TiO}_{2}$, was used as an internal standard for 2-theta calibration. Identification was done on 2-theta calibrated data. This material is predominantly amorphous as indicated by the very broad peak system from about 12 to 37 degrees 2-theta. Sodium uranium oxide hydrate $\left[\mathrm{Na}_{2} \mathrm{U}_{2} \mathrm{O}_{7} \cdot 6 \mathrm{H}_{2} \mathrm{O}\right]$ was a good fit to all peaks but one in the pattern. The peak at $27.5^{\circ} 2$-theta has a significant intensity mismatch. Clarkeite $\left[\mathrm{Na}\left(\mathrm{UO}_{2}\right) \mathrm{O}(\mathrm{OH})\right.$, crystal density $6.744 \mathrm{~g} / \mathrm{cm}^{3}, \mathrm{JADE}$ Version 8.0$]$ is a good fit to the data and has a small crystallite size. Hematite $\left(\mathrm{Fe}_{2} \mathrm{O}_{3}\right.$, crystal density $5.269 \mathrm{~g} / \mathrm{cm}^{3}$, JADE Version 8.0$)$ is an excellent fit to the data. Sodium uranium oxide $\left(\mathrm{Na}_{2} \mathrm{U}_{2} \mathrm{O}_{7}\right.$, crystal density $6.554 \mathrm{~g} / \mathrm{cm}^{3}, \mathrm{JADE}$ Version 8.0$)$ is a good fit to the data. 
(a)

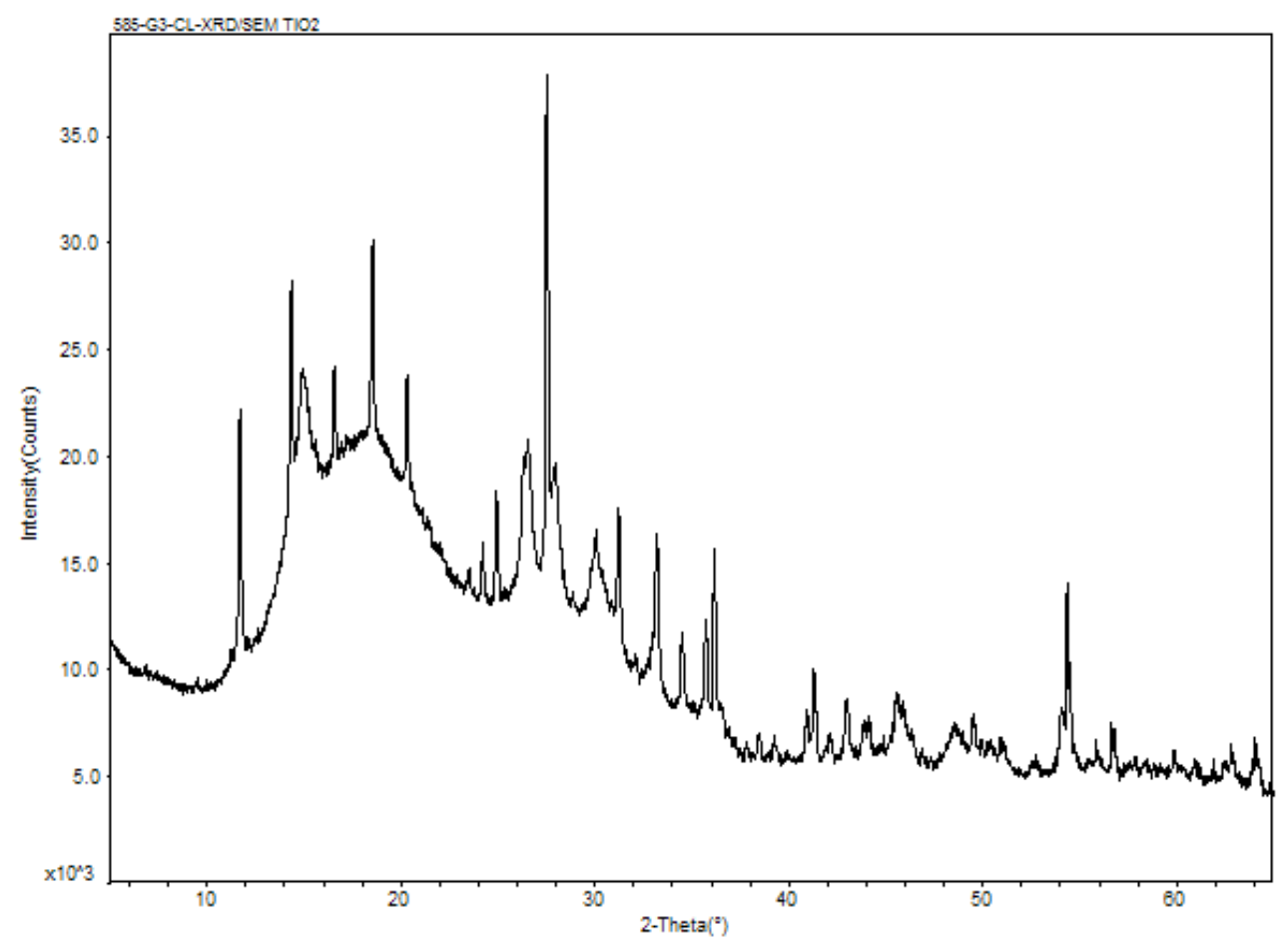

(b)

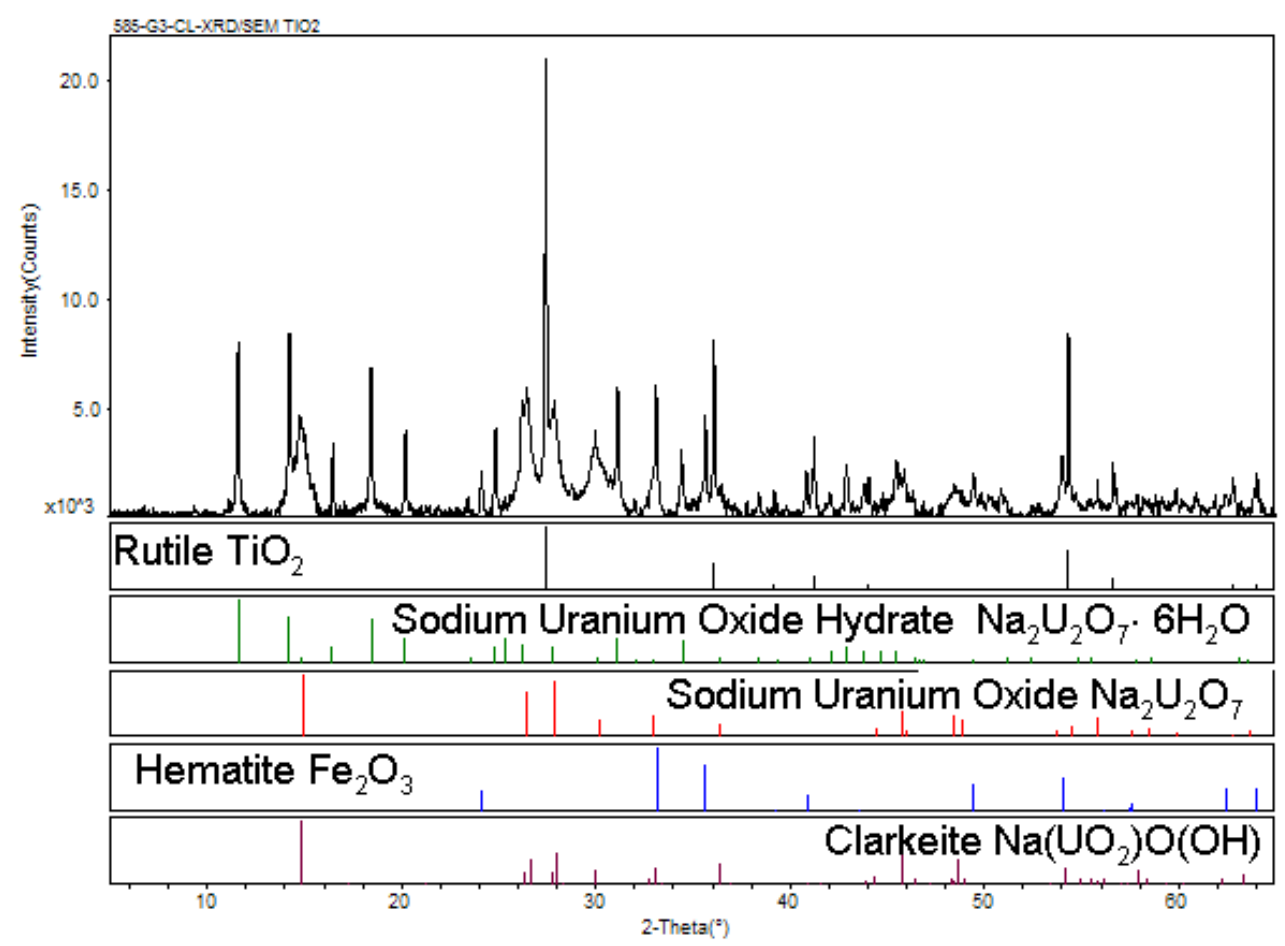

Figure 3.37. XRD Pattern of Caustic-Leached Group 3 CWP Sludge with Rutile $\left(\mathrm{TiO}_{2}\right)$ Internal Standard (a) Raw Data and (b) Background-Subtracted with Stick-Figure Peak Identification 


\subsection{SEM and TEM}

Several SEM images are shown in Figure 3.38. Particles seen in these images are typically on the order of $<1$ to $10 \mu \mathrm{m}$, as well as agglomerates (Figure 3.38c) that are larger than $10 \mu \mathrm{m}$, which is consistent with the PSD data reported above.

(a)

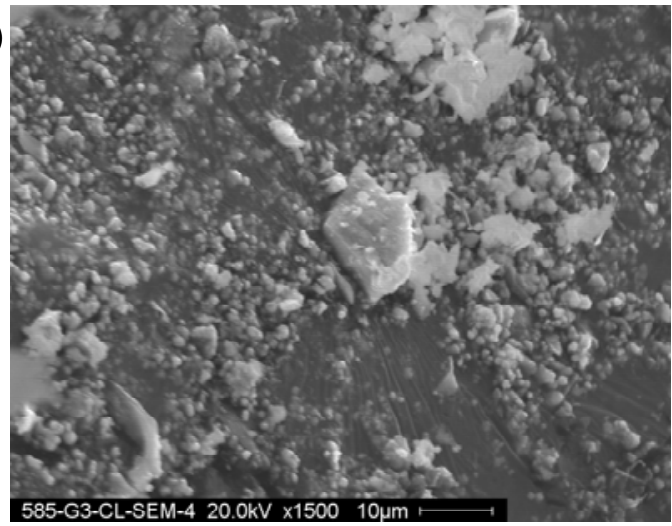

(c)

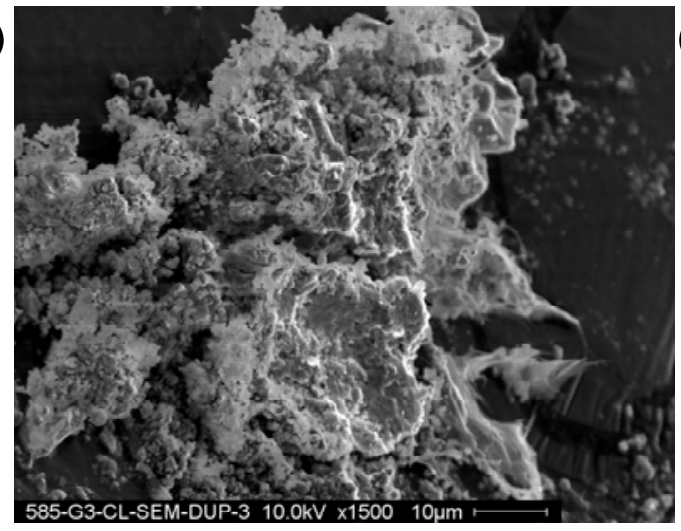

(b)

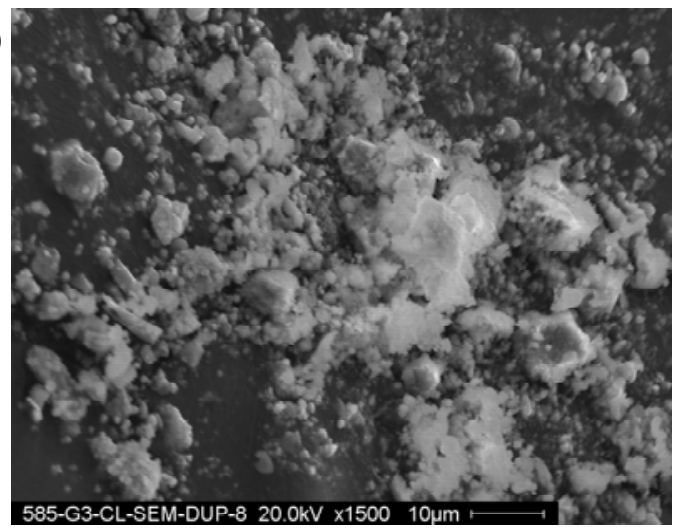

(d)

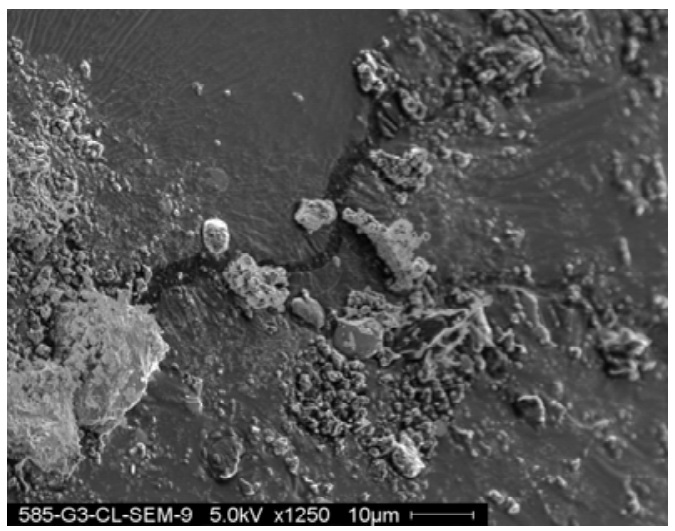

Figure 3.38. SEM Images of Group 3 CWP Sludge Caustic Leached and Washed Solids (a) $20 \mathrm{kV}$, $1500 \times$; (b) $20 \mathrm{kV}, 1500 \times$; (c) $10 \mathrm{kV}, 1500 \times$; (d) $5 \mathrm{kV}, 1250 \times$

Figure 3.39 and Figure 3.40 each show an SEM image along with EDS spectra of three different particles for each. The elemental analysis shows a large amount of oxygen and carbon, which is an artifact of the sample preparation (carbon is sputtered onto the sample to eliminate problems with charging). If this is removed, and the other constituents are normalized, the weight percentages shown in Table 3.21 for each analysis are obtained. It is interesting to note that there is a great deal of variability between particles. The particle at spot 1 in Figure 3.39 consists mainly of $\mathrm{Na}$ and $\mathrm{U}$ as well as a small amount of $\mathrm{Ca}$. This is in agreement with either of the uranium compounds seen by XRD (sodium uranium oxide or clarkeite). The particle at spot 4 in Figure 3.40 also consists mainly of $\mathrm{Na}$ and $\mathrm{U}$.

The remaining four particles that were examined by EDS and shown in these two figures were composed of several different elements. Two have very similar compositions to one another. The particles at spots 3 and 8 in Figure 3.39 have high concentrations of $\mathrm{Na}$ (23 to 33\%), U (17 to 33\%), and Fe (14 to 25\%) as 
well as smaller concentrations $(<10 \%)$ of several other analytes. The particles at spots 1 and 3 in Figure 3.40 have larger amounts of $\mathrm{Al}(17$ and 30\%) than were seen in other particles.
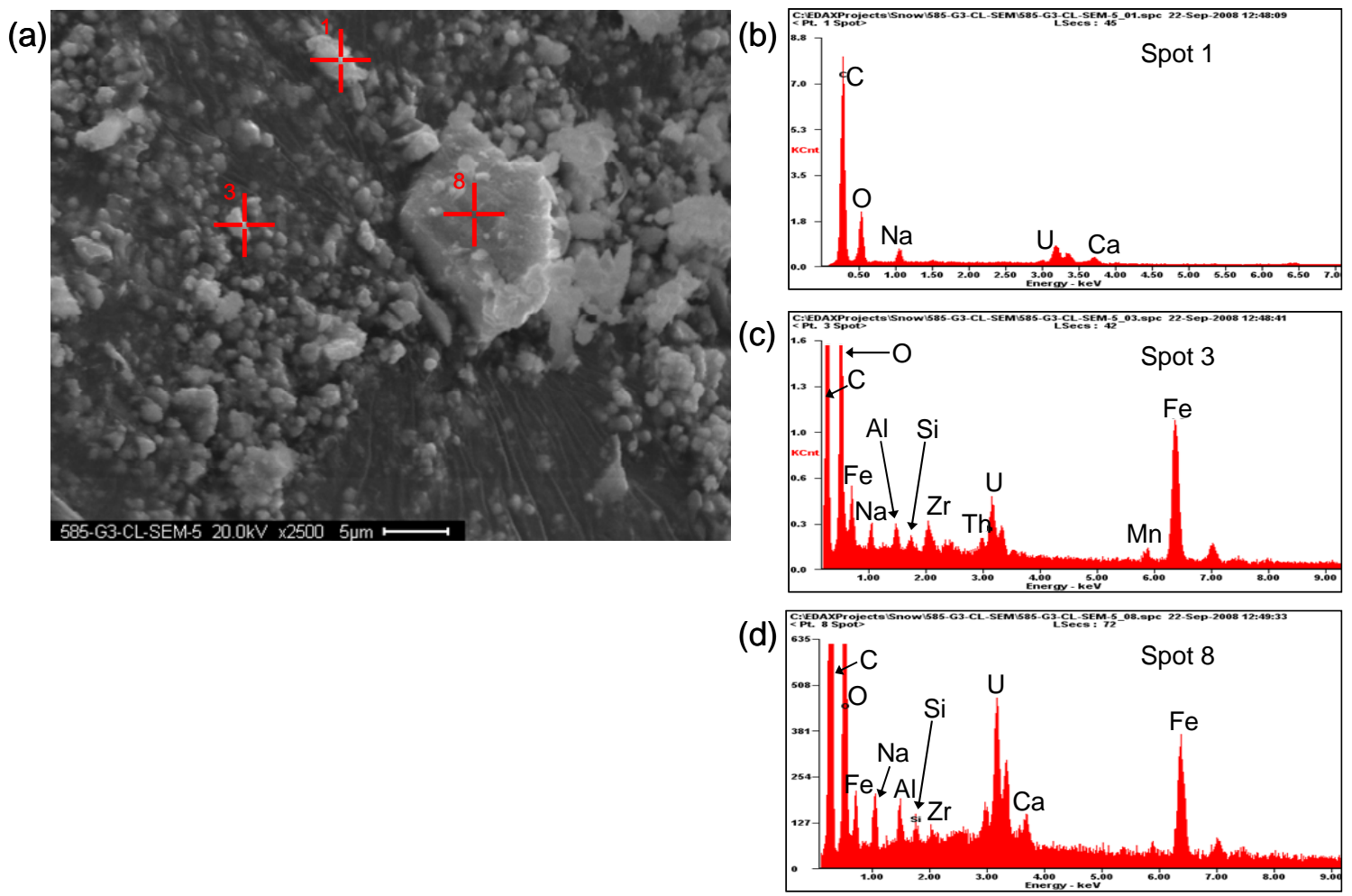

Figure 3.39. SEM Image of Group 3 CWP Sludge Caustic Leached and Washed Solids with EDS Spectra (a) SEM Image; (b) EDS Spectra of Spot 1; (c) EDS Spectra of Spot 3; (d) EDS Spectra of Spot 8 
(a)

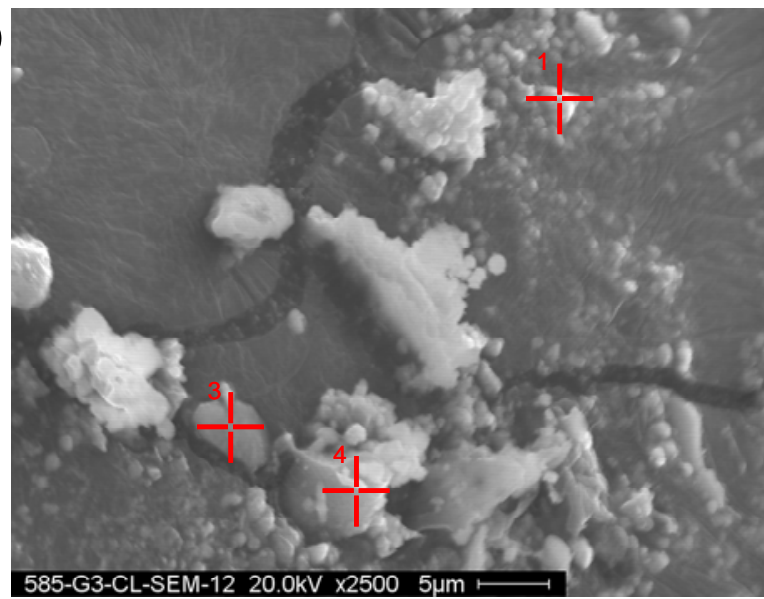

(b)

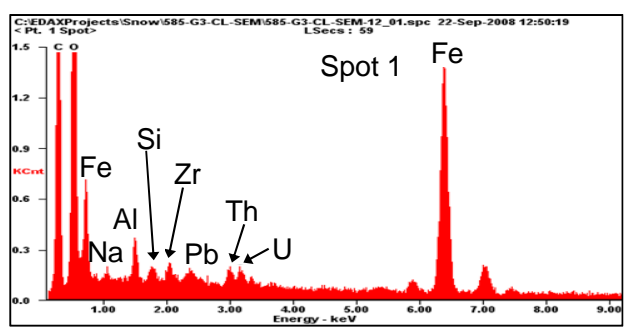

(c)

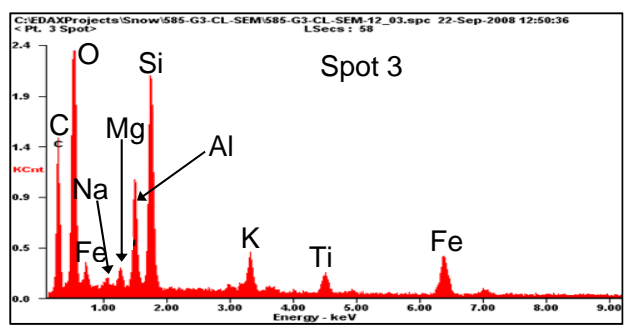

(d)

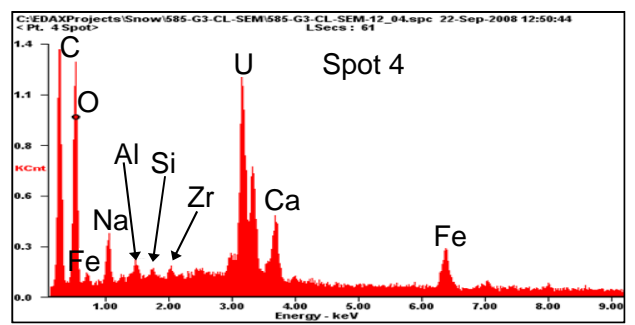

Figure 3.40. SEM Image of Group 3 CWP Sludge Caustic Leached and Washed Solids with EDS Spectra (a) SEM Image; (b) EDS Spectra of Spot 1; (c) EDS Spectra of Spot 3; (d) EDS Spectra of Spot 4

Table 3.21. Normalized Weight Percents for Various Analytes Found by EDS of SEM Images for Figure 3.39 and Figure 3.40

\begin{tabular}{|c|c|c|c|c|c|c|}
\hline & \multicolumn{7}{|c|}{ Normalized Weight Percent } \\
\cline { 2 - 7 } Element & $\begin{array}{c}\text { Fig 3.39 } \\
\text { Spot 1 }\end{array}$ & $\begin{array}{c}\text { Fig 3.39 } \\
\text { Spot 3 }\end{array}$ & $\begin{array}{c}\text { Fig 3.39 } \\
\text { Spot 8 }\end{array}$ & $\begin{array}{c}\text { Fig 3.40 } \\
\text { Spot 1 }\end{array}$ & $\begin{array}{c}\text { Fig 3.40 } \\
\text { Spot 3 }\end{array}$ & $\begin{array}{c}\text { Fig 3.40 } \\
\text { Spot 4 }\end{array}$ \\
\hline $\mathrm{Na}$ & 63.20 & 23.31 & 33.39 & 11.63 & 5.21 & 27.52 \\
\hline $\mathrm{Al}$ & 0 & 9.80 & 9.49 & 16.84 & 30.07 & 4.03 \\
\hline $\mathrm{Si}$ & 0 & 3.89 & 3.28 & 4.17 & 47.13 & 2.09 \\
\hline $\mathrm{Zr}$ & 0 & 13.68 & 4.56 & 9.37 & 0 & 3.80 \\
\hline $\mathrm{Bi}$ & 0 & 0 & 0 & 0.52 & 0 & 0 \\
\hline $\mathrm{Th}$ & 0 & 5.07 & 0 & 6.42 & 0 & 0 \\
\hline $\mathrm{U}$ & 33.43 & 17.40 & 33.21 & 3.82 & 0 & 51.78 \\
\hline $\mathrm{Mn}$ & 0 & 1.69 & 0 & 0 & 0 & 0 \\
\hline $\mathrm{Fe}$ & 0 & 25.17 & 14.05 & 39.24 & 5.30 & 5.50 \\
\hline $\mathrm{Ca}$ & 3.37 & 0 & 2.01 & 0 & 0 & 5.27 \\
\hline $\mathrm{Pb}$ & 0 & 0 & 0 & 7.99 & 0 & 0 \\
\hline $\mathrm{Mg}$ & 0 & 0 & 0 & 0 & 6.91 & 0 \\
\hline $\mathrm{K}$ & 0 & 0 & 0 & 0 & 3.59 & 0 \\
\hline $\mathrm{Ti}$ & 0 & 0 & 0 & 0 & 1.80 & 0 \\
\hline
\end{tabular}


The TEM sample grid contained very few particles, and several samples were examined to determine if the results were representative of the overall sample. Several different types of agglomerate particles were observed. In Figure 3.41, the analysis of a metallic particle is shown. Nickel alloys have been observed in the tank waste sludge samples. The TEM image of the material was consistent with a metal as the material was highly deformed. The EDS analysis using a thin-window detector demonstrates that oxygen is not present. Electron diffraction from this phase is given in Table 3.22, showing that the observed d-spacing matches that of a nickel-iron phase. The ring diffraction pattern indicates a fine grain structure rather than a single metallic grain.

(a)

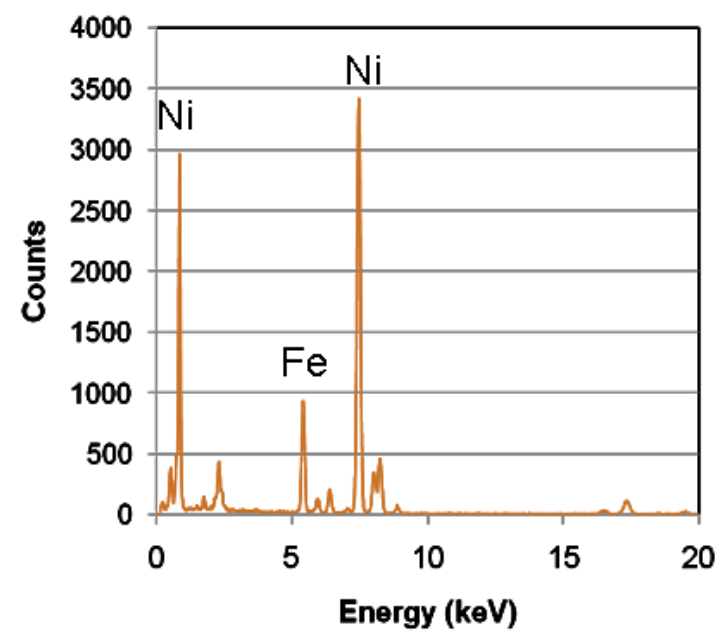

(b)

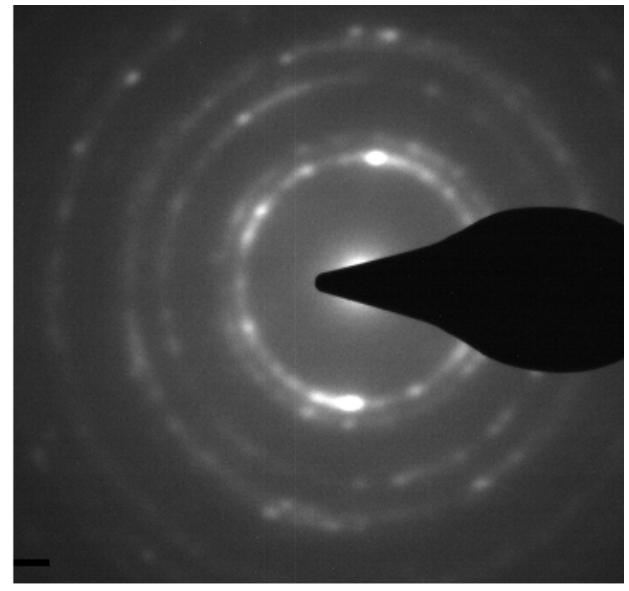

Figure 3.41. (a) TEM-EDS Analysis and (b) Selected Area Electron Diffraction Pattern of Nickel Alloy Particle

Table 3.22. EDS Analysis of Nickel-Iron Phase Shown in Figure 3.41

\begin{tabular}{|c|c|c|}
\hline $1 / d_{\text {(obs) }}$ & d-spacing (obs) & Ni-Fe (lit) \\
\hline 0.484 & 2.068 & 2.08 \\
\hline 0.568 & 1.761 & 1.80 \\
\hline 0.790 & 1.266 & 1.27 \\
\hline 0.967 & 1.034 & 1.04 \\
\hline 1.136 & 0.880 & 0.90 \\
\hline 1.580 & 0.633 & 0.64 \\
\hline 1.824 & 0.548 & -- \\
\hline 1.953 & 0.512 & 0.52 \\
\hline 2.281 & 0.438 & 0.45 \\
\hline 2.414 & 0.414 & 0.54 \\
\hline 2.974 & 0.336 & -- \\
\hline
\end{tabular}

In Figure 3.42, a more typical agglomerate is shown. The agglomerate contains thin wispy structures and elongated particles. An analysis of these phases revealed uranium-rich phases. Although XRD was able to identify $\mathrm{U}(\mathrm{VI})$ compounds such as clarkeite and sodium uranium oxide hydrate, TEM was able to further identify $\mathrm{U}_{3} \mathrm{O}_{8}$ in the sample. In Figure 3.43, analysis of an opaque particle where it was not 
possible to distinguish individual phases indicated iron and uranium as the major components. The EDS analysis of this agglomerate is shown in Table 3.23.

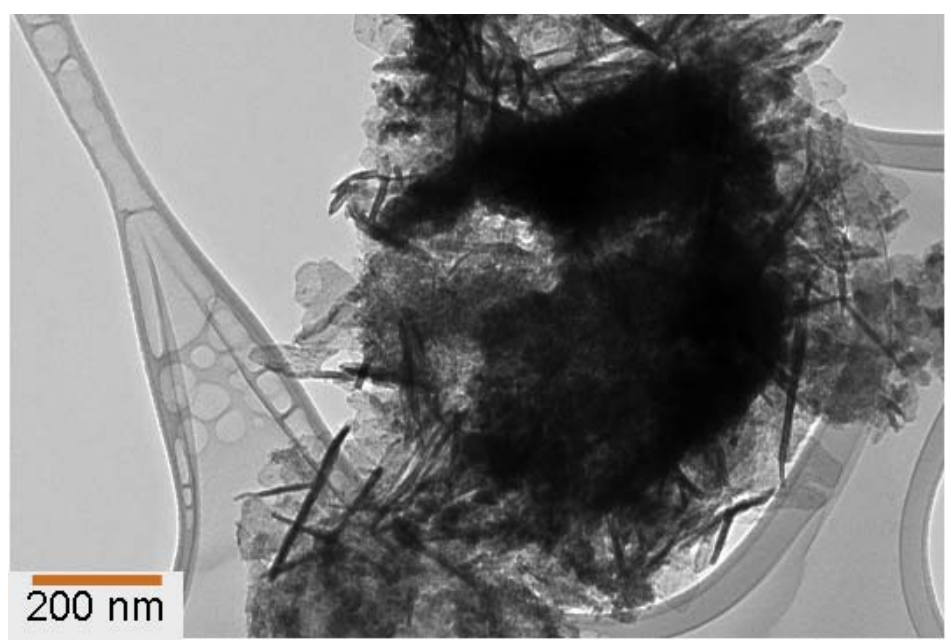

Figure 3.42. TEM Image of a Typical Particle Agglomerate Found in the Caustic-Leached Sample

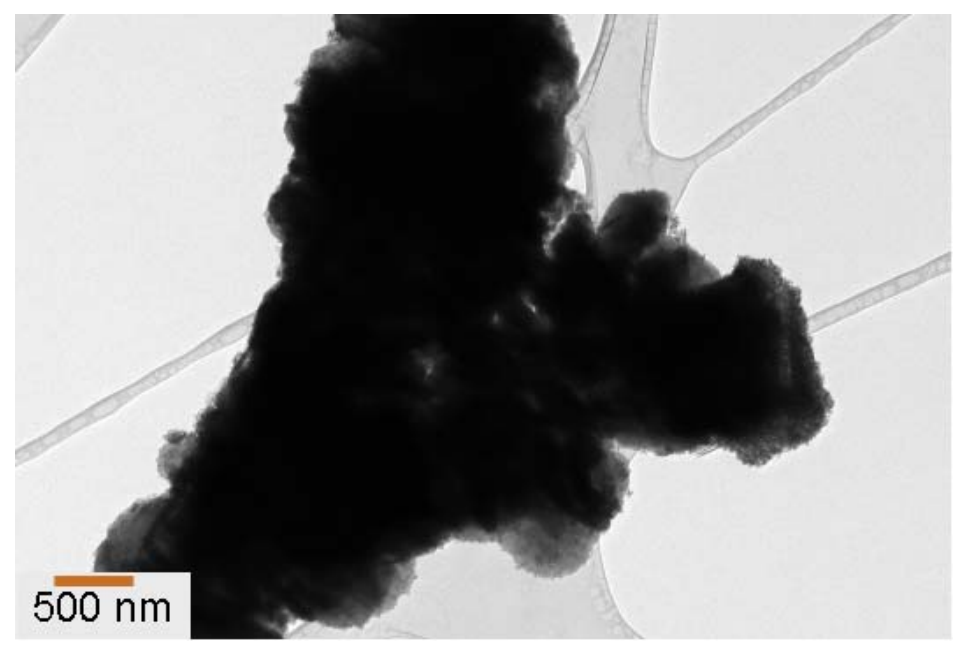

Figure 3.43. TEM Image of a Large Electron Opaque Iron/Uranium Particle 
Table 3.23. EDS Analysis of Particle Agglomerate Shown in Figure 3.43

\begin{tabular}{||c|c||}
\hline Element & Weight Percent \\
\hline $\mathrm{Mg}(\mathrm{K})$ & 1.2 \\
\hline $\mathrm{Al}(\mathrm{K})$ & 4.4 \\
\hline $\mathrm{Si}(\mathrm{K})$ & 1.8 \\
\hline $\mathrm{P}(\mathrm{K})$ & 0.8 \\
\hline $\mathrm{Mn}(\mathrm{K})$ & 1.5 \\
\hline $\mathrm{Fe}(\mathrm{K})$ & 30.0 \\
\hline $\mathrm{Ni}(\mathrm{K})$ & 14.7 \\
\hline $\mathrm{Zn}(\mathrm{K})$ & 1.5 \\
\hline $\mathrm{Pb}(\mathrm{L})$ & 3.0 \\
\hline $\mathrm{Bi}(\mathrm{L})$ & 2.6 \\
\hline $\mathrm{U}(\mathrm{L})$ & 38.4 \\
\hline
\end{tabular}

In Figure 3.44, the analysis of another almost opaque particle indicated slightly higher concentrations of uranium. The electron diffraction pattern in Figure $3.44 \mathrm{~b}$ shows several phases as a single crystal pattern can be made out along with a ring pattern. The diffraction pattern of the uranium phase in Figure 3.45, where a small probe was used to isolate the uranium phase, was not consistent with any U(VI) phase such as clarkeite. In Table 3.24, the electron diffraction spacings are compared to $\mathrm{UO}_{2}$ and $\mathrm{U}_{3} \mathrm{O}_{8}$. A small EDS probe shows that the particle is an almost pure uranium phase. The iron and nickel signals are undoubtedly coming from neighboring regions. The overall diffraction pattern was more consistent with $\alpha-\mathrm{U}_{3} \mathrm{O}_{8}$.

(a)

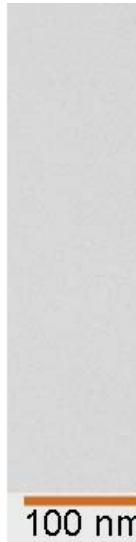

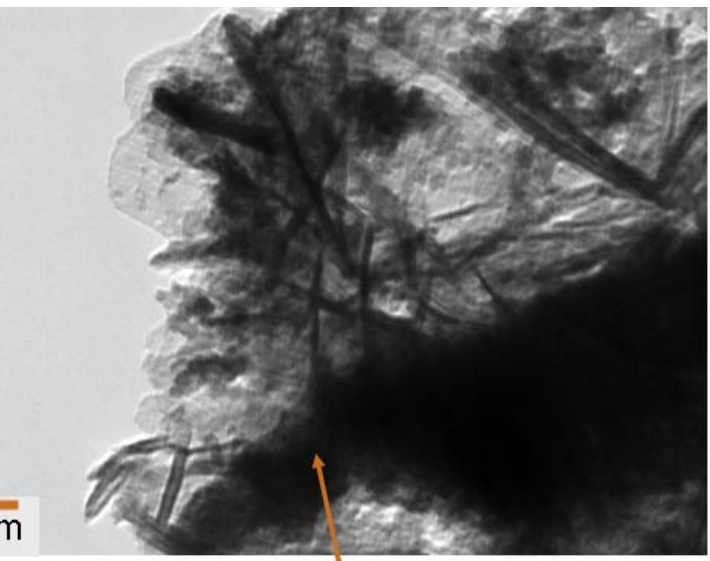

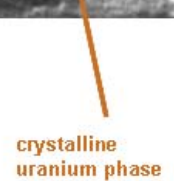

(c) (b)

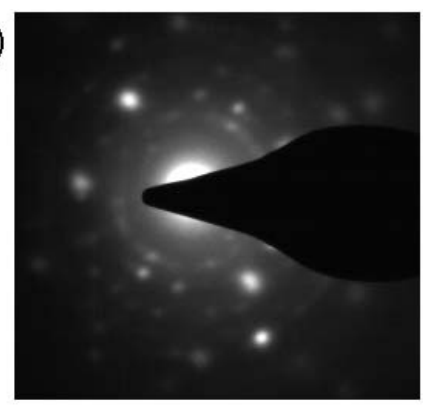

EDS003

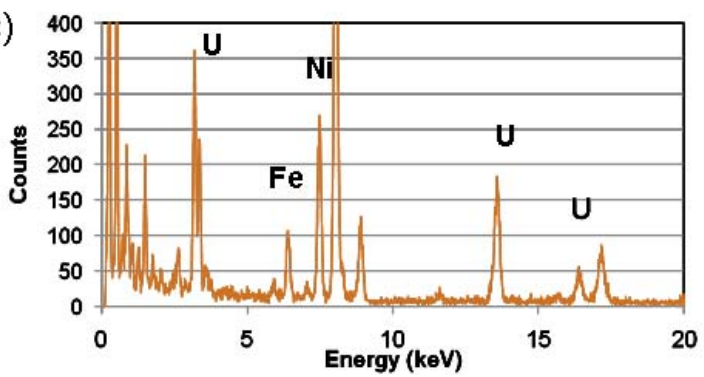

Figure 3.44. (a) TEM Image, (b) Selected Area Diffraction, and (c) EDS Analysis of an Iron-Rich Phase in the Caustic Leached Group 3 Sample 
Table 3.24. Selected Area Electron Diffraction Results from a Uranium Phase in the Caustic Leached Group 3 Sample

\begin{tabular}{|c|c|c|c|}
\hline $\begin{array}{c}\text { d-spacing } \mathbf{(} \mathbf{\AA}) \\
\text { (observed) }\end{array}$ & $\begin{array}{c}\mathbf{U}_{\mathbf{3}} \mathbf{O}_{\mathbf{8}} \\
\text { (PDF 31-1425) }^{\text {(PDF 5-0550) }}\end{array}$ & $\begin{array}{c}\mathbf{U O}_{\mathbf{2}} \\
\text { (PDarkeite (Finch }^{\text {(a) Ewing 1997) }}{ }^{\text {(a) }}\end{array}$ \\
\hline 4.292 & 4.141 & -- & -- \\
\hline 3.049 & 2.95 & 3.158 & -- \\
\hline 2.222 & 2.22 & -- & -- \\
\hline 2.174 & 2.07 & -- & -- \\
\hline 1.842 & 1.77 & 1.9339 & 1.85 \\
\hline 1.403 & 1.42 & -- & -- \\
\hline 1.387 & 1.38 & -- & 1.39 \\
\hline 1.233 & 1.23 & 1.2231 & 1.23 \\
\hline 1.074 & 1.07 & 1.0519 & 1.06 \\
\hline 0.936 & 0.939 & 0.924 & 0.937 \\
\hline 0.836 & 0.834 & 0.834 & -- \\
\hline
\end{tabular}

(a) Many major reflections from clarkeite could not be matched to the observed pattern.

(a)

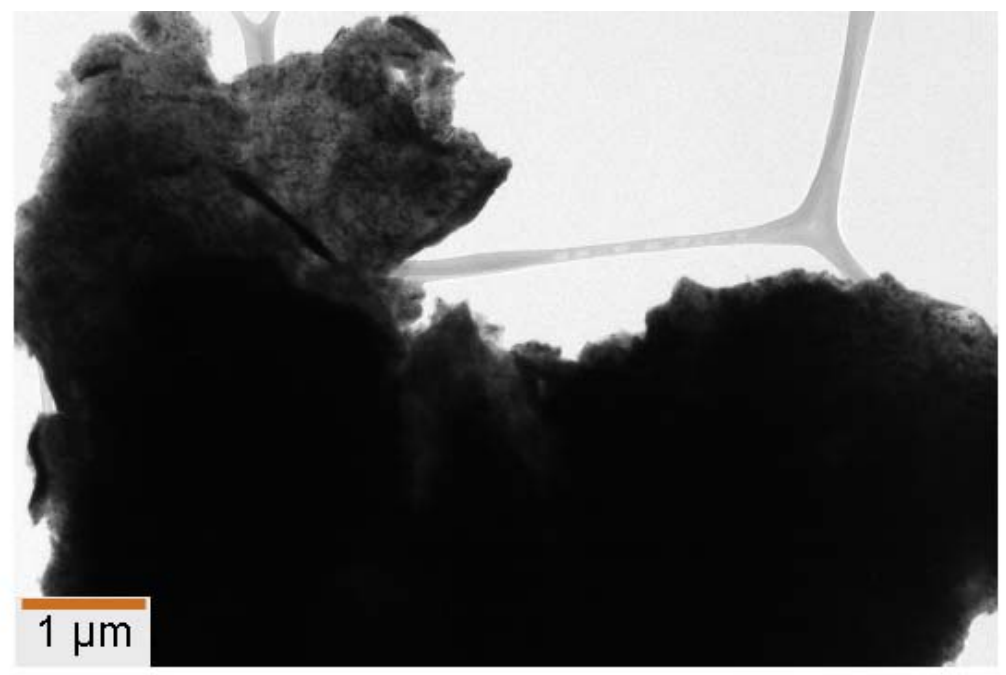

(b)
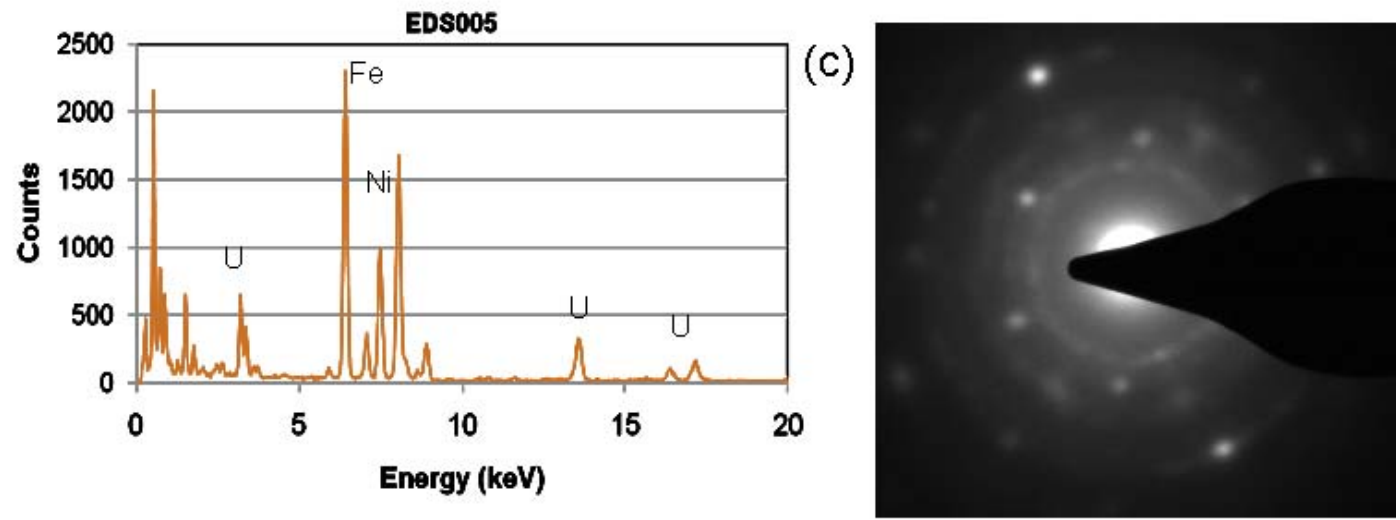

Figure 3.45. (a) TEM Image, (b) EDS Analysis, and (c) Selected Area Diffraction of Uranium Phase in the Caustic Leached Group 3 Sample 


\subsection{Group 4 Characterization and Leaching}

This section reports and discusses the characterization activities, analytical results, parametric leach testing, and leaching results for the Group 4 REDOX Cladding Waste (CWR) sludge slurry composite.

\subsection{Group 4 Characterization Experimental}

This section reports and discusses the initial characterization results for the Group 4 CWR sludge slurry composite, supernatant, and washed solids. Table 4.1 lists the Group 4 characterization samples that were taken during the homogenization and sample-splitting activities described in Section 2. Figure 4.1 ${ }^{\text {(a) }}$ summarizes the sample processing performed to characterize the Group 4 sample.

The supernatant results represent the equilibrated aqueous phase in contact with the solids; the solids characterization results were obtained after washing with $0.01 \mathrm{M} \mathrm{NaOH}$. Solids washing was considered crucial to better understand the nature of the solids, free of complications associated with supernatant entrainment.

Table 4.1. Group 4 Characterization Samples

\begin{tabular}{|l|l|c|c||}
\hline Sample ID & Characterization Activity & $\begin{array}{c}\text { Slurry } \\
\text { Volume, mL }\end{array}$ & $\begin{array}{c}\text { Slurry } \\
\text { Mass, g }\end{array}$ \\
\hline TI514-G4-AR-S1 & Physical Properties & 10.2 & 13.938 \\
\hline TI514-G4-AR-S2 & Physical Properties & 9.9 & 12.760 \\
\hline TI514-G4-AR-S3 & Physical Properties & 10.0 & 13.429 \\
\hline TI514-G4-AR-C1 & $\begin{array}{l}\text { Chemical characterization } \\
\text { and crystal habit }\end{array}$ & 13.75 & 18.874 \\
\hline TI514-G4-AR-C2 & $\begin{array}{l}\text { Chemical characterization } \\
\text { and crystal habit }\end{array}$ & 12.5 & 16.378 \\
\hline TI514-G4-AR-RH1 & Rheology & 88 & 116.283 \\
\hline
\end{tabular}

(a) The physical-property testing was conducted according to TI-RPP-WTP-514, Group 4 - REDOX Cladding Sludge Hanford Tank Waste Sample Compositing, Homogenization, and Sub-Division, R. Swoboda, 10/3/07; the solids washing and sample handling was conducted according to TI-RPP-WTP-547, Initial Characterization of Group 4 Tank Waste: REDOX Cladding Waste Sludge, S Fiskum, 9/20/07. 


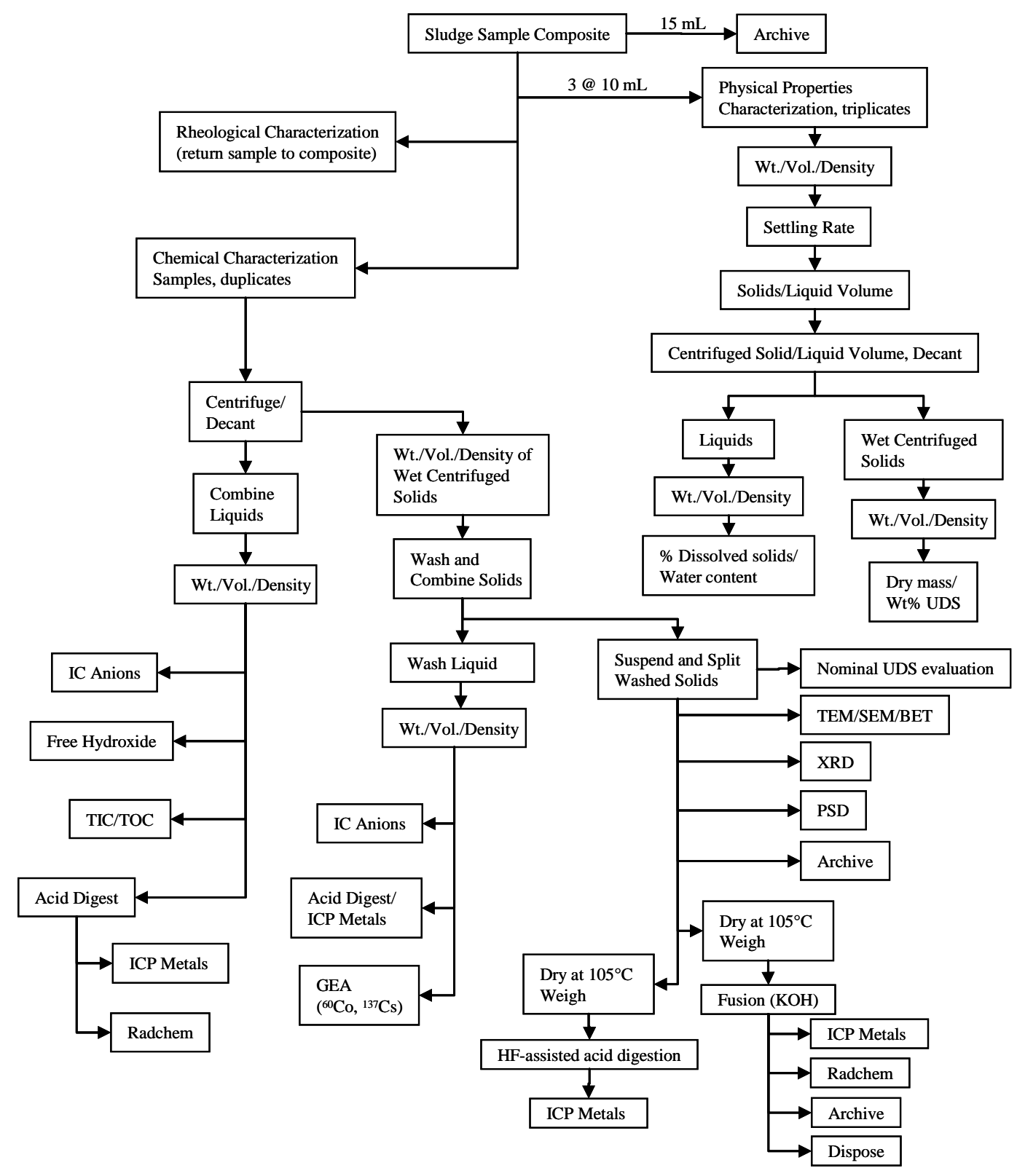

Figure 4.1. Composite Group 4 Analysis Scheme

\subsection{Characterization Results}

\subsubsection{Physical Properties of the Composite Group 4 CWR Slurry}

All physical characterization methods discussed here are described in Appendices B and C. Figure 4.2 shows the settling curves of the triplicate samples of the Group 4 CWR composited solids. Results are shown in two ways: 1 ) volume percent settled solids as a function of time and 2) height of settled solids as a function of time. As with the Group 3 CWP composite, settling was essentially complete after $1 \mathrm{hr}$. 
a)

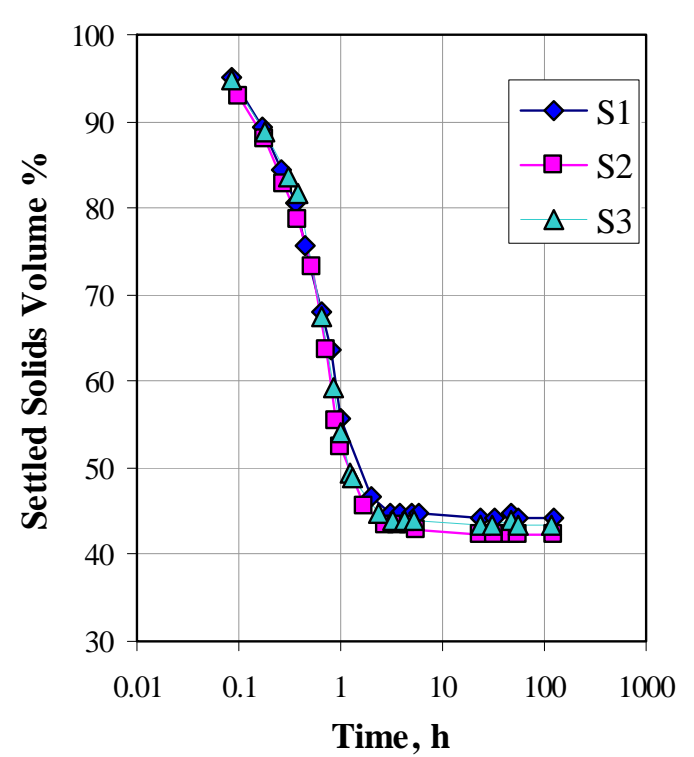

b)

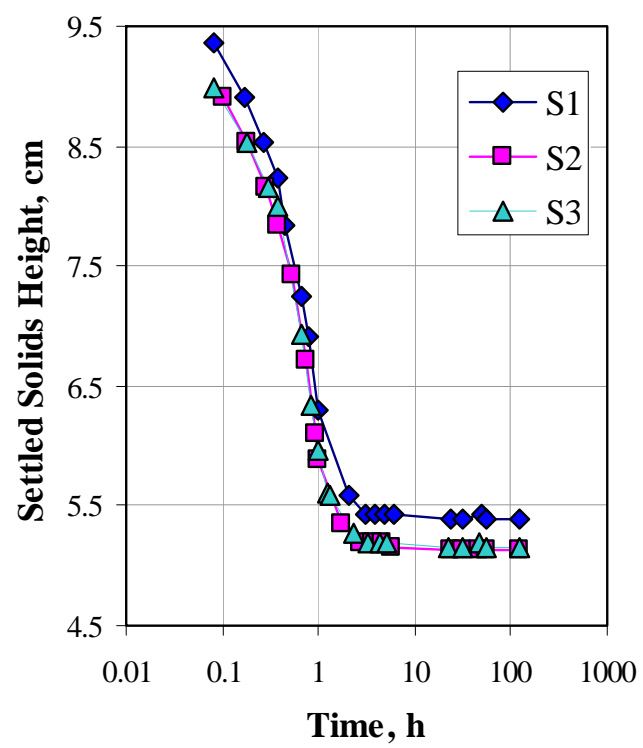

Figure 4.2. Group 4 CWR Settling Test

Physical-property results for the Group 4 CWR sludge are summarized in Table 4.2 along with the propagated 1- $\sigma$ errors, averages, and relative standard deviations. Good precision was obtained for the sample set. Density and vol\% values associated with this testing were generally limited to 2 significant figures because of the small sample size $(<10 \mathrm{~mL})$ and the volume measure uncertainty in the graduated centrifuge tubes and cylinders $(\sim 0.2 \mathrm{~mL})$; the third significant figure is shown for indication only. The supernatant density was determined to be $1.16 \pm 0.002 \mathrm{~g} / \mathrm{mL}\left(26^{\circ} \mathrm{C}\right)$ as part of the chemical analysis processing. 
Table 4.2. Physical Property Measurements of Homogenized Group 4 CWR Slurry

\begin{tabular}{|c|c|c|c|c|c|c|}
\hline Description & AR-S1 & AR-S2 & AR-S3 & $\begin{array}{l}\text { Nominal } \\
1 \sigma \text { error }\end{array}$ & Avg. & $\operatorname{RSD}^{(a)}(\%)$ \\
\hline \multicolumn{7}{|c|}{ Bulk Sample } \\
\hline Sample Size (mL) & 10.2 & 10.0 & 9.8 & 0.2 & NA & NA \\
\hline Sample Size (g) & 13.775 & 13.176 & 13.122 & 0.003 & NA & NA \\
\hline Density (g/mL) & 1.35 & 1.34 & $1.35^{(\mathrm{b})}$ & 0.027 & 1.35 & 0.4 \\
\hline Total Solids (wt\%) & 41.2 & 43.1 & 42.9 & 0.027 & 42.4 & 1.1 \\
\hline Total Undissolved Solids (wt\%) & 31.2 & 29.1 & 28.9 & 0.023 & 29.7 & 1.3 \\
\hline Settling Rate $(\mathrm{cm} / \mathrm{h})$ & 3.25 & 3.27 & 3.33 & 3.28 & NA & 1.3 \\
\hline \multicolumn{7}{|c|}{ Settled Solids } \\
\hline Density $(\mathrm{g} / \mathrm{mL})^{(\mathrm{b})}$ & 1.42 & 1.43 & 1.47 & 0.068 & 1.44 & 2.3 \\
\hline $\mathrm{Vol}^{(\mathrm{b})}$ & 44.6 & 42.9 & 42.9 & 2.2 & 43.4 & 1.0 \\
\hline $\mathrm{Wt} \%$ & 47.3 & 46.1 & 46.6 & 2.9 & 46.7 & 0.6 \\
\hline Total Undissolved Solids (wt\%) & 65.9 & 63.2 & 60.6 & 3.9 & 63.2 & 2.7 \\
\hline \multicolumn{7}{|c|}{ Wet Centrifuged Solids } \\
\hline Density $(\mathrm{g} / \mathrm{mL})^{(\mathrm{b})}$ & 1.75 & 1.94 & 1.70 & 0.10 & 1.80 & 12 \\
\hline $\mathrm{Vol}^{(\mathrm{b})}$ & 37.3 & 32.7 & 37.1 & 2.1 & 35.7 & 2.6 \\
\hline $\mathrm{Wt} \%$ & 48.5 & 47.3 & 47.0 & 0.023 & 47.6 & 0.8 \\
\hline Total Undissolved Solids (wt\%) & 77.4 & 79.9 & 68.9 & 5.7 & 75.4 & 5.7 \\
\hline Total Solids (wt\%) & 69.2 & 68.8 & 68.7 & 0.040 & 68.9 & 0.2 \\
\hline \multicolumn{7}{|c|}{ Supernatant } \\
\hline Density $(\mathrm{g} / \mathrm{mL})^{(\mathrm{b})}$ & 1.28 & 1.27 & 1.25 & 0.024 & 1.27 & 1.7 \\
\hline Total Dissolved Solids (wt\%) & 13.6 & 18.8 & 19.0 & 0.040 & 17.1 & 3.1 \\
\hline Water Content (g/g) & 0.864 & 0.812 & 0.810 & 0.001 & 0.829 & 3.1 \\
\hline
\end{tabular}

The two samples taken for chemical characterization (AR-C1 and -C2) were evaluated for density and wt $\%$ and vol\% centrifuged solids as part of the initial phase separation providing supplemental physical property results. Results are shown in Table 4.3. In this case, the density and vol\% of centrifuged solids agreed with those from the physical-property samples (AR-S1, -S2, and -S3). However, the supernatant density and $w t \%$ centrifuged solids in the characterization sample were significantly lower than those of the physical-property samples. The centrifuging conditions were the same in each case ( $1 \mathrm{~h}$ at $1000 \mathrm{G})$. The differences in values provide more objective evidence of the experimental method uncertainties (inclusive of sub-sampling and analysis). The supernatant density derived from the chemical analysis samples is considered more accurate (see discussion in Section 4.2.3). 
Table 4.3. Supplemental Physical Properties from Chemical Characterization Samples

\begin{tabular}{|c|c|c|c|c|c|c|}
\hline Description & AR-C1 & AR-C2 & $\begin{array}{l}\text { Nominal } \\
1 \sigma \text { error }\end{array}$ & Avg. & $\begin{array}{c}\mathbf{R P D}^{(\mathbf{a})} \\
(\%)\end{array}$ & $\begin{array}{l}\text { Comparison to } \\
\text { Table } 4.2 \\
\text { Results } \\
\end{array}$ \\
\hline Sample Size (mL) & 12.7 & 11.3 & 1 & na & na & na \\
\hline Sample Size (g) & 18.775 & 15.929 & 0.004 & na & na & na \\
\hline Bulk Density (g/mL) ${ }^{(b)}$ & 1.48 & 1.41 & 0.12 & 1.44 & 4.8 & $+7 \%$ \\
\hline $\begin{array}{l}\text { Wet Centrifuged Solids } \\
\text { Density }(\mathrm{g} / \mathrm{mL})^{(\mathrm{b})}\end{array}$ & 1.73 & 1.67 & 0.12 & 1.70 & 3.9 & $-6 \%$ \\
\hline Vol\% Centrifuged Solids ${ }^{(b)}$ & 35.4 & 35.4 & 3.9 & 35.4 & 0 & equal \\
\hline Wt\% Centrifuged Solids & 41.5 & 41.8 & 0.01 & 41.7 & 0.8 & $-12 \%$ \\
\hline Supernatant Density (g/mL) & \multicolumn{2}{|c|}{1.158} & 0.0024 & na & na & $-9 \%$ \\
\hline \multicolumn{7}{|c|}{$\begin{array}{l}\text { (a) RPD = relative percent difference } \\
\text { (b) The density and vol\% values are only valid to two significant figures since the volume measures were } \\
\text { determined to two significant figures; the third significant figure is provided for indication only. } \\
\text { Bolded values indicate differences exceeding the uncertainties. }\end{array}$} \\
\hline
\end{tabular}

\subsubsection{Rheology of the Composite Group 4 CWR Slurry}

A single Group 4 slurry sample, Jar TI514-G4-AR-RH1, was provided for shear-strength and flow-curve testing. The failure of a thermocouple employed for flow-curve measurements prevented verification of test temperature. As a result, all flow-curve data and any information derived from these data are marked "For Information Only." Additional details are provided in NCR 38963.1. Shear-strength measurements were conducted at ambient cell temperature and are not affected by this failure because the temperature could be verified with an alternate calibrated thermocouple. As such, flow-curve and shear-strength analyses produced the following reportable data for the Group 4 initial characterization sample:

- a single measurement of settled-solids shear strength after 72 hours

- flow-curve data for Group 4 slurries at $25^{\circ} \mathrm{C}, 40^{\circ} \mathrm{C}$, and $60^{\circ} \mathrm{C}$ (For Information Only-See NCR 38963.1)

- best-fit Newtonian viscosities at $25^{\circ} \mathrm{C}, 40^{\circ} \mathrm{C}$, and $60 \mathrm{C}$ (For Information Only-See NCR 38963.1).

The waste slurry and settled solids were tested "as-is"; no sample treatment was performed before analysis with the exception of the mechanical agitation required to disperse the waste solids in the Group 4 slurry sample jar TI514-G4-AR-RH1.

\subsubsection{Shear Strength}

Shear strength was measured as described in Appendix C, section C.2.1. Settled solids in sample jar TI514-G4-AR-RH1 were measured for shear strength. Before shear-strength testing, the settled solids were dispersed uniformly by vigorously shaking the jar on the vortex mixer. The dispersion was then allowed to settle for 72 hours. After this period of time, the shear strength of the settled solids was measured.

Because the height of the settled solids in the test jar was limited, it was not possible to fully insert the vane tool. The total height of settled solids was $\sim 10 \mathrm{~mm}$. To avoid contact with the bottom of the 
container, only $8 \mathrm{~mm}$ of the total $16 \mathrm{~mm}$ of vane length was inserted. As such, the shear-strength results for this sample are not independent of container geometry. Because only limited vane insertion was possible, the shear strengths reported are likely much lower than those observed on a fully immersed vane. No correction for partial vane immersion was attempted. Reported shear strengths should be taken as a lower-bound estimate of actual Group 4 settled-solids strength. Test jar TI514-G4-AR-RH1 provided sufficient width for three separate shear strength tests. The vane was inserted at the center of the jar for the first test. For the second and third tests, the vane was inserted into the solids at radial positions near the jar wall. Vane test locations were selected to prevent test overlap. As such, the vane was always positioned in undisturbed solids.

Table 4.4 shows the results of Group 4 initial characterization shear-strength testing. Three separate observations after 72 hours of settling time indicate a shear strength ranging from 100 to $340 \mathrm{~Pa}$. The single measurement at the central location suggests a shear strength of approximately $100 \mathrm{~Pa}$. Significantly higher shear strengths were encountered during measurements made near the container walls. The two radial measurements indicate shear strengths of 340 and $290 \mathrm{~Pa}$ and are likely influenced by vane-wall interactions.

These results should be approached with caution. The geometric constraints required for shear-strength testing could not be met because of limited settled-solids volume. As a result, all reported values are likely influenced by container geometry. In addition, because only half-vane immersion could be achieved in these tests, the shear-strength values listed in Table 4.4 likely underestimate shear strength. It is expected that full vane immersion would yield a factor of 2 increase in the reported values. Based on this, it is speculated that the actual shear strength for Group 4 settled solids ranges from 200 to $700 \mathrm{~Pa}$.

Table 4.4. Shear Strength of Group 4 Initial Characterization Settled Solids at Ambient Hot-Cell Temperature (sample TI514-G4-AR-RH1)

\begin{tabular}{||c|c|c|c|c||}
\hline $\begin{array}{c}\text { Test } \\
\text { Number }\end{array}$ & Location & $\begin{array}{c}\text { Temperature } \\
{\left[{ }^{\circ} \mathbf{C}\right]}\end{array}$ & Settling Time & $\begin{array}{c}\text { Shear Strength } \\
{[\mathbf{P a}]}\end{array}$ \\
\hline 1 & Center & 27.7 & 72 hours & $100 \mathrm{~Pa}$ \\
\hline 2 & Radial (Near Wall) & 27.8 & 72 hours & $340 \mathrm{~Pa}$ \\
\hline 3 & Radial (Near Wall) & 27.9 & 72 hours & $290 \mathrm{~Pa}$ \\
\hline
\end{tabular}

\subsubsection{Flow Curve}

Flow-curve testing was performed as described in Appendix C, section C.2.2. Flow-curve testing for slurry sample TI514-G4-AR-RH1 was performed at $25^{\circ} \mathrm{C}, 40^{\circ} \mathrm{C}$, and $60^{\circ} \mathrm{C}$. Two measurements (an initial and replicate) were performed at $25^{\circ} \mathrm{C}$ to assess reproducibility. Immediately before flow-curve testing, waste solids were dispersed uniformly by vigorously shaking the jar on a vortex mixer. A subsample of slurry was transferred to the rheometer measuring cup. Visual inspection of the slurry during and after transfer found no immediately observable solids settling.

Each flow-curve analysis was performed over a 15-minute period, split into three 5-minute intervals. Over the first 5 minutes, the shear rate was smoothly increased from zero to $1000 \mathrm{~s}^{-1}$. For the second 5 minutes, the shear rate was held constant at $1000 \mathrm{~s}^{-1}$. For the final 5 minutes, the shear rate was smoothly reduced back to zero. During this time, the resisting torque and rotational rate were 
continuously recorded. Each flow-curve measurement was preceded by a 3-minute shearing step intended to break sample structure and to verify that the rotor was properly centered.

After the flow-curve measurement was complete, visual inspection of the cup contents found a significant layer (1 to $2 \mathrm{~mm}$ thick) of settled solids. It is likely that solids settling influenced rheology measurements. The consequence of solids settling would be lowered solids concentration in the suspending phase (especially of large aggregates), which would yield a weaker fluid rheology (i.e., lowered yield stress and consistency).

Figure 4.3 shows the initial flow curve measured for the Group 4 initial characterization slurry sample, TI514-G4-AR-RH1, at $25^{\circ} \mathrm{C}$. This measurement indicates Newtonian flow behavior. Although the curves show a finite offset of $\sim 0.1 \mathrm{~Pa}$, this falls below the instrument's yield sensitivity limit of $0.5 \mathrm{~Pa}$. Flow-curve data show a linear stress response over shear rates from zero up to $\sim 500 \mathrm{~s}^{-1}$. At higher shear rates, flow-curve data show an increase in the slope of the stress response curve. This increase is likely a result of Taylor vortex formation onset (i.e., unstable/turbulent flow), which renders the affected data unusable. The flow curves at $40^{\circ} \mathrm{C}$ and $60^{\circ} \mathrm{C}$ show similar stress response, and suggest Newtonian slurry behavior over the entire range of temperatures tested $\left(25^{\circ} \mathrm{C}\right.$ to $\left.60^{\circ} \mathrm{C}\right)$. At higher temperatures, the slope of the linear portion of the flow curve is reduced, indicating a decrease in slurry viscosity at increased slurry temperature (cf. Table 4.5). This viscosity-temperature trend is likely a result of a lowered suspending phase viscosity at increased temperature.

The flow curve shown in Figure 4.3 is relatively free of hysteresis. Specifically, the up- and down-ramp data generally agree with the instrument limits of accuracy ( 0.5 Pa). Any difference can easily be attributed to rotor inertial effects. The lack of hysteresis suggests that the measurements are not significantly affected by shearing or settling of the sample. It should be noted that lack of hysteresis does not necessarily mean that these effects are absent because any changes could have taken place during the shearing step or before the sample was analyzed. As stated before, significant settled solids were observed on the bottom of the measuring cup after completion of the measurement. It is likely that these solids settled out before the measurement took place. The effect of settling on the measurement results reported herein is that viscosities regressed from the flow curve may be lower than for the fully dispersed slurry. Unfortunately, without additional information on how slurry rheology acts as a function of solids concentration, it is difficult to evaluate how large a decrease in slurry viscosity occurs as a result of settling.

The analysis of the flow-curve data is affected by the small (but statistically insignificant) stress offset and the formation of Taylor vortices. Given the $\pm 0.1 \mathrm{~Pa}$ typical stress variation in measurement data, the best description of the current flow behavior that can be concluded, based on the current measurement data, is Newtonian. As such, Newtonian viscosity was derived for each flow-curve measurement. However, the analysis employed a Bingham-Plastic fitting model to account for the small but finite stress offset. Here, Newtonian viscosity is equated with the Bingham consistency index (i.e., Bingham-Plastic slope). Next, data believed to be influenced by Taylor vortex formation are excluded from the fits. The shear-rate range for all fits is limited to data below $450 \mathrm{~s}^{-1}, 270 \mathrm{~s}^{-1}$, and $240 \mathrm{~s}^{-1}$ at $25^{\circ} \mathrm{C}, 40^{\circ} \mathrm{C}$, and $60^{\circ} \mathrm{C}$, respectively. Finally, rotor inertial effects and measurement noise sometimes caused down-ramp stress data to fall below zero. Less than zero stress measurements are reported as zero by the RheoWin software, which can result in fit bias. The replicate $25^{\circ} \mathrm{C}$ down-ramp flow-curve measurement was 
impacted significantly by the less-than-zero stress correction by the RheoWin software. To correct for this, the fitting analysis for the replicate $25^{\circ} \mathrm{C}$ measurement was limited to the up-ramp data.

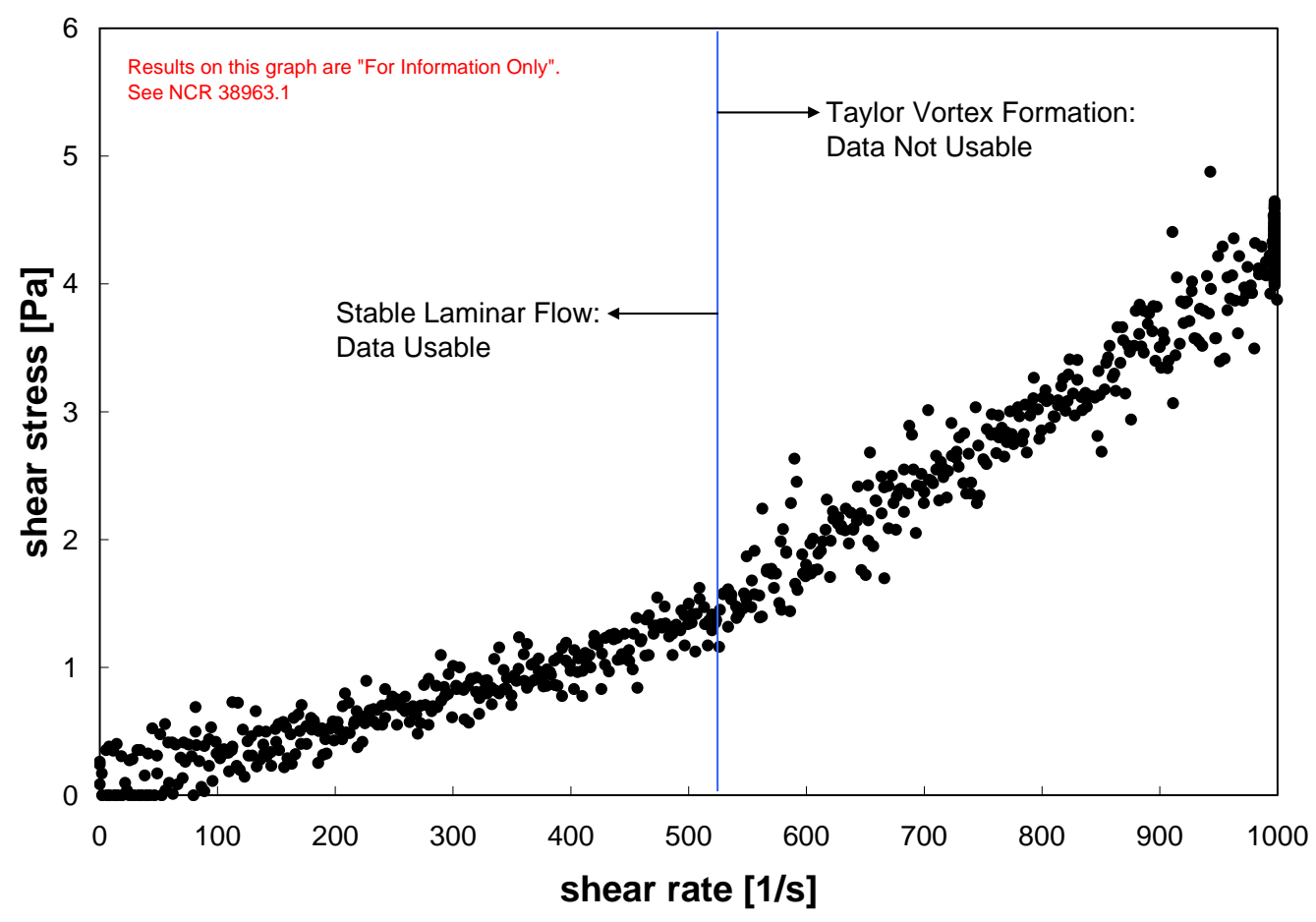

Figure 4.3. Flow Curve (shear stress versus shear rate) for the Group 4 Initial Characterization Slurry Sample TI514-G4-AR-RH1 at $25^{\circ} \mathrm{C}$ (initial measurement). Measurements at other temperature set points produced similar results. The temperature corresponding to this measurement could not be verified. The result is "For Information Only"; see NCR 38963.1 for details.

Table 4.5 summarizes the Newtonian viscosity results derived from flow-curve data for sample TI514G4-AR-RH1. It should be stressed that these results are "For Information Only"-NCR 38963.1 provides additional details regarding the quality status for these data. Table 4.5 indicates a Group 4 slurry viscosity that generally falls between 1.1 and $2.4 \mathrm{cP}$, depending on temperature. An increased temperature yields a decrease in the slurry viscosity, likely as a result of decreasing suspending phase viscosity. The initial and replicate viscosity measurement at $25^{\circ} \mathrm{C}$ compare well with each other and are within the accepted limit of variation (15\%). 
Table 4.5. Results of Fitting Analysis for Group 4 Initial Characterization Sample TI514-G4-AR-RH1. Unless specified otherwise, flow-curve viscosities are determined by fitting both up- and down-ramp data.

\begin{tabular}{||c|c|c|c|c||}
\hline Model & $\begin{array}{c}\text { Temperature } \\
{\left[{ }^{\circ} \mathbf{C}\right]}\end{array}$ & Range & $\begin{array}{c}\text { Viscosity } \\
{[\text { MPA·S }]}\end{array}$ & R \\
\hline \multirow{3}{*}{$\begin{array}{c}\text { Newtonian } \\
\text { (Flow Curve) }\end{array}$} & $25(1$ of 2$)$ & $0-450 \mathrm{~s}^{-1}$ & 2.3 & 0.91 \\
\cline { 2 - 5 } & $25(2$ of 2$)$ & $0-450 \mathrm{~s}^{-1}(\mathrm{a})$ & 2.4 & 0.91 \\
\cline { 2 - 5 } & 40 & $0-270 \mathrm{~s}^{-1}$ & 1.4 & 0.76 \\
\cline { 2 - 5 } & 60 & $0-240 \mathrm{~s}^{-1}$ & 1.1 & 0.41 \\
\hline
\end{tabular}

Test Plan TP-RPP-WTP-467 requests a determination of apparent viscosity at $33 \mathrm{~s}^{-1}$. For the current measurement, measurement noise and the low slurry viscosity $(<5 \mathrm{cP})$ makes determination of apparent viscosity at a shear rate of $33 \mathrm{~s}^{-1}$ difficult and subject to significant error. In terms of calculated apparent viscosities, the Newtonian results reported in Table 4.5 represent the apparent viscosity over the entire range of shear and should provide a reasonable estimation of the apparent viscosity at $33 \mathrm{~s}^{-1}$. Thus, the determination of apparent viscosity from measurement data is forgone in favor of the results in Table 4.5.

In summary, flow-curve analysis for the Group 4 Initial Characterization slurry sample, TI514-G4-ARRH1, suggests Newtonian rheology. Regression analysis of the flow-curve data finds a slurry viscosity ranging from 2.3 to $2.4 \mathrm{cP}$ at $25^{\circ} \mathrm{C}$ and $1.1 \mathrm{cP}$ at $60^{\circ} \mathrm{C}$. As indicated by the results, an increased slurry temperature yields a lower slurry viscosity, likely as a result of the suspending phase viscosity being lowered. The flow-curve data are relatively free of hysteresis, which suggests that settling and/or shearing effects are minimal or occur before flow-curve measurement.

\subsubsection{Chemical and Radiochemical Composition of the Group 4 CWR Slurry}

A photograph of one of the two characterization samples is shown in Figure 4.4a following centrifuging the sample. The gray centrifuged solids appeared generally uniform top to bottom. The supernatant was pale yellow, most likely because of the presence of chromate ion. The supernatant density was determined to be $1.16 \mathrm{~g} / \mathrm{mL}$ ( $\mathrm{T}=26^{\circ} \mathrm{C}$ ) based on the average masses of four 1-mL volume deliveries. The characterization sample density was significantly lower than the density determined as part of the physical- property testing procedure (density $=1.27 \mathrm{~g} / \mathrm{mL}$ ). The source of the difference is not well understood. Since the Na concentration in the supernatant is $2.84 \mathrm{M}$, the lower density appears to more appropriately represent the material. 
a)

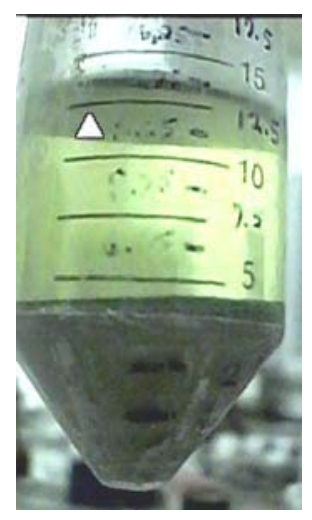

b)

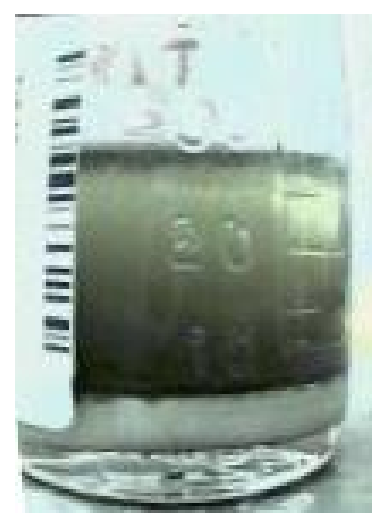

Figure 4.4. Chemical Characterization Sample of Group 4 CWR Sludge a) Centrifuged Solids b) Combined Washed Solids

The specific washing scheme for the Group 4 CWR sludge is provided in Figure 4.5. With each successive washing step, the CS packing was more easily disturbed during the course of supernatant removal with the transfer pipette. The hydroxide concentration in the final wash solution was $\sim 0.01 \mathrm{M}$. The CS volumes were estimated based on the centrifuge-tube graduations. There was no measurable decrease in the centrifuged solids volume during the washing process. A photograph of the washed Group 4 solids is shown in Figure 4.4b; the white solids settled readily, whereas gray solids remained suspended. The solids suspension was attributed to the low ionic strength or relatively low $\mathrm{pH}$ of the final aqueous phase and the corresponding dispersion associated with particle electrostatic repulsion.

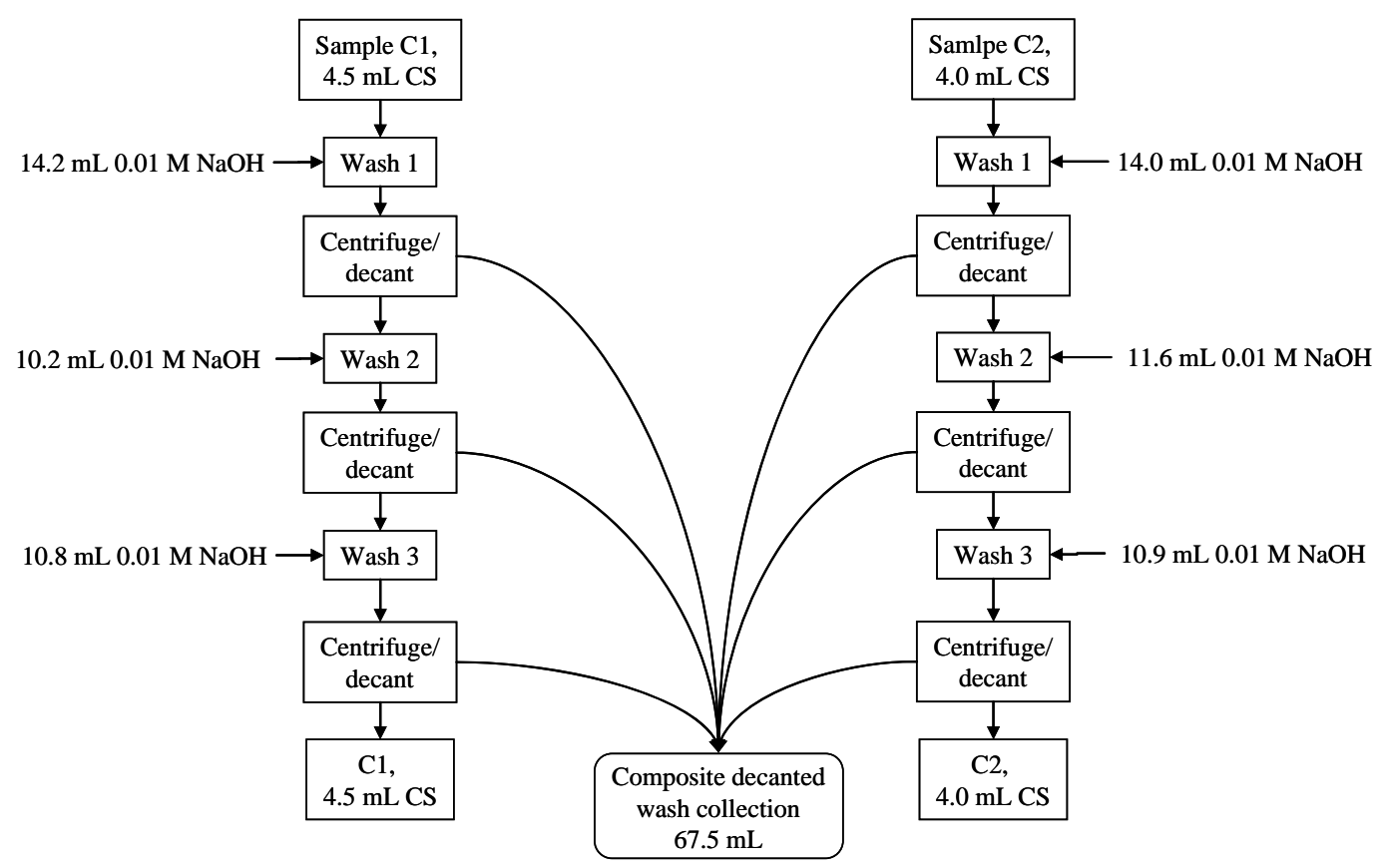

Figure 4.5. Wash Sequence of Group 4 CWR Sludge Supporting Initial Characterization 
The average radioanalytical results for the supernatant, composited wash solution, and washed solids are provided in Table 4.6 along with the applicable RPD. The concentrations of the gross-beta results and the sum of beta emitters, ${ }^{137} \mathrm{Cs}$ and ${ }^{90} \mathrm{Sr}$ (in secular equilibrium with ${ }^{90} \mathrm{Y}$ ), were essentially equivalent (ratio close to 1.0). The reasonably good agreement between these values indicated that no other major source of beta activity was present. Similarly, the gross-alpha activity agreed reasonably well with the sum of the alpha emitters $\left({ }^{238} \mathrm{Pu},{ }^{239+240} \mathrm{Pu}\right.$, and detected $\left.{ }^{241} \mathrm{Am}\right)$, indicating that no other significant source of alpha activity was present.

Table 4.6. Radionuclide Characterization of the Group 4 CWR Sludge

\begin{tabular}{|c|c|c|c|c|c|c|}
\hline \multirow{3}{*}{$\begin{array}{l}\text { Sample ID> } \\
\text { Analyte } \\
\end{array}$} & \multirow{2}{*}{\multicolumn{2}{|c|}{$\begin{array}{c}\text { Supernatant } \\
08-00160 \\
\end{array}$}} & \multirow{2}{*}{\multicolumn{2}{|c|}{$\begin{array}{c}\text { Wash composite } \\
0^{08-00161} \\
\end{array}$}} & \multirow{2}{*}{\multicolumn{2}{|c|}{$\begin{array}{c}\text { Washed solids }^{(\mathbf{a})} \\
08-00162 \\
\end{array}$}} \\
\hline & & & & & & \\
\hline & $\mu \mathrm{Ci} / \mathrm{mL}$ & RPD & $\mu \mathrm{Ci} / \mathrm{mL}$ & RPD & $\mu \mathrm{Ci} / \mathrm{g}$ & RPD \\
\hline${ }^{137} \mathrm{Cs}$ & $1.80 \mathrm{E}+1$ & 0.00 & $1.07 \mathrm{E}+0$ & \multirow{3}{*}{ na } & $7.66 \mathrm{E}+0$ & 1.4 \\
\hline${ }^{60} \mathrm{Co}$ & $3.26 \mathrm{E}-3$ & 0.31 & $1.97 \mathrm{E}-4$ & & $1.15 \mathrm{E}-2^{(\mathrm{d})}$ & 62 \\
\hline${ }^{241} \mathrm{Am}$ & $8.47 \mathrm{E}-3$ & $\mathrm{na}^{(\mathrm{c})}$ & $3.84 \mathrm{E}-4$ & & 6.92E-1 & 3.8 \\
\hline${ }^{238} \mathrm{Pu}$ & $6.35 \mathrm{E}-5$ & 15 & \multirow{9}{*}{\multicolumn{2}{|c|}{$\mathrm{n} / \mathrm{a}$}} & 2.67E-2 & 15 \\
\hline${ }^{239+240} \mathrm{Pu}$ & $4.53 \mathrm{E}-4$ & 1.8 & & & $1.73 \mathrm{E}-1$ & 8.1 \\
\hline Gross alpha & $9.73 \mathrm{E}-3$ & 38 & & & 8.29E-1 & 18 \\
\hline Gross beta & $2.04 \mathrm{E}+1$ & 1.5 & & & $8.05 \mathrm{E}+1$ & 2.0 \\
\hline${ }^{90} \mathrm{Sr}$ & $6.07 \mathrm{E}-1$ & 1.5 & & & $3.41 \mathrm{E}+1$ & 1.8 \\
\hline Alpha sum & 8.99E-3 & 16 & & & 8.92E-1 & 0.89 \\
\hline$\alpha$ gross/sum & 1.08 & 23 & & & 0.93 & 19 \\
\hline Beta sum & $1.92 \mathrm{E}+1$ & 0.09 & & & $7.59 \mathrm{E}+1$ & 1.7 \\
\hline$\beta$ gross/sum & 1.06 & 1.6 & & & 1.06 & 0.25 \\
\hline \multicolumn{7}{|c|}{ Opportunistic } \\
\hline${ }^{154} \mathrm{Eu}$ & $5.00 \mathrm{E}-3$ & 7.0 & $3.45 \mathrm{E}-4$ & na & $2.08 \mathrm{E}-1$ & 1.4 \\
\hline${ }^{155} \mathrm{Eu}$ & $<3 . \mathrm{E}-3$ & na & $<2 . \mathrm{E}-4$ & na & $7.29 \mathrm{E}-2$ & 4.0 \\
\hline \multicolumn{7}{|c|}{$\begin{array}{l}\text { Reference date for all radionuclides is November } 1,2007 . \\
\text { (a) Analyte concentrations are calculated on a dry-mass basis. } \\
\text { (b) This sample was not required to be run in duplicate; therefore, an RPD was not calculated. } \\
\text { (c) The duplicate sample resulted in }<7 \mathrm{E}-3 \mu \mathrm{Ci} / \mathrm{mL}{ }^{241} \mathrm{Am} \text {. } \\
\text { (d) The }{ }^{60} \mathrm{Co} \text { in the preparation blank was equivalent to the }{ }^{60} \mathrm{Co} \text { in the sample. Therefore, this } \\
\text { result should be considered an upper bound. } \\
\text { Notes: na = not applicable; } \mathrm{n} / \mathrm{a}=\text { not analyzed }\end{array}$} \\
\hline
\end{tabular}

The chemical compositions of the washed Group 4 CWR supernatant, composite wash solution, and solids (both dissolution methods) are provided in Table 4.7. The results from the acid digestion resulted in an overall factor of $1.14 \times$ higher than the results from solids fusion method within the stated analytical uncertainty of $\pm 15 \%$. The washed water-insoluble solids averaged $\sim 32 \mathrm{wt} \% \mathrm{Al}$; other analytes were $<1.2 \mathrm{wt} \%$. The supernatant was primarily sodium salts (mainly nitrate, nitrite, carbonate, and hydroxide). The anionic and cationic charge balance was evaluated for the supernatant, resulting in a $7.9 \%$ difference, well within analytical uncertainties. 
Analyte water-wash factors were calculated as shown in Equation 3.1. The fractional distributions of selected analytes in the supernatant, wash, and solids phases are shown in Table 4.8 and Figure 4.6. A large portion (>90\%) of the $\mathrm{Na}$ and $\mathrm{P}$ partitioned to the aqueous phase. An examination of Figure 4.6 shows that additional $\mathrm{P}$ was mobilized from the solids phase as a result of the washing process. Thus, the supernatant matrix was sufficiently high in salt concentration to repress the solubility of a water-soluble phosphate phase. About $77 \%$ of the $\mathrm{Cr}$ remained in the solids phase. The $\mathrm{Al}$ remained primarily in the solids phase.

The water-wash factors obtained from the current testing were compared with the weighted mean of the water-wash factors obtained from the TWINS database. The weighting factors were obtained from the relative masses of tank waste that were used to create the composite. The experimentally obtained Cr, $\mathrm{Na}$, and $\mathrm{P}$ wash factors resulted in reasonably good correspondence with the TWINS water-wash factors. The experimentally obtained Al wash factor was significantly lower than the TWINS factor. Direct cross comparison of these water-wash factors with those in the TWINS database was confounded by the specific sample selection process. Samples high in Al were selected for testing, and these did not necessarily represent the tank composite. Furthermore, the difference in Al wash factors might have been influenced by extended sample storage times and associated sample drying during the long storage period at 222S. 
Table 4.7. Chemical Characterization of the Group 4 CWR Sludge

\begin{tabular}{|c|c|c|c|c|c|c|c|c|c|c|}
\hline \multirow{4}{*}{$\begin{array}{l}\text { Matrix > } \\
\text { Sample ID> } \\
\text { Preparation } \\
\text { Analyte } \\
\end{array}$} & \multirow{3}{*}{\multicolumn{3}{|c|}{$\begin{array}{c}\text { Supernatant } \\
\text { 08-00826 } \\
\text { Acid Digest }\end{array}$}} & \multirow{3}{*}{\multicolumn{3}{|c|}{$\begin{array}{c}\text { Wash composite } \\
\text { 08-00827 }^{(\mathbf{b})} \\
\text { Acid Digest }\end{array}$}} & \multirow{2}{*}{\multicolumn{4}{|c|}{$\begin{array}{c}\text { Washed solids }^{(\mathrm{a})} \\
08-00828\end{array}$}} \\
\hline & & & & & & & & & & \\
\hline & & & & & & & \multicolumn{2}{|c|}{ Fusion } & \multicolumn{2}{|c|}{ Acid Digest } \\
\hline & $\mu \mathrm{g} / \mathrm{mL}$ & $\mathbf{M}$ & RPD & $\mu \mathrm{g} / \mathrm{mL}$ & $\mathbf{M}$ & RPD & $\mu \mathrm{g} / \mathrm{g}$ & RPD & $\mu \mathrm{g} / \mathrm{g}$ & RPD \\
\hline $\mathrm{Al}$ & 505 & $1.87 \mathrm{E}-2$ & 0.0 & 60.2 & $2.23 \mathrm{E}-3$ & \multirow{17}{*}{ na } & 296,500 & 3.0 & 343,500 & 0.29 \\
\hline B & 160 & $1.48 \mathrm{E}-2$ & 1.9 & [12] & [1.1E-3] & & $<72$ & na & na & na \\
\hline $\mathrm{Bi}$ & $<2.3$ & $<1.1 \mathrm{E}-5$ & na & $<2.3$ & $<1.1 \mathrm{E}-5$ & & {$[1,100]$} & {$[0]$} & 1,425 & 2.1 \\
\hline $\mathrm{Cd}$ & 5.74 & $5.11 \mathrm{E}-5$ & 0.70 & {$[0.29]$} & [2.6E-6] & & [7.9] & [20] & [8.0] & [18] \\
\hline $\mathrm{Cr}$ & 221 & $4.25 \mathrm{E}-3$ & 0.0 & 15.9 & $3.06 \mathrm{E}-4$ & & 1,610 & 1.2 & 1,910 & 1.0 \\
\hline $\mathrm{Fe}$ & [3.0] & [5.5E-5] & {$[3.3]$} & $<2.1$ & $<3.7 \mathrm{E}-5$ & & 5,090 & 7.1 & 5,675 & 0.18 \\
\hline K & 278 & $7.11 \mathrm{E}-3$ & 0.0 & [13] & [3.3E-4] & & na & na & $<135$ & na \\
\hline $\mathrm{Mn}$ & {$[0.81]$} & [1.5E-5] & [0] & $<0.21$ & $<3.8 \mathrm{E}-6$ & & 1,545 & 1.9 & 1,870 & 2.1 \\
\hline $\mathrm{Na}$ & 65,300 & $2.84 \mathrm{E}+0$ & 0.0 & 7,350 & $3.20 \mathrm{E}-1$ & & {$[11,000]$} & {$[0]$} & 11,400 & 1.8 \\
\hline $\mathrm{Ni}$ & 37.5 & $6.38 \mathrm{E}-4$ & 1.9 & [2.1] & [3.6E-5] & & na & na & [55] & [48] \\
\hline $\mathrm{P}$ & 3,755 & $1.21 \mathrm{E}-1$ & 0.27 & 1,370 & $4.42 \mathrm{E}-2$ & & $<129$ & na & [365] & [25] \\
\hline S & 551 & $1.72 \mathrm{E}-2$ & 0.91 & [41] & [1.3E-3] & & {$[815]^{(\mathrm{b})}$} & [40] & [431] & na \\
\hline Si & [6.2] & [2.2E-4] & {$[3.2]$} & [6.3] & [2.2E-4] & & 5,985 & 13 & na & na \\
\hline $\mathrm{Sr}$ & {$[0.10]$} & [1.2E-6] & [38] & $<0.02$ & $<1.9 \mathrm{E}-7$ & & [24] & {$[0]$} & 25.1 & 0.80 \\
\hline $\mathrm{U}$ & [65] & [2.7E-4] & {$[4.7]$} & $<8.45$ & $<3.6 \mathrm{E}-5$ & & {$[3,400]$} & {$[0]$} & 4,090 & 1.0 \\
\hline Zn & $<0.56$ & $<8.6 \mathrm{E}-6$ & na & $<0.57$ & $<8.8 \mathrm{E}-6$ & & 723 & 1.4 & 870 & 0.92 \\
\hline $\mathrm{Zr}$ & $<0.80$ & $<8.8 \mathrm{E}-6$ & na & $<0.82$ & $<9.0 \mathrm{E}-6$ & & $<48$ & na & 128 & 0.78 \\
\hline U KPA & \multicolumn{6}{|c|}{$\mathrm{n} / \mathrm{a}$} & 3,540 & 1.1 & na & na \\
\hline nitrite & 10,400 & 2.26E-1 & 0.0 & 561 & $1.22 \mathrm{E}-2$ & 0.54 & \multirow{8}{*}{\multicolumn{4}{|c|}{$\mathrm{n} / \mathrm{a}$}} \\
\hline nitrate & 100,150 & $1.62 \mathrm{E}+0$ & 1.7 & 5,500 & $9.00 \mathrm{E}-2$ & 2.9 & & & & \\
\hline phosphate & 12,250 & $1.29 \mathrm{E}-1$ & 0.82 & 4,570 & $4.81 \mathrm{E}-2$ & 0.0 & & & & \\
\hline sulfate & 1,925 & $2.00 \mathrm{E}-2$ & 0.52 & 106 & $1.10 \mathrm{E}-3$ & 0.0 & & & & \\
\hline oxalate & 3,675 & $4.18 \mathrm{E}-2$ & 0.27 & 1,475 & $1.68 \mathrm{E}-2$ & 0.68 & & & & \\
\hline free hydroxide & 1,760 & $1.04 \mathrm{E}-1$ & 0.97 & & & & & & & \\
\hline TOC as $\mathrm{C}$ & 3600 & $3.00 \mathrm{E}-1$ & 1.1 & & & & & & & \\
\hline TIC as $\mathrm{C}$ & 3,065 & $2.55 \mathrm{E}-1$ & 2.9 & & & & & & & \\
\hline \multicolumn{11}{|l|}{ Opportunistic } \\
\hline fluoride & 1,300 & $6.84 \mathrm{E}-2$ & 0.00 & 458 & $2.42 \mathrm{E}-2$ & 0.44 & \multirow{2}{*}{\multicolumn{4}{|c|}{$\mathrm{n} / \mathrm{a}$}} \\
\hline chloride & 881.5 & 2.49E-2 & 1.70 & 56 & $1.55 \mathrm{E}-3$ & 1.80 & & & & \\
\hline $\mathrm{Ag}$ & $<0.42$ & $<3.9 \mathrm{E}-6$ & na & $<0.43$ & $<4.0 \mathrm{E}-6$ & \multirow{8}{*}{ na } & $<14$ & na & [12] & {$[0]$} \\
\hline As & $<6.9$ & $<9.2 \mathrm{E}-5$ & na & $<7.0$ & $<9.4 \mathrm{E}-5$ & & [275] & [4] & [260] & [7.7] \\
\hline $\mathrm{Ba}$ & $<0.34$ & $<2.4 \mathrm{E}-6$ & na & $<0.34$ & $<2.5 \mathrm{E}-6$ & & $<36$ & na & [15] & {$[0]$} \\
\hline $\mathrm{Be}$ & $<0.01$ & $<1.3 \mathrm{E}-6$ & na & $<0.01$ & $<1.4 \mathrm{E}-6$ & & $<1$ & na & {$[0.27]$} & [11] \\
\hline $\mathrm{Ca}$ & 42.7 & $1.07 \mathrm{E}-3$ & 3.3 & [4.4] & [1.1E-4] & & $<2520$ & na & 1,045 & 2.9 \\
\hline $\mathrm{Ce}$ & $<1.2$ & $<8.5 \mathrm{E}-6$ & na & $<1.2$ & $<8.6 \mathrm{E}-6$ & & $<166$ & na & [56] & [14] \\
\hline Co & $<0.38$ & $<6.5 \mathrm{E}-6$ & na & $<0.39$ & $<6.6 \mathrm{E}-6$ & & $<17$ & na & $<4.3$ & na \\
\hline $\mathrm{Cu}$ & [4.8] & [7.5E-5] & {$[2.9]$} & {$[0.51]$} & [8.0E-6] & & [46] & {$[22]$} & [23] & [8.7] \\
\hline
\end{tabular}


Table 4.7 (Contd)

\begin{tabular}{|c|c|c|c|c|c|c|c|c|c|c|}
\hline Matrix > & \multicolumn{3}{|c|}{ Supernatant } & \multicolumn{3}{|c|}{ "Wash composite } & \multicolumn{4}{|c|}{ Washed solids } \\
\hline Sample ID> & \multicolumn{3}{|c|}{ 07-00365 } & \multicolumn{3}{|c|}{ 07-00366 } & \multicolumn{4}{|c|}{ 07-00367 } \\
\hline Preparation & \multicolumn{3}{|c|}{ Acid Digest } & \multicolumn{3}{|c|}{ Acid Digest } & \multicolumn{2}{|c|}{ Fusion } & \multicolumn{2}{|c|}{ Acid Digest } \\
\hline Analyte & $\mu \mathrm{g} / \mathrm{mL}$ & $\mathbf{M}$ & RPD & $\mu \mathrm{g} / \mathrm{mL}$ & $\mathbf{M}$ & RPD & $\mu \mathrm{g} / \mathrm{g}$ & RPD & $\mu \mathrm{g} / \mathrm{g}$ & RPD \\
\hline Dy & $<0.35$ & $<2.1 \mathrm{E}-6$ & na & $<0.35$ & $<2.2 \mathrm{E}-6$ & \multirow{22}{*}{ na } & $<42$ & na & $<3.9$ & na \\
\hline $\mathrm{Eu}$ & $<0.11$ & $<7.1 \mathrm{E}-7$ & na & $<0.11$ & $<7.2 \mathrm{E}-7$ & & $<14$ & na & $<1.2$ & na \\
\hline $\mathrm{La}$ & {$[0.30]$} & [2.1E-6] & [3.4] & $<0.13$ & $<9.7 \mathrm{E}-7$ & & [20] & [5.1] & 27.1 & na \\
\hline $\mathrm{Li}$ & $<0.54$ & $<7.8 \mathrm{E}-5$ & na & $<0.55$ & $<7.9 \mathrm{E}-5$ & & {$[39]^{(b)}$} & [65] & [10] & [19] \\
\hline $\mathrm{Mg}$ & $<0.69$ & $<2.9 \mathrm{E}-5$ & na & $<0.71$ & $<2.9 \mathrm{E}-5$ & & [640] & [3.1] & 670 & 0.30 \\
\hline Mo & [5.7] & [5.9E-5] & [3.5] & $<0.66$ & $<6.9 \mathrm{E}-6$ & & $<24$ & na & $<7.3$ & na \\
\hline $\mathrm{Nd}$ & $<1.7$ & $<1.2 \mathrm{E}-5$ & na & $<1.7$ & $<1.2 \mathrm{E}-5$ & & $<255$ & na & [73] & [10] \\
\hline $\mathrm{Pb}$ & 759 & $3.66 \mathrm{E}-3$ & 0.00 & 38.8 & $1.25 \mathrm{E}-3$ & & 2,245 & 3.1 & 2,825 & 1.8 \\
\hline $\mathrm{Pd}$ & [1.3] & [1.2E-5] & [3.6] & $<1.3$ & $<1.2 \mathrm{E}-5$ & & $<151$ & na & $<14$ & na \\
\hline $\mathrm{Rh}$ & $<2.5$ & $<2.4 \mathrm{E}-5$ & na & $<2.5$ & $<2.5 \mathrm{E}-5$ & & $<99$ & na & $<28$ & na \\
\hline $\mathrm{Ru}$ & [1.9] & [1.8E-5] & [38] & $<0.8$ & $<8.2 \mathrm{E}-6$ & & $<42$ & na & $<9.1$ & na \\
\hline $\mathrm{Sb}$ & $<3.2$ & $<2.7 \mathrm{E}-5$ & na & $<3.2$ & $<2.6 \mathrm{E}-5$ & & $<140$ & na & [39] & {$[21]$} \\
\hline Se & $<4.9$ & $<6.1 \mathrm{E}-5$ & na & $<4.9$ & $<6.3 \mathrm{E}-5$ & & $<239$ & na & [92] & [17] \\
\hline Sn & $<2.0$ & $<1.7 \mathrm{E}-5$ & na & $<2.0$ & $<1.7 \mathrm{E}-5$ & & $<224$ & na & $<22$ & na \\
\hline $\mathrm{Ta}$ & $<1.3$ & $<7.3 \mathrm{E}-6$ & na & $<1.3$ & $<7.4 \mathrm{E}-6$ & & $<48$ & na & [39] & [0] \\
\hline $\mathrm{Te}$ & $<3.1$ & $<2.5 \mathrm{E}-5$ & na & $<3.2$ & $<2.5 \mathrm{E}-5$ & & $<190$ & na & $<35$ & na \\
\hline Th & $<1.2$ & $<5.1 \mathrm{E}-6$ & na & $<1.2$ & $<5.2 \mathrm{E}-6$ & & $<148$ & na & [49] & {$[0]$} \\
\hline $\mathrm{Ti}$ & $<0.10$ & $<2.1 \mathrm{E}-6$ & na & $<0.10$ & $<2.0 \mathrm{E}-6$ & & $<25$ & na & 20.8 & 4.3 \\
\hline $\mathrm{Tl}$ & $<6.4$ & $<3.1 \mathrm{E}-5$ & na & $<6.6$ & $<3.2 \mathrm{E}-5$ & & $<172$ & na & $<72$ & na \\
\hline $\mathrm{V}$ & {$[1.8]$} & [3.5E-5] & [0] & [1.1] & [2.2E-5] & & $<11$ & na & [6.2] & [23] \\
\hline $\mathrm{W}$ & [4.7] & [2.5E-5] & [28] & $<1.5$ & $<8.2 \mathrm{E}-6$ & & $<75$ & na & $<17$ & na \\
\hline $\mathrm{Y}$ & $<0.08$ & $<9.4 \mathrm{E}-7$ & na & $<0.09$ & $<9.6 \mathrm{E}-7$ & & $<16$ & na & [8.2] & [2.4] \\
\hline \multicolumn{11}{|l|}{$\begin{array}{l}\text { (b) The blan } \\
\text { respectiv }\end{array}$} \\
\hline \multicolumn{11}{|c|}{$\begin{array}{l}\text { Analyte uncertainties were typically within } \pm 15 \% \text { (2-s); results in brackets indicate that the analyte } \\
\text { concentrations were greater than the minimum detection limit (MDL) and less than the estimated } \\
\text { quantitation limit (EQL), and uncertainties were }>15 \% \text {. }\end{array}$} \\
\hline \multicolumn{11}{|c|}{$\begin{array}{l}\text { Opportunistic analytes are reported for information only; quality control (QC) requirements did not } \\
\text { apply to these analytes. } \\
\text { na = not applicable } \\
\text { n/a = not analyzed }\end{array}$} \\
\hline
\end{tabular}


Table 4.8. Phase Distribution of Selected Analytes in Group 4 CWR Sludge

\begin{tabular}{|c|c|c|c|c|c|}
\hline Analyte & $\begin{array}{c}\text { Supernatant } \\
\text { wt } \%\end{array}$ & $\begin{array}{c}\text { Wash Solution } \\
\text { wt } \%\end{array}$ & $\begin{array}{c}\text { Water-Wash } \\
\text { Factor } \\
\text { wt } \%\end{array}$ & $\begin{array}{c}\text { TWINS Water- } \\
\text { Wash Factor }^{(a)} \\
\text { wt } \%\end{array}$ & $\begin{array}{l}\text { Solids } \\
\text { wt } \%\end{array}$ \\
\hline $\mathrm{Cr}$ & 18 & 4.9 & 23 & 29 & 77 \\
\hline $\mathrm{Al}$ & 0.29 & 0.13 & 0.42 & 19 & 99.6 \\
\hline $\mathrm{Na}$ & 65 & 28 & 94 & 99 & 6.2 \\
\hline $\mathrm{P}$ & 41 & 57 & [98] & 85(b) & [2.2] \\
\hline \multicolumn{6}{|c|}{$\begin{array}{l}\text { (a) The water-wash factor represents the weighted mean of the five represented tank-waste sources from the } \\
\text { TWINS database. } \\
\text { (b) TWINS reported a phosphate water-wash factor. } \\
\text { TWINS report date was } 6 / 3 / 08 \text {. } \\
\text { Results in brackets indicate that the analyte concentrations were >MDL and <EQL. }\end{array}$} \\
\hline
\end{tabular}



Supernatant Fraction $\square$ Wash Fraction $\square$ Solids Fraction

Figure 4.6. Selected Analyte Phase Distribution for Group 4 CWR Sludge

\subsubsection{Particle Size}

Particle size was measured as described in Appendix C, section C.3.1 on a Mastersizer 2000 (Malvern Instruments, Inc., Southborough, MA 01772 USA). Figure 4.7 through Figure 4.9 and Table 4.9 and Table 4.10 present the results of Group 4 initial characterization particle-size analysis as a function of test condition. Figure 4.7 through Figure 4.9 show the differential volume population distribution for the primary Group 4 initial characterization sample and allow a qualitative examination of the PSD behavior with respect to pump speed and sonication. Table 4.9 is a summary of the measured oversize diameter percentiles (by volume/weight) for the primary sample, TI547-G4-S-WL-PSD-1. Table 4.10 presents the same results for the duplicate sample, TI547-G4-S-WL-PSD -2. Both tables present cumulative oversize diameters corresponding to the $\mathrm{d}(10), \mathrm{d}(50)$, and $\mathrm{d}(90)$. These tables will be used to quantitatively examine reproducibility and changes in particle size. 
Figure 4.7 shows the PSD for the primary Group 4 initial characterization sample as a function of pump speed before sonication. The distribution of particles ranges from 0.2 to $200 \mu \mathrm{m}$ with varying peaks depending on the pump speed. At 2000 RPM, the distribution is uni-modal with a maximum population between 12 to $14 \mu \mathrm{m}$ and low shoulder populations on both ends of the range. As the pump speed increased, the distribution became bi-modal with the primary peak between 55 to $65 \mu \mathrm{m}$ and a secondary peak in the range of 12 to $14 \mu \mathrm{m}$. As in the 2000 RPM case, there is a shoulder between 0.2 to $2 \mu \mathrm{m}$, although at 3000 RPM there is no shoulder at larger diameters after the peak. At 4000 RPM, the major peak is between 50 to $60 \mu \mathrm{m}$, and there are two shoulders, one between 0.2 to $2 \mu \mathrm{m}$ and one between 12 to $14 \mu \mathrm{m}$. The distribution at $4000 \mathrm{RPM}$ is dominated by the population of larger particles, and the original 12- to $14-\mu \mathrm{m}$ peak now exists as a shoulder distribution to the primary peak centered at 50 to $60 \mu \mathrm{m}$. These results indicate that the distribution was highly influenced by the flow rate and suggest the presence of large, difficult-to-suspend particles or particle agglomerates.

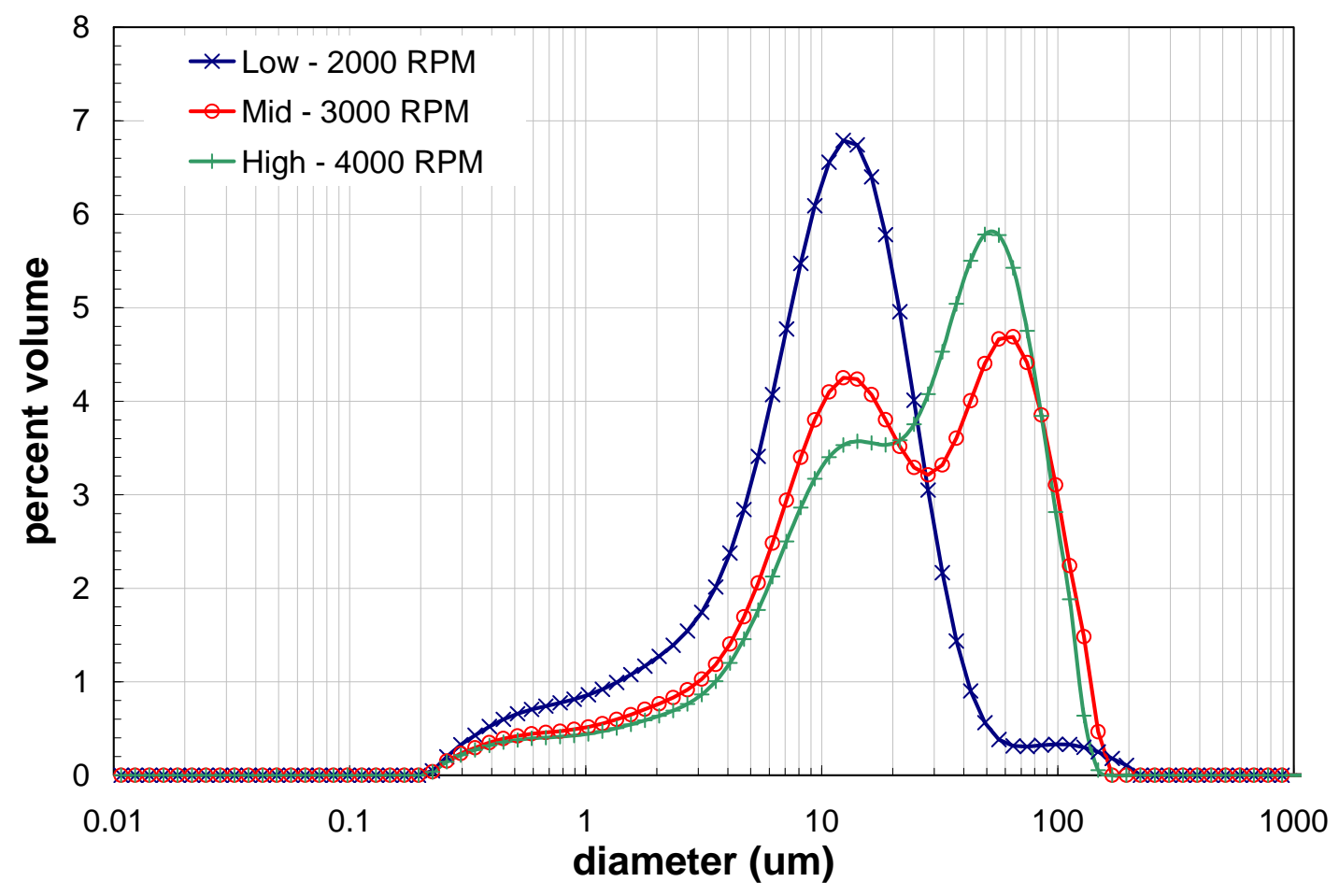

Figure 4.7. Pre-S Volume Distribution Result for the Primary Group 4 Initial Characterization Sample as a Function of Pump Speed

Figure 4.8 shows the PSD as a function of sonication. This figure indicates that sonication shifts the entire particle population to smaller diameters and substantially increases the central (9- to 11- $\mu \mathrm{m}$ ) population of particles. This result suggests that the solids species making up the 20- to 200- $\mu \mathrm{m}$ population are particle agglomerates. During sonication, the particle diameter range reduces from 0.2 to $200 \mu \mathrm{m}$ to 0.2 to $35 \mu \mathrm{m}$. This reduction is likely a result of agglomerate disruption during sonication. After sonication, agglomeration is again seen as the particle diameter range extends up to 0.2 to $150 \mu \mathrm{m}$. Therefore, although sonication may disrupt agglomerates, there is some recovery of these agglomerates on the time scale of the measurement. 


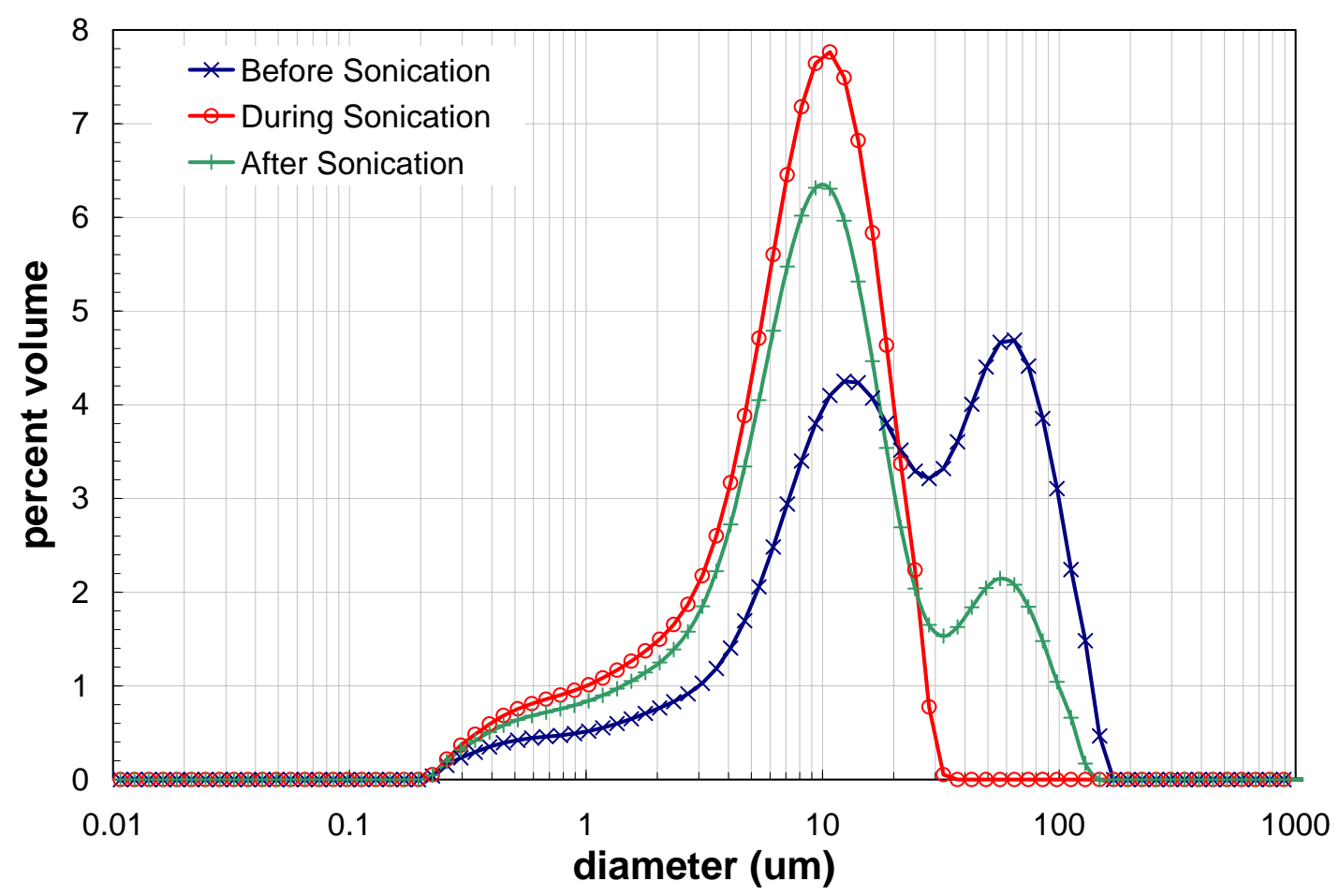

Figure 4.8. Volume Distribution Result for the Primary Group 4 Initial Characterization Sample as a Function of Sonication. Note: the during-sonication condition corresponds to measurement condition 6: 3,000 RPM at 75\% Sonication.

Figure 4.9 shows the primary Group 4 initial characterization PSD as a function of pump speed after the sample has been sonicated. Here again, changes in pump speed show a large discrepancy in particle diameter distribution. At $2000 \mathrm{RPM}$, the particle diameter ranges from 0.2 to $40 \mu \mathrm{m}$ with a peak around 9 to $11 \mu \mathrm{m}$. As the pump speed increases to 3000 RPM, larger particle diameters are seen as evident by the broader range of 0.2 to $150 \mu \mathrm{m}$. At both 3000 and 4000 RPM, there is a secondary peak from 45 to $65 \mu \mathrm{m}$. The percent volume of particles and/or agglomerates within this range increases significantly at 4000 RPM, indicating that higher pump speeds are able to keep more larger diameter particles and/or agglomerates in suspension, while at 2000 RPM, these may quickly settle out. 


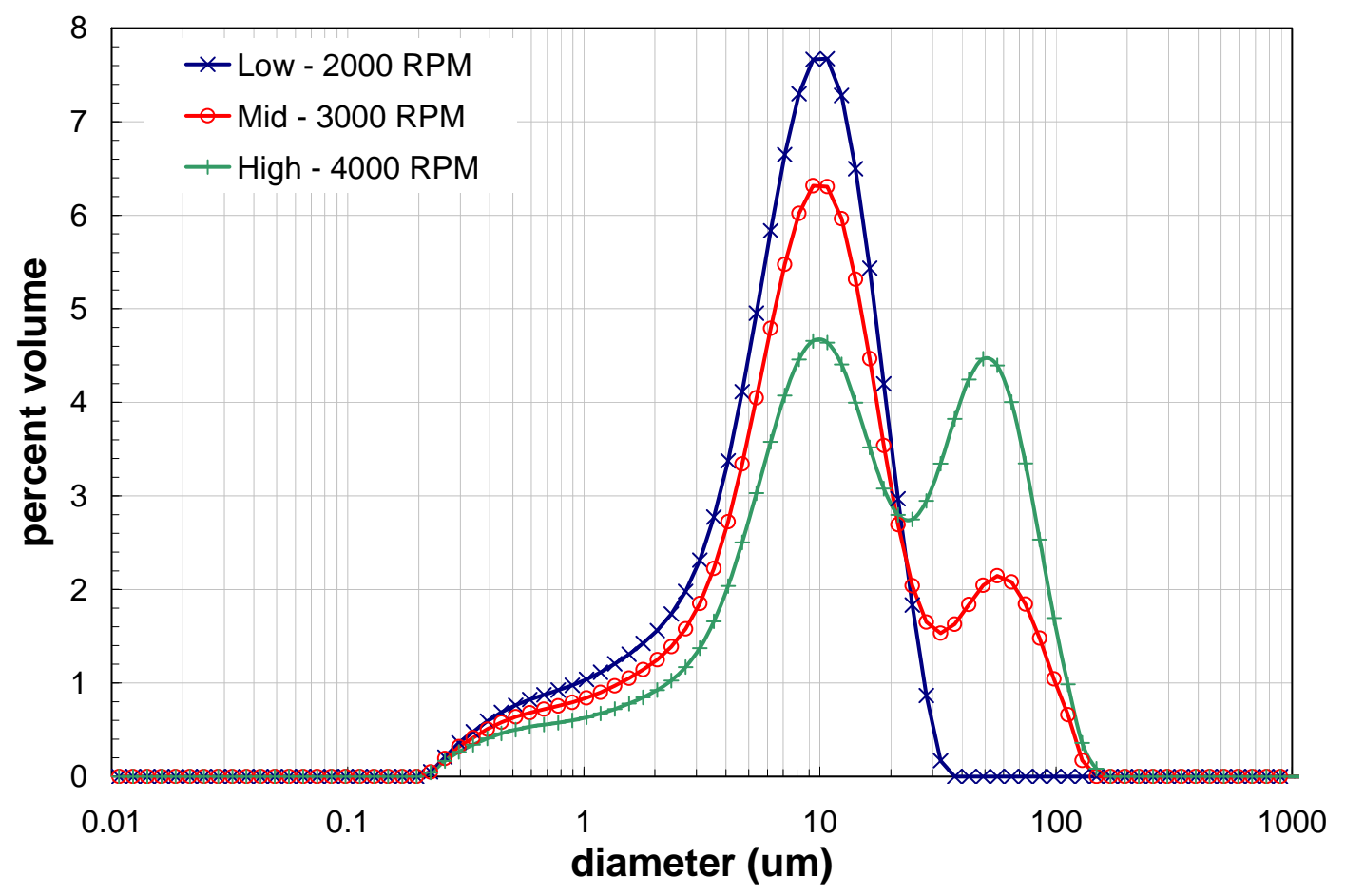

Figure 4.9. Post-Sonication Volume Distribution Result for the Primary Group 4 Initial Characterization Sample as a Function of Pump Speed

Table 4.9 and Table 4.10 show select cumulative oversize percentiles for the primary and duplicate Group 4 particle dispersions. Using the primary results as a reference, the behavior of Group 4 initial characterization particle size as a function of pump speed and sonication can be quantitatively evaluated. Specifically, the following observations can be made:

- In general, the d(10) falls between 1.4 and $3.9 \mu \mathrm{m}$, the $\mathrm{d}(50)$ between 7.9 and $26 \mu \mathrm{m}$, and the $\mathrm{d}(90)$ between 17 and $83 \mu \mathrm{m}$.

- The listed diameter percentiles appear to be sensitive to changes in pump speed, both before and after sonication. Increases in flow rate appear to influence increases in the mean diameter [i.e., the d(50)]. For example, decreasing the pump speed from 4000 RPM to 2000 RPM reduces the mean diameter from 26 to $10 \mu \mathrm{m}$, which is a difference of $\sim 62 \%$. This effect is reduced after sonication, although it is still prevalent because a difference of the same reading is $\sim 44 \%$.

- Sonication of the Group 4 solids dispersion decreases the apparent particle size. The PSD results at 3000 RPM indicate that sonication lowers the mean particle diameter from 20 to $9.7 \mu \mathrm{m}$. This represents a decrease of $\sim 52 \%$ and is significant relative to the measurement accuracy (10\%). 
Table 4.9. Particle-Size Analysis Percentile Results from Primary Group 4 Initial Characterization Sample, TI547-G4-S-WL-PSD-1

\begin{tabular}{||c|c|c|c|c|c||}
\hline $\begin{array}{c}\text { Measurement } \\
\text { Condition }\end{array}$ & Pump Speed & Sonication & $\begin{array}{c}\mathbf{d}(\mathbf{1 0}) \\
{[\boldsymbol{\mu m}]}\end{array}$ & $\begin{array}{c}\mathbf{d}(\mathbf{5 0}) \\
{[\boldsymbol{\mu m}]}\end{array}$ & $\begin{array}{c}\mathbf{d}(\mathbf{9 0}) \\
{[\boldsymbol{\mu m}]}\end{array}$ \\
\hline 1 & 3000 & pre-sonic & 3.2 & 20 & 83 \\
\hline 2 & 4000 & pre-sonic & 3.9 & 26 & 78 \\
\hline 3 & 2000 & pre-sonic & 1.7 & 10 & 27 \\
\hline 4 & 3000 & $25 \%$ & 1.6 & 10 & 23 \\
\hline 5 & 3000 & $50 \%$ & 1.5 & 9.1 & 21 \\
\hline 6 & 3000 & $75 \%$ & 1.5 & 8.2 & 18 \\
\hline 7 & 3000 & post-sonic & 1.8 & 9.7 & 51 \\
\hline 8 & 4000 & post-sonic & 2.5 & 14 & 67 \\
\hline 9 & 2000 & post-sonic & 1.4 & 7.9 & 17 \\
\hline
\end{tabular}

Table 4.10. Particle-Size Analysis Percentile Results from Duplicate Group 4 Initial Characterization Sample, TI547-G4-S-WL-PSD-2

\begin{tabular}{||c|c|c|c|c|c||}
\hline $\begin{array}{c}\text { Measurement } \\
\text { Condition }\end{array}$ & Pump Speed & Sonication & $\begin{array}{c}\mathbf{d}(\mathbf{1 0}) \\
{[\boldsymbol{\mu m}]}\end{array}$ & $\begin{array}{c}\mathbf{d}(\mathbf{5 0}) \\
{[\boldsymbol{\mu m}]}\end{array}$ & $\begin{array}{c}\mathbf{d}(\mathbf{9 0}) \\
{[\mathbf{\mu m}]}\end{array}$ \\
\hline 1 & 3000 & pre-sonic & 2.1 & 12 & 34 \\
\hline 2 & 4000 & pre-sonic & 2.5 & 15 & 48 \\
\hline 3 & 2000 & pre-sonic & 1.8 & 11 & 27 \\
\hline 4 & 3000 & $25 \%$ & 1.8 & 11 & 25 \\
\hline 5 & 3000 & $50 \%$ & 1.7 & 9.3 & 21 \\
\hline 6 & 3000 & $75 \%$ & 1.5 & 8.0 & 17 \\
\hline 7 & 3000 & post-sonic & 1.6 & 8.0 & 19 \\
\hline 8 & 4000 & post-sonic & 1.8 & 9.2 & 36 \\
\hline 9 & 2000 & post-sonic & 1.5 & 7.7 & 17 \\
\hline
\end{tabular}

The behavior of the duplicate sample PSD with respect to pump speed and sonication is similar to that of the primary sample. However, the PSD of the duplicate sample favors consistently smaller diameters than that of the primary at equivalent measurement conditions. Table 4.11 shows the absolute relative percent difference, calculated according to Eq. 3.2, between the $d(10), d(50)$, and $d(90)$ values determined for the primary and duplicate Group 4 initial characterization samples. The listed RPDs indicate that there is a difference between samples.

For particle-size measurements on the Malvern Mastersizer 2000, RPDs of up to $10 \%$ are generally expected given the accuracy of the instrument. The results for Group 4 initial characterization samples are shown in Table 4.11. Before and after sonication, the RPDs varied between 2.3 to $63 \%$, although during sonication, the RPDs remained below $10 \%$. This may indicate that the differences between the primary and duplicate samples are largely a result of agglomeration. 
Table 4.11. Absolute Relative Percent Difference Between Primary and Duplicate Group 4 Initial Characterization Samples

\begin{tabular}{||c|c|c|c|c|c||}
\hline \multirow{2}{*}{$\begin{array}{c}\text { Measurement } \\
\text { Condition }\end{array}$} & \multirow{2}{*}{ Pump Speed } & Sonication & \multicolumn{3}{|c||}{ Absolute RPD } \\
\cline { 4 - 6 } & & $\mathbf{d}(\mathbf{1 0})$ & $\mathbf{d}(\mathbf{5 0 )}$ & $\mathbf{d}(\mathbf{9 0})$ \\
\hline 1 & 3000 & pre-sonic & $34 \%$ & $39 \%$ & $59 \%$ \\
\hline 2 & 4000 & pre-sonic & $34 \%$ & $43 \%$ & $38 \%$ \\
\hline 3 & 2000 & pre-sonic & $5.9 \%$ & $4.9 \%$ & $2.4 \%$ \\
\hline 4 & 3000 & $25 \%$ & $11 \%$ & $7.7 \%$ & $9.9 \%$ \\
\hline 5 & 3000 & $50 \%$ & $8.7 \%$ & $2.8 \%$ & $1.7 \%$ \\
\hline 6 & 3000 & $75 \%$ & $4.8 \%$ & $1.9 \%$ & $2.7 \%$ \\
\hline 7 & 3000 & post-sonic & $13 \%$ & $17 \%$ & $63 \%$ \\
\hline 8 & 4000 & post-sonic & $28 \%$ & $35 \%$ & $46 \%$ \\
\hline 9 & 2000 & post-sonic & $4.4 \%$ & $2.3 \%$ & $3.6 \%$ \\
\hline
\end{tabular}

Figure 4.10 and Figure 4.11 show how the differences in the primary and duplicate PSDs described in the preceding paragraphs manifest in the differential volume distributions. Figure 4.10 compares the primary and duplicate PSDs at 3000 RPM before sonication. There are two major discrepancies in the pre-sonic measurements between the PSD of the primary and the duplicate. The duplicate sample demonstrates a uni-modal peak that ranges from 0.2 to $100 \mu \mathrm{m}$, while the primary sample exhibits a bi-modal peak with a range from 0.2 to $170 \mu \mathrm{m}$.

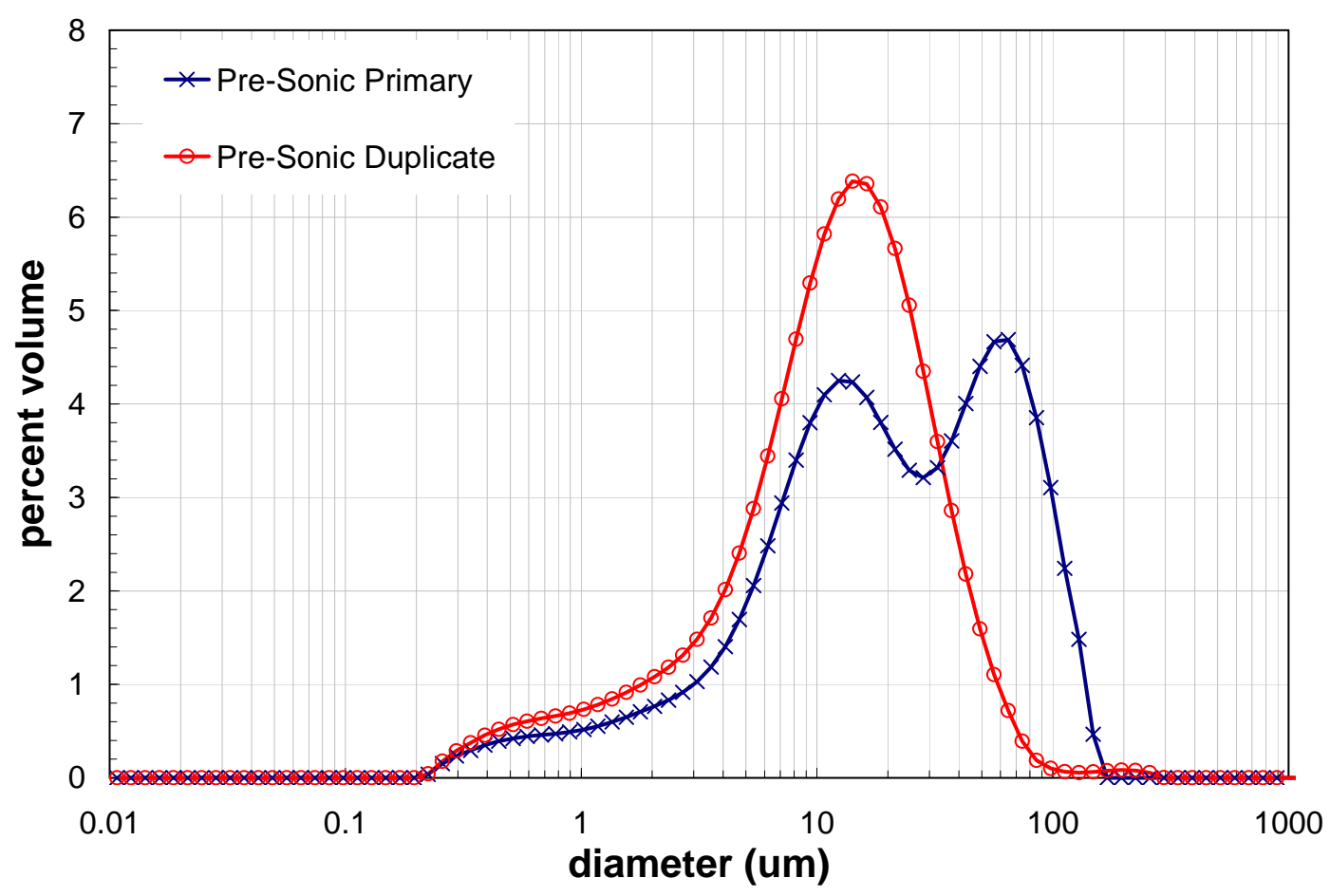

Figure 4.10. Comparison of Primary and Duplicate Sample Differential Volume PSD of Group 4 Initial Characterization at 3000 RPM before Sonication 
The after-sonication distribution, shown in Figure 4.11, exhibits more similar trends than were observed before sonication. Both the primary and duplicate ranged from approximately 0.2 to $130 \mu \mathrm{m}$, although the primary extended slightly to $150 \mu \mathrm{m}$. In both instances, a major peak was observed around 9 to $11 \mu \mathrm{m}$, and a minor peak was observed around 50 to $75 \mu \mathrm{m}$. The primary had a larger secondary peak, which, in accordance with the before-sonication comparison, would indicate that the primary sample had a greater degree of agglomeration as this secondary peak did not exist during sonication. Therefore, the primary sample may have resulted in a higher fraction of larger particles and/or agglomerates than the secondary.

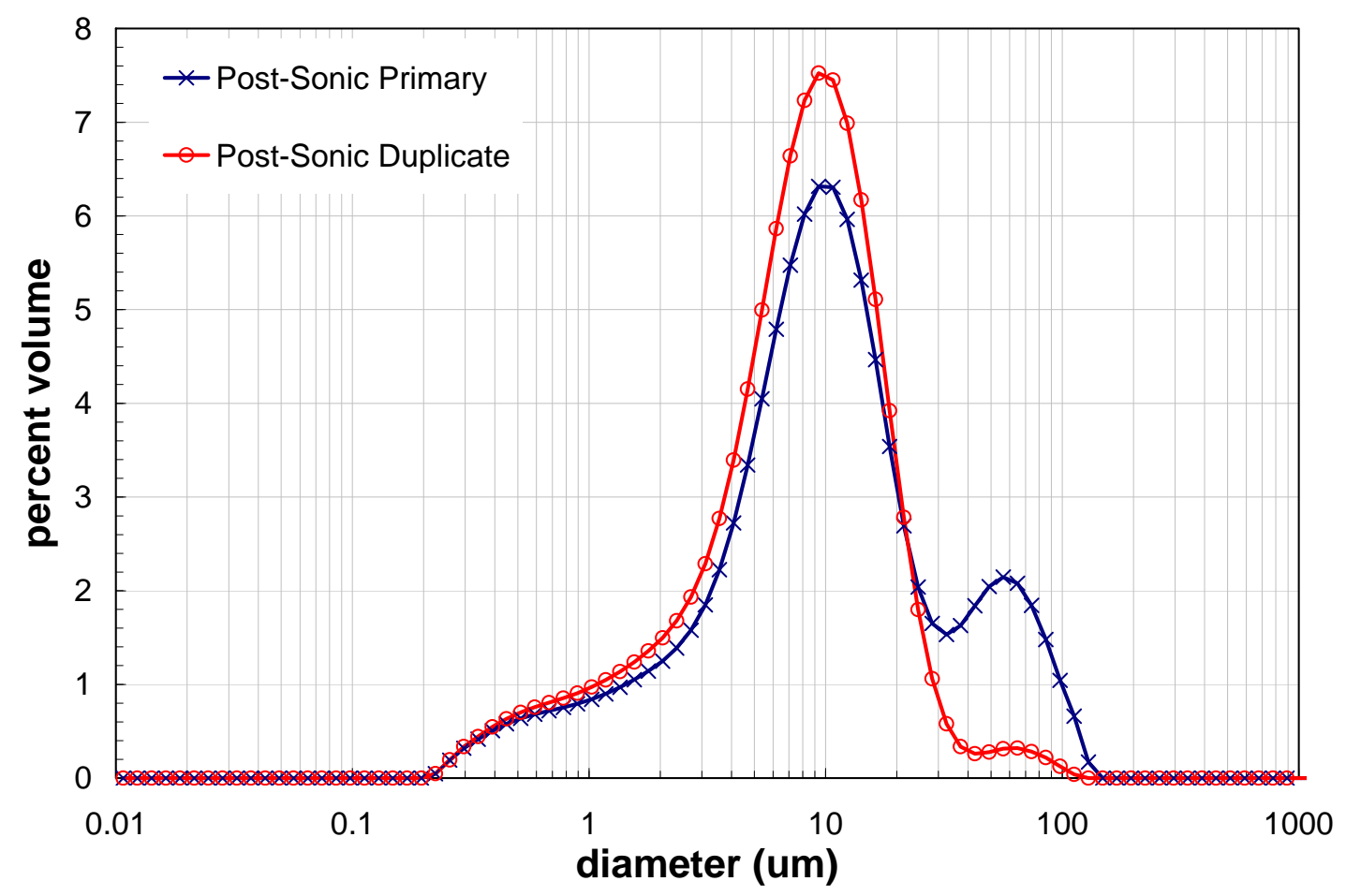

Figure 4.11. Comparison of Primary and Duplicate Sample Differential Volume PSD of Group 4 Initial Characterization at 3000 RPM after Sonication

In summary, the results of the initial characterization of Group 4 (CWR sludge solids) samples indicate a broad distribution ranging from 0.2 to $200 \mu \mathrm{m}$. The PSD was heavily influenced by the pump speed, with a rise in population of $>30-\mu \mathrm{m}$ particles as the flow rate was increased. The larger solids appear to be agglomerates as they are easily disrupted by sonication. These agglomerates are recovered after sonication, although recovery was not complete during the time of the measurement.

\subsubsection{Surface Area}

Surface area was measured as discussed in Appendix C, section C.3.2. Duplicate samples (0.46 g each) tested for surface area resulted in 3.2 and $2.5 \mathrm{~m}^{2} / \mathrm{g}$, averaging $2.8 \mathrm{~m}^{2} / \mathrm{g}$, with a relative percent difference of $\pm 13 \%$. 


\subsubsection{Crystal Form and Habit}

The raw and background-subtracted XRD patterns for Group 4 CWR are provided in Figure 4.12; the background-subtracted XRD pattern is presented with the stick-figure phase identification. The XRD pattern was dominated by gibbsite (crystal density $2.420 \mathrm{~g} / \mathrm{cm}^{3}$, JADE Version 8.0 ) with a nearly perfect lineup with the standard gibbsite diffraction peaks. The low background in the raw spectrum indicated that the material was highly crystalline. 
(a)

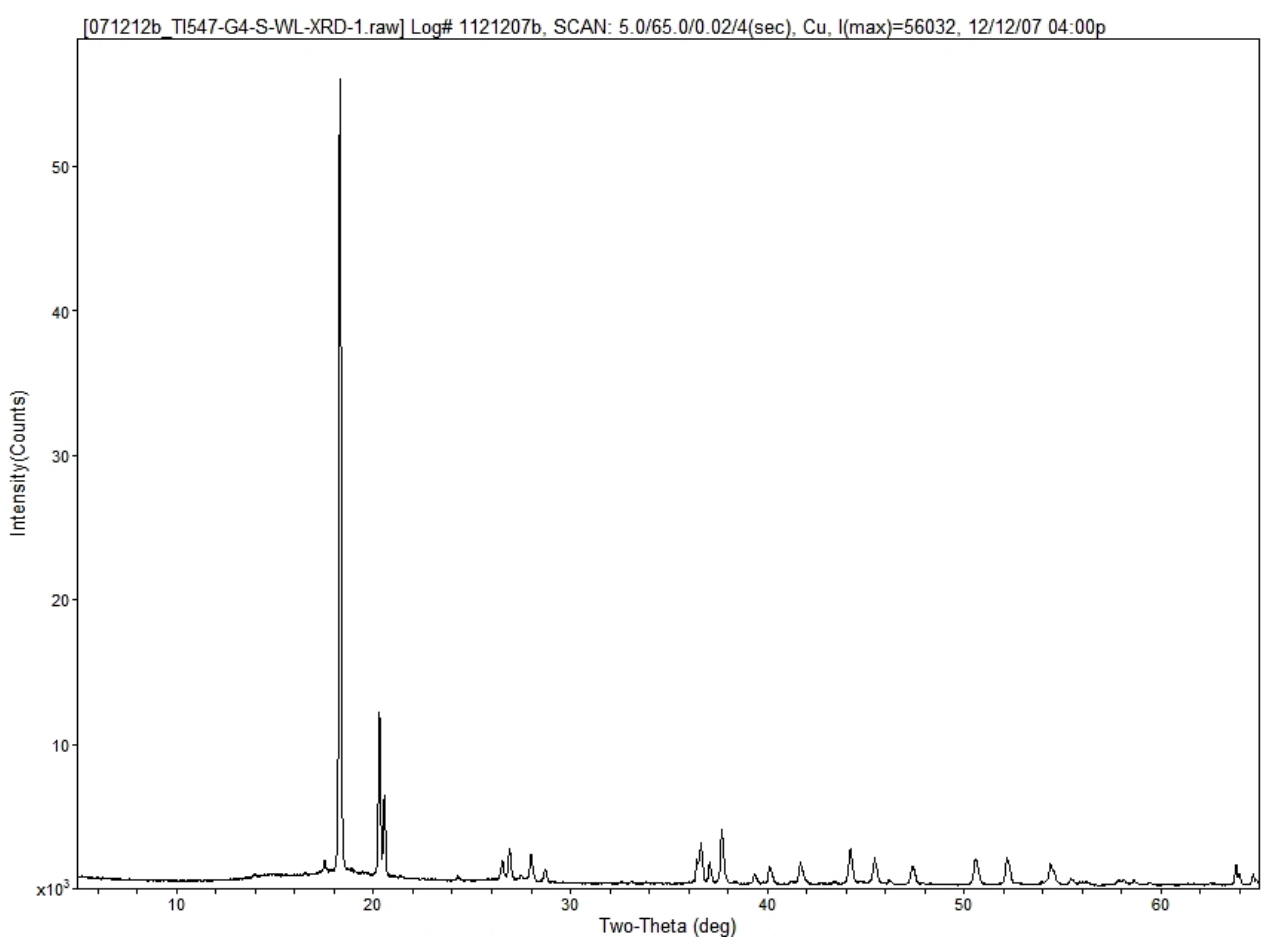

(b)

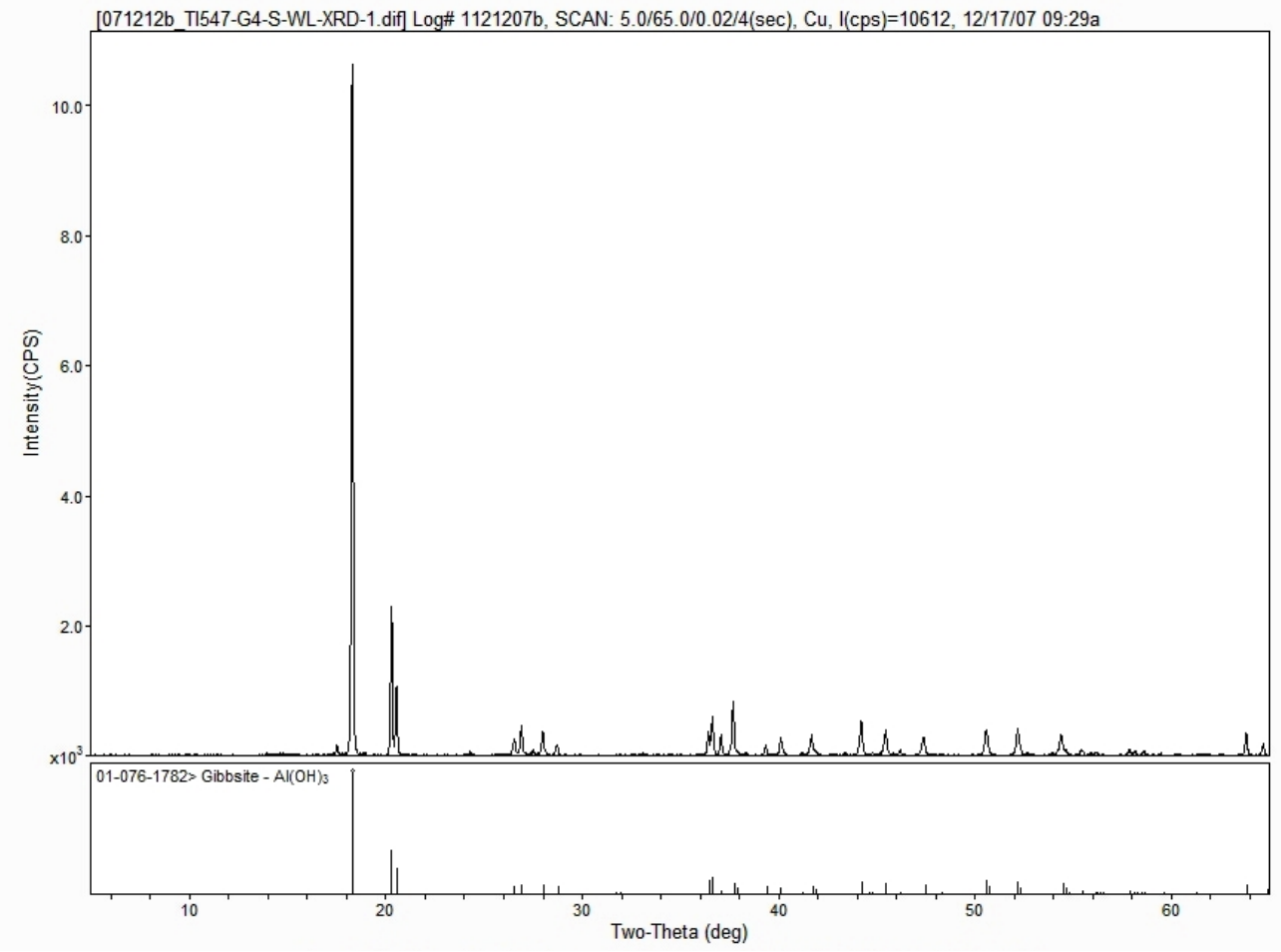

Figure 4.12. XRD Pattern of Washed Group 4 CWR Sludge, (a) Raw Diffraction Pattern and (b) Background-Subtracted Diffraction Pattern with Stick-Figure Peak Identification of Gibbsite 
Figure 4.13 shows the background-subtracted spectrum with an expanded intensity-scale to better discern the lower intensity peaks. In this sample, rutile $\left(\mathrm{TiO}_{2}\right)$ was added as an internal standard. A minor phase of sodium aluminum silicate hydrate $\left[\left(\mathrm{Na}_{2} \mathrm{O}\right)_{1.31} \mathrm{Al}_{2} \mathrm{O}_{3}\left(\mathrm{SiO}_{2}\right)_{2.01}\left(\mathrm{H}_{2} \mathrm{O}\right)_{1.65}\right]$ (crystal density $6.766 \mathrm{~g} / \mathrm{cm}^{3}$, JADE Version 8.0) was found with a good fit to the major and confirming diffraction lines. Minor contributions from boehmite (AlOOH, crystal density $2.672 \mathrm{~g} / \mathrm{cm}^{3}$, JADE Version 8.0), quartz $\left(\mathrm{SiO}_{2}\right.$, crystal density $2.765 \mathrm{~g} / \mathrm{cm}^{3}$, JADE Version 8.0$)$, vaterite $\left(\mathrm{CaCO}_{3}\right.$, crystal density $2.600 \mathrm{~g} / \mathrm{cm}^{3}$, JADE Version 8.0), sodium uranium oxide $\left(\mathrm{Na}_{6} \mathrm{U}_{7} \mathrm{O}_{24}\right.$, crystal density $22.609 \mathrm{~g} / \mathrm{cm}^{3}$, JADE Version 8.0), and lepidocrocite $(\mathrm{FeO}[\mathrm{OH}])$ were shown as possibly present. In these cases, only one diffraction line was identified; intensities of confirming lines were too low to detect.

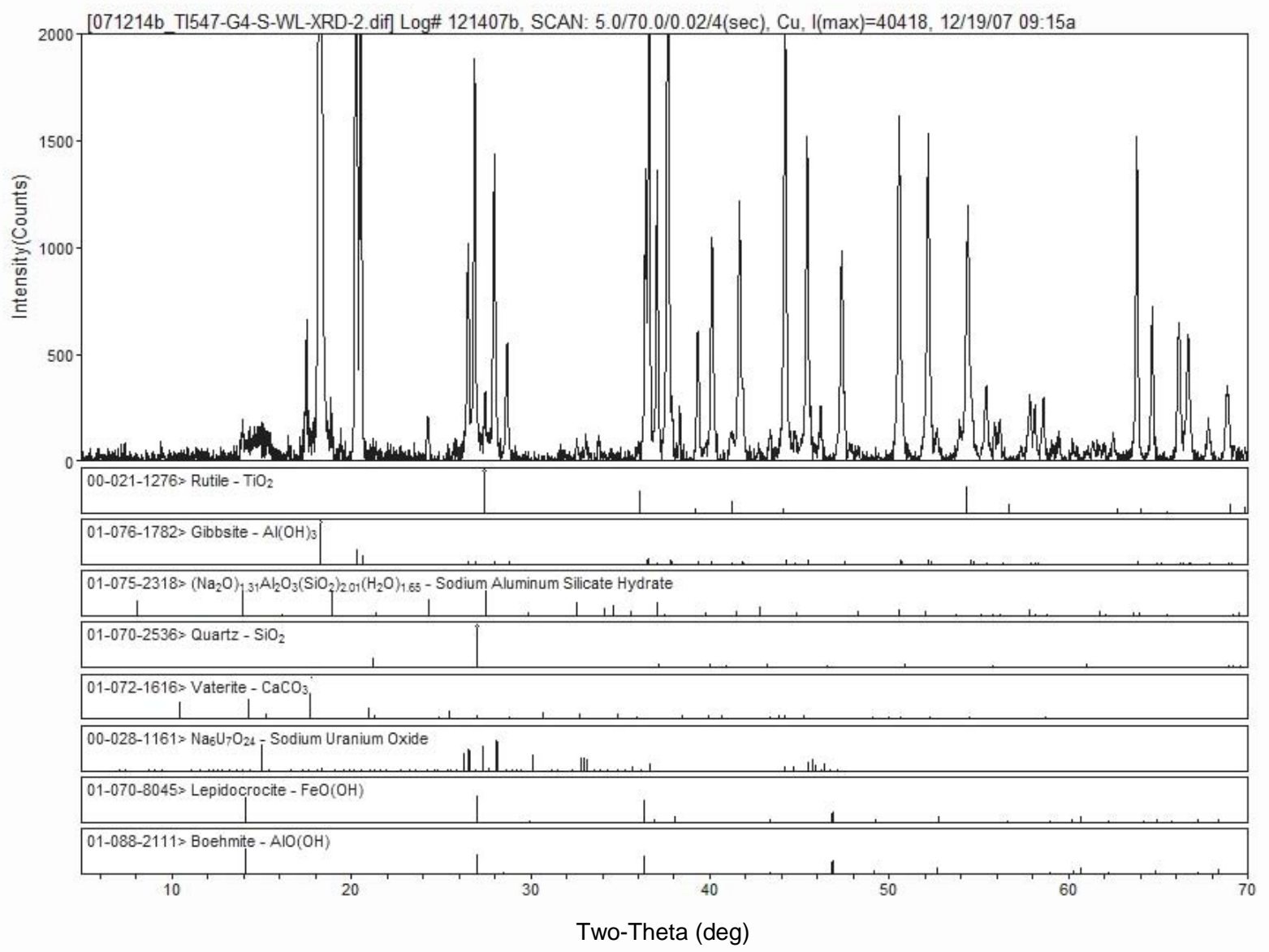

Figure 4.13. XRD Pattern of Washed Group 4 CWR Sludge Focusing on Lower-Intensity Lines, Background-Subtracted with Stick-Figure Peak Identification (rutile is the internal standard)

In an effort to better understand the concentration of $\mathrm{Al}$ as gibbsite in this material, the relative abundances of Al-bearing phases, sodium aluminum silicate hydrate and boehmite, were evaluated relative to gibbsite. An indication of the relative concentrations of these phases was obtained from Whole Pattern Fitting analysis using relative intensity ratio (RIR) values. The average sodium aluminum silicate hydrate-to-gibbsite phase ratio from four XRD sample preparations was 0.0163. Similarly, the boehmite- 
to-gibbsite phase ratio was determined to be 0.0080 . Both values were associated with high uncertainty because of their low peak intensities.

Using the phase ratios in conjunction with the chemical analysis, the approximate mass percent of the Albearing phases was determined. Table 4.12 summarizes the best estimate of mass percent of phases in the solids. Phases are listed as "observed" if recognized in the XRD pattern. The minor phases determined based on only one diffraction peak (low intensity) were assigned as "possible” phases.

Table 4.12. Weight Percent of Group 4 CWR Sludge Mineral Phases, Best Estimate

\begin{tabular}{|c|c|c|c|}
\hline Crystalline Phase & Chemical Structure & $\begin{array}{l}\text { Weight } \\
\%\end{array}$ & Basis $^{(a)}$ \\
\hline Gibbsite & $\mathrm{Al}(\mathrm{OH})_{3}$ & 91.2 & Observed/RIR \\
\hline Sodium aluminum silicate hydrate & $\left(\mathrm{Na}_{2} \mathrm{O}\right)_{1.31} \mathrm{Al}_{2} \mathrm{O}_{3}\left(\mathrm{SiO}_{2}\right)_{2.0}$ & 1.5 & Observed/RIR \\
\hline Boehmite & $\mathrm{AlOOH}$ & 0.73 & e/RIR \\
\hline Sodium uranium oxide & 24 & & \\
\hline $\begin{array}{l}\text { Bi, Ca, Cr, Fe, Mn, Pb, Si, Sr, and } \\
\mathrm{Zn}\end{array}$ & Unknown formulation & 1.5 & \\
\hline $\mathrm{Na}$ (unknown compound) & 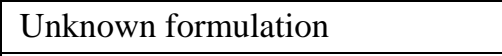 & 0.81 & lated \\
\hline Entra & V arious (NalNu 3 , NalN & 0.027 & \\
\hline Balanc & Assu & 3.73 & \\
\hline \multicolumn{2}{|l|}{ Sum } & 100.0 & \\
\hline \multicolumn{4}{|c|}{$\begin{array}{l}\text { (a) Observed indicates that the characteristic crystal diffraction pattern of the identified } \\
\text { crystalline phase was observed in the sample XRD pattern. } \\
\text { RIR indicates that the mass fraction was determined in conjunction with the relative phase } \\
\text { ratios from XRD examination. } \\
\text { Possible indicates that only one line of the characteristic crystal diffraction pattern was } \\
\text { observed, and its intensity was only slightly above background. Intensities of confirming lines } \\
\text { were too low to detect; therefore, the assigned crystalline phase should be considered with } \\
\text { caution. } \\
\text { Chemical Analysis indicates that the mass fraction was based strictly on the chemical analysis } \\
\text { and is associated with the metals; counterions are not included in the mass fraction; phase } \\
\text { identification could not be discerned. } \\
\text { Calculated for the Na indicates the Na mass fraction remaining after subtracting the Na } \\
\text { associated with other compounds (sodium aluminum silicate hydrate and sodium uranium } \\
\text { oxide). Calculated for the entrained supernatant indicates the mass associated with } \\
\text { supernatant entrainment based on the dilution factor during solids washing. } \\
\text { Weight percent values are calculated based on the concentrations of analytes as measured by } \\
\text { ICP. }\end{array}$} \\
\hline
\end{tabular}

Only one Si-bearing phase was identified; therefore, all of the [Si] in the solids was attributed to this phase. Similarly, the entire concentration of $U$ in the solids was applied to the possible phase of sodium uranium oxide; the presence of other $U$ phases would simply serve to decrease this phase concentration to $<0.49 \mathrm{wt} \%$. The [Al] associated with the sodium aluminum silicate hydrate was subtracted from the gross [Al], and the net remaining $\mathrm{Al}$ was mathematically split between the two phases gibbsite and boehmite per the XRD-determined phase ratios. The entrained-salts component was determined from the calculated dilution of entrained supernatant in the wet centrifuged solids; because of the extensive washing, 
supernatant entrainment was small. The relative Na masses associated with other phases (sodium uranium oxide and sodium aluminum silicate hydrate) and entrainment were subtracted from the total solids Na concentration, resulting in a net $72 \mathrm{wt} \%$ Na unaccounted for; this correlated to $~ 0.81 \mathrm{wt} \%$ of the composite solids and indicated that other unidentified minor mineral phases containing Na were present.

Figure 4.14 shows the best estimate of the phase ratios after correcting for the entrained supernatant salts (only $0.027 \mathrm{wt} \%$ ) from the composition. Gibbsite comprised $91 \mathrm{wt} \%$ of the mass fraction of the total washed solids composite. The best estimate of the Al fractionation in Group 4 CWR waste is that $>98$ $\mathrm{wt} \%$ of the $\mathrm{Al}$ is present in the form of gibbsite.

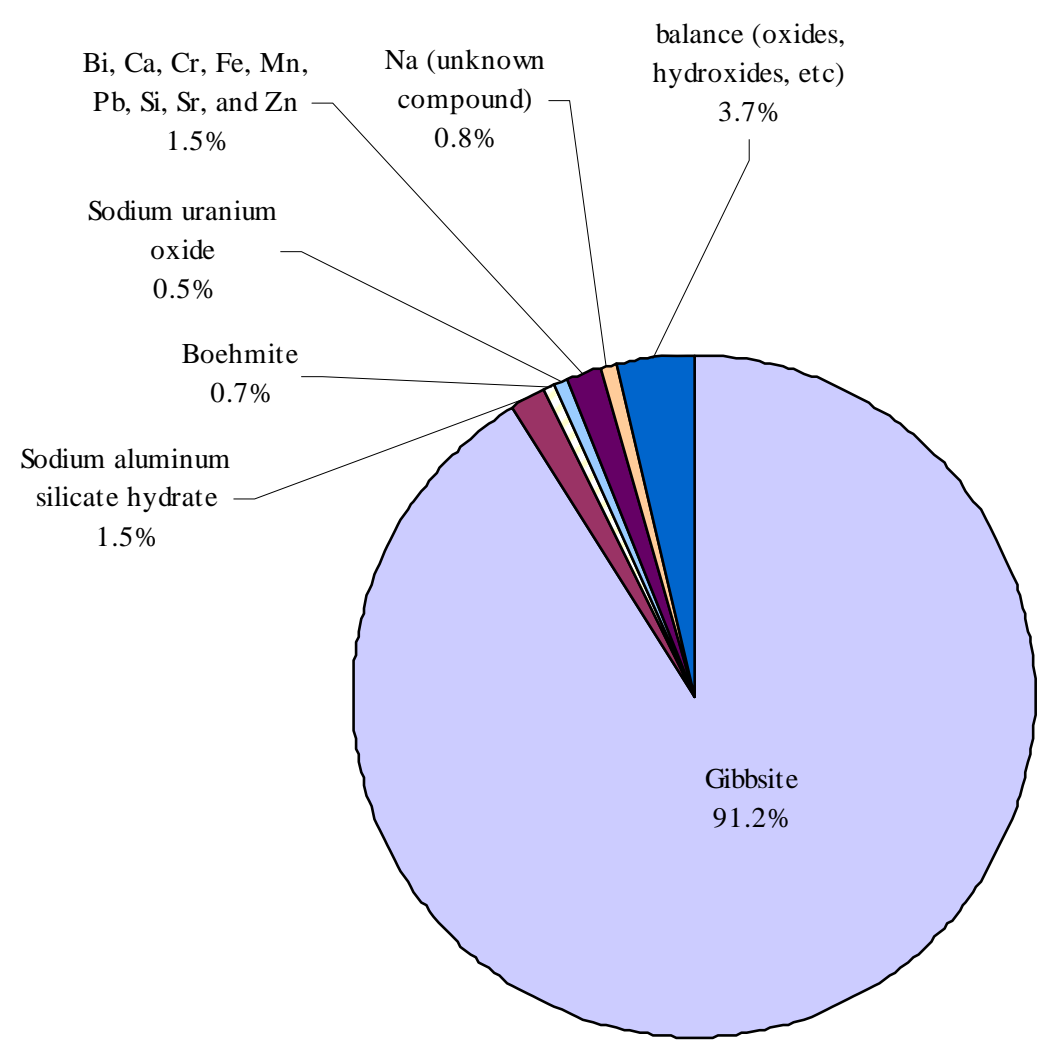

Figure 4.14. Washed Group 4 CWR Sludge Phase Composition (entrained supernatant removed), Best Estimate

The nominal gibbsite crystallite size was estimated to be 1700, 3150, 1280, and $1770 \AA$ (average $2000 \pm 800 \AA$ or $0.20 \pm 0.08 \mu \mathrm{m}$ ) based on the application of a simplistic crystallite size evaluation to four sample preparation mounts. ${ }^{\text {(a) }}$ The variation in crystallite size highlights the uncertainties in the analysis, and interpretations should be used with caution.

Several SEM images of the washed solids are shown in Figure 4.15 though Figure 4.20. The material is dominated by gibbsite. Typical gibbsite structures are seen as monoclinic prismatic-tabular platelets,

(a) The Jade operating software applied the Scherrer equation to estimate the crystallite size (Klug and Alexander 1974). 
consistent with the XRD analysis. Figure 4.15 shows blade-like material, rod-like acicular shapes, and non-descript globular materials. Rectangular platelets are also present where the $90^{\circ}$ external angles clearly do not match the $60^{\circ}$ and $120^{\circ}$ angles found in the gibbsite. Figure 4.16 and Figure 4.17 show a large ( $\sim 00 \mathrm{~m}$ diameter) amorphous structure; its composition is undefined. 


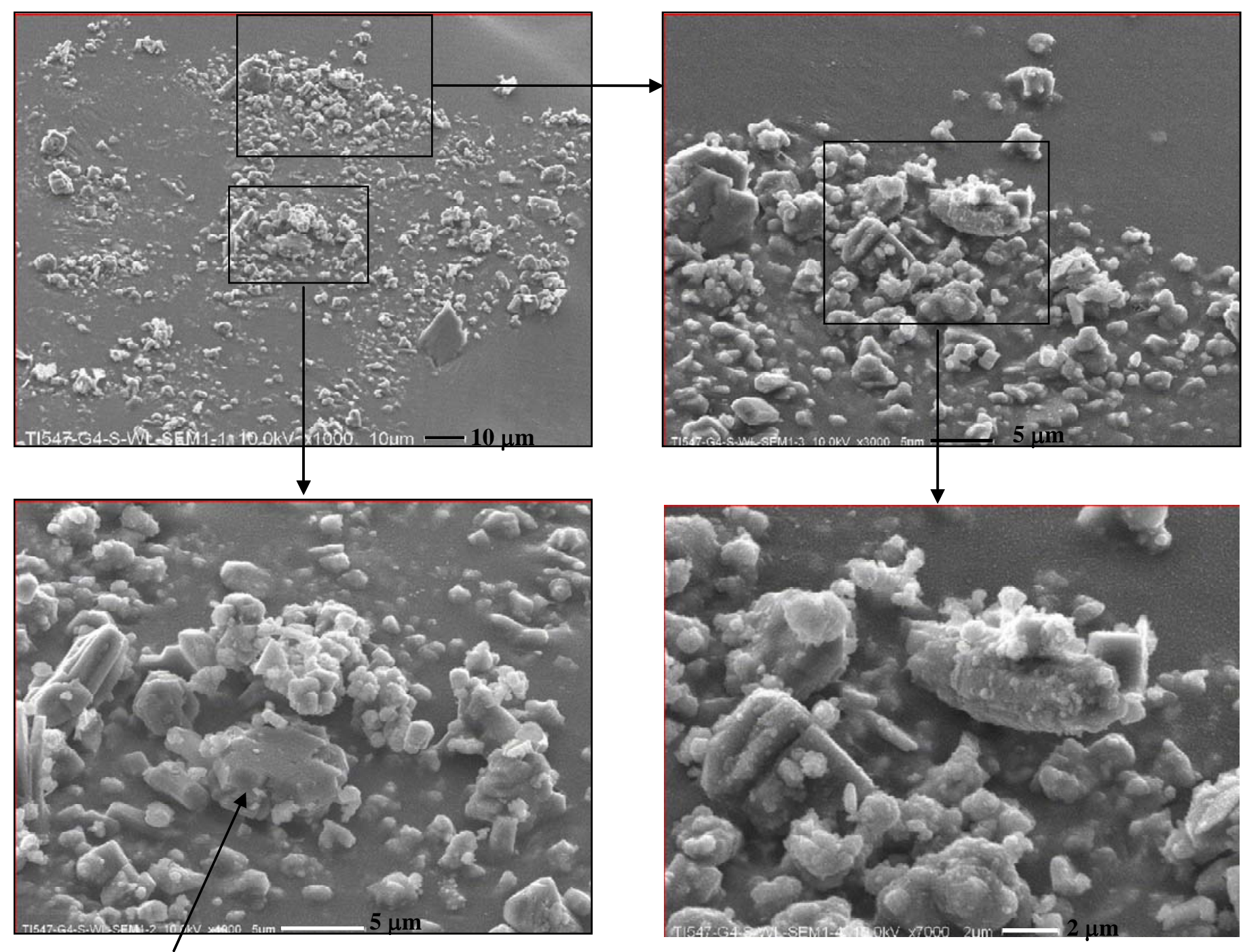

Typical gibbsite structures

Figure 4.15. SEM Images of Washed Group 4 CWR Sludge, Various Magnifications and Views 


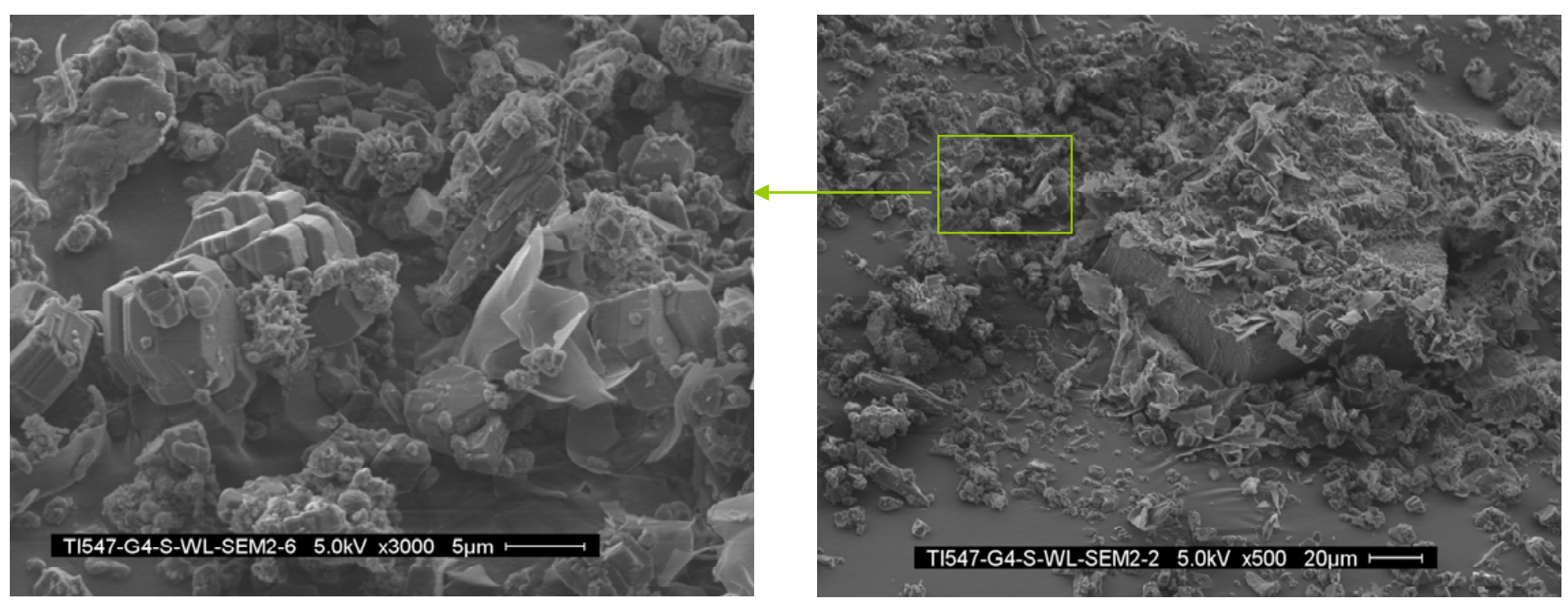

$\stackrel{\overrightarrow{0}}{0}$

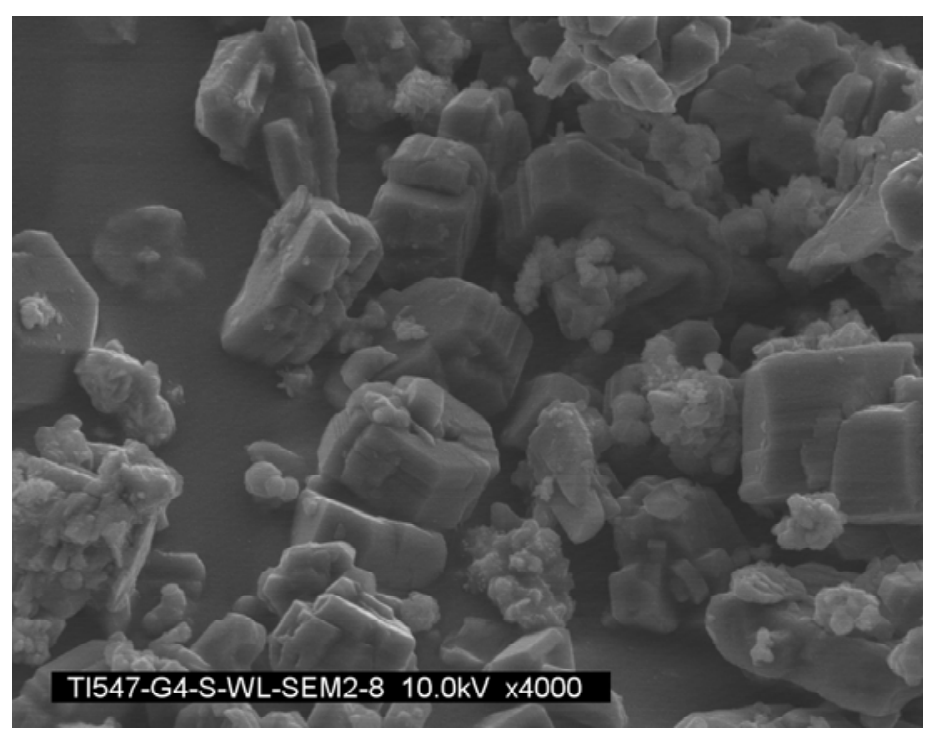

Figure 4.16. SEM Images of Washed Group 4 CWR Sludge 
Figure 4.17 shows three magnifications of particles associated with the large amorphous structure. Also evident are thin sheets (like tissue paper), which are also not defined.

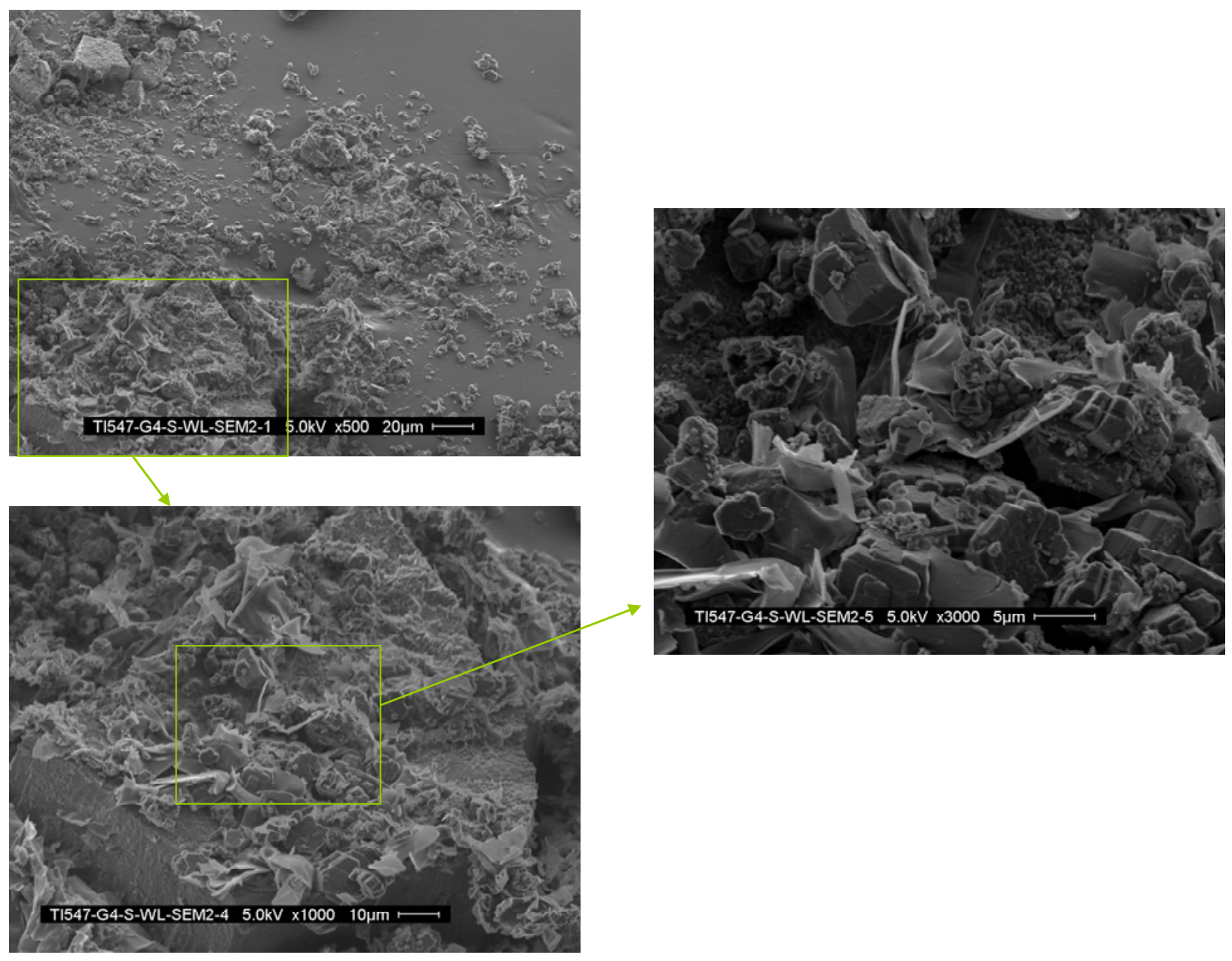

Figure 4.17. SEM Images of Washed Group 4 CWR Sludge

Figure 4.18 through Figure 4.20 show SEM images with EDS evaluations. Most structures in the sample were associated with $\mathrm{Al}$ and $\mathrm{O}$, confirming the gibbsite composition. The rod-like acicular material was associated with $\mathrm{Al}, \mathrm{Si}, \mathrm{Na}, \mathrm{O}$ and possibly C. Figure 4.20 pictures large angular fragments with possible conchoidal fracture (similar structures were noted with the Group 3 CWP SEM images). Spot and area EDS scans resulted in the detection of $\mathrm{Na}, \mathrm{Al}, \mathrm{O}, \mathrm{C}, \mathrm{Si}, \mathrm{Pb}, \mathrm{U}, \mathrm{Ca}, \mathrm{Cr}, \mathrm{Mn}$, and Fe. The elemental mixture may represent more than one compound. 


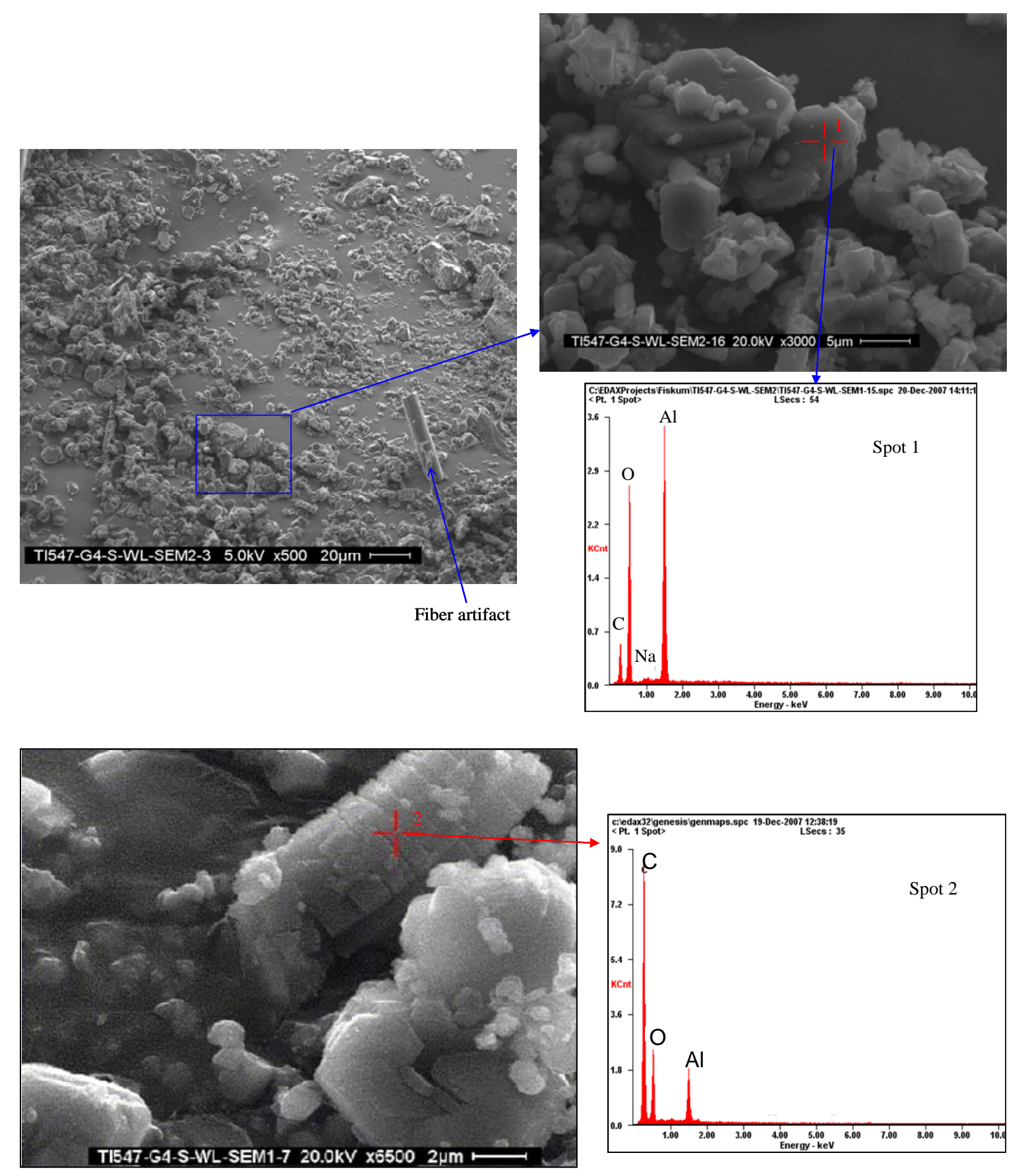

Figure 4.18. SEM Images with EDS of Washed Group 4 CWR Sludge 

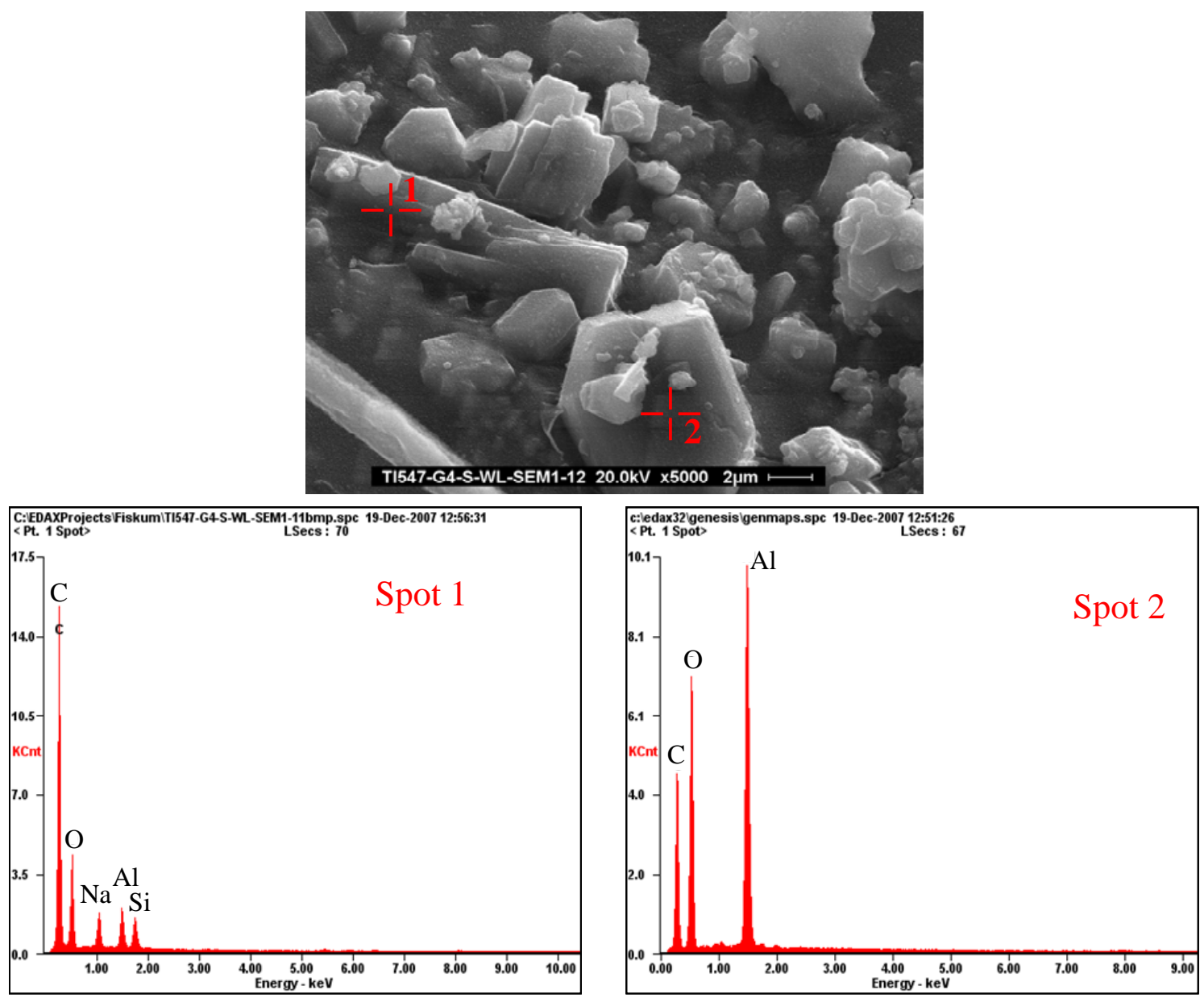

Figure 4.19. SEM Image with EDS of Group 4 CWR with EDS Examination 

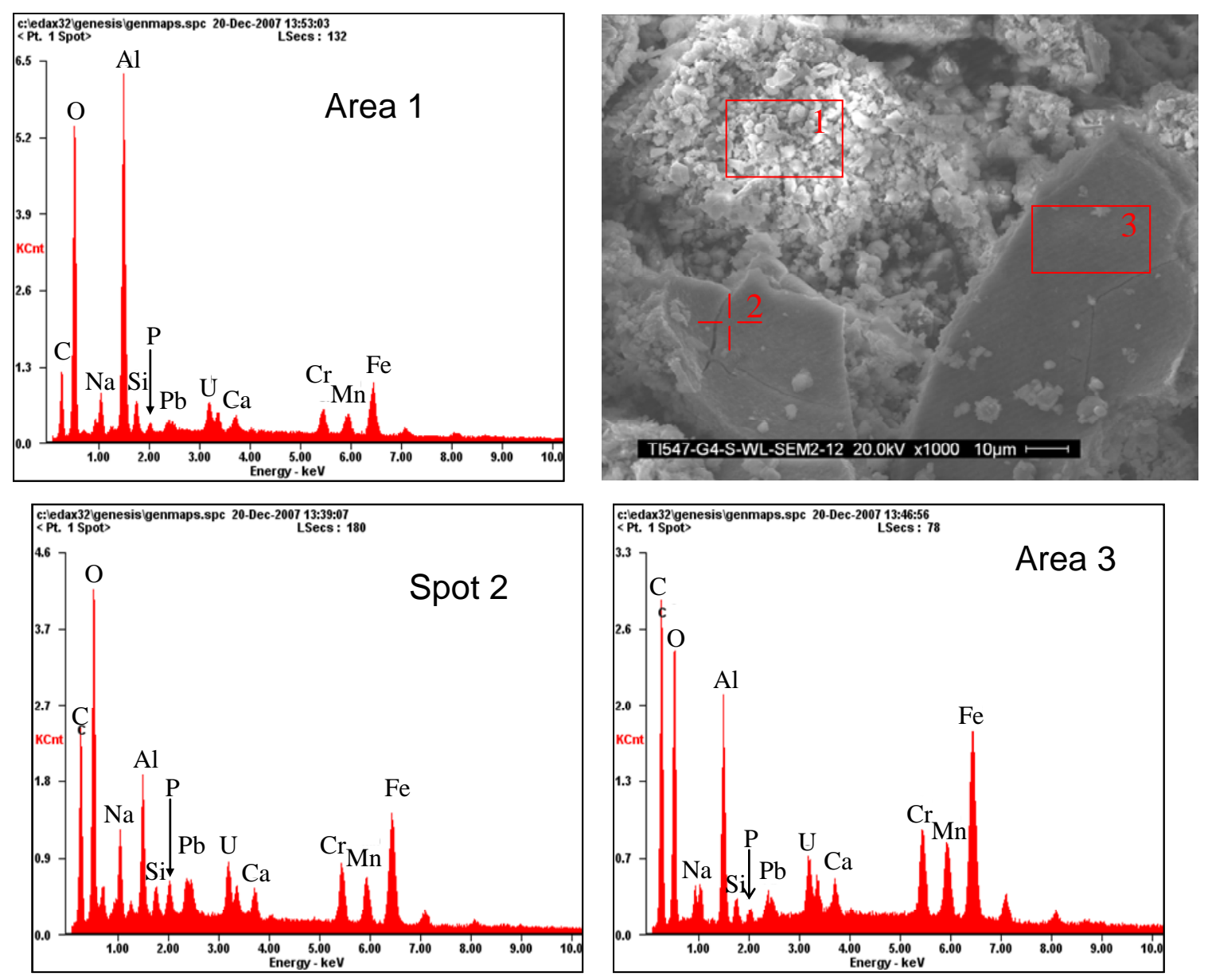

Figure 4.20. SEM Image with EDS of Group 4 CWR with EDS Examination

As determined by XRD and SEM analyses, the Group 4 solids were mainly composed of gibbsite. A gibbsite particle as imaged by STEM is shown in Figure 4.21a (large bright particle in center of micrograph). The particle was identified as an aluminum oxide compound (gibbsite) by EDS analysis (Figure 4.21b). The wispy material in the vicinity of the white gibbsite particle is an iron-chromium oxide. 
(a)

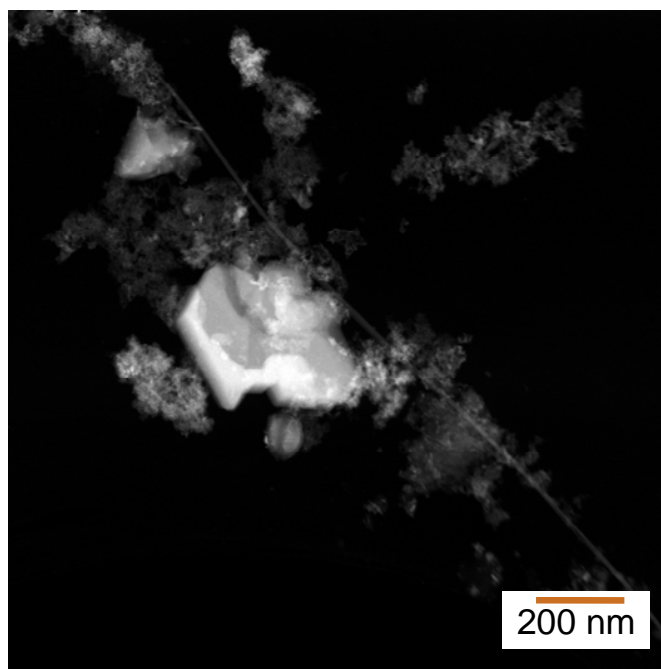

(b)

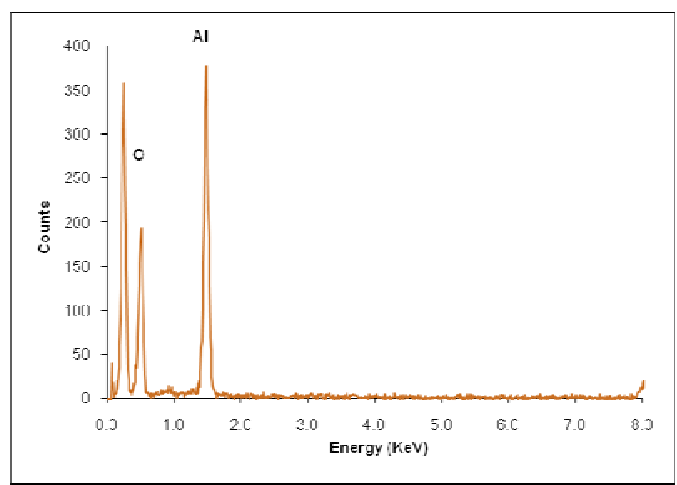

Figure 4.21. (a) STEM-HAADF Image and (b) EDS Analysis of a Gibbsite Particle in Washed Group 4 Solids.

The morphological features of the relatively large gibbsite particles were not well-represented in transmission electron micrographs, possibly because their large size may have led them to be artificially excluded during sample preparation (i.e., they were too large to become attached to the TEM grid). However, large aluminum oxide particles were observed during the TEM analysis that were consistent with gibbsite. The gibbsite particles were well-characterized by SEM. Therefore, TEM was used to identify other materials of interest in the washed Group 4 solids. Several minor or trace phases were observed in the solids by TEM, including uranium phases, iron phases, cancrinite, boehmite, and iron silicates.

A transmission electron micrograph of an agglomerated particle is shown in Figure 4.22. The particle contained several different phases, and this illustrates some of the great variety in particle morphologies and sizes seen in typical Hanford tank-waste sludge. Overall, the agglomerate was 10 to $15 \mu \mathrm{m}$ across; it was non-spherical and highly heterogeneous. Individual phases within the agglomerate ranged in size from a few microns (the cancrinite phase) to a few nanometers (the iron phase). The regions ( $a$ and $b$ ) highlighted in Figure 4.22 are described in more detail in Figure 4.24. 


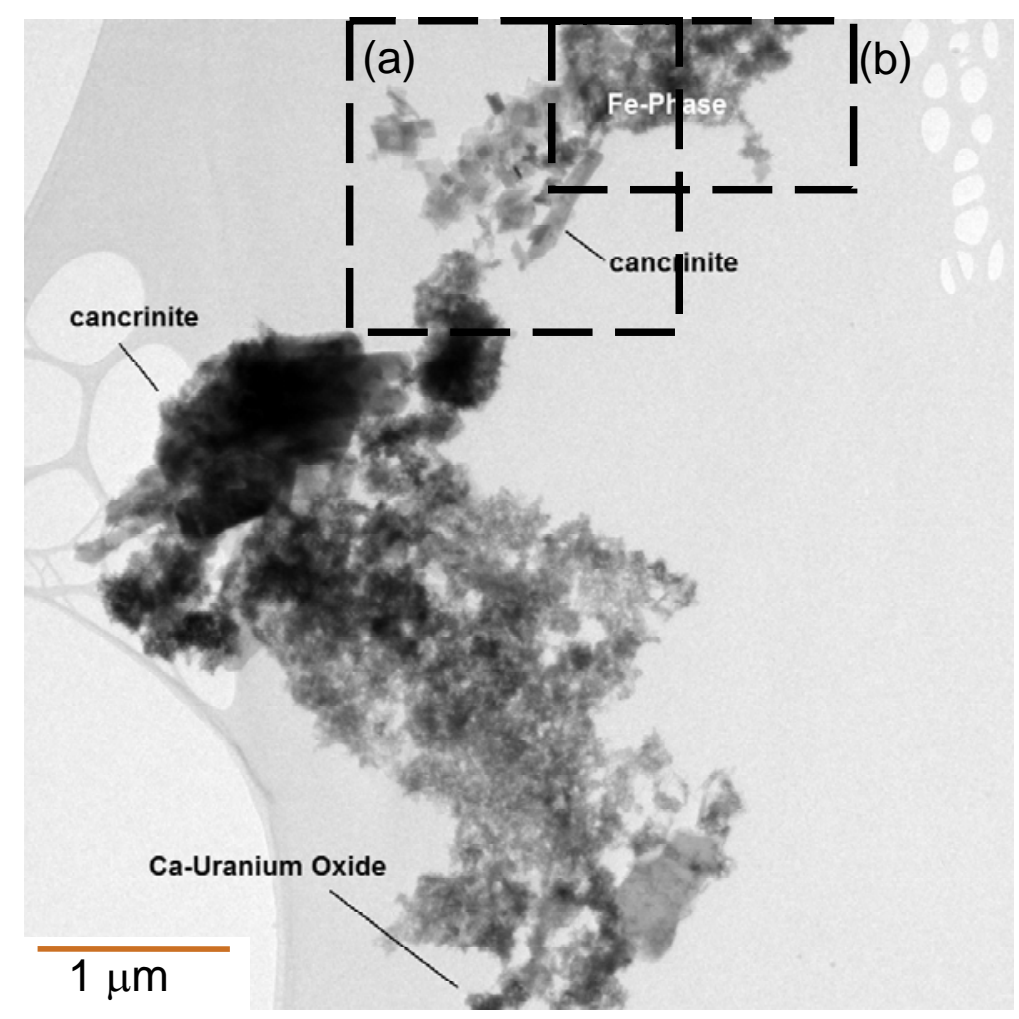

Figure 4.22. TEM Image of Particle Agglomerate Showing an Amorphous Iron-Bearing Region, Cancrinite, and a Calcium Uranium Oxide

Figure 4.23 shows a wispy-like material in the washed Group 4 solids. When an EDS nano-probe was placed on a region within the material, the analysis revealed a large number of different elements. This demonstrated the very fine phase nature of the tank-sludge sample. The compositional analysis indicated the presence of aluminum, silicon, lead, iron, calcium, uranium, chromium, manganese, and phosphorusbearing particles as major components (similar to the SEM/EDS examination provided in Figure 4.20).

(a)

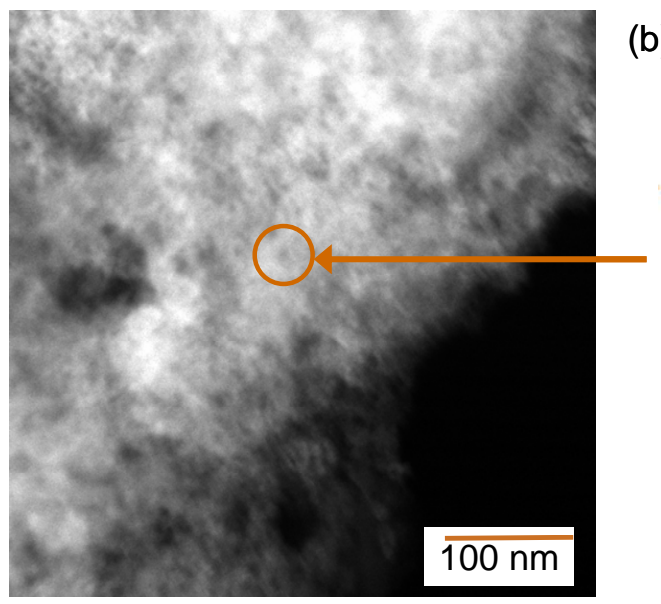

(b)

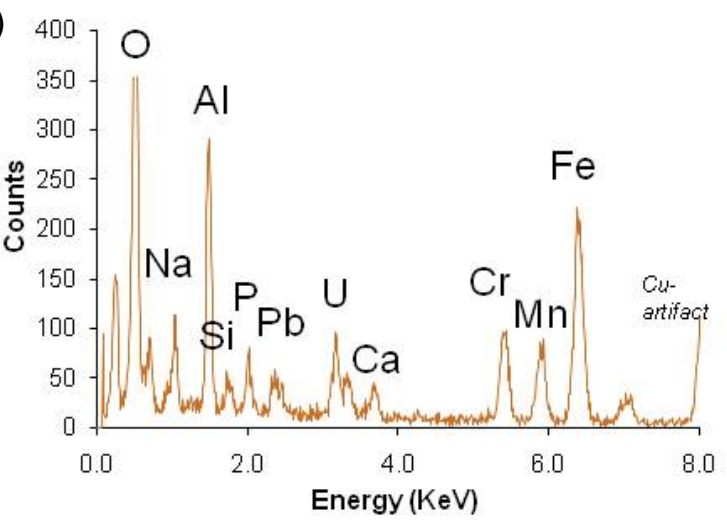

Figure 4.23. (a) High Magnification STEM-HAADF Image and (b) EDS Analysis of Uranium-Bearing Material in the Washed Group 4 Solids. 
Boehmite particles were also found in the Group 4 solids, supporting the possible identification by XRD (Figure 4.13 and Table 4.12). TEM images of the boehmite particles are shown in Figure 4.24. The boehmite particles ranged in size from $50 \mathrm{~nm}$ to $300 \mathrm{~nm}$ across. They have a platy nature and appeared in many cases to be tenaciously stuck to other boehmite particles and other amorphous particulates. The boehmite particles exhibited the classical morphology that has been observed in other Hanford tanksludge samples. The image of these particles is taken from a small region shown in Figure 4.22.
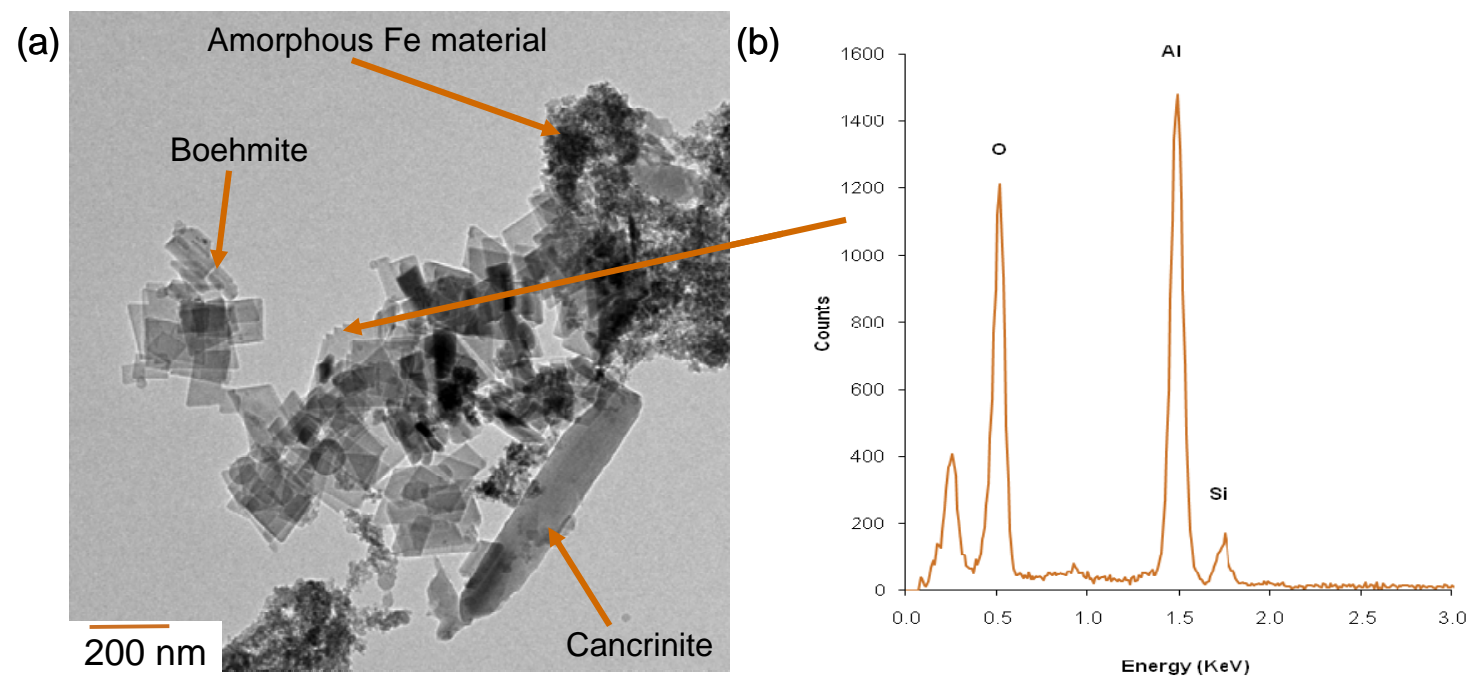

Figure 4.24. TEM Images of Washed Group 4 Solids. (a) Boehmite crystals and a cancrinite particle, (b) EDS of the boehmite phase.

Cancrinite was observed throughout the sample. An example of large 2- to 3- $\mu \mathrm{m}$ size particles is shown in Figure 4.25 and Figure 4.26. Figure 4.26 also shows an electron diffraction analysis of the cancrinite phase. The morphology of the cancrinite particles observed in the Group 4 solids is considerably different from that seen for the Group 3 solids (Section 3.3). 


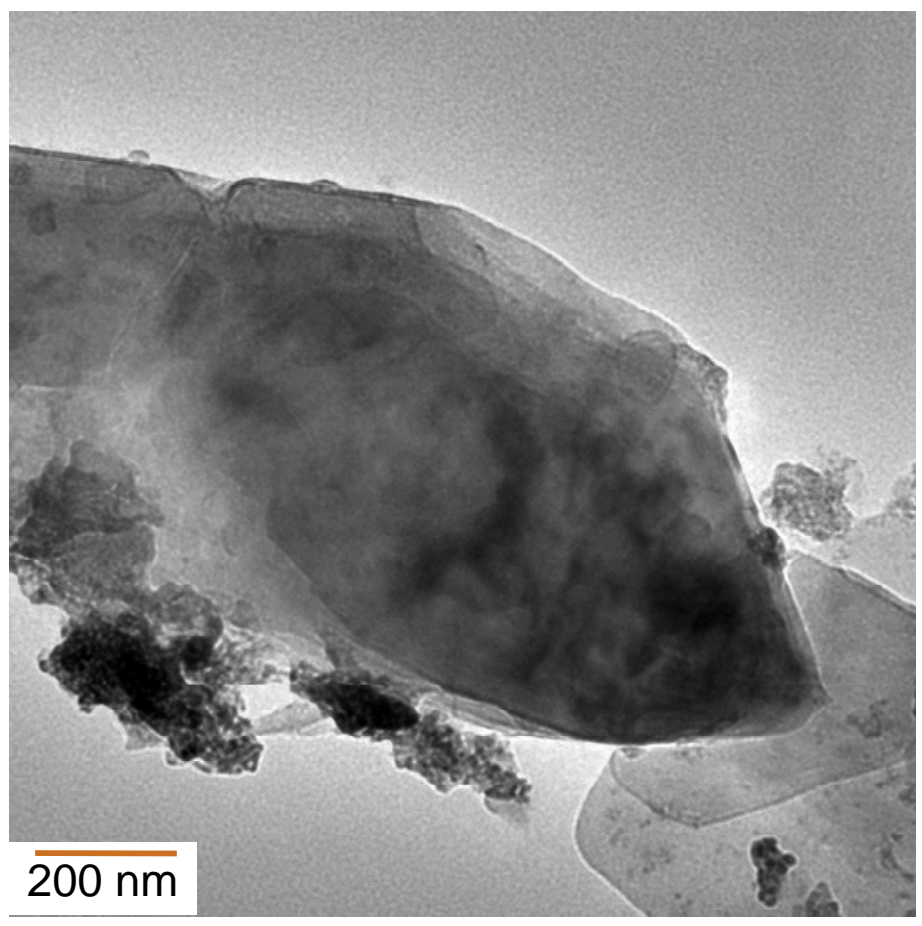

Figure 4.25. TEM Image of Large Cancrinite Crystal in the Washed Group 4 Solids

(a)

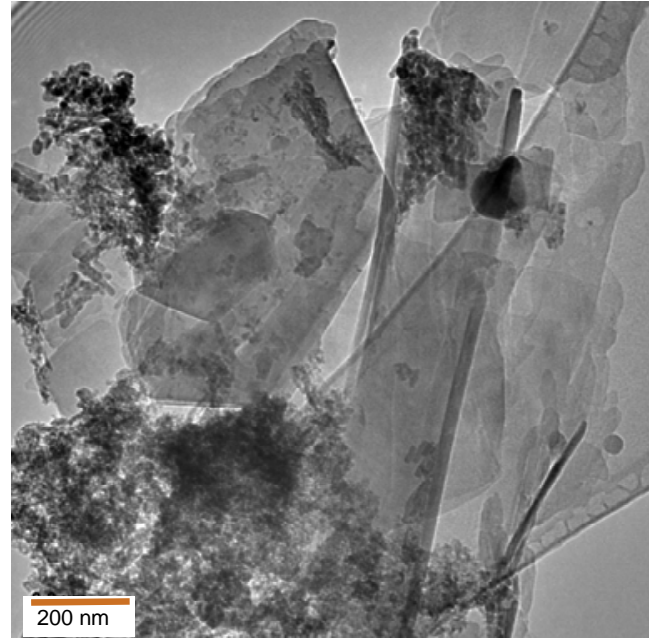

(b)



(c)

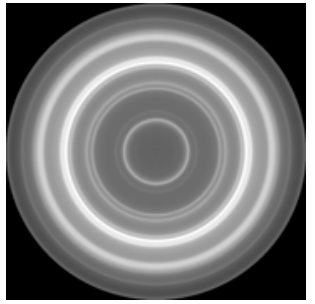

Figure 4.26. (a) TEM Image of Cancrinite Crystals, (b) Electron Diffraction Pattern, and (c) Rotational Averaged Diffraction Pattern

The analyses described in Figure 4.27 indicated the presence of alumino-silicate and uranium-bearing phases. EDS analyses of these phases is imprecise, and it was not clear if the uranium phases contained other elements. The results from the EDS analyses of the four areas shown in Figure 4.27 are given in Table 4.13 and show high $\mathrm{Al}, \mathrm{Ca}, \mathrm{Fe}$, and $\mathrm{Pb}$ levels in these analyses along with the uranium. The compositional analysis of the alumino-silicate particle, identified as cancrinite, shown in Figure 4.27a (EDS-056 and -057) indicated that there was strong overlap with a uranium phase in the vicinity. The $\mathrm{Al}: \mathrm{Si}$ ratio was in close agreement with the expected 1:1 value for the zeolitic alumino-silicate. 

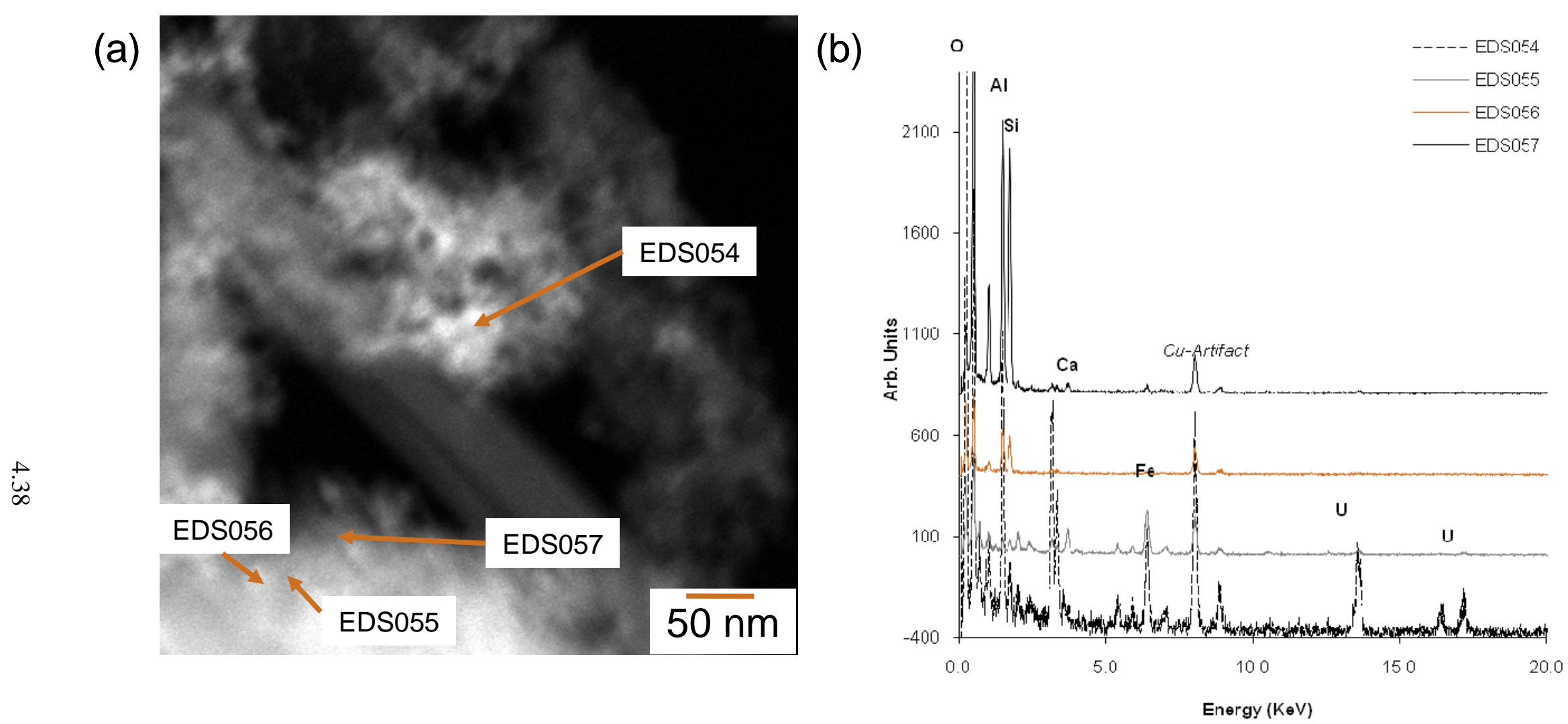

Figure 4.27. (a) STEM-HAADF Image of Washed Group 4 Solids, and (b) EDS Analyses of Washed Group 4 Solids 
Table 4.13. Results from EDS Analyses of Areas Shown in Figure 4.27

\begin{tabular}{|c|c|c|c|c|c|c|}
\hline \multirow[b]{2}{*}{ Element } & \multicolumn{2}{|c|}{ EDS 054} & \multicolumn{2}{|c|}{ EDS 055} & \multirow{2}{*}{$\begin{array}{c}\text { EDS } 056 \\
\text { Weight \% }\end{array}$} & \multirow{2}{*}{$\begin{array}{l}\text { EDS } 057 \\
\text { Weight \% }\end{array}$} \\
\hline & Weight \% & Atomic \% & Weight \% & Atomic \% & & \\
\hline $\mathrm{Al}$ & 9.9 & 42.8 & ND & ND & 32.7 & 46.1 \\
\hline $\mathrm{Fe}$ & 8.3 & 17.3 & 34.7 & 44.7 & 4.1 & ND \\
\hline $\mathrm{U}$ & 81.8 & 39.9 & 26.6 & 8.0 & 29.3 & 7.8 \\
\hline $\mathrm{P}$ & ND & ND & 4.6 & 10.8 & $\mathrm{ND}$ & $\mathrm{ND}$ \\
\hline $\mathrm{Ca}$ & ND & ND & 9.0 & 16.3 & ND & 2.0 \\
\hline $\mathrm{Cr}$ & ND & ND & 6.6 & 9.2 & $\mathrm{ND}$ & $\mathrm{ND}$ \\
\hline $\mathrm{Mn}$ & ND & ND & 4.9 & 6.4 & $\mathrm{ND}$ & $\mathrm{ND}$ \\
\hline $\mathrm{Pb}$ & ND & ND & 13.6 & 4.7 & 9.0 & $\mathrm{ND}$ \\
\hline $\mathrm{Si}$ & ND & ND & ND & ND & 24.9 & 41.9 \\
\hline
\end{tabular}

A typical particle agglomerate is shown in Figure 4.28. The STEM-HAADF image highlights the uranium-bearing solids in the center and top of the micrograph. The compositional analysis reveals a large number of different elements that most likely arise from several phases. Table 4.14 shows EDS results from the uranium-rich region of the agglomerate shown in Figure 4.28.

(a)

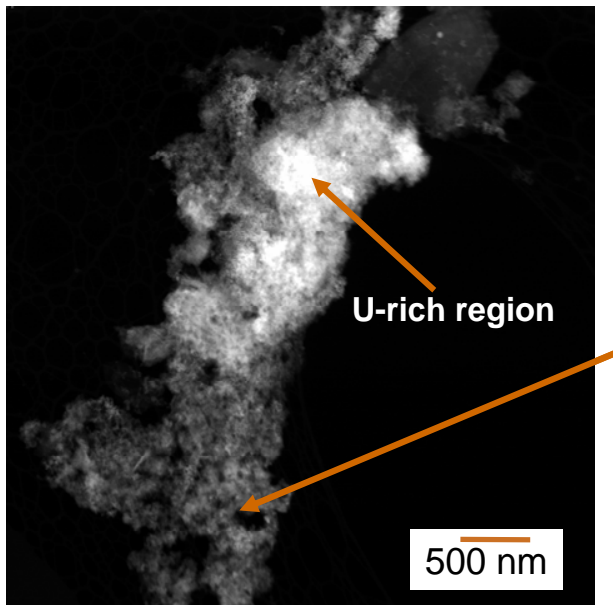

(b) 100

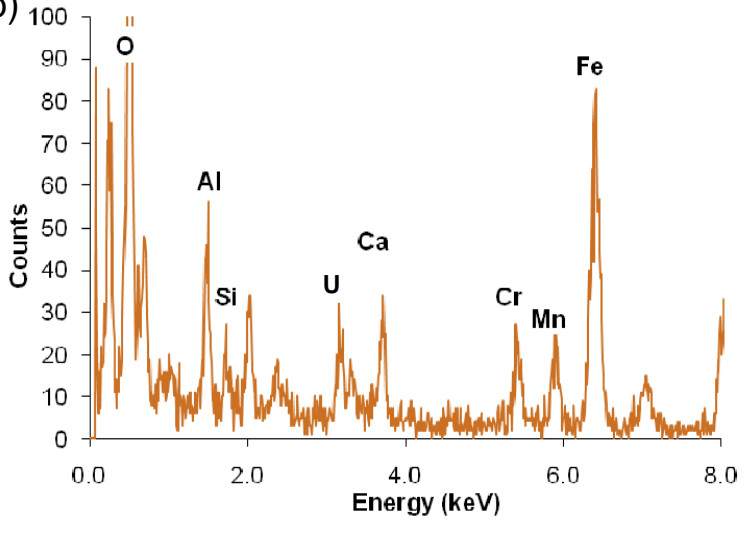

Figure 4.28. (a) STEM-HAADF Image of an Agglomerate in the Washed Group 4 Solids, (b) EDS Analysis of the Agglomerate 
Table 4.14. Results from EDS Analysis of Agglomerate Shown in Figure 4.28

\begin{tabular}{|c|c|}
\hline Element & Weight Percent \\
\hline $\mathrm{Al}$ & 2.3 \\
\hline $\mathrm{P}$ & 2.0 \\
\hline $\mathrm{Cr}$ & 6.1 \\
\hline $\mathrm{Mn}$ & 8.1 \\
\hline $\mathrm{Fe}$ & 17.3 \\
\hline $\mathrm{Pb}$ & 7.5 \\
\hline $\mathrm{U}$ & 54.7 \\
\hline
\end{tabular}

In Figure 4.29, a large ( $300 \mathrm{~nm}$ long) white iron silicate particle can be seen associated with a large amount of other sludge phases.

(a)



(b)

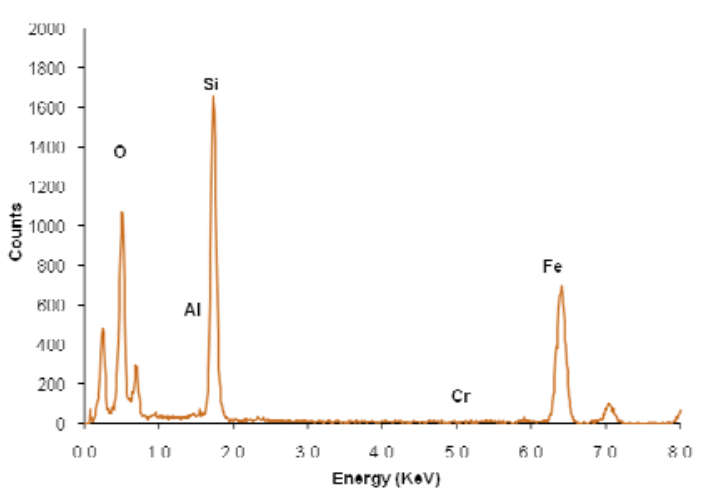

Figure 4.29. (a) STEM-HAADF Image of Iron-Silicate Particle in Washed Group 4 Solids, (b) EDS Analysis of the Iron-Silicate Particle

\subsection{Group 4 CWR Sludge Batch Parametric Leaching: Experimental}

Parametric caustic-leaching tests were performed on the Group 4 CWR sludge sample to determine the behavior of gibbsite during leaching at different conditions. The composite Group 4 sample material was rinsed with $0.01 \mathrm{M} \mathrm{NaOH}$, subdivided, and subjected to a parametric test matrix for caustic-leach testing as discussed in the following sections.

\subsubsection{Initial Washing of the Group 4 Solids}

The Group 4 composite solids sample was washed in the same manner as the Group 3 sample (Section 3.2.1). In this case, a 49.94-g aliquot of the homogenized slurry was removed with a large transfer pipette and transferred to a 200-mL centrifuge bottle. At a concentration of $0.28 \mathrm{~g}$ dry waterinsoluble solids per gram of slurry, the 49 .9-g slurry contained $\sim 14 \mathrm{~g}$ of water-insoluble solids. After centrifuging at $\sim 1200 \mathrm{G}$ for $30 \mathrm{~min}$, the supernatant liquid was removed, and the centrifuged solids 
volume was determined to be $\sim 15 \mathrm{~mL}$ based on volume graduations on the sample bottle. Approximately $45 \mathrm{~mL}$ ( $3 \times$ the centrifuged solids volume) of $0.01 \mathrm{M} \mathrm{NaOH}$ was added to wash the solids, and the slurry was placed on a vortex mixer to loosen the solids and shaken for 15 minutes on a shaker table. The slurry was centrifuged at $1200 \mathrm{G}$ for $15 \mathrm{~min}$, and then the supernatant was removed. The washing steps were repeated twice for a total of three washes. The last wash was centrifuged for 1 hour because the solids were not settled at 15 minutes. Note that the final wash solution was light brown, and the solids were not completely settled. This final supernatant was not entirely decanted (approximately $20 \mathrm{~mL}$ of the wash solution was left with the solids) because of this presence of suspended solids in the solution.

\subsubsection{Division of the Washed Group 4 Solids}

To subdivide the washed Group 4 solids for the leaching tests, $68.5 \mathrm{~mL}$ of DI water was added to the solids, resulting in slurry containing 14 g solids in $116.5 \mathrm{~g}$ of slurry, equivalent to $12.0 \mathrm{wt} \%$ UDS.

The thinned slurry was homogenized with an overhead mixer equipped with a 3-bladed stainless steel impeller. Thirteen $\sim$-g slurry samples were transferred to 125-mL HDPE bottles with a large disposable polyethylene pipette. Each sample contained $\sim 1 \mathrm{~g}$ UDS. The samples were removed from the hot cell for follow-on processing at the fume hood workstation.

One additional sample (562-G4-WL-Solids) containing approximately $7.3 \mathrm{~g}$ of slurry (equivalent to $0.88 \mathrm{~g}$ dry solids) was transferred to a 60 -mL HDPE bottle. A portion of this sample was submitted for a $\mathrm{KOH}$ fusion and the following subsequent analyses: ICP-OES metals, GEA, Pu, total alpha, total beta,

${ }^{90} \mathrm{Sr}$, and U by KPA. These analyses were performed to establish the starting composition of the washed solids.

\subsubsection{Caustic Leaching of the Washed Group 4 Solids}

The leaching test matrix for the 13 samples is summarized in Table 4.15. The test matrix evaluated the effects of free-hydroxide concentration (1 to $5 \mathrm{M} \mathrm{NaOH}$ ), temperature (60 to $100^{\circ} \mathrm{C}$ ), and sodium nitrate concentration (1 to $5 \mathrm{M} \mathrm{NaNO}_{3}$ ) on gibbsite leaching kinetics. The test matrix was proposed to and approved by BNI. Copies of the request and concurrence letters can be found in appendix M.

The Group 4 leaching tests were conducted in the same manner as the Group 3 leaching tests (see Section 3.2.3). Sodium hydroxide (19 M) was added to each aliquot of washed solids slurry in the following amounts: $5.3 \mathrm{~mL}$ to yield $1 \mathrm{M} \mathrm{NaOH}, 15.8 \mathrm{~mL}$ to yield $3 \mathrm{M} \mathrm{NaOH}$, and $26.3 \mathrm{~mL}$ to yield $5 \mathrm{M}$ $\mathrm{NaOH}$. Sodium nitrate $(10 \mathrm{M})$ was added to two of the samples in the following amounts: $10 \mathrm{~mL}$ to yield $1 \mathrm{M} \mathrm{NaNO}_{3}$ and $50 \mathrm{~mL}$ to yield $5 \mathrm{M} \mathrm{NaNO}_{3}$. This concentration $(10 \mathrm{M})$ of sodium nitrate is very near the solubility limit at $25^{\circ} \mathrm{C}$; therefore, the solution was heated before pipetting it into the leaching bottles. The leaching mixtures were then diluted to a final volume of $100 \mathrm{~mL}$ (with an estimated uncertainty of 2 $\mathrm{mL}$ ) with DI water. (The 100-mL volume had been pre-marked on each sample bottle.) The contact time with the concentrated $\mathrm{NaOH}$ was brief $(<5 \mathrm{~min})$. The remainder of the procedure was identical to that for the Group 3 tests.

There was an error while preparing two of the $80^{\circ} \mathrm{C}$ samples; only $15.8 \mathrm{~mL}$ of $\mathrm{NaOH}$ was added to sample G4-80-5, and $26.3 \mathrm{~mL}$ of $\mathrm{NaOH}$ was added to sample G4-80-5N-3. This was not noticed until after adding water to the $100-\mathrm{mL}$ mark. An additional $14.3 \mathrm{~mL}$ of $\mathrm{NaOH}$ was added to G4-80-5, giving it 
a final concentration of $5 \mathrm{M}$ in a larger volume of $114.3 \mathrm{~mL}$. Sample G4-80-5N-3 was run with $5 \mathrm{M}$ $\mathrm{NaOH}$ and $5 \mathrm{M} \mathrm{NaNO}_{3}$.

The equilibrium concentration values for free hydroxide, sodium, and nitrate are shown in Table 4.15 and were based on results from the samples taken at 48 hours.

Table 4.15. Group 4 Caustic-Leaching Conditions

\begin{tabular}{|c|c|c|c|c|c|c|c|}
\hline \multirow[b]{2}{*}{ Bottle ID } & \multicolumn{2}{|c|}{ Free $\mathrm{OH}, \mathrm{M}$} & \multicolumn{2}{|c|}{$\mathrm{Na}, \mathrm{M}$} & \multicolumn{2}{|c|}{$\mathrm{NO}_{3}^{-}, \mathrm{M}$} & \multirow{2}{*}{$\begin{array}{c}\text { Temperature } \\
{ }^{\circ} \mathrm{C}^{(\mathrm{c})}\end{array}$} \\
\hline & Target & Measured $^{(a)}$ & Target & Measured $^{(a)}$ & Target & Measured $^{(\mathbf{b})}$ & \\
\hline G4-60-1 & 1 & 0.98 & 1 & 1.13 & NA & NA & 60 \\
\hline G4-60-3 & 3 & 3.04 & 3 & 3.20 & NA & NA & 60 \\
\hline G4-60-5 & 5 & 5.31 & 5 & 5.49 & NA & NA & 60 \\
\hline G4-80-1 & 1 & 0.96 & 1 & 1.14 & NA & NA & 80 \\
\hline G4-80-3a & 3 & 3.17 & 3 & 3.46 & NA & NA & 80 \\
\hline G4-80-3b & 3 & 3.14 & 3 & 3.36 & NA & NA & 80 \\
\hline G4-80-3c & 3 & 3.08 & 3 & 3.40 & NA & NA & 80 \\
\hline G4-80-1N-3 & 3 & 3.01 & 4 & 4.41 & 1 & 1.39 & 80 \\
\hline $\begin{array}{c}\text { G4-80-5N- } \\
3^{(\mathrm{d})}\end{array}$ & 3 & 5.67 & 8 & 11.17 & 5 & 5.66 & 80 \\
\hline G4-80-5 & 5 & 5.28 & 5 & 6.33 & NA & NA & 80 \\
\hline G4-100-1 & 1 & 1.00 & 1 & 1.17 & NA & NA & 100 \\
\hline G4-100-3 & 3 & 3.42 & 3 & 3.55 & NA & NA & 100 \\
\hline G4-100-5 & 5 & 5.53 & 5 & 5.47 & NA & NA & 100 \\
\hline \multicolumn{8}{|c|}{$\begin{array}{l}\text { (a) The measured analyte concentrations represent the concentration obtained after a } 48 \text {-h contact time. } \\
\text { (b) The measured } \mathrm{NO}_{3}{ }^{-} \text {concentrations are an average of seven measurements over the entire sampling period. } \\
\text { (c) The temperature uncertainty was } \pm 2.5^{\circ} \mathrm{C} \text {. } \\
\text { (d) The sample with } 5 \mathrm{M} \text { NaNO} \\
\text { Note: All analyte concentrations were measured at ambient }\left(\sim 21^{\circ} \mathrm{C}\right) \text { temperature. } \\
\text { Analytical Service Requests (ASRs): } 8063,8163\end{array}$} \\
\hline
\end{tabular}

\subsubsection{Washing of Caustic-Leached Group 4 Solids for Analysis}

The solids from the triplicate samples (G4-80-3a, -3b, and -3c, leached at $80^{\circ} \mathrm{C}$ in $3 \mathrm{M} \mathrm{NaOH}$, and each consisting of $\sim 1$ g centrifuged slurry) were prepared for characterization as shown in Figure 4.30. Again, the process followed was essentially the same as that for the leached Group 3 solids (Section 3.2.4). Nearly the entire sample was dissolved during the caustic leaching test, leaving only $\sim 0.05$ g dry solids from all three samples combined, so PSD, XRD, TEM, SEM, and BET measurements were not performed. The entire sample of residual solids was submitted for a $\mathrm{KOH}$ fusion with subsequent analysis for ICP-OES metals, GEA, Pu, total alpha, total beta, ${ }^{90} \mathrm{Sr}$, and U by KPA. 


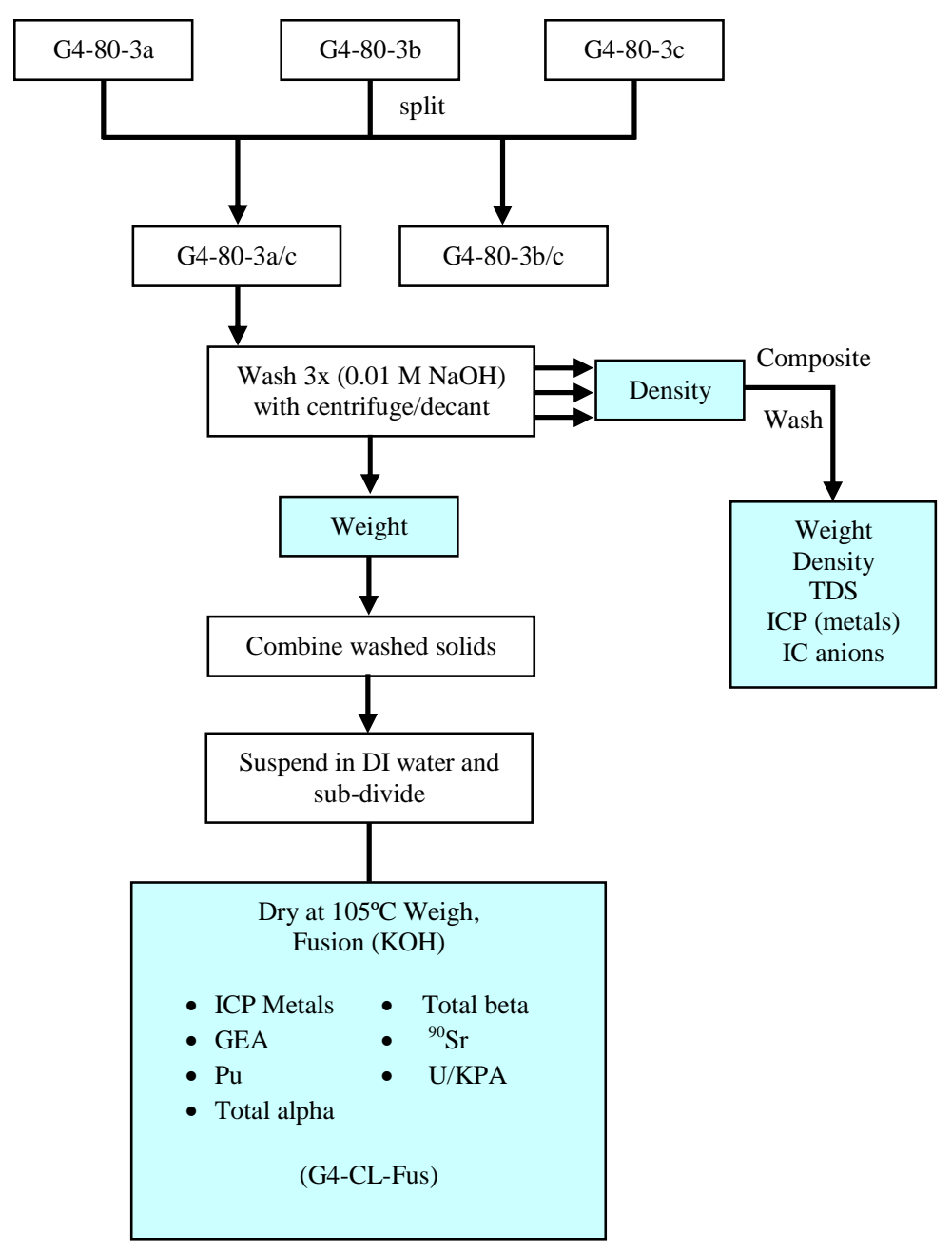

Figure 4.30. Washing, Subdivision, and Analysis Scheme for the Group 4 Caustic-Leached Solids

\subsection{Group 4 CWR Sludge Parametric Caustic-Leaching Test Results}

The $\mathrm{Al}$ component in the Group 4 waste was nearly pure gibbsite. The parametric leach testing of this waste sample was directed toward understanding gibbsite dissolution in the actual tank waste to understand and subsequently match the dissolution properties to a simulant material. The parametric leaching results and residual solids composition are discussed in the following sections. Data for the figures in this section can be found in Appendix L.

\subsubsection{Time, Temperature, and Hydroxide Effects on Aluminum Dissolution from the Group 4 Solids}

The rate and extent of $\mathrm{Al}$ removal from the washed Group 4 solids were investigated as a function of time, temperature, and free-hydroxide concentration. Based on the total Al concentration in the washed Group 4 solids (332 mg/g - free of residual supernatant), the complete dissolution of $\mathrm{Al}$ would result in a concentration of $3.3 \mathrm{mg} \mathrm{Al} / \mathrm{mL}$ or $0.123 \mathrm{M}$. 
The aluminum leaching data at 60,80 , and $100^{\circ} \mathrm{C}$ at varying free-hydroxide concentrations are plotted in Figure 4.31 through Figure 4.33, respectively. A measure of experimental precision is shown by the triplicate tests conducted at $3 \mathrm{M}$ free hydroxide and at $80^{\circ} \mathrm{C}$ in Figure 4.32 . The scatter in the data was within the analytical characterization uncertainty of $\pm 15 \%$.

At $60^{\circ} \mathrm{C}$, the $\mathrm{Al}$ dissolution appears to take up to 48 hours to reach steady state in $1 \mathrm{M} \mathrm{NaOH}$ and between 4 and 8 hours in 3 and $5 \mathrm{M} \mathrm{NaOH}$. The reaction does not reach complete dissolution in $1 \mathrm{M}$ $\mathrm{NaOH}$ during this time period at $60^{\circ} \mathrm{C}$. It is not clear why $100 \%$ dissolution was not reached in $1 \mathrm{M}$ $\mathrm{NaOH}$, as the conditions used were slightly below the solubility limit for gibbsite at $60^{\circ} \mathrm{C}$ in $1 \mathrm{M} \mathrm{NaOH}$ of 0.19 M as calculated from the empirical model developed by Misra (1970) and referenced by Li et al. (2005). At $80^{\circ} \mathrm{C}$, the $\mathrm{Al}$ dissolution is rapid and complete at all hydroxide levels, reaching completion between 2 and 4 hours for all cases. There was very little increase in dissolution with increasing $\mathrm{NaOH}$ concentrations. At $100^{\circ} \mathrm{C}$, the reactions reached steady-state values in the first hour. However, the observed $\mathrm{Al}$ behavior for the $100^{\circ} \mathrm{C}$ leaching samples was unexpected. In particular, the extent of removal at 3 and $5 \mathrm{M} \mathrm{NaOH}$ was less than that for $1 \mathrm{M} \mathrm{NaOH}$. The essentially complete removal at $1 \mathrm{M}$ $\mathrm{NaOH} / 100^{\circ} \mathrm{C}$ is consistent with the trend of increasing $\mathrm{Al}$ removal with increasing temperature.

Although we cannot offer a definitive explanation as to why the Al removal was lower for leaching with 3 $\mathrm{M}$ and $5 \mathrm{M} \mathrm{NaOH}$ at $100^{\circ} \mathrm{C}$, the most likely explanation is that the amount of insoluble sludge solids in these samples was less than expected (perhaps caused by sample inhomogeneity during the sub-sampling process). The results obtained at $3 \mathrm{M}$ and $5 \mathrm{M} \mathrm{NaOH}$ at $100^{\circ} \mathrm{C}$ should be viewed as suspect.

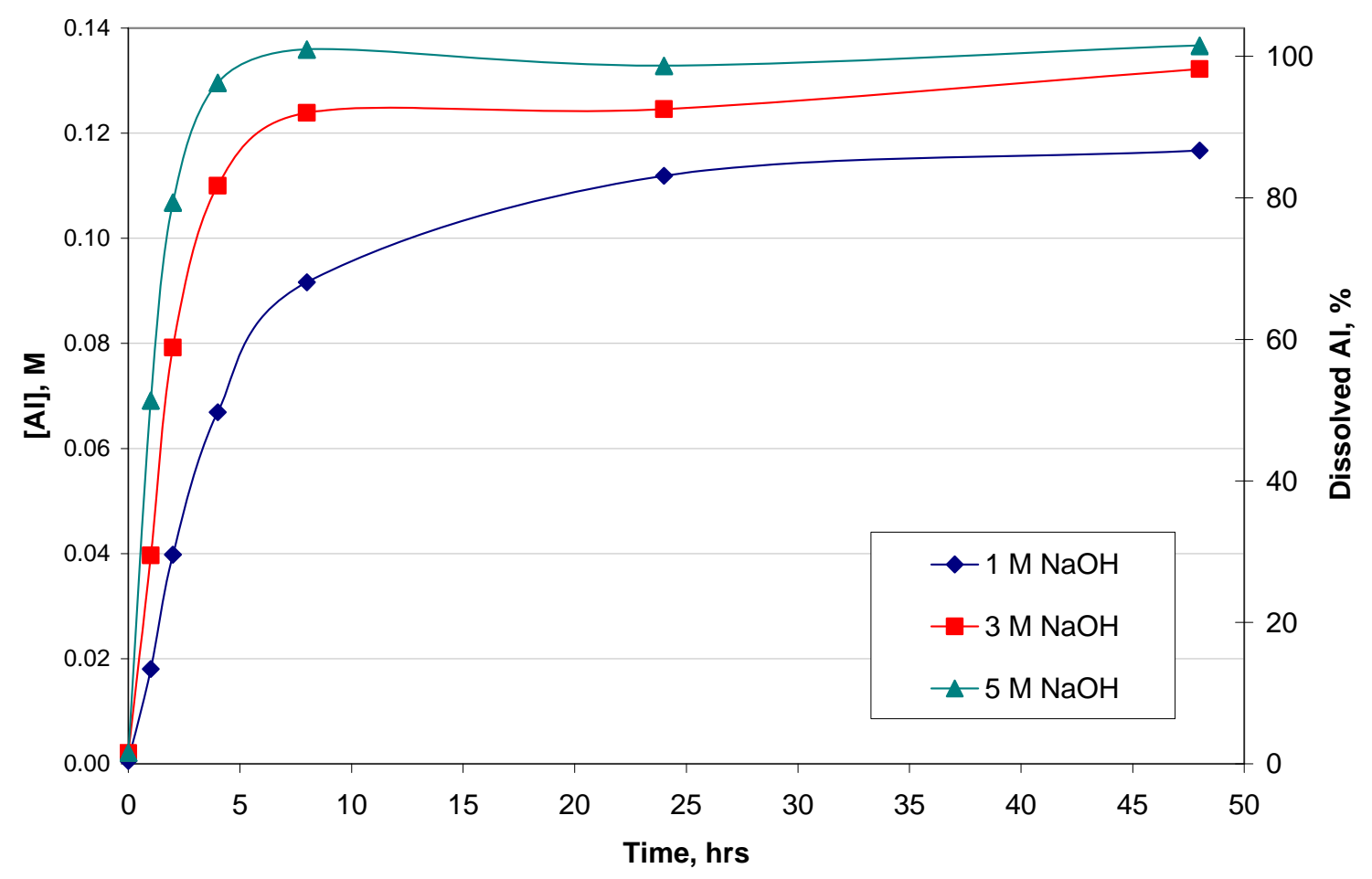

Figure 4.31. Aluminum Concentration and Percent Removed Versus Time at $60^{\circ} \mathrm{C}$ for Leaching of the Group 4 Washed Solids in 1, 3, and $5 \mathrm{M} \mathrm{NaOH}$ 


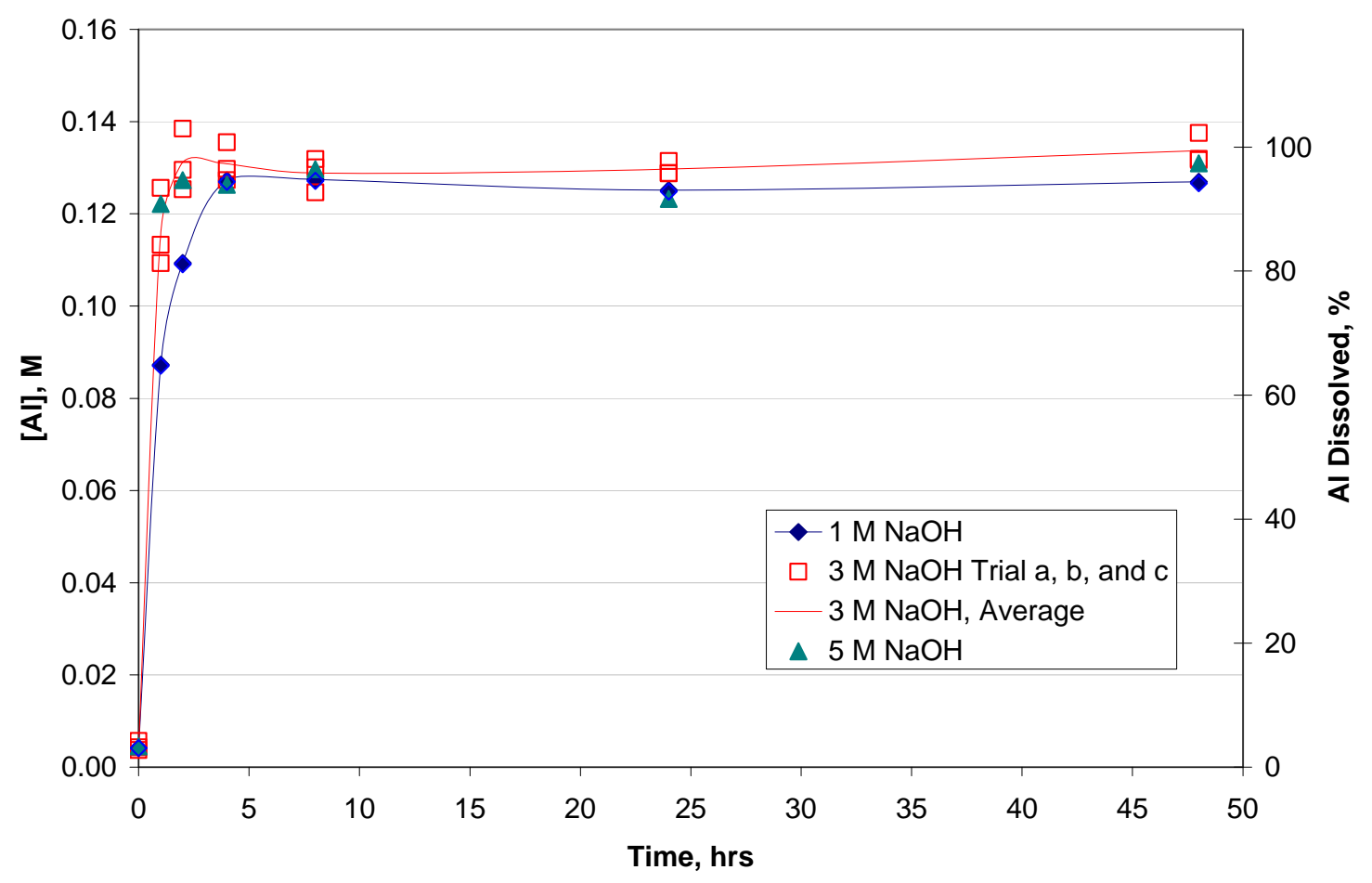

Figure 4.32. Aluminum Concentration and Percent Removed Versus Time at $80^{\circ} \mathrm{C}$ for Leaching of the Group 4 Washed Solids in 1, 3, and $5 \mathrm{M} \mathrm{NaOH}$

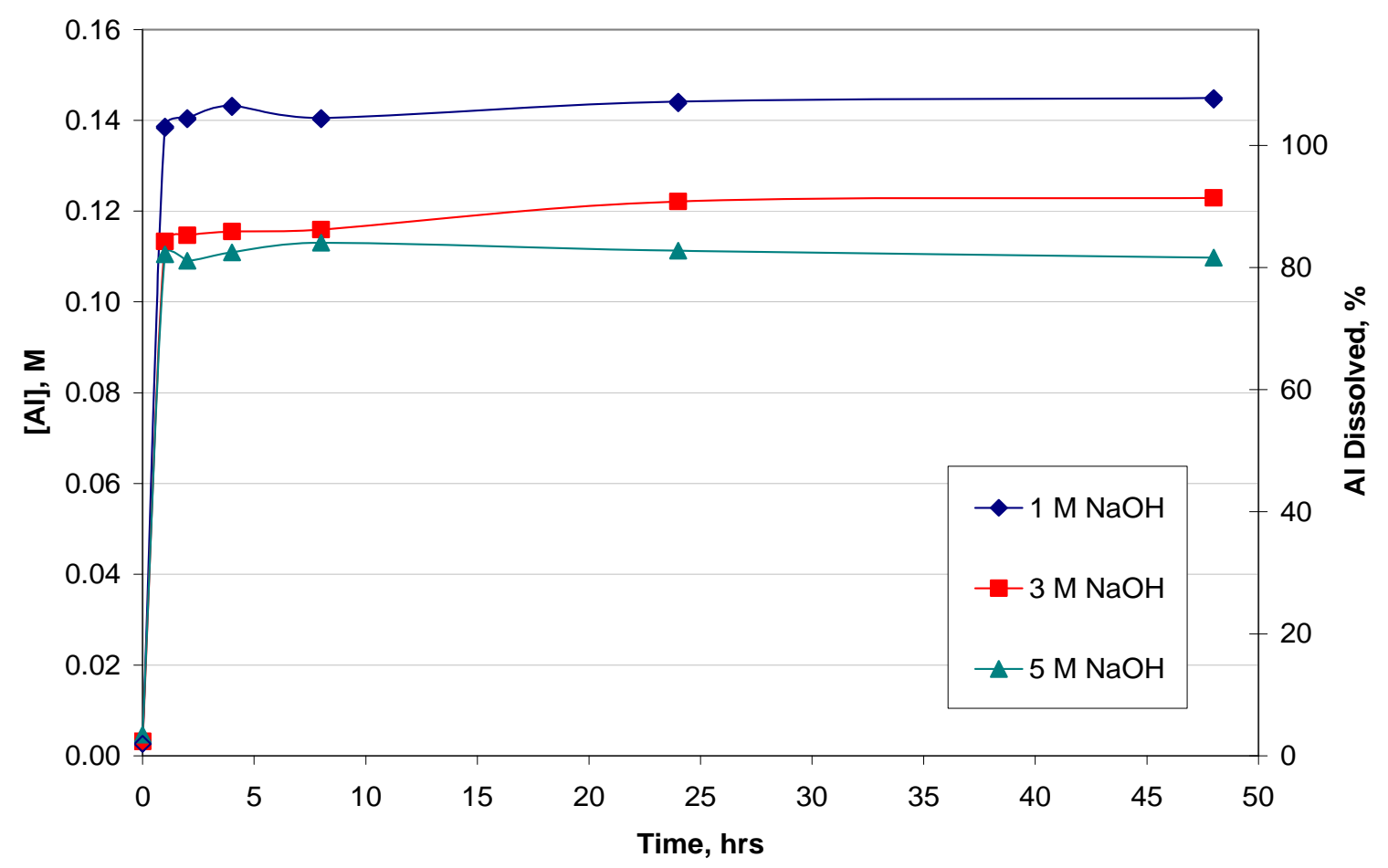

Figure 4.33. Aluminum Concentration and Percent Removed Versus Time at $100^{\circ} \mathrm{C}$ for Leaching of the Group 4 Washed Solids in 1, 3, and $5 \mathrm{M} \mathrm{NaOH}$ 
The same data are re-plotted in Figure 4.34 through Figure 4.36 to show the effect of temperature at constant free-hydroxide concentrations of 1,3 , and $5 \mathrm{M} \mathrm{NaOH}$, respectively. Generally, the temperature had a small effect on the gibbsite dissolution rate, with the reaction at $60^{\circ} \mathrm{C}$ taking longer than the reaction at 80 and $100^{\circ} \mathrm{C}$. In $1 \mathrm{M} \mathrm{NaOH}$, the reaction at 80 and $100^{\circ} \mathrm{C}$ reached a steady state within 4 hours, reaching nearly $100 \mathrm{wt} \% \mathrm{Al}$ removal. The reaction at $60^{\circ} \mathrm{C}$ was slower, taking between 24 and 48 hours to reach a steady-state. Complete dissolution of $\mathrm{Al}$ was not reached under these conditions. In $3 \mathrm{M}$ $\mathrm{NaOH}$, the reaction was rapid and nearly complete at all temperatures. The reaction at $60^{\circ} \mathrm{C}$ was slower, taking up to 8 hours to reach its steady-state value, while this was achieved in 1 to 2 hours at the higher temperatures. In $5 \mathrm{M} \mathrm{NaOH}$, the reactions reached steady-state values in the first 1 to 2 hours. Again, the values pertaining to the fraction of $\mathrm{Al}$ removed during leaching with $3 \mathrm{M}$ and $5 \mathrm{M} \mathrm{NaOH}$ at $100^{\circ} \mathrm{C}$ should be viewed as suspect (but the discussion regarding the relative time required to reach steady-state under these conditions is valid).

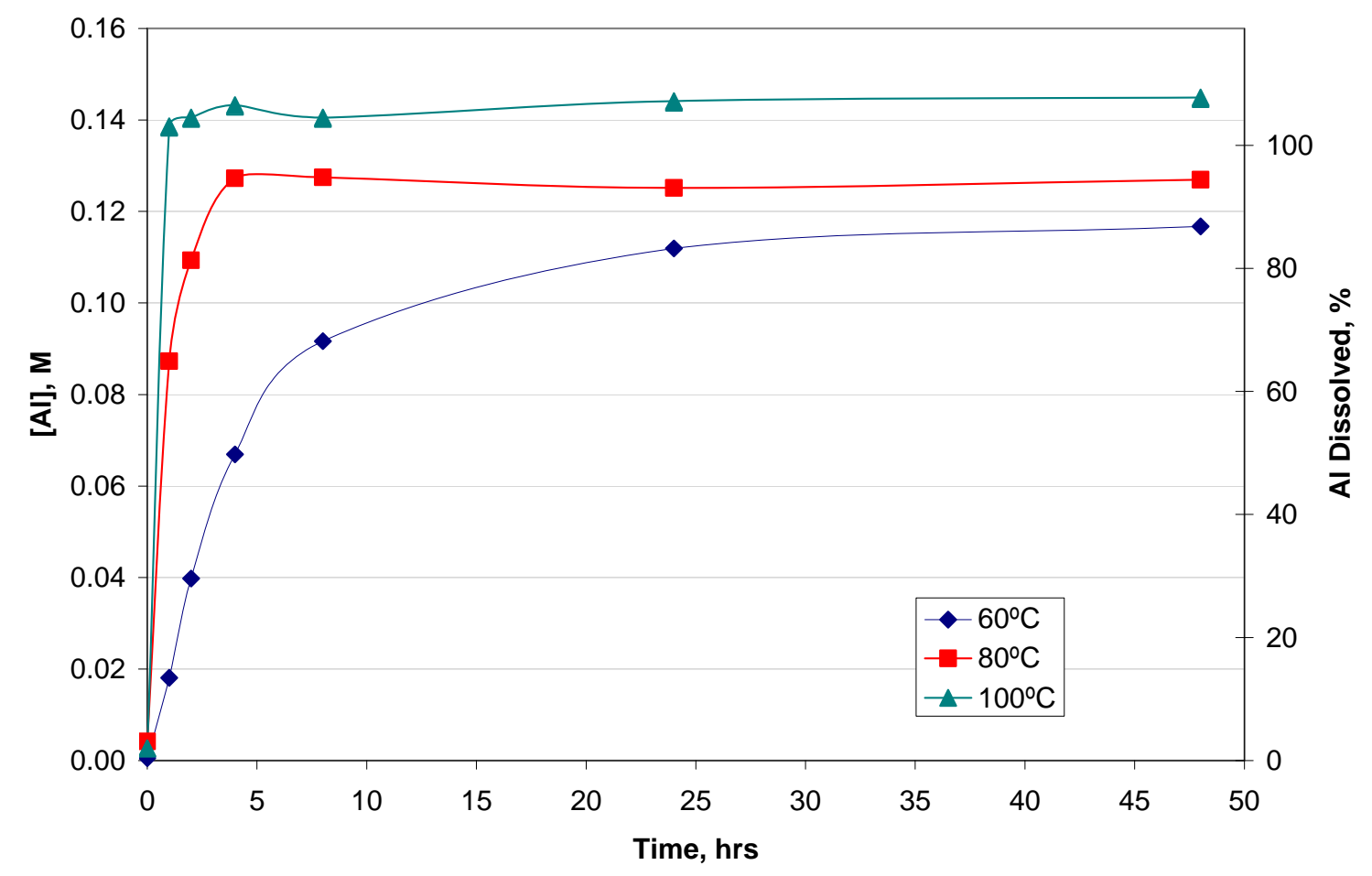

Figure 4.34. Aluminum Concentration and Percent Dissolved in $1 \mathrm{M} \mathrm{NaOH}$ 


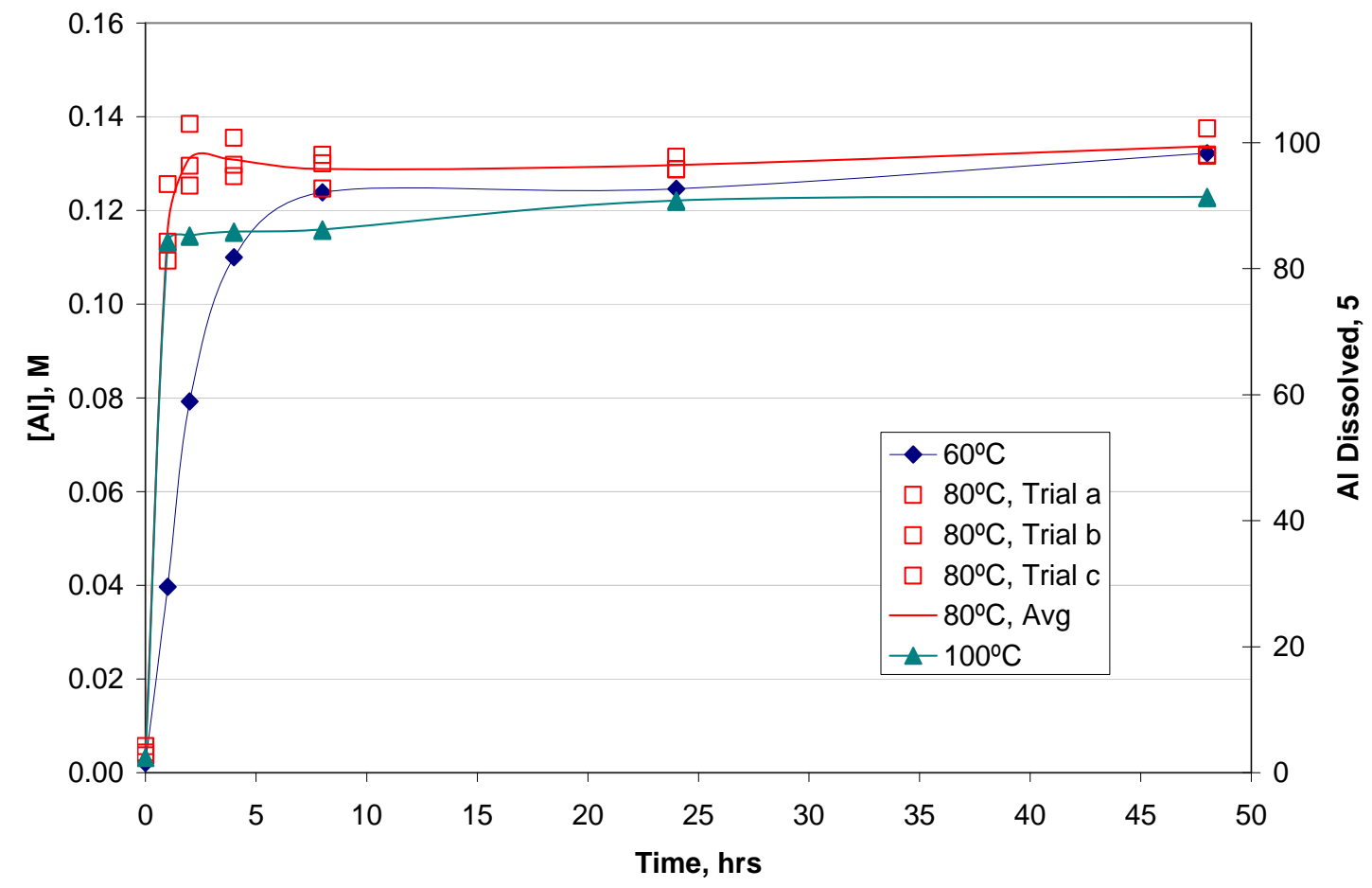

Figure 4.35. Aluminum Concentration and Percent Dissolved in $3 \mathrm{M} \mathrm{NaOH}$

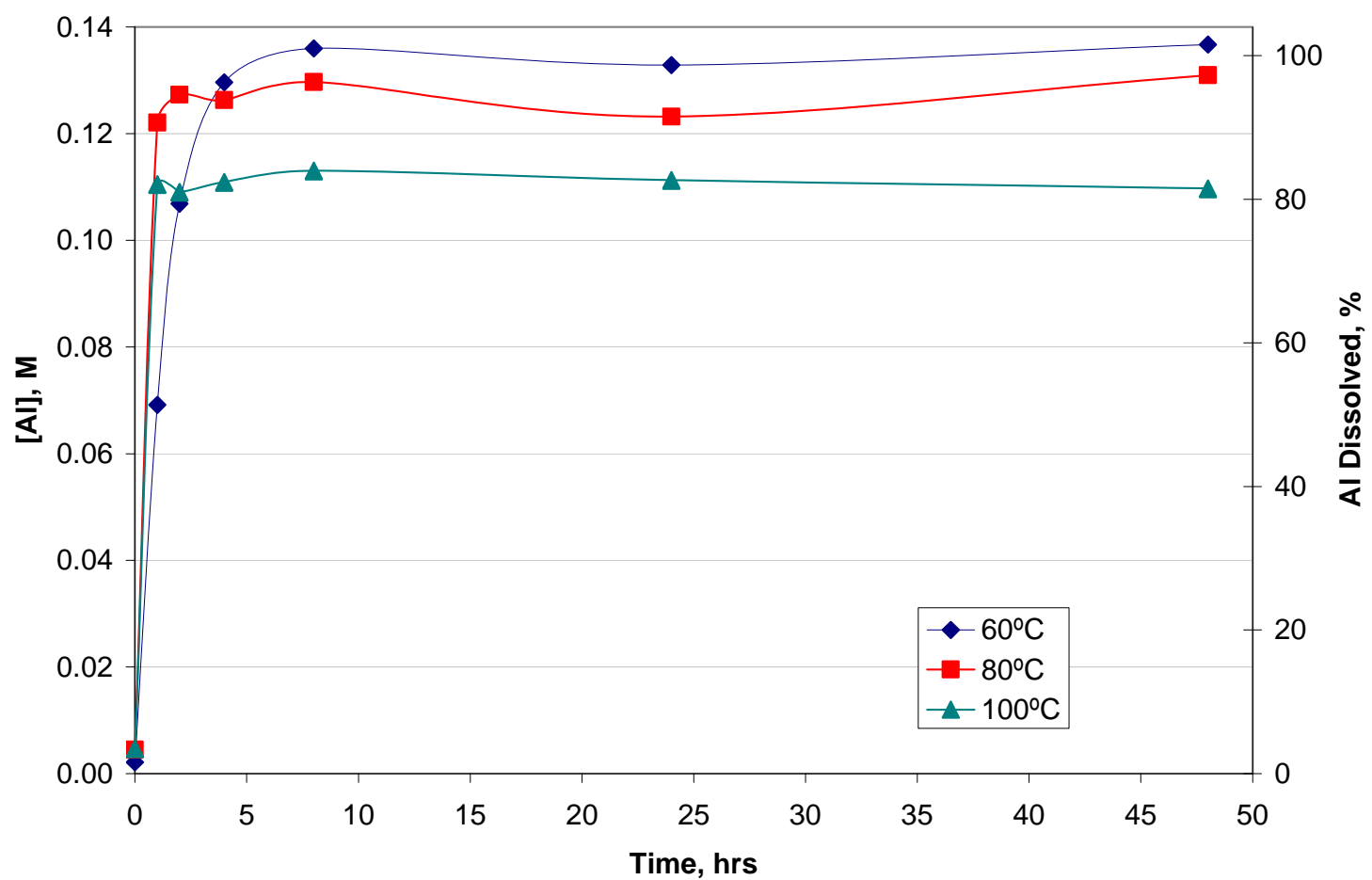

Figure 4.36. Aluminum Concentration and Percent Dissolved in $5 \mathrm{M} \mathrm{NaOH}$ 


\subsubsection{Effect of lonic Strength on Aluminum Dissolution}

The effect of ionic strength on the $\mathrm{Al}$ dissolution behavior was assessed by increasing the $\mathrm{NaNO}_{3}$ concentration during leaching of the Group 4 solids in 3 and $5 \mathrm{M} \mathrm{NaOH}$ at $80^{\circ} \mathrm{C}$. As discussed earlier, the plan was to increase the total $\mathrm{Na}$ concentrations in $3 \mathrm{M} \mathrm{NaOH}$ at $80^{\circ} \mathrm{C}$ to $4 \mathrm{M}$ by adding $1 \mathrm{M} \mathrm{NaNO}_{3}$ and to $8 \mathrm{M}$ by adding $5 \mathrm{M} \mathrm{NaNO}_{3}$. However, the sample with $5 \mathrm{M} \mathrm{NaNO}_{3}$ was inadvertently prepared in a $5 \mathrm{M} \mathrm{NaOH}$ solution, resulting in a leaching solution of $5 \mathrm{M} \mathrm{NaOH}$ with $5 \mathrm{M} \mathrm{NaNO}_{3}$, for a total $\mathrm{Na}$ concentration of $10 \mathrm{M}$. Figure 4.37 summarizes the results. In the figure, the results from triplicate tests conducted in $3 \mathrm{M}$ Na (i.e., no added $\mathrm{NaNO}_{3}$ ) are also included. Within the experimental uncertainty, no clear effect of changing $\mathrm{Na}$ molarity on the rate of $\mathrm{Al}$ dissolution was evident.



Figure 4.37. Matrix Effect of $\mathrm{Na}$ Concentration on $\mathrm{Al}$ (Gibbsite) Dissolution, in 3 and $5 \mathrm{M} \mathrm{NaOH}$ at $80^{\circ} \mathrm{C}$

\subsubsection{Anions, Phosphorus, Silicon, $\mathrm{Cr}$, and Iron Leaching Behavior}

The concentrations of $\mathrm{Cr}, \mathrm{Fe}, \mathrm{P}$, and Si were measured by ICP-OES. The anionic compositions were also assessed at each sampling period. The Cr concentrations were generally above the EQL and generally increase with increasing contact time. The Fe data were generally above the EQL and increased slightly over the first 8 hours, and then they stayed at a steady value. The Si data were generally above the EQL and did not significantly change during the leach test. The $\mathrm{P}$ was generally below the EQL. Fluoride, nitrite, and sulfate were generally below the EQL. The nitrate and phosphate were generally above the EQL. The Si, P, and anion concentrations in the leachate did not significantly change during the leach testing. The results are summarized in Appendix L. 


\subsubsection{Assessment of Final Leaching Conditions}

A summary of the final (48-h) leach solution chemistry and physical parameters is shown in Table 4.16. The final free-hydroxide and sodium concentrations were at the targeted values within the uncertainty of the analytical methods $( \pm 15 \%)$. The calculated percentage of aluminum that was removed at each leaching condition is also shown. Appendix L provides a compilation of the concentrations of all analytes, including $\mathrm{Al}, \mathrm{Cr}, \mathrm{Fe}, \mathrm{Na}, \mathrm{P}, \mathrm{Si}$, nitrite, nitrate, phosphate, and sulfate in the final leaching solutions. The GEA results for ${ }^{60} \mathrm{Co}$ and ${ }^{241} \mathrm{Am}$ were $<\mathrm{MDL}$; the GEA results are also provided in Appendix L.

Table 4.16. Group 4 REDOX Cladding Waste Sludge Leaching Final (48 hr) Aqueous Phase Conditions

\begin{tabular}{|c|c|c|c|c|c|c|}
\hline Temp., ${ }^{\circ} \mathrm{C}$ & $\begin{array}{c}\text { Density, } \\
\mathrm{g} / \mathrm{mL}\end{array}$ & $\begin{array}{c}\text { Free OH, } \\
\text { M }\end{array}$ & $\mathrm{NO}_{3}^{-}, \mathrm{M}$ & Na, M & Al, $\mathbf{M}$ & $\begin{array}{r}\text { Wt \% Al } \\
\text { Removed }^{(b)}\end{array}$ \\
\hline 60 & 1.05 & 0.98 & NA & 1.13 & 0.117 & 87 \\
\hline 60 & 1.13 & 3.04 & NA & 3.20 & 0.132 & 98 \\
\hline 60 & 1.20 & 5.31 & NA & 5.49 & 0.137 & 101 \\
\hline 80 & 1.08 & 0.96 & NA & 1.14 & 0.127 & 94 \\
\hline 80 trial a & 1.18 & 3.17 & NA & 3.46 & 0.137 & 102 \\
\hline 80 trial b & 1.16 & 3.14 & NA & 3.36 & 0.132 & 98 \\
\hline 80 trial c & 1.16 & 3.08 & NA & 3.40 & 0.132 & 98 \\
\hline 80 with $1 \mathrm{M} \mathrm{NaNO}_{3}$ & 1.21 & 3.01 & $1.39^{(\mathrm{a})}$ & 4.41 & 0.125 & 93 \\
\hline 80 with $5 \mathrm{M} \mathrm{NaNO}_{3}$ & 1.53 & 5.67 & $5.66^{(a)}$ & 11.17 & 0.133 & 99 \\
\hline 80 & 1.23 & 5.28 & NA & 6.33 & 0.131 & 97 \\
\hline 100 & 1.05 & 1.00 & NA & 1.17 & 0.145 & 108 \\
\hline 100 & 1.14 & 3.42 & NA & 3.55 & 0.123 & 91 \\
\hline 100 & 1.21 & 5.53 & NA & 5.47 & 0.110 & 81 \\
\hline \multicolumn{7}{|c|}{$\begin{array}{l}\text { (a) Average of seven measurements over the entire sampling period. } \\
\text { (b) Values greater than 100\% can be interpreted as essentially 100\% Al removal. } \\
\text { Analytical Service Request (ASR) } 8063\end{array}$} \\
\hline
\end{tabular}

\subsubsection{Comparison of Initial and Caustic-Leached and Washed Solids Properties}

The Group 4 solids that had been caustic leached at $80^{\circ} \mathrm{C}$ in $3 \mathrm{M} \mathrm{NaOH}$ for 48 hrs were combined and washed in preparation for analysis. The wash-solution composition and the washed-solids chemical and radiochemical compositions are discussed. Nearly all of the sample dissolved during caustic leaching, leaving only enough material for a single fusion and subsequent analysis of the sample, so particle size, crystal habit by TEM and SEM, XRD, and surface area by BET measurements were not performed.

\subsubsection{Leached Solids Wash Solution}

After the third washing of the caustic-leached Group 4 solids, the wet centrifuged solids mass was $0.45 \mathrm{~g}$. The densities of the three sequential wash solutions were $1.012 \mathrm{~g} / \mathrm{mL}, 1.006 \mathrm{~g} / \mathrm{mL}$, and $1.004 \mathrm{~g} / \mathrm{mL}$, respectively. The composite wash solution (105.7 mL volume) density, ICP metals, and anion composition are shown in Table 4.17. Concentrations of additional analytes are given in Appendix L. 
The analysis of the wash solution by ICP for metal content indicated the presence of primarily Na, Al, Si, and nitrate. There was no evidence of additional dissolution of these species during the washing process.

Table 4.17. Group 4 Solids Wash Solution Composition and Density

\begin{tabular}{|c|c|c|c|c|c||}
\hline Analyte & $\boldsymbol{\mu} \mathbf{g} / \mathbf{m L}$ & Analyte & $\boldsymbol{\mu g} / \mathbf{m L}$ & Density Measurement & Value \\
\cline { 1 - 4 } $\mathrm{Al}$ & 180.3 & $\mathrm{Si}$ & 3.74 & Density, $\mathrm{g} / \mathrm{mL}$ & 1.011 \\
\hline $\mathrm{Cr}$ & 0.864 & nitrate & 80.1 & & \\
\cline { 1 - 3 } $\mathrm{Na}$ & 4,129 & phosphate & $<1.79$ & & \\
\cline { 1 - 3 } $\mathrm{P}$ & $<1.61$ & sulfate & $<2.2$ & & \\
\hline
\end{tabular}

\subsubsection{Chemical and Radiochemical Composition}

The initial composition of washed solids (before caustic leaching) is provided in Table 4.18 along with selected results from the initial characterization study. The solids composition after leaching in $3 \mathrm{M} \mathrm{NaOH}$ at $80^{\circ} \mathrm{C}$ for 48 hours and washing is also shown in Table 4.18. Both the initial solids for characterization and the "before leaching" material had been extensively washed, i.e., little or no salt entrainment was expected (except for $\mathrm{NaOH}$ from the washing liquid). The composition of the initial characterization sample was generally consistent with that for the "before leaching” material.

Table 4.18. Group 4 REDOX Cladding Waste Sludge Leached Solids Composition and Leach Factors (Dry Mass Basis) for Caustic-Leaching at $80^{\circ} \mathrm{C}$ in $3 \mathrm{M} \mathrm{NaOH}$ for $48 \mathrm{hrs}$

\begin{tabular}{||c|c|c|c|c||}
\hline \hline Analyte & $\begin{array}{c}\text { Avg. Initial } \\
\text { Charac. } \\
\mathbf{\mu g} / \mathbf{g} \\
\text { (ASR 8035) }\end{array}$ & $\begin{array}{c}\text { Avg. Before } \\
\text { Leaching, } \\
\mathbf{\mu g} / \mathbf{g} \\
\text { (ASR 8063) }\end{array}$ & $\begin{array}{c}\text { Avg. After } \\
\text { Leaching, } \\
\mathbf{\mu g} / \mathbf{g} \\
\text { (ASR 8063) }\end{array}$ & $\begin{array}{c}\text { Fraction } \\
\text { Leached }\end{array}$ \\
\hline $\mathrm{Al}$ & 296,500 & 332,500 & {$[38,000]$} & 0.99 \\
\hline $\mathrm{B}$ & $<72$ & $<52.6$ & {$[410]$} & -- \\
\hline $\mathrm{Bi}$ & {$[1,100]$} & 2,310 & 33,000 & 0 \\
\hline $\mathrm{Cd}$ & {$[7.9]$} & $<19.0$ & {$[240]$} & -- \\
\hline $\mathrm{Cr}$ & 1,610 & 6,100 & 16,500 & 0.81 \\
\hline $\mathrm{Fe}$ & 5,090 & 16,200 & 232,000 & 0 \\
\hline $\mathrm{Mn}$ & 1,545 & 5,195 & 97,200 & 0 \\
\hline $\mathrm{Na}$ & {$[11,000]$} & {$[37,000]$} & {$[38,000]$} & -- \\
\hline $\mathrm{Ni}$ & $\mathrm{na}$ & $\mathrm{na}$ & $\mathrm{na}$ & -- \\
\hline $\mathrm{P}$ & $<129$ & 4,480 & 13,800 & 0.79 \\
\hline $\mathrm{S}$ & {$[815]$} & $<1,112$ & {$[5,300]$} & -- \\
\hline $\mathrm{Si}$ & 5,985 & 15,050 & 56,000 & 0.74 \\
\hline $\mathrm{Sr}$ & {$[24]$} & 76.8 & 1,500 & -- \\
\hline $\mathrm{U}$ & {$[3,400]$} & 13,000 & 151,000 & 0 \\
\hline $\mathrm{Zn}$ & 723 & 1,065 & 2,840 & 0.81 \\
\hline $\mathrm{Zr}$ & $<48$ & {$[120]$} & {$[330]$} & -- \\
\hline
\end{tabular}


Table 4.18 (Contd)

\begin{tabular}{|c|c|c|c|c|}
\hline Analyte & $\begin{array}{c}\text { Avg. Initial } \\
\text { Charac. } \\
\mu g / g \\
\text { (ASR 7874) }\end{array}$ & $\begin{array}{c}\text { Avg. Before } \\
\text { Leaching, } \\
\mu \mathrm{g} / \mathrm{g} \\
\text { (ASR 8032) }\end{array}$ & $\begin{array}{c}\text { Avg. After } \\
\text { Leaching, } \\
\mu g / g \\
\text { (ASR 8032) }\end{array}$ & $\begin{array}{c}\text { Observed } \\
\text { Leach } \\
\text { Factor }\end{array}$ \\
\hline U KPA & 3,540 & $1.02 \mathrm{E}+04$ & $1.29 \mathrm{E}+05$ & 0 \\
\hline${ }^{60} \mathrm{Co}$ & $1.15 \mathrm{E}-2$ & 1.70E-02 & $2.59 \mathrm{E}-01$ & 0 \\
\hline${ }^{90} \mathrm{Sr}$ & $3.41 \mathrm{E}+1$ & $1.43 \mathrm{E}+02$ & $2.21 \mathrm{E}+03$ & 0 \\
\hline${ }^{137} \mathrm{Cs}$ & $7.66 \mathrm{E}+0$ & $2.88 \mathrm{E}+01$ & $1.11 \mathrm{E}-02$ & 1.0 \\
\hline${ }^{154} \mathrm{Eu}$ & $2.08 \mathrm{E}-1$ & $5.60 \mathrm{E}-01$ & $1.24 \mathrm{E}+01$ & 0 \\
\hline${ }^{155} \mathrm{Eu}$ & $7.29 \mathrm{E}-2$ & 1.88E-01 & $4.51 \mathrm{E}+00$ & 0 \\
\hline${ }^{238} \mathrm{Pu}$ & $2.67 \mathrm{E}-2$ & $9.13 \mathrm{E}-02$ & $1.16 \mathrm{E}+00$ & 0 \\
\hline${ }^{239+240} \mathrm{Pu}$ & $1.73 \mathrm{E}-1$ & 6.30E-01 & $8.90 \mathrm{E}+00$ & 0 \\
\hline${ }^{241} \mathrm{Am}$ & $6.92 \mathrm{E}-1$ & $2.77 \mathrm{E}+00$ & $4.39 \mathrm{E}+01$ & 0 \\
\hline total alpha & $8.29 \mathrm{E}-1$ & $3.09 \mathrm{E}+00$ & $5.20 \mathrm{E}+01$ & 0 \\
\hline total beta & $8.05 E+1$ & $2.96 \mathrm{E}+02$ & $4.23 \mathrm{E}+03$ & 0 \\
\hline \multicolumn{5}{|l|}{ Opportunistic } \\
\hline $\mathrm{Ag}$ & $<14$ & [54] & 547 & 0.29 \\
\hline As & [275] & [620] & $<564$ & -- \\
\hline $\mathrm{Ba}$ & $<36$ & 72.0 & 1,480 & 0 \\
\hline $\mathrm{Be}$ & $<1$ & {$[0.54]$} & {$[0.90]$} & -- \\
\hline $\mathrm{Ca}$ & $<2520$ & $<7,198$ & {$[50,000]$} & -- \\
\hline $\mathrm{Ce}$ & $<166$ & $<54.3$ & 1,900 & -- \\
\hline Co & $<17$ & {$[36]$} & 430 & -- \\
\hline $\mathrm{Cu}$ & [46] & [51] & [260] & -- \\
\hline Dy & $<42$ & {$[22]$} & $<42$ & -- \\
\hline $\mathrm{Eu}$ & $<14$ & $<2.64$ & [41] & -- \\
\hline $\mathrm{La}$ & [20] & [55] & 996 & -- \\
\hline $\mathrm{Li}$ & [39] & [27] & [140] & -- \\
\hline $\mathrm{Mg}$ & [640] & 1,500 & 30,900 & 0 \\
\hline Mo & $<24$ & $<47.1$ & $<104$ & -- \\
\hline $\mathrm{Nd}$ & $<255$ & {$[86]$} & 2,730 & -- \\
\hline $\mathrm{Pb}$ & 2,245 & 4,870 & 11.8 & 0.83 \\
\hline $\mathrm{Pd}$ & $<151$ & $<41.9$ & $<92.5$ & -- \\
\hline $\mathrm{Rh}$ & $<99$ & $<85.1$ & $<188$ & -- \\
\hline $\mathrm{Ru}$ & $<42$ & $<43.8$ & $<97$ & -- \\
\hline $\mathrm{Sb}$ & $<140$ & [214] & {$[1,100]$} & -- \\
\hline Se & $<239$ & [817] & {$[2,900]$} & -- \\
\hline Sn & $<224$ & $<164$ & [560] & -- \\
\hline $\mathrm{Ta}$ & $<48$ & $<131$ & $<289$ & -- \\
\hline $\mathrm{Te}$ & $<190$ & $<170$ & $<376$ & -- \\
\hline Th & $<148$ & [58] & 2,110 & -- \\
\hline $\mathrm{Ti}$ & $<25$ & 48.4 & 1,010 & 0 \\
\hline $\mathrm{Tl}$ & $<172$ & [255] & $<434$ & -- \\
\hline V & $<11$ & $<21$ & $<46$ & -- \\
\hline $\mathrm{W}$ & $<75$ & $<137$ & [340] & -- \\
\hline $\mathrm{Y}$ & $<16$ & [20] & 349 & 0 \\
\hline
\end{tabular}


The data from the Group 4 caustic-leaching experiments were analyzed by the concentration factor method (Method 3) described in Section 3.4.5.2 for determining the percent of each component removed during leaching. An analysis of the caustic-leachate solutions indicated that $\mathrm{Bi}, \mathrm{Fe}, \mathrm{U}, \mathrm{Co}, \mathrm{Eu}, \mathrm{Am}, \mathrm{Sr}$, and $\mathrm{Pu}$ did not dissolve after the caustic leach. The relative concentration factor of these analytes averaged 14.36 in the final leached solids, based on the ratio of the analyte concentrations after leaching to before leaching (after washing). This term was used to determine the specific analyte leach factors according to Equation 4.1

$$
L F_{3}=1-\left(\frac{C_{L}}{C_{W} \times 14.36}\right)
$$

where $\mathrm{LF}_{3}$ is the caustic leach factor, $\mathrm{C}_{\mathrm{L}}$ is the leached analyte concentration, and $\mathrm{C}_{\mathrm{W}}$ is the washed analyte concentration.

Notably, extended (48-h) leaching time did not mobilize U, Sr, Mn, or Pu to the aqueous phase.

Consistent with previous leaching tests with Hanford sludge solids, all of the ${ }^{137}$ Cs reported was dissolved and would be routed to the LAW pretreatment facility.

Approximately 89\% of the mass dissolved with a 48-h leach time. As shown in Figure 4.38, in this case, iron, uranium, and manganese were the predominant residual metals.

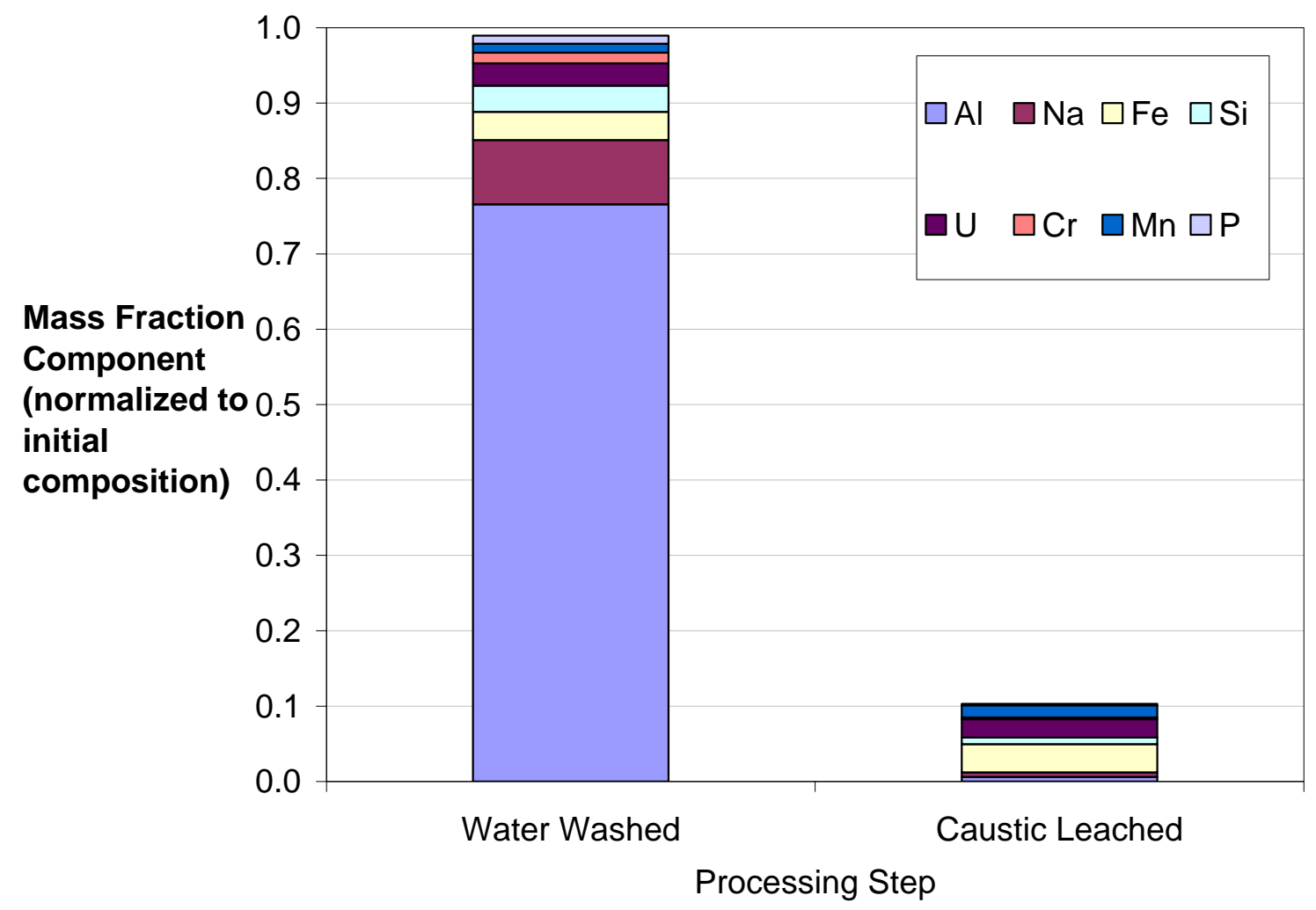

Figure 4.38. Group 4 CWR Sludge Reduction in Solid Mass with Water Washing and Caustic Leaching 


\subsection{Summary}

Tank waste sludge and saltcake at the Hanford Site have been categorized into eight general groupings representing $\sim 75 \mathrm{wt} \%$ of the total high-level waste mass expected to be processed through the WTP. Two of the eight groups, Group 3 and Group 4, are the subject of this report. Group 3 represents CWP sludge, and Group 4 represents CWR sludge, both containing large fractions of the tank waste aluminum as gibbsite.

Multiple samples representative of these two waste groups, all of which had been stored for $\sim 10$ years or more, were identified in the 222S sample archive. Materials representative of Group 3 (and containing high Al) were obtained from archived samples from Tanks C-103, C-104, C-105, B-108, B-109, and BY-109, although half of the sample composite used was made up of the BY-109 waste. Materials representative of Group 4 were selected from archived samples from Tanks U-105, U-201, U-202, U-203, and U-204, although over half of the sample composite used was made up of the U-105 and U-202 waste. These materials were combined into their respective composite groups using water to suspend the solids during mixing and dissolve the water-soluble species.

The tank waste composites were extensively characterized for physical properties, rheological properties, and chemical composition of the solids and liquid phases as well as the crystal habit of the insoluble solids. Table 5.1 summarizes the physical properties for the Group 3 and Group 4 samples, and Table 5.2 summarizes selected elemental analysis information.

Table 5.1. Summary of Major Physical Properties and Mineral Phases of Group 3 PUREX Cladding Waste Sludge and Group 4 REDOX Cladding Waste Sludge

\begin{tabular}{|c|c|c|}
\hline \multirow{2}{*}{$\begin{array}{l}\text { Physical } \\
\text { Properties }\end{array}$} & $\begin{array}{c}\text { Group } 3 \text { PUREX Cladding } \\
\text { Waste Sludge }\end{array}$ & $\begin{array}{c}\text { Group } 4 \text { REDOX Cladding } \\
\text { Waste Sludge }\end{array}$ \\
\hline & Slurry & Slurry \\
\hline Total slurry volume & $750 \mathrm{~mL}$ & $800 \mathrm{~mL}$ \\
\hline Total UDS & $28.8 \mathrm{wt} \%$ & 29.7 wt $\%$ \\
\hline Bulk density & $1.46 \mathrm{~g} / \mathrm{mL}$ & $1.35 \mathrm{~g} / \mathrm{mL}$ \\
\hline Centrifuged solids & 39.4 vol\% & 35.7 vol\% \\
\hline Shear strength & $700^{(\mathrm{a})} \mathrm{Pa}$ & 100 to $340^{(\mathrm{b})} \mathrm{Pa}$ \\
\hline Apparent viscosity & 1.7 to $3.6 \mathrm{cP}^{(\mathrm{c})}$ & 1.1 to $2.4 \mathrm{cP}^{(\mathrm{d})}$ \\
\hline Behavior & Newtonian & Newtonian \\
\hline Bingham Yield Stress & $0 \mathrm{~Pa}$ & Not Measured \\
\hline PSD & $\begin{array}{l}\text { Peak: } 11 \text { to } 15 \mu \mathrm{m} \\
\text { Range: } 0.2 \text { to } 40 \mu \mathrm{m}\end{array}$ & $\begin{array}{c}\text { Peak: } 10 \mu \mathrm{m} \\
\text { Range: } 0.2 \text { to } 200 \mu \mathrm{m}\end{array}$ \\
\hline Surface Area & $4.2 \mathrm{~m}^{2} / \mathrm{g}$ & $2.8 \mathrm{~m}^{2} / \mathrm{g}$ \\
\hline \multicolumn{3}{|c|}{$\begin{array}{l}\text { (a) Value corresponds to test where only half-vane immersion is achieved. Actually, } \\
\text { the shear strength is likely on the order of } 1500 \mathrm{~Pa} \text {. } \\
\text { (b) Value corresponds to test where only half-vane immersion is achieved. Actually, } \\
\text { the shear strength is likely on the order of } 200 \text { to } 700 \mathrm{~Pa} \text {. } \\
\text { (c) Apparent viscosity taken over the entire range of shear rate }\left(0 \text { to } 400 \mathrm{~s}^{-1}\right) \text {. } \\
\text { (d) Apparent viscosity taken over the entire range of shear rate }\left(0 \text { to } 450 \mathrm{~s}^{-1}\right) \text {. }\end{array}$} \\
\hline
\end{tabular}


Table 5.2. Summary of Elemental Composition of Group 3 CWP Sludge and Group 4 CWR Sludge Slurries

\begin{tabular}{|c|c|c|c|c|}
\hline \multirow[b]{2}{*}{ Major Analytes } & \multicolumn{2}{|c|}{ Group 3 CWP Sludge } & \multicolumn{2}{|c|}{ Group 4 CWR Sludge } \\
\hline & Solids, $\mu \mathrm{g} / \mathrm{g}^{(\mathrm{a})}$ & Aqueous, $\mu \mathrm{g} / \mathrm{mL}$ & Solids, $\mu \mathrm{g} / \mathrm{g}^{(\mathrm{a})}$ & Aqueous, $\mu \mathrm{g} / \mathrm{mL}$ \\
\hline $\mathrm{Al}$ & 311,500 & 2,035 & 320,000 & 505 \\
\hline $\mathrm{Bi}$ & 758 & $<3.61$ & 1,263 & $<2.3$ \\
\hline $\mathrm{Cr}$ & 324 & 261 & 1,760 & 221 \\
\hline $\mathrm{Fe}$ & 14,775 & {$[1.35]$} & 5,383 & [3.0] \\
\hline $\mathrm{Mn}$ & 1,022 & {$[0.37]$} & 1,708 & {$[0.81]$} \\
\hline $\mathrm{Na}$ & 14,825 & 73,700 & 11,200 & 65,300 \\
\hline $\mathrm{P}$ & 1,230 & 1,545 & [365] & 3,755 \\
\hline $\mathrm{S}$ & [110] & 7,260 & [431] & 551 \\
\hline $\mathrm{Si}$ & 8,980 & {$[3.80]$} & 5,985 & {$[6.2]$} \\
\hline $\mathrm{U}$ & 13,325 & [17] & 3,745 & [65] \\
\hline \multicolumn{5}{|c|}{$\begin{array}{l}\text { (a) Dry mass basis of washed solids. } \\
\text { Analyte uncertainties were typically within } \pm 15 \%(2-\sigma) \text {; results in brackets indicate that the analyte } \\
\text { concentrations were less than the minimum detection limit (MDL) and greater than the estimated quantitation } \\
\text { limit (EQL), and uncertainties were }>15 \% \text {. }\end{array}$} \\
\hline
\end{tabular}

\section{Group 3 Parametric Testing}

The Group 3 CWP sludge was subjected to parametric caustic leach testing to understand gibbsite dissolution characteristics and to support the development of a suitable simulant material for this type of waste (although simulant development was outside the scope of the work reported here). Leaching was conducted in a 1:100 solids-mass to solution-volume ratio under varying hydroxide concentrations (1, 3 , and $5 \mathrm{M}$ ), varying temperature $\left(60,80\right.$, and $\left.100^{\circ} \mathrm{C}\right)$, and sodium nitrate concentration (1 and $5 \mathrm{M} \mathrm{NaNO}_{3}$ ). Periodic sampling ( 0 to $48 \mathrm{~h}$ ) and analysis was conducted to determine the reaction behavior at each reaction condition. Composition of the caustic-leached solids and the leach factors for select analytes are given in Table 5.3. The following are the conclusions from this work.

- Under all caustic-leaching conditions examined, with the exception of the low hydroxide levels at $60^{\circ} \mathrm{C}$, aluminum removal from the Group 3 solids was rapid and complete. Al removal was achieved within the first 2 hours at $100^{\circ} \mathrm{C}$. At $80^{\circ} \mathrm{C}$, the reaction reached completion between 4 and 8 hours. At $60^{\circ} \mathrm{C}$, the reaction took 48 hours to reach steady state in $1 \mathrm{M} \mathrm{NaOH}$, and between 8 and 24 hours in $3 \mathrm{M} \mathrm{NaOH}$. In $5 \mathrm{M} \mathrm{NaOH}$ at $60^{\circ} \mathrm{C}$, the reaction reached completion between 8 and 24 hours. The reaction does not appear to reach complete dissolution in either 1 or $3 \mathrm{M} \mathrm{NaOH}$ during this time period at $60^{\circ} \mathrm{C}$. At 80 and $100^{\circ} \mathrm{C}$, there was very little increase in dissolution with increasing $\mathrm{NaOH}$ concentration.

- The Group 3 solids were determined to be primarily gibbsite by XRD analysis. The approximate mass percent of the chemical phases in the Group 3 washed solids was determined by evaluating the identified crystalline species in conjunction with the elemental concentrations. The approximate mass percent of gibbsite in the Group 3 washed solids was $87.6 \%$.

- Hematite, hydroxycancrinite, and/or nitrate cancrinite were identified as phases present in minor amounts. XRD analysis indicated that the sample was highly crystalline.

- 83 to $100 \%$ of the $\mathrm{Al}$ present in the washed Group 3 solids is readily dissolved in caustic media. 
- Uranium would likely be the component constraining waste loading in the HLW glass for the Group 3 solids remaining after leaching in $3 \mathrm{M} \mathrm{NaOH}$ at $80^{\circ} \mathrm{C}$ for 48 hours.

- The particle size distribution (PSD) for the leached Group 3 solids shows that before sonication, caustic leaching and washing reduces the number of 13- $\mu \mathrm{m}$ particles while increasing the number of $100-\mu \mathrm{m}$ particles. Post-sonication, caustic leaching and washing reduces the number of $9-\mu \mathrm{m}$ particles while increasing the fraction contribution of the 0.2 - to $2-\mu \mathrm{m}$ and 11 - to 170 - $\mu \mathrm{m}$ particles.

Table 5.3. Composition of Caustic-Leached Group 3 Solids with Leach Factors of Selected Analytes (3 $\mathrm{M} \mathrm{NaOH}, 80^{\circ} \mathrm{C}, 48 \mathrm{~h}$ )

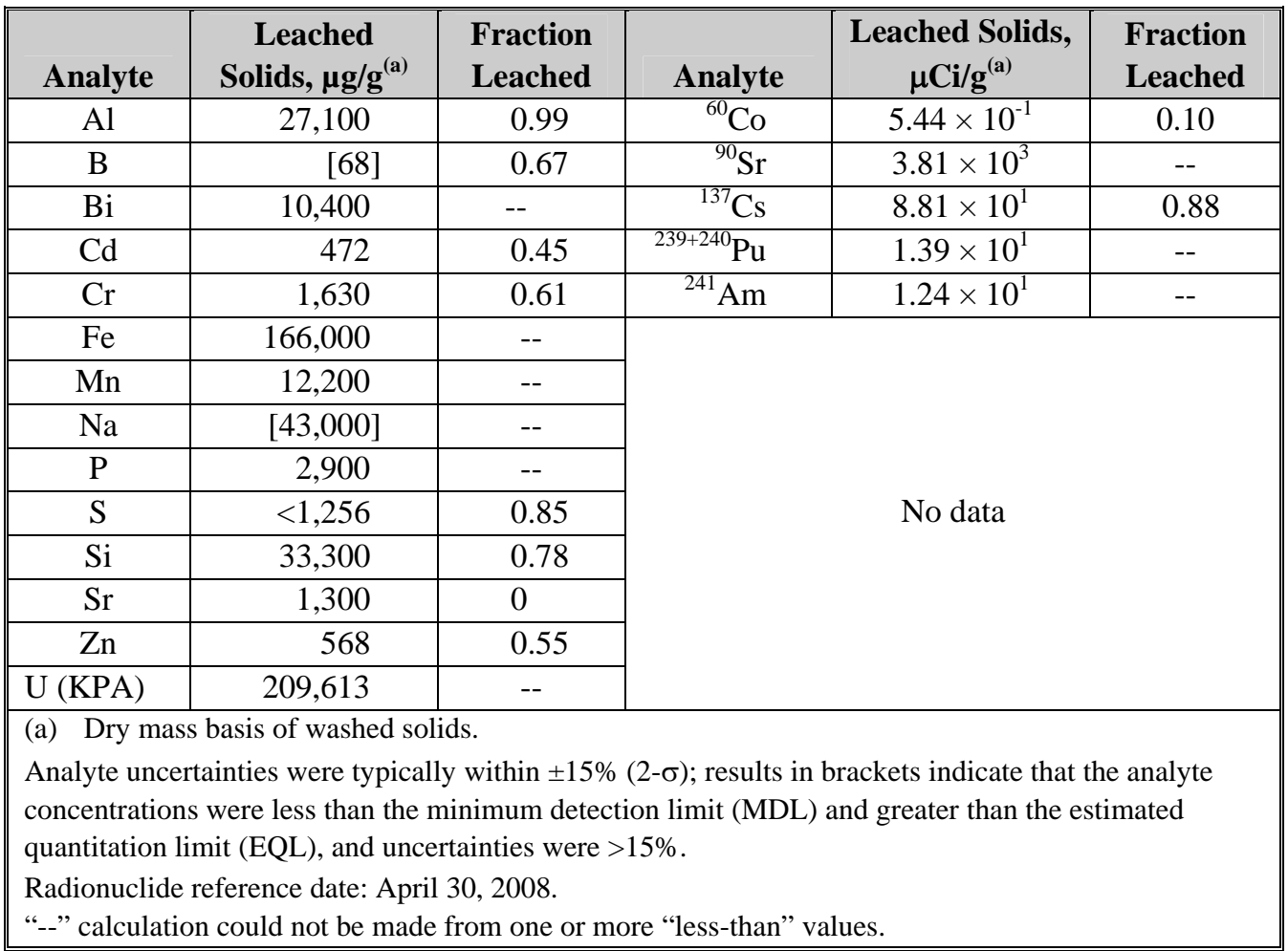

\section{Group 4 Parametric Testing}

As was the case with the Group 3 sample, the Group 4 CWR sludge was subjected to parametric caustic leach testing to understand gibbsite dissolution characteristics and to support the separate development of a suitable simulant material for this type of waste. Leaching was conducted in a 1:100 solids-mass to solution-volume ratio under varying hydroxide concentrations (1, 3, and $5 \mathrm{M}$ ), varying temperature (60, 80 , and $100^{\circ} \mathrm{C}$ ), and sodium nitrate concentration (1 to $5 \mathrm{M} \mathrm{NaNO}_{3}$ ). Periodic sampling (0 to $48 \mathrm{~h}$ ) and analysis was conducted to determine the reaction behavior at each reaction condition. Composition of the caustic-leached solids and the leach factors for select analytes are given in Table 5.4. The following are the key conclusions from this work.

- At $60^{\circ} \mathrm{C}$, the $\mathrm{Al}$ dissolution appears to take up to 48 hours to reach steady state in $1 \mathrm{M} \mathrm{NaOH}$ and between 4 and 8 hours in 3 and $5 \mathrm{M} \mathrm{NaOH}$. The reaction does not reach complete dissolution in $1 \mathrm{M}$ $\mathrm{NaOH}$ during this time period at $60^{\circ} \mathrm{C}$. At $80^{\circ} \mathrm{C}$, the $\mathrm{Al}$ dissolution is rapid and complete at all hydroxide levels, reaching completion between 2 and 4 hours for all cases. There was very little 
increase in dissolution with increasing $\mathrm{NaOH}$ concentrations. At $100^{\circ} \mathrm{C}$, the reactions reached steady-state values in the first hour. However, anomalous $\mathrm{Al}$ dissolution behavior in $3 \mathrm{M}$ and $5 \mathrm{M}$ $\mathrm{NaOH}$ at $100^{\circ} \mathrm{C}$ led to suspect $\mathrm{Al}$ leach factors under these conditions.

- As expected, the Group 4 solids were determined to be primarily gibbsite by XRD analysis. The approximate mass percent of the chemical phases in the Group 4 washed solids was determined by evaluating the identified crystalline species in conjunction with the elemental concentrations. The approximate mass percent of gibbsite in the Group 4 washed solids was 91.2\%.

- Sodium aluminum silicate hydrate was found, as well as minor contributions from boehmite, quartz, vaterite, sodium uranium oxide, and lepidocrocite, which were shown as possibly present. XRD analysis indicated that the sample was highly crystalline.

- 81 to $100 \%$ of the $\mathrm{Al}$ present in the washed Group 4 solids is readily dissolved in caustic media.

Table 5.4. Composition of Caustic-Leached Group 4 Solids with Leach Factors of Selected Analytes (3 $\mathrm{M} \mathrm{NaOH}, 80^{\circ} \mathrm{C}, 48 \mathrm{~h}$ )

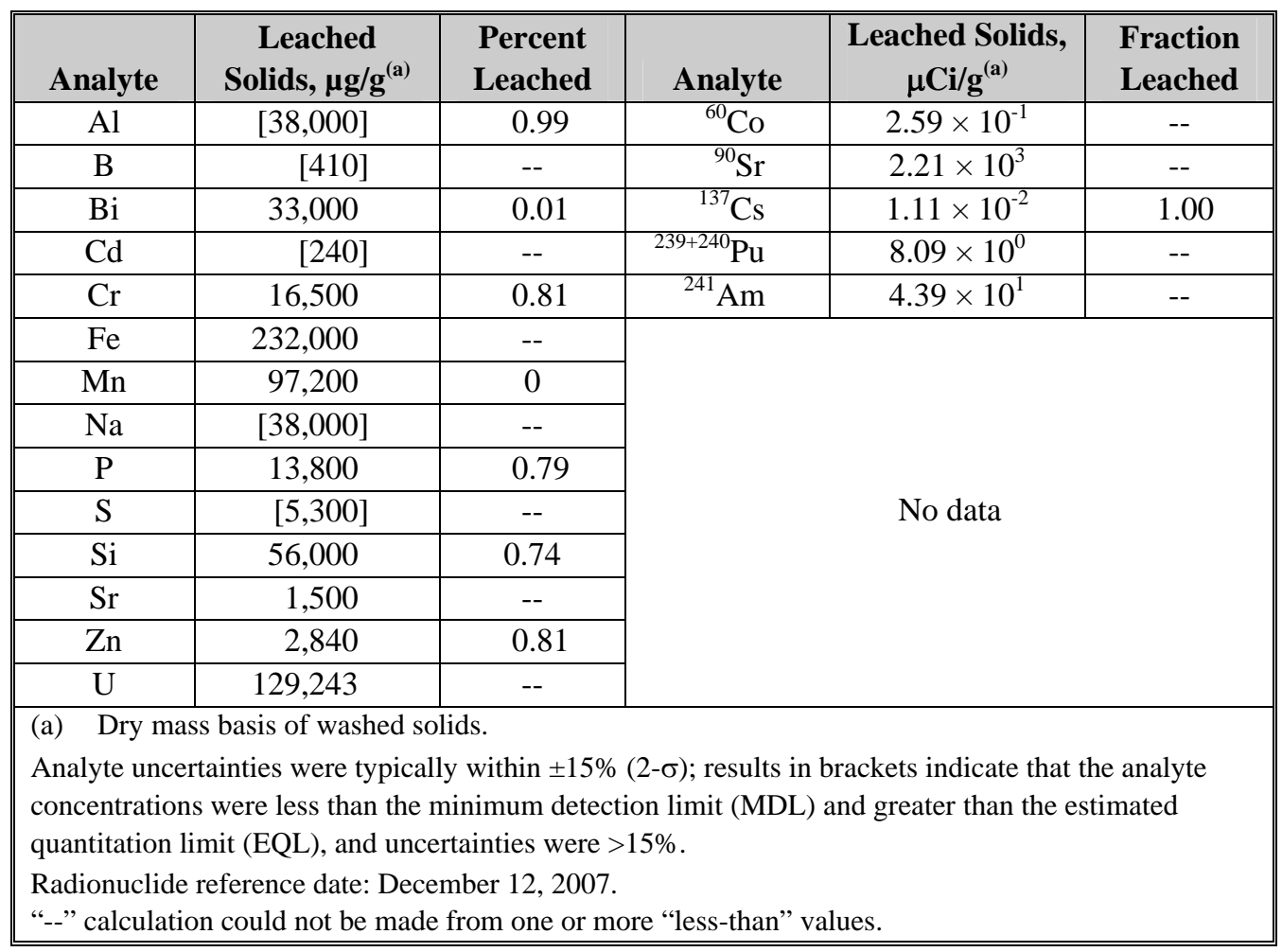


Appendix A

Supplemental Information Regarding Sample Selection 


\section{Appendix A}

\section{Supplemental Information Regarding Sample Selection}

The process used for selecting the 222S archive samples to be used to prepare the Group 3 and Group 4 composites was described in Section 2.1. However, some of the samples originally identified in this process were ultimately not used in preparing the composites. This appendix provides details as to why some samples were not included in the Group 3 and Group 4 composites.

\section{A.1 Group 3 Samples}

Table A.1 summarizes the individual samples (sample date, tank ID, sample core, and segment) from the archive that were initially chosen for the Group 3 sample. Also shown in Table A.1 are the anticipated aluminum concentrations (wet sample basis) and the mass assumed available based on the archive inventory in 2002.

A total of $0.90 \mathrm{~kg}$ of PUREX cladding sludge was assumed to be available and sufficient for the complete testing scope. However, several samples were not available. These are highlighted in Table A.1. The sample of Tank C-105 in jar 6896 had previously been transferred to jar 19798. The samples of tank C-104 in jars 11355 and 11367 had been previously depleted. The samples of Tank C-103 in jars 6395 and 13260 had also been previously depleted. The sample of Tank C-107 in jar 16043 was not used because it appeared to be at least $50 \% \mathrm{SRR}^{\text {(a) }}$ (Meacham 2003) based on the aluminum content. ${ }^{(\mathrm{b})} \mathrm{A}$ sample of Tank B-109 in jar 11486 was added to the test matrix as a replacement for this sample. Table A. 2 shows the sample jars that were ultimately used for the Group 3 sample.

(a) SRR is high-level waste transfers during later B-Plant operations, including solids centrifuged from Purex Acidified Sludge feed, Sr purification waste, and Waste Encapsulation and Storage Facility or cell drainage with high-level waste activity.

(b) Personal (email) communication from B. A. Higley, CH2M Hill Hanford Group, Inc, 11/30/06. 
Table A.1. Group 3 Originally Targeted Samples and Masses from 222S Archive

\begin{tabular}{|c|c|c|c|c|c|c|}
\hline $\begin{array}{c}\text { Tank } \\
\text { Sampling } \\
\text { Date }^{(a)}\end{array}$ & Jar \# & Tank & Core & Segment & $\begin{array}{l}\text { Estimated } \\
\text { Al, mg/g }\end{array}$ & $\begin{array}{l}\text { Net Sample } \\
\text { Weight (g) }\end{array}$ \\
\hline 4/10/1995 & $6896^{(\mathrm{c})}$ & C-105 & 72 & 3 & 219 & 53.72 \\
\hline $4 / 4 / 1996$ & 9765 & C-105 & 72 & 3 & 219 & 32 \\
\hline 9/15/1996 & 11356 & C-104 & 162 & 4 & 215 & 19.9 \\
\hline 9/15/1996 & 11355 & C-104 & 162 & 4 & 215 & 86.1 \\
\hline 9/4/1996 & 11244 & C-104 & 165 & 6 & 197 & 21.9 \\
\hline 9/16/1996 & 11366 & C-104 & 165 & 6 & 197 & 31.9 \\
\hline 9/16/1996 & 11245 & C-104 & 165 & 6 & 197 & 7 \\
\hline 9/17/1996 & 11367 & C-104 & 165 & 6 & 197 & 71 \\
\hline 7/1/1997 & 13043 & BY-109 & 203 & 7 & 197 & 55 \\
\hline 7/1/1997 & 13044 & BY-109 & 203 & 7 & 197 & 101.6 \\
\hline $1 / 21 / 2002$ & 19098 & BY-109 & 203 & 7 & 197 & 121.2 \\
\hline 2/4/2002 & 19134 & BY-109 & 203 & 7 & 197 & 17.5 \\
\hline 3/6/1995 & 6440 & C-103 & 66 & 4 & 192 & 18.84 \\
\hline $1 / 27 / 1995$ & 6395 & C-103 & 63 & 4 & 192 & 56.51 \\
\hline 9/8/1997 & 13260 & C-103 & 63 & 4 & 192 & 17 \\
\hline 10/18/1996 & 11505 & B-108 & 173 & 1 & 98.9 & 12.06 \\
\hline 10/18/1996 & 11506 & B-108 & 173 & 1 & 98.9 & 53.95 \\
\hline 10/17/1996 & 11507 & B-108 & 173 & Comp & 79.2 & 22.4 \\
\hline $3 / 14 / 2001$ & 16043 & C-107 & 288 & 2 & 70.0 & 103.9 \\
\hline & & & & & Sum & 903 \\
\hline \multicolumn{7}{|c|}{$\begin{array}{l}\text { (a) Sample date is defined in the Tank Waste Information Network System (TWINS) database. } \\
\text { (b) Wet mass basis, as defined in TWINS database. } \\
\text { (c) This sample had been transferred to jar } 19798 \\
\text { Samples highlighted were either previously depleted or not used for testing }\end{array}$} \\
\hline
\end{tabular}


Table A.2. Group 3 Samples Actually Used and Their Masses from 222S Archive

\begin{tabular}{|c|c|c|c|c|c|c|}
\hline $\begin{array}{c}\text { Tank } \\
\begin{array}{c}\text { Sampling } \\
\text { Date }\end{array}\end{array}$ & Jar \# & Tank & Core & Segment & $\begin{array}{c}\text { Estimated } \\
\text { Al, mg/g }\end{array}$ & $\begin{array}{c}\text { Net Sample } \\
\text { Weight (g) }\end{array}$ \\
\hline $4 / 10 / 1995$ & 19798 & C-105 & 72 & 3 & 219 & 53.72 \\
\hline $4 / 4 / 1996$ & 9765 & C-105 & 72 & 3 & 219 & 32 \\
\hline $9 / 15 / 1996$ & 11356 & C-104 & 162 & 4 & 215 & 19.9 \\
\hline $9 / 4 / 1996$ & 11244 & C-104 & 165 & 6 & 197 & 21.9 \\
\hline $9 / 16 / 1996$ & 11366 & C-104 & 165 & 6 & 197 & 31.9 \\
\hline $9 / 16 / 1996$ & 11245 & C-104 & 165 & 6 & 197 & 7 \\
\hline $7 / 1 / 1997$ & 13043 & BY-109 & 203 & 7 & 197 & 55 \\
\hline $7 / 1 / 1997$ & 13044 & BY-109 & 203 & 7 & 197 & 101.6 \\
\hline $1 / 21 / 2002$ & 19098 & BY-109 & 203 & 7 & 197 & 121.2 \\
\hline $2 / 4 / 2002$ & 19134 & BY-109 & 203 & 7 & 197 & 17.5 \\
\hline $3 / 6 / 1995$ & 6440 & C-103 & 66 & 4 & 192 & 18.84 \\
\hline $10 / 18 / 1996$ & 11505 & B-108 & 173 & 1 & 98.9 & 12.06 \\
\hline $10 / 18 / 1996$ & 11506 & B-108 & 173 & 1 & 98.9 & 53.95 \\
\hline $10 / 17 / 1996$ & 11507 & B-108 & 173 & Comp & 79.2 & 22.4 \\
\hline 9/17/1996 & 11486 & B-109 & 169 & 2 & 104 & 59.3 \\
\hline \multicolumn{7}{|l}{} \\
\hline $\begin{array}{l}\text { (a) Sample date is defined in TWINS database. } \\
\text { (b) Wet mass basis, as defined in TWINS database. }\end{array}$ \\
\hline
\end{tabular}

\section{A.2 Group 4 Samples}

Table A.3 summarizes the individual samples (sample date, tank ID, sample core, and segment) from the archive that were initially chosen for the Group 4 sample. Also shown in Table A.3 are the anticipated aluminum concentrations (wet sample basis) and the mass assumed available based on the archive inventory in 2002.

A total of $0.66 \mathrm{~kg}$ of REDOX cladding sludge was assumed to be available and sufficient for the complete testing scope. However, the sample of Tank U-204 in jar 19437 had been previously depleted. Based on this change to the samples used and the gross and tare weights provided along with the samples, this lowered the expected value of REDOX cladding sludge to $0.574 \mathrm{~kg}$. Table A.4 shows the sample jars that were ultimately used for the Group 4 sample. 
Table A.3. Group 4 Originally Targeted Samples and Masses from 222S Archive

\begin{tabular}{|c|c|c|c|c|c|c|}
\hline $\begin{array}{c}\text { Tank } \\
\text { Sampling } \\
\text { Date }^{(a)}\end{array}$ & Jar \# & Tank & Core & Segment & $\begin{array}{l}\text { Estimated } \\
\mathrm{Al}, \mathrm{mg} / \mathrm{g}^{(\mathrm{b})}\end{array}$ & $\begin{array}{l}\text { Net Sample } \\
\text { Weight (g) }\end{array}$ \\
\hline 4/6/1995 & 6916 & U-202 & 78 & 1 & 309 & 75.16 \\
\hline 4/6/1995 & 6911 & U-202 & 78 & 1 & 309 & 73.53 \\
\hline 11/19/1998 & 15011 & U-202 & 78 & 1 & 309 & 28.8 \\
\hline 9/17/1997 & 13486 & U-202 & 78 & 1 & 309 & 12.4 \\
\hline $8 / 7 / 2002$ & 19169 & U-202 & 78 & Comp & 309 & 31.6 \\
\hline 4/6/1995 & 6882 & U-201 & 70 & 2 & 250 & 32.1 \\
\hline $8 / 8 / 2002$ & 19154 & U-201 & 70 & Comp & 250 & 25.6 \\
\hline 9/26/1997 & 13462 & U-201 & 74 & 1 & 250 & 31.4 \\
\hline 11/19/1998 & 15020 & U-204 & 82 & 1 & 229 & 32.9 \\
\hline 7/30/2002 & 19476 & U-203 & 80 & 1 & 212 & 31.5 \\
\hline $8 / 18 / 1999$ & 16961 & U-105 & 136 & $9 \mathrm{~A}$ & 165 & 120.9 \\
\hline $4 / 5 / 1996$ & 9711 & U-105 & 136 & 9A & 165 & 79.29 \\
\hline 4/3/1996 & 9702 & U-105 & 136 & 9A & 165 & 11.97 \\
\hline 9/8/1997 & 13072 & U-204 & 81 & 1 & 148 & 65.09 \\
\hline $7 / 30 / 2002$ & 19437 & U-204 & 81 & 1 & 148 & 5 \\
\hline \multicolumn{5}{|c|}{$x_{1}^{2}$} & Sum & 657 \\
\hline \multicolumn{7}{|c|}{$\begin{array}{l}\text { (a) Sample date is defined in TWINS database. } \\
\text { (b) Wet mass basis, as defined in TWINS database. } \\
\text { Samples highlighted were either previously depleted }\end{array}$} \\
\hline
\end{tabular}

Table A.4. Group 4 Samples Actually Used and Their Masses from 222S Archive

\begin{tabular}{|c|c|c|c|c|c|c|}
\hline $\begin{array}{c}\text { Tank } \\
\text { Sampling } \\
\text { Date }^{(a)}\end{array}$ & Jar \# & Tank & Core & Segment & $\begin{array}{l}\text { Estimated } \\
\mathrm{Al}, \mathrm{mg} / \mathrm{g}^{(\mathrm{b})}\end{array}$ & $\begin{array}{l}\text { Net Sample } \\
\text { Weight (g) }\end{array}$ \\
\hline 4/6/1995 & 6916 & U-202 & 78 & 1 & 309 & 75.16 \\
\hline 4/6/1995 & 6911 & U-202 & 78 & 1 & 309 & 73.53 \\
\hline 11/19/1998 & 15011 & U-202 & 78 & 1 & 309 & 28.8 \\
\hline 9/17/1997 & 13486 & U-202 & 78 & 1 & 309 & 12.4 \\
\hline $8 / 7 / 2002$ & 19169 & U-202 & 78 & Comp & 309 & 31.6 \\
\hline 4/6/1995 & 6882 & U-201 & 70 & 2 & 250 & 32.1 \\
\hline $8 / 8 / 2002$ & 19154 & U-201 & 70 & Comp & 250 & 25.6 \\
\hline 9/26/1997 & 13462 & U-201 & 74 & 1 & 250 & 31.4 \\
\hline 11/19/1998 & 15020 & U-204 & 82 & 1 & 229 & 32.9 \\
\hline 7/30/2002 & 19476 & U-203 & 80 & 1 & 212 & 31.5 \\
\hline $8 / 18 / 1999$ & 16961 & U-105 & 136 & $9 \mathrm{~A}$ & 165 & 120.9 \\
\hline $4 / 5 / 1996$ & 9711 & U-105 & 136 & $9 \mathrm{~A}$ & 165 & 79.29 \\
\hline 4/3/1996 & 9702 & U-105 & 136 & 9A & 165 & 11.97 \\
\hline 9/8/1997 & 13072 & U-204 & 81 & 1 & 148 & 65.09 \\
\hline \multirow{2}{*}{\multicolumn{5}{|c|}{ (a) Sample date is defined in TWINS database. }} & Sum & 652 \\
\hline & & & & & & \\
\hline
\end{tabular}


Appendix B

\section{Analytical Methods}




\section{Appendix B}

\section{Analytical Methods}

This section describes the analytical methods used to determine the chemical and radiochemical composition of the Group 3 and Group 4 samples.

\section{B.1 Sample Preparation for Chemical Characterization}

The samples taken for chemical characterization were centrifuged at $1000 \mathrm{G}$ for $1 \mathrm{hr}$, and then the supernatant liquids were decanted. The solids were washed with three successive additions of $0.01 \mathrm{M}$ $\mathrm{NaOH}^{(\mathrm{a})}$ After adding each washing solution, the sample was agitated for $15 \mathrm{~min}$ and centrifuged $30 \mathrm{~min}$ at $1000 \mathrm{G}$, and the liquid phase was removed. The three wash solutions were combined into a composite and passed through a 0.45 -micron pore size nylon filter. The supernatant and wash-solution densities were determined by measuring the masses of $1-\mathrm{mL}$ volume deliveries four times per sample.

More $0.01 \mathrm{M} \mathrm{NaOH}$ was added to the washed solids so that the slurry could be easily mixed with a Teflon-coated stirbar, and the solids were suspended. Aliquots of the suspended-solids slurries were taken for chemical and radiochemical analysis, particle-size distribution (PSD), Brunauer, Emmett, and Teller (a method for measuring surface areas) (BET), scanning electron microscopy (SEM), transmission electron microscopy (TEM), and X-ray diffraction (XRD) analyses. The washed solids slurry sample aliquots taken for chemical analysis were dried to constant mass at $105^{\circ} \mathrm{C}$; the solids chemical analysis was based on the dry sample mass. The supernatant liquid and the filtered solids washing solution were provided directly to the Analytical Services Operation (ASO) for chemical characterization.

\section{B.2 Chemical and Radioisotope Characterization}

The following sections describe the procedures used to support the chemical and radiochemical characterization of the solids and aqueous samples. Aqueous samples were distributed directly to the free hydroxide, ion chromatrography (IC), and total inorganic carbon/total organic carbon (TIC/TOC) analytical workstations. The solids and liquids required a digestion step before distribution to the ICP-OES and radiochemistry workstations.

\section{B.2.1 Free Hydroxide}

The free-hydroxide concentration was determined by potentiometric titration with standardized $\mathrm{HCl}$ according to procedure RPG-CMC-228, Determination of Hydroxyl $(\mathrm{OH})$ and Alkalinity of Aqueous Solutions, Leachates, and Supernates and Operation of Brinkman 636 Auto-Titrator. The free hydroxide was defined as the first inflection point on the titration curve. Quality control (QC) samples were generated at the analytical workstation and included a sample replicate determination, process blank, blank spike (BS), and matrix spike (MS).

(a) Specific wash volumes are provided in the context of the results discussion. 


\section{B.2.2 Anions}

Anions were determined by IC using a Dionix ICS-2500 IC system equipped with a conductivity detector according to procedure RPG-CMC-212, Determination of Common Anions by Ion Chromatography. Additional sample dilutions from $100 \times$ to $25,000 \times$ were required to accurately measure the analytes. QC samples were generated at the analytical workstation and included a sample replicate determination, process blank, BS, and MS.

\section{B.2.3 TIC/TOC}

The TIC was determined by using silver-catalyzed hot persulfate (HP) oxidation according to procedure RPG-CMC-385, Carbon Measured in Solids, Sludge, and Liquid Matrices. The HP wet oxidation method was used. This method takes advantage of acid decomposition of the carbonate (TIC measure) followed by oxidation of organic carbon (TOC measure) using acidic potassium persulfate at 92 to $95^{\circ} \mathrm{C}$. QC samples were generated at the analytical workstation and included a sample replicate determination, process blank, BS, and MS.

\section{B.2.4 Acid Digestion}

Aqueous samples were digested with acid according to procedure PNL-ALO-128, $\mathrm{HNO}_{3}-\mathrm{HCl}$ Acid Extraction of Liquids for Metals Analysis Using a Dry-Block Heater. The acid-digested solutions were brought to a nominal 25-mL volume (resulting in a nominal $25 \times$ dilution where the initial sample size was 1-mL); absolute volumes were determined based on final solution weights and densities. As part of the analytical preparation batch, the ASO processed a digestion preparation blank (PB), a BS, and an MS. The spike solution contained a broad suite of stable elements; radionuclides were not included in the digestion preparation. Aliquots of the BS, MS, and $\mathrm{PB}$, along with the sample aliquots, were delivered to the inductively coupled plasma-optical emission spectroscopy (ICP-OES) workstation for analysis; sample and PB aliquots were delivered to the radiochemical workstations for separations supporting specific radioisotope analysis.

\section{B.2.5 KOH Fusion}

The potassium hydroxide $(\mathrm{KOH})$ fusion was conducted in the shielded analytical facility (hot cells)

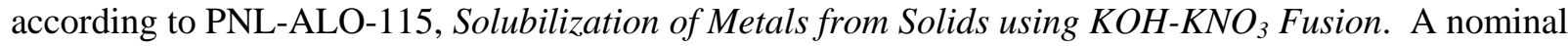
sample size of 0.1 to $0.2 \mathrm{~g}$ dry solids was combined with a $\mathrm{KOH} / \mathrm{KNO}_{3}$ flux mixture and fused at $550^{\circ} \mathrm{C}$ for 1 hour in a nickel crucible. The fused material was acidified with $\mathrm{HNO}_{3}$, taken to a $100-\mathrm{mL}$ volume with DI water, and then split for metals and radionuclide analysis. Samples were typically prepared in duplicate along with a fusion blank and a laboratory control sample (LCS) (SRM-2710, Montana Soil, purchased from the National Institute for Science and Technology [NIST]).

\section{B.2.6 NaOH/Na2O2 Fusion}

The $\mathrm{NaOH} / \mathrm{Na}_{2} \mathrm{O}_{2}$ fusion was conducted in the shielded analytical facility (hot cells) according to PNL-ALO-114, Solubilization of Metals from Solids using a $\mathrm{Na}_{2} \mathrm{O}_{2}-\mathrm{NaOH}$ Fusion. A nominal sample size of 0.1 to $0.2 \mathrm{~g}$ dry solids was combined with an $\mathrm{NaOH} / \mathrm{Na}_{2} \mathrm{O}_{2}$ flux mixture and fused at $550^{\circ} \mathrm{C}$ for 1 hour in a zirconium crucible. The fused material was acidified with $\mathrm{HNO}_{3}$, taken to a 100 -mL volume 
with DI water, and then split for metals analysis. The sample was prepared in duplicate along with a fusion blank and an LCS (SRM-2710, Montana Soil).

\section{B.2.7 HF-Assisted Acid Digestion}

The HF-assisted acid digestion was conducted in the Sample Receiving and Preparation Laboratory according to PNL-ALO-138, $\mathrm{HNO}_{3}-\mathrm{HF}-\mathrm{HCl}$ Acid Digestion of Solids for Metals Analyses Using a Dry Block Heater. A nominal sample size of 0.1 to $0.2 \mathrm{~g}$ dry solids was contacted with a mixture of concentrated $\mathrm{HF}$ and $\mathrm{HNO}_{3}$ and evaporated to dryness in a Teflon ${ }^{\circledR}$ reaction tube. Concentrated $\mathrm{HCl}$ was then added, and the sample was evaporated to dryness a second time. Additional concentrated $\mathrm{HNO}_{3}$ and $\mathrm{HCl}$ were added, the reaction tube was capped tightly, and the mixture was heated in a dry-block heater at $95^{\circ} \mathrm{C}$ for $6.5 \mathrm{~h}$. The digestate was cooled, brought to a 50-mL volume, and then split for metals analysis. The sample was prepared in duplicate along with a fusion blank and an LCS (SRM-2710, Montana Soil).

\section{B.2.8 Metals Analysis by ICP-OES}

Metals were measured by ICP-OES according to procedure RPG-CMC-211, Determination of Elemental Composition by Inductively Coupled Argon Plasma Optical Emission Spectrometry (ICPOES). The preparative QC samples (duplicate, $\mathrm{PB}, \mathrm{BS}, \mathrm{MS}$ ) were processed along with analytical workstation QC (post digestion spike and serial dilution).

\section{B.2.9 U (KPA)}

Uranium was determined directly from samples prepared by $\mathrm{KOH}$ fusion using a Chem Chek Instruments kinetic phosphorescence analysis (KPA) according to procedure RPG-CMC-4014, Rev. 1, Uranium by Kinetic Phosphorescence Analysis. The LCS did not contain U, so preparative QC was limited to the duplicate and PB. A post-digestion spike was conducted at the analytical workstation.

\section{B.2.10 Gamma Energy Analysis}

Gamma energy analysis was performed with direct or diluted samples that were prepared from acid digestion, fusion, or neat. Sample counting was conducted according to procedure RPG-CMC-450, Gamma Energy Analysis (GEA) and Low-Energy Photon Spectroscopy (LEPS), using high-purity germanium detectors. Extended count times (up to $20 \mathrm{~h}$ ) were employed as needed to achieve low detection limits. In many cases, the Compton background from the high ${ }^{137} \mathrm{Cs}$ activity $(661 \mathrm{keV})$ limited the achievable detection limit of lower-energy gamma emitters (e.g., ${ }^{241} \mathrm{Am}$ at $59 \mathrm{keV}$ ). The QC associated with the GEA analysis was composed of the sample duplicate and PB; because this is a direct analysis, no additional QC samples were required.

\section{B.2.11 Gross Alpha and Gross Beta}

Aqueous samples were prepared for gross alpha and beta determinations by acid-digestion, and the washed-solids samples were prepared by $\mathrm{KOH} / \mathrm{KNO}_{3}$ fusion. Prepared sample aliquots were plated directly onto stainless steel planchets according to procedure RPG-CMC-4001, Source Preparation for Gross Alpha and Gross Beta Analysis. The mounts prepared for gross alpha analysis were counted with Ludlum alpha scintillation counters. The gross alpha analysis tends to be confounded by the dissolved 
solids in the sample matrix. The solids can absorb the alpha particles, decreasing the intensity relative to the detector, which biases the results low. The sources prepared for gross beta analysis were counted with an LB4100 gas-proportional counter. In both cases, counting operations were conducted according to procedure RPG-CMC-408, Rev.1, Total Alpha and Total Beta Analysis. The preparative QC included the sample duplicates and the preparation blank. The BS and MS were prepared at the analytical workstation on sample dilutions.

\section{B.2.12 Pu Isotopes: 238Pu and 239+240Pu}

The ${ }^{238} \mathrm{Pu}$ and ${ }^{239+240} \mathrm{Pu}$ activities were measured from aqueous samples prepared by acid-digestion, and washed solids samples were prepared by $\mathrm{KOH} / \mathrm{KNO}_{3}$ fusion. Radiochemical separations were conducted according to procedure RPG-CMC-4017, Analysis of Environmental Water Samples for Actinides and Strontium-90 (analyte purification using ion exchange); source preparation was conducted according to RPG-CMC-496, Coprecipitation Mounting of Actinides for Alpha Spectroscopy (co-precipitation of $\mathrm{PuF}_{3}$ with $\mathrm{LaF}_{3}$ ); and alpha counting was conducted according to RPG-CMC-422, Rev.1, Solutions Analysis: Alpha Spectrometry. The preparative QC included the sample duplicates and the preparation blank. The BS and MS were prepared at the analytical workstation on sample dilutions.

\section{B.2.13 Strontium-90}

The ${ }^{90} \mathrm{Sr}$ activities were measured from aqueous samples prepared by acid-digestion, and washed-solids samples were prepared by $\mathrm{KOH} / \mathrm{KNO}_{3}$ fusion. Radiochemical separation was conducted according to procedure RPG-CMC-476, Strontium-90 Separation Using Eichrom Strontium Resin; source preparation and beta counting were conducted according RPG-CMC-474, Measurement of Alpha and Beta Activity by Liquid Scintillation Spectrometry. 
Appendix C

Physical Properties Determination and Rheology Methods 


\section{Appendix C}

\section{Physical Properties Determination and Rheology Methods}

This appendix describes the experimental methods used to determine rheological properties and physical properties, including particle-size distribution and surface-area measurements.

\section{C.1 Physical Properties}

The physical-property characterization was conducted according to procedure RPL-COLLOID-02, Rev. 1, Measurement of Physical and Rheological Properties of Solutions, Slurries and Sludges, which is consistent with the WTP guidelines document. ${ }^{(a)}$ Samples for physical-properties characterization were taken in triplicate near the beginning (S1), middle (S2), and end (S3) of the aliquoting activity following slurry homogenization. Samples sizes were generally between 10 and $15 \mathrm{~mL}$. The samples were collected in 10-mL, volume-graduated, glass centrifuge tubes (Kimble-Kontes product number 45200-10).

Settling studies were conducted at ambient temperature by thoroughly agitating the samples and then allowing the solids to settle by gravity with periodic measurement of the settled-solids volume. The sample tubes were undisturbed over the 3-day settling period. Following the settling measurements, the samples were centrifuged at $\sim 1000 \mathrm{G}$ for 1 hour. The total sample volume and solids volume were recorded to assess the vol\% wet centrifuged solids (WCSs). The centrifuged supernatants were decanted and transferred to tared graduated cylinders; the net solution masses and volumes were determined. The remaining WCSs were weighed in the centrifuge tubes to assess gross densities. The supernatant samples were transferred to tared glass vials. Both the supernatant fractions and the residual solids fractions (containing interstitial supernatant) were air-dried and then transferred to a $105^{\circ} \mathrm{C}$ oven for continued drying until constant mass was attained. The data collected were processed as described by Smith and Prindiville ${ }^{(a)}$ to determine the volume and weight percent of wet solids (total, settled, and centrifuged), densities, total undissolved solids, and dissolved solids content.

\section{C.2 Rheology}

Rheological testing was conducted on the solids in contact with the supernatant generated as part of the homogenization process. Testing was conducted according to RPL-COLLOID-02, Measurement of Physical and Rheological Properties of Solutions, Slurries and Sludges. For the current study, two regions of tank waste flow behavior are considered: 1 ) incipient motion in settled tank waste solids (shear strength) and 2) non-elastic flow of tank waste slurries and supernates (flow curve).

\section{C.2.1 Shear-Strength Testing}

For tank waste slurries, a finite stress must be applied before the material will begin to flow. The stress required to transition the material from elastic deformation to viscous flow is referred to as the shear strength, and its origin can be attributed to static and kinetic friction between individual particles and/or

(a) 24590-WTP-GPG-RTD-001, Rev 0, "Guidelines for Performing Chemical, Physical, and Rheological Properties Measurements,” G. L. Smith and K. Prindiville, May 2002. 
aggregates, the strength of the matrix supporting the coarse fraction (i.e., the interstitial fluid), and sludge cohesion arising from interparticle adhesive forces such as van der Waals forces.

The shear strength was measured using the vane method. For the vane technique, the stress required to begin motion is determined by slowly rotating a vane immersed in the test sample's settled solids while continuously monitoring the resisting torque as a function of time. A material's static shear strength is then associated with the maximum torque measured during the transition from initial to steady-state vane rotation.

The maximum torque required for incipient motion is dependent on vane geometry. To account for vane geometry effects, the shear strength is expressed in terms of the uniform and isotropic stress acting over the surface area of the cylinder of rotation swept out by the vane. The shear strength is related to the maximal torque during incipient motion according to Equation C.1 (Barnes and Dzuy 2001):

$$
\tau_{S S}=\frac{M_{\max }}{4 \pi R^{3}\left(\frac{H}{2 R}+\frac{1}{3}\right)}
$$

Here, $\tau_{s s}$ is the shear strength $\left[\mathrm{N} / \mathrm{m}^{2}\right], M_{\max }$ is the maximum torque [N·m], and $R$ and $H$ are the radius and height of the cylinder of rotation swept out by the vane $[\mathrm{m}]$. Because the shear band observed upon slow rotation of the vane does not extend appreciably beyond the vane paddles, $R$ and $H$ are taken to be the dimensions of the vane itself.

\section{C.2.2 Flow-Curve Testing}

The non-elastic flow of tank waste slurries and supernates is characterized with rotational viscometry. The typical result of such testing is a set of flow-curve data that show the stress response of a material to a range of applied rates-of-deformation. Specifically, flow-curve testing allows characterization of a material's shear stress, $\tau$, and response as a function of applied shear rate, $\dot{\gamma}$. Once measured, flowcurve data can be interpreted with several constitutive equations for the viscous stress/rate-of-strain relationship. Such analysis allows the flow behavior over a broad range of conditions to be described with just a few rheological descriptors such as viscosity, yield stress, consistency, and flow index.

A concentric cylinder rotational viscometer operated in controlled-rate mode was used for flow-curve testing of tank waste slurries and supernates. Rotational viscometers operate by placing a given volume of test sample into a measurement cup of known geometry. A cylindrical rotor attached to a torque sensor is then lowered into the sample until the slurry is even with, but does not cover, the top of the rotor. A single-point determination of a fluid's flow properties is made by spinning a rotor at a known rotational speed, $\Omega$, and measuring the resisting torque, $M$, acting on the rotor. The torque acting on the rotor can be directly related to the shear stress $(\tau)$ at the rotor using the equation,

$$
\tau=\frac{M}{2 \pi H R_{I}^{2}}
$$


where $R_{I}$ and $H$ are the radius and height of the rotor, respectively (see Figure C.1). Shear stress has units of force per area $\left(\mathrm{N} / \mathrm{m}^{2}\right)$. The rotational rate is related to the shear rate. However, calculating the fluid shear rate at the rotor is complicated by the fact that the shear rate depends on both the measurement system geometry and the fluid rheological properties. For the simplest fluids (i.e., Newtonian fluids), the shear rate $(\dot{\gamma})$ of the fluid at the rotor can be calculated given the geometry of the cup rotor shear by using the equation,

$$
\dot{\gamma}=\left(\frac{2 R_{O}^{2}}{R_{O}^{2}-R_{I}^{2}}\right) \Omega
$$

Here, $R_{I}$ is the inner radius of the cup, such that the gap width between cup and rotor is $\left(R_{O}\right.$ to $\left.R_{I}\right)$. The shear rate has units of inverse seconds $\left[\mathrm{s}^{-1}\right]$. Calculating the shear rate for materials showing more complex shear-stress versus shear-rate behavior (i.e., non-Newtonian fluids) requires estimates of yield stress and degree of shear-thinning or shear-thickening. As the goal of rheological testing is to determine and quantify such behavior, these values are typically not known. This requirement can be circumvented by using a cup-and-rotor system with a small gap $(\sim 1 \mathrm{~mm})$ for fluid shear. For fluid flow in small gap cup-and-rotor systems, shear-rate effects introduced by fluid properties are minimized such that Equation C.3 provides an accurate determination of shear rate for non-Newtonian materials. Shear rates examined in this study spanned the range from 1 to $1000 \mathrm{~s}^{-1}$.

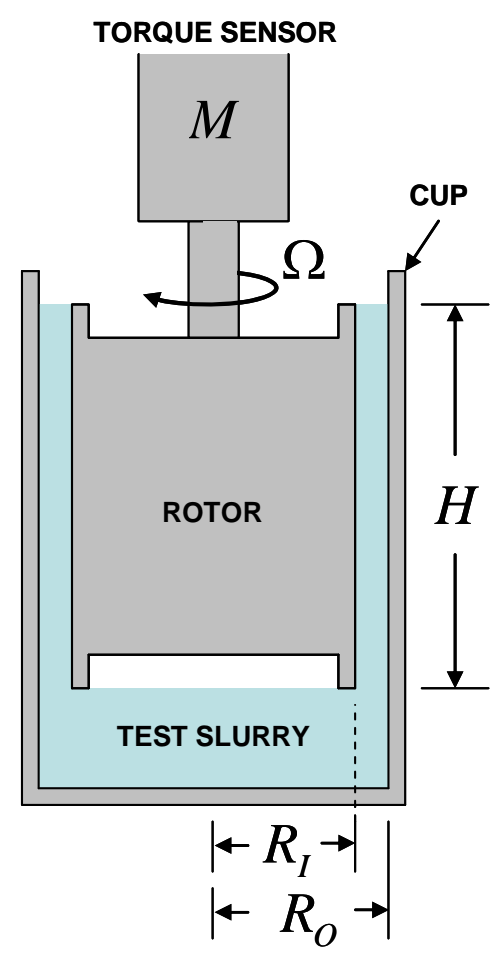

Figure C.1. Rotor and Cup Geometry Used in Rotational Viscometry Testing

The resistance of a fluid to flow is often described in terms of the fluid's apparent viscosity, $\eta_{a p p}$, which is defined as the ratio of the shear stress to shear rate: 


$$
\eta_{a p p}=\frac{\tau}{\dot{\gamma}}
$$

For Newtonian fluids, the apparent viscosity is independent of shear rate. For non-Newtonian fluids, the apparent viscosity will vary as a function of shear rate. The units of apparent viscosity are Pa·s, although it is typically reported in units of centipoise (cP; where $1 \mathrm{cP}=1 \mathrm{mPa} \cdot \mathrm{s})$.

Flow-curve data are usually combined plots of $\tau$ and $\eta_{\text {app }}$ as a function of $\dot{\gamma}$. As stated above, flow-curve data can be interpreted with several constitutive equations (i.e., flow curves), allowing the data to be characterized with just a few rheological descriptors. The behavior of tank waste sludges, slurries, and supernates can typically be described by one of five common flow-curve equations:

- Newtonian-Newtonian fluids flow as a result of any applied stress and show constant viscosity over all shear conditions. The flow curve for Newtonian fluids is,

$$
\tau=\eta \dot{\gamma}
$$

where $\eta$ is the Newtonian viscosity.

- Ostwald (Power Law) - Power-law fluids flow as a result of any applied stress and have viscosities that either increase or decrease with increasing shear rate. They are described by

$$
\tau=m \dot{\gamma}^{n}
$$

where $m$ is the power-law consistency index, and $n$ is the power-law index. Power-law fluids with $n<1$ are referred to as pseudoplastic (shear-thinning), whereas power-law fluids with $n>1$ are referred to as dilatant (shear-thickening).

- Bingham Plastic - Bingham plastics are fluids that show finite yield points. A finite stress (i.e., the yield stress), must be exceeded before these types of materials flow. Once flow is initiated, the stress response of the material is Newtonian over the rest of the shear-rate range. Bingham plastics are described by

$$
\tau=\tau_{O}^{B}+k_{B} \dot{\gamma}
$$

where $\tau_{O}^{B}$ is the Bingham yield index, and $k_{B}$ is the Bingham consistency index.

- Herschel-Bulkley-Fluids that behave in accordance with a Herschel-Bulkley model show a finite yield followed by power-law behavior over the rest of the shear-rate range. They are described by

$$
\tau=\tau_{O}^{H}+k_{H} \dot{\gamma}^{b}
$$


where $\tau_{O}^{H}$ is the Herschel-Bulkley yield index, $k_{H}$ is the Herschel-Bulkley consistency index, and b is the Herschel-Bulkley power-law index.


pseudoplastic behavior. They are described by

$$
(\tau)^{0.5}=\left(\tau_{o}^{C}\right)^{0.5}+\left(k_{C} \dot{\gamma}\right)^{0.5}
$$

where $\tau_{o}^{C}$ is the Casson yield index, and $k_{C}$ is the Casson consistency index. Although more limited in the types of flow behavior it can describe relative to the Herschel-Bulkley equation, the Casson model is popular because it is capable of accurately describing many shear-thinning fluids and because units on the parameters are more physically meaningful (e.g., the consistency is in Pa.s versus Pa $\cdot \mathrm{s}^{\mathrm{n}}$ for the Herschel-Bulkely model).

Power-law fluids, Bingham plastics, and Herschel-Bulkley fluids are examples of non-Newtonian fluids. In general, liquids without internal and/or interconnected structures (such as tank waste supernates) are Newtonian. Sludges and slurries are typically non-Newtonian, but their exact behavior depends on the concentration of solids and suspending phase chemistry. Sufficiently dilute slurries may show Newtonian behavior.

\section{C.2.3 Rheology Instrumentation}

Rheological characterization was accomplished with a Rotovisco ${ }^{\circledR}$ RV20 Measuring System M equipped with an M5 measuring head sold by HAAKE Mess-Technik GmbH u. Co. (now the Thermo Electron Corporation, Madison, WI). The M5 measuring head is a "Searle" type viscometer capable of producing rotational speeds up to 500 revolutions per minute (RPM) and measuring torques up to $0.049 \mathrm{~N} \cdot \mathrm{m}$. The minimum rotational speed and torque resolution achievable by this measuring head are 0.05 RPM and $0.49 \mathrm{mN} \cdot \mathrm{m}$, respectively.

Specific measurement tools, such as cup-and-rotor assemblies and shear vanes, are attached to measure selected rheological properties. Shear-strength measurements employed an 8-mm × 16-mm (radius $\times$ height) shear vane tool. Flow-curve measurements employed an MV1 stainless steel measuring cup and rotor. The dimensions of the MV1 and vane measuring systems are listed in Table C.1.

Table C.1. Vane and Cup and Rotor Measuring System Dimensions

\begin{tabular}{||c|c|c|c|c||}
\hline \hline $\begin{array}{c}\text { MEASURING } \\
\text { SYSTEM }\end{array}$ & $\begin{array}{c}\text { VANE/ROTOR } \\
\text { RADIUS, } \\
\text { MM }\end{array}$ & $\begin{array}{c}\text { VANE/ROTOR } \\
\text { HEIGHT, } \\
\text { MM }\end{array}$ & $\begin{array}{c}\text { CUP } \\
\text { RADIUS, } \\
\text { MM }\end{array}$ & $\begin{array}{c}\text { GAP } \\
\text { WIDTH, } \\
\text { MM }\end{array}$ \\
\hline Vane Tool & 8 & 16 & $>16$ & $>8$ \\
\hline MV1 & 20.04 & 60 & 21 & 0.96 \\
\hline
\end{tabular}

The temperature was controlled with a combination of the standard measuring system $\mathrm{M}$ temperature jacket and a Cole-Parmer ${ }^{\circledR}$ Polystat ${ }^{\circledR}$ Temperature-Controlled Recirculator, Model Number C-12920-00. The temperature jacket provided a heat-transfer area between the cup and the recirculating fluid. The 
jacket temperature was monitored using a Type-K thermocouple (Omega Model TJ36-CASS-116-G-6CC). Temperature control was employed only for flow-curve measurements. The shear strengths ( $\left.\tau_{s s}\right)$ were measured at ambient temperature $\left(25\right.$ to $30^{\circ} \mathrm{C}$ in the hot cells).

The rheometer was controlled and data were acquired with a remote computer connection using the RheoWin Pro Job Manager Software, Version 2.96 (Thermo Electron Corporation, Copyright ${ }^{\complement} 1997$ ). During measurement, the software automatically collects and converts rotor torque readings into shear stresses based on Equation C.1 (for vane testing) or Equation C.2 (for flow-curve testing). Likewise, the software also automatically converts the rotational rate readings into shear rates based on Equation C.3.

\section{C.2.4 Rheology Materials and Methods}

No sample treatment was performed before analysis with the exception of the mechanical agitation required to mix and sub-sample selected waste jars.

\section{C.2.4.1 Shear-Strength Testing}

Before testing, the tank waste slurry samples were mixed thoroughly and subsequently allowed to settle for 48 to $72 \mathrm{~h}$. When possible, the shear strength was measured by immersing the $8-\times 16$-mm vane tool to a depth of $16 \mathrm{~mm}$ into the settled solids. The vane was slowly rotated at $0.3 \mathrm{RPM}$ for $180 \mathrm{~s}$. For the entire duration of rotation, the time, rotational rate, and vane torque were continuously monitored and recorded. At the end of the measurement, shear stress-versus-time data were parsed, and the maximum measured shear stress (i.e., the material's shear strength) was determined.

\section{C.2.4.2 Flow-Curve Testing}

Each flow curve was measured over a 15-min period and split into three 5-min intervals. Over the first $5 \mathrm{~min}$, the shear rate was smoothly increased from zero to $1000 \mathrm{~s}^{-1}$. For the second $5 \mathrm{~min}$, the shear rate was held constant at $1000 \mathrm{~s}^{-1}$. For the final $5 \mathrm{~min}$, the shear rate was smoothly reduced back to zero. During this time, the resisting torque and rotational rate were continuously monitored and recorded.

Before each test, the sample was left undisturbed in the measuring system for 5 min to allow temperature equilibration. The sample was then mixed for 3 min using the measuring system rotor to re-disperse any settled solids and to pre-shear slurries before measurement.

Flow-curve tests were run at 25,40 , and $60^{\circ} \mathrm{C}$. Because of limited sample volume, all three temperature tests were performed on the same sample. To combat the effects of sample evaporation, a moisture barrier was installed over the opening at the top of the temperature jacket during testing, and after each test, the cup was raised so that fresh sludge/slurry filled the measurement gap.

\section{C.3 Particle-Size Attributes}

Determination of particle physical attributes, including size distribution and surface area, are discussed in the following sections. 


\section{C.3.1 Particle-Size Distribution}

Particle size distributions (PSDs) were characterized according to procedure RPL-COLLOID-01, Rev. 1, Particle Size Analysis Using Malvern MS2000. This procedure uses a Mastersizer 2000 (Malvern Instruments, Inc., Southborough, MA 01772 USA) with a Hydro $\mu$ P wet dispersion accessory. Malvern lists the Mastersizer particle-size measurement range as nominally 0.02 to $2000 \mu \mathrm{m}$. The actual PSD measurement range is dependent on the accessory used as well as the properties of the solids being analyzed. When coupled with the Hydro $\mu \mathrm{P}$ wet dispersion accessory, the nominal listed measuring range is reduced to 0.02 to $150 \mu \mathrm{m}$. The Malvern 2000 uses laser diffraction technology to define PSD.

The Hydro $\mu$ P wet-dispersion accessory consisted of a 20-mL sample flow cell with a continuous variable and independent pump and ultrasound. Both flow and sonication can be controlled and altered during measurement. PSD measurements were made before, during, and after sonication, allowing determination of the influence of each on the sample PSD. The primary measurement functions of the Malvern analyzer were controlled through Mastersizer 2000 software, Version 5.1 (Malvern Instruments, Ltd. Copyright ${ }^{\circledR}$ 1998-2002).

The optical properties applied to the test samples are summarized in Table C.2. For initial characterization samples, the optical properties of boehmite $(\mathrm{AlOOH})$ were assumed. For the parametric sample (after caustic-leaching), the optical properties of bismuth oxide $\left(\mathrm{Bi}_{2} \mathrm{O}_{3}\right)$ were assumed. It should be noted that using boehmite and $\mathrm{Bi}_{2} \mathrm{O}_{3}$ properties (as well as a single species refractive index) to represent the optical properties of the mixture of solid species and mineral phases in the tank waste is not exact. However, given the species diversity in the sample and the tendency for tank waste particles to aggregate, the measurement analysis still provides an adequate representation of the apparent particle size of the wastes. Correcting assumed refractive indexes to a more accurate value typically does not significantly alter the PSD determined by the original analysis.

The solids were dispersed in $0.01 \mathrm{M} \mathrm{NaOH}$ for the PSD measurements. The sample dispersion was added drop-wise to the instrument (while the pump was active) until an $~ 10 \%$ obscuration was reached. For all samples, less than $10 \mathrm{mg}$ of solids was required to reach the desired obscuration in the 20 -mL flow cell.

Table C.2. Optical Properties Applied To Test Materials

\begin{tabular}{|c|c|c|c|}
\hline Test & $\begin{array}{c}\text { Material Selected for } \\
\text { Optical Properties }^{(\mathbf{a})}\end{array}$ & $\begin{array}{c}\text { Refractive Index } \\
\text { (RI) }\end{array}$ & Absorption \\
\hline Initial Characterization & & & \\
\hline Group 3 & Boehmite & 1.655 & 1.0 \\
\hline Group 4 & Boehmite & 1.655 & 1.0 \\
\hline Parametric Testing & & 1.91 & 1.0 \\
\hline Group 3 & Bismuth Oxide & 1.33 \\
\hline All/Suspending Phase & Water ${ }^{(a)}$ & \\
\hline (a) See Ref Malvern Instruments Ltd., April 1997. & \\
\hline
\end{tabular}

The size distributions of particles were measured under varying flow conditions before, during, and after sonication. The test matrix employed for analysis is shown in Table C.3. For each condition, three successive 20-second measurements of PSD were taken. An average of these measurements was then 
generated by the analyzer software. Both individual measurement and average were saved to the analyzer data file. Once measurements were complete, the sonic power for the next condition was set, the sample was given 30 to 60 seconds to equilibrate, and the next set of measurements was taken.

Table C.3. Prototypic Particle-Size Analysis Test Matrix

\begin{tabular}{|c|c|c|c|}
\hline Condition No. & Pump Speed (RPM) & Sonic Power & Comment \\
\hline 1 & 3000 & $0 \%$ & pre-sonic measurement \\
\hline 2 & 4000 & $0 \%$ & pre-sonic measurement \\
\hline 3 & 2000 & $0 \%$ & pre-sonic measurement \\
\hline 4 & 3000 & $25 \%$ & sonicated measurement \\
\hline 5 & 3000 & $50 \%$ & sonicated measurement \\
\hline 6 & 3000 & $75 \%$ & sonicated measurement \\
\hline 7 & 3000 & $0 \%$ & post-sonic measurement \\
\hline 8 & 4000 & $0 \%$ & post-sonic measurement \\
\hline 9 & 2000 & $0 \%$ & post-sonic measurement \\
\hline
\end{tabular}

\section{C.3.2 Surface Area (BET)}

Samples were prepared for surface-area measurements in an effort to minimize solidification into a monolith upon drying. To this end, the solids were rinsed twice with ethanol and twice again with diethyl ether according to procedure TPR-RPP-WTP-486, Procedure for BET Sample Preparation Using Ethanol and Ethyl Ether as Drying Agents. Each rinse was conducted in a centrifuge tube. The solids were well suspended in the rinse solution, and then the phases were separated by centrifuging and decanting. The final diethyl ether rinse was used to transfer the solids slurry to the sample cell. The diethyl ether was then evaporated at room temperature directly from the sample cell.

The sample was further dried and out-gassed using the Quantachrome Instruments Monosorb Model MS-21 (Boynton Beach, FL) outgassing station. This entailed pre-flushing nitrogen through the sample cell for $\sim 10 \mathrm{~min}$ and then heating and flushing for overnight $(>10 \mathrm{~h})$ at $110^{\circ} \mathrm{C}$.

The surface-area measurements were conducted according to OCRWM-BET-01, Surface Area Measurement with a Monosorb Gas Analyzer, which is consistent with the American Society for Testing and Materials method D5604-96, Test Method B (Single-Point Surface Area by Flowing Gas Apparatus). The flow gas used in the measurement mode was composed of $30 \%$ nitrogen in helium. The system was calibrated per manufacturer instructions. The system performance was assessed using a $29.9 \pm 0.75 \mathrm{~m}^{2} / \mathrm{g}$ carbon surface area standard Lot D-6 obtained from Micromeritics (Norcross, GA). 
Appendix D

\section{Crystal Form and Habit}




\section{Appendix D}

\section{Crystal Form and Habit}

This section describes the methods used to determine the crystal forms and habits of the tank solids samples. The solids crystal characteristics were determined on small aliquots of the solids. In all cases, the solids sample fractions were allowed to air dry at room temperature in preparation for analysis. This effort was intended to minimize morphological changes that might occur upon heating. The methods applied for X-ray diffraction (XRD), scanning electron microscopy (SEM), and transmission electron microscopy (TEM) evaluations are discussed in the following sections.

\section{D.1 X-Ray Diffraction}

The sample mounts for XRD examination were prepared from the dried solids according to procedure RPL-PIP-4, Preparing Sealed Radioactive Samples for XRD and Other Purposes. Specimens were pulverized to a powder with a boron carbide mortar and pestle, mixed with an internal standard (rutile, $\mathrm{TiO}_{2}$, or alumina, $\mathrm{Al}_{2} \mathrm{O}_{3}$ ), and mounted on a glass slide. In some cases, the internal standard was omitted to provide better clarity of the sample diffraction pattern free from potential interference from the internal standard diffraction pattern. The XRD examination was conducted according to procedure PNNL-RPG268, Solids Analysis, X-Ray Diffraction Using RGD \#34. Process parameters included examining the $\mathrm{X}$-ray 2-theta range from 5 to 65 degrees with a step size of 0.02 degrees and a dwell time of 20 seconds.

Phase identification was performed with JADE, Version 8.0 (Materials Data Inc., Livermore, CA) software search and peak match routines with comparison to the International Centre for Diffraction Data (ICDD) database PDF-2, Version 2.0602 (2006). The ICDD database included the Inorganic Crystal Structure Database (ICSD) maintained by Fachinformationszentrum, Karlsuhe, Germany. Phase identification incorporated chemistry restrictions based on the elements determined from chemical analysis.

\section{D.2 Scanning Electron Microscopy}

A small sample was transferred with a wooden Q-tip stem onto carbon tape supported by an aluminum pedestal mount. The sample was analyzed using the radiation-shielded Amray Model 1610T SEM according to RPL-611A-SEM, Scanning Electron Microscope Examinations. In selected cases, the mount was carbon-coated. Selected sample areas were evaluated by energy dispersive X-ray spectroscopy (EDS) for qualitative elemental composition.

\section{D.3 Transmission Electron Microscopy}

The TEM samples were prepared in a two-step methanol rinsing process. A small amount of the sludge slurry was mixed and transferred into methanol; a drop of the methanol slurry was transferred into a second vial containing methanol; then a drop of this second solution was deposited onto a lacey carbon TEM grid. The particles were air-dried on the lacey grid. Note that the sample drying process may induce changes in the morphology of the particle agglomerates. However, the objective of the TEM investigation was to look at the fundamental characteristics and sizes of individual particle crystallites that are not dependent on drying effects. 
The TEM examinations were performed on an FEI Tecnai G2-30 (FEI Inc., Hillsboro, OR) with a field emission filament operating at $300 \mathrm{keV}$ equipped with a Scanning Transmission Unit and High Angle Annular Dark-Field Detector (HAADF), EDS detector, and a Gatan Imaging Filter (GIF), model GIF2000 (Gatan Inc., Pleasanton, CA). Particle or area analysis was performed by identifying the composition with EDS and electron energy-loss spectroscopy (EELS). Images were obtained with either the scanning transmission electron microscopy (STEM) system or normal bright-field imaging. Energy-filtered images were also obtained with the image filter to produce element-specific area maps.

\section{D.4 Electron Energy-Loss Spectroscopy}

The EELS spectra were obtained with a 0.6-mm entrance aperture and an energy dispersion of $0.1 \mathrm{eV} /$ channel. Low-loss spectra (including the zero loss peak) were acquired with an integration time of $<0.2 \mathrm{~s}$ and core-loss spectra between 2 and $5 \mathrm{~s}$. To reduce potential beam reduction, the acquisition time was kept as small as possible. The spectra were collected in the imaging mode of the transmission electron microscope and were corrected for dark current and channel-to-channel gain variation of the charge coupled device (CCD) detector.

The core-loss regime was energy calibrated, and the energy drift was measured while data were being acquired by collecting zero-loss spectra before or after core-loss spectra were collected. The position of the C-K (1s) peak at $284 \mathrm{eV}$ (arising from transitions to the $\pi^{*}$ molecular orbital) from the TEM lacy carbon support film was used to evaluate the energy calibration and roughly check that the energy resolution was sufficient for collecting data. 
Appendix E

\section{Quality Assurance and Quality Control}




\section{Appendix E}

\section{Quality Assurance and Quality Control}

This appendix describes the quality assurance (QA) program and quality control (QC) measures applied to the conduct of work.

\section{E.1 Application of WTPSP Quality Assurance Requirements}

PNNL's QA program is based on requirements defined in DOE Order 414.1C, “Quality Assurance,” and 10 CFR 830, Energy/Nuclear Safety Management, Subpart A-“Quality Assurance Requirements” (a.k.a., the Quality Rule). PNNL has chosen to implement the requirements of DOE Order 414.1C and 10 CFR 830, Subpart A by integrating them into the laboratory's management systems and daily operating processes. The procedures necessary to implement the requirements are documented through PNNL’s Standards-Based Management System.

PNNL implemented the RPP-WTP quality requirements by performing work in accordance with the River Protection Project - Waste Treatment Plant Support Program (RPP-WTP) Quality Assurance Plan (RPPWTP-QA-001, QAP). Work was performed to the quality requirements of NQA-1-1989 Part I, Basic and Supplementary Requirements, NQA-2a-1990, Part 2.7, and DOE/RW-0333P, Rev 13, Quality Assurance Requirements and Descriptions (QARD). These quality requirements are implemented through the River Protection Project - Waste Treatment Plant Support Program (RPP-WTP) Quality Assurance Manual (RPP-WTP-QA-003, QAM).

A matrix that cross-references the NQA-1, NQA-2a, and QA requirements and descriptions (QARD) requirements with PNNL's procedures for this work was given in the test plan, TP-RPP-WTP-467. ${ }^{\text {(a) }}$ It included justification for those requirements not implemented. The QA requirements of DOE/RW0333P, Rev 13, QARD, and DOE Order 414.1C were not identified as a requirement for this work in the test specification.

\section{E.2 Conduct of Experimental and Analytical Work}

Experiments that were not method-specific were performed in accordance with PNNL's procedures QA-RPP-WTP-1101 "Scientific Investigations” and QA-RPP-WTP-1201 "Calibration and Control of M\&TE," verifying that sufficient data were taken with properly calibrated measuring and test equipment (M\&TE) to obtain quality results.

As specified in the supporting Test Specification, 24590-PTF-TSP-RT-06-0001, Rev. 0, BNI's Quality Assurance Project Plan (QAPjP), PL-24590-QA00001, was not applicable because the work was not performed in support of environmental/regulatory testing, and the data will not be used as such.

(a) SK Fiskum, TP-RPP-WTP-467, Rev. 0, 2/2/07 and Rev. 1 7/31/07, Characterization and Small Scale Testing of Hanford Wastes to Support the Development and Demonstration of Leaching and Ultrafiltration Pretreatment Processes, Pacific Northwest National Laboratory, Richland, WA. 
Balances are calibrated annually by a certified contractor, QC Services, Portland, Oregon. A balance performance check was conducted each day the balance was used.

The Analytical Services Operation (ASO) conducted analytical testing according to the Statement of Work RPP-WTP-QA-005, Rev. 2, Analytical Support by the PNNL RPL Analytical Support Operation. The analytical results and raw data are traceable through the project files according to the Analytical Services Request number and Radiochemical Processing Laboratory number.

\section{E.3 Internal Data Verification and Validation}

PNNL addressed internal verification and validation activities by conducting an independent technical review of the final data report in accordance with PNNL's procedure QA-RPP-WTP-604. This review verified that the reported results were traceable, that inferences and conclusions were soundly based, and the reported work satisfied the Test Plan objectives. This review procedure is part of PNNL's RPP-WTP Quality Assurance Manual. 


\section{Appendix F}

\section{Duplicate Sample Differential Particle Size Plots for the Initial Group 3 Sample}




\section{Appendix F}

\section{Duplicate Sample Differential Particle Size Plots for the Initial Group 3 Sample}

Figures F.1, F.2, and F.3 show the differential volume distribution as a function of particle diameter for the duplicate Group 3 initial characterization sample, TI550-G3-S-WL-PSD-2. Specifically, F.1 shows the pre-sonication PSDs as a function of pump speed, F.2 shows the PSDs as a function of sonication, and F.3 shows the post-sonication PSDs as a function of pump speed.

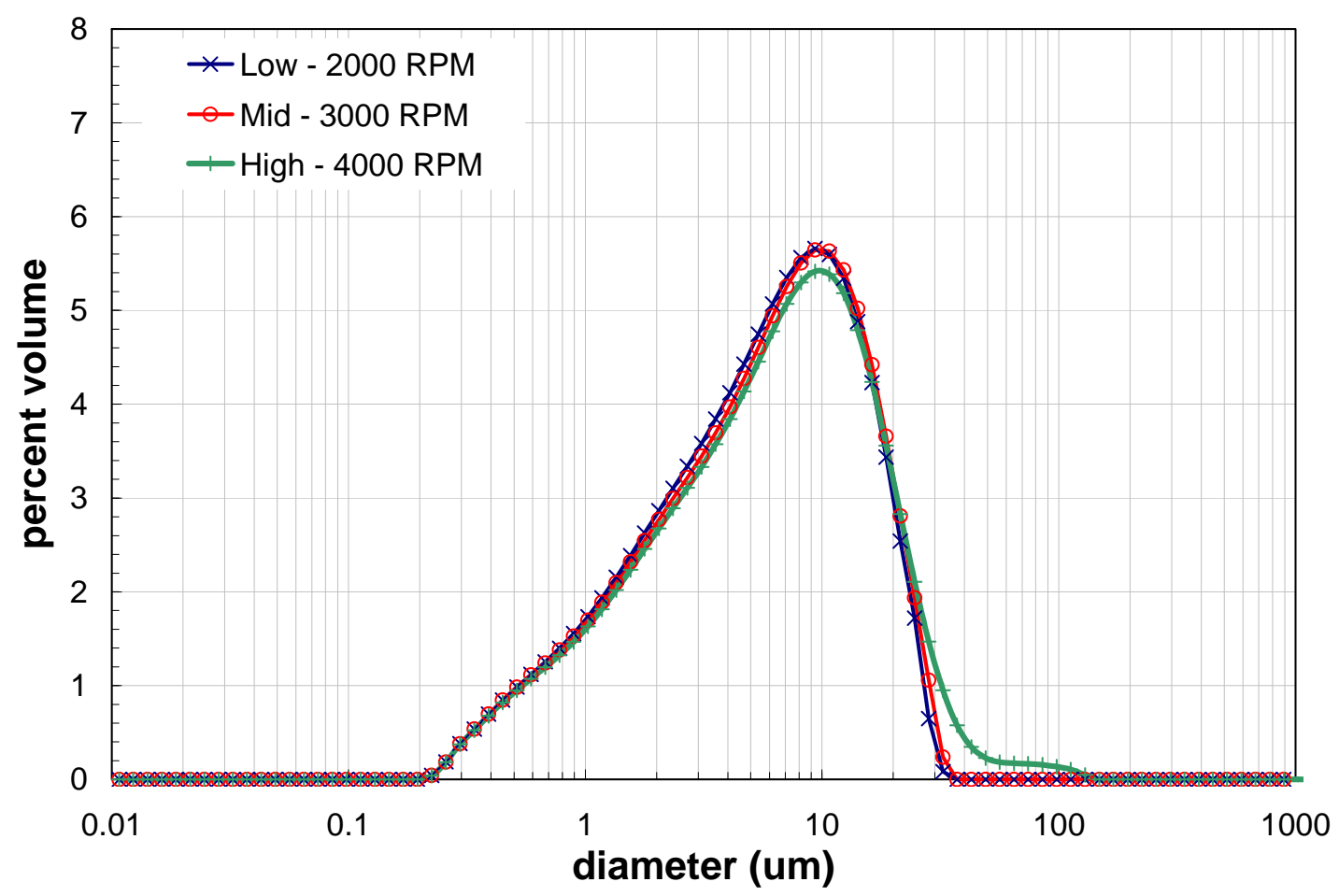

Figure F.1. Pre-Sonication Volume Distribution Result for the Duplicate Group 3 Initial Characterization Sample as a Function of Pump Speed 


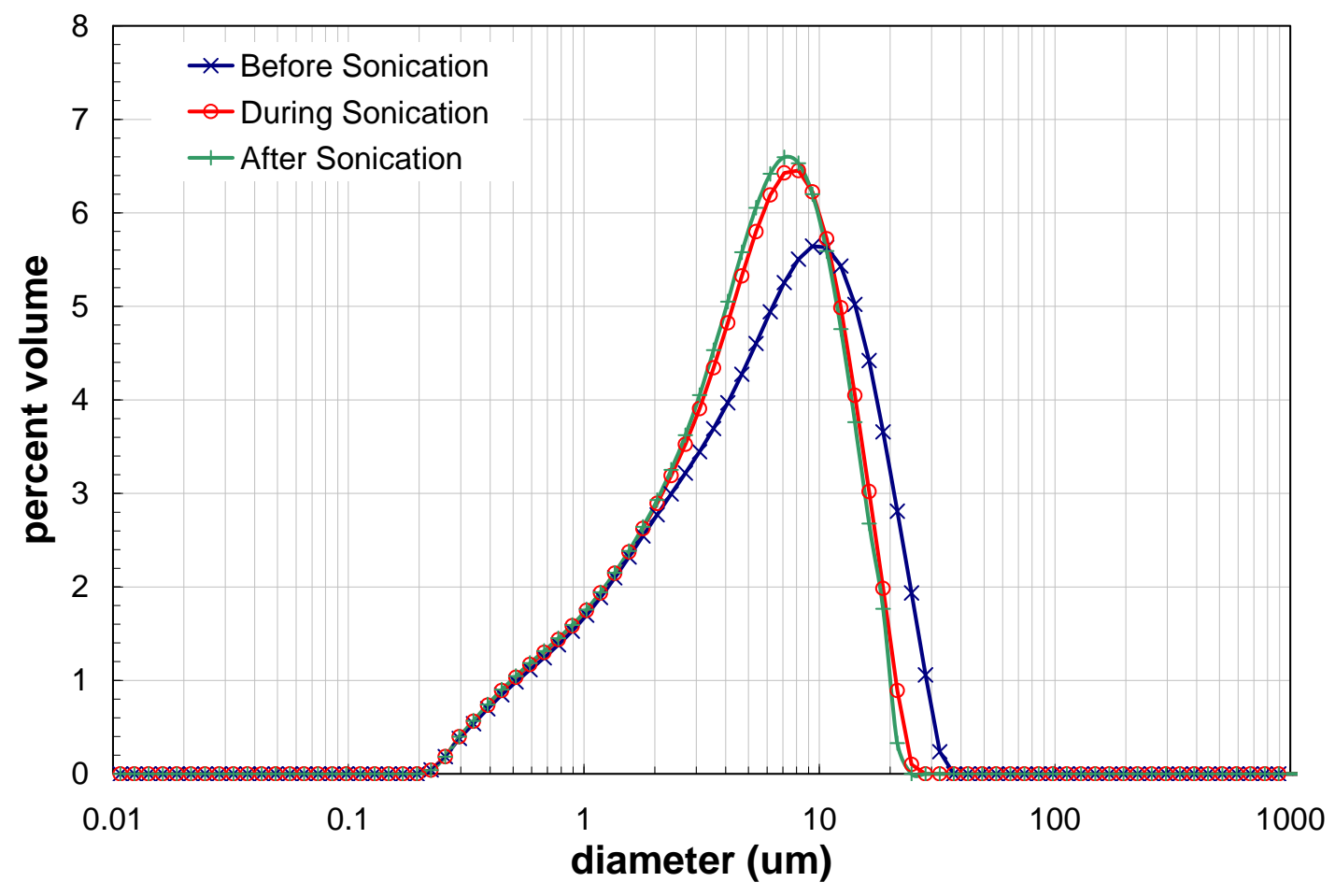

Figure F.2. Volume Distribution Result for the Duplicate Group 3 Initial Characterization Sample as a Function of Sonication. Note: the during-sonication condition corresponds to measurement condition 6 (3,000 RPM, 75\% Sonication). 


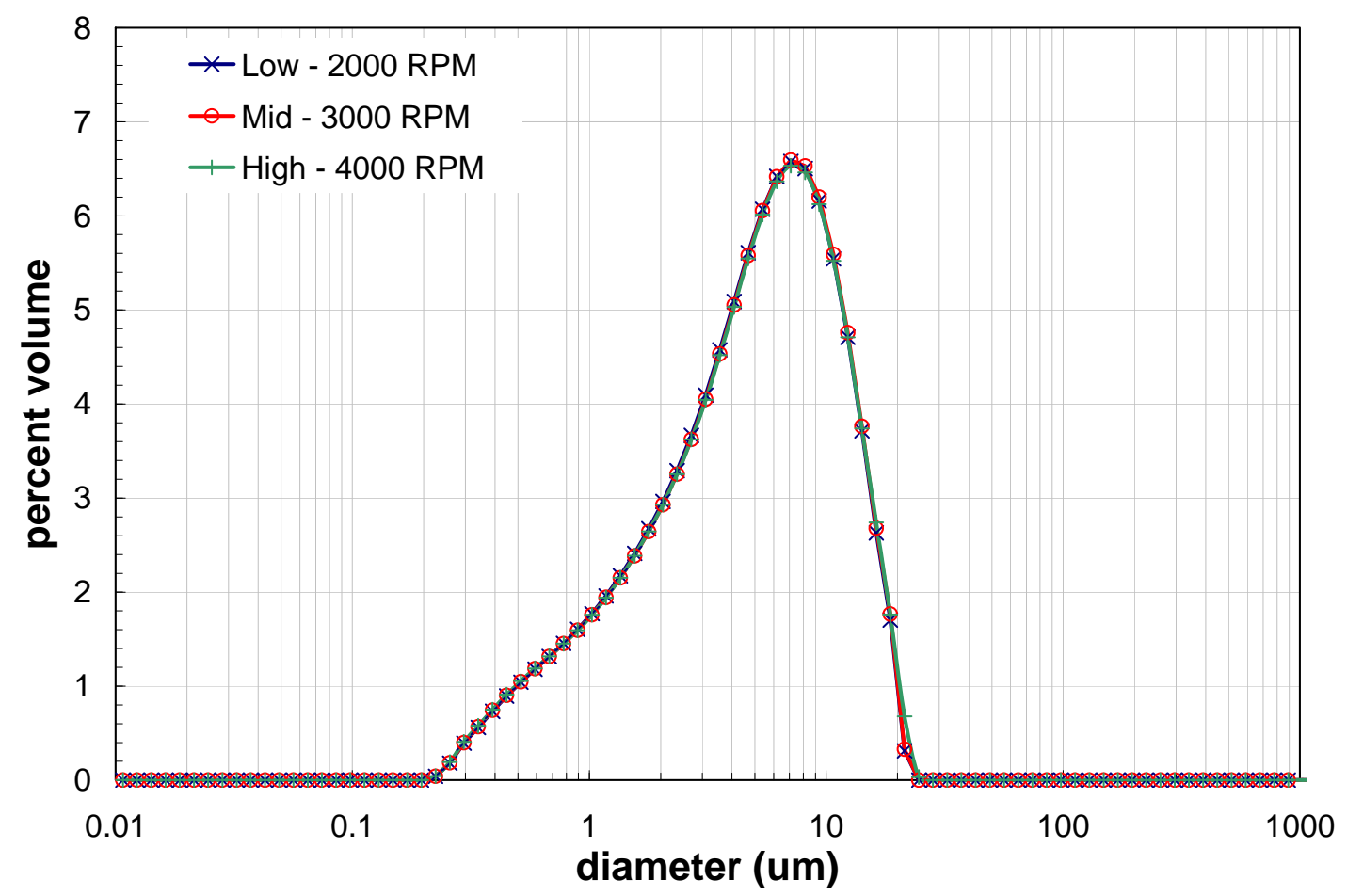

Figure F.3. Post-Sonication Volume Distribution Result for the Duplicate Group 3 Initial Characterization Sample as a Function of Pump Speed 
Appendix G

Detailed Cumulative PSD for the Initial Group 3 Sample 


\section{Appendix G}

\section{Detailed Cumulative PSD for the Initial Group 3 Sample}

Tables G.1 and G.2 present detailed cumulative oversize distributions (by volume/weight) for Group 3 initial characterization samples TI550-G3-S-WL-PSD-1 and -2, respectively. Results are reported as a function of test condition. This appendix does not provide a discussion of the detailed distributions; however, a portion of these results (specifically, the $10^{\text {th }}, 50^{\text {th }}$, and $90^{\text {th }}$ diameter percentiles) are presented and discussed in the main body of the report.

Table G.1. Cumulative Oversize Diameter Distributions for the Primary Group 3 Initial Characterization Sample, TI550-G3-S-WL-PSD-1

\begin{tabular}{|c|c|c|c|c|c|c|c|c|c|c|c|c|c|c|c|}
\hline \multirow{2}{*}{\begin{tabular}{|l|} 
Test \\
Condition
\end{tabular}} & \multicolumn{15}{|c|}{ Volume / Weight Cumulative Oversize Diameter $(\mu \mathrm{m})$} \\
\hline & $1 \%$ & $5 \%$ & $10 \%$ & $20 \%$ & $25 \%$ & $30 \%$ & $40 \%$ & $50 \%$ & $60 \%$ & $70 \%$ & $75 \%$ & $80 \%$ & $90 \%$ & $95 \%$ & $99 \%$ \\
\hline $\begin{array}{l}\mathbf{1}-3000 / \\
\text { pre-sonic }\end{array}$ & 0.36 & 0.70 & 1.2 & 2.3 & 2.9 & 3.7 & 5.5 & 7.7 & 10 & 13 & 14 & 16 & 22 & 26 & 33 \\
\hline $\begin{array}{l}2 \text { - } 4000 / \\
\text { pre-sonic }\end{array}$ & 0.37 & 0.73 & 1.3 & 2.5 & 3.3 & 4.2 & 6.3 & 8.8 & 12 & 15 & 17 & 20 & 30 & 44 & 100 \\
\hline $\begin{array}{l}3 \text { - } 2000 / \\
\text { pre-sonic }\end{array}$ & 0.35 & 0.67 & 1.1 & 2.1 & 2.7 & 3.3 & 4.9 & 6.9 & 9.1 & 12 & 13 & 15 & 20 & 23 & 30 \\
\hline \begin{tabular}{|l}
$4-3000 /$ \\
$25 \%$
\end{tabular} & 0.34 & 0.61 & 0.97 & 1.9 & 2.4 & 3.0 & 4.4 & 6.3 & 8.4 & 11 & 12 & 14 & 18 & 22 & 27 \\
\hline \begin{tabular}{|l}
$5-3000 /$ \\
$50 \%$
\end{tabular} & 0.34 & 0.60 & 0.97 & 1.8 & 2.4 & 3.0 & 4.4 & 6.0 & 7.8 & 10 & 11 & 13 & 16 & 20 & 25 \\
\hline \begin{tabular}{|l|}
$6-3000 /$ \\
$75 \%$
\end{tabular} & 0.34 & 0.60 & 0.96 & 1.8 & 2.3 & 2.9 & 4.2 & 5.6 & 7.2 & 9.0 & 10 & 11 & 15 & 17 & 22 \\
\hline \begin{tabular}{|l|l}
7 - $3000 / 1$ \\
post-sonic
\end{tabular} & 0.35 & 0.67 & 1.1 & 2.1 & 2.7 & 3.3 & 4.6 & 6.0 & 7.5 & 9.2 & 10 & 11 & 15 & 17 & 22 \\
\hline \begin{tabular}{|l|} 
- -4000 / \\
post-sonic
\end{tabular} & 0.35 & 0.67 & 1.1 & 2.1 & 2.7 & 3.4 & 4.7 & 6.1 & 7.7 & 9.5 & 11 & 12 & 15 & 19 & 25 \\
\hline \begin{tabular}{|l} 
- $2000 /$ \\
post-sonic
\end{tabular} & 0.34 & 0.62 & 1.0 & 1.9 & 2.4 & 3.0 & 4.2 & 5.5 & 7.0 & 8.7 & 9.7 & 11 & 14 & 17 & 21 \\
\hline
\end{tabular}


Table G.2. Cumulative Oversize Diameter Distributions for the Duplicate Group 3 Initial Characterization Sample, TI550-G3-S-WL-PSD-2

\begin{tabular}{|c|c|c|c|c|c|c|c|c|c|c|c|c|c|c|c|}
\hline \multirow{2}{*}{\begin{tabular}{|l|} 
Test \\
Condition
\end{tabular}} & \multicolumn{15}{|c|}{ Volume / Weight Cumulative Oversize Diameter $(\mu \mathrm{m})$} \\
\hline & $1 \%$ & $5 \%$ & $10 \%$ & $20 \%$ & $25 \%$ & $30 \%$ & $40 \%$ & $50 \%$ & $60 \%$ & $70 \%$ & $75 \%$ & $80 \%$ & $90 \%$ & $95 \%$ & $99 \%$ \\
\hline $\begin{array}{l}\text { - } 3000 / \\
\text { pre-sonic }\end{array}$ & 0.35 & 0.65 & 1.0 & 2.0 & 2.5 & 3.1 & 4.4 & 6.0 & 7.9 & 10 & 11 & 13 & 17 & 21 & 27 \\
\hline $\begin{array}{l}2-4000 / \\
\text { pre-sonic }\end{array}$ & 0.35 & 0.66 & 1.1 & 2.0 & 2.6 & 3.2 & 4.6 & 6.3 & 8.3 & 11 & 12 & 14 & 20 & 25 & 51 \\
\hline $\begin{array}{l}3 \text { - 2000 / } \\
\text { pre-sonic }\end{array}$ & 0.35 & 0.65 & 1.0 & 1.9 & 2.4 & 3.0 & 4.3 & 5.8 & 7.5 & 9.6 & 11 & 12 & 16 & 20 & 26 \\
\hline \begin{tabular}{|l|}
$4-3000 / /$ \\
$25 \%$
\end{tabular} & 0.35 & 0.64 & 1.0 & 1.9 & 2.4 & 3.0 & 4.3 & 5.7 & 7.4 & 9.4 & 11 & 12 & 16 & 19 & 25 \\
\hline $\begin{array}{l}5-3000 / \\
50 \%\end{array}$ & 0.35 & 0.64 & 1.0 & 1.9 & 2.4 & 3.0 & 4.2 & 5.5 & 7.0 & 8.8 & 9.9 & 11 & 14 & 17 & 22 \\
\hline $\begin{array}{l}6-3000 / \\
75 \%\end{array}$ & 0.35 & 0.63 & 1.0 & 1.9 & 2.4 & 2.9 & 4.0 & 5.2 & 6.6 & 8.2 & 9.1 & 10 & 13 & 16 & 20 \\
\hline $\begin{array}{l}7 \text { - 3000 / } \\
\text { post-sonic }\end{array}$ & 0.35 & 0.63 & 1.0 & 1.9 & 2.4 & 2.9 & 4.0 & 5.1 & 6.4 & 7.9 & 8.7 & 9.8 & 13 & 15 & 19 \\
\hline $\begin{array}{l}8 \text { - } 4000 \text { / } \\
\text { post-sonic }\end{array}$ & 0.35 & 0.62 & 1.0 & 1.9 & 2.4 & 2.9 & 3.9 & 5.1 & 6.4 & 7.9 & 8.8 & 9.8 & 13 & 15 & 19 \\
\hline $\begin{array}{l}9 \text { - 2000 / } \\
\text { post-sonic }\end{array}$ & 0.35 & 0.63 & 1.0 & 1.9 & 2.4 & 2.9 & 3.9 & 5.1 & 6.3 & 7.8 & 8.7 & 9.7 & 13 & 15 & 19 \\
\hline
\end{tabular}

Table G.3 shows the absolute relative percent difference (RPD) between primary and duplicate results, which is calculated as:

$$
R P D=\left|\frac{d_{d}(n)-d_{p}(n)}{d_{p}(n)}\right|
$$

where $d_{p}(n)$ and $d_{d}(n)$ are the primary and duplicate cumulative oversize diameters corresponding to the $n^{\text {th }}$ percentile. As before, this appendix does not provide a discussion of the RPD results; however, the RPD for the $10^{\text {th }}, 50^{\text {th }}$, and $90^{\text {th }}$ diameter percentiles are presented and discussed in the main body of this interim report. 
Table G.3. Relative Percent Difference Between Primary and Duplicate Group 3 Initial Characterization Samples (TI550-G3-S-WL-PSD -1 and -2, respectively) as a Function of Test Condition

\begin{tabular}{|c|c|c|c|c|c|c|c|c|c|c|c|c|c|c|c|}
\hline \multirow{2}{*}{\begin{tabular}{|l} 
Test \\
Condition
\end{tabular}} & \multicolumn{15}{|c|}{ "Absolute RPD (\%) } \\
\hline & $1 \%$ & $5 \%$ & $10 \%$ & $20 \%$ & $25 \%$ & $30 \%$ & $40 \%$ & $50 \%$ & $60 \%$ & $70 \%$ & $75 \%$ & $80 \%$ & $90 \%$ & $95 \%$ & $99 \%$ \\
\hline \begin{tabular}{|l}
1 - 3000 / \\
pre-sonic
\end{tabular} & 1.4 & 7.3 & 11 & 14 & 15 & 17 & 20 & 22 & 22 & 21 & 21 & 21 & 20 & 20 & 19 \\
\hline $\mid$\begin{tabular}{|l}
$2-4000 /$ \\
pre-sonic
\end{tabular} & 3.6 & 10 & 15 & 19 & 22 & 24 & 27 & 28 & 29 & 29 & 30 & 30 & 34 & 42 & 50 \\
\hline $\begin{array}{l}3 \text { - } 2000 / \\
\text { pre-sonic }\end{array}$ & 0.00 & 3.7 & 5.8 & 7.6 & 8.8 & 10 & 14 & 16 & 17 & 17 & 17 & 17 & 16 & 15 & 13 \\
\hline \begin{tabular}{|l}
$4-3000 /$ \\
$25 \%$
\end{tabular} & 3.9 & 5.9 & 5.7 & 3.4 & 2.1 & 0.40 & 4.3 & 8.8 & 12 & 13 & 13 & 13 & 13 & 12 & 11 \\
\hline \begin{tabular}{|l}
$5-3000 /$ \\
$50 \%$
\end{tabular} & 3.9 & 5.6 & 5.5 & 3.8 & 2.5 & 0.58 & 4.1 & 8.0 & 10 & 12 & 12 & 12 & 12 & 12 & 12 \\
\hline \begin{tabular}{|l}
$\mid \begin{array}{l}\text { 6 - 3000 / } \\
75 \%\end{array}$ \\
\end{tabular} & 3.6 & 5.5 & 5.3 & 3.7 & 2.1 & 0.14 & 4.0 & 6.9 & 8.5 & 9.3 & 9.5 & 9.6 & 9.5 & 9.2 & 8.8 \\
\hline \begin{tabular}{|l}
7 - 3000 / \\
post-sonic
\end{tabular} & 1.4 & 6.0 & 9.2 & 11 & 12 & 13 & 15 & 15 & 15 & 15 & 15 & 15 & 14 & 13 & 14 \\
\hline \begin{tabular}{|l}
8 - 4000 / \\
post-sonic
\end{tabular} & 2.0 & 6.3 & 9.9 & 12 & 14 & 15 & 16 & 17 & 17 & 17 & 17 & 17 & 17 & 18 & 21 \\
\hline \begin{tabular}{|l}
9 - $2000 /$ \\
post-sonic
\end{tabular} & 3.2 & 2.1 & 0.80 & 0.80 & 2.2 & 3.9 & 7.0 & 9.0 & 10 & 11 & 11 & 11 & 11 & 10 & 11 \\
\hline
\end{tabular}


Appendix $\mathrm{H}$

Detailed Cumulative PSD for the Caustic Leached Group 3 Sample 


\section{Appendix $\mathrm{H}$}

\section{Detailed Cumulative PSD for the Caustic Leached Group 3 Sample}

Table H.1 presents detailed cumulative oversize distributions (by volume/weight) for Group 3 parametric testing sample TI585-G3-CL-PSD. Results are reported as a function of test condition. This appendix does not provide a discussion of the detailed distributions; however, a portion of these results (specifically, the $10^{\text {th }}, 50^{\text {th }}$, and $90^{\text {th }}$ diameter percentiles) are presented and discussed in the main body of the report.

Table H.1. Cumulative Oversize Diameter Distributions for the Group 3 Parametric Testing Sample, TI585-G3-CL-PSD

\begin{tabular}{|c|c|c|c|c|c|c|c|c|c|c|c|c|c|c|c|}
\hline \multirow{2}{*}{\begin{tabular}{|l|} 
Test \\
Condition
\end{tabular}} & \multicolumn{15}{|c|}{ Volume / Weight Cumulative Oversize Diameter $(\mu \mathrm{m})$} \\
\hline & $1 \%$ & $5 \%$ & $10 \%$ & $20 \%$ & $25 \%$ & $30 \%$ & $40 \%$ & $50 \%$ & $60 \%$ & $70 \%$ & $75 \%$ & $80 \%$ & $90 \%$ & $95 \%$ & $99 \%$ \\
\hline $\begin{array}{l}\text { - } 3000 / \\
\text { pre-sonic }\end{array}$ & 0.37 & 0.71 & 1.1 & 2.3 & 3.2 & 4.4 & 7.5 & 11 & 15 & 22 & 27 & 36 & 90 & 140 & 220 \\
\hline $\begin{array}{l}2 \text { - } 4000 / \\
\text { pre-sonic }\end{array}$ & 0.38 & 0.74 & 1.2 & 2.5 & 3.2 & 4.1 & 6.4 & 9.7 & 15 & 23 & 30 & 46 & 130 & 270 & 1600 \\
\hline $\begin{array}{l}\text { - 2000 / } \\
\text { pre-sonic }\end{array}$ & 0.36 & 0.69 & 1.1 & 2.2 & 2.9 & 3.7 & 6.1 & 9.5 & 14 & 20 & 24 & 31 & 84 & 130 & 200 \\
\hline $\begin{array}{l}4-3000 / \\
25 \%\end{array}$ & 0.35 & 0.61 & 0.92 & 1.6 & 2.0 & 2.6 & 4.5 & 11 & 17 & 24 & 28 & 35 & 74 & 110 & 150 \\
\hline $\begin{array}{l}5-3000 / \\
50 \%\end{array}$ & 0.32 & 0.50 & 0.71 & 1.2 & 1.4 & 1.7 & 2.6 & 7.8 & 17 & 24 & 28 & 34 & 69 & 98 & 140 \\
\hline $\begin{array}{l}6-3000 / \\
75 \%\end{array}$ & 0.29 & 0.42 & 0.57 & 0.88 & 1.1 & 1.3 & 1.8 & 2.7 & 13 & 20 & 24 & 29 & 59 & 90 & 130 \\
\hline \begin{tabular}{|l|}
7 - $3000 /$ \\
post-sonic
\end{tabular} & 0.29 & 0.41 & 0.54 & 0.83 & 1.0 & 1.2 & 1.7 & 2.4 & 11 & 19 & 23 & 28 & 60 & 92 & 130 \\
\hline $\begin{array}{l}8 \text { - } 4000 \text { / } \\
\text { post-sonic }\end{array}$ & 0.28 & 0.42 & 0.57 & 0.94 & 1.2 & 1.4 & 2.1 & 3.2 & 6.5 & 16 & 22 & 31 & 120 & 1200 & 1600 \\
\hline $\begin{array}{l}9 \text { - } 2000 / \\
\text { post-sonic }\end{array}$ & 0.27 & 0.40 & 0.53 & 0.84 & 1.0 & 1.2 & 1.7 & 2.4 & 3.6 & 7.6 & 12 & 17 & 33 & 96 & 140 \\
\hline
\end{tabular}





\section{Appendix I}

\section{Group 3 Analytical Results}

from Parametric Leaching 


\section{Appendix I}

\section{Group 3 Analytical Results from Parametric Leaching}

Table I.1 provides information about analyte concentrations during leaching at various time increments at $60^{\circ} \mathrm{C}$ in units of $\mu \mathrm{g} / \mathrm{mL}$, Table I.2 at $60^{\circ} \mathrm{C}$ in units of M, Tables I.3 and I.4 at $80^{\circ} \mathrm{C}$ in units of $\mu \mathrm{g} / \mathrm{mL}$ and $\mathrm{M}$, respectively, and Tables I.5 and I.6 at $100^{\circ} \mathrm{C}$ in units of $\mu \mathrm{g} / \mathrm{mL}$ and $\mathrm{M}$, respectively. Table I.7 provides information about analyte concentrations in the wash solution from washing the solid samples that were leached at $80^{\circ} \mathrm{C}$ in $3 \mathrm{M} \mathrm{NaOH}$.

Table I.1. Analyte Concentrations as a Function of Time for Leaching at $60^{\circ} \mathrm{C}$, in $\mu \mathrm{g} / \mathrm{mL}$

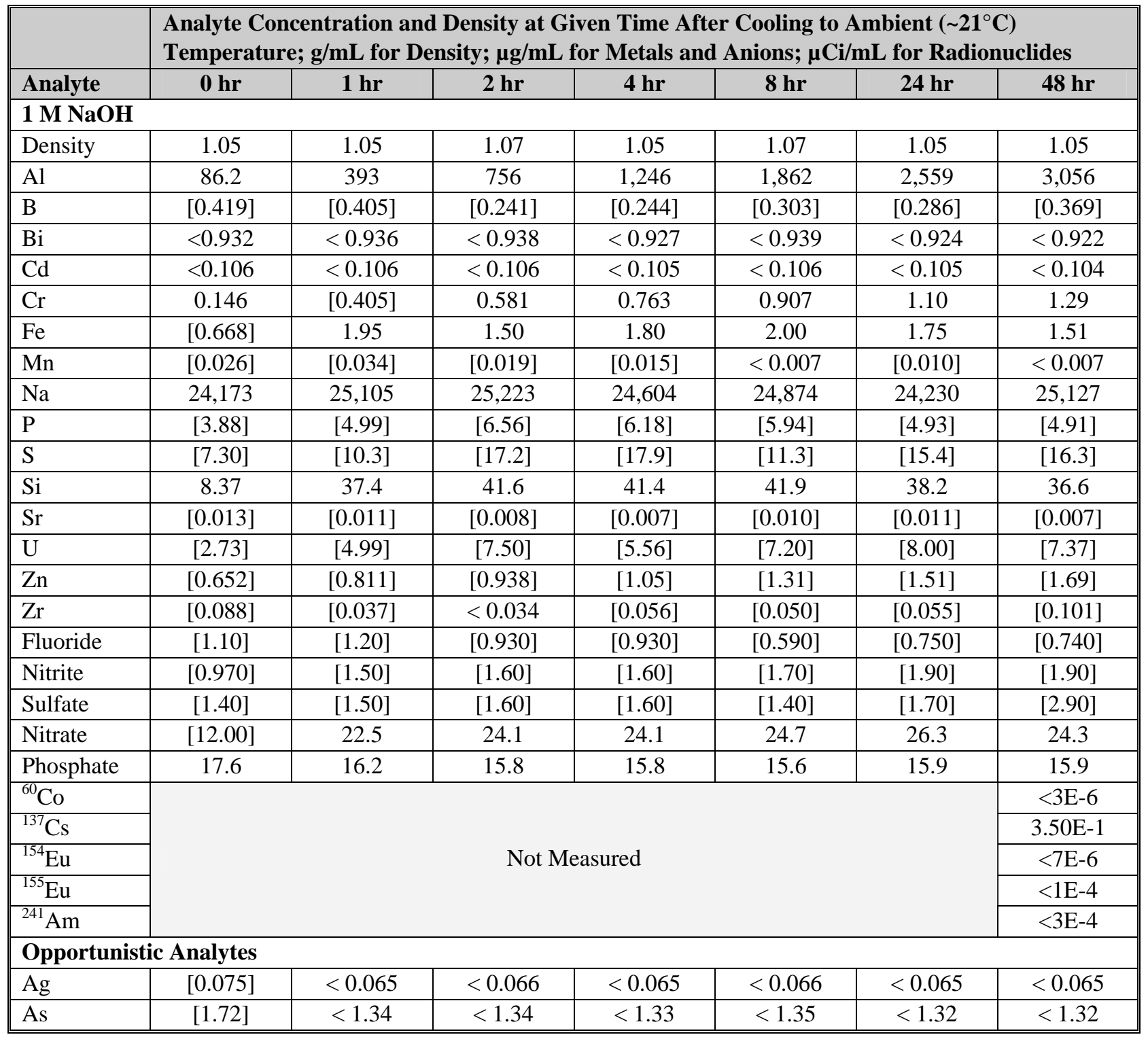


Table I.1 (Contd)

\begin{tabular}{|c|c|c|c|c|c|c|c|}
\hline \multirow[b]{2}{*}{ Analyte } & \multicolumn{7}{|c|}{$\begin{array}{l}\text { Analyte Concentration and Density at Given Time After Cooling to Ambient }\left(\sim 21^{\circ} \mathrm{C}\right) \\
\text { Temperature; } g / \mathrm{mL} \text { for Density; } \mu \mathrm{g} / \mathrm{mL} \text { for Metals and Anions; } \mu \mathrm{Ci} / \mathrm{mL} \text { for Radionuclides }\end{array}$} \\
\hline & O hr & $1 \mathrm{hr}$ & $2 \mathrm{hr}$ & $4 \mathrm{hr}$ & $8 \mathrm{hr}$ & $24 \mathrm{hr}$ & $48 \mathrm{hr}$ \\
\hline $\mathrm{Ba}$ & 0.228 & 0.243 & {$[0.125]$} & 0.176 & 0.426 & 0.213 & {$[0.141]$} \\
\hline $\mathrm{Be}$ & {$[0.016]$} & 0.023 & 0.024 & 0.024 & 0.024 & 0.027 & 0.026 \\
\hline $\mathrm{Ca}$ & [0.481] & {$[0.206]$} & $<0.191$ & $<0.189$ & $<0.191$ & $<0.188$ & $<0.187$ \\
\hline $\mathrm{Ce}$ & $<0.311$ & $<0.312$ & $<0.313$ & $<0.309$ & $<0.313$ & $<0.308$ & $<0.307$ \\
\hline Co & $<0.075$ & $<0.075$ & $<0.075$ & $<0.074$ & $<0.075$ & $<0.074$ & $<0.074$ \\
\hline $\mathrm{Cu}$ & {$[0.175]$} & {$[0.181]$} & {$[0.238]$} & [0.340] & 0.454 & 0.446 & 0.473 \\
\hline Dy & $<0.090$ & $<0.090$ & $<0.091$ & $<0.090$ & $<0.091$ & $<0.089$ & $<0.089$ \\
\hline $\mathrm{Eu}$ & $<0.034$ & $<0.034$ & $<0.034$ & $<0.034$ & $<0.034$ & [0.049] & $<0.034$ \\
\hline $\mathrm{K}$ & {$[2.64]$} & {$[3.74]$} & [5.31] & [8.04] & {$[8.76]$} & {$[4.00]$} & [6.45] \\
\hline $\mathrm{La}$ & $<0.087$ & $<0.087$ & $<0.088$ & $<0.087$ & $<0.088$ & $<0.086$ & $<0.086$ \\
\hline $\mathrm{Li}$ & [0.124] & 0.415 & 0.553 & 0.380 & 0.407 & [0.369] & 0.378 \\
\hline $\mathrm{Mg}$ & $<0.071$ & $<0.072$ & $<0.072$ & $<0.071$ & $<0.072$ & $<0.071$ & $<0.071$ \\
\hline Mo & $<0.161$ & $<0.162$ & $<0.163$ & $<0.161$ & $<0.163$ & $<0.160$ & $<0.160$ \\
\hline $\mathrm{Nd}$ & $<0.168$ & $<0.168$ & $<0.169$ & $<0.167$ & {$[0.253]$} & $<0.166$ & $<0.166$ \\
\hline $\mathrm{Ni}$ & {$[0.109]$} & {$[0.181]$} & {$[0.091]$} & $<0.07$ & {$[0.078]$} & {$[0.182]$} & {$[0.151]$} \\
\hline $\mathrm{Pb}$ & [1.91] & [2.93] & {$[4.06]$} & [4.02] & {$[5.01]$} & [5.85] & [5.53] \\
\hline $\mathrm{Pd}$ & $<0.300$ & {$[0.405]$} & {$[0.228]$} & $<0.195$ & [0.344] & [0.339] & [0.224] \\
\hline $\mathrm{Rh}$ & $<0.373$ & $<0.374$ & $<0.375$ & $<0.371$ & $<0.375$ & $<0.369$ & $<0.369$ \\
\hline $\mathrm{Ru}$ & $<0.264$ & $<0.265$ & $<0.266$ & $<0.263$ & $<0.266$ & $<0.262$ & $<0.261$ \\
\hline $\mathrm{Sb}$ & [0.699] & [1.19] & $<0.625$ & {$[0.896]$} & $<0.626$ & $<0.616$ & {$[1.14]$} \\
\hline Se & [4.52] & [3.74] & [5.31] & [7.73] & [4.69] & [4.93] & [5.84] \\
\hline Sn & $<0.838$ & $<0.842$ & $<0.844$ & $<0.835$ & $<0.845$ & $<0.831$ & $<0.829$ \\
\hline $\mathrm{Ta}$ & $<0.528$ & $<0.530$ & $<0.531$ & $<0.525$ & $<0.532$ & $<0.523$ & $<0.522$ \\
\hline $\mathrm{Te}$ & $<0.807$ & $<0.811$ & $<0.813$ & $<0.804$ & $<0.813$ & $<0.800$ & $<0.799$ \\
\hline Th & $<0.304$ & $<0.306$ & $<0.306$ & $<0.303$ & $<0.307$ & [0.339] & $<0.301$ \\
\hline $\mathrm{Ti}$ & $<0.014$ & $<0.013$ & $<0.013$ & {$[0.016]$} & $<0.013$ & [0.015] & $<0.013$ \\
\hline $\mathrm{Tl}$ & $<1.18$ & $<1.19$ & $<1.19$ & $<1.17$ & $<1.19$ & $<1.17$ & $<1.17$ \\
\hline $\mathrm{V}$ & [0.085] & {$[0.106]$} & [0.119] & {$[0.108]$} & {$[0.103]$} & [0.135] & [0.129] \\
\hline $\mathrm{W}$ & $<0.590$ & $<0.593$ & $<0.594$ & $<0.587$ & [0.626] & $<0.585$ & $<0.584$ \\
\hline $\mathrm{Y}$ & $<0.014$ & $<0.014$ & $<0.014$ & $<0.014$ & $<0.014$ & $<0.014$ & $<0.014$ \\
\hline \multicolumn{8}{|c|}{$3 \mathrm{M} \mathrm{NaOH}$} \\
\hline Density & 1.13 & 1.13 & 1.14 & 1.13 & 1.14 & 1.13 & 1.13 \\
\hline $\mathrm{Al}$ & 92.3 & 764 & 1,384 & 2,022 & 2,543 & 2,740 & 2,778 \\
\hline B & $<0.743$ & $<0.754$ & $<0.753$ & $<0.739$ & [1.02] & $<0.746$ & $<0.741$ \\
\hline $\mathrm{Bi}$ & $<4.64$ & [5.03] & $<4.71$ & $<4.62$ & $<4.63$ & [4.98] & $<4.63$ \\
\hline $\mathrm{Cd}$ & $<0.526$ & $<0.534$ & $<0.533$ & $<0.523$ & $<0.525$ & $<0.529$ & $<0.525$ \\
\hline $\mathrm{Cr}$ & $<0.263$ & {$[0.723]$} & {$[0.816]$} & [1.17] & [1.45] & {$[1.74]$} & [1.45] \\
\hline $\mathrm{Fe}$ & [1.39] & 14.0 & [5.33] & 36.9 & [6.18] & {$[6.22]$} & [6.17] \\
\hline $\mathrm{Mn}$ & $<0.036$ & [0.088] & {$[0.066]$} & {$[0.071]$} & $<0.036$ & $<0.036$ & $<0.036$ \\
\hline $\mathrm{Na}$ & 71,826 & 73,209 & 73,107 & 73,861 & 72,909 & 73,077 & 74,093 \\
\hline $\mathrm{P}$ & $<7.74$ & $<7.86$ & $<7.84$ & $<7.69$ & $<7.72$ & $<7.77$ & [8.95] \\
\hline$S$ & [58.8] & {$[50.3]$} & {$[78.4]$} & {$[21.5]$} & [19.5] & {$[56.0]$} & {$[64.8]$} \\
\hline $\mathrm{Si}$ & 11.9 & 52.5 & 55.8 & 57.6 & 59.3 & 60.3 & 60.8 \\
\hline
\end{tabular}


Table I.1 (Contd)

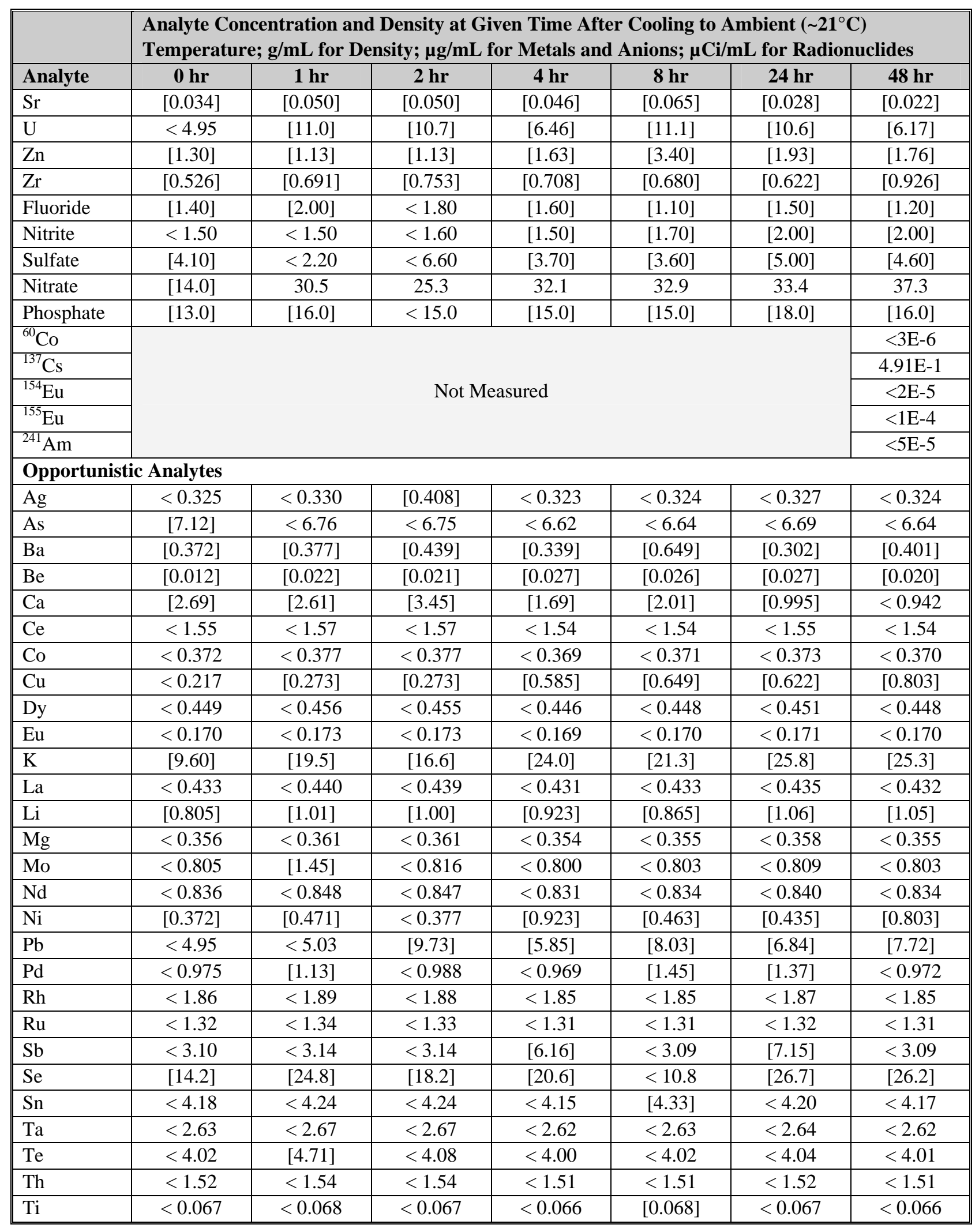


Table I.1 (Contd)

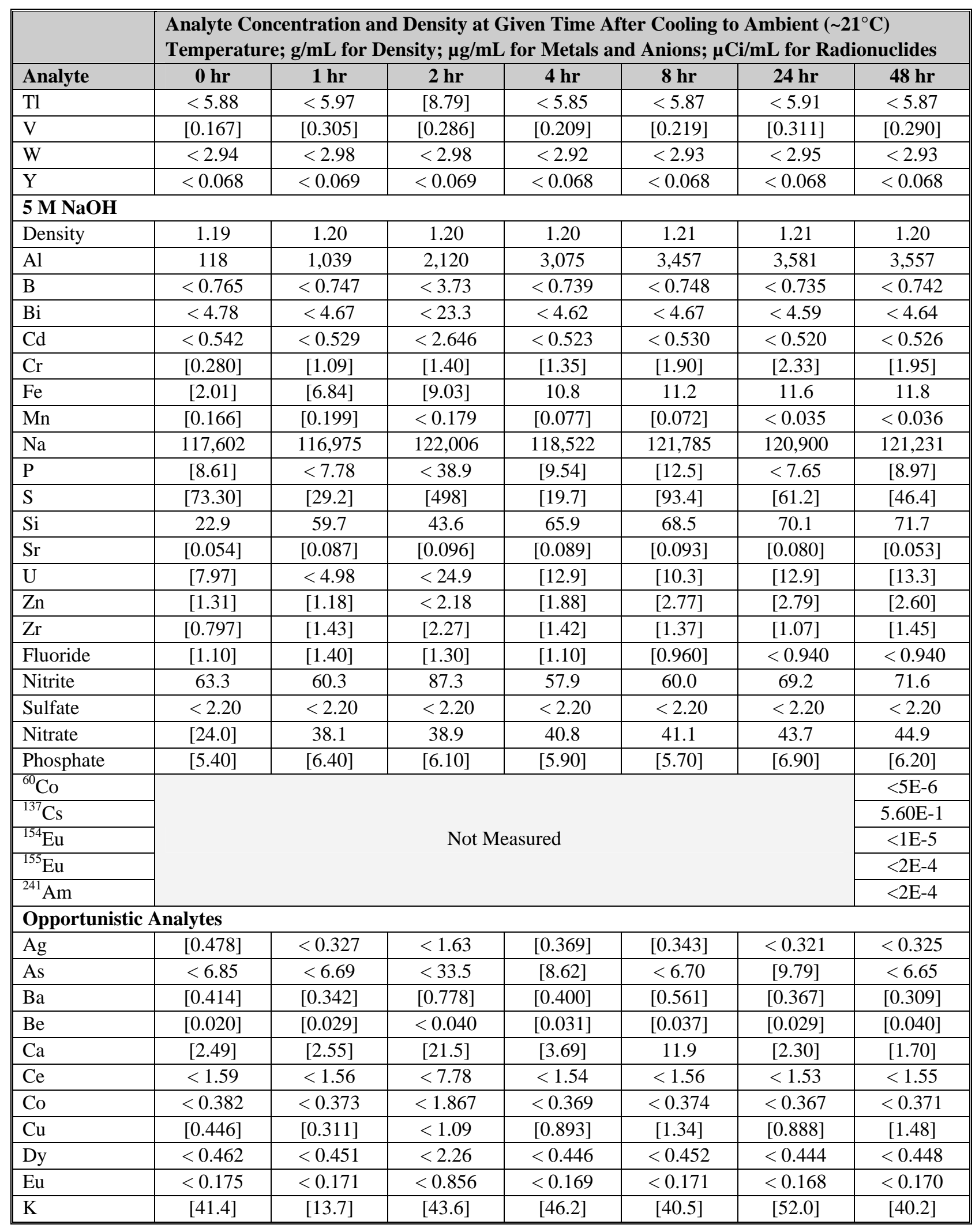


Table I.1 (Contd)

\begin{tabular}{|c|c|c|c|c|c|c|c|}
\hline \multirow[b]{2}{*}{ Analyte } & \multicolumn{7}{|c|}{$\begin{array}{l}\text { Analyte Concentration and Density at Given Time After Cooling to Ambient }\left(\sim 21^{\circ} \mathrm{C}\right) \\
\text { Temperature; } \mathrm{g} / \mathrm{mL} \text { for Density; } \mu \mathrm{g} / \mathrm{mL} \text { for Metals and Anions; } \mu \mathrm{Ci} / \mathrm{mL} \text { for Radionuclides }\end{array}$} \\
\hline & o hr & $1 \mathrm{hr}$ & $2 \mathrm{hr}$ & $4 \mathrm{hr}$ & $8 \mathrm{hr}$ & $24 \mathrm{hr}$ & $48 \mathrm{hr}$ \\
\hline $\mathrm{La}$ & $<0.446$ & $<0.436$ & $<2.179$ & $<0.431$ & $<0.436$ & $<0.429$ & $<0.433$ \\
\hline $\mathrm{Li}$ & [0.188] & {$[0.467]$} & {$[3.02]$} & [0.893] & [1.03] & {$[0.826]$} & [1.14] \\
\hline $\mathrm{Mg}$ & $<0.367$ & $<0.358$ & $<1.79$ & $<0.354$ & $<0.358$ & $<0.352$ & $<0.356$ \\
\hline Mo & $<0.829$ & $<0.809$ & $<4.05$ & $<0.800$ & $<0.810$ & $<0.796$ & $<0.804$ \\
\hline $\mathrm{Nd}$ & $<0.861$ & $<0.840$ & $<4.20$ & $<0.831$ & $<0.841$ & $<0.826$ & $<0.835$ \\
\hline $\mathrm{Ni}$ & $<0.382$ & {$[0.716]$} & $<1.87$ & {$[0.493]$} & [0.654] & $<0.367$ & $<0.371$ \\
\hline $\mathrm{Pb}$ & $<5.10$ & [6.84] & $<24.9$ & [8.93] & [9.34] & {$[11.0]$} & {$[10.8]$} \\
\hline $\mathrm{Pd}$ & $<1.00$ & [1.34] & [9.34] & {$[1.08]$} & $<0.981$ & [1.19] & [1.89] \\
\hline $\mathrm{Rh}$ & $<1.91$ & $\begin{array}{l}<1.87 \\
\end{array}$ & $<<9.34$ & $<1.85$ & $<1.87$ & $<1.84$ & $<1.86$ \\
\hline $\mathrm{Ru}$ & $<1.35$ & $<1.32$ & $<6.61$ & $<1.31$ & $<1.32$ & $<1.30$ & $<1.31$ \\
\hline $\mathrm{Sb}$ & $<3.19$ & [3.42] & $<15.6$ & [4.93] & $<3.11$ & $<3.06$ & [4.95] \\
\hline Se & [12.4] & [31.1] & [124] & [33.9] & [17.1] & [23.6] & $<10.8$ \\
\hline Sn & $<4.30$ & $<4.20$ & $<21.0$ & $<4.16$ & $<4.20$ & $<4.13$ & $<4.18$ \\
\hline $\mathrm{Ta}$ & $<2.71$ & $<2.64$ & $<13.23$ & $<2.62$ & $<2.65$ & $<2.60$ & $<2.63$ \\
\hline $\mathrm{Te}$ & $<4.14$ & $<4.04$ & $<20.23$ & $<4.00$ & $<4.05$ & $<3.98$ & $<4.02$ \\
\hline Th & $<1.56$ & $<1.52$ & $<7.63$ & $<1.51$ & $<1.53$ & $<1.50$ & $<1.52$ \\
\hline $\mathrm{Ti}$ & $<0.069$ & $<0.067$ & $<0.335$ & $<0.066$ & $<0.067$ & {$[0.080]$} & $<0.066$ \\
\hline $\mathrm{Tl}$ & $<6.06$ & $<5.91$ & $<29.57$ & $<5.85$ & $<5.92$ & $<5.82$ & $<5.88$ \\
\hline $\mathrm{V}$ & {$[0.382]$} & {$[0.373]$} & {$[1.46]$} & {$[0.431]$} & {$[0.561]$} & {$[0.520]$} & {$[0.464]$} \\
\hline $\mathrm{W}$ & $<3.03$ & $<2.96$ & $<14.8$ & $<2.92$ & $<2.96$ & $<2.91$ & $<2.94$ \\
\hline $\mathrm{Y}$ & $<0.070$ & $<0.068$ & $<0.342$ & $<0.068$ & $<0.069$ & $<0.067$ & $<0.068$ \\
\hline \multicolumn{8}{|c|}{$\begin{array}{l}\text { Analyte uncertainties were typically within } \pm 15 \%(2-s) \text {; results in brackets indicate that the analyte concentrations } \\
\text { were less than the minimum detection limit (MDL) and greater than the estimated quantitation limit (EQL), and } \\
\text { uncertainties were }>15 \% \text {. }\end{array}$} \\
\hline
\end{tabular}


Table I.2. Analyte Concentrations as a Function of Time for Leaching at $60^{\circ} \mathrm{C}$, in $\mathrm{M}$

\begin{tabular}{|c|c|c|c|c|c|c|c|}
\hline \multirow[b]{2}{*}{ Analyte } & \multicolumn{7}{|c|}{$\begin{array}{l}\text { Analyte Concentration and Density at Given Time After Cooling to Ambient }\left(\sim 21^{\circ} \mathrm{C}\right) \\
\text { Temperature; } \mathrm{g} / \mathrm{mL} \text { for Density; } \mathrm{M} \text { for Metals and Anions }\end{array}$} \\
\hline & o hr & $1 \mathrm{hr}$ & $2 \mathrm{hr}$ & $4 \mathrm{hr}$ & $8 \mathrm{hr}$ & $24 \mathrm{hr}$ & $48 \mathrm{hr}$ \\
\hline \multicolumn{8}{|l|}{$1 \mathrm{M} \mathrm{NaOH}$} \\
\hline Density & 1.05 & 1.05 & 1.07 & 1.05 & 1.07 & 1.05 & 1.05 \\
\hline $\mathrm{Al}$ & 3.19E-03 & $1.46 \mathrm{E}-02$ & $2.80 \mathrm{E}-02$ & 4.62E-02 & 6.90E-02 & 9.48E-02 & $1.13 \mathrm{E}-01$ \\
\hline B & [3.88E-05] & [3.75E-05] & {$[2.23 \mathrm{E}-05]$} & [2.26E-05] & [2.81E-05] & [2.65E-05] & [3.41E-05] \\
\hline $\mathrm{Bi}$ & $<4.46 \mathrm{E}-06$ & $<4.48 \mathrm{E}-06$ & $<4.49 \mathrm{E}-06$ & $<4.44 \mathrm{E}-06$ & $<4.49 \mathrm{E}-06$ & $<4.42 \mathrm{E}-06$ & $<4.41 \mathrm{E}-06$ \\
\hline $\mathrm{Cd}$ & $<$ <9.39E-07 & $<<9.43 \mathrm{E}-07$ & $<<9.45 \mathrm{E}-07$ & $<<9.35 \mathrm{E}-07$ & $<<9.46 \mathrm{E}-07$ & $<<9.31 \mathrm{E}-07$ & $<<9.29 \mathrm{E}-07$ \\
\hline $\mathrm{Cr}$ & [2.81E-06] & [7.80E-06] & 1.12E-05 & $1.47 \mathrm{E}-05$ & 1.75E-05 & 2.12E-05 & $2.48 \mathrm{E}-05$ \\
\hline $\mathrm{Fe}$ & [1.20E-05] & $3.48 \mathrm{E}-05$ & 2.69E-05 & 3.23E-05 & $3.58 \mathrm{E}-05$ & 3.14E-05 & 2.71E-05 \\
\hline $\mathrm{Mn}$ & [4.80E-07] & [6.24E-07] & [3.53E-07] & [2.64E-07] & $<1.31 \mathrm{E}-07$ & [1.91E-07] & $<1.29 \mathrm{E}-07$ \\
\hline $\mathrm{Na}$ & 1.05 & 1.09 & 1.10 & 1.07 & 1.08 & 1.05 & 1.09 \\
\hline $\mathrm{P}$ & [1.25E-04] & [1.61E-04] & [2.12E-04] & [2.00E-04] & [1.92E-04] & [1.59E-04] & [1.59E-04] \\
\hline$S$ & [2.28E-04] & [3.21E-04] & [5.36E-04] & [5.59E-04] & [3.51E-04] & {$[4.80 \mathrm{E}-04]$} & [5.08E-04] \\
\hline $\mathrm{Si}$ & 2.98E-04 & $1.33 \mathrm{E}-03$ & $1.48 \mathrm{E}-03$ & $1.47 \mathrm{E}-03$ & $1.49 \mathrm{E}-03$ & $1.36 \mathrm{E}-03$ & $1.30 \mathrm{E}-03$ \\
\hline $\mathrm{Sr}$ & [1.49E-07] & [1.28E-07] & [9.63E-08] & [8.11E-08] & [1.14E-07] & [1.26E-07] & [7.71E-08] \\
\hline $\mathrm{U}$ & [1.15E-05] & [2.10E-05] & [3.15E-05] & [2.34E-05] & [3.02E-05] & [3.36E-05] & [3.10E-05] \\
\hline $\mathrm{Zn}$ & [9.97E-06] & [1.24E-05] & [1.43E-05] & [1.61E-05] & [2.01E-05] & [2.31E-05] & [2.58E-05] \\
\hline $\mathrm{Zr}$ & [9.70E-07] & [4.10E-07] & $<3.77 \mathrm{E}-07$ & [6.10E-07] & [5.49E-07] & [6.08E-07] & [1.11E-06] \\
\hline Fluoride & [5.79E-05] & [6.32E-05] & [4.90E-05] & [4.90E-05] & [3.11E-05] & [3.95E-05] & [3.90E-05] \\
\hline Nitrite & [2.11E-05] & [3.26E-05] & [3.48E-05] & [3.48E-05] & [3.70E-05] & [4.13E-05] & [4.13E-05] \\
\hline Sulfate & [1.46E-05] & [1.56E-05] & [1.67E-05] & [1.67E-05] & [1.46E-05] & [1.77E-05] & [3.02E-05] \\
\hline Nitrate & [1.94E-04] & 3.63E-04 & 3.89E-04 & 3.89E-04 & 3.98E-04 & $4.24 \mathrm{E}-04$ & 3.92E-04 \\
\hline Phosphate & 1.85E-04 & $1.71 \mathrm{E}-04$ & 1.66E-04 & 1.66E-04 & 1.64E-04 & 1.67E-04 & 1.67E-04 \\
\hline \multicolumn{8}{|l|}{$3 \mathrm{M}$ NaOH } \\
\hline Density & 1.13 & 1.13 & 1.14 & 1.13 & 1.14 & 1.13 & 1.13 \\
\hline $\mathrm{Al}$ & 3.42E-03 & 2.83E-02 & 5.13E-02 & 7.49E-02 & 9.42E-02 & $1.02 \mathrm{E}-01$ & 1.03E-01 \\
\hline B & $<6.87 \mathrm{E}-05$ & $<6.98 \mathrm{E}-05$ & $<6.97 \mathrm{E}-05$ & $<6.83 \mathrm{E}-05$ & [9.43E-05] & $<6.90 \mathrm{E}-05$ & $<6.85 \mathrm{E}-05$ \\
\hline $\mathrm{Bi}$ & $<2.22 \mathrm{E}-05$ & [2.41E-05] & $<2.25 \mathrm{E}-05$ & $<2.21 \mathrm{E}-05$ & $<2.22 \mathrm{E}-05$ & [2.38E-05] & $<2.22 \mathrm{E}-05$ \\
\hline $\mathrm{Cd}$ & $<4.68 \mathrm{E}-06$ & $<4.75 \mathrm{E}-06$ & $<4.75 \mathrm{E}-06$ & $<4.65 \mathrm{E}-06$ & $<4.67 \mathrm{E}-06$ & $<4.70 \mathrm{E}-06$ & $<4.67 \mathrm{E}-06$ \\
\hline $\mathrm{Cr}$ & $<5.06 \mathrm{E}-06$ & [1.39E-05] & [1.57E-05] & $2.25 \mathrm{E}-05$ & [2.79E-05] & [3.35E-05] & [2.79E-05] \\
\hline $\mathrm{Fe}$ & [2.49E-05] & $2.50 \mathrm{E}-04$ & [9.55E-05] & $6.61 \mathrm{E}-04$ & [1.11E-04] & [1.11E-04] & [1.11E-04] \\
\hline $\mathrm{Mn}$ & $<6.48 \mathrm{E}-07$ & [1.60E-06] & [1.20E-06] & [1.29E-06] & $<6.47 \mathrm{E}-07$ & $<6.51 \mathrm{E}-07$ & $<6.46 \mathrm{E}-07$ \\
\hline $\mathrm{Na}$ & 3.12 & 3.18 & 3.18 & 3.21 & 3.17 & 3.18 & 3.22 \\
\hline $\mathrm{P}$ & $<2.50 \mathrm{E}-04$ & $<2.54 \mathrm{E}-04$ & $<2.53 \mathrm{E}-04$ & $<2.48 \mathrm{E}-04$ & $<2.49 \mathrm{E}-04$ & $<2.51 \mathrm{E}-04$ & [2.89E-04] \\
\hline $\mathrm{S}$ & [1.83E-03] & [1.57E-03] & [2.45E-03] & [6.72E-04] & [6.07E-04] & [1.75E-03] & [2.02E-03] \\
\hline $\mathrm{Si}$ & $4.22 \mathrm{E}-04$ & $1.87 \mathrm{E}-03$ & 1.99E-03 & 2.05E-03 & $2.11 \mathrm{E}-03$ & $2.15 \mathrm{E}-03$ & 2.17E-03 \\
\hline $\mathrm{Sr}$ & [3.89E-07] & [5.74E-07] & [5.73E-07] & [5.27E-07] & [7.40E-07] & [3.16E-07] & [2.50E-07] \\
\hline $\mathrm{U}$ & $<2.08 \mathrm{E}-05$ & [4.62E-05] & [4.48E-05] & [2.72E-05] & [4.67E-05] & [4.44E-05] & [2.59E-05] \\
\hline $\mathrm{Zn}$ & [1.99E-05] & [1.73E-05] & [1.73E-05] & [2.49E-05] & [5.20E-05] & [2.95E-05] & [2.69E-05] \\
\hline $\mathrm{Zr}$ & [5.77E-06] & [7.58E-06] & [8.26E-06] & [7.76E-06] & [7.45E-06] & [6.82E-06] & [1.02E-05] \\
\hline Fluoride & [7.37E-05] & [1.05E-04] & $<9.47 \mathrm{E}-05$ & [8.42E-05] & [5.79E-05] & [7.90E-05] & [6.32E-05] \\
\hline Nitrite & $<0.000$ & $<3.26 \mathrm{E}-05$ & $<3.48 \mathrm{E}-05$ & [3.26E-05] & [3.70E-05] & [4.35E-05] & [4.35E-05] \\
\hline Sulfate & [4.27E-05] & $<2.29 \mathrm{E}-05$ & $<6.87 \mathrm{E}-05$ & [3.85E-05] & [3.75E-05] & [5.21E-05] & [4.79E-05] \\
\hline Nitrate & [2.26E-04] & 4.92E-04 & $4.08 \mathrm{E}-04$ & 5.18E-04 & 5.31E-04 & 5.39E-04 & 6.02E-04 \\
\hline Phosphate & [1.37E-04] & [1.68E-04] & $<1.58 \mathrm{E}-04$ & [1.58E-04] & [1.58E-04] & [1.90E-04] & [1.68E-04] \\
\hline
\end{tabular}


Table I.2 (Contd)

\begin{tabular}{|c|c|c|c|c|c|c|c|}
\hline \multirow[b]{2}{*}{ Analyte } & \multicolumn{7}{|c|}{$\begin{array}{l}\text { Analyte Concentration and Density at Given Time After Cooling to Ambient }\left(\sim 21^{\circ} \mathrm{C}\right) \\
\text { Temperature; } \mathrm{g} / \mathrm{mL} \text { for Density; } \mathrm{M} \text { for Metals and Anions }\end{array}$} \\
\hline & $0 \mathrm{hr}$ & $1 \mathrm{hr}$ & $2 \mathrm{hr}$ & $4 \mathrm{hr}$ & $8 \mathrm{hr}$ & $24 \mathrm{hr}$ & $48 \mathrm{hr}$ \\
\hline \multicolumn{8}{|c|}{$5 \mathrm{M} \mathrm{NaOH}$} \\
\hline Density & 1.19 & 1.20 & 1.20 & 1.20 & 1.21 & 1.21 & 1.20 \\
\hline $\mathrm{Al}$ & 4.36E-03 & 3.85E-02 & 7.86E-02 & $1.14 \mathrm{E}-01$ & $1.28 \mathrm{E}-01$ & 1.33E-01 & $1.32 \mathrm{E}-01$ \\
\hline $\mathrm{B}$ & $<7.08 \mathrm{E}-05$ & $<6.91 \mathrm{E}-05$ & $<3.46 \mathrm{E}-04$ & $<6.83 \mathrm{E}-05$ & $<6.92 \mathrm{E}-05$ & $<6.80 \mathrm{E}-05$ & $<6.87 \mathrm{E}-05$ \\
\hline $\mathrm{Bi}$ & $<2.29 \mathrm{E}-05$ & $<2.23 \mathrm{E}-05$ & $<1.12 \mathrm{E}-04$ & $<2.21 \mathrm{E}-05$ & $<2.24 \mathrm{E}-05$ & $<2.20 \mathrm{E}-05$ & $<2.22 \mathrm{E}-05$ \\
\hline $\mathrm{Cd}$ & $<4.82 \mathrm{E}-06$ & $<4.70 \mathrm{E}-06$ & $<2.35 \mathrm{E}-05$ & $<4.66 \mathrm{E}-06$ & $<4.71 \mathrm{E}-06$ & $<4.63 \mathrm{E}-06$ & $<4.68 \mathrm{E}-06$ \\
\hline $\mathrm{Cr}$ & [5.39E-06] & [2.09E-05] & [2.69E-05] & [2.61E-05] & [3.65E-05] & [4.47E-05] & [3.75E-05] \\
\hline $\mathrm{Fe}$ & [3.60E-05] & [1.23E-04] & [1.62E-04] & $1.94 \mathrm{E}-04$ & $2.01 \mathrm{E}-04$ & $2.07 \mathrm{E}-04$ & $2.10 \mathrm{E}-04$ \\
\hline $\mathrm{Mn}$ & [3.02E-06] & [3.62E-06] & $<3.26 \mathrm{E}-06$ & [1.40E-06] & [1.30E-06] & $<6.41 \mathrm{E}-07$ & $<6.47 \mathrm{E}-07$ \\
\hline $\mathrm{Na}$ & 5.12 & 5.09 & 5.31 & 5.16 & 5.30 & 5.26 & 5.27 \\
\hline $\mathrm{P}$ & [2.78E-04] & $<2.51 \mathrm{E}-04$ & $<1.26 \mathrm{E}-03$ & [3.08E-04] & [4.02E-04] & $<2.47 \mathrm{E}-04$ & [2.90E-04] \\
\hline$S$ & [2.29E-03] & [9.12E-04] & [1.55E-02] & [6.15E-04] & [2.91E-03] & [1.91E-03] & [1.45E-03] \\
\hline $\mathrm{Si}$ & $8.14 \mathrm{E}-04$ & $2.13 E-03$ & $1.55 \mathrm{E}-03$ & $2.35 \mathrm{E}-03$ & 2.44E-03 & $2.50 \mathrm{E}-03$ & $2.55 \mathrm{E}-03$ \\
\hline $\mathrm{Sr}$ & [6.18E-07] & [9.94E-07] & [1.10E-06] & [1.02E-06] & [1.07E-06] & [9.08E-07] & [6.00E-07] \\
\hline $\mathrm{U}$ & [3.35E-05] & $<2.09 \mathrm{E}-05$ & $<1.05 \mathrm{E}-04$ & [5.43E-05] & [4.32E-05] & [5.40E-05] & [5.59E-05] \\
\hline $\mathrm{Zn}$ & [2.00E-05] & [1.81E-05] & $<3.33 \mathrm{E}-05$ & [2.87E-05] & [4.24E-05] & [4.26E-05] & [3.97E-05] \\
\hline $\mathrm{Zr}$ & [8.73E-06] & [1.57E-05] & [2.49E-05] & [1.55E-05] & [1.50E-05] & [1.17E-05] & [1.59E-05] \\
\hline Fluoride & [5.79E-05] & [7.37E-05] & [6.84E-05] & [5.79E-05] & [5.05E-05] & $<4.95 \mathrm{E}-05$ & $<4.95 \mathrm{E}-05$ \\
\hline Nitrite & $1.38 \mathrm{E}-03$ & $1.31 \mathrm{E}-03$ & $1.90 \mathrm{E}-03$ & $1.26 \mathrm{E}-03$ & $1.30 \mathrm{E}-03$ & $1.50 \mathrm{E}-03$ & $1.56 \mathrm{E}-03$ \\
\hline Sulfate & $<2.29 \mathrm{E}-05$ & $<2.29 \mathrm{E}-05$ & $<2.29 \mathrm{E}-05$ & $<2.29 \mathrm{E}-05$ & $<2.29 \mathrm{E}-05$ & $<2.29 \mathrm{E}-05$ & $<2.29 \mathrm{E}-05$ \\
\hline Nitrate & [3.87E-04] & $6.15 \mathrm{E}-04$ & $6.27 \mathrm{E}-04$ & $6.58 \mathrm{E}-04$ & 6.63E-04 & $7.05 \mathrm{E}-04$ & $7.24 \mathrm{E}-04$ \\
\hline Phosphate & [5.69E-05] & [6.74E-05] & [6.42E-05] & [6.21E-05] & [6.00E-05] & [7.27E-05] & [6.53E-05] \\
\hline
\end{tabular}


Table I.3. Analyte Concentrations as a Function of Time for Leaching at $80^{\circ} \mathrm{C}$, in $\mu \mathrm{g} / \mathrm{mL}$

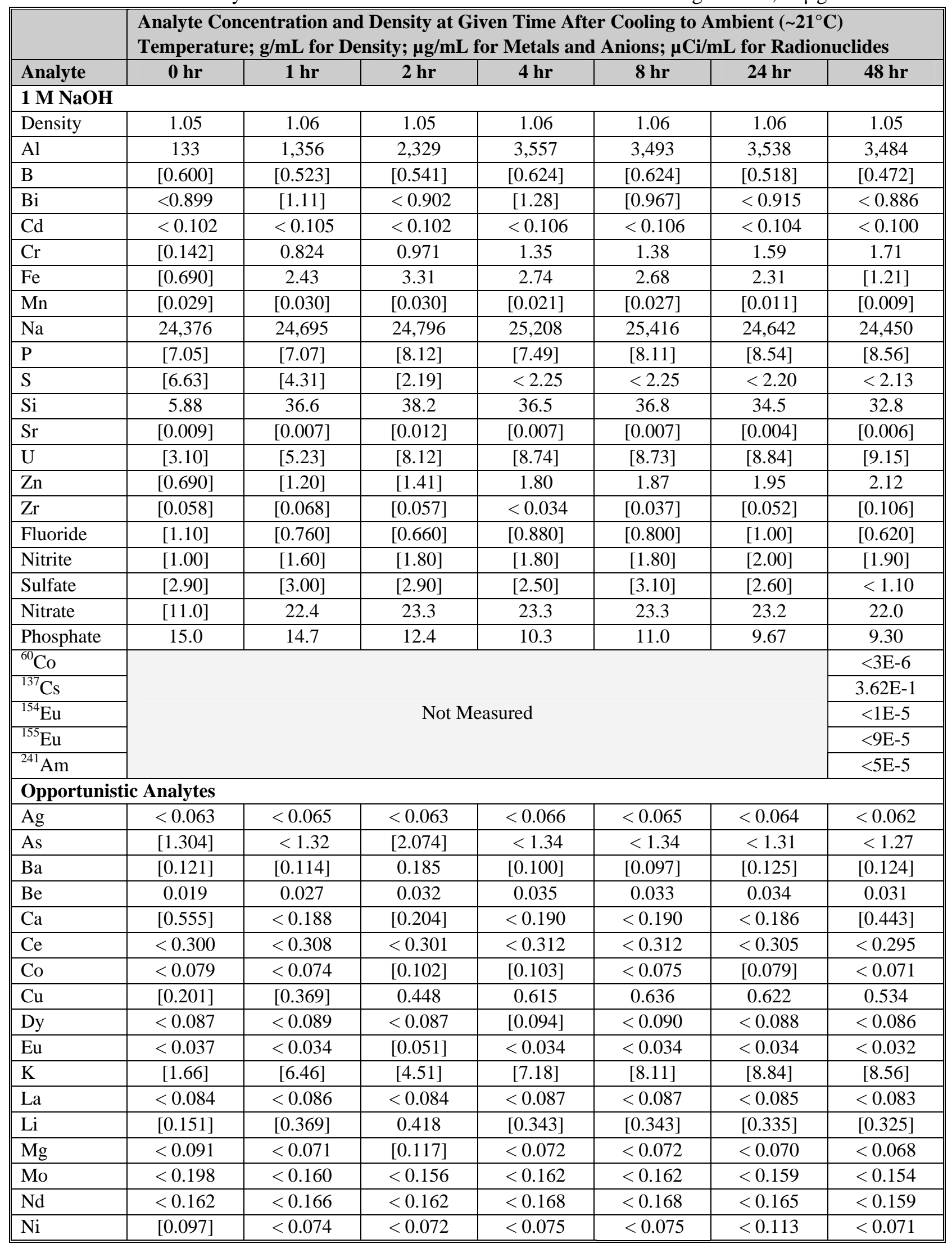


Table I.3 (Contd)

\begin{tabular}{|c|c|c|c|c|c|c|c|}
\hline \multirow[b]{2}{*}{ Analyte } & \multicolumn{7}{|c|}{$\begin{array}{l}\text { Analyte Concentration and Density at Given Time After Cooling to Ambient }\left(\sim 21^{\circ} \mathrm{C}\right) \\
\text { Temperature; } g / \mathrm{mL} \text { for Density; } \mu \mathrm{g} / \mathrm{mL} \text { for Metals and Anions; } \mu \mathrm{Ci} / \mathrm{mL} \text { for Radionuclides }\end{array}$} \\
\hline & o hr & $1 \mathrm{hr}$ & $2 \mathrm{hr}$ & $4 \mathrm{hr}$ & $8 \mathrm{hr}$ & $24 \mathrm{hr}$ & $48 \mathrm{hr}$ \\
\hline $\mathrm{Pb}$ & [2.13] & {$[4.61]$} & [6.31] & [7.18] & {$[8.11]$} & {$[8.23]$} & {$[6.50]$} \\
\hline $\mathrm{Pd}$ & {$[0.282]$} & $<0.194$ & {$[0.222]$} & {$[0.287]$} & $<0.196$ & {$[0.232]$} & {$[0.213]$} \\
\hline $\mathrm{Rh}$ & {$[0.435]$} & {$[0.431]$} & {$[0.691]$} & {$[0.624]$} & {$[0.530]$} & {$[0.640]$} & $<0.354$ \\
\hline $\mathrm{Ru}$ & {$[0.354]$} & $<0.261$ & $<0.255$ & $<0.265$ & [0.437] & $<0.259$ & $<0.251$ \\
\hline $\mathrm{Sb}$ & $<0.600$ & $<0.615$ & $<0.601$ & {$[0.686]$} & $<0.624$ & $<0.610$ & $<0.591$ \\
\hline Se & $<2.10$ & $<2.15$ & $<2.10$ & $<2.18$ & $<2.18$ & $<2.13$ & $<2.07$ \\
\hline Sn & $\begin{array}{l}1.06] \\
\end{array}$ & {$[1.05]$} & {$[1.74]$} & $<0.842$ & [1.12] & {$[1.80]$} & {$[1.83]$} \\
\hline $\mathrm{Ta}$ & $<0.510$ & $<0.523$ & $<0.511$ & $<0.530$ & $<0.530$ & $<0.518$ & $<0.502$ \\
\hline $\mathrm{Te}$ & $<0.780$ & $<0.800$ & $<0.781$ & $<0.811$ & $<0.811$ & $<0.793$ & $<0.768$ \\
\hline Th & $<0.342$ & $<0.301$ & [0.511] & $<0.306$ & $<0.306$ & $<0.299$ & $<0.289$ \\
\hline $\mathrm{Ti}$ & $<0.013$ & $<0.013$ & {$[0.014]$} & $<0.013$ & $<0.013$ & $<0.013$ & $<0.013$ \\
\hline $\mathrm{Tl}$ & $<1.14$ & $<1.17$ & $<1.14$ & $<1.19$ & $<1.19$ & [1.77] & [2.63] \\
\hline $\mathrm{V}$ & {$[0.084]$} & [0.101] & [0.111] & {$[0.106]$} & {$[0.106]$} & {$[0.140]$} & {$[0.136]$} \\
\hline $\mathrm{W}$ & $<0.570$ & $<0.584$ & $<0.571$ & $<0.593$ & $<0.593$ & $<0.579$ & $<0.561$ \\
\hline $\mathrm{Y}$ & $<0.013$ & $<0.014$ & $<0.013$ & $<0.014$ & $<0.014$ & $<0.013$ & $<0.013$ \\
\hline \multicolumn{8}{|c|}{3 M NaOH, Trial a } \\
\hline Density & 1.13 & 1.13 & 1.13 & 1.14 & 1.14 & 1.13 & 1.13 \\
\hline $\mathrm{Al}$ & 175 & 2,699 & 3,433 & 3,625 & 3,643 & 3,466 & 3,730 \\
\hline B & [1.75] & {$[1.71]$} & {$[2.02]$} & $<0.750$ & $<0.735$ & {$[0.874]$} & [1.28] \\
\hline$\overline{\mathrm{Bi}}$ & $<4.72$ & $<4.68$ & $<4.60$ & $<4.69$ & [5.20] & [6.93] & [5.97] \\
\hline $\mathrm{Cd}$ & $<0.535$ & $<0.530$ & $<0.521$ & $<0.531$ & $<0.520$ & $<0.512$ & $<0.507$ \\
\hline $\mathrm{Cr}$ & $<0.267$ & [1.03] & {$[1.32]$} & {$[1.50]$} & [1.38] & {$[1.87]$} & {$[2.21]$} \\
\hline $\mathrm{Fe}$ & {$[2.14]$} & 8.04 & 8.77 & 9.09 & 8.97 & 8.30 & 7.64 \\
\hline $\mathrm{Mn}$ & [0.154] & [0.184] & {$[0.110]$} & {$[0.106]$} & {$[0.086]$} & $<0.035$ & $<0.034$ \\
\hline $\mathrm{Na}$ & 73,158 & 72,312 & 72,637 & 71,880 & 73,466 & 68,258 & 73,706 \\
\hline $\mathrm{P}$ & $<7.87$ & $<7.79$ & $<7.66$ & $<7.81$ & {$[7.96]$} & [13.6] & $<7.46$ \\
\hline $\mathrm{S}$ & [24.5] & [23.1] & [26.4] & {$[40.6]$} & $<11.0$ & [14.5] & $<10.7$ \\
\hline $\mathrm{Si}$ & 14.1 & 55.5 & 59.8 & 62.5 & 65.2 & 62.1 & 69.5 \\
\hline $\mathrm{Sr}$ & {$[0.027]$} & [0.031] & {$[0.037]$} & {$[0.030]$} & [0.027] & {$[0.032]$} & {$[0.066]$} \\
\hline $\mathrm{U}$ & {$[8.02]$} & [8.10] & {$[14.4]$} & {$[9.06]$} & [11.9] & [14.6] & [20.6] \\
\hline $\mathrm{Zn}$ & $<0.44$ & {$[1.22]$} & [1.01] & {$[0.906]$} & {$[1.01]$} & {$[1.24]$} & {$[1.22]$} \\
\hline $\mathrm{Zr}$ & [0.393] & [0.935] & {$[0.858]$} & {$[0.875]$} & {$[0.704]$} & [0.558] & {$[0.746]$} \\
\hline Fluoride & {$[1.60]$} & {$[1.50]$} & {$[1.40]$} & {$[1.20]$} & {$[1.50]$} & {$[1.50]$} & {$[1.20]$} \\
\hline Nitrite & $<1.50$ & [1.60] & {$[1.60]$} & [1.70] & {$[1.80]$} & {$[2.00]$} & {$[2.10]$} \\
\hline Sulfate & $<2.20$ & $<2.20$ & {$[4.40]$} & {$[3.80]$} & $<2.20$ & [6.10] & {$[5.20]$} \\
\hline Nitrate & [13.0] & {$[29.0]$} & 31.2 & 35.1 & 33.5 & 32.2 & 35.3 \\
\hline Phosphate & {$[16.0]$} & {$[17.0]$} & {$[17.0]$} & {$[18.0]$} & {$[17.0]$} & 21.5 & 19.9 \\
\hline${ }^{60} \mathrm{Co}$ & \multirow{5}{*}{\multicolumn{6}{|c|}{ Not Measured }} & $<3 \mathrm{E}-6$ \\
\hline${ }^{137} \mathrm{Cs}$ & & & & & & & $4.91 \mathrm{E}-1$ \\
\hline${ }^{154} \mathrm{Eu}$ & & & & & & & $<2 \mathrm{E}-5$ \\
\hline${ }^{155} \mathrm{Eu}$ & & & & & & & $<1 \mathrm{E}-4$ \\
\hline${ }^{241} \mathrm{Am}$ & & & & & & & $<3 \mathrm{E}-4$ \\
\hline
\end{tabular}


Table I.3 (Contd)

\begin{tabular}{|c|c|c|c|c|c|c|c|}
\hline \multirow[b]{2}{*}{ Analyte } & \multicolumn{7}{|c|}{$\begin{array}{l}\text { Analyte Concentration and Density at Given Time After Cooling to Ambient }\left(\sim 21^{\circ} \mathrm{C}\right) \\
\text { Temperature; } g / \mathrm{mL} \text { for Density; } \mu \mathrm{g} / \mathrm{mL} \text { for Metals and Anions; } \mu \mathrm{Ci} / \mathrm{mL} \text { for Radionuclides }\end{array}$} \\
\hline & o hr & $1 \mathrm{hr}$ & $2 \mathrm{hr}$ & $4 \mathrm{hr}$ & $8 \mathrm{hr}$ & $24 \mathrm{hr}$ & $48 \mathrm{hr}$ \\
\hline \multicolumn{8}{|c|}{ Opportunistic Analytes } \\
\hline $\mathrm{Ag}$ & $<0.330$ & $<0.327$ & $<0.322$ & $<0.328$ & $<0.321$ & $<0.316$ & $<0.313$ \\
\hline As & $<6.77$ & $<6.70$ & $<6.59$ & $<6.72$ & $<6.58$ & $<6.48$ & $<6.42$ \\
\hline $\mathrm{Ba}$ & [0.074] & $<0.042$ & $<0.041$ & $<0.042$ & $<0.041$ & [0.143] & [0.149] \\
\hline $\mathrm{Be}$ & [0.025] & {$[0.037]$} & {$[0.034]$} & [0.041] & {$[0.037]$} & [0.051] & {$[0.060]$} \\
\hline $\mathrm{Ca}$ & [2.82] & [6.23] & [1.69] & [3.13] & [4.59] & {$[3.78]$} & [5.07] \\
\hline $\mathrm{Ce}$ & $<1.57$ & $<1.56$ & $<1.53$ & $<1.56$ & $<1.53$ & {$[2.34]$} & {$[2.24]$} \\
\hline Co & $<0.378$ & $<0.374$ & $<0.368$ & $<0.375$ & $<0.367$ & $<0.362$ & $<0.358$ \\
\hline $\mathrm{Cu}$ & {$[0.425]$} & [1.03] & [1.04] & {$[1.25]$} & [1.53] & {$[0.237]$} & [0.328] \\
\hline Dy & $<0.456$ & $<0.452$ & $<0.444$ & $<0.453$ & $<0.444$ & $<0.437$ & $<0.433$ \\
\hline $\mathrm{Eu}$ & $<0.173$ & $<0.171$ & $<0.169$ & $<0.172$ & $<0.168$ & $<0.166$ & {$[0.230]$} \\
\hline $\mathrm{K}$ & [6.77] & [11.5] & [9.50] & {$[5.94]$} & [14.7] & [15.5] & [16.1] \\
\hline $\mathrm{La}$ & $<0.441$ & $<0.436$ & $<0.429$ & $<0.438$ & $<0.429$ & $<0.422$ & $<0.418$ \\
\hline $\mathrm{Li}$ & [0.771] & {$[0.904]$} & {$[0.950]$} & {$[1.00]$} & [0.918] & $<0.090$ & $<0.090$ \\
\hline $\mathrm{Mg}$ & $<0.448$ & $<0.358$ & $<0.352$ & $<0.359$ & $<0.352$ & $<0.347$ & {$[0.627]$} \\
\hline Mo & $<0.818$ & $<0.810$ & $<0.797$ & $<0.813$ & $<0.796$ & $<0.784$ & $<0.776$ \\
\hline $\mathrm{Nd}$ & $<0.850$ & $<0.842$ & $<0.828$ & $<0.844$ & $<0.826$ & $<0.814$ & $<0.806$ \\
\hline $\mathrm{Ni}$ & [0.409] & $<0.374$ & $<0.368$ & $<0.375$ & $<0.367$ & $<0.362$ & $<0.358$ \\
\hline $\mathrm{Pb}$ & $<5.03$ & [4.99] & {$[10.1]$} & {$[11.3]$} & [11.6] & [9.94] & [9.55] \\
\hline $\mathrm{Pd}$ & $<0.991$ & $<0.982$ & $<0.965$ & $<0.984$ & $<0.964$ & $<0.949$ & $<0.940$ \\
\hline $\mathrm{Rh}$ & $<1.89$ & $\begin{array}{l}<1.87 \\
\end{array}$ & $<1.84$ & $\begin{array}{l}<1.88 \\
\end{array}$ & $<1.84$ & $<1.81$ & $<1.79$ \\
\hline $\mathrm{Ru}$ & $<1.34$ & $<1.32$ & $<1.30$ & $<1.33$ & $<1.30$ & $<1.28$ & $<1.27$ \\
\hline $\mathrm{Sb}$ & $<3.15$ & $<3.12$ & $<3.06$ & $<3.13$ & $<3.06$ & {$[6.03]$} & $<2.98$ \\
\hline Se & $<11.0$ & $<10.9$ & $<10.7$ & $<10.9$ & $<10.7$ & {$[14.3]$} & $<10.4$ \\
\hline Sn & $<4.25$ & $<4.21$ & $<4.14$ & $<4.22$ & $<4.13$ & $<4.07$ & $<4.03$ \\
\hline $\mathrm{Ta}$ & $<2.67$ & $<2.65$ & $<2.61$ & $<2.66$ & $<2.60$ & $<2.56$ & $<2.54$ \\
\hline $\mathrm{Te}$ & $<4.09$ & $<4.05$ & $<3.98$ & $<4.06$ & $<3.98$ & $<3.92$ & $<3.88$ \\
\hline Th & $<1.70$ & $<1.53$ & $<1.50$ & $<1.53$ & $<1.50$ & $<1.48$ & $<1.46$ \\
\hline $\mathrm{Ti}$ & $<0.068$ & $<0.067$ & $<0.066$ & $<0.067$ & $<0.066$ & $<0.065$ & $<0.064$ \\
\hline $\mathrm{Tl}$ & $<5.98$ & $<5.92$ & {$[9.50]$} & $<5.94$ & $<5.82$ & {$[8.74]$} & [13.4] \\
\hline $\mathrm{V}$ & [0.239] & {$[0.343]$} & {$[0.337]$} & {$[0.275]$} & {$[0.178]$} & $<0.112$ & $<0.110$ \\
\hline $\mathrm{W}$ & $<2.99$ & $<2.96$ & $<2.91$ & $<2.97$ & $<2.91$ & $<2.86$ & $<2.83$ \\
\hline $\mathrm{Y}$ & $<0.069$ & $<0.069$ & $<0.067$ & $<0.069$ & $<0.067$ & $<0.066$ & {$[0.075]$} \\
\hline \multicolumn{8}{|c|}{$3 \mathrm{M}$ NaOH, Trial b } \\
\hline Density & 1.13 & 1.14 & 1.13 & 1.14 & 1.15 & 1.12 & 1.13 \\
\hline $\mathrm{Al}$ & 241 & 2,473 & 3,033 & 3,109 & 3,216 & 2,691 & 3,159 \\
\hline $\mathrm{B}$ & [2.62] & [2.01] & {$[2.04]$} & [1.45] & [1.72] & {$[1.26]$} & [1.28] \\
\hline $\mathrm{Bi}$ & [6.09] & $<4.64$ & {$[7.41]$} & $<4.62$ & {$[9.37]$} & {$[7.70]$} & $<4.47$ \\
\hline $\mathrm{Cd}$ & $<0.517$ & $<0.525$ & $<0.525$ & $<0.523$ & $<0.531$ & $<0.523$ & $<0.507$ \\
\hline $\mathrm{Cr}$ & {$[0.286]$} & {$[1.21]$} & [1.45] & {$[1.69]$} & {$[1.31]$} & {$[1.76]$} & {$[1.91]$} \\
\hline $\mathrm{Fe}$ & {$[2.56]$} & [7.42] & 8.59 & 9.05 & 9.15 & 7.82 & 7.18 \\
\hline $\mathrm{Mn}$ & $<0.035$ & $<0.036$ & $<0.036$ & $<0.035$ & $<0.036$ & $<0.035$ & $<0.034$ \\
\hline $\mathrm{Na}$ & 70,294 & 70,786 & 72,589 & 73,259 & 76,182 & 62,819 & 73,898 \\
\hline $\mathrm{P}$ & [7.91] & {$[15.8]$} & $<7.72$ & {$[11.1]$} & {$[11.6]$} & {$[14.8]$} & $<7.45$ \\
\hline
\end{tabular}


Table I.3 (Contd)

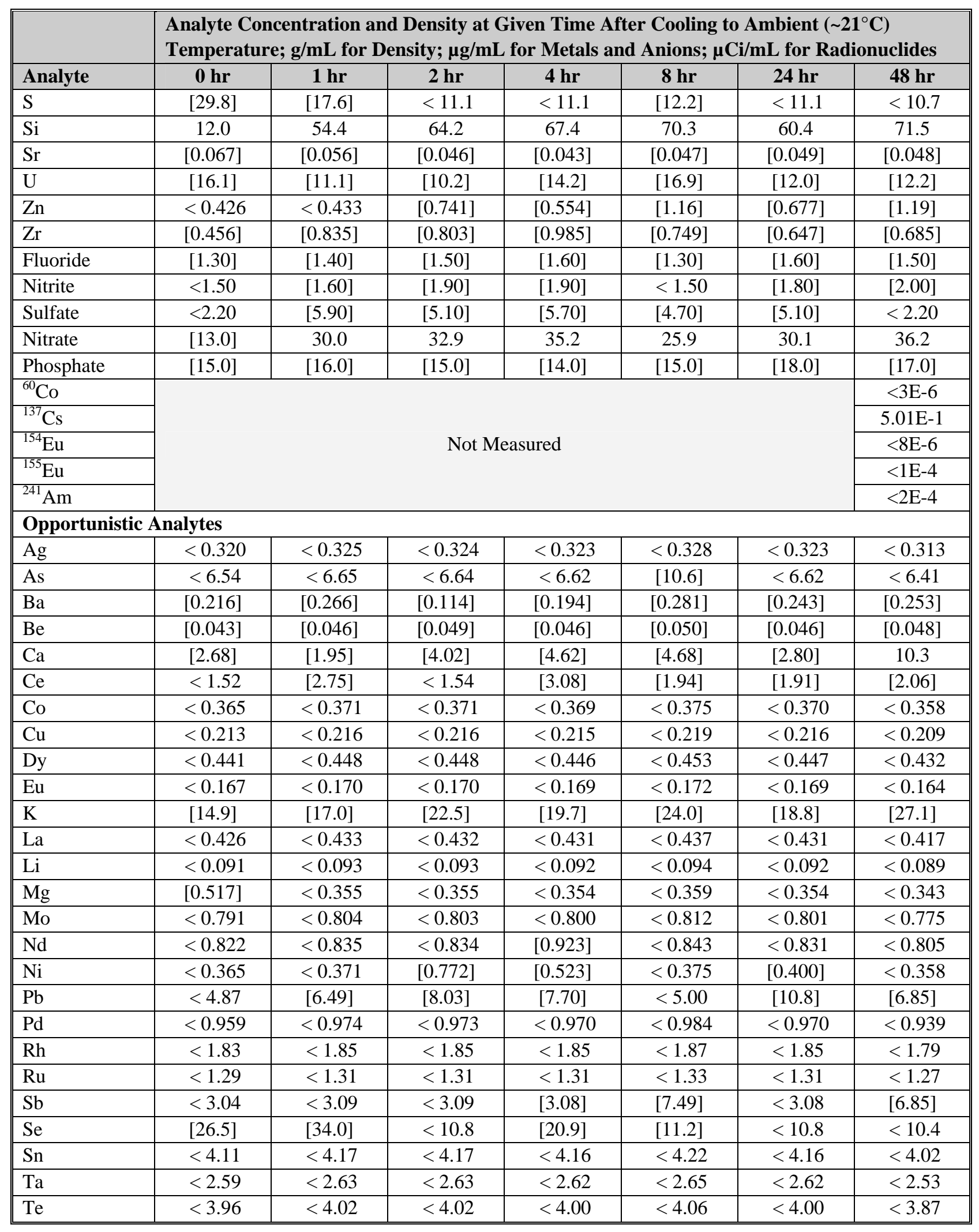


Table I.3 (Contd)

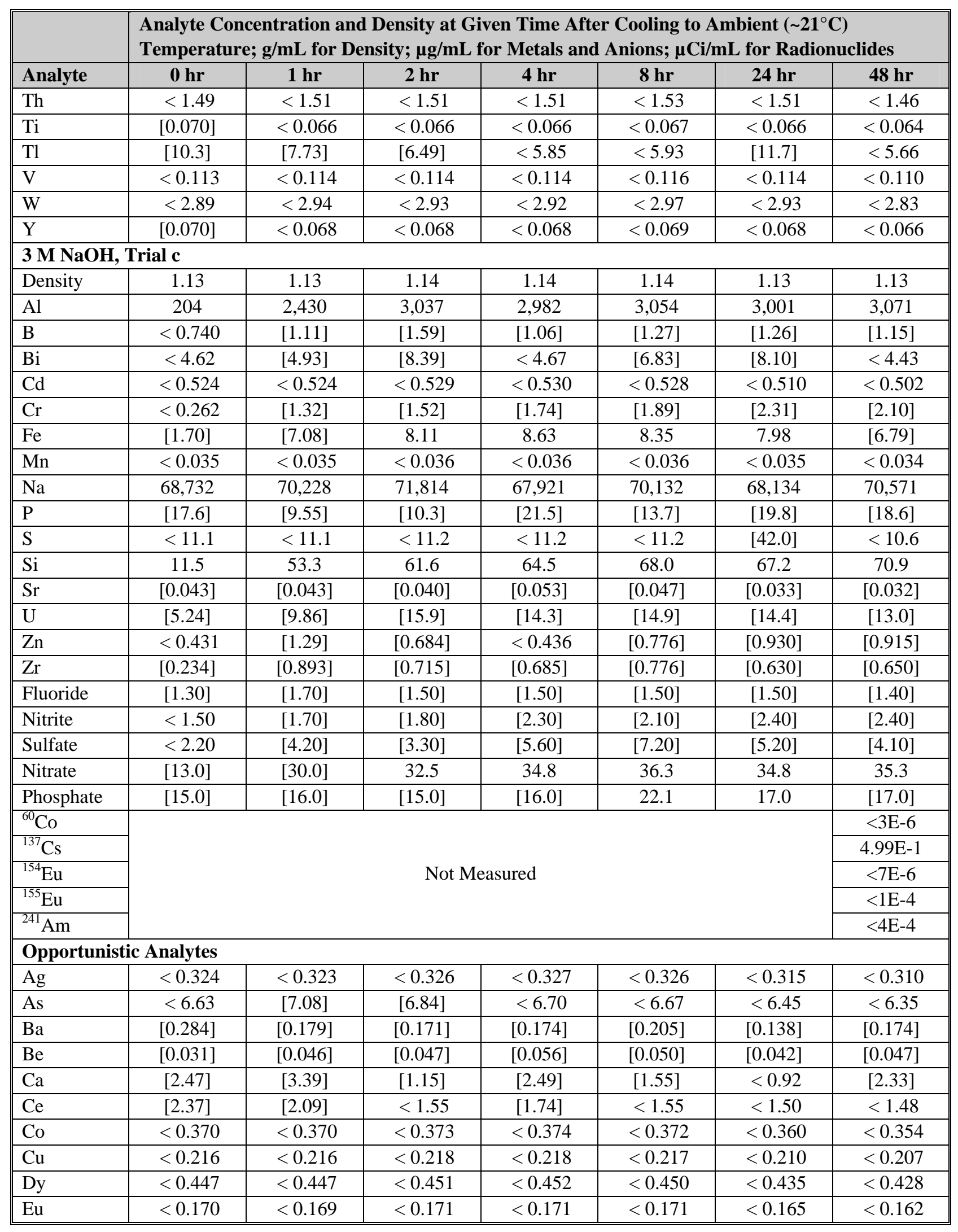


Table I.3 (Contd)

\begin{tabular}{|c|c|c|c|c|c|c|c|}
\hline \multirow[b]{2}{*}{ Analyte } & \multicolumn{7}{|c|}{$\begin{array}{l}\text { Analyte Concentration and Density at Given Time After Cooling to Ambient }\left(\sim 21^{\circ} \mathrm{C}\right) \\
\text { Temperature; } g / m L \text { for Density; } \mu \mathrm{g} / \mathrm{mL} \text { for Metals and Anions; } \mu \mathrm{Ci} / \mathrm{mL} \text { for Radionuclides }\end{array}$} \\
\hline & o hr & $1 \mathrm{hr}$ & $2 \mathrm{hr}$ & $4 \mathrm{hr}$ & $8 \mathrm{hr}$ & $24 \mathrm{hr}$ & $48 \mathrm{hr}$ \\
\hline $\mathrm{K}$ & {$[22.5]$} & [33.9] & [31.1] & [15.6] & {$[20.8]$} & {$[24.6]$} & {$[32.5]$} \\
\hline $\mathrm{La}$ & {$[0.462]$} & $<0.431$ & $<0.435$ & $<0.436$ & $<0.434$ & $<0.420$ & $<0.413$ \\
\hline $\mathrm{Li}$ & $<0.092$ & $<0.092$ & $<0.093$ & $<0.093$ & $<0.093$ & $<0.090$ & $<0.089$ \\
\hline $\mathrm{Mg}$ & $<0.354$ & $<0.354$ & $<0.358$ & $<0.358$ & $<0.357$ & $<0.345$ & $<0.340$ \\
\hline Mo & $<0.801$ & $<0.801$ & $<0.808$ & $<0.810$ & $<0.807$ & $<0.780$ & $<0.768$ \\
\hline $\mathrm{Nd}$ & $<0.832$ & $<0.832$ & $<0.839$ & $<0.841$ & $<0.838$ & {$[0.930]$} & $<0.797$ \\
\hline $\mathrm{Ni}$ & {$[0.462]$} & $<0.370$ & $<0.373$ & $<0.374$ & $<0.372$ & $<0.360$ & {$[0.856]$} \\
\hline $\mathrm{Pb}$ & $<4.93$ & [8.32] & [6.84] & [9.35] & {$[7.76]$} & {$[7.50]$} & [6.79] \\
\hline $\mathrm{Pd}$ & $<0.971$ & $<0.970$ & $<0.979$ & $<0.981$ & $<0.977$ & $<0.945$ & $<0.930$ \\
\hline $\mathrm{Rh}$ & $<1.85$ & $<1.85$ & $<1.87$ & $<1.87$ & $\begin{array}{l}<1.86 \\
\end{array}$ & $<1.80$ & $<1.77$ \\
\hline $\mathrm{Ru}$ & $<1.31$ & $<1.31$ & $<1.32$ & $<1.32$ & $<1.32$ & $<1.28$ & $<1.25$ \\
\hline $\mathrm{Sb}$ & [5.55] & [4.31] & [5.91] & $<3.12$ & [6.52] & $<3.00$ & $<2.95$ \\
\hline Se & $<10.8$ & [11.7] & [18.3] & [34.3] & $<10.9$ & {$[17.7]$} & {$[38.4]$} \\
\hline Sn & $<4.16$ & $<4.16$ & $<4.20$ & $<4.21$ & $<4.19$ & $<4.05$ & $<3.99$ \\
\hline $\mathrm{Ta}$ & $<2.62$ & $<2.62$ & $<2.64$ & $<2.65$ & $<2.64$ & $<2.55$ & $<2.51$ \\
\hline $\mathrm{Te}$ & $<4.01$ & $<4.00$ & $<4.04$ & $<4.05$ & $<4.03$ & $<3.90$ & $<3.84$ \\
\hline Th & $<1.51$ & $<1.51$ & $<1.52$ & $<1.53$ & $<1.52$ & $<1.47$ & $<1.45$ \\
\hline $\mathrm{Ti}$ & $<0.066$ & $<0.066$ & $<0.067$ & $<0.067$ & $<0.067$ & $<0.065$ & $<0.063$ \\
\hline $\mathrm{Tl}$ & {$[14.5]$} & $<5.85$ & $<5.91$ & [6.85] & $<5.90$ & [9.90] & {$[7.68]$} \\
\hline $\mathrm{V}$ & $<0.114$ & $<0.114$ & $<0.115$ & $<0.115$ & $<0.115$ & $<0.111$ & $<0.109$ \\
\hline $\mathrm{W}$ & $<2.93$ & $<2.93$ & $<2.95$ & $<2.96$ & $<2.95$ & $<2.85$ & $<2.81$ \\
\hline $\mathrm{Y}$ & $<0.068$ & $<0.068$ & $<0.068$ & $<0.069$ & $<0.068$ & $<0.066$ & $<0.065$ \\
\hline \multicolumn{8}{|c|}{$3 \mathrm{M}$ NaOH, with $1 \mathrm{M} \mathrm{NaNO}_{3}$} \\
\hline Density & 1.18 & 1.18 & 1.17 & 1.18 & 1.19 & 1.17 & 1.17 \\
\hline $\mathrm{Al}$ & 232 & 2,485 & 2,792 & 2,839 & 2,871 & 2,801 & 2,790 \\
\hline $\mathrm{B}$ & [1.98] & [1.78] & {$[1.47]$} & {$[0.929]$} & [2.11] & {$[1.75]$} & {$[1.72]$} \\
\hline $\mathrm{Bi}$ & $<4.65$ & $<4.68$ & $<4.68$ & $<4.64$ & [4.97] & {$[5.23]$} & [6.11] \\
\hline $\mathrm{Cd}$ & $<0.527$ & $<0.530$ & $<0.531$ & $<0.526$ & $<0.528$ & $<0.523$ & $<0.495$ \\
\hline $\mathrm{Cr}$ & $<0.263$ & [1.34] & [1.53] & {$[1.36]$} & [1.93] & {$[2.12]$} & {$[2.09]$} \\
\hline $\mathrm{Fe}$ & [2.04] & 8.108 & 8.556 & 8.576 & 9.664 & 8.363 & [6.69] \\
\hline $\mathrm{Mn}$ & {$[0.065]$} & {$[0.075]$} & {$[0.037]$} & {$[0.040]$} & $<0.036$ & $<0.035$ & $<0.033$ \\
\hline $\mathrm{Na}$ & 91,376 & 93,243 & 91,496 & 92,258 & 92,605 & 91,933 & 90,766 \\
\hline $\mathrm{P}$ & [13.3] & {$[13.4]$} & {$[9.06]$} & {$[12.4]$} & [14.9] & {$[9.22]$} & $<7.27$ \\
\hline $\mathrm{S}$ & $<11.2$ & $<11.2$ & $<11.2$ & {$[28.2]$} & [31.1] & $<11.1$ & $<10.5$ \\
\hline $\mathrm{Si}$ & [2.82] & 13.7 & 14.1 & 14.9 & 16.6 & 14.4 & 13.2 \\
\hline $\mathrm{Sr}$ & {$[0.030]$} & {$[0.041]$} & {$[0.041]$} & {$[0.034]$} & {$[0.084]$} & {$[0.040]$} & [0.035] \\
\hline $\mathrm{U}$ & $<4.96$ & [6.86] & [11.2] & {$[9.60]$} & {$[11.2]$} & {$[12.6]$} & [5.53] \\
\hline $\mathrm{Zn}$ & [1.05] & [1.93] & {$[2.50]$} & {$[2.38]$} & [2.39] & [2.12] & {$[2.36]$} \\
\hline $\mathrm{Zr}$ & [0.496] & [1.12] & [1.09] & [1.05] & [1.09] & [1.05] & {$[1.02]$} \\
\hline Fluoride & $<5.00$ & $<5.00$ & [5.30] & $<5.00$ & $<5.00$ & $<5.00$ & $<5.00$ \\
\hline Nitrite & $<8.00$ & $<8.00$ & $<8.00$ & $<8.00$ & $<8.00$ & $<8.00$ & $<8.00$ \\
\hline Sulfate & $<12.0$ & $<12.0$ & $<12.0$ & $<12.0$ & $<12.0$ & $<<12.0$ & $<<12.0$ \\
\hline Nitrate & 63,100 & 65,800 & 65,900 & 64,500 & 65,900 & 65,000 & 64,800 \\
\hline Phosphate & [49.0] & [31.0] & [26.0] & $<9.60$ & $<9.60$ & $<9.60$ & $<9.60$ \\
\hline
\end{tabular}


Table I.3 (Contd)

\begin{tabular}{|c|c|c|c|c|c|c|c|}
\hline \multirow[b]{2}{*}{ Analyte } & \multicolumn{7}{|c|}{$\begin{array}{l}\text { Analyte Concentration and Density at Given Time After Cooling to Ambient }\left(\sim 21^{\circ} \mathrm{C}\right) \\
\text { Temperature; } g / m L \text { for Density; } \mu \mathrm{g} / \mathrm{mL} \text { for Metals and Anions; } \mu \mathrm{Ci} / \mathrm{mL} \text { for Radionuclides }\end{array}$} \\
\hline & o hr & $1 \mathrm{hr}$ & $2 \mathrm{hr}$ & $4 \mathrm{hr}$ & $8 \mathrm{hr}$ & $24 \mathrm{hr}$ & $48 \mathrm{hr}$ \\
\hline${ }^{60} \mathrm{Co}$ & \multirow{5}{*}{\multicolumn{6}{|c|}{ Not Measured }} & $<3 \mathrm{E}-6$ \\
\hline${ }^{137} \mathrm{Cs}$ & & & & & & & $2.00 \mathrm{E}-1$ \\
\hline${ }^{154} \mathrm{Eu}$ & & & & & & & $<1 \mathrm{E}-5$ \\
\hline${ }^{155} \mathrm{Eu}$ & & & & & & & $<7 \mathrm{E}-5$ \\
\hline${ }^{241} \mathrm{Am}$ & & & & & & & $<4 \mathrm{E}-5$ \\
\hline \multicolumn{8}{|c|}{ Opportunistic Analytes } \\
\hline $\mathrm{Ag}$ & $<0.325$ & $<0.327$ & $<0.328$ & $<0.325$ & $<0.326$ & $<0.323$ & {$[0.640]$} \\
\hline As & $<6.66$ & [8.42] & $<6.71$ & $<6.66$ & $<6.68$ & $<6.61$ & $<6.25$ \\
\hline $\mathrm{Ba}$ & {$[0.232]$} & {$[0.278]$} & {$[0.256]$} & {$[0.223]$} & {$[0.202]$} & {$[0.151]$} & {$[0.291]$} \\
\hline $\mathrm{Be}$ & {$[0.030]$} & {$[0.031]$} & {$[0.031]$} & {$[0.034]$} & {$[0.037]$} & {$[0.034]$} & {$[0.032]$} \\
\hline $\mathrm{Ca}$ & {$[1.55]$} & {$[1.12]$} & $<0.952$ & {$[2.38]$} & [3.73] & {$[1.88]$} & $<0.887$ \\
\hline Ce & $<1.55$ & $<1.56$ & $<1.56$ & $<1.55$ & $<1.55$ & $<1.54$ & $<1.45$ \\
\hline Co & {$[0.681]$} & $<0.374$ & {$[0.468]$} & {$[0.402]$} & $<0.373$ & $<0.369$ & $<0.349$ \\
\hline $\mathrm{Cu}$ & {$[0.434]$} & {$[0.811]$} & [1.25] & {$[0.805]$} & [0.901] & {$[0.922]$} & {$[0.844]$} \\
\hline Dy & $<0.449$ & $<0.452$ & $<0.453$ & $<0.449$ & $<0.451$ & $<0.446$ & $<0.422$ \\
\hline $\mathrm{Eu}$ & $<0.170$ & $<0.172$ & $<0.172$ & $<0.170$ & {$[0.196]$} & $<0.169$ & $<0.160$ \\
\hline $\mathrm{K}$ & {$[37.2]$} & [26.8] & [30.9] & [30.6] & [17.7] & {$[19.4]$} & [23.6] \\
\hline $\mathrm{La}$ & $<0.434$ & $<0.437$ & $<0.437$ & $<0.433$ & $<0.435$ & $<0.430$ & $<0.407$ \\
\hline $\mathrm{Li}$ & {$[0.805]$} & {$[0.624]$} & {$[0.593]$} & [0.929] & {$[0.901]$} & {$[0.738]$} & {$[0.785]$} \\
\hline $\mathrm{Mg}$ & $<0.356$ & $<0.359$ & $<0.359$ & $<0.356$ & {$[0.466]$} & {$[0.584]$} & $<0.335$ \\
\hline Mo & $<0.805$ & [1.43] & $<0.812$ & [0.929] & [1.34] & $<0.799$ & {$[1.08]$} \\
\hline $\mathrm{Nd}$ & $<0.836$ & $<0.842$ & $<0.843$ & $<0.836$ & $<0.839$ & $<0.830$ & $<0.785$ \\
\hline $\mathrm{Ni}$ & [0.712] & [0.593] & {$[0.531]$} & $<0.372$ & $<0.373$ & {$[0.461]$} & $<0.349$ \\
\hline $\mathrm{Pb}$ & [5.58] & {$[8.42]$} & [12.2] & [9.91] & [11.5] & {$[12.0]$} & {$[10.8]$} \\
\hline $\mathrm{Pd}$ & $<0.976$ & $<0.982$ & $<0.984$ & $<0.975$ & $<0.979$ & $<0.969$ & $<0.916$ \\
\hline $\mathrm{Rh}$ & [3.04] & [2.46] & [2.40] & {$[2.94]$} & [3.05] & {$[2.67]$} & [3.78] \\
\hline $\mathrm{Ru}$ & $\begin{array}{l}<1.32 \\
\end{array}$ & $<1.33$ & $<1.33$ & $<1.32$ & $<1.32$ & $<1.31$ & $<1.24$ \\
\hline $\mathrm{Sb}$ & $<3.10$ & $<3.12$ & $<3.12$ & $<3.10$ & $<3.11$ & $<3.07$ & $<2.91$ \\
\hline Se & $<10.8$ & $<10.9$ & $<10.9$ & $<10.8$ & $<10.9$ & $<10.8$ & $<10.2$ \\
\hline Sn & $<4.18$ & [9.36] & [9.99] & [8.36] & $<4.20$ & {$[6.15]$} & [10.5] \\
\hline $\mathrm{Ta}$ & $<2.63$ & $<2.65$ & $<2.65$ & $<2.63$ & $<2.64$ & $<2.61$ & $<2.47$ \\
\hline $\mathrm{Te}$ & $<4.03$ & $<4.05$ & $<4.06$ & $<4.02$ & $<4.04$ & $<4.00$ & $<3.78$ \\
\hline Th & $<1.52$ & $<1.53$ & $<1.53$ & $<1.52$ & [3.01] & {$[2.52]$} & $<1.43$ \\
\hline $\mathrm{Ti}$ & $<0.067$ & $<0.067$ & $<0.067$ & $<0.067$ & $<0.067$ & $<0.066$ & $<0.063$ \\
\hline $\mathrm{Tl}$ & $<5.89$ & $<5.93$ & {$[8.12]$} & {$[11.8]$} & [13.1] & $<5.84$ & {$[11.1]$} \\
\hline $\mathrm{V}$ & {$[0.121]$} & {$[0.119]$} & {$[0.156]$} & {$[0.217]$} & $<0.11$ & {$[0.280]$} & {$[0.262]$} \\
\hline $\mathrm{W}$ & $<2.94$ & $<2.96$ & $<2.97$ & $<2.94$ & $<2.95$ & $<2.92$ & $<2.76$ \\
\hline $\mathrm{Y}$ & $<0.068$ & $<0.069$ & $<0.069$ & $<0.068$ & $<0.068$ & $<0.068$ & $<0.064$ \\
\hline \multicolumn{8}{|c|}{$3 \mathrm{M} \mathrm{NaOH}$, with $5 \mathrm{M} \mathrm{NaNO}_{3}$} \\
\hline Density & 1.38 & 1.38 & 1.38 & 1.39 & 1.39 & 1.35 & 1.38 \\
\hline $\mathrm{Al}$ & 184 & 3,097 & 3,127 & 3,280 & 3,191 & 2,968 & 3,092 \\
\hline $\mathrm{B}$ & {$[1.77]$} & [1.43] & [1.82] & $<1.35$ & $<1.34$ & $<1.35$ & $<1.26$ \\
\hline $\mathrm{Bi}$ & $<8.39$ & $<8.38$ & $<8.47$ & $<8.44$ & {$[9.91]$} & {$[9.04]$} & $<7.88$ \\
\hline $\mathrm{Cd}$ & $<0.950$ & $<0.950$ & $<0.960$ & $<0.956$ & $<0.948$ & $<0.954$ & $<0.893$ \\
\hline
\end{tabular}


Table I.3 (Contd)

\begin{tabular}{|c|c|c|c|c|c|c|c|}
\hline \multirow[b]{2}{*}{ Analyte } & \multicolumn{7}{|c|}{$\begin{array}{l}\text { Analyte Concentration and Density at Given Time After Cooling to Ambient }\left(\sim 21^{\circ} \mathrm{C}\right) \\
\text { Temperature; } \mathrm{g} / \mathrm{mL} \text { for Density; } \mu \mathrm{g} / \mathrm{mL} \text { for Metals and Anions; } \mu \mathrm{Ci} / \mathrm{mL} \text { for Radionuclides }\end{array}$} \\
\hline & o hr & $1 \mathrm{hr}$ & $2 \mathrm{hr}$ & $4 \mathrm{hr}$ & $8 \mathrm{hr}$ & $24 \mathrm{hr}$ & $48 \mathrm{hr}$ \\
\hline $\mathrm{Cr}$ & {$[0.528]$} & [1.18] & [2.23] & [1.72] & [1.58] & [1.62] & {$[2.16]$} \\
\hline $\mathrm{Fe}$ & {$[1.80]$} & [10.2] & [11.0] & [11.6] & [11.2] & [10.3] & [9.33] \\
\hline $\mathrm{Mn}$ & {$[0.152]$} & {$[0.140]$} & [0.082] & $<0.065$ & $<0.064$ & $<0.065$ & $<0.060$ \\
\hline $\mathrm{Na}$ & 187,893 & 185,574 & 185,372 & 190,892 & 189,580 & 174,568 & 184,934 \\
\hline $\mathrm{P}$ & [16.1] & $<14.0$ & $<14.1$ & [22.8] & [14.6] & [31.2] & {$[25.7]$} \\
\hline $\mathrm{S}$ & [25.2] & {$[83.8]$} & {$[56.5]$} & [40.6] & $<20.1$ & $<20.2$ & $<18.9$ \\
\hline $\mathrm{Si}$ & [3.01] & [3.41] & [3.14] & [3.75] & [2.08] & $<1.57$ & $<1.47$ \\
\hline $\mathrm{Sr}$ & {$[0.059]$} & {$[0.053]$} & {$[0.056]$} & {$[0.066]$} & {$[0.056]$} & {$[0.072]$} & [0.035] \\
\hline $\mathrm{U}$ & $<8.94$ & $<8.94$ & $<9.03$ & $<9.00$ & $<8.92$ & [10.6] & $<8.40$ \\
\hline $\mathrm{Zn}$ & [0.994] & [2.51] & [2.57] & $\begin{array}{l}2.37] \\
\end{array}$ & [3.41] & [1.56] & [2.77] \\
\hline $\mathrm{Zr}$ & {$[0.404]$} & [1.92] & {$[2.10]$} & [1.97] & [1.98] & [1.93] & {$[1.60]$} \\
\hline Fluoride & $<13.0$ & $<13.0$ & $<13.0$ & $<13.0$ & $<13.0$ & $<13.0$ & $<13.0$ \\
\hline Nitrite & $<20.0$ & $<20.0$ & $<20.0$ & $<20.0$ & $<20.0$ & $<20.0$ & $<20.0$ \\
\hline Sulfate & $<30.0$ & $<30.0$ & $<30.0$ & $<30.0$ & $<30.0$ & $<30.0$ & $<30.0$ \\
\hline Nitrate & 337,000 & 334,000 & 331,000 & 333,000 & 332,000 & 316,000 & 332,000 \\
\hline Phosphate & $<24.0$ & $<24.0$ & $<24.0$ & $<24.0$ & $<24.0$ & $<24.0$ & $<24.0$ \\
\hline${ }^{60} \mathrm{Co}$ & \multirow{5}{*}{\multicolumn{6}{|c|}{ Not Measured }} & $<3 \mathrm{E}-6$ \\
\hline${ }^{137} \mathrm{Cs}$ & & & & & & & $1.32 \mathrm{E}-1$ \\
\hline${ }^{154} \mathrm{Eu}$ & & & & & & & $<7 \mathrm{E}-6$ \\
\hline${ }^{155} \mathrm{Eu}$ & & & & & & & $<7 \mathrm{E}-5$ \\
\hline${ }^{241} \mathrm{Am}$ & & & & & & & $<1 \mathrm{E}-4$ \\
\hline \multicolumn{8}{|c|}{ Opportunistic Analytes } \\
\hline $\mathrm{Ag}$ & $<0.587$ & $<0.587$ & $<0.587$ & $<0.587$ & $<0.587$ & $<0.587$ & [0.729] \\
\hline As & $<12.0$ & $<12.0$ & $<12.1$ & $<12.1$ & $<12.0$ & $<12.1$ & $<11.3$ \\
\hline $\mathrm{Ba}$ & {$[0.252]$} & {$[0.310]$} & [0.439] & {$[0.375]$} & {$[0.527]$} & {$[0.343]$} & {$[0.321]$} \\
\hline $\mathrm{Be}$ & {$[0.029]$} & {$[0.037]$} & [0.041] & [0.044] & [0.050] & {$[0.026]$} & [0.041] \\
\hline $\mathrm{Ca}$ & $<1.71$ & $\begin{array}{l}<1.70 \\
\end{array}$ & $<1.72$ & {$[5.00]$} & $\begin{array}{l}<1.70 \\
\end{array}$ & $\begin{array}{l}<1.71 \\
\end{array}$ & $<1.60$ \\
\hline $\mathrm{Ce}$ & $<2.80$ & $<2.79$ & $<2.82$ & $<2.81$ & $<2.79$ & $<2.81$ & $<2.63$ \\
\hline Co & {$[0.745]$} & $<0.587$ & $<0.587$ & $<0.587$ & $<0.587$ & $<0.587$ & $<0.587$ \\
\hline $\mathrm{Cu}$ & $<0.391$ & {$[1.21]$} & {$[1.41]$} & {$[1.25]$} & {$[1.12]$} & {$[0.966]$} & {$[0.992]$} \\
\hline Dy & $<0.587$ & $<0.587$ & $<0.587$ & $<0.587$ & $<0.587$ & $<0.587$ & $<0.587$ \\
\hline $\mathrm{Eu}$ & $<0.587$ & $<0.587$ & $<0.587$ & $<0.587$ & $<0.587$ & $<0.587$ & $<0.587$ \\
\hline $\mathrm{K}$ & {$[80.7]$} & {$[62.1]$} & [72.1] & {$[84.4]$} & [65.1] & {$[81.0]$} & [78.8] \\
\hline $\mathrm{La}$ & $<0.587$ & $<0.587$ & $<0.587$ & $<0.587$ & $<0.587$ & $<0.587$ & $<0.587$ \\
\hline $\mathrm{Li}$ & $<0.587$ & [1.37] & [0.659] & [1.19] & [0.743] & [0.810] & [0.613] \\
\hline $\mathrm{Mg}$ & $<0.587$ & $<0.587$ & $<0.587$ & $<0.587$ & $<0.587$ & $<0.587$ & $<0.587$ \\
\hline Mo & $<1.45$ & [1.68] & [2.85] & $<1.46$ & $<1.45$ & {$[1.62]$} & $<1.37$ \\
\hline $\mathrm{Nd}$ & $<1.51$ & $<1.51$ & $<1.52$ & $<1.52$ & $<1.51$ & $<1.51$ & $<1.42$ \\
\hline $\mathrm{Ni}$ & $<0.587$ & $<0.587$ & $<0.587$ & {$[0.781]$} & $<0.587$ & $<0.587$ & {$[0.671]$} \\
\hline $\mathrm{Pb}$ & [9.32] & [14.3] & [9.41] & [14.1] & [19.2] & [12.8] & [9.04] \\
\hline $\mathrm{Pd}$ & $<1.76$ & $<1.76$ & $<1.78$ & $<1.77$ & $<1.76$ & [1.87] & $<1.65$ \\
\hline $\mathrm{Rh}$ & [6.52] & {$[4.34]$} & $<3.39$ & {$[5.00]$} & {$[4.34]$} & [3.43] & [4.96] \\
\hline $\mathrm{Ru}$ & $<2.38$ & $<2.37$ & $<2.40$ & $<2.39$ & $<2.37$ & $<2.38$ & $<2.23$ \\
\hline $\mathrm{Sb}$ & $<5.59$ & $<5.59$ & $<5.65$ & $<5.62$ & $<5.58$ & $<5.61$ & $<5.25$ \\
\hline
\end{tabular}


Table I.3 (Contd)

\begin{tabular}{|c|c|c|c|c|c|c|c|}
\hline \multirow[b]{2}{*}{ Analyte } & \multicolumn{7}{|c|}{$\begin{array}{l}\text { Analyte Concentration and Density at Given Time After Cooling to Ambient }\left(\sim 21^{\circ} \mathrm{C}\right) \\
\text { Temperature; } g / m L \text { for Density; } \mu \mathrm{g} / \mathrm{mL} \text { for Metals and Anions; } \mu \mathrm{Ci} / \mathrm{mL} \text { for Radionuclides }\end{array}$} \\
\hline & $0 \mathrm{hr}$ & $1 \mathrm{hr}$ & $2 \mathrm{hr}$ & $4 \mathrm{hr}$ & 8 hr & $24 \mathrm{hr}$ & $48 \mathrm{hr}$ \\
\hline Se & $<19.6$ & {$[20.8]$} & [25.4] & $<19.7$ & $<19.5$ & $<19.6$ & $<18.4$ \\
\hline Sn & [12.1] & {$[7.76]$} & [9.10] & {$[18.4]$} & {$[8.36]$} & {$[13.1]$} & [13.1] \\
\hline Ta & $<4.75$ & $<4.75$ & $<4.80$ & $<4.78$ & $<4.74$ & $<4.77$ & $<4.46$ \\
\hline $\mathrm{Te}$ & $<7.27$ & $<7.26$ & $<7.34$ & $<7.31$ & $<7.25$ & $<7.29$ & $<6.83$ \\
\hline Th & $<2.74$ & $<2.74$ & $<2.77$ & $<2.76$ & $<2.73$ & $<2.75$ & $<2.57$ \\
\hline $\mathrm{Ti}$ & $<0.587$ & $<0.587$ & $<0.587$ & $<0.587$ & $<0.587$ & $<0.587$ & $<0.587$ \\
\hline $\mathrm{Tl}$ & [14.3] & $<10.61$ & $<10.73$ & $<10.68$ & [16.1] & $<10.66$ & $<9.98$ \\
\hline $\mathrm{V}$ & $<0.207$ & $<0.207$ & {$[0.270]$} & [0.531] & {$[0.434]$} & [0.499] & [0.289] \\
\hline $\mathrm{W}$ & $<5.31$ & $<5.31$ & $<5.36$ & $<5.34$ & $<5.30$ & $<5.33$ & $<4.99$ \\
\hline $\mathrm{Y}$ & $<0.587$ & $<0.587$ & $<0.587$ & $<0.587$ & $<0.587$ & $<0.587$ & $<0.587$ \\
\hline \multicolumn{8}{|c|}{$5 \mathrm{M} \mathrm{NaOH}$} \\
\hline Density & 1.19 & 1.20 & 1.20 & 1.25 & 1.20 & 1.20 & 1.20 \\
\hline $\mathrm{Al}$ & 237 & 3,426 & 3,612 & 3,748 & 3,606 & 3,726 & 3,538 \\
\hline $\mathrm{B}$ & [1.29] & {$[0.966]$} & [1.26] & {$[0.884]$} & $<0.752$ & [1.19] & $<0.720$ \\
\hline $\mathrm{Bi}$ & $<4.61$ & $<4.67$ & [4.59] & {$[4.88]$} & [8.78] & $<4.70$ & $<4.50$ \\
\hline $\mathrm{Cd}$ & $<0.522$ & $<0.529$ & $<0.520$ & $<0.518$ & $<0.533$ & $<0.532$ & $<0.510$ \\
\hline $\mathrm{Cr}$ & {$[0.307]$} & [1.59] & [1.78] & {$[1.86]$} & [1.98] & {$[2.00]$} & [2.40] \\
\hline $\mathrm{Fe}$ & [2.77] & 13.0 & 13.7 & 14.3 & 14.4 & 14.2 & 12.4 \\
\hline $\mathrm{Mn}$ & {$[0.194]$} & {$[0.190]$} & {$[0.119]$} & [0.107] & {$[0.060]$} & [0.044] & $<0.034$ \\
\hline $\mathrm{Na}$ & 114,319 & 113,998 & 114,796 & 119,767 & 113,815 & 116,777 & 111,850 \\
\hline $\mathrm{P}$ & {$[10.8]$} & {$[21.2]$} & [15.9] & {$[19.2]$} & [20.1] & [10.3] & {$[17.4]$} \\
\hline $\mathrm{S}$ & $<11.1$ & $<11.2$ & $<11.0$ & $<11.0$ & [31.4] & [13.5] & $<10.8$ \\
\hline $\mathrm{Si}$ & 19.8 & 68.8 & 75.0 & 82.9 & 82.8 & 84.8 & 84.0 \\
\hline $\mathrm{Sr}$ & {$[0.043]$} & {$[0.065]$} & {$[0.061]$} & {$[0.058]$} & {$[0.053]$} & {$[0.038]$} & [0.039] \\
\hline $\mathrm{U}$ & {$[4.92]$} & {$[11.5]$} & [15.6] & {$[11.6]$} & [9.41] & [12.5] & {$[12.9]$} \\
\hline $\mathrm{Zn}$ & [1.81] & [2.15] & [2.88] & [1.95] & [2.95] & [2.35] & [2.37] \\
\hline $\mathrm{Zr}$ & {$[0.707]$} & {$[1.40]$} & [1.07] & [0.579] & [1.13] & [1.10] & [1.62] \\
\hline Fluoride & [1.20] & {$[0.980]$} & {$[0.980]$} & {$[1.00]$} & {$[0.980]$} & [1.20] & $<0.940$ \\
\hline Nitrite & 53.3 & 56.8 & 57.0 & 57.5 & 52.8 & 58.3 & 51.8 \\
\hline Sulfate & $<2.20$ & $<2.20$ & $<2.20$ & $<2.20$ & $<2.20$ & $<2.20$ & $<2.20$ \\
\hline Nitrate & [24.0] & 41.4 & 44.4 & 50.7 & 50.7 & 98.9 & 50.0 \\
\hline Phosphate & [4.50] & {$[5.50]$} & [5.70] & {$[6.10]$} & [7.20] & [6.60] & [6.60] \\
\hline${ }^{60} \mathrm{Co}$ & \multirow{5}{*}{\multicolumn{6}{|c|}{ Not Measured }} & $<3 \mathrm{E}-6$ \\
\hline${ }^{137} \mathrm{Cs}$ & & & & & & & $5.98 \mathrm{E}-1$ \\
\hline${ }^{154} \mathrm{Eu}$ & & & & & & & $<2 \mathrm{E}-5$ \\
\hline${ }^{155} \mathrm{Eu}$ & & & & & & & $<1 \mathrm{E}-4$ \\
\hline${ }^{241} \mathrm{Am}$ & & & & & & & $<3 \mathrm{E}-4$ \\
\hline \multicolumn{8}{|c|}{ Opportunistic Analytes } \\
\hline $\mathrm{Ag}$ & $<0.323$ & $<0.327$ & $<0.321$ & $<0.320$ & $<0.329$ & {$[0.344]$} & {$[0.510]$} \\
\hline As & $<6.61$ & $<6.70$ & $<6.58$ & $<6.55$ & $<6.74$ & {$[10.0]$} & $<6.45$ \\
\hline $\mathrm{Ba}$ & {$[0.338]$} & {$[0.308]$} & {$[0.337]$} & {$[0.293]$} & {$[0.314]$} & {$[0.276]$} & {$[0.285]$} \\
\hline $\mathrm{Be}$ & {$[0.034]$} & {$[0.047]$} & {$[0.046]$} & {$[0.055]$} & {$[0.050]$} & {$[0.047]$} & [0.045] \\
\hline $\mathrm{Ca}$ & {$[9.22]$} & {$[3.08]$} & {$[2.79]$} & {$[2.65]$} & [1.29] & $<0.955$ & {$[2.19]$} \\
\hline Ce & $<1.54$ & $<1.56$ & $<1.53$ & $<1.52$ & $<1.57$ & $<1.57$ & $<1.50$ \\
\hline
\end{tabular}


Table I.3 (Contd)

\begin{tabular}{|c|c|c|c|c|c|c|c|}
\hline \multirow[b]{2}{*}{ Analyte } & \multicolumn{7}{|c|}{$\begin{array}{l}\text { Analyte Concentration and Density at Given Time After Cooling to Ambient }\left(\sim 21^{\circ} \mathrm{C}\right) \\
\text { Temperature; } g / \mathrm{mL} \text { for Density; } \mu \mathrm{g} / \mathrm{mL} \text { for Metals and Anions; } \mu \mathrm{Ci} / \mathrm{mL} \text { for Radionuclides }\end{array}$} \\
\hline & o hr & $1 \mathrm{hr}$ & $2 \mathrm{hr}$ & $4 \mathrm{hr}$ & $8 \mathrm{hr}$ & $24 \mathrm{hr}$ & $48 \mathrm{hr}$ \\
\hline Co & $<0.369$ & $<0.374$ & $<0.367$ & $<0.366$ & $<0.376$ & $<0.376$ & {$[0.360]$} \\
\hline $\mathrm{Cu}$ & {$[0.400]$} & [1.15] & [1.50] & [1.49] & [1.00] & [1.31] & [1.05] \\
\hline Dy & $<0.446$ & $<0.452$ & $<0.444$ & $<0.442$ & $<0.455$ & $<0.454$ & $<0.435$ \\
\hline $\mathrm{Eu}$ & $<0.169$ & $<0.171$ & $<0.168$ & $<0.168$ & $<0.172$ & $<0.172$ & $<0.165$ \\
\hline $\mathrm{K}$ & {$[27.0]$} & [37.4] & [42.9] & [39.6] & [47.0] & {$[40.7]$} & {$[51.0]$} \\
\hline $\mathrm{La}$ & $<0.430$ & $<0.436$ & $<0.429$ & $<0.427$ & $<0.439$ & $<0.438$ & $<0.420$ \\
\hline $\mathrm{Li}$ & {$[0.108]$} & {$[0.810]$} & {$[0.888]$} & {$[0.884]$} & {$[0.815]$} & {$[1.00]$} & [0.660] \\
\hline $\mathrm{Mg}$ & $<0.353$ & $<0.358$ & $<0.352$ & $<0.366$ & $<0.361$ & $<0.360$ & $<0.345$ \\
\hline Mo & [1.41] & $<0.810$ & $<0.796$ & $<0.792$ & $<0.815$ & $<0.814$ & $<0.780$ \\
\hline $\mathrm{Nd}$ & $<0.830$ & $<0.841$ & $<0.827$ & $<0.823$ & $<0.847$ & $<0.845$ & $<0.810$ \\
\hline $\mathrm{Ni}$ & {$[0.584]$} & $<0.374$ & {$[0.857]$} & $<0.366$ & $<0.376$ & $<0.376$ & $<0.360$ \\
\hline $\mathrm{Pb}$ & [6.45] & [13.4] & [13.5] & [14.9] & [13.8] & {$[17.5]$} & {$[10.8]$} \\
\hline $\mathrm{Pd}$ & $<0.968$ & $<0.981$ & $<0.964$ & $<0.960$ & $<0.988$ & $<0.986$ & $<0.945$ \\
\hline $\mathrm{Rh}$ & $<1.84$ & $<1.87$ & $<1.84$ & [2.10] & $<1.88$ & {$[2.35]$} & {$[2.82]$} \\
\hline $\mathrm{Ru}$ & $<1.31$ & [1.34] & $<1.30$ & $<1.30$ & $<1.33$ & $<1.33$ & $<1.27$ \\
\hline $\mathrm{Sb}$ & $<3.07$ & $<3.11$ & $<3.06$ & $<3.05$ & $<3.14$ & $<3.13$ & $<3.00$ \\
\hline Se & $<10.8$ & $<10.9$ & $<10.7$ & $<10.7$ & [12.2] & $<11.0$ & $<10.5$ \\
\hline Sn & [10.1] & [10.3] & {$[5.20]$} & {$[7.01]$} & [6.58] & [5.64] & [5.70] \\
\hline $\mathrm{Ta}$ & $<2.61$ & $<2.65$ & $<2.60$ & $<2.59$ & $<2.67$ & $<2.66$ & $<2.55$ \\
\hline $\mathrm{Te}$ & $<4.00$ & $<4.05$ & $<3.98$ & $<3.96$ & $<4.08$ & $<4.07$ & $<3.90$ \\
\hline Th & $<1.51$ & $<1.53$ & $<1.50$ & $<1.49$ & $<1.54$ & $<1.53$ & $<1.47$ \\
\hline $\mathrm{Ti}$ & $<0.066$ & $<0.067$ & $<0.066$ & $<0.066$ & $<0.067$ & $<0.067$ & $<0.064$ \\
\hline $\mathrm{Tl}$ & $<5.84$ & $<5.92$ & [8.88] & $<5.79$ & $<5.96$ & [9.39] & [10.8] \\
\hline $\mathrm{V}$ & [0.283] & [0.218] & [0.245] & {$[0.274]$} & [0.169] & {$[0.260]$} & [0.261] \\
\hline $\mathrm{W}$ & $<2.92$ & $<2.96$ & $<2.91$ & $<2.90$ & $<2.98$ & $<2.97$ & $<2.85$ \\
\hline $\mathrm{Y}$ & $<0.068$ & $<0.069$ & $<0.067$ & $<0.067$ & $<0.069$ & $<0.069$ & $<0.066$ \\
\hline
\end{tabular}


Table I.4. Analyte Concentrations as a Function of Time for Leaching at $80^{\circ} \mathrm{C}$, in $\mathrm{M}$

\begin{tabular}{|c|c|c|c|c|c|c|c|}
\hline \multirow[b]{2}{*}{ Analyte } & \multicolumn{7}{|c|}{$\begin{array}{l}\text { Analyte Concentration and Density at Given Time After Cooling to Ambient }\left(\sim 21^{\circ} \mathrm{C}\right) \\
\text { Temperature; } \mathrm{g} / \mathrm{mL} \text { for Density; } \mathrm{M} \text { for Metals and Anions }\end{array}$} \\
\hline & $0 \mathrm{hr}$ & $1 \mathrm{hr}$ & $2 \mathrm{hr}$ & $4 \mathrm{hr}$ & $8 \mathrm{hr}$ & $24 \mathrm{hr}$ & $48 \mathrm{hr}$ \\
\hline \multicolumn{8}{|l|}{$1 \mathrm{M} \mathrm{NaOH}$} \\
\hline Density & 1.05 & 1.06 & 1.05 & 1.06 & 1.06 & 1.06 & 1.05 \\
\hline $\mathrm{Al}$ & 4.95E-03 & 5.03E-02 & 8.63E-02 & $1.32 \mathrm{E}-01$ & $1.29 \mathrm{E}-01$ & $1.31 \mathrm{E}-01$ & $1.29 \mathrm{E}-01$ \\
\hline B & [5.55E-05] & [4.84E-05] & [5.00E-05] & [5.77E-05] & [5.77E-05] & [4.80E-05] & [4.37E-05] \\
\hline $\mathrm{Bi}$ & $<4.30 \mathrm{E}-06$ & [5.30E-06] & $<4.31 \mathrm{E}-06$ & [6.12E-06] & [4.63E-06] & $<4.38 \mathrm{E}-06$ & $<4.24 \mathrm{E}-06$ \\
\hline $\mathrm{Cd}$ & $<<9.07 \mathrm{E}-07$ & $<<9.30 \mathrm{E}-07$ & $<<9.09 \mathrm{E}-07$ & $<9.44 \mathrm{E}-07$ & $<9.43 \mathrm{E}-07$ & $<<9.22 \mathrm{E}-07$ & $<<8.93 \mathrm{E}-07$ \\
\hline $\mathrm{Cr}$ & [2.74E-06] & $1.59 \mathrm{E}-05$ & $1.87 \mathrm{E}-05$ & 2.59E-05 & 2.66E-05 & 3.05E-05 & $3.29 \mathrm{E}-05$ \\
\hline $\mathrm{Fe}$ & [1.23E-05] & 4.35E-05 & 5.92E-05 & 4.91E-05 & $4.80 \mathrm{E}-05$ & 4.13E-05 & [2.17E-05] \\
\hline $\mathrm{Mn}$ & [5.32E-07] & [5.37E-07] & [5.47E-07] & [3.86E-07] & [4.88E-07] & [1.94E-07] & [1.72E-07] \\
\hline $\mathrm{Na}$ & 1.06 & 1.07 & 1.08 & 1.10 & 1.11 & 1.07 & 1.06 \\
\hline $\mathrm{P}$ & [2.27E-04] & [2.28E-04] & [2.62E-04] & [2.42E-04] & [2.62E-04] & [2.76E-04] & [2.76E-04] \\
\hline$S$ & [2.07E-04] & [1.34E-04] & [6.84E-05] & $<7.01 \mathrm{E}-05$ & $<7.00 \mathrm{E}-05$ & $<6.85 \mathrm{E}-05$ & $<6.63 \mathrm{E}-05$ \\
\hline $\mathrm{Si}$ & 2.09E-04 & $1.30 \mathrm{E}-03$ & $1.36 \mathrm{E}-03$ & $1.30 \mathrm{E}-03$ & $1.31 \mathrm{E}-03$ & 1.23E-03 & 1.17E-03 \\
\hline $\mathrm{Sr}$ & [9.92E-08] & [7.72E-08] & [1.37E-07] & [8.55E-08] & [7.47E-08] & [4.52E-08] & [7.41E-08] \\
\hline $\mathrm{U}$ & [1.30E-05] & [2.20E-05] & [3.41E-05] & [3.67E-05] & [3.67E-05] & [3.72E-05] & [3.85E-05] \\
\hline $\mathrm{Zn}$ & [1.05E-05] & [1.83E-05] & [2.16E-05] & $2.75 \mathrm{E}-05$ & $2.86 \mathrm{E}-05$ & 2.98E-05 & 3.24E-05 \\
\hline $\mathrm{Zr}$ & [6.41E-07] & [7.42E-07] & [6.26E-07] & $<3.76 \mathrm{E}-07$ & [4.10E-07] & [5.68E-07] & [1.17E-06] \\
\hline Fluoride & [5.79E-05] & [4.00E-05] & [3.47E-05] & [4.63E-05] & [4.21E-05] & [5.26E-05] & [3.26E-05] \\
\hline Nitrite & [2.17E-05] & [3.48E-05] & [3.91E-05] & [3.91E-05] & [3.91E-05] & [4.35E-05] & [4.13E-05] \\
\hline Sulfate & [3.02E-05] & [3.12E-05] & [3.02E-05] & [2.60E-05] & [3.23E-05] & [2.71E-05] & $<1.15 \mathrm{E}-05$ \\
\hline Nitrate & [1.77E-04] & 3.61E-04 & $3.76 \mathrm{E}-04$ & $3.76 \mathrm{E}-04$ & 3.76E-04 & 3.74E-04 & 3.55E-04 \\
\hline Phosphate & $1.58 \mathrm{E}-04$ & 1.55E-04 & $1.31 \mathrm{E}-04$ & $1.08 \mathrm{E}-04$ & $1.16 \mathrm{E}-04$ & 1.02E-04 & 9.79E-05 \\
\hline \multicolumn{8}{|c|}{3 M NaOH, Trial a } \\
\hline Density & 1.13 & 1.13 & 1.13 & 1.14 & 1.14 & 1.13 & 1.13 \\
\hline $\mathrm{Al}$ & 6.47E-03 & 1.00E-01 & $1.27 \mathrm{E}-01$ & 1.34E-01 & 1.35E-01 & $1.28 \mathrm{E}-01$ & 1.38E-01 \\
\hline B & [1.62E-04] & [1.59E-04] & [1.87E-04] & $<6.94 \mathrm{E}-05$ & $<6.80 \mathrm{E}-05$ & [8.08E-05] & [1.19E-04] \\
\hline $\mathrm{Bi}$ & $<2.26 \mathrm{E}-05$ & $<2.24 \mathrm{E}-05$ & $<2.20 \mathrm{E}-05$ & $<2.24 \mathrm{E}-05$ & [2.49E-05] & [3.32E-05] & [2.86E-05] \\
\hline $\mathrm{Cd}$ & $<4.76 \mathrm{E}-06$ & $<4.71 \mathrm{E}-06$ & $<4.64 \mathrm{E}-06$ & $<4.73 \mathrm{E}-06$ & $<4.63 \mathrm{E}-06$ & $<4.56 \mathrm{E}-06$ & $<4.51 \mathrm{E}-06$ \\
\hline $\mathrm{Cr}$ & $<5.14 \mathrm{E}-06$ & [1.98E-05] & [2.53E-05] & [2.89E-05] & 2.65E-05 & [3.59E-05] & [4.25E-05] \\
\hline $\mathrm{Fe}$ & [3.83E-05] & $1.44 \mathrm{E}-04$ & $1.57 \mathrm{E}-04$ & 1.63E-04 & $1.61 \mathrm{E}-04$ & 1.49E-04 & 1.37E-04 \\
\hline $\mathrm{Mn}$ & [2.81E-06] & [3.35E-06] & [2.01E-06] & [1.93E-06] & [1.56E-06] & $<6.31 \mathrm{E}-07$ & $<6.25 \mathrm{E}-07$ \\
\hline $\mathrm{Na}$ & 3.18 & 3.15 & 3.16 & 3.13 & 3.20 & 2.97 & 3.21 \\
\hline $\mathrm{P}$ & $<2.54 \mathrm{E}-04$ & $<2.52 \mathrm{E}-04$ & $<2.47 \mathrm{E}-04$ & $<2.52 \mathrm{E}-04$ & [2.57E-04] & [4.38E-04] & $<2.41 \mathrm{E}-04$ \\
\hline $\mathrm{S}$ & [7.66E-04] & [7.19E-04] & [8.22E-04] & [1.27E-03] & $<3.44 \mathrm{E}-04$ & [4.51E-04] & $<3.35 \mathrm{E}-04$ \\
\hline $\mathrm{Si}$ & $5.04 \mathrm{E}-04$ & $1.98 \mathrm{E}-03$ & $2.13 \mathrm{E}-03$ & $2.23 \mathrm{E}-03$ & $2.32 \mathrm{E}-03$ & $2.21 \mathrm{E}-03$ & $2.48 \mathrm{E}-03$ \\
\hline $\mathrm{Sr}$ & [3.07E-07] & [3.56E-07] & [4.20E-07] & [3.39E-07] & [3.11E-07] & [3.61E-07] & [7.49E-07] \\
\hline $\mathrm{U}$ & [3.37E-05] & [3.41E-05] & [6.05E-05] & [3.81E-05] & [5.02E-05] & [6.14E-05] & [8.65E-05] \\
\hline $\mathrm{Zn}$ & $<6.74 \mathrm{E}-06$ & [1.86E-05] & [1.55E-05] & [1.39E-05] & [1.55E-05] & [1.89E-05] & [1.87E-05] \\
\hline $\mathrm{Zr}$ & [4.31E-06] & [1.03E-05] & [9.41E-06] & [9.59E-06] & [7.72E-06] & [6.11E-06] & [8.18E-06] \\
\hline Fluoride & [8.42E-05] & [7.90E-05] & [7.37E-05] & [6.32E-05] & [7.90E-05] & [7.90E-05] & [6.32E-05] \\
\hline Nitrite & $<3.26 \mathrm{E}-05$ & [3.48E-05] & [3.48E-05] & [3.70E-05] & [3.91E-05] & [4.35E-05] & [4.57E-05] \\
\hline Sulfate & $<2.29 \mathrm{E}-05$ & $<2.29 \mathrm{E}-05$ & [4.58E-05] & [3.96E-05] & $<2.29 \mathrm{E}-05$ & [6.35E-05] & [5.41E-05] \\
\hline Nitrate & [2.10E-04] & [4.68E-04] & 5.03E-04 & 5.66E-04 & $5.40 \mathrm{E}-04$ & 5.19E-04 & 5.69E-04 \\
\hline Phosphate & [1.68E-04] & [1.79E-04] & [1.79E-04] & [1.90E-04] & [1.79E-04] & $2.26 \mathrm{E}-04$ & $2.10 \mathrm{E}-04$ \\
\hline
\end{tabular}


Table I.4 (Contd)

\begin{tabular}{|c|c|c|c|c|c|c|c|}
\hline \multirow[b]{2}{*}{ Analyte } & \multicolumn{7}{|c|}{$\begin{array}{l}\text { Analyte Concentration and Density at Given Time After Cooling to Ambient }\left(\sim 21^{\circ} \mathrm{C}\right) \\
\text { Temperature; } \mathrm{g} / \mathrm{mL} \text { for Density; } \mathrm{M} \text { for Metals and Anions }\end{array}$} \\
\hline & $0 \mathrm{hr}$ & $1 \mathrm{hr}$ & $2 \mathrm{hr}$ & $4 \mathrm{hr}$ & $8 \mathrm{hr}$ & $24 \mathrm{hr}$ & $48 \mathrm{hr}$ \\
\hline \multicolumn{8}{|c|}{3 M NaOH, Trial b } \\
\hline Density & 1.13 & 1.14 & 1.13 & 1.14 & 1.15 & 1.12 & 1.13 \\
\hline $\mathrm{Al}$ & 8.93E-03 & 9.17E-02 & $1.12 \mathrm{E}-01$ & $1.15 \mathrm{E}-01$ & 1.19E-01 & 9.98E-02 & 1.17E-01 \\
\hline $\mathrm{B}$ & $2.42 \mathrm{E}-04$ & $1.86 \mathrm{E}-04$ & 1.89E-04 & $<1.34 \mathrm{E}-04$ & $1.59 \mathrm{E}-04$ & $1.17 \mathrm{E}-04$ & 1.19E-04 \\
\hline $\mathrm{Bi}$ & 2.91E-05 & $<2.22 \mathrm{E}-05$ & 3.55E-05 & $<2.21 \mathrm{E}-05$ & 4.48E-05 & 3.68E-05 & $<2.14 \mathrm{E}-05$ \\
\hline $\mathrm{Cd}$ & $<4.60 \mathrm{E}-06$ & $<4.67 \mathrm{E}-06$ & $<4.67 \mathrm{E}-06$ & $<4.66 \mathrm{E}-06$ & $<4.72 \mathrm{E}-06$ & $<4.66 \mathrm{E}-06$ & $<4.51 \mathrm{E}-06$ \\
\hline $\mathrm{Cr}$ & $5.50 \mathrm{E}-06$ & 2.32E-05 & 2.79E-05 & 3.26E-05 & $2.52 \mathrm{E}-05$ & 3.38E-05 & 3.67E-05 \\
\hline $\mathrm{Fe}$ & 4.58E-05 & 1.33E-04 & $1.54 \mathrm{E}-04$ & $1.62 \mathrm{E}-04$ & $1.64 \mathrm{E}-04$ & $1.40 \mathrm{E}-04$ & $1.29 \mathrm{E}-04$ \\
\hline Mn & $<6.37 \mathrm{E}-07$ & $<6.47 \mathrm{E}-07$ & $<6.47 \mathrm{E}-07$ & 6.44E-07 & $<6.54 \mathrm{E}-07$ & $<6.45 \mathrm{E}-07$ & $<6.24 \mathrm{E}-07$ \\
\hline $\mathrm{Na}$ & 3.06 & 3.08 & 3.16 & 3.19 & 3.31 & 2.73 & 3.21 \\
\hline $\mathrm{P}$ & $2.55 \mathrm{E}-04$ & 5.09E-04 & $<2.49 \mathrm{E}-04$ & $<3.58 \mathrm{E}-04$ & 3.73E-04 & 4.77E-04 & $<2.41 \mathrm{E}-04$ \\
\hline $\mathrm{S}$ & $9.30 \mathrm{E}-04$ & $5.50 \mathrm{E}-04$ & $<3.47 \mathrm{E}-04$ & $3.46 \mathrm{E}-04$ & $3.80 \mathrm{E}-04$ & $<3.46 \mathrm{E}-04$ & $<3.35 \mathrm{E}-04$ \\
\hline $\mathrm{Si}$ & $4.28 \mathrm{E}-04$ & $1.94 \mathrm{E}-03$ & 2.29E-03 & $2.40 \mathrm{E}-03$ & $2.50 \mathrm{E}-03$ & 2.15E-03 & $2.55 \mathrm{E}-03$ \\
\hline $\mathrm{Sr}$ & 7.64E-07 & 6.35E-07 & 5.29E-07 & 4.92E-07 & 5.35E-07 & 5.62E-07 & $5.44 \mathrm{E}-07$ \\
\hline $\mathrm{U}$ & $6.78 \mathrm{E}-05$ & $4.68 \mathrm{E}-05$ & $4.28 \mathrm{E}-05$ & 5.95E-05 & 7.08E-05 & 5.05E-05 & 5.13E-05 \\
\hline $\mathrm{Zn}$ & $<6.52 \mathrm{E}-06$ & $<6.62 \mathrm{E}-06$ & 1.13E-05 & 8.47E-06 & $1.77 \mathrm{E}-05$ & $1.04 \mathrm{E}-05$ & 1.82E-05 \\
\hline $\mathrm{Zr}$ & $5.00 \mathrm{E}-06$ & 9.15E-06 & 8.80E-06 & $1.08 \mathrm{E}-05$ & $8.21 \mathrm{E}-06$ & 7.09E-06 & 7.51E-06 \\
\hline Fluoride & 6.84E-05 & 7.37E-05 & 7.90E-05 & 8.42E-05 & $6.84 \mathrm{E}-05$ & 8.42E-05 & 7.90E-05 \\
\hline Nitrite & $<3.26 \mathrm{E}-05$ & 3.48E-05 & 4.13E-05 & 4.13E-05 & $<3.26 \mathrm{E}-05$ & 3.91E-05 & 4.35E-05 \\
\hline Sulfate & $<2.29 \mathrm{E}-05$ & 6.14E-05 & 5.31E-05 & 5.93E-05 & 4.89E-05 & 5.31E-05 & $<2.29 \mathrm{E}-05$ \\
\hline Nitrate & $2.10 \mathrm{E}-04$ & 4.84E-04 & 5.31E-04 & $5.68 \mathrm{E}-04$ & $4.18 \mathrm{E}-04$ & $4.85 \mathrm{E}-04$ & 5.84E-04 \\
\hline Phosphate & $1.58 \mathrm{E}-04$ & $1.68 \mathrm{E}-04$ & $1.58 \mathrm{E}-04$ & $1.47 \mathrm{E}-04$ & $1.58 \mathrm{E}-04$ & $1.90 \mathrm{E}-04$ & 1.79E-04 \\
\hline \multicolumn{8}{|c|}{$3 \mathrm{M}$ NaOH, Trial c } \\
\hline Density & 1.13 & 1.13 & 1.14 & 1.14 & 1.14 & 1.13 & 1.13 \\
\hline $\mathrm{Al}$ & 7.56E-03 & 9.01E-02 & 1.13E-01 & $1.11 \mathrm{E}-01$ & 1.13E-01 & $1.11 \mathrm{E}-01$ & $1.14 \mathrm{E}-01$ \\
\hline $\mathrm{B}$ & $<6.84 \mathrm{E}-05$ & 1.03E-04 & $1.47 \mathrm{E}-04$ & $9.80 \mathrm{E}-05$ & $1.18 \mathrm{E}-04$ & $1.17 \mathrm{E}-04$ & $1.07 \mathrm{E}-04$ \\
\hline $\mathrm{Bi}$ & $<2.21 \mathrm{E}-05$ & $2.36 \mathrm{E}-05$ & $4.02 \mathrm{E}-05$ & $<2.24 \mathrm{E}-05$ & $3.27 \mathrm{E}-05$ & $3.88 \mathrm{E}-05$ & $<2.12 \mathrm{E}-05$ \\
\hline $\mathrm{Cd}$ & $<4.66 \mathrm{E}-06$ & $<4.66 \mathrm{E}-06$ & $<4.70 \mathrm{E}-06$ & $<4.71 \mathrm{E}-06$ & $<4.69 \mathrm{E}-06$ & $<4.54 \mathrm{E}-06$ & $<4.47 \mathrm{E}-06$ \\
\hline $\mathrm{Cr}$ & $<5.04 \mathrm{E}-06$ & 2.55E-05 & 2.93E-05 & 3.36E-05 & 3.64E-05 & 4.44E-05 & 4.03E-05 \\
\hline $\mathrm{Fe}$ & 3.04E-05 & $1.27 \mathrm{E}-04$ & $1.45 \mathrm{E}-04$ & $1.55 \mathrm{E}-04$ & $1.49 \mathrm{E}-04$ & $1.43 \mathrm{E}-04$ & $1.22 \mathrm{E}-04$ \\
\hline Mn & $<6.45 \mathrm{E}-07$ & $<6.45 \mathrm{E}-07$ & $<6.51 \mathrm{E}-07$ & $<6.52 \mathrm{E}-07$ & $<6.50 \mathrm{E}-07$ & $<6.28 \mathrm{E}-07$ & $<6.18 \mathrm{E}-07$ \\
\hline $\mathrm{Na}$ & 2.99 & 3.05 & 3.12 & 2.95 & 3.05 & 2.96 & 3.07 \\
\hline $\mathrm{P}$ & $5.67 \mathrm{E}-04$ & 3.08E-04 & 3.31E-04 & $6.94 \mathrm{E}-04$ & $4.41 \mathrm{E}-04$ & $6.40 \mathrm{E}-04$ & 6.01E-04 \\
\hline $\mathrm{S}$ & $<3.46 \mathrm{E}-04$ & $<3.46 \mathrm{E}-04$ & $<3.49 \mathrm{E}-04$ & $<3.50 \mathrm{E}-04$ & $<3.48 \mathrm{E}-04$ & $1.31 \mathrm{E}-03$ & $<3.32 \mathrm{E}-04$ \\
\hline $\mathrm{Si}$ & $4.10 \mathrm{E}-04$ & $1.90 \mathrm{E}-03$ & 2.19E-03 & 2.30E-03 & $2.42 \mathrm{E}-03$ & $2.39 \mathrm{E}-03$ & 2.52E-03 \\
\hline $\mathrm{Sr}$ & 4.92E-07 & 4.92E-07 & 4.61E-07 & 6.04E-07 & 5.31E-07 & 3.77E-07 & 3.71E-07 \\
\hline $\mathrm{U}$ & 2.20E-05 & 4.14E-05 & 6.66E-05 & 6.02E-05 & $6.26 \mathrm{E}-05$ & 6.05E-05 & 5.46E-05 \\
\hline $\mathrm{Zn}$ & $<6.60 \mathrm{E}-06$ & $1.98 \mathrm{E}-05$ & $1.05 \mathrm{E}-05$ & $<6.67 \mathrm{E}-06$ & $1.19 \mathrm{E}-05$ & $1.42 \mathrm{E}-05$ & $1.40 \mathrm{E}-05$ \\
\hline $\mathrm{Zr}$ & $2.57 \mathrm{E}-06$ & 9.79E-06 & 7.84E-06 & 7.51E-06 & $8.50 \mathrm{E}-06$ & $6.91 \mathrm{E}-06$ & 7.12E-06 \\
\hline Fluoride & 6.84E-05 & 8.95E-05 & 7.90E-05 & 7.90E-05 & 7.90E-05 & 7.90E-05 & 7.37E-05 \\
\hline Nitrite & $<3.26 \mathrm{E}-05$ & 3.696E-05 & 3.913E-05 & $5.000 \mathrm{E}-05$ & 4.565E-05 & 5.217E-05 & 5.22E-05 \\
\hline Sulfate & $<2.29 \mathrm{E}-05$ & 4.372E-05 & 3.435E-05 & 5.830E-05 & 7.495E-05 & 5.413E-05 & 4.27E-05 \\
\hline Nitrate & $2.10 \mathrm{E}-04$ & 4.84E-04 & $5.24 \mathrm{E}-04$ & 5.61E-04 & 5.85E-04 & $5.61 \mathrm{E}-04$ & 5.69E-04 \\
\hline Phosphate & $1.58 \mathrm{E}-04$ & $1.68 \mathrm{E}-04$ & $1.58 \mathrm{E}-04$ & $1.68 \mathrm{E}-04$ & 2.33E-04 & $1.79 \mathrm{E}-04$ & 1.79E-04 \\
\hline
\end{tabular}


Table I.4 (Contd)

\begin{tabular}{|c|c|c|c|c|c|c|c|}
\hline \multirow[b]{2}{*}{ Analyte } & \multicolumn{7}{|c|}{$\begin{array}{l}\text { Analyte Concentration and Density at Given Time After Cooling to Ambient }\left(\sim 21^{\circ} \mathrm{C}\right) \\
\text { Temperature; } \mathrm{g} / \mathrm{mL} \text { for Density; } \mathrm{M} \text { for Metals and Anions }\end{array}$} \\
\hline & $0 \mathrm{hr}$ & $1 \mathrm{hr}$ & $2 \mathrm{hr}$ & $4 \mathrm{hr}$ & $8 \mathrm{hr}$ & $24 \mathrm{hr}$ & $48 \mathrm{hr}$ \\
\hline \multicolumn{8}{|c|}{$3 \mathrm{M} \mathrm{NaOH}$, with $1 \mathrm{M} \mathrm{NaNO}_{3}$} \\
\hline Density & 1.18 & 1.18 & 1.17 & 1.18 & 1.19 & 1.17 & 1.17 \\
\hline $\mathrm{Al}$ & 8.60E-03 & $9.21 \mathrm{E}-02$ & $1.03 \mathrm{E}-01$ & $1.05 \mathrm{E}-01$ & $1.06 \mathrm{E}-01$ & $1.04 \mathrm{E}-01$ & $1.03 \mathrm{E}-01$ \\
\hline B & $1.83 \mathrm{E}-04$ & $1.64 \mathrm{E}-04$ & $1.36 \mathrm{E}-04$ & 8.59E-05 & $1.95 \mathrm{E}-04$ & $1.62 \mathrm{E}-04$ & $1.59 \mathrm{E}-04$ \\
\hline $\mathrm{Bi}$ & $<2.22 \mathrm{E}-05$ & $<2.24 \mathrm{E}-05$ & $<2.24 \mathrm{E}-05$ & $<2.22 \mathrm{E}-05$ & $2.38 \mathrm{E}-05$ & $2.50 \mathrm{E}-05$ & 2.92E-05 \\
\hline $\mathrm{Cd}$ & $<4.68 \mathrm{E}-06$ & $<4.72 \mathrm{E}-06$ & $<4.72 \mathrm{E}-06$ & $<4.68 \mathrm{E}-06$ & $<4.70 \mathrm{E}-06$ & $<4.65 \mathrm{E}-06$ & $<4.40 \mathrm{E}-06$ \\
\hline $\mathrm{Cr}$ & $<5.06 \mathrm{E}-06$ & $2.58 \mathrm{E}-05$ & $2.94 \mathrm{E}-05$ & $2.62 \mathrm{E}-05$ & $3.71 \mathrm{E}-05$ & $4.08 \mathrm{E}-05$ & 4.03E-05 \\
\hline $\mathrm{Fe}$ & 3.66E-05 & $1.45 \mathrm{E}-04$ & $1.53 \mathrm{E}-04$ & $1.54 \mathrm{E}-04$ & $1.73 \mathrm{E}-04$ & $1.50 \mathrm{E}-04$ & $1.20 \mathrm{E}-04$ \\
\hline $\mathrm{Mn}$ & $1.18 \mathrm{E}-06$ & $1.36 \mathrm{E}-06$ & 6.82E-07 & 7.33E-07 & $<6.50 \mathrm{E}-07$ & $<6.44 \mathrm{E}-07$ & $<6.09 \mathrm{E}-07$ \\
\hline $\mathrm{Na}$ & 3.97 & 4.06 & 3.98 & 4.01 & 4.03 & 4.00 & 3.95 \\
\hline $\mathrm{P}$ & 4.30E-04 & 4.33E-04 & 2.92E-04 & $4.00 \mathrm{E}-04$ & 4.82E-04 & 2.98E-04 & $<2.35 \mathrm{E}-04$ \\
\hline$S$ & $<3.48 \mathrm{E}-04$ & $<3.50 \mathrm{E}-04$ & $<3.51 \mathrm{E}-04$ & 8.79E-04 & 9.69E-04 & $<3.45 \mathrm{E}-04$ & $<3.27 \mathrm{E}-04$ \\
\hline $\mathrm{Si}$ & $1.00 \mathrm{E}-04$ & 4.89E-04 & 5.01E-04 & $5.29 \mathrm{E}-04$ & $5.91 \mathrm{E}-04$ & 5.12E-04 & $4.70 \mathrm{E}-04$ \\
\hline $\mathrm{Sr}$ & $3.46 \mathrm{E}-07$ & 4.63E-07 & 4.63E-07 & 3.89E-07 & $9.58 \mathrm{E}-07$ & $4.56 \mathrm{E}-07$ & 3.98E-07 \\
\hline $\mathrm{U}$ & $<2.08 \mathrm{E}-05$ & $2.88 \mathrm{E}-05$ & 4.72E-05 & 4.03E-05 & $4.70 \mathrm{E}-05$ & $5.30 \mathrm{E}-05$ & 2.32E-05 \\
\hline $\mathrm{Zn}$ & $1.61 \mathrm{E}-05$ & 2.96E-05 & 3.82E-05 & 3.65E-05 & 3.66E-05 & 3.24E-05 & 3.60E-05 \\
\hline $\mathrm{Zr}$ & 5.43E-06 & $1.23 \mathrm{E}-05$ & $1.20 \mathrm{E}-05$ & $1.15 \mathrm{E}-05$ & $1.19 \mathrm{E}-05$ & $1.15 \mathrm{E}-05$ & $1.12 \mathrm{E}-05$ \\
\hline Fluoride & $<2.63 \mathrm{E}-04$ & $<2.63 \mathrm{E}-04$ & 2.79E-04 & $<2.63 \mathrm{E}-04$ & $<2.63 \mathrm{E}-04$ & $<2.63 \mathrm{E}-04$ & $<2.63 \mathrm{E}-04$ \\
\hline Nitrite & $<1.74 \mathrm{E}-04$ & $<1.74 \mathrm{E}-04$ & $<1.74 \mathrm{E}-04$ & $<1.74 \mathrm{E}-04$ & $<1.74 \mathrm{E}-04$ & $<1.74 \mathrm{E}-04$ & $<1.74 \mathrm{E}-04$ \\
\hline Sulfate & $<1.25 \mathrm{E}-04$ & $<1.25 \mathrm{E}-04$ & $<1.25 \mathrm{E}-04$ & $<1.25 \mathrm{E}-04$ & $<1.25 \mathrm{E}-04$ & $<1.25 \mathrm{E}-04$ & $<1.25 \mathrm{E}-04$ \\
\hline Nitrate & 1.02 & 1.06 & 1.06 & 1.04 & 1.06 & 1.05 & 1.05 \\
\hline Phosphate & $5.16 \mathrm{E}-04$ & $3.26 \mathrm{E}-04$ & $2.74 \mathrm{E}-04$ & $<1.01 \mathrm{E}-04$ & $<1.01 \mathrm{E}-04$ & $<1.01 \mathrm{E}-04$ & $<1.01 \mathrm{E}-04$ \\
\hline \multicolumn{8}{|c|}{$3 \mathrm{M} \mathrm{NaOH}$, with $5 \mathrm{M} \mathrm{NaNO}_{3}$} \\
\hline Density & 1.38 & 1.38 & 1.38 & 1.39 & 1.39 & 1.35 & 1.38 \\
\hline $\mathrm{Al}$ & 6.84E-03 & 1.15E-01 & $1.16 \mathrm{E}-01$ & $1.22 \mathrm{E}-01$ & $1.18 \mathrm{E}-01$ & $1.10 \mathrm{E}-01$ & $1.15 \mathrm{E}-01$ \\
\hline $\mathrm{B}$ & $1.64 \mathrm{E}-04$ & $1.32 \mathrm{E}-04$ & $1.68 \mathrm{E}-04$ & $<1.25 \mathrm{E}-04$ & $<1.24 \mathrm{E}-04$ & $<1.25 \mathrm{E}-04$ & $<1.17 \mathrm{E}-04$ \\
\hline $\mathrm{Bi}$ & $<4.01 \mathrm{E}-05$ & $<4.01 \mathrm{E}-05$ & $<4.05 \mathrm{E}-05$ & $<4.04 \mathrm{E}-05$ & 4.74E-05 & 4.33E-05 & $<3.77 \mathrm{E}-05$ \\
\hline $\mathrm{Cd}$ & $<8.45 \mathrm{E}-06$ & $<8.45 \mathrm{E}-06$ & $<8.54 \mathrm{E}-06$ & $<8.50 \mathrm{E}-06$ & $<8.43 \mathrm{E}-06$ & $<8.49 \mathrm{E}-06$ & $<7.94 \mathrm{E}-06$ \\
\hline $\mathrm{Cr}$ & $1.02 \mathrm{E}-05$ & $2.27 \mathrm{E}-05$ & $4.28 \mathrm{E}-05$ & $3.30 \mathrm{E}-05$ & $3.04 \mathrm{E}-05$ & $3.12 \mathrm{E}-05$ & 4.15E-05 \\
\hline $\mathrm{Fe}$ & 3.23E-05 & 1.83E-04 & 1.97E-04 & 2.07E-04 & $2.00 \mathrm{E}-04$ & $1.84 \mathrm{E}-04$ & 1.67E-04 \\
\hline $\mathrm{Mn}$ & 2.77E-06 & $2.54 \mathrm{E}-06$ & $1.48 \mathrm{E}-06$ & $<1.18 \mathrm{E}-06$ & $<1.17 \mathrm{E}-06$ & $<1.17 \mathrm{E}-06$ & $<1.10 \mathrm{E}-06$ \\
\hline $\mathrm{Na}$ & 8.17 & 8.07 & 8.06 & 8.30 & 8.25 & 7.59 & 8.04 \\
\hline $\mathrm{P}$ & $5.21 \mathrm{E}-04$ & $<4.51 \mathrm{E}-04$ & $<4.56 \mathrm{E}-04$ & 7.36E-04 & $4.70 \mathrm{E}-04$ & $1.01 \mathrm{E}-03$ & $8.29 \mathrm{E}-04$ \\
\hline $\mathrm{S}$ & 7.85E-04 & 2.61E-03 & $1.76 \mathrm{E}-03$ & $1.27 \mathrm{E}-03$ & $<6.26 \mathrm{E}-04$ & $<6.30 \mathrm{E}-04$ & $<5.90 \mathrm{E}-04$ \\
\hline $\mathrm{Si}$ & 1.07E-04 & $1.22 \mathrm{E}-04$ & $1.12 \mathrm{E}-04$ & $1.33 \mathrm{E}-04$ & 7.39E-05 & $<5.59 \mathrm{E}-05$ & $<5.23 \mathrm{E}-05$ \\
\hline $\mathrm{Sr}$ & 6.73E-07 & 6.02E-07 & 6.44E-07 & 7.49E-07 & $6.36 \mathrm{E}-07$ & $8.18 \mathrm{E}-07$ & 3.99E-07 \\
\hline $\mathrm{U}$ & $<3.76 \mathrm{E}-05$ & $<3.76 \mathrm{E}-05$ & $<3.80 \mathrm{E}-05$ & $<3.78 \mathrm{E}-05$ & $<3.75 \mathrm{E}-05$ & 4.45E-05 & $<3.53 \mathrm{E}-05$ \\
\hline $\mathrm{Zn}$ & $1.52 \mathrm{E}-05$ & 3.84E-05 & 3.93E-05 & 3.63E-05 & $5.21 \mathrm{E}-05$ & $2.38 \mathrm{E}-05$ & $4.24 \mathrm{E}-05$ \\
\hline $\mathrm{Zr}$ & 4.43E-06 & $2.11 \mathrm{E}-05$ & 2.30E-05 & 2.16E-05 & 2.17E-05 & 2.12E-05 & $1.76 \mathrm{E}-05$ \\
\hline $\begin{array}{l}\text { Fluoride } \\
\end{array}$ & $<6.84 \mathrm{E}-04$ & $<6.84 \mathrm{E}-04$ & $<6.84 \mathrm{E}-04$ & $<6.84 \mathrm{E}-04$ & $<6.84 \mathrm{E}-04$ & $<6.84 \mathrm{E}-04$ & $<6.84 \mathrm{E}-04$ \\
\hline Nitrite & $<4.35 \mathrm{E}-04$ & $<4.35 \mathrm{E}-04$ & $<4.35 \mathrm{E}-04$ & $<4.35 \mathrm{E}-04$ & $<4.35 \mathrm{E}-04$ & $<4.35 \mathrm{E}-04$ & $<4.35 \mathrm{E}-04$ \\
\hline Sulfate & $<3.12 \mathrm{E}-04$ & $<3.12 \mathrm{E}-04$ & $<3.12 \mathrm{E}-04$ & $<3.12 \mathrm{E}-04$ & $<3.12 \mathrm{E}-04$ & $<3.12 \mathrm{E}-04$ & $<3.12 \mathrm{E}-04$ \\
\hline Nitrate & 5.44 & 5.39 & 5.34 & 5.37 & 5.35 & 5.10 & 5.35 \\
\hline Phosphate & $<2.53 \mathrm{E}-04$ & $<2.53 \mathrm{E}-04$ & $<2.53 \mathrm{E}-04$ & $<2.53 \mathrm{E}-04$ & $<2.53 \mathrm{E}-04$ & $<2.53 \mathrm{E}-04$ & $<2.53 \mathrm{E}-04$ \\
\hline
\end{tabular}


Table I.4 (Contd)

\begin{tabular}{|c|c|c|c|c|c|c|c|}
\hline \multirow[b]{2}{*}{ Analyte } & \multicolumn{7}{|c|}{$\begin{array}{l}\text { Analyte Concentration and Density at Given Time After Cooling to Ambient }\left(\sim 21^{\circ} \mathrm{C}\right) \\
\text { Temperature; } \mathrm{g} / \mathrm{mL} \text { for Density; } \mathrm{M} \text { for Metals and Anions }\end{array}$} \\
\hline & $0 \mathrm{hr}$ & $1 \mathrm{hr}$ & $2 \mathrm{hr}$ & $4 \mathrm{hr}$ & $8 \mathrm{hr}$ & $24 \mathrm{hr}$ & $48 \mathrm{hr}$ \\
\hline \multicolumn{8}{|l|}{$5 \mathrm{M} \mathrm{NaOH}$} \\
\hline Density & 1.19 & 1.20 & 1.20 & 1.25 & 1.20 & 1.20 & 1.20 \\
\hline$\overline{\mathrm{Al}}$ & 8.79E-03 & $1.27 \mathrm{E}-01$ & $1.34 \mathrm{E}-01$ & 1.39E-01 & $1.34 \mathrm{E}-01$ & $1.38 \mathrm{E}-01$ & 1.31E-01 \\
\hline $\mathrm{B}$ & 1.19E-04 & 8.93E-05 & $1.16 \mathrm{E}-04$ & 8.18E-05 & $<6.96 \mathrm{E}-05$ & 1.10E-04 & $<6.66 \mathrm{E}-05$ \\
\hline $\mathrm{Bi}$ & $<2.21 \mathrm{E}-05$ & $<2.24 \mathrm{E}-05$ & 2.20E-05 & 2.33E-05 & 4.20E-05 & $<2.25 \mathrm{E}-05$ & $<2.15 \mathrm{E}-05$ \\
\hline $\mathrm{Cd}$ & $<4.65 \mathrm{E}-06$ & $<4.71 \mathrm{E}-06$ & $<4.63 \mathrm{E}-06$ & $<4.61 \mathrm{E}-06$ & $<4.74 \mathrm{E}-06$ & $<4.73 \mathrm{E}-06$ & $<4.53 \mathrm{E}-06$ \\
\hline $\mathrm{Cr}$ & 5.91E-06 & 3.06E-05 & $3.41 \mathrm{E}-05$ & 3.58E-05 & $3.80 \mathrm{E}-05$ & 3.85E-05 & 4.61E-05 \\
\hline $\mathrm{Fe}$ & 4.95E-05 & $2.32 \mathrm{E}-04$ & $2.46 \mathrm{E}-04$ & 2.56E-04 & $2.58 \mathrm{E}-04$ & 2.53E-04 & 2.23E-04 \\
\hline $\mathrm{Mn}$ & 3.52E-06 & $3.46 \mathrm{E}-06$ & $2.17 \mathrm{E}-06$ & $1.94 \mathrm{E}-06$ & $1.08 \mathrm{E}-06$ & $7.98 \mathrm{E}-07$ & $<6.28 \mathrm{E}-07$ \\
\hline $\mathrm{Na}$ & 4.97 & 4.96 & 4.99 & 5.21 & 4.95 & 5.08 & 4.87 \\
\hline $\mathrm{P}$ & 3.47E-04 & 6.84E-04 & 5.14E-04 & $6.20 \mathrm{E}-04$ & $6.48 \mathrm{E}-04$ & 3.34E-04 & 5.62E-04 \\
\hline $\mathrm{S}$ & $<3.45 \mathrm{E}-04$ & $<3.50 \mathrm{E}-04$ & $<3.44 \mathrm{E}-04$ & $<3.42 \mathrm{E}-04$ & $9.78 \mathrm{E}-04$ & $4.20 \mathrm{E}-04$ & $<3.37 \mathrm{E}-04$ \\
\hline Si & 7.04E-04 & 2.45E-03 & 2.67E-03 & 2.95E-03 & $2.95 \mathrm{E}-03$ & 3.02E-03 & 2.99E-03 \\
\hline $\mathrm{Sr}$ & 4.91E-07 & 7.47E-07 & 6.99E-07 & 6.61E-07 & $6.08 \mathrm{E}-07$ & 4.29E-07 & $4.45 \mathrm{E}-07$ \\
\hline $\mathrm{U}$ & $2.07 \mathrm{E}-05$ & 4.84E-05 & $6.56 \mathrm{E}-05$ & 4.87E-05 & 3.95E-05 & 5.26E-05 & 5.42E-05 \\
\hline $\mathrm{Zn}$ & 2.77E-05 & $3.29 \mathrm{E}-05$ & 4.40E-05 & $2.98 \mathrm{E}-05$ & $4.51 \mathrm{E}-05$ & 3.59E-05 & 3.62E-05 \\
\hline $\mathrm{Zr}$ & 7.75E-06 & $1.54 \mathrm{E}-05$ & $1.17 \mathrm{E}-05$ & 6.35E-06 & $1.24 \mathrm{E}-05$ & $1.20 \mathrm{E}-05$ & $1.78 \mathrm{E}-05$ \\
\hline Fluoride & 6.32E-05 & 5.16E-05 & $5.16 \mathrm{E}-05$ & 5.26E-05 & 5.16E-05 & 6.32E-05 & $<4.95 \mathrm{E}-05$ \\
\hline Nitrite & $1.16 \mathrm{E}-03$ & 1.23E-03 & $1.24 \mathrm{E}-03$ & $1.25 \mathrm{E}-03$ & $1.15 \mathrm{E}-03$ & $1.27 \mathrm{E}-03$ & 1.13E-03 \\
\hline Sulfate & $<2.29 \mathrm{E}-05$ & $<2.29 \mathrm{E}-05$ & $<2.29 \mathrm{E}-05$ & $<2.29 \mathrm{E}-05$ & $<2.29 \mathrm{E}-05$ & $<2.29 \mathrm{E}-05$ & $<2.29 \mathrm{E}-05$ \\
\hline Nitrate & 3.87E-04 & 6.68E-04 & 7.16E-04 & 8.18E-04 & $8.18 \mathrm{E}-04$ & 1.60E-03 & $8.06 \mathrm{E}-04$ \\
\hline Phosphate & 4.74E-05 & 5.79E-05 & 6.00E-05 & 6.42E-05 & 7.58E-05 & 6.95E-05 & 6.95E-05 \\
\hline \multicolumn{8}{|c|}{$\begin{array}{l}\text { Analyte uncertainties were typically within } \pm 15 \% \text { (2-s); results in brackets indicate that the analyte concentrations } \\
\text { were less than the minimum detection limit (MDL) and greater than the estimated quantitation limit (EQL), and } \\
\text { uncertainties were }>15 \% \text {. }\end{array}$} \\
\hline
\end{tabular}


Table I.5. Analyte Concentrations as a Function of Time for Leaching at $100^{\circ} \mathrm{C}$, in $\mu \mathrm{g} / \mathrm{mL}$

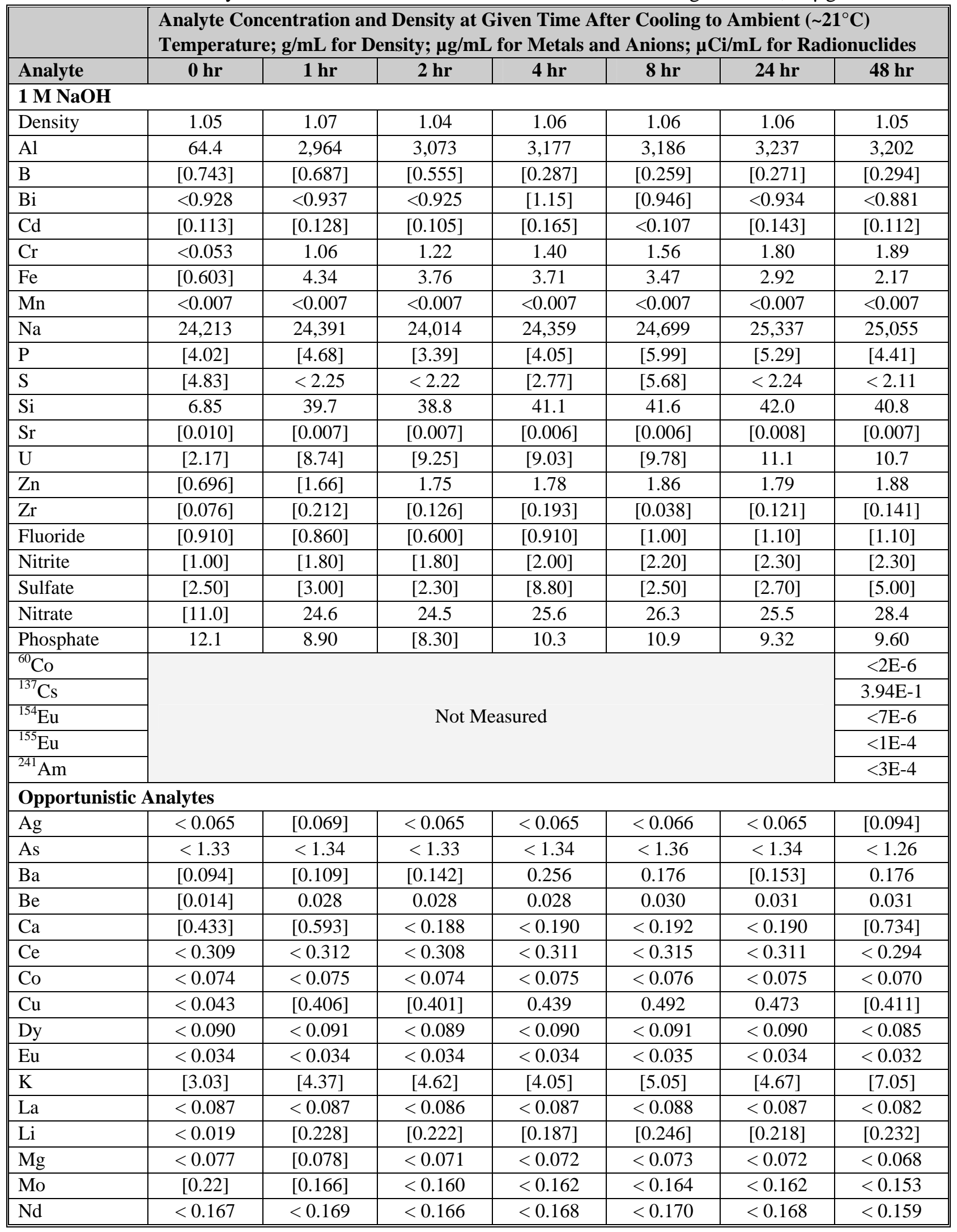


Table I.5 (Contd)

\begin{tabular}{|c|c|c|c|c|c|c|c|}
\hline \multirow[b]{2}{*}{ Analyte } & \multicolumn{7}{|c|}{$\begin{array}{l}\text { Analyte Concentration and Density at Given Time After Cooling to Ambient }\left(\sim 21^{\circ} \mathrm{C}\right) \\
\text { Temperature; } g / \mathrm{mL} \text { for Density; } \mu \mathrm{g} / \mathrm{mL} \text { for Metals and Anions; } \mu \mathrm{Ci} / \mathrm{mL} \text { for Radionuclides }\end{array}$} \\
\hline & $0 \mathrm{hr}$ & $1 \mathrm{hr}$ & $2 \mathrm{hr}$ & $4 \mathrm{hr}$ & $8 \mathrm{hr}$ & $24 \mathrm{hr}$ & $48 \mathrm{hr}$ \\
\hline $\mathrm{Ni}$ & {$[0.094]$} & {$[0.078]$} & {$[0.086]$} & $<0.075$ & $<0.076$ & {$[0.187]$} & $<0.070$ \\
\hline $\mathrm{Pb}$ & [1.11] & [6.56] & [6.47] & {$[7.48]$} & [7.89] & [8.09] & [7.34] \\
\hline $\mathrm{Pd}$ & $<0.195$ & $<0.197$ & $<0.194$ & $<0.196$ & $<0.199$ & $<0.196$ & $<0.185$ \\
\hline $\mathrm{Rh}$ & $<0.371$ & $<0.375$ & $<0.370$ & $<0.374$ & $<0.379$ & $<0.374$ & $<0.352$ \\
\hline $\mathrm{Ru}$ & $<0.263$ & $<0.265$ & $<0.262$ & $<0.265$ & $<0.268$ & $<0.265$ & $<0.250$ \\
\hline $\mathrm{Sb}$ & [1.59] & $<0.625$ & $<0.617$ & [0.903] & $<0.631$ & [0.747] & [1.15] \\
\hline Se & [2.94] & [4.06] & $<2.16$ & [5.30] & $<2.21$ & [3.05] & $<2.06$ \\
\hline Sn & [1.24] & {$[0.874]$} & [1.29] & $<0.841$ & $<0.852$ & $<0.840$ & [1.03] \\
\hline $\mathrm{Ta}$ & $<0.526$ & $<0.531$ & $<0.524$ & $<0.530$ & $<0.536$ & $<0.529$ & $<0.499$ \\
\hline $\mathrm{Te}$ & $<0.805$ & $<0.812$ & $<0.801$ & $<0.810$ & $<0.820$ & $<0.809$ & $<0.764$ \\
\hline Th & $<0.303$ & $<0.306$ & $<0.302$ & $<0.305$ & $<0.309$ & $<0.305$ & $<0.288$ \\
\hline $\mathrm{Ti}$ & $<0.013$ & $<0.013$ & $<0.013$ & $<0.013$ & $<0.014$ & $<0.013$ & $<0.013$ \\
\hline $\mathrm{Tl}$ & [1.45] & [1.22] & $<1.17$ & [1.28] & [1.51] & {$[2.74]$} & $<1.12$ \\
\hline $\mathrm{V}$ & {$[0.053]$} & {$[0.091]$} & {$[0.062]$} & [0.053] & [0.088] & [0.093] & [0.094] \\
\hline $\mathrm{W}$ & $<0.588$ & $<0.593$ & $<0.586$ & $<0.592$ & $<0.599$ & $<0.591$ & $<0.558$ \\
\hline $\mathrm{Y}$ & $<0.014$ & $<0.014$ & $<0.014$ & $<0.014$ & $<0.014$ & $<0.014$ & $<0.013$ \\
\hline \multicolumn{8}{|c|}{$3 \mathrm{M} \mathrm{NaOH}$} \\
\hline Density & 1.13 & 1.15 & 1.13 & 1.14 & 1.14 & 1.13 & 1.13 \\
\hline $\mathrm{Al}$ & 143 & 3,059 & 3,144 & 3,193 & 3,252 & 3,254 & 3,297 \\
\hline B & $<0.738$ & $<0.743$ & $<0.740$ & $<0.744$ & $<0.743$ & $<0.730$ & {$[0.713]$} \\
\hline $\mathrm{Bi}$ & $<4.61$ & [7.74] & $<4.62$ & {$[4.96]$} & $<4.65$ & $<4.56$ & $<4.46$ \\
\hline $\mathrm{Cd}$ & $<0.523$ & $<0.526$ & {$[0.616]$} & [0.992] & [0.898] & {$[0.760]$} & [0.654] \\
\hline $\mathrm{Cr}$ & $<0.261$ & [1.21] & [1.66] & [1.83] & [1.77] & {$[2.25]$} & {$[2.29]$} \\
\hline $\mathrm{Fe}$ & [1.38] & 10.5 & 11.0 & 11.3 & 11.3 & 10.4 & 10.1 \\
\hline $\mathrm{Mn}$ & $<0.035$ & $<0.036$ & $<0.035$ & $<0.036$ & $<0.036$ & $<0.035$ & $<0.034$ \\
\hline $\mathrm{Na}$ & 73,471 & 76,473 & 74,899 & 75,960 & 75,883 & 77,244 & 79,016 \\
\hline $\mathrm{P}$ & $<7.69$ & $<7.74$ & $<7.71$ & $<7.75$ & [10.5] & $<7.60$ & [11.9] \\
\hline S & [23.7] & [26.3] & $<11.1$ & $<11.2$ & [29.7] & {$[19.5]$} & [19.6] \\
\hline $\mathrm{Si}$ & 15.5 & 68.7 & 76.1 & 79.7 & 80.8 & 83.9 & 87.3 \\
\hline $\mathrm{Sr}$ & {$[0.074]$} & {$[0.043]$} & {$[0.046]$} & [0.059] & {$[0.046]$} & {$[0.027]$} & [0.053] \\
\hline $\mathrm{U}$ & $<4.92$ & [14.6] & [11.1] & [15.2] & [21.7] & [17.6] & [17.5] \\
\hline $\mathrm{Zn}$ & [1.26] & [2.32] & {$[2.84]$} & {$[2.85]$} & {$[2.88]$} & {$[2.49]$} & [3.27] \\
\hline $\mathrm{Zr}$ & {$[0.461]$} & [1.61] & [1.39] & {$[1.36]$} & [0.991] & [1.19] & [1.13] \\
\hline Fluoride & {$[2.10]$} & [1.90] & [2.60] & [1.90] & [1.90] & {$[2.00]$} & [1.30] \\
\hline Nitrite & $<1.50$ & [2.10] & $<1.50$ & $<1.50$ & $<1.50$ & $<1.50$ & $<1.50$ \\
\hline Sulfate & $<2.20$ & [7.60] & $<2.20$ & $<2.20$ & $<2.20$ & $<2.20$ & $<2.20$ \\
\hline Nitrate & [18.0] & 36.7 & 39.4 & 41.1 & 41.8 & 48.3 & 48.3 \\
\hline Phosphate & [14.0] & [15.0] & [16.0] & 19.5 & 19.3 & 18.0 & 17.0 \\
\hline${ }^{60} \mathrm{Co}$ & \multirow{5}{*}{\multicolumn{6}{|c|}{ Not Measured }} & $<5$ E-6 \\
\hline${ }^{137} \mathrm{Cs}$ & & & & & & & $5.82 \mathrm{E}-1$ \\
\hline${ }^{154} \mathrm{Eu}$ & & & & & & & $<1 \mathrm{E}-5$ \\
\hline${ }^{155} \mathrm{Eu}$ & & & & & & & $<2 \mathrm{E}-4$ \\
\hline${ }^{241} \mathrm{Am}$ & & & & & & & $<2 \mathrm{E}-4$ \\
\hline
\end{tabular}


Table I.5 (Contd)

\begin{tabular}{|c|c|c|c|c|c|c|c|}
\hline \multirow[b]{2}{*}{ Analyte } & \multicolumn{7}{|c|}{$\begin{array}{l}\text { Analyte Concentration and Density at Given Time After Cooling to Ambient }\left(\sim 21^{\circ} \mathrm{C}\right) \\
\text { Temperature; } g / \mathrm{mL} \text { for Density; } \mu \mathrm{g} / \mathrm{mL} \text { for Metals and Anions; } \mu \mathrm{Ci} / \mathrm{mL} \text { for Radionuclides }\end{array}$} \\
\hline & o hr & $1 \mathrm{hr}$ & $2 \mathrm{hr}$ & $4 \mathrm{hr}$ & $8 \mathrm{hr}$ & 24 hr & $48 \mathrm{hr}$ \\
\hline \multicolumn{8}{|c|}{ Opportunistic Analytes } \\
\hline $\mathrm{Ag}$ & $<0.323$ & {$[0.372]$} & $<0.324$ & $<0.326$ & $<0.325$ & $<0.319$ & $<0.312$ \\
\hline As & $<6.61$ & $<6.66$ & $<6.63$ & $<6.67$ & $<6.66$ & $<6.54$ & $<6.39$ \\
\hline $\mathrm{Ba}$ & {$[0.215]$} & {$[0.260]$} & {$[0.200]$} & [0.465] & 0.991 & [0.304] & {$[0.250]$} \\
\hline $\mathrm{Be}$ & [0.019] & {$[0.037]$} & [0.043] & [0.043] & [0.043] & [0.043] & [0.045] \\
\hline $\mathrm{Ca}$ & [4.92] & {$[2.48]$} & [1.79] & 12.9 & [3.72] & [1.82] & [2.97] \\
\hline Ce & $<1.54$ & $<1.55$ & $<1.54$ & $<1.55$ & $<1.55$ & $<1.52$ & $<1.49$ \\
\hline Co & $<0.369$ & $<0.372$ & $<0.370$ & $<0.372$ & $<0.372$ & $<0.365$ & $<0.356$ \\
\hline $\mathrm{Cu}$ & $<0.215$ & $<0.217$ & [0.339] & [0.558] & {$[0.465]$} & {$[0.547]$} & {$[0.386]$} \\
\hline Dy & $<0.446$ & $<0.449$ & $<0.447$ & $<0.450$ & $<0.449$ & $<0.441$ & $<0.431$ \\
\hline $\mathrm{Eu}$ & $<0.169$ & $<0.170$ & $<0.170$ & $<0.171$ & $<0.170$ & $<0.167$ & $<0.163$ \\
\hline $\mathrm{K}$ & [11.7] & [14.2] & [23.7] & {$[16.4]$} & [18.9] & {$[22.5]$} & [9.73] \\
\hline $\mathrm{La}$ & $<0.430$ & $<0.433$ & $<0.432$ & $<0.434$ & $<0.434$ & $<0.426$ & $<0.416$ \\
\hline $\mathrm{Li}$ & {$[0.240]$} & {$[0.464]$} & {$[0.370]$} & [0.403] & {$[0.496]$} & {$[0.365]$} & {$[0.654]$} \\
\hline $\mathrm{Mg}$ & $<0.354$ & $<0.356$ & $<0.354$ & $<0.357$ & $<0.356$ & $<0.350$ & {$[0.356]$} \\
\hline Mo & [1.11] & $<0.805$ & $<0.801$ & $<0.806$ & [1.21] & [1.03] & [0.772] \\
\hline $\mathrm{Nd}$ & $<0.830$ & $<0.836$ & $<0.832$ & $<0.837$ & $<0.836$ & $<0.821$ & $<0.802$ \\
\hline $\mathrm{Ni}$ & $<0.369$ & [1.05] & $<0.370$ & [0.589] & $<0.372$ & $<0.365$ & $<0.356$ \\
\hline $\mathrm{Pb}$ & $<4.92$ & [10.5] & [10.5] & [11.8] & [9.91] & [7.60] & [12.2] \\
\hline $\mathrm{Pd}$ & $<0.968$ & $<0.975$ & $<0.971$ & $<0.977$ & $<0.976$ & $<0.958$ & [1.13] \\
\hline $\mathrm{Rh}$ & $<1.84$ & $<1.86$ & $<1.85$ & $<1.86$ & $<1.86$ & $<1.82$ & $<1.78$ \\
\hline $\mathrm{Ru}$ & $<1.31$ & $<1.32$ & $<1.31$ & $<1.32$ & $<1.32$ & $<1.29$ & $<1.26$ \\
\hline $\mathrm{Sb}$ & $<3.07$ & $<3.10$ & [3.39] & $<3.10$ & $<3.10$ & [3.65] & $<2.97$ \\
\hline Se & $<10.8$ & $<10.8$ & $<10.8$ & [15.8] & [10.8] & $\begin{array}{l}<10.6 \\
\end{array}$ & $<10.4$ \\
\hline Sn & $<4.15$ & $<4.18$ & $<4.16$ & [4.96] & $<4.18$ & $<4.11$ & [6.54] \\
\hline $\mathrm{Ta}$ & $<2.61$ & $<2.63$ & $<2.62$ & $<2.64$ & $<2.63$ & $<2.58$ & $<2.52$ \\
\hline $\mathrm{Te}$ & [4.30] & $<4.02$ & $<4.01$ & $<4.03$ & $<4.03$ & $<3.95$ & $<3.86$ \\
\hline Th & $<1.51$ & $<1.52$ & $<1.51$ & $<1.52$ & $<1.52$ & $<1.49$ & $<1.46$ \\
\hline $\mathrm{Ti}$ & $<0.066$ & $<0.067$ & $<0.066$ & $<0.067$ & $<0.067$ & $<0.065$ & $<0.064$ \\
\hline $\mathrm{Tl}$ & [6.15] & $<5.88$ & {$[12.0]$} & $<5.89$ & [6.50] & $<5.78$ & $<5.64$ \\
\hline $\mathrm{V}$ & $<0.114$ & $<0.115$ & [0.120] & {$[0.276]$} & $<0.115$ & [0.149] & [0.211] \\
\hline $\mathrm{W}$ & $<2.92$ & $<2.94$ & $<2.93$ & $<2.95$ & $<2.94$ & $<2.89$ & [2.94] \\
\hline $\mathrm{Y}$ & $<0.068$ & $<0.068$ & $<0.068$ & $<0.068$ & $<0.068$ & $<0.067$ & $<0.065$ \\
\hline \multicolumn{8}{|c|}{$5 \mathrm{M} \mathrm{NaOH}$} \\
\hline Density & 1.20 & 1.21 & 1.21 & 1.19 & 1.21 & 1.21 & 1.20 \\
\hline $\mathrm{Al}$ & 112 & 3,379 & 3,432 & 3,406 & 3,438 & 3,482 & 3,503 \\
\hline $\mathrm{B}$ & $<0.741$ & $<0.758$ & $<0.749$ & $<0.750$ & {$[0.743]$} & $<0.753$ & $<0.701$ \\
\hline $\mathrm{Bi}$ & $<4.63$ & [8.21] & $<4.68$ & {$[5.94]$} & [6.81] & [6.27] & $<4.38$ \\
\hline $\mathrm{Cd}$ & $<0.525$ & $<0.537$ & {$[0.780]$} & {$[0.906]$} & {$[0.558]$} & {$[0.816]$} & [1.02] \\
\hline $\mathrm{Cr}$ & $<0.262$ & [1.86] & [2.03] & [2.06] & {$[2.08]$} & [2.32] & {$[2.48]$} \\
\hline $\mathrm{Fe}$ & [2.35] & 16.8 & 17.6 & 17.7 & 17.9 & 17.6 & 17.3 \\
\hline $\mathrm{Mn}$ & $<0.035$ & $<0.036$ & $<0.036$ & $<0.036$ & $<0.036$ & $<0.036$ & $<0.034$ \\
\hline $\mathrm{Na}$ & 123,164 & 123,791 & 125,110 & 123,415 & 124,209 & 127,994 & 129,015 \\
\hline $\mathrm{P}$ & $<7.72$ & $<7.89$ & [8.42] & [9.69] & $<7.74$ & $<7.84$ & $<7.30$ \\
\hline
\end{tabular}


Table I.5 (Contd)

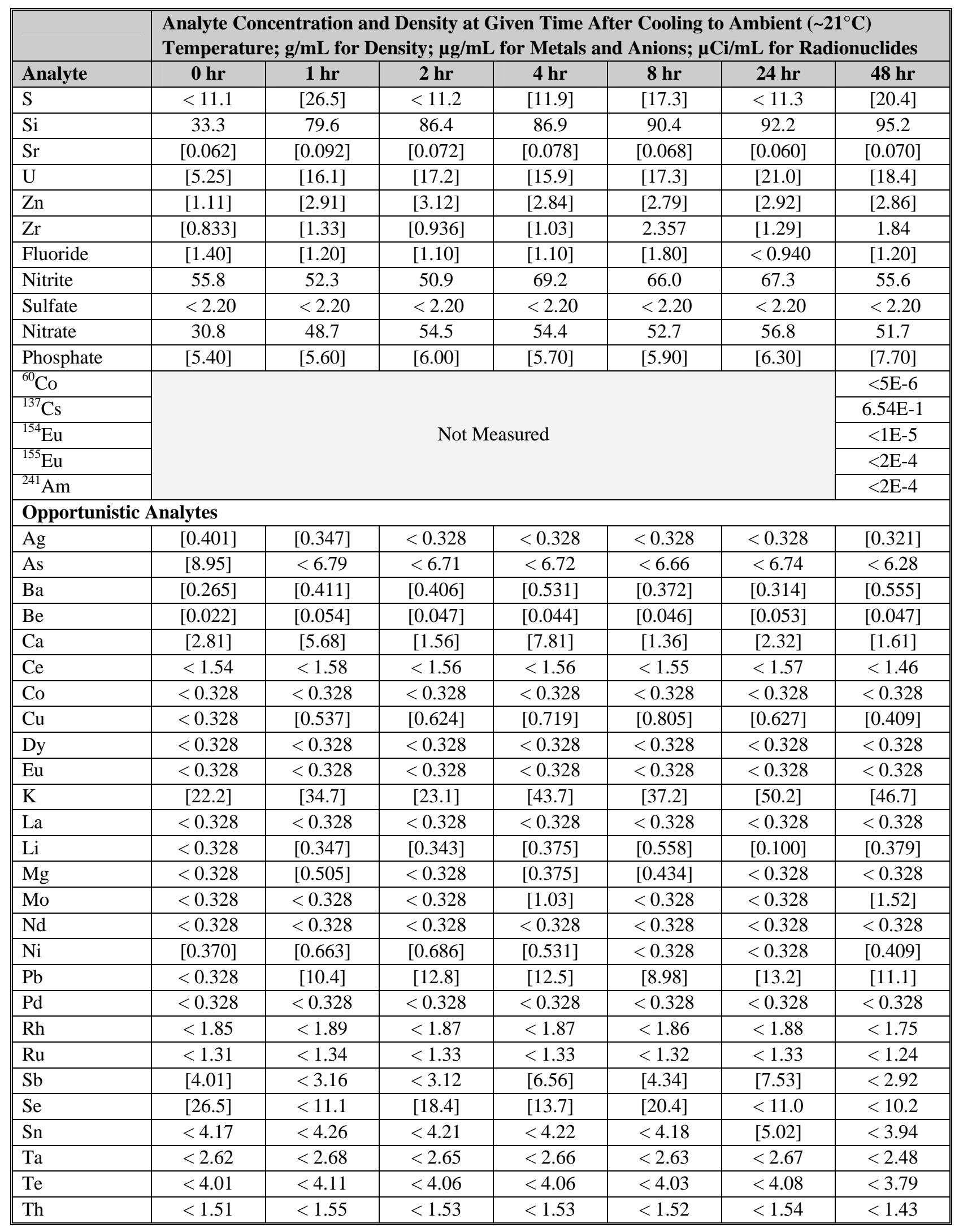


Table I.5 (Contd)

\begin{tabular}{|c|c|c|c|c|c|c|c|}
\hline \multirow[b]{2}{*}{ Analyte } & \multicolumn{7}{|c|}{$\begin{array}{l}\text { Analyte Concentration and Density at Given Time After Cooling to Ambient }\left(\sim 21^{\circ} \mathrm{C}\right) \\
\text { Temperature; } \mathrm{g} / \mathrm{mL} \text { for Density; } \mu \mathrm{g} / \mathrm{mL} \text { for Metals and Anions; } \mu \mathrm{Ci} / \mathrm{mL} \text { for Radionuclides }\end{array}$} \\
\hline & $0 \mathrm{hr}$ & $1 \mathrm{hr}$ & $2 \mathrm{hr}$ & $4 \mathrm{hr}$ & $8 \mathrm{hr}$ & $24 \mathrm{hr}$ & $48 \mathrm{hr}$ \\
\hline $\mathrm{Ti}$ & $<0.328$ & $<0.328$ & $<0.328$ & $<0.328$ & $<0.328$ & $<0.328$ & $<0.328$ \\
\hline $\mathrm{Tl}$ & $<5.86$ & [11.4] & [12.5] & [9.69] & $<5.89$ & $<5.96$ & [12.6] \\
\hline $\mathrm{V}$ & {$[0.167]$} & {$[0.133]$} & {$[0.209]$} & {$[0.237]$} & {$[0.133]$} & {$[0.254]$} & $<0.328$ \\
\hline $\mathrm{W}$ & $<2.93$ & $<3.00$ & $<2.96$ & $<2.97$ & $<2.94$ & $<2.98$ & $<2.77$ \\
\hline $\mathrm{Y}$ & $<0.328$ & $<0.328$ & $<0.328$ & $<0.328$ & $<0.328$ & $<0.328$ & $<0.328$ \\
\hline
\end{tabular}


Table I.6. Analyte Concentrations as a Function of Time for Leaching at $100^{\circ} \mathrm{C}$, in $\mathrm{M}$

\begin{tabular}{|c|c|c|c|c|c|c|c|}
\hline \multirow[b]{2}{*}{ Analyte } & \multicolumn{7}{|c|}{$\begin{array}{l}\text { Analyte Concentration and Density at Given Time After Cooling to Ambient }\left(\sim 21^{\circ} \mathrm{C}\right) \\
\text { Temperature; } \mathrm{g} / \mathrm{mL} \text { for Density; } \mathrm{M} \text { for Metals and Anions }\end{array}$} \\
\hline & o hr & $1 \mathrm{hr}$ & $2 \mathrm{hr}$ & $4 \mathrm{hr}$ & $8 \mathrm{hr}$ & $24 \mathrm{hr}$ & $48 \mathrm{hr}$ \\
\hline \multicolumn{8}{|l|}{$1 \mathrm{M} \mathrm{NaOH}$} \\
\hline Density & 1.05 & 1.07 & 1.04 & 1.06 & 1.06 & 1.06 & 1.05 \\
\hline $\mathrm{Al}$ & 2.39E-03 & $1.10 \mathrm{E}-01$ & $1.14 \mathrm{E}-01$ & $1.18 \mathrm{E}-01$ & $1.18 \mathrm{E}-01$ & $1.20 \mathrm{E}-01$ & 1.19E-01 \\
\hline B & 6.87E-05 & 6.36E-05 & 5.13E-05 & 2.65E-05 & 2.39E-05 & $2.51 \mathrm{E}-05$ & 2.72E-05 \\
\hline $\mathrm{Bi}$ & $<4.44 \mathrm{E}-06$ & $<4.48 \mathrm{E}-06$ & $<4.43 \mathrm{E}-06$ & 5.52E-06 & 4.53E-06 & $<4.47 \mathrm{E}-06$ & $<4.22 \mathrm{E}-06$ \\
\hline $\mathrm{Cd}$ & $1.00 \mathrm{E}-06$ & $1.14 \mathrm{E}-06$ & 9.32E-07 & $1.47 \mathrm{E}-06$ & $<9.54 \mathrm{E}-07$ & $1.27 \mathrm{E}-06$ & 9.93E-07 \\
\hline $\mathrm{Cr}$ & $<1.01 \mathrm{E}-06$ & $2.05 \mathrm{E}-05$ & $2.35 \mathrm{E}-05$ & 2.68E-05 & 3.00E-05 & $3.46 \mathrm{E}-05$ & 3.64E-05 \\
\hline $\mathrm{Fe}$ & $1.08 \mathrm{E}-05$ & 7.77E-05 & 6.73E-05 & 6.64E-05 & $6.21 \mathrm{E}-05$ & 5.23E-05 & 3.88E-05 \\
\hline $\mathrm{Mn}$ & $<1.30 \mathrm{E}-07$ & $<1.31 \mathrm{E}-07$ & $<1.29 \mathrm{E}-07$ & $<1.30 \mathrm{E}-07$ & $<1.32 \mathrm{E}-07$ & $<1.30 \mathrm{E}-07$ & $<1.23 \mathrm{E}-07$ \\
\hline $\mathrm{Na}$ & 1.05 & 1.06 & 1.04 & 1.06 & 1.07 & 1.10 & 1.09 \\
\hline $\mathrm{P}$ & 1.30E-04 & $1.51 \mathrm{E}-04$ & 1.09E-04 & $1.31 \mathrm{E}-04$ & 1.93E-04 & $1.71 \mathrm{E}-04$ & $1.42 \mathrm{E}-04$ \\
\hline$S$ & $1.51 \mathrm{E}-04$ & $<>7.01 \mathrm{E}-05$ & $<6.92 \mathrm{E}-05$ & 8.65E-05 & $1.77 \mathrm{E}-04$ & $<6.99 \mathrm{E}-05$ & $<6.60 \mathrm{E}-05$ \\
\hline $\mathrm{Si}$ & 2.44E-04 & $1.41 \mathrm{E}-03$ & 1.38E-03 & $1.46 \mathrm{E}-03$ & $1.48 \mathrm{E}-03$ & $1.50 \mathrm{E}-03$ & $1.45 \mathrm{E}-03$ \\
\hline $\mathrm{Sr}$ & $1.15 \mathrm{E}-07$ & 7.84E-08 & 7.74E-08 & 7.11E-08 & 6.84E-08 & $9.24 \mathrm{E}-08$ & 8.38E-08 \\
\hline $\mathrm{U}$ & $9.10 \mathrm{E}-06$ & 3.67E-05 & 3.89E-05 & 3.80E-05 & $4.11 \mathrm{E}-05$ & $4.68 \mathrm{E}-05$ & 4.50E-05 \\
\hline $\mathrm{Zn}$ & 1.06E-05 & 2.53E-05 & $2.67 \mathrm{E}-05$ & 2.73E-05 & $2.84 \mathrm{E}-05$ & 2.73E-05 & $2.88 \mathrm{E}-05$ \\
\hline $\mathrm{Zr}$ & 8.31E-07 & $2.33 \mathrm{E}-06$ & 1.39E-06 & $2.12 \mathrm{E}-06$ & $4.15 \mathrm{E}-07$ & $1.33 \mathrm{E}-06$ & $1.55 \mathrm{E}-06$ \\
\hline Fluoride & 4.79E-05 & 4.53E-05 & 3.16E-05 & 4.79E-05 & 5.26E-05 & 5.79E-05 & 5.79E-05 \\
\hline Nitrite & 2.17E-05 & 3.91E-05 & 3.91E-05 & 4.35E-05 & 4.78E-05 & $5.00 \mathrm{E}-05$ & 5.00E-05 \\
\hline Sulfate & 2.60E-05 & 3.12E-05 & 2.39E-05 & $9.16 \mathrm{E}-05$ & $2.60 \mathrm{E}-05$ & 2.81E-05 & $5.21 \mathrm{E}-05$ \\
\hline Nitrate & $1.77 \mathrm{E}-04$ & 3.97E-04 & 3.95E-04 & $4.13 \mathrm{E}-04$ & $4.24 \mathrm{E}-04$ & $4.11 \mathrm{E}-04$ & $4.58 \mathrm{E}-04$ \\
\hline Phosphate & 1.27E-04 & 9.37E-05 & 8.74E-05 & $1.08 \mathrm{E}-04$ & $1.15 \mathrm{E}-04$ & $9.81 \mathrm{E}-05$ & 1.01E-04 \\
\hline \multicolumn{8}{|l|}{$3 \mathrm{M}$ NaOH } \\
\hline Density & 1.13 & 1.15 & 1.13 & 1.14 & 1.14 & 1.13 & 1.13 \\
\hline $\mathrm{Al}$ & 5.30E-03 & 1.13E-01 & 1.17E-01 & $1.18 \mathrm{E}-01$ & $1.21 \mathrm{E}-01$ & $1.21 \mathrm{E}-01$ & 1.22E-01 \\
\hline B & $<6.83 \mathrm{E}-05$ & $<6.87 \mathrm{E}-05$ & $<6.84 \mathrm{E}-05$ & $<6.88 \mathrm{E}-05$ & $<6.88 \mathrm{E}-05$ & $<6.75 \mathrm{E}-05$ & 6.60E-05 \\
\hline $\mathrm{Bi}$ & $<2.21 \mathrm{E}-05$ & 3.70E-05 & $<2.21 \mathrm{E}-05$ & 2.37E-05 & $<2.22 \mathrm{E}-05$ & $<2.18 \mathrm{E}-05$ & $<2.13 \mathrm{E}-05$ \\
\hline $\mathrm{Cd}$ & $<4.65 \mathrm{E}-06$ & $<4.68 \mathrm{E}-06$ & 5.48E-06 & 8.83E-06 & 7.99E-06 & 6.76E-06 & 5.81E-06 \\
\hline $\mathrm{Cr}$ & $<5.03 \mathrm{E}-06$ & 2.32E-05 & 3.20E-05 & 3.52E-05 & 3.40E-05 & 4.33E-05 & 4.40E-05 \\
\hline $\mathrm{Fe}$ & $2.48 \mathrm{E}-05$ & $1.88 \mathrm{E}-04$ & $1.96 \mathrm{E}-04$ & 2.03E-04 & $2.02 \mathrm{E}-04$ & $1.86 \mathrm{E}-04$ & $1.81 \mathrm{E}-04$ \\
\hline $\mathrm{Mn}$ & $<6.43 \mathrm{E}-07$ & $<6.48 \mathrm{E}-07$ & $<6.45 \mathrm{E}-07$ & $<6.49 \mathrm{E}-07$ & $<6.48 \mathrm{E}-07$ & $<6.37 \mathrm{E}-07$ & $<6.22 \mathrm{E}-07$ \\
\hline $\mathrm{Na}$ & 3.20 & 3.33 & 3.26 & 3.30 & 3.30 & 3.36 & 3.44 \\
\hline $\mathrm{P}$ & $<2.48 \mathrm{E}-04$ & $<2.50 \mathrm{E}-04$ & $<2.49 \mathrm{E}-04$ & $<2.50 \mathrm{E}-04$ & $3.40 \mathrm{E}-04$ & $<2.45 \mathrm{E}-04$ & 3.84E-04 \\
\hline $\mathrm{S}$ & 7.38E-04 & 8.21E-04 & $<3.46 \mathrm{E}-04$ & $<3.48 \mathrm{E}-04$ & 9.27E-04 & 6.07E-04 & $6.12 \mathrm{E}-04$ \\
\hline $\mathrm{Si}$ & $5.52 \mathrm{E}-04$ & $2.45 \mathrm{E}-03$ & $2.71 \mathrm{E}-03$ & $2.84 \mathrm{E}-03$ & $2.88 \mathrm{E}-03$ & $2.99 \mathrm{E}-03$ & $3.11 \mathrm{E}-03$ \\
\hline $\mathrm{Sr}$ & 8.42E-07 & $4.95 \mathrm{E}-07$ & $5.28 \mathrm{E}-07$ & 6.72E-07 & 5.30E-07 & 3.09E-07 & 6.10E-07 \\
\hline $\mathrm{U}$ & $<2.07 \mathrm{E}-05$ & 6.11E-05 & $4.66 \mathrm{E}-05$ & 6.38E-05 & $9.11 \mathrm{E}-05$ & 7.41E-05 & 7.36E-05 \\
\hline Zn & 1.93E-05 & 3.55E-05 & $4.34 \mathrm{E}-05$ & 4.36E-05 & $4.41 \mathrm{E}-05$ & 3.81E-05 & $5.00 \mathrm{E}-05$ \\
\hline $\mathrm{Zr}$ & 5.06E-06 & $1.76 \mathrm{E}-05$ & 1.52E-05 & $1.50 \mathrm{E}-05$ & $1.09 \mathrm{E}-05$ & $1.30 \mathrm{E}-05$ & $1.24 \mathrm{E}-05$ \\
\hline Fluoride & 1.11E-04 & $1.00 \mathrm{E}-04$ & 1.37E-04 & $1.00 \mathrm{E}-04$ & $1.00 \mathrm{E}-04$ & $1.05 \mathrm{E}-04$ & $6.84 \mathrm{E}-05$ \\
\hline Nitrite & $<3.26 \mathrm{E}-05$ & 4.57E-05 & $<3.26 \mathrm{E}-05$ & $<3.26 \mathrm{E}-05$ & $<3.26 \mathrm{E}-05$ & $<3.26 \mathrm{E}-05$ & $<3.26 \mathrm{E}-05$ \\
\hline Sulfate & $<2.29 \mathrm{E}-05$ & 7.91E-05 & $<2.29 \mathrm{E}-05$ & $<2.29 \mathrm{E}-05$ & $<2.29 \mathrm{E}-05$ & $<2.29 \mathrm{E}-05$ & $<2.29 \mathrm{E}-05$ \\
\hline Nitrate & 2.90E-04 & 5.92E-04 & 6.35E-04 & 6.63E-04 & 6.74E-04 & 7.79E-04 & 7.79E-04 \\
\hline Phosphate & $1.47 \mathrm{E}-04$ & $1.58 \mathrm{E}-04$ & $1.58 \mathrm{E}-04$ & 2.05E-04 & 2.03E-04 & $1.90 \mathrm{E}-04$ & 1.79E-04 \\
\hline
\end{tabular}


Table I.6 (Contd)

\begin{tabular}{|c|c|c|c|c|c|c|c|}
\hline \multirow[b]{2}{*}{ Analyte } & \multicolumn{7}{|c|}{$\begin{array}{l}\text { Analyte Concentration and Density at Given Time After Cooling to Ambient }\left(\sim 21^{\circ} \mathrm{C}\right) \\
\text { Temperature; } \mathrm{g} / \mathrm{mL} \text { for Density; } \mathrm{M} \text { for Metals and Anions }\end{array}$} \\
\hline & $0 \mathrm{hr}$ & $1 \mathrm{hr}$ & $2 \mathrm{hr}$ & $4 \mathrm{hr}$ & $8 \mathrm{hr}$ & $24 \mathrm{hr}$ & $48 \mathrm{hr}$ \\
\hline \multicolumn{8}{|l|}{$5 \mathrm{M} \mathrm{NaOH}$} \\
\hline Density & 1.20 & 1.21 & 1.21 & 1.19 & 1.21 & 1.21 & 1.20 \\
\hline $\mathrm{Al}$ & $4.16 \mathrm{E}-03$ & $1.25 \mathrm{E}-01$ & $1.27 \mathrm{E}-01$ & $1.26 \mathrm{E}-01$ & $1.27 \mathrm{E}-01$ & $1.29 \mathrm{E}-01$ & $1.30 \mathrm{E}-01$ \\
\hline $\mathrm{B}$ & $<6.85 \mathrm{E}-05$ & $<7.01 \mathrm{E}-05$ & $<6.93 \mathrm{E}-05$ & $<6.94 \mathrm{E}-05$ & 6.88E-05 & $<6.96 \mathrm{E}-05$ & $<6.48 \mathrm{E}-05$ \\
\hline $\mathrm{Bi}$ & $<2.22 \mathrm{E}-05$ & 3.93E-05 & $<2.24 \mathrm{E}-05$ & $2.84 \mathrm{E}-05$ & $3.26 \mathrm{E}-05$ & $3.00 \mathrm{E}-05$ & $<2.10 \mathrm{E}-05$ \\
\hline $\mathrm{Cd}$ & $<4.67 \mathrm{E}-06$ & $<4.78 \mathrm{E}-06$ & 6.94E-06 & 8.06E-06 & 4.96E-06 & 7.26E-06 & 9.09E-06 \\
\hline $\mathrm{Cr}$ & $<5.05 \mathrm{E}-06$ & 3.58E-05 & 3.90E-05 & 3.97E-05 & 3.99E-05 & 4.46E-05 & 4.77E-05 \\
\hline $\mathrm{Fe}$ & $4.20 \mathrm{E}-05$ & 3.01E-04 & 3.15E-04 & 3.17E-04 & $3.21 \mathrm{E}-04$ & $3.16 \mathrm{E}-04$ & $3.10 \mathrm{E}-04$ \\
\hline $\mathrm{Mn}$ & $<6.46 \mathrm{E}-07$ & $<<6.61 \mathrm{E}-07$ & $<6.53 \mathrm{E}-07$ & $<6.54 \mathrm{E}-07$ & $<6.48 \mathrm{E}-07$ & $<6.57 \mathrm{E}-07$ & $<6.11 \mathrm{E}-07$ \\
\hline $\mathrm{Na}$ & 5.36 & 5.38 & 5.44 & 5.37 & 5.40 & 5.57 & 5.61 \\
\hline $\mathrm{P}$ & $<2.49 \mathrm{E}-04$ & $<2.55 \mathrm{E}-04$ & 2.72E-04 & 3.13E-04 & $<2.50 \mathrm{E}-04$ & $<2.53 \mathrm{E}-04$ & $<2.36 \mathrm{E}-04$ \\
\hline$S$ & $<3.47 \mathrm{E}-04$ & $8.27 \mathrm{E}-04$ & $<3.50 \mathrm{E}-04$ & $3.70 \mathrm{E}-04$ & $5.41 \mathrm{E}-04$ & $<3.52 \mathrm{E}-04$ & 6.37E-04 \\
\hline $\mathrm{Si}$ & 1.19E-03 & 2.83E-03 & 3.08E-03 & 3.09E-03 & 3.22E-03 & $3.28 \mathrm{E}-03$ & 3.39E-03 \\
\hline $\mathrm{Sr}$ & 7.05E-07 & 1.05E-06 & 8.19E-07 & 8.91E-07 & 7.78E-07 & 6.80E-07 & 8.00E-07 \\
\hline $\mathrm{U}$ & 2.20E-05 & 6.77E-05 & 7.21E-05 & 6.70E-05 & $7.29 \mathrm{E}-05$ & 8.83E-05 & 7.73E-05 \\
\hline $\mathrm{Zn}$ & 1.70E-05 & 4.44E-05 & 4.77E-05 & 4.35E-05 & $4.26 \mathrm{E}-05$ & 4.46E-05 & 4.38E-05 \\
\hline $\mathrm{Zr}$ & $9.14 \mathrm{E}-06$ & $1.45 \mathrm{E}-05$ & 1.03E-05 & 1.13E-05 & $2.58 \mathrm{E}-05$ & $1.41 \mathrm{E}-05$ & 2.01E-05 \\
\hline Fluoride & 7.37E-05 & 6.32E-05 & 5.79E-05 & 5.79E-05 & 9.47E-05 & $<4.95 \mathrm{E}-05$ & $6.32 \mathrm{E}-05$ \\
\hline Nitrite & $1.21 \mathrm{E}-03$ & $1.14 \mathrm{E}-03$ & $1.11 \mathrm{E}-03$ & $1.50 \mathrm{E}-03$ & $1.43 \mathrm{E}-03$ & $1.46 \mathrm{E}-03$ & $1.21 \mathrm{E}-03$ \\
\hline Sulfate & $<2.29 \mathrm{E}-05$ & $<2.29 \mathrm{E}-05$ & $<2.29 \mathrm{E}-05$ & $<2.29 \mathrm{E}-05$ & $<2.29 \mathrm{E}-05$ & $<2.29 \mathrm{E}-05$ & $<2.29 \mathrm{E}-05$ \\
\hline Nitrate & 4.97E-04 & 7.85E-04 & 8.79E-04 & $8.77 \mathrm{E}-04$ & $8.50 \mathrm{E}-04$ & $9.16 \mathrm{E}-04$ & 8.34E-04 \\
\hline Phosphate & 5.69E-05 & 5.90E-05 & 6.32E-05 & 6.00E-05 & $6.21 \mathrm{E}-05$ & 6.63E-05 & 8.11E-05 \\
\hline \multicolumn{8}{|c|}{$\begin{array}{l}\text { Analyte uncertainties were typically within } \pm 15 \% \text { (2-s); results in brackets indicate that the analyte concentrations } \\
\text { were less than the minimum detection limit (MDL) and greater than the estimated quantitation limit (EQL), and } \\
\text { uncertainties were }>15 \% \text {. }\end{array}$} \\
\hline
\end{tabular}


Table I.7. Analyte Concentrations for Composite Wash Solution for Wash of Samples Leached at $80^{\circ} \mathrm{C}$ in $3 \mathrm{M} \mathrm{NaOH}$

\begin{tabular}{|c|c|c|c|}
\hline Analyte & $\begin{array}{c}\text { Concentration } \\
(\mu \mathrm{g} / \mathrm{mL})\end{array}$ & $\begin{array}{c}\text { Opportunistic } \\
\text { Analytes }\end{array}$ & $\begin{array}{c}\text { Concentration } \\
(\mu \mathrm{g} / \mathrm{mL})\end{array}$ \\
\hline $\mathrm{Al}$ & 111 & $\mathrm{Ag}$ & $<0.064$ \\
\hline B & [0.396] & As & $<1.31$ \\
\hline $\mathrm{Bi}$ & $<0.913$ & $\mathrm{Ba}$ & 0.247 \\
\hline $\mathrm{Cd}$ & [0.161] & $\mathrm{Be}$ & $<0.002$ \\
\hline $\mathrm{Cr}$ & $<0.052$ & $\mathrm{Ca}$ & 2.84 \\
\hline $\mathrm{Fe}$ & {$[0.396]$} & $\mathrm{Ce}$ & $<0.304$ \\
\hline $\mathrm{Mn}$ & $<0.007$ & Co & $<0.073$ \\
\hline $\mathrm{Na}$ & 2,553 & $\mathrm{Cu}$ & 1.74 \\
\hline $\mathrm{P}$ & $<1.52$ & Dy & $<0.088$ \\
\hline S & {$[2.28]$} & $\mathrm{Eu}$ & $<0.033$ \\
\hline $\mathrm{Si}$ & 5.48 & $\mathrm{~K}$ & [2.95] \\
\hline $\mathrm{Sr}$ & [0.023] & $\mathrm{La}$ & $<0.085$ \\
\hline $\mathrm{U}$ & [1.40] & $\mathrm{Li}$ & $<0.018$ \\
\hline $\mathrm{Zn}$ & [1.22] & $\mathrm{Mg}$ & {$[0.106]$} \\
\hline $\mathrm{Zr}$ & {$[0.055]$} & Mo & $<0.158$ \\
\hline Fluoride & {$[0.350]$} & $\mathrm{Nd}$ & $<0.164$ \\
\hline Nitrite & $<0.500$ & $\mathrm{Ni}$ & {$[0.228]$} \\
\hline Nitrate & {$[4.40]$} & $\mathrm{Pb}$ & $<0.974$ \\
\hline Phosphate & $<0.600$ & $\mathrm{Pd}$ & $<0.192$ \\
\hline Sulfate & $<0.750$ & $\mathrm{Rh}$ & $<0.365$ \\
\hline & & $\mathrm{Ru}$ & $<0.259$ \\
\hline & & $\mathrm{Sb}$ & $<0.609$ \\
\hline & & Se & [5.17] \\
\hline & & Sn & $<0.821$ \\
\hline & & $\mathrm{Ta}$ & $<0.517$ \\
\hline & & $\mathrm{Te}$ & $<0.791$ \\
\hline & & Th & $<0.298$ \\
\hline & & $\mathrm{Ti}$ & $<0.013$ \\
\hline & & $\mathrm{Tl}$ & [1.67] \\
\hline & & $\mathrm{V}$ & [0.049] \\
\hline & & $\mathrm{W}$ & $<0.578$ \\
\hline & & $\mathrm{Y}$ & $<0.013$ \\
\hline
\end{tabular}




\section{Appendix J}

\section{Duplicate Sample Differential Particle Size Plots for the Initial Group 4 Sample}




\section{Appendix $\mathbf{J}$}

\section{Duplicate Sample Differential Particle Size Plots for the Initial Group 4 Sample}

Figures J.1, J.2, and J.3 show the differential volume distribution as a function of particle diameter for the duplicate Group 4 initial characterization sample, TI547-G4-S-WL-PSD-2. Specifically, J.1 shows the pre-sonication PSDs as a function of pump speed, J.2 shows the PSDs as a function of sonication, and J.3 shows the post-sonication PSDs as a function of pump speed.

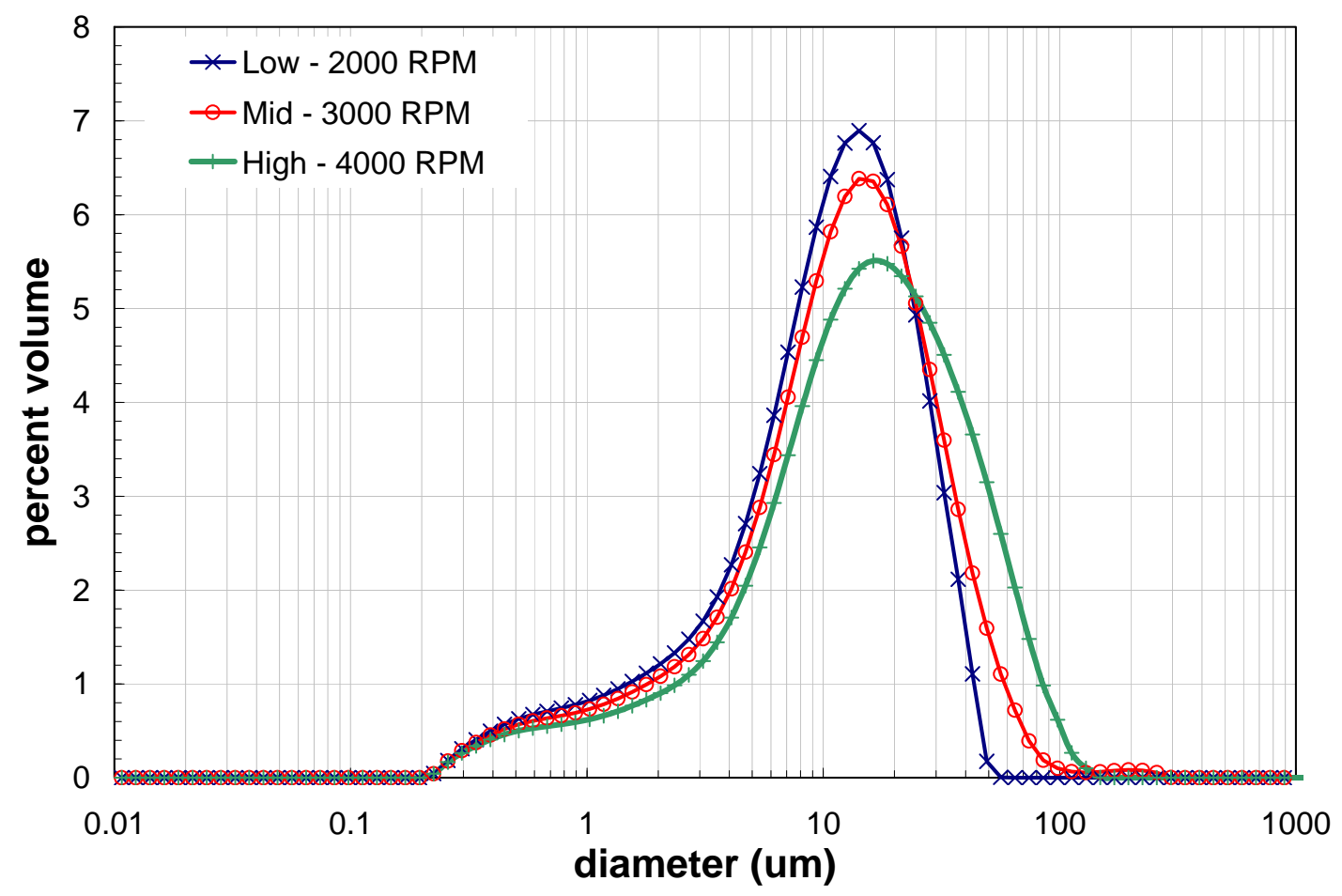

Figure J.1. Pre-Sonication Volume Distribution Result for the Duplicate Group 4 Initial Characterization Sample as a Function of Pump Speed 


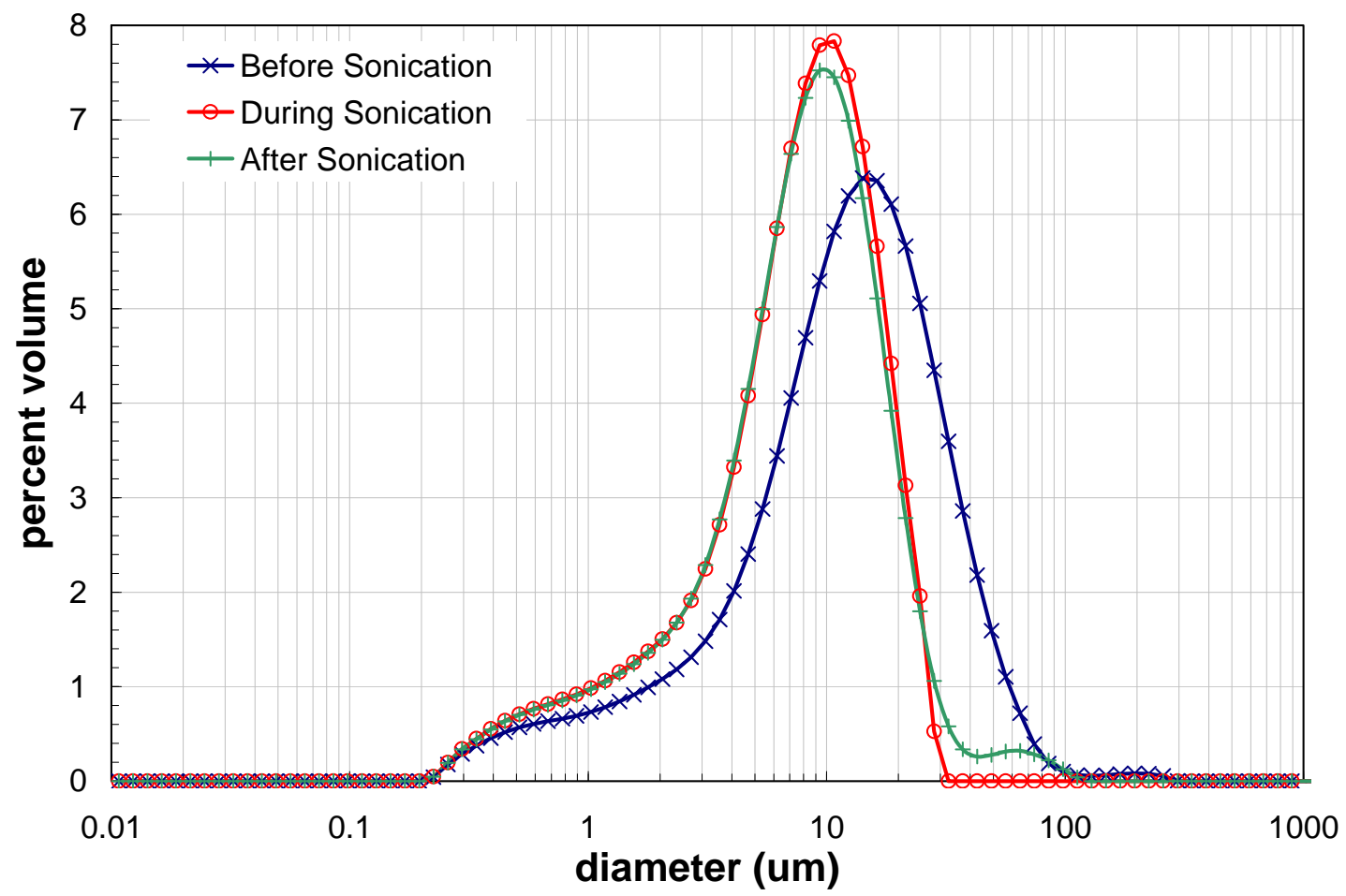

Figure J.2. Volume Distribution Result for the Duplicate Group 4 Initial Characterization Sample as a Function of Sonication. Note: the during-sonication condition corresponds to measurement condition 6 (3,000 RPM, 75\% Sonication). 


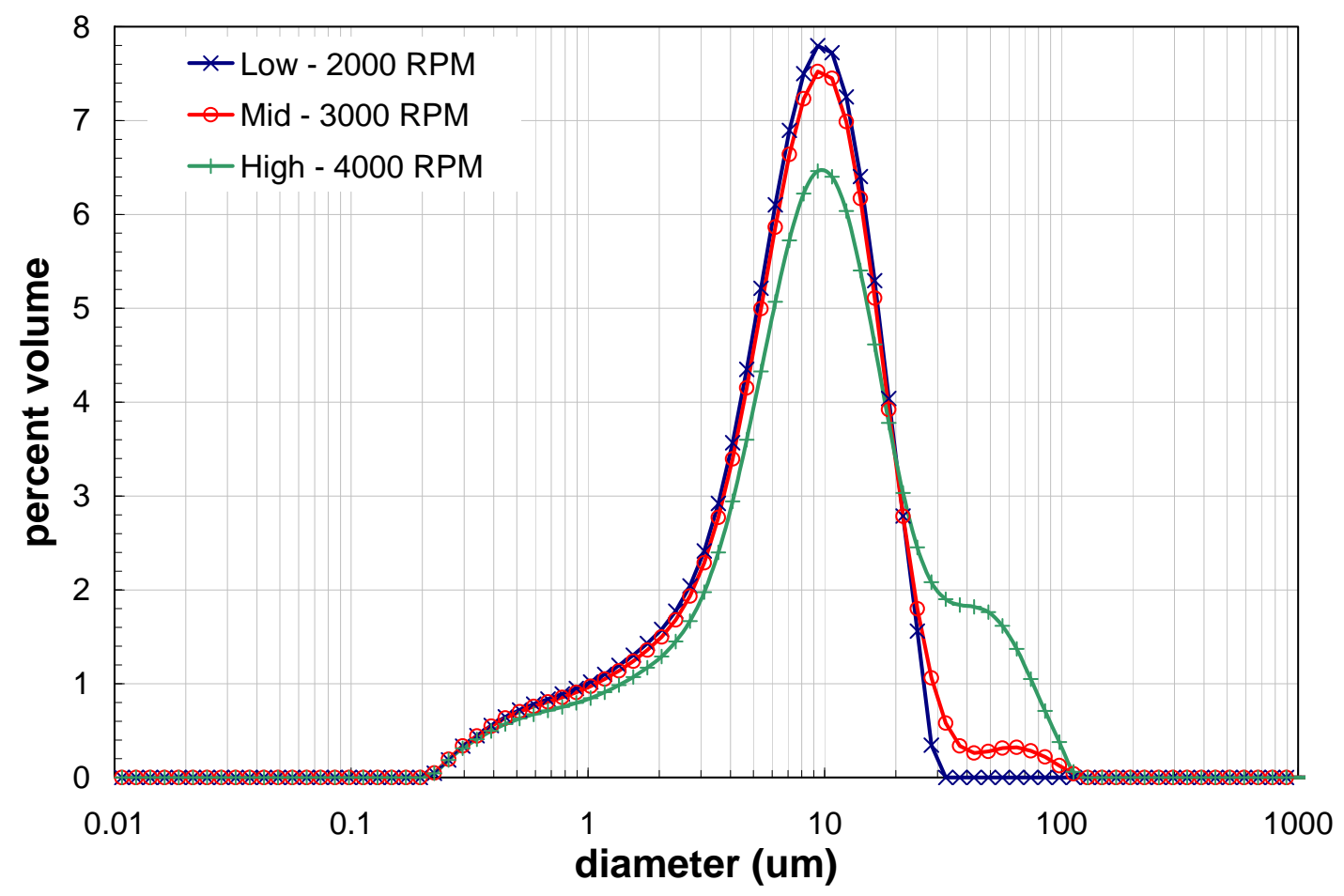

Figure J.3. Post-Sonication Volume Distribution Result for the Duplicate Group 4 Initial Characterization Sample as a Function of Pump Speed 
Appendix K

Detailed Cumulative PSD for the Initial Group 4 Sample 


\section{Appendix K}

\section{Detailed Cumulative PSD for the Initial Group 4 Sample}

Tables K.1 and K.2 present detailed cumulative oversize distributions (by volume/weight) for Group 4 initial characterization samples TI547-G4-S-WL-PSD-1 and -2, respectively. Results are reported as a function of test condition. This appendix does not provide a discussion of the detailed distributions; however, a portion of these results (specifically, the $10^{\text {th }}, 50^{\text {th }}$, and $90^{\text {th }}$ diameter percentiles) are presented and discussed in the main body of this interim report.

Table K.1. Cumulative Oversize Diameter Distributions for the Primary Group 4 Initial Characterization Sample, TI547-G4-S-WL-PSD-1

\begin{tabular}{|c|c|c|c|c|c|c|c|c|c|c|c|c|c|c|c|}
\hline \multirow{2}{*}{\begin{tabular}{|c|} 
Test \\
Condition
\end{tabular}} & \multicolumn{15}{|c|}{ "Volume / Weight Cumulative Oversize Diameter $(\mu \mathrm{m})$} \\
\hline & $1 \%$ & $5 \%$ & $10 \%$ & $20 \%$ & $25 \%$ & $30 \%$ & $40 \%$ & $50 \%$ & $60 \%$ & $70 \%$ & $75 \%$ & $80 \%$ & $90 \%$ & $95 \%$ & $99 \%$ \\
\hline \begin{tabular}{|l|}
1 - $3000 / 1$ \\
pre-sonic
\end{tabular} & 0.41 & 1.3 & 3.2 & 6.9 & 8.6 & 10 & 14 & 20 & 31 & 45 & 52 & 61 & 83 & 100 & 130 \\
\hline \begin{tabular}{|l|} 
- 4000 / \\
pre-sonic
\end{tabular} & 0.42 & 1.5 & 3.9 & 8.0 & 10 & 12 & 18 & 26 & 36 & 47 & 53 & 59 & 78 & 93 & 120 \\
\hline \begin{tabular}{|l|}
3 - $2000 / 1$ \\
pre-sonic
\end{tabular} & 0.36 & 0.83 & 1.7 & 4.1 & 5.2 & 6.3 & 8.4 & 10 & 13 & 16 & 18 & 20 & 27 & 37 & 110 \\
\hline \begin{tabular}{|l|}
$4-3000 /$ \\
$25 \%$
\end{tabular} & 0.36 & 0.79 & 1.6 & 3.9 & 4.9 & 6.0 & 7.9 & 9.9 & 12 & 15 & 16 & 18 & 23 & 27 & 34 \\
\hline \begin{tabular}{|l}
$5-3000 /$ \\
$50 \%$ \\
\end{tabular} & 0.35 & 0.77 & 1.5 & 3.6 & 4.6 & 5.6 & 7.3 & 9.1 & 11 & 13 & 15 & 16 & 21 & 24 & 30 \\
\hline $\begin{array}{l}6-3000 / \\
75 \%\end{array}$ & 0.35 & 0.75 & 1.5 & 3.4 & 4.3 & 5.1 & 6.6 & 8.2 & 9.8 & 12 & 13 & 14 & 18 & 21 & 26 \\
\hline \begin{tabular}{|l|}
7 - 3000 / \\
post-sonic \\
\end{tabular} & 0.37 & 0.85 & 1.8 & 4.0 & 5.0 & 5.9 & 7.7 & 9.7 & 12 & 16 & 18 & 23 & 51 & 70 & 100 \\
\hline \begin{tabular}{|l|}
8 - 4000 / \\
post-sonic
\end{tabular} & 0.39 & 1.1 & 2.5 & 5.3 & 6.5 & 7.7 & 10 & 14 & 22 & 35 & 41 & 48 & 67 & 82 & 110 \\
\hline $\begin{array}{l}\text { - } 2000 \text { / } \\
\text { post-sonic }\end{array}$ & 0.35 & 0.74 & 1.4 & 3.2 & 4.1 & 4.9 & 6.4 & 7.9 & 9.5 & 11 & 12 & 14 & 17 & 21 & 26 \\
\hline
\end{tabular}


Table K.2. Cumulative Oversize Diameter Distributions for the Duplicate Group 4 Initial Characterization Sample, TI547-G4-S-WL-PSD-2

\begin{tabular}{|c|c|c|c|c|c|c|c|c|c|c|c|c|c|c|c|}
\hline \multirow[b]{2}{*}{ Test Condition } & \multicolumn{15}{|c|}{ Volume / Weight Cumulative Oversize Diameter $(\mu \mathrm{m})$} \\
\hline & $1 \%$ & $5 \%$ & $10 \%$ & $20 \%$ & $25 \%$ & $30 \%$ & $40 \%$ & $50 \%$ & $60 \%$ & $70 \%$ & $75 \%$ & $80 \%$ & $90 \%$ & $95 \%$ & $99 \%$ \\
\hline$-3000 /$ & 0.38 & 0.95 & 2.1 & 4.9 & 6.2 & 7.4 & 9.8 & 12 & 15 & 19 & 22 & 25 & 34 & 44 & 72 \\
\hline$-4000 /$ & 39 & 1.1 & 2.5 & 8 & 7.2 & 8.6 & 12 & 15 & & 25 & 29 & r & 48 & 62 & 91 \\
\hline $3-2000 /$ & .37 & 0.87 & 1.8 & 4.3 & 5.5 & 6.6 & 8.8 & 11 & 13 & 17 & 18 & 20 & 27 & 32 & 41 \\
\hline $4-3000$ & 37 & 0.86 & 1.8 & 4.2 & 5.4 & 6.5 & 8.5 & 11 & 13 & 16 & 17 & 19 & 25 & 30 & 38 \\
\hline $5-3000$ & 36 & 0.82 & 1.7 & 3.9 & 4.9 & 5.8 & 7.6 & 9.3 & 11 & 13 & 15 & 16 & 21 & 25 & 31 \\
\hline $6-3000 /$ & 0.36 & 0.78 & 1.5 & 3.4 & 4.3 & 5.1 & 6.5 & 8.0 & 9.6 & 11 & 13 & 14 & 17 & 20 & 25 \\
\hline $7-3000$ & .36 & 0.79 & 1.6 & 3.4 & 4.3 & 5.1 & 6.5 & 8.0 & 9.6 & 12 & 13 & 14 & 19 & 24 & 60 \\
\hline $8-4000 / 1$ & 0.37 & 0.86 & 1.8 & 3.9 & 4.9 & 5.7 & 7.4 & 9.2 & 11 & 15 & 17 & 20 & 36 & 53 & 81 \\
\hline 9 - 2000 / post-sonic & 0.36 & 0.78 & 1.5 & 3.3 & 4.1 & 4.9 & 6.3 & 7.7 & 9.2 & 11 & 12 & 13 & 17 & 20 & 24 \\
\hline
\end{tabular}

Table K.3 shows the absolute relative percent difference (RPD) between primary and duplicate results, which is calculated as:

$$
R P D=\left|\frac{d_{d}(n)-d_{p}(n)}{d_{p}(n)}\right|
$$

where $d_{p}(n)$ and $d_{d}(n)$ are the primary and duplicate cumulative oversize diameters corresponding to the $n^{\text {th }}$ percentile. As before, this appendix does not provide a discussion of the RPD results; however, the RPD for the $10^{\text {th }}, 50^{\text {th }}$, and $90^{\text {th }}$ diameter percentiles are presented and discussed in the main body of this interim report. 
Table K.3. Relative Percent Difference Between Primary and Duplicate Group 4 Initial Characterization Samples (TI547-G4-S-WL-PSD -1 and -2, respectively) as a Function of Test Condition

\begin{tabular}{|c|c|c|c|c|c|c|c|c|c|c|c|c|c|c|c|}
\hline \multirow[b]{2}{*}{ Test Condition } & \multicolumn{15}{|c|}{ Absolute RPD (\%) } \\
\hline & $1 \%$ & $5 \%$ & $10 \%$ & $20 \%$ & $25 \%$ & $30 \%$ & $40 \%$ & $50 \%$ & $60 \%$ & $70 \%$ & $75 \%$ & $80 \%$ & $90 \%$ & $95 \%$ & $99 \%$ \\
\hline $\mathbf{1}$ - 3000 / pre-sonic & 7.4 & 28 & 34 & 29 & 28 & 28 & 31 & 39 & 50 & 57 & 59 & 60 & 59 & 56 & 44 \\
\hline 2 - 4000 / pre-sonic & 7.4 & 29 & 34 & 28 & 28 & 29 & 36 & 43 & 47 & 46 & 45 & 43 & 38 & 33 & 22 \\
\hline 3 - 2000 / pre-sonic & 1.7 & 4.3 & 5.9 & 5.4 & 5.0 & 4.8 & 4.8 & 4.9 & 4.8 & 4.4 & 3.8 & 2.9 & 2.4 & 13 & 64 \\
\hline $4-3000 / 25 \%$ & 2.5 & 8.3 & 11 & 10 & 9.1 & 8.4 & 7.8 & 7.7 & 7.9 & 8.3 & 8.6 & 8.9 & 9.9 & 11 & 12 \\
\hline $5-3000 / 50 \%$ & 2.3 & 7.2 & 8.7 & 7.1 & 5.7 & 4.8 & 3.6 & 2.8 & 2.4 & 2.1 & 1.9 & 1.8 & 1.7 & 1.7 & 1.9 \\
\hline $6-3000 / 75 \%$ & 2.0 & 4.8 & 4.8 & 1.5 & 0.14 & 0.65 & 1.5 & 1.9 & 2.2 & 2.4 & 2.4 & 2.5 & 2.7 & 2.9 & 2.7 \\
\hline 7 - 3000 / post-sonic & 1.4 & 7.3 & 13 & 15 & 15 & 15 & 16 & 17 & 20 & 25 & 30 & 38 & 63 & 66 & 41 \\
\hline 8 - 4000 / post-sonic & 5.2 & 20 & 28 & 26 & 25 & 26 & 29 & 35 & 47 & 58 & 59 & 59 & 46 & 35 & 26 \\
\hline 9 - 2000 / post-sonic & 2.3 & 4.7 & 4.4 & 1.0 & 0.29 & 1.1 & 1.9 & 2.3 & 2.6 & 2.8 & 2.9 & 3.1 & 3.6 & 4.5 & 7.2 \\
\hline
\end{tabular}



Appendix L

Group 4 Analytical Results from Parametric Leaching 


\section{Appendix L}

\section{Group 4 Analytical Results from Parametric Leaching}

Tables L.1and L.2 provide information about analyte concentrations during leaching at various time increments at $60^{\circ} \mathrm{C}$ in units of $\mu \mathrm{g} / \mathrm{mL}$ and $\mathrm{M}$, respectively, Tables L.3 and L.4 at $80^{\circ} \mathrm{C}$ in units of $\mu \mathrm{g} / \mathrm{mL}$ and $\mathrm{M}$, respectively, and Tables L.5 and L.6 at $100^{\circ} \mathrm{C}$ in units of $\mu \mathrm{g} / \mathrm{mL}$ and $\mathrm{M}$, respectively. Table L.7 provides analyte concentrations in the wash solution from solid samples leached at $80^{\circ} \mathrm{C} / 3 \mathrm{M} \mathrm{NaOH}$.

Table L.1. Analyte Concentrations as a Function of Time for Leaching at $60^{\circ} \mathrm{C}$, in $\mu \mathrm{g} / \mathrm{mL}$

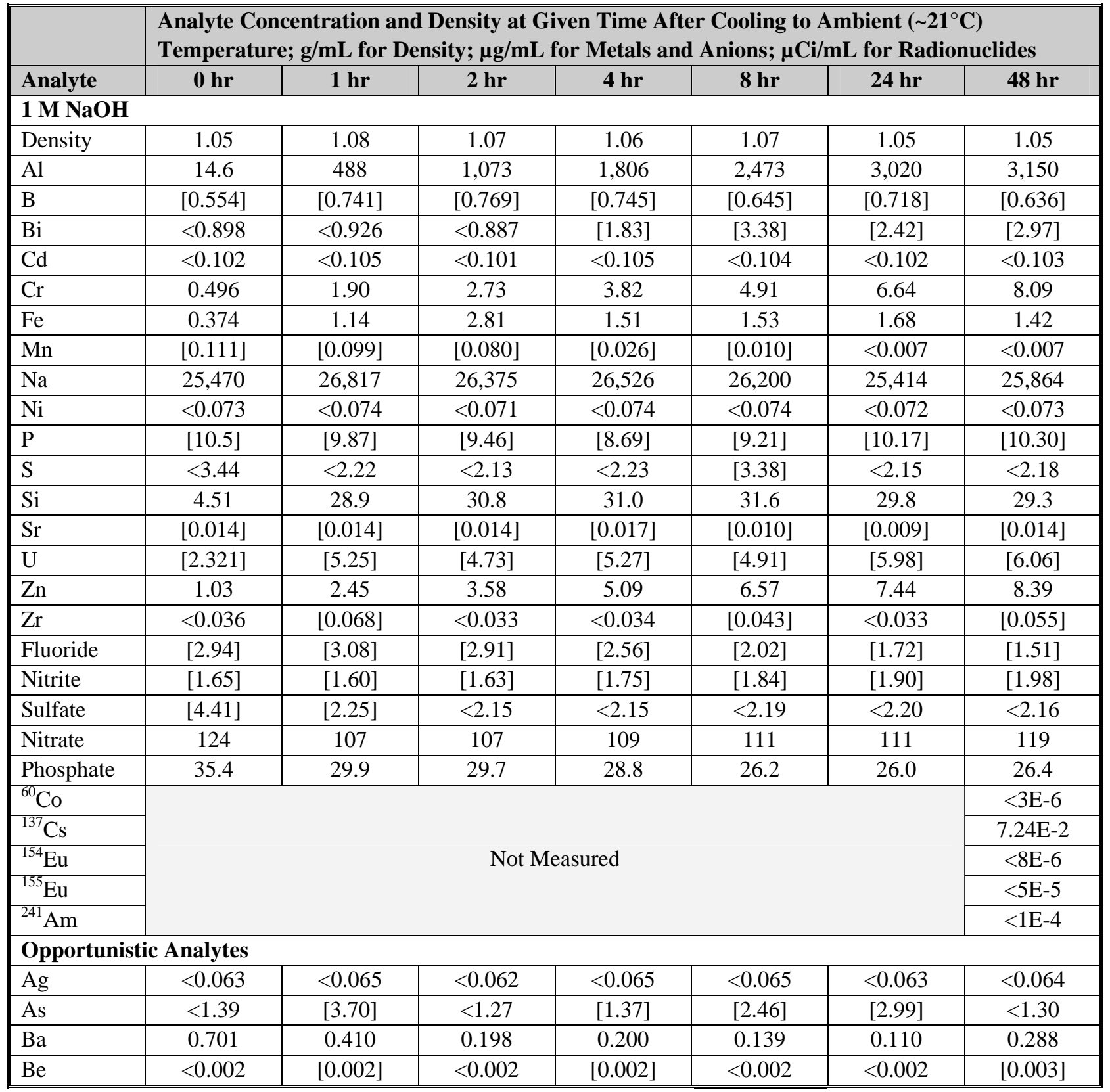


Table L.1 (Contd)

\begin{tabular}{|c|c|c|c|c|c|c|c|}
\hline \multirow[b]{2}{*}{ Analyte } & \multicolumn{7}{|c|}{$\begin{array}{l}\text { Analyte Concentration and Density at Given Time After Cooling to Ambient }\left(\sim 21^{\circ} \mathrm{C}\right) \\
\text { Temperature; } \mathrm{g} / \mathrm{mL} \text { for Density; } \mu \mathrm{g} / \mathrm{mL} \text { for Metals and Anions; } \mu \mathrm{Ci} / \mathrm{mL} \text { for Radionuclides }\end{array}$} \\
\hline & O hr & $1 \mathrm{hr}$ & $2 \mathrm{hr}$ & $4 \mathrm{hr}$ & $8 \mathrm{hr}$ & $24 \mathrm{hr}$ & $48 \mathrm{hr}$ \\
\hline $\mathrm{Ca}$ & $<0.099$ & {$[0.148]$} & {$[0.296]$} & 1.247 & $<0.101$ & $<0.099$ & $<0.100$ \\
\hline $\mathrm{Ce}$ & $<0.299$ & $<0.309$ & {$[0.296]$} & $<0.310$ & $<0.307$ & [0.329] & $<0.303$ \\
\hline Co & $<0.072$ & $<0.074$ & {$[0.106]$} & $<0.074$ & $<0.074$ & $<0.072$ & $<0.073$ \\
\hline $\mathrm{Cu}$ & $<0.042$ & $<0.043$ & $<0.041$ & {$[0.096]$} & $<0.043$ & [0.048] & {$[0.048]$} \\
\hline Dy & $<0.087$ & $<0.089$ & [0.103] & $<0.090$ & [0.089] & $<0.087$ & $<0.088$ \\
\hline $\mathrm{Eu}$ & $<0.013$ & {$[0.049]$} & {$[0.050]$} & {$[0.029]$} & $<0.014$ & $<0.013$ & $<0.013$ \\
\hline K & [2.85] & [3.70] & {$[3.25]$} & [5.89] & {$[7.68]$} & [5.98] & [6.36] \\
\hline $\mathrm{La}$ & $<0.084$ & $<0.086$ & $<0.083$ & $<0.087$ & $<0.086$ & $<0.084$ & $<0.085$ \\
\hline $\mathrm{Li}$ & $<0.018$ & [0.111] & [0.109] & $<0.019$ & $<0.018$ & $<0.018$ & $<0.018$ \\
\hline $\mathrm{Mg}$ & $<0.042$ & $<0.043$ & {$[0.047]$} & $<0.043$ & $<0.043$ & $<0.042$ & $<0.042$ \\
\hline Mo & $<0.156$ & $<0.160$ & $<0.154$ & $<0.161$ & $<0.160$ & $<0.155$ & $<0.157$ \\
\hline $\mathrm{Nd}$ & $<0.162$ & $<0.167$ & $<0.160$ & $<0.168$ & $<0.166$ & $<0.161$ & $<0.164$ \\
\hline $\mathrm{Pb}$ & {$[5.84]$} & {$[9.26]$} & 12.1 & 14.1 & 17.0 & 19.0 & 18.5 \\
\hline $\mathrm{Pd}$ & $<0.189$ & {$[0.284]$} & [0.251] & $<0.195$ & $<0.194$ & $<0.188$ & $<0.191$ \\
\hline $\mathrm{Rh}$ & $<0.359$ & $<0.370$ & $<0.355$ & $<0.372$ & $<0.369$ & $<0.359$ & $<0.363$ \\
\hline $\mathrm{Ru}$ & $<0.255$ & $<0.262$ & $<0.251$ & $<0.264$ & $<0.261$ & $<0.254$ & $<0.257$ \\
\hline $\mathrm{Sb}$ & $<0.599$ & $<0.617$ & [0.769] & {$[1.15]$} & $<0.614$ & {$[1.05]$} & [1.06] \\
\hline Se & $<2.10$ & $<2.16$ & $<2.07$ & $<2.17$ & $<2.15$ & $<2.09$ & $<2.12$ \\
\hline Sn & $<0.809$ & $<0.833$ & $<0.798$ & $<0.838$ & $<0.829$ & $<0.807$ & $<0.818$ \\
\hline $\mathrm{Ta}$ & $<0.509$ & [0.833] & $<0.503$ & $<0.527$ & $<0.522$ & $<0.508$ & $<0.515$ \\
\hline $\mathrm{Te}$ & $<0.779$ & $<0.802$ & $<0.769$ & $<0.807$ & $<0.799$ & $<0.777$ & $<0.787$ \\
\hline Th & $<0.293$ & {$[0.302]$} & {$[0.444]$} & $<0.304$ & $<0.301$ & $<0.293$ & $<0.297$ \\
\hline $\mathrm{Ti}$ & {$[0.015]$} & {$[0.024]$} & [0.030] & {$[0.016]$} & {$[0.018]$} & [0.014] & {$[0.015]$} \\
\hline $\mathrm{Tl}$ & $<1.14$ & $<1.17$ & $<1.12$ & $<1.18$ & $<1.17$ & $<1.14$ & $<1.15$ \\
\hline $\mathrm{V}$ & {$[0.096]$} & {$[0.117]$} & [0.145] & [0.130] & {$[0.126]$} & [0.120] & {$[0.139]$} \\
\hline $\mathrm{W}$ & $<0.569$ & $<0.586$ & $<0.562$ & {$[0.714]$} & $<0.584$ & $<0.568$ & $<0.575$ \\
\hline $\mathrm{Y}$ & $<0.010$ & {$[0.014]$} & [0.020] & $<0.010$ & $<0.010$ & [0.010] & $<0.010$ \\
\hline \multicolumn{8}{|c|}{$3 \mathrm{M}$ NaOH } \\
\hline Density & 1.12 & 1.13 & 1.14 & 1.16 & 1.14 & 1.13 & 1.13 \\
\hline $\mathrm{Al}$ & 55.7 & 1,070 & 2,138 & 2,968 & 3,342 & 3,362 & 3,568 \\
\hline B & {$[0.933]$} & $<0.732$ & {$[0.815]$} & $<0.740$ & $<0.729$ & $<0.747$ & {$[0.816]$} \\
\hline $\mathrm{Bi}$ & $<4.52$ & $<4.57$ & $<4.53$ & [9.87] & [5.77] & [4.67] & [4.84] \\
\hline $\mathrm{Cd}$ & $<0.512$ & $<0.518$ & $<0.513$ & $<0.524$ & $<0.517$ & $<0.529$ & $<0.514$ \\
\hline $\mathrm{Cr}$ & [1.415] & 3.69 & 5.04 & 6.54 & 7.96 & 10.3 & 11.6 \\
\hline $\mathrm{Fe}$ & [1.084] & 4.91 & 5.53 & 6.42 & 7.75 & 7.56 & 8.10 \\
\hline Mn & {$[0.283]$} & {$[0.366]$} & {$[0.214]$} & {$[0.040]$} & $<0.035$ & $<0.036$ & $<0.035$ \\
\hline $\mathrm{Na}$ & 74,663 & 76,818 & 77,305 & 79,289 & 79,003 & 71,904 & 73,469 \\
\hline $\mathrm{Ni}$ & $<0.361$ & $<0.366$ & $<0.362$ & $<0.370$ & $<0.365$ & $<0.374$ & $<0.363$ \\
\hline $\mathrm{P}$ & $<7.53$ & $<7.62$ & [11.5] & [18.2] & $<>7.60$ & $<<9.65$ & $<7.56$ \\
\hline$S$ & {$[22.0]$} & $<10.97$ & [39.3] & [30.9] & {$[15.2]$} & [11.2] & [51.4] \\
\hline $\mathrm{Si}$ & [7.53] & 38.1 & 40.2 & 41.6 & 42.8 & 43.0 & 47.2 \\
\hline $\mathrm{Sr}$ & {$[0.033]$} & {$[0.040]$} & {$[0.039]$} & {$[0.046]$} & {$[0.043]$} & {$[0.034]$} & {$[0.039]$} \\
\hline $\mathrm{U}$ & [5.12] & [9.14] & [12.1] & [14.5] & [11.5] & {$[16.8]$} & [12.1] \\
\hline $\mathrm{Zn}$ & {$[1.66]$} & {$[4.27]$} & 6.70 & 8.48 & 9.39 & 9.06 & 9.61 \\
\hline
\end{tabular}


Table L.1 (Contd)

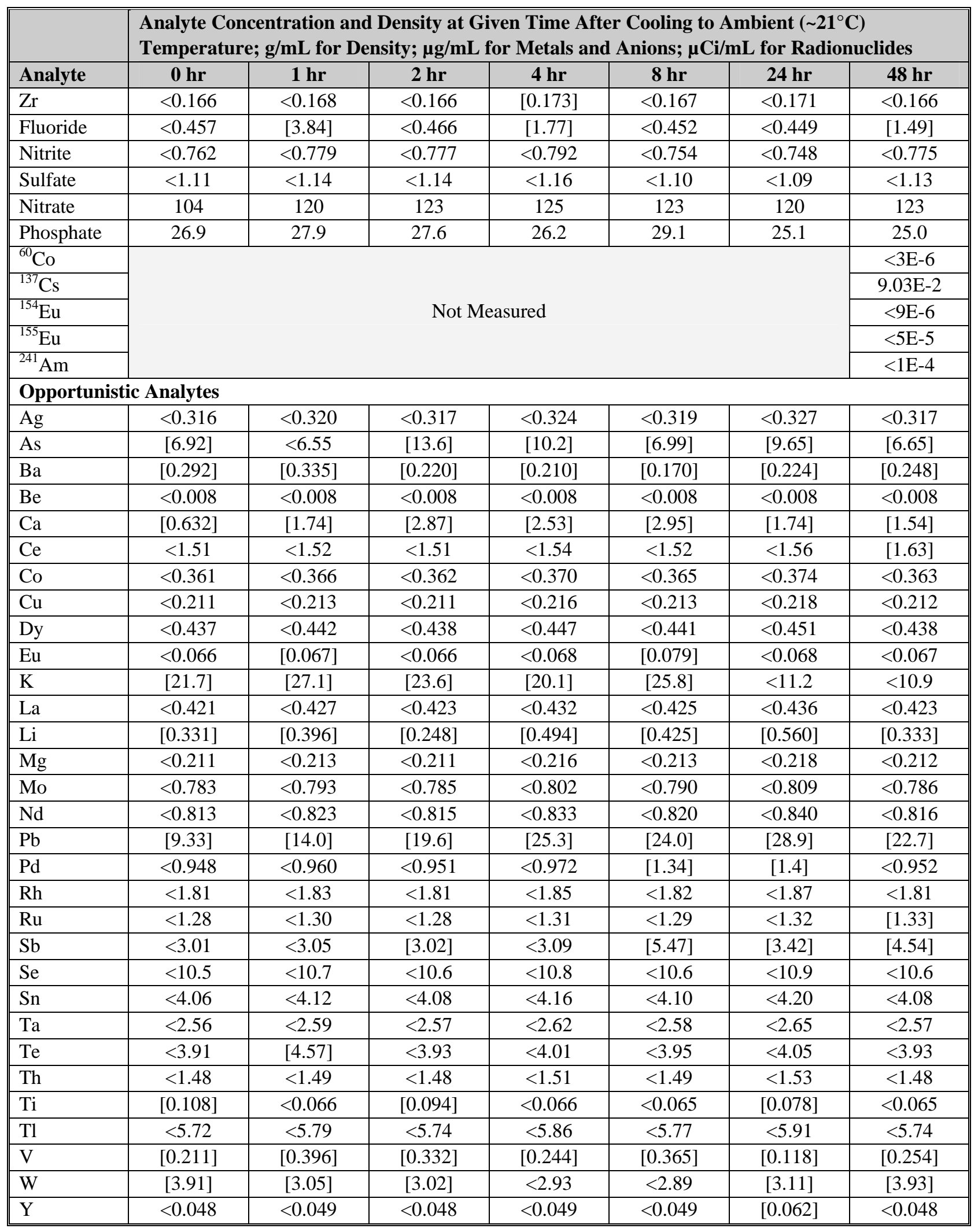


Table L.1 (Contd)

\begin{tabular}{|c|c|c|c|c|c|c|c|}
\hline \multirow[b]{2}{*}{ Analyte } & \multicolumn{7}{|c|}{$\begin{array}{l}\text { Analyte Concentration and Density at Given Time After Cooling to Ambient }\left(\sim 21^{\circ} \mathrm{C}\right) \\
\text { Temperature; } \mathrm{g} / \mathrm{mL} \text { for Density; } \mu \mathrm{g} / \mathrm{mL} \text { for Metals and Anions; } \mu \mathrm{Ci} / \mathrm{mL} \text { for Radionuclides }\end{array}$} \\
\hline & o hr & $1 \mathrm{hr}$ & $2 \mathrm{hr}$ & $4 \mathrm{hr}$ & $8 \mathrm{hr}$ & $24 \mathrm{hr}$ & $48 \mathrm{hr}$ \\
\hline \multicolumn{8}{|l|}{$5 \mathrm{M}$ NaOH } \\
\hline Density & 1.19 & 1.22 & 1.21 & 1.21 & 1.22 & 1.20 & 1.20 \\
\hline $\mathrm{Al}$ & 57.9 & 1,866 & 2,883 & 3,497 & 3,669 & 3,586 & 3,688 \\
\hline B & $<0.743$ & $<0.740$ & $<0.718$ & $<0.730$ & $<0.722$ & $<0.735$ & $<0.714$ \\
\hline $\mathrm{Bi}$ & $<4.65$ & [6.79] & [9.57] & [11.6] & {$[10.2]$} & {$[10.7]$} & [11.9] \\
\hline $\mathrm{Cd}$ & $<0.526$ & $<0.524$ & $<0.508$ & $<0.517$ & $<0.511$ & $<0.521$ & $<0.506$ \\
\hline $\mathrm{Cr}$ & [1.42] & 4.78 & 6.61 & 8.58 & 10.3 & 12.5 & 13.6 \\
\hline $\mathrm{Fe}$ & {$[1.83]$} & 8.14 & 10.4 & 18.1 & 13.7 & 15.7 & 16.4 \\
\hline $\mathrm{Mn}$ & [0.619] & 1.14 & 0.775 & {$[0.456]$} & [0.189] & $<0.035$ & $<0.034$ \\
\hline $\mathrm{Na}$ & 140,599 & 137,255 & 127,417 & 128,947 & 129,624 & 125,034 & 126,121 \\
\hline $\mathrm{Ni}$ & $<0.372$ & $<0.370$ & $<0.359$ & $<0.365$ & $<0.361$ & $<0.368$ & $<0.357$ \\
\hline $\mathrm{P}$ & $<7.74$ & {$[8.94]$} & {$[8.67]$} & $<7.60$ & [11.4] & $<7.66$ & [9.22] \\
\hline $\mathrm{S}$ & $<11.1$ & $<11.1$ & $<10.8$ & [20.4] & {$[27.7]$} & $<11.0$ & $<10.7$ \\
\hline $\mathrm{Si}$ & 10.3 & 38.9 & 41.3 & 44.1 & 47.2 & 49.6 & 52.9 \\
\hline $\mathrm{Sr}$ & {$[0.065]$} & {$[0.068]$} & {$[0.060]$} & {$[0.076]$} & {$[0.075]$} & {$[0.083]$} & {$[0.068]$} \\
\hline $\mathrm{U}$ & [9.29] & [8.64] & {$[8.67]$} & [11.6] & [15.0] & [15.3] & [10.4] \\
\hline $\mathrm{Zn}$ & {$[1.92]$} & 6.72 & 8.94 & 11.1 & 10.3 & 10.7 & 10.6 \\
\hline $\mathrm{Zr}$ & {$[0.235]$} & $<0.170$ & $<0.165$ & $<0.167$ & {$[0.177]$} & $<0.169$ & [0.199] \\
\hline Fluoride & [5.72] & {$[5.30]$} & $<0.952$ & $<0.956$ & $<0.957$ & $<0.986$ & $<0.918$ \\
\hline Nitrite & $<1.52$ & $<1.49$ & $<1.49$ & $<1.49$ & $<1.49$ & $<1.54$ & $<1.43$ \\
\hline Sulfate & $<2.25$ & $<2.20$ & $<2.20$ & $<2.21$ & $<2.21$ & $<2.28$ & $<2.12$ \\
\hline Nitrate & 124 & 123 & 129 & 134 & 126 & 132 & 129 \\
\hline Phosphate & 39.4 & 34.8 & 34.0 & 361.1 & 31.5 & 30.5 & 30.9 \\
\hline${ }^{60} \mathrm{Co}$ & \multirow{5}{*}{\multicolumn{6}{|c|}{ Not Measured }} & $<2 \mathrm{E}-6$ \\
\hline${ }^{137} \mathrm{Cs}$ & & & & & & & $9.59 \mathrm{E}-2$ \\
\hline${ }^{154} \mathrm{Eu}$ & & & & & & & $<9 \mathrm{E}-6$ \\
\hline${ }^{155} \mathrm{Eu}$ & & & & & & & $<5 \mathrm{E}-5$ \\
\hline${ }^{241} \mathrm{Am}$ & & & & & & & $<1 \mathrm{E}-4$ \\
\hline \multicolumn{8}{|c|}{ Opportunistic Analytes } \\
\hline $\mathrm{Ag}$ & $<0.325$ & $<0.324$ & $<0.314$ & $<0.319$ & $<0.316$ & $<0.322$ & $<0.312$ \\
\hline As & {$[14.6]$} & {$[8.02]$} & $<6.43$ & $<6.54$ & {$[10.83]$} & $<6.59$ & $<6.40$ \\
\hline $\mathrm{Ba}$ & {$[0.403]$} & [0.432] & {$[0.248]$} & {$[0.365]$} & [0.391] & {$[0.337]$} & [0.327] \\
\hline $\mathrm{Be}$ & $<0.008$ & $<0.008$ & $<0.008$ & $<0.008$ & $<0.008$ & $<0.008$ & {$[0.008]$} \\
\hline $\mathrm{Ca}$ & {$[4.34]$} & [3.70] & [4.49] & 6.20 & {$[2.92]$} & {$[4.60]$} & [3.57] \\
\hline $\mathrm{Ce}$ & $<1.55$ & $<1.54$ & $<1.50$ & $<1.52$ & $<1.50$ & $<1.53$ & $<1.49$ \\
\hline Co & $<0.372$ & $<0.370$ & $<0.359$ & $<0.365$ & $<0.361$ & $<0.368$ & $<0.357$ \\
\hline $\mathrm{Cu}$ & $<0.217$ & $<0.216$ & $<0.209$ & $<0.213$ & $<0.211$ & $<0.215$ & $<0.208$ \\
\hline Dy & $<0.449$ & $<0.447$ & $<0.434$ & $<0.441$ & $<0.436$ & $<0.444$ & $<0.431$ \\
\hline $\mathrm{Eu}$ & $<0.068$ & $<0.068$ & $<0.066$ & $<0.067$ & $<0.066$ & $<0.067$ & $<0.065$ \\
\hline $\mathrm{K}$ & {$[31.0]$} & [28.1] & [32.9] & [36.5] & {$[36.1]$} & [39.8] & {$[41.6]$} \\
\hline $\mathrm{La}$ & $<0.434$ & [0.494] & $<0.419$ & $<0.426$ & $<0.421$ & $<0.429$ & $<0.416$ \\
\hline $\mathrm{Li}$ & $<0.093$ & [0.099] & {$[0.508]$} & {$[0.547]$} & {$[0.451]$} & {$[0.398]$} & {$[0.274]$} \\
\hline $\mathrm{Mg}$ & $<0.217$ & $<0.216$ & $<0.209$ & $<0.213$ & $<0.211$ & $<0.215$ & $<0.208$ \\
\hline Mo & $<0.805$ & $<0.802$ & $<0.778$ & $<0.791$ & $<0.782$ & $<0.797$ & $<0.773$ \\
\hline
\end{tabular}


Table I.1 (Contd)

\begin{tabular}{|c|c|c|c|c|c|c|c|}
\hline \multirow[b]{2}{*}{ Analyte } & \multicolumn{7}{|c|}{$\begin{array}{l}\text { Analyte Concentration and Density at Given Time After Cooling to Ambient }\left(\sim 21^{\circ} \mathrm{C}\right) \\
\text { Temperature; } \mathrm{g} / \mathrm{mL} \text { for Density; } \mu \mathrm{g} / \mathrm{mL} \text { for Metals and Anions; } \mu \mathrm{Ci} / \mathrm{mL} \text { for Radionuclides }\end{array}$} \\
\hline & o hr & $1 \mathrm{hr}$ & $2 \mathrm{hr}$ & $4 \mathrm{hr}$ & $8 \mathrm{hr}$ & $24 \mathrm{hr}$ & $48 \mathrm{hr}$ \\
\hline $\mathrm{Nd}$ & $<0.836$ & $<0.833$ & $<0.808$ & $<0.821$ & $<0.812$ & $<0.827$ & $<0.803$ \\
\hline $\mathrm{Pb}$ & [5.88] & {$[15.4]$} & {$[23.9]$} & {$[27.1]$} & {$[23.5]$} & {$[26.4]$} & $\begin{array}{l}{[24.7]} \\
\end{array}$ \\
\hline $\mathrm{Pd}$ & [1.18] & {$[1.05]$} & {$[1.05]$} & $<0.958$ & $<0.947$ & $<0.965$ & $<0.937$ \\
\hline $\mathrm{Rh}$ & $<1.86$ & $<1.85$ & $<1.79$ & $<1.82$ & $<1.80$ & $<1.84$ & $<1.78$ \\
\hline $\mathrm{Ru}$ & $<1.32$ & $<1.31$ & $<1.27$ & $<1.29$ & $<1.28$ & $<1.30$ & $<1.26$ \\
\hline $\mathrm{Sb}$ & [4.03] & $<3.08$ & {$[5.98]$} & {$[8.82]$} & $<3.01$ & [4.29] & $<2.97$ \\
\hline Se & $<10.8$ & $<10.8$ & $<10.5$ & $<10.6$ & $<10.5$ & $<10.7$ & $<10.4$ \\
\hline Sn & [4.65] & $<4.16$ & $<4.04$ & $<4.11$ & $<4.06$ & $<4.14$ & $<4.02$ \\
\hline $\mathrm{Ta}$ & $<2.63$ & $<2.62$ & $<2.54$ & $<2.59$ & $<2.56$ & {$[2.82]$} & $<2.53$ \\
\hline $\mathrm{Te}$ & $<4.03$ & $<4.01$ & $<3.89$ & [6.08] & $<3.91$ & $<3.98$ & $<3.87$ \\
\hline Th & $<1.52$ & $<1.51$ & $<1.47$ & $<1.49$ & $<1.47$ & $<1.50$ & $<1.46$ \\
\hline $\mathrm{Ti}$ & {$[0.093]$} & {$[0.096]$} & $<0.064$ & $<0.065$ & {$[0.087]$} & $<0.066$ & $<0.064$ \\
\hline $\mathrm{Tl}$ & $<5.88$ & $<5.86$ & $<5.68$ & $<5.78$ & $<5.71$ & $<5.82$ & $<5.65$ \\
\hline $\mathrm{V}$ & {$[0.282]$} & {$[0.308]$} & {$[0.230]$} & {$[0.426]$} & {$[0.271]$} & {$[0.267]$} & {$[0.446]$} \\
\hline $\mathrm{W}$ & $<2.94$ & $<2.93$ & [3.59] & $<2.89$ & $<2.86$ & $<2.91$ & $<2.83$ \\
\hline $\mathrm{Y}$ & $<0.050$ & $<0.049$ & $<0.048$ & $<0.049$ & $<0.048$ & $<0.049$ & $<0.048$ \\
\hline \multicolumn{8}{|c|}{$\begin{array}{l}\text { Analyte uncertainties were typically within } \pm 15 \% \text { (2-s); results in brackets indicate that the analyte concentrations } \\
\text { were less than the minimum detection limit (MDL) and greater than the estimated quantitation limit (EQL), and } \\
\text { uncertainties were }>15 \% \text {. }\end{array}$} \\
\hline
\end{tabular}


Table L.2. Analyte Concentrations as a Function of Time for Leaching at $60^{\circ} \mathrm{C}$, in $\mathrm{M}$

\begin{tabular}{|c|c|c|c|c|c|c|c|}
\hline \multirow[b]{2}{*}{ Analyte } & \multicolumn{7}{|c|}{$\begin{array}{l}\text { Analyte Concentration and Density at Given Time After Cooling to Ambient }\left(\sim 21^{\circ} \mathrm{C}\right) \\
\text { Temperature; } \mathrm{g} / \mathrm{mL} \text { for Density; } \mathrm{M} \text { for Metals and Anions }\end{array}$} \\
\hline & $0 \mathrm{hr}$ & $1 \mathrm{hr}$ & $2 \mathrm{hr}$ & $4 \mathrm{hr}$ & $8 \mathrm{hr}$ & $24 \mathrm{hr}$ & $48 \mathrm{hr}$ \\
\hline \multicolumn{8}{|l|}{$1 \mathrm{M} \mathrm{NaOH}$} \\
\hline Density & 1.05 & 1.08 & 1.07 & 1.06 & 1.07 & 1.05 & 1.05 \\
\hline$\overline{\mathrm{Al}}$ & 5.39E-04 & $1.81 \mathrm{E}-02$ & 3.98E-02 & 6.69E-02 & 9.16E-02 & 1.12E-01 & 1.17E-01 \\
\hline B & [5.13E-05] & [6.85E-05] & [7.11E-05] & [6.89E-05] & [5.97E-05] & [6.64E-05] & [5.88E-05] \\
\hline $\mathrm{Bi}$ & $<4.30 \mathrm{E}-06$ & $<4.43 \mathrm{E}-06$ & $<4.24 \mathrm{E}-06$ & [8.76E-06] & [1.62E-05] & [1.16E-05] & [1.42E-05] \\
\hline $\mathrm{Cd}$ & $<9.06 \mathrm{E}-07$ & $<<9.33 \mathrm{E}-07$ & $<<8.94 \mathrm{E}-07$ & $<<9.38 \mathrm{E}-07$ & $<9.29 \mathrm{E}-07$ & $<9.04 \mathrm{E}-07$ & $<<9.16 \mathrm{E}-07$ \\
\hline $\mathrm{Cr}$ & 9.53E-06 & 3.66E-05 & $5.24 \mathrm{E}-05$ & 7.34E-05 & $9.45 \mathrm{E}-05$ & $1.28 \mathrm{E}-04$ & $1.56 \mathrm{E}-04$ \\
\hline $\mathrm{Fe}$ & [6.70E-06] & $2.04 \mathrm{E}-05$ & 5.04E-05 & $2.70 \mathrm{E}-05$ & $2.74 \mathrm{E}-05$ & 3.00E-05 & $2.54 \mathrm{E}-05$ \\
\hline $\mathrm{Mn}$ & {$[2.02 \mathrm{E}-06]$} & [1.80E-06] & [1.45E-06] & [4.80E-07] & [1.73E-07] & $<1.25 \mathrm{E}-07$ & $<1.27 \mathrm{E}-07$ \\
\hline $\mathrm{Na}$ & $1.11 \mathrm{E}+00$ & $1.17 \mathrm{E}+00$ & $1.15 \mathrm{E}+00$ & $1.15 \mathrm{E}+00$ & $<1.14 \mathrm{E} 00$ & $1.11 \mathrm{E}+00$ & $1.13 \mathrm{E}+00$ \\
\hline $\mathrm{Ni}$ & [1.25E-06] & $<1.26 \mathrm{E}-06$ & $<1.21 \mathrm{E}-06$ & $<1.27 \mathrm{E}-06$ & $<1.26 \mathrm{E}-06$ & $<1.22 \mathrm{E}-06$ & $<1.24 \mathrm{E}-06$ \\
\hline $\mathrm{P}$ & [3.38E-04] & [3.19E-04] & [3.05E-04] & {$[2.80 \mathrm{E}-04]$} & [2.97E-04] & [3.28E-04] & [3.32E-04] \\
\hline$S$ & [1.07E-04] & $<6.93 \mathrm{E}-05$ & $<6.64 \mathrm{E}-05$ & $<6.97 \mathrm{E}-05$ & [1.05E-04] & $<6.71 \mathrm{E}-05$ & $<6.80 \mathrm{E}-05$ \\
\hline $\mathrm{Si}$ & $1.60 \mathrm{E}-04$ & $1.03 \mathrm{E}-03$ & $1.09 \mathrm{E}-03$ & $1.10 \mathrm{E}-03$ & 1.13E-03 & $1.06 \mathrm{E}-03$ & $1.04 \mathrm{E}-03$ \\
\hline $\mathrm{Sr}$ & [1.62E-07] & [1.55E-07] & [1.62E-07] & [1.91E-07] & [1.16E-07] & [1.06E-07] & [1.59E-07] \\
\hline $\mathrm{U}$ & [9.75E-06] & [2.20E-05] & [1.99E-05] & [2.22E-05] & [2.06E-05] & [2.51E-05] & [2.55E-05] \\
\hline $\mathrm{Zn}$ & $1.57 \mathrm{E}-05$ & $3.75 E-05$ & 5.47E-05 & 7.78E-05 & $1.01 \mathrm{E}-04$ & $1.14 \mathrm{E}-04$ & $1.28 \mathrm{E}-04$ \\
\hline $\mathrm{Zr}$ & $<3.94 \mathrm{E}-07$ & [7.44E-07] & $<3.57 \mathrm{E}-07$ & $<3.74 \mathrm{E}-07$ & [4.71E-07] & $<3.61 \mathrm{E}-07$ & [5.98E-07] \\
\hline Fluoride & [1.55E-04] & [1.62E-04] & [1.53E-04] & [1.35E-04] & [1.06E-04] & [9.08E-05] & [7.97E-05] \\
\hline Nitrite & [3.59E-05] & [3.47E-05] & [3.54E-05] & [3.80E-05] & [4.00E-05] & [4.14E-05] & [4.31E-05] \\
\hline Sulfate & [4.59E-05] & [2.34E-05] & $<2.24 \mathrm{E}-05$ & $<2.24 \mathrm{E}-05$ & $<2.28 \mathrm{E}-05$ & $<2.29 \mathrm{E}-05$ & $<2.24 \mathrm{E}-05$ \\
\hline Nitrate & 1.99E-03 & 1.73E-03 & $1.72 \mathrm{E}-03$ & $1.76 \mathrm{E}-03$ & $1.80 \mathrm{E}-03$ & $1.78 \mathrm{E}-03$ & $1.92 \mathrm{E}-03$ \\
\hline Phosphate & 3.73E-04 & $3.15 \mathrm{E}-04$ & 3.13E-04 & 3.04E-04 & $3.04 \mathrm{E}-04$ & 2.74E-04 & $2.78 \mathrm{E}-04$ \\
\hline \multicolumn{8}{|l|}{$3 \mathrm{M}$ NaOH } \\
\hline Density & 1.12 & 1.13 & 1.14 & 1.16 & 1.14 & 1.13 & 1.13 \\
\hline $\mathrm{Al}$ & $2.06 \mathrm{E}-03$ & 3.97E-02 & 7.92E-02 & 1.10E-01 & 1.24E-01 & $1.25 \mathrm{E}-01$ & 1.32E-01 \\
\hline B & [8.63E-05] & $<6.77 \mathrm{E}-05$ & [7.54E-05] & $<6.85 \mathrm{E}-05$ & $<6.75 \mathrm{E}-05$ & $<6.91 \mathrm{E}-05$ & [7.55E-05] \\
\hline $\mathrm{Bi}$ & $<2.16 \mathrm{E}-05$ & $<2.19 \mathrm{E}-05$ & $<2.17 \mathrm{E}-05$ & [4.72E-05] & [2.76E-05] & [2.23E-05] & [2.31E-05] \\
\hline $\mathrm{Cd}$ & $<4.55 \mathrm{E}-06$ & $<4.61 \mathrm{E}-06$ & $<4.57 \mathrm{E}-06$ & $<4.67 \mathrm{E}-06$ & $<4.60 \mathrm{E}-06$ & $<4.71 \mathrm{E}-06$ & $<4.57 \mathrm{E}-06$ \\
\hline $\mathrm{Cr}$ & [2.72E-05] & 7.09E-05 & 9.70E-05 & $1.26 \mathrm{E}-04$ & 1.53E-04 & $1.98 \mathrm{E}-04$ & $2.23 \mathrm{E}-04$ \\
\hline $\mathrm{Fe}$ & [1.94E-05] & $8.79 \mathrm{E}-05$ & $9.90 \mathrm{E}-05$ & $1.15 \mathrm{E}-04$ & $1.39 \mathrm{E}-04$ & $1.35 \mathrm{E}-04$ & $1.45 \mathrm{E}-04$ \\
\hline $\mathrm{Mn}$ & [5.15E-06] & [6.66E-06] & [3.90E-06] & [7.30E-07] & $<<6.36 \mathrm{E}-07$ & $<6.52 \mathrm{E}-07$ & $<6.33 \mathrm{E}-07$ \\
\hline $\mathrm{Na}$ & $3.25 \mathrm{E}+00$ & $3.34 \mathrm{E}+00$ & $3.36 \mathrm{E}+00$ & $3.45 \mathrm{E}+00$ & $3.44 \mathrm{E}+00$ & $3.13 \mathrm{E}+00$ & $3.20 \mathrm{E}+00$ \\
\hline $\mathrm{Ni}$ & $<6.15 \mathrm{E}-06$ & $<6.23 \mathrm{E}-06$ & $<6.17 \mathrm{E}-06$ & $<6.31 \mathrm{E}-06$ & $<6.21 \mathrm{E}-06$ & $<6.36 \mathrm{E}-06$ & $<6.18 \mathrm{E}-06$ \\
\hline $\mathrm{P}$ & $<2.43 \mathrm{E}-04$ & $<2.46 \mathrm{E}-04$ & [3.70E-04] & [5.88E-04] & $<2.45 \mathrm{E}-04$ & $<3.12 \mathrm{E}-04$ & $<2.44 \mathrm{E}-04$ \\
\hline $\mathrm{S}$ & {$[6.86 \mathrm{E}-04]$} & $<3.42 \mathrm{E}-04$ & [1.22E-03] & [9.62E-04] & [4.74E-04] & [3.50E-04] & [1.60E-03] \\
\hline $\mathrm{Si}$ & [2.68E-04] & $1.36 \mathrm{E}-03$ & $1.43 \mathrm{E}-03$ & $1.48 \mathrm{E}-03$ & $1.53 \mathrm{E}-03$ & 1.53E-03 & $1.68 \mathrm{E}-03$ \\
\hline $\mathrm{Sr}$ & [3.78E-07] & [4.52E-07] & [4.48E-07] & [5.28E-07] & [4.86E-07] & [3.91E-07] & [4.49E-07] \\
\hline $\mathrm{U}$ & [2.15E-05] & [3.84E-05] & [5.08E-05] & [6.09E-05] & [4.85E-05] & [7.06E-05] & [5.08E-05] \\
\hline $\mathrm{Zn}$ & [2.53E-05] & [6.53E-05] & $1.03 \mathrm{E}-04$ & $1.30 \mathrm{E}-04$ & $1.44 \mathrm{E}-04$ & $1.39 \mathrm{E}-04$ & $1.47 \mathrm{E}-04$ \\
\hline $\mathrm{Zr}$ & $<1.82 \mathrm{E}-06$ & $<1.84 \mathrm{E}-06$ & $<1.82 \mathrm{E}-06$ & [1.89E-06] & $<1.83 \mathrm{E}-06$ & $<1.88 \mathrm{E}-06$ & $<1.82 \mathrm{E}-06$ \\
\hline Fluoride & $<2.41 \mathrm{E}-05$ & [2.02E-04] & $<2.46 \mathrm{E}-05$ & [9.30E-05] & $<2.38 \mathrm{E}-05$ & $<2.36 \mathrm{E}-05$ & [7.85E-05] \\
\hline Nitrite & $1.68 \mathrm{E}-03$ & $1.93 \mathrm{E}-03$ & $1.98 \mathrm{E}-03$ & $2.02 \mathrm{E}-03$ & $1.98 \mathrm{E}-03$ & 1.93E-03 & $1.98 \mathrm{E}-03$ \\
\hline Sulfate & 2.83E-04 & $2.94 \mathrm{E}-04$ & $2.90 \mathrm{E}-04$ & $2.76 \mathrm{E}-04$ & $3.06 \mathrm{E}-04$ & $2.64 \mathrm{E}-04$ & 2.63E-04 \\
\hline
\end{tabular}


Table L.2 (Contd)

\begin{tabular}{|c|c|c|c|c|c|c|c|}
\hline \multirow[b]{2}{*}{ Analyte } & \multicolumn{7}{|c|}{$\begin{array}{l}\text { Analyte Concentration and Density at Given Time After Cooling to Ambient }\left(\sim 21^{\circ} \mathrm{C}\right) \\
\text { Temperature; } \mathrm{g} / \mathrm{mL} \text { for Density; } \mathrm{M} \text { for Metals and Anions }\end{array}$} \\
\hline & $0 \mathrm{hr}$ & $1 \mathrm{hr}$ & $2 \mathrm{hr}$ & $4 \mathrm{hr}$ & $8 \mathrm{hr}$ & $24 \mathrm{hr}$ & $48 \mathrm{hr}$ \\
\hline \multicolumn{8}{|l|}{$5 \mathrm{M} \mathrm{NaOH}$} \\
\hline Density & 1.19 & 1.22 & 1.21 & 1.21 & 1.22 & 1.20 & 1.20 \\
\hline $\mathrm{Al}$ & 2.15E-03 & 6.92E-02 & $1.07 \mathrm{E}-01$ & 1.30E-01 & 1.36E-01 & 1.33E-01 & 1.37E-01 \\
\hline B & $<6.88 \mathrm{E}-05$ & $<<6.85 \mathrm{E}-05$ & $<66.64 \mathrm{E}-05$ & $<6.75 \mathrm{E}-05$ & $<<6.68 \mathrm{E}-05$ & $<6.80 \mathrm{E}-05$ & $<6.60 \mathrm{E}-05$ \\
\hline $\mathrm{Bi}$ & $<2.22 \mathrm{E}-05$ & [3.25E-05] & [4.58E-05] & [5.53E-05] & [4.89E-05] & [5.13E-05] & [5.69E-05] \\
\hline $\mathrm{Cd}$ & $<4.68 \mathrm{E}-06$ & $<4.66 \mathrm{E}-06$ & $<4.52 \mathrm{E}-06$ & $<4.60 \mathrm{E}-06$ & $<4.55 \mathrm{E}-06$ & $<4.63 \mathrm{E}-06$ & $<4.50 \mathrm{E}-06$ \\
\hline $\mathrm{Cr}$ & [2.74E-05] & $9.19 \mathrm{E}-05$ & $1.27 \mathrm{E}-04$ & $1.65 \mathrm{E}-04$ & $1.97 \mathrm{E}-04$ & $2.40 \mathrm{E}-04$ & 2.61E-04 \\
\hline $\mathrm{Fe}$ & [3.27E-05] & $1.46 \mathrm{E}-04$ & $1.86 \mathrm{E}-04$ & $3.24 \mathrm{E}-04$ & $2.44 \mathrm{E}-04$ & $2.81 \mathrm{E}-04$ & 2.93E-04 \\
\hline $\mathrm{Mn}$ & [1.13E-05] & $2.08 \mathrm{E}-05$ & $1.41 \mathrm{E}-05$ & [8.30E-06] & [3.45E-06] & $<6.41 \mathrm{E}-07$ & $<6.23 \mathrm{E}-07$ \\
\hline $\mathrm{Na}$ & $6.12 \mathrm{E}+00$ & $5.97 \mathrm{E}+00$ & $5.54 \mathrm{E}+00$ & $5.61 \mathrm{E}+00$ & $5.64 \mathrm{E}+00$ & $5.44 \mathrm{E}+00$ & $5.49 \mathrm{E}+00$ \\
\hline $\mathrm{Ni}$ & $<6.33 \mathrm{E}-06$ & $<<6.31 \mathrm{E}-06$ & $<6.11 \mathrm{E}-06$ & $<6.22 \mathrm{E}-06$ & $<6.15 \mathrm{E}-06$ & $<6.26 \mathrm{E}-06$ & $<6.08 \mathrm{E}-06$ \\
\hline $\mathrm{P}$ & $<2.50 \mathrm{E}-04$ & [2.89E-04] & [2.80E-04] & $<2.45 \mathrm{E}-04$ & [3.69E-04] & $<2.47 \mathrm{E}-04$ & [2.98E-04] \\
\hline$S$ & $<3.48 \mathrm{E}-04$ & $<3.46 \mathrm{E}-04$ & $<3.36 \mathrm{E}-04$ & [6.36E-04] & [8.63E-04] & $<3.44 \mathrm{E}-04$ & $<3.34 \mathrm{E}-04$ \\
\hline $\mathrm{Si}$ & $3.66 \mathrm{E}-04$ & $1.38 \mathrm{E}-03$ & $1.47 \mathrm{E}-03$ & $1.57 \mathrm{E}-03$ & $1.68 \mathrm{E}-03$ & $1.77 \mathrm{E}-03$ & 1.89E-03 \\
\hline $\mathrm{Sr}$ & [7.42E-07] & [7.74E-07] & [6.83E-07] & [8.68E-07] & [8.58E-07] & [9.44E-07] & [7.81E-07] \\
\hline $\mathrm{U}$ & [3.90E-05] & [3.63E-05] & [3.64E-05] & [4.86E-05] & [6.32E-05] & [6.44E-05] & [4.37E-05] \\
\hline $\mathrm{Zn}$ & [2.94E-05] & $1.03 \mathrm{E}-04$ & $1.37 \mathrm{E}-04$ & $1.70 \mathrm{E}-04$ & $1.57 \mathrm{E}-04$ & $1.64 \mathrm{E}-04$ & $1.62 \mathrm{E}-04$ \\
\hline $\mathrm{Zr}$ & [2.58E-06] & $<1.86 \mathrm{E}-06$ & $<1.80 \mathrm{E}-06$ & $<1.83 \mathrm{E}-06$ & [1.95E-06] & $<1.85 \mathrm{E}-06$ & [2.18E-06] \\
\hline Fluoride & [3.01E-04] & [2.79E-04] & $<5.01 \mathrm{E}-05$ & $<5.03 \mathrm{E}-05$ & $<5.04 \mathrm{E}-05$ & $<5.19 \mathrm{E}-05$ & $<4.83 \mathrm{E}-05$ \\
\hline Nitrite & $<3.31 \mathrm{E}-05$ & $<3.23 \mathrm{E}-05$ & $<3.23 \mathrm{E}-05$ & $<3.25 \mathrm{E}-05$ & $<3.25 \mathrm{E}-05$ & $<3.35 \mathrm{E}-05$ & $<3.12 \mathrm{E}-05$ \\
\hline Sulfate & $<2.34 \mathrm{E}-05$ & $<2.29 \mathrm{E}-05$ & $<2.29 \mathrm{E}-05$ & $<2.30 \mathrm{E}-05$ & $<2.30 \mathrm{E}-05$ & $<2.37 \mathrm{E}-05$ & $<2.21 \mathrm{E}-05$ \\
\hline Nitrate & $2.00 \mathrm{E}-03$ & $1.98 \mathrm{E}-03$ & $2.08 \mathrm{E}-03$ & 2.17E-03 & 2.02E-03 & 2.13E-03 & 2.07E-03 \\
\hline Phosphate & $4.15 \mathrm{E}-04$ & 3.67E-04 & $3.58 \mathrm{E}-04$ & $3.80 \mathrm{E}-03$ & 3.32E-04 & $3.21 \mathrm{E}-04$ & $3.25 \mathrm{E}-04$ \\
\hline \multicolumn{8}{|c|}{$\begin{array}{l}\text { Analyte uncertainties were typically within } \pm 15 \% \text { (2-s); results in brackets indicate that the analyte concentrations } \\
\text { were less than the minimum detection limit (MDL) and greater than the estimated quantitation limit (EQL), and } \\
\text { uncertainties were }>15 \% \text {. }\end{array}$} \\
\hline
\end{tabular}


Table L.3. Analyte Concentrations as a Function of Time for Leaching at $80^{\circ} \mathrm{C}$, in $\mu \mathrm{g} / \mathrm{mL}$

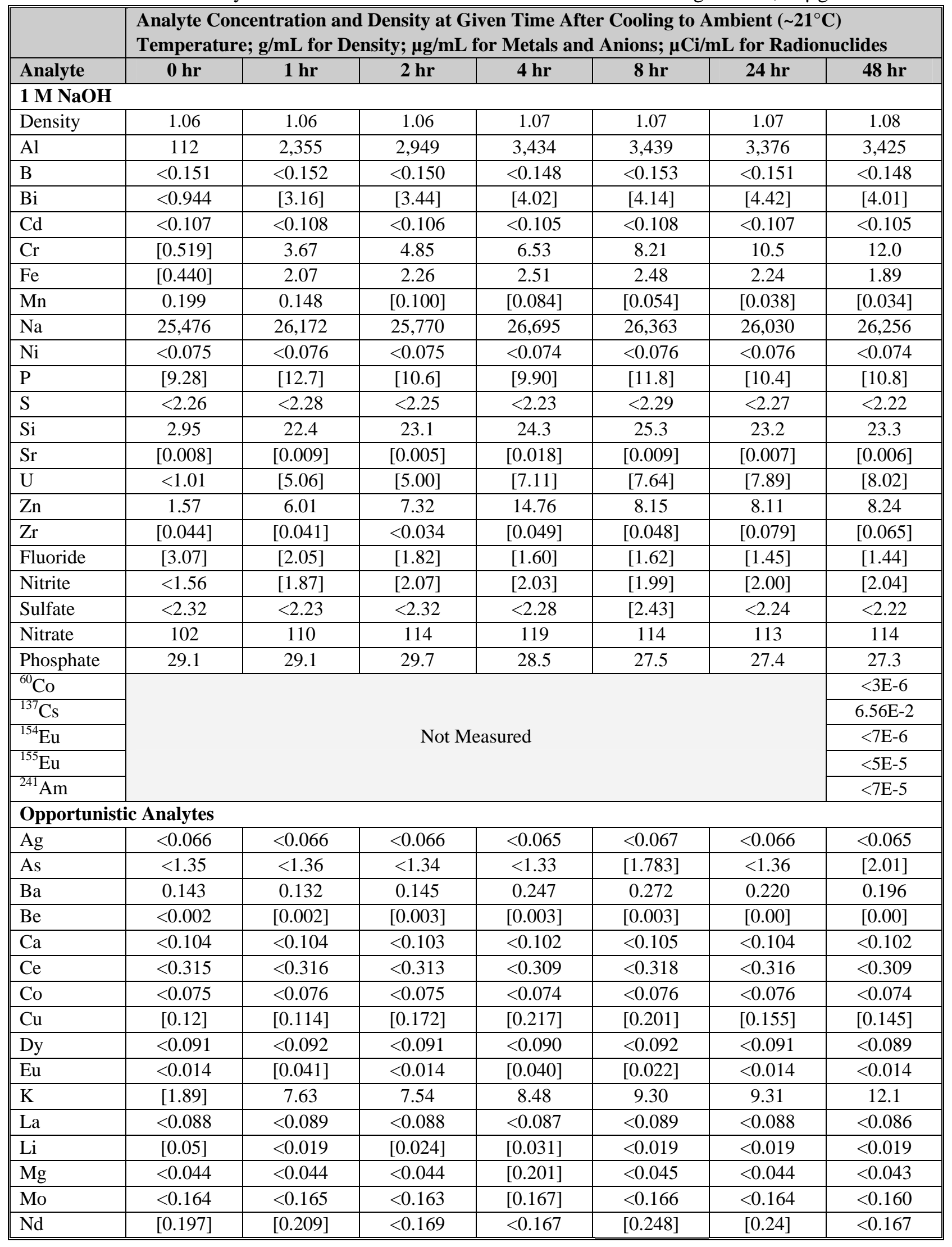


Table L.3 (Contd)

\begin{tabular}{|c|c|c|c|c|c|c|c|}
\hline \multirow[b]{2}{*}{ Analyte } & \multicolumn{7}{|c|}{$\begin{array}{l}\text { Analyte Concentration and Density at Given Time After Cooling to Ambient }\left(\sim 21^{\circ} \mathrm{C}\right) \\
\text { Temperature; } \mathrm{g} / \mathrm{mL} \text { for Density; } \mu \mathrm{g} / \mathrm{mL} \text { for Metals and Anions; } \mu \mathrm{Ci} / \mathrm{mL} \text { for Radionuclides }\end{array}$} \\
\hline & o hr & $1 \mathrm{hr}$ & $2 \mathrm{hr}$ & $4 \mathrm{hr}$ & $8 \mathrm{hr}$ & $24 \mathrm{hr}$ & $48 \mathrm{hr}$ \\
\hline $\mathrm{Pb}$ & [6.92] & 16.0 & 18.9 & 22.1 & 20.0 & 19.6 & 20.1 \\
\hline $\mathrm{Pd}$ & {$[0.211]$} & $<0.199$ & {$[0.213]$} & [0.495] & {$[0.382]$} & {$[0.218]$} & $<0.194$ \\
\hline $\mathrm{Rh}$ & $<0.377$ & $<0.380$ & $<0.375$ & $<0.371$ & $<0.382$ & $<0.379$ & $<0.370$ \\
\hline $\mathrm{Ru}$ & $<0.267$ & $<0.269$ & $<0.266$ & $<0.263$ & $<0.271$ & $<0.268$ & $<0.262$ \\
\hline $\mathrm{Sb}$ & $<0.629$ & $<0.633$ & $<0.625$ & $<0.619$ & $<0.637$ & $<0.631$ & $<0.617$ \\
\hline Se & {$[2.67]$} & $<2.22$ & $<2.19$ & $<2.17$ & $<2.23$ & $<2.21$ & $<2.16$ \\
\hline Sn & $<0.849$ & $<<0.854$ & $<0.844$ & $<0.835$ & $<0.860$ & {$[0.883]$} & $<0.833$ \\
\hline $\mathrm{Ta}$ & $<0.535$ & $<0.538$ & $<0.532$ & $<0.526$ & $<0.541$ & $<0.536$ & $<0.525$ \\
\hline $\mathrm{Te}$ & $<0.818$ & $<0.823$ & $<0.813$ & $<0.804$ & $<0.828$ & $<0.820$ & $<0.802$ \\
\hline Th & $<0.308$ & {$[0.506]$} & {$[0.313]$} & $<0.303$ & {$[0.318]$} & $<0.309$ & $<0.302$ \\
\hline $\mathrm{Ti}$ & $<0.014$ & $<0.014$ & $<0.013$ & {$[0.015]$} & $<0.014$ & $<0.014$ & $<0.013$ \\
\hline $\mathrm{Tl}$ & $<1.20$ & $<1.20$ & [1.376] & [1.516] & $<1.21$ & $<1.20$ & $<1.17$ \\
\hline $\mathrm{V}$ & {$[0.025]$} & {$[0.051]$} & {$[0.056]$} & {$[0.068]$} & [0.051] & [0.011] & {$[0.06]$} \\
\hline $\mathrm{W}$ & $<0.598$ & $<0.601$ & $<0.594$ & $<0.588$ & $<0.605$ & {$[0.60]$} & $<0.586$ \\
\hline $\mathrm{Y}$ & $<0.010$ & $<0.010$ & $<0.010$ & $<0.010$ & $<0.010$ & $<0.010$ & $<0.010$ \\
\hline \multicolumn{8}{|c|}{$3 \mathrm{M}$ NaOH, Trial a } \\
\hline Density & 1.14 & 1.17 & 1.16 & 1.13 & 1.14 & 1.14 & 1.18 \\
\hline $\mathrm{Al}$ & 153 & 3,390 & 3,494 & 3,657 & 3,558 & 3,473 & 3,710 \\
\hline $\mathrm{B}$ & $<0.725$ & {$[3.90]$} & {$[2.60]$} & {$[2.38]$} & {$[1.64]$} & {$[2.18]$} & {$[2.84]$} \\
\hline $\mathrm{Bi}$ & $<4.53$ & [10.9] & {$[8.35]$} & [9.86] & [10.5] & [11.1] & [13.7] \\
\hline $\mathrm{Cd}$ & $<0.513$ & $<0.531$ & $<0.526$ & $<0.541$ & $<0.526$ & $<0.523$ & $<0.530$ \\
\hline $\mathrm{Cr}$ & {$[1.54]$} & 7.17 & 8.81 & 11.7 & 12.3 & 14.4 & 15.8 \\
\hline $\mathrm{Fe}$ & [2.57] & 8.73 & 9.59 & 11.1 & 11.6 & 11.7 & 11.8 \\
\hline $\mathrm{Mn}$ & {$[0.544]$} & {$[0.515]$} & {$[0.201]$} & {$[0.140]$} & $<0.036$ & $<0.035$ & $<0.036$ \\
\hline $\mathrm{Na}$ & 78,815 & 79,193 & 77,619 & 78,540 & 76,104 & 75,923 & 79,494 \\
\hline $\mathrm{Ni}$ & $<0.362$ & {$[0.453]$} & $<0.371$ & [0.509] & $<0.371$ & {$[0.430]$} & $<0.374$ \\
\hline $\mathrm{P}$ & $<7.55$ & [9.06] & {$[8.66]$} & $<7.95$ & {$[11.1]$} & [8.61] & $<7.79$ \\
\hline$S$ & $<10.9$ & {$[24.4]$} & $<11.1$ & $<11.4$ & {$[11.4]$} & {$[24.3]$} & [11.5] \\
\hline $\mathrm{Si}$ & [7.85] & 37.2 & 39.6 & 43.2 & 44.5 & 46.7 & 50.8 \\
\hline $\mathrm{Sr}$ & {$[0.042]$} & {$[0.045]$} & {$[0.043]$} & {$[0.060]$} & {$[0.053]$} & {$[0.055]$} & [0.053] \\
\hline $\mathrm{U}$ & {$[5.13]$} & [9.53] & {$[8.04]$} & {$[14.0]$} & {$[13.6]$} & {$[16.6]$} & {$[16.8]$} \\
\hline $\mathrm{Zn}$ & {$[2.60]$} & 9.93 & 10.2 & 11.3 & 10.8 & 10.2 & 10.9 \\
\hline $\mathrm{Zr}$ & $<0.166$ & {$[0.211]$} & $<0.170$ & $<0.175$ & [0.195] & {$[0.227]$} & [0.343] \\
\hline Fluoride & {$[4.41]$} & $<0.481$ & $<0.459$ & $<0.462$ & $<0.462$ & $<0.469$ & $<0.470$ \\
\hline Nitrite & $<0.754$ & $<0.801$ & $<0.765$ & $<0.770$ & $<0.770$ & $<0.781$ & $<0.784$ \\
\hline Sulfate & $<1.10$ & $<1.17$ & $<1.12$ & $<1.12$ & $<1.13$ & $<1.14$ & $<1.15$ \\
\hline Nitrate & 100 & 125 & 125 & 124 & 129 & 682 & 136 \\
\hline Phosphate & 28.2 & 29.2 & 27.9 & 26.1 & 26.1 & 133.1 & 25.8 \\
\hline${ }^{60} \mathrm{Co}$ & \multirow{5}{*}{\multicolumn{6}{|c|}{ Not Measured }} & $<3 \mathrm{E}-6$ \\
\hline${ }^{137} \mathrm{Cs}$ & & & & & & & $9.46 \mathrm{E}-2$ \\
\hline${ }^{154} \mathrm{Eu}$ & & & & & & & $<8 \mathrm{E}-6$ \\
\hline${ }^{155} \mathrm{Eu}$ & & & & & & & $<5 \mathrm{E}-5$ \\
\hline${ }^{241} \mathrm{Am}$ & & & & & & & $<1 \mathrm{E}-4$ \\
\hline
\end{tabular}


Table L.3 (Contd)

\begin{tabular}{|c|c|c|c|c|c|c|c|}
\hline \multirow[b]{2}{*}{ Analyte } & \multicolumn{7}{|c|}{$\begin{array}{l}\text { Analyte Concentration and Density at Given Time After Cooling to Ambient }\left(\sim 21^{\circ} \mathrm{C}\right) \\
\text { Temperature; } g / m L \text { for Density; } \mu \mathrm{g} / \mathrm{mL} \text { for Metals and Anions; } \mu \mathrm{Ci} / \mathrm{mL} \text { for Radionuclides }\end{array}$} \\
\hline & o hr & $1 \mathrm{hr}$ & $2 \mathrm{hr}$ & $4 \mathrm{hr}$ & $8 \mathrm{hr}$ & $24 \mathrm{hr}$ & $48 \mathrm{hr}$ \\
\hline \multicolumn{8}{|c|}{ Opportunistic Analytes } \\
\hline $\mathrm{Ag}$ & $<0.317$ & {$[0.445]$} & $<0.325$ & [0.350] & $<0.325$ & {$[0.338]$} & $<0.327$ \\
\hline As & $<6.49$ & $<6.72$ & $<6.65$ & $<6.84$ & $<6.65$ & $<6.61$ & $<6.70$ \\
\hline $\mathrm{Ba}$ & {$[0.260]$} & {$[0.437]$} & {$[0.223]$} & {$[0.350]$} & {$[0.433]$} & {$[0.369]$} & {$[0.284]$} \\
\hline $\mathrm{Be}$ & $<0.008$ & $<0.010$ & {$[0.011]$} & [0.009] & {$[0.011]$} & {$[0.012]$} & {$[0.014]$} \\
\hline $\mathrm{Ca}$ & {$[1.57]$} & {$[2.56]$} & {$[2.97]$} & [3.18] & {$[7.42]$} & {$[4.30]$} & [1.71] \\
\hline $\mathrm{Ce}$ & [1.51] & $<1.56$ & $<1.55$ & $<1.59$ & $<1.55$ & $<1.54$ & $<1.56$ \\
\hline Co & $<0.362$ & $<0.375$ & $<0.371$ & $<0.382$ & $<0.371$ & $<0.369$ & $<0.374$ \\
\hline $\mathrm{Cu}$ & $<0.211$ & {$[0.562]$} & {$[0.402]$} & {$[0.242]$} & {$[0.526]$} & $<0.215$ & {$[0.468]$} \\
\hline Dy & $<0.438$ & $<0.453$ & $<0.448$ & $<0.461$ & $<0.449$ & $<0.446$ & $<0.452$ \\
\hline $\mathrm{Eu}$ & $<0.066$ & $<0.069$ & {$[0.093]$} & $<0.070$ & $<0.068$ & $<0.068$ & $<0.069$ \\
\hline $\mathrm{K}$ & {$[26.9]$} & $<11.2$ & $<11.1$ & $<11.4$ & $<11.1$ & $<11.1$ & $<11.2$ \\
\hline $\mathrm{La}$ & {$[0.453]$} & {$[0.453]$} & {$[0.526]$} & $<0.445$ & $<0.433$ & $<0.430$ & $<0.436$ \\
\hline $\mathrm{Li}$ & {$[0.332]$} & {$[0.562]$} & {$[0.588]$} & {$[0.636]$} & {$[0.650]$} & {$[0.400]$} & {$[0.592]$} \\
\hline $\mathrm{Mg}$ & $<0.211$ & $<0.219$ & $<0.216$ & $<0.223$ & $<0.217$ & $<0.215$ & $<0.218$ \\
\hline Mo & $<0.785$ & $<0.812$ & $<0.804$ & $<0.827$ & $<0.804$ & $<0.799$ & $<0.811$ \\
\hline $\mathrm{Nd}$ & $<0.815$ & {$[0.859]$} & $<0.835$ & $<0.859$ & $<0.835$ & $<0.830$ & $<0.842$ \\
\hline $\mathrm{Pb}$ & {$[8.76]$} & [23.1] & [26.6] & [26.4] & [26.6] & [26.7] & [24.0] \\
\hline $\mathrm{Pd}$ & {$[1.66]$} & $<0.984$ & {$[1.02]$} & {$[1.02]$} & $<0.974$ & $<0.968$ & $<0.982$ \\
\hline $\mathrm{Rh}$ & $<1.81$ & $<1.87$ & $<1.86$ & $<1.91$ & $<1.86$ & $<1.84$ & $<1.87$ \\
\hline $\mathrm{Ru}$ & $<1.28$ & $<1.33$ & $<1.31$ & $<1.35$ & $<1.31$ & $<1.31$ & $<1.32$ \\
\hline $\mathrm{Sb}$ & $<3.02$ & $<3.44$ & $<3.09$ & $<3.18$ & $<3.09$ & $<3.07$ & $<3.12$ \\
\hline Se & $<10.6$ & $<10.9$ & [16.4] & $<11.1$ & [16.4] & $<10.8$ & $<10.9$ \\
\hline Sn & $<4.08$ & $<4.22$ & $<4.17$ & $<4.29$ & $<4.18$ & $<4.15$ & $<4.21$ \\
\hline $\mathrm{Ta}$ & $<2.57$ & $<2.66$ & $<2.63$ & $<2.70$ & $<2.63$ & $<2.61$ & $<2.65$ \\
\hline $\mathrm{Te}$ & $<3.93$ & [4.37] & $<4.02$ & $<4.13$ & {$[5.88]$} & $<4.00$ & $<4.05$ \\
\hline Th & $<1.48$ & $<1.53$ & $<1.52$ & $<1.56$ & $<1.52$ & $<1.51$ & $<1.53$ \\
\hline $\mathrm{Ti}$ & $<0.065$ & $<0.067$ & {$[0.071]$} & $<0.068$ & $<0.067$ & $<0.066$ & $<0.067$ \\
\hline $\mathrm{Tl}$ & $<5.74$ & [7.19] & [13.0] & $<6.042$ & $<5.878$ & $<5.840$ & $<5.923$ \\
\hline $\mathrm{V}$ & {$[0.362]$} & {$[0.248]$} & {$[0.294]$} & {$[0.350]$} & {$[0.247]$} & {$[0.338]$} & {$[0.374]$} \\
\hline $\mathrm{W}$ & $<2.87$ & [3.59] & $<2.94$ & $<3.02$ & {$[3.00]$} & $<2.92$ & $<2.96$ \\
\hline $\mathrm{Y}$ & {$[0.060]$} & $<0.050$ & $<0.049$ & $<0.051$ & $<0.049$ & $<0.049$ & $<0.050$ \\
\hline \multicolumn{8}{|c|}{$3 \mathrm{M}$ NaOH, Trial b } \\
\hline Density & 1.13 & 1.15 & 1.14 & 1.14 & 1.14 & 1.13 & 1.16 \\
\hline $\mathrm{Al}$ & 115 & 3,057 & 3,381 & 3,435 & 3,363 & 3,546 & 3,552 \\
\hline B & {$[1.75]$} & {$[1.25]$} & {$[1.86]$} & $<0.749$ & $<0.747$ & $<0.767$ & $<0.748$ \\
\hline $\mathrm{Bi}$ & $<4.598$ & [11.23] & {$[9.44]$} & {$[6.87]$} & {$[11.2]$} & {$[8.95]$} & {$[8.72]$} \\
\hline $\mathrm{Cd}$ & $<0.521$ & $<0.545$ & $<0.518$ & $<0.531$ & {$[0.716]$} & $<0.543$ & $<0.530$ \\
\hline $\mathrm{Cr}$ & [1.47] & 6.54 & 8.44 & 10.1 & 11.7 & 14.2 & 15.2 \\
\hline $\mathrm{Fe}$ & [1.62] & 8.08 & 9.41 & 10.9 & 11.3 & 11.8 & 11.4 \\
\hline Mn & {$[0.521]$} & {$[0.545]$} & {$[0.256]$} & {$[0.215]$} & {$[0.181]$} & {$[0.137]$} & {$[0.122]$} \\
\hline $\mathrm{Na}$ & 74,181 & 76,676 & 74,018 & 76,813 & 75,976 & 77,636 & 77,276 \\
\hline $\mathrm{Ni}$ & $<0.368$ & $<0.385$ & $<0.366$ & $<0.375$ & $<0.374$ & $<0.383$ & $<0.374$ \\
\hline $\mathrm{P}$ & {$[8.89]$} & $<8.02$ & $<>7.62$ & [12.5] & {$[13.4]$} & {$[13.4]$} & [11.2] \\
\hline
\end{tabular}


Table L.3 (Contd)

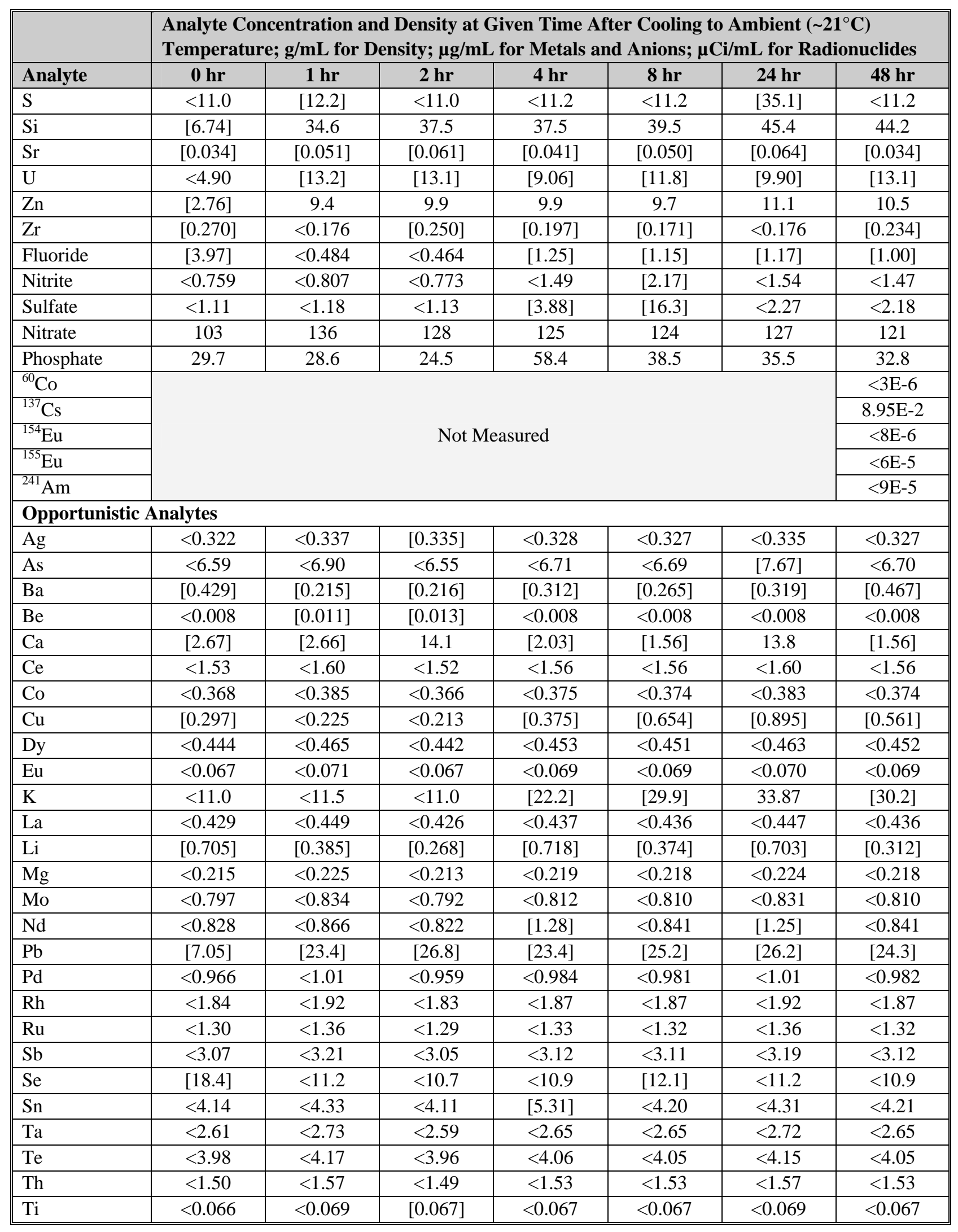


Table L.3 (Contd)

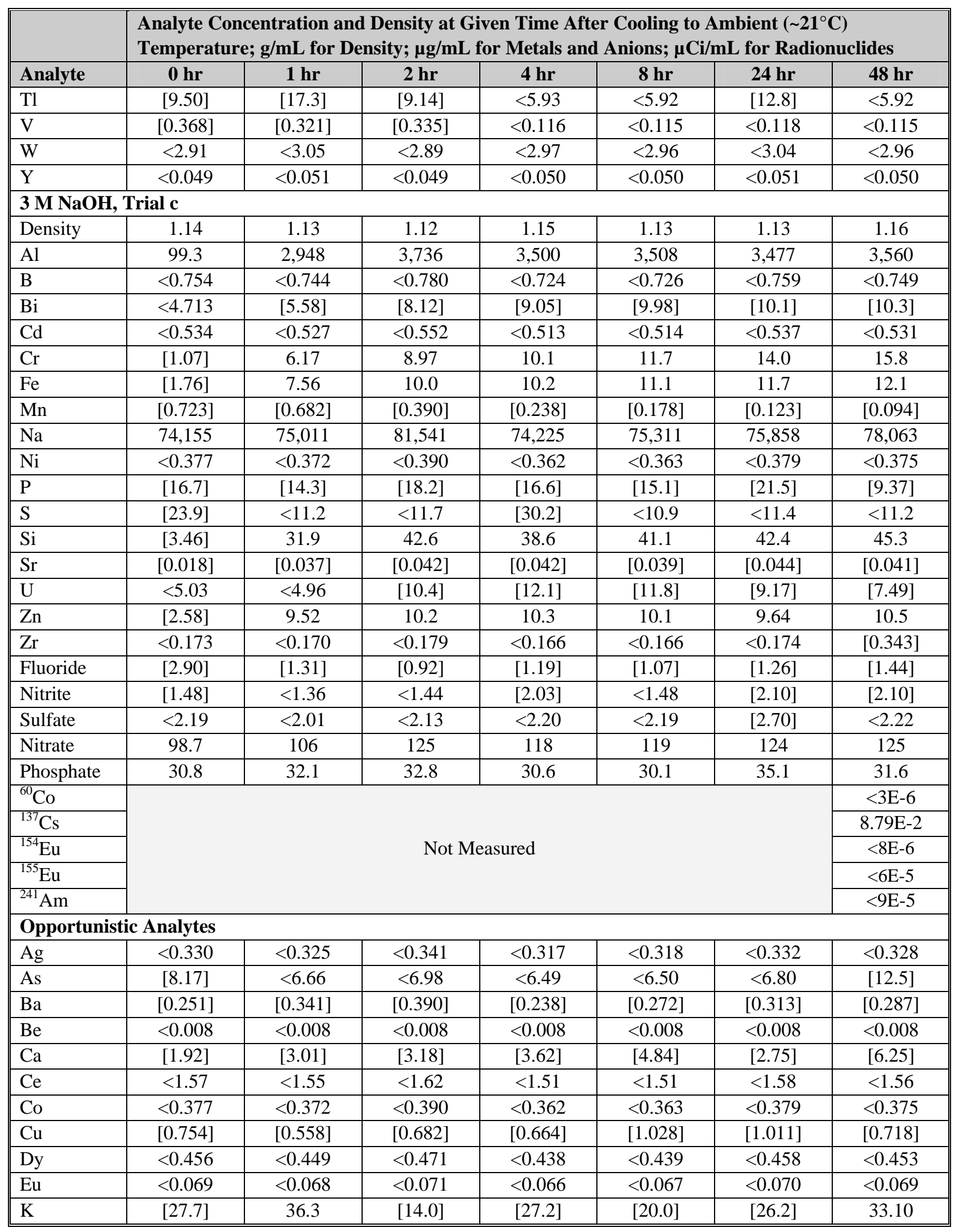


Table L.3 (Contd)

\begin{tabular}{|c|c|c|c|c|c|c|c|}
\hline \multirow[b]{2}{*}{ Analyte } & \multicolumn{7}{|c|}{$\begin{array}{l}\text { Analyte Concentration and Density at Given Time After Cooling to Ambient }\left(\sim 21^{\circ} \mathrm{C}\right) \\
\text { Temperature; } \mathrm{g} / \mathrm{mL} \text { for Density; } \mu \mathrm{g} / \mathrm{mL} \text { for Metals and Anions; } \mu \mathrm{Ci} / \mathrm{mL} \text { for Radionuclides }\end{array}$} \\
\hline & o hr & $1 \mathrm{hr}$ & $2 \mathrm{hr}$ & $4 \mathrm{hr}$ & $8 \mathrm{hr}$ & $24 \mathrm{hr}$ & $48 \mathrm{hr}$ \\
\hline $\mathrm{La}$ & $<0.440$ & $<0.434$ & $<0.455$ & $<0.422$ & $<0.423$ & $<0.443$ & $<0.437$ \\
\hline $\mathrm{Li}$ & [0.597] & [0.651] & {$[0.617]$} & [0.483] & [0.635] & [0.632] & [0.749] \\
\hline $\mathrm{Mg}$ & $<0.220$ & $<0.217$ & $<0.227$ & $<0.211$ & $<0.212$ & $<0.221$ & $<0.219$ \\
\hline Mo & $<0.817$ & $<0.806$ & $<0.845$ & $<0.784$ & $<0.786$ & $<0.822$ & $<0.812$ \\
\hline $\mathrm{Nd}$ & {$[0.974]$} & $<0.837$ & $<0.877$ & $<0.815$ & [0.998] & $<0.853$ & $<0.843$ \\
\hline $\mathrm{Pb}$ & {$[6.60]$} & {$[27.6]$} & [28.6] & [25.6] & [26.3] & [23.7] & [28.7] \\
\hline $\mathrm{Pd}$ & $<0.990$ & $<0.976$ & $<1.02$ & [0.966] & $<0.953$ & [1.11] & $<0.984$ \\
\hline $\mathrm{Rh}$ & $<1.89$ & $<1.86$ & $<1.95$ & $<1.81$ & $<1.81$ & $<1.90$ & $<1.87$ \\
\hline $\mathrm{Ru}$ & $<1.34$ & $<1.32$ & $<1.38$ & $<1.28$ & $<1.29$ & $<1.34$ & $<1.33$ \\
\hline $\mathrm{Sb}$ & $<3.14$ & $<3.10$ & $<3.25$ & $<3.02$ & $<3.02$ & $<3.16$ & $<3.12$ \\
\hline Se & $<11.0$ & $<10.8$ & $<11.4$ & $<10.6$ & $<10.6$ & [14.5] & $<10.9$ \\
\hline Sn & $<4.24$ & $<4.18$ & $<4.39$ & $<4.07$ & $<4.08$ & $<4.27$ & $<4.22$ \\
\hline $\mathrm{Ta}$ & $<2.67$ & $<2.63$ & $<2.76$ & $<2.56$ & $<2.57$ & $<<2.69$ & $<2.65$ \\
\hline $\mathrm{Te}$ & $<4.08$ & $<4.03$ & $<4.22$ & $<3.92$ & $<3.93$ & $<4.11$ & $<4.06$ \\
\hline Th & $<1.54$ & $<1.52$ & $<1.59$ & $<1.48$ & $<1.48$ & $<1.55$ & $<1.53$ \\
\hline $\mathrm{Ti}$ & $<0.068$ & $<0.067$ & [0.081] & $<0.065$ & $<0.065$ & $<0.068$ & $<0.067$ \\
\hline $\mathrm{Tl}$ & $<5.97$ & $<5.89$ & {$[8.77]$} & $<5.73$ & {$[8.77]$} & {$[10.1]$} & $<5.93$ \\
\hline V & $<0.116$ & $<0.115$ & $<0.120$ & $<0.112$ & $<0.112$ & $<0.117$ & $<0.116$ \\
\hline $\mathrm{W}$ & $<2.99$ & $<2.94$ & $<3.09$ & $<2.87$ & $<2.87$ & $<3.00$ & $<2.97$ \\
\hline $\mathrm{Y}$ & $<0.050$ & $<0.050$ & $<0.052$ & $<0.048$ & $<0.048$ & $<0.051$ & $<0.050$ \\
\hline \multicolumn{8}{|c|}{$3 \mathrm{M}$ NaOH, with $1 \mathrm{M} \mathrm{NaNO}_{3}$} \\
\hline Density & 1.18 & 1.20 & 1.19 & 1.20 & 1.20 & 1.17 & 1.21 \\
\hline $\mathrm{Al}$ & 276 & 3,172 & 3,290 & 3,327 & 3,377 & 3,067 & 3,381 \\
\hline B & $<0.722$ & $<0.761$ & $<0.759$ & $<0.753$ & $<0.757$ & $<0.737$ & $<0.751$ \\
\hline $\mathrm{Bi}$ & $<4.51$ & {$[6.98]$} & {$[10.4]$} & [8.79] & {$[9.78]$} & {$[9.52]$} & {$[9.70]$} \\
\hline $\mathrm{Cd}$ & $<0.512$ & $<0.539$ & $<0.538$ & $<0.533$ & $<0.537$ & $<0.522$ & $<0.532$ \\
\hline $\mathrm{Cr}$ & {$[1.56]$} & 6.82 & 8.70 & 10.7 & 12.2 & 13.0 & 15.2 \\
\hline $\mathrm{Fe}$ & {$[2.86]$} & 8.50 & 9.65 & 10.8 & 12.1 & 10.5 & 11.7 \\
\hline $\mathrm{Mn}$ & 0.969 & [0.634] & [0.380] & {$[0.257]$} & [0.193] & {$[0.138]$} & [0.138] \\
\hline $\mathrm{Na}$ & 98,405 & 102,127 & 99,323 & 101,992 & 101,309 & 91,185 & 101,424 \\
\hline $\mathrm{Ni}$ & $<0.361$ & $<0.381$ & $<0.380$ & $<0.377$ & $<0.379$ & $<0.368$ & $<0.376$ \\
\hline $\mathrm{P}$ & [13.8] & [17.1] & {$[15.8]$} & [25.1] & [9.15] & $<7.68$ & [11.3] \\
\hline$S$ & $<10.8$ & [31.4] & [31.6] & $<11.3$ & [15.1] & {$[36.8]$} & $<11.3$ \\
\hline $\mathrm{Si}$ & $<0.843$ & [4.12] & [4.43] & [5.02] & [6.94] & [5.53] & {$[6.26]$} \\
\hline $\mathrm{Sr}$ & [0.039] & [0.048] & [0.070] & [0.038] & [0.069] & [0.061] & [0.059] \\
\hline $\mathrm{U}$ & $<4.81$ & [5.07] & $<5.06$ & [9.10] & {$[14.2]$} & [11.1] & [8.77] \\
\hline $\mathrm{Zn}$ & [3.31] & 10.1 & 10.3 & 9.85 & 9.94 & 9.46 & 10.7 \\
\hline $\mathrm{Zr}$ & $<0.166$ & $<0.174$ & $<0.174$ & $<0.173$ & {$[0.240]$} & [0.196] & [0.279] \\
\hline Fluoride & $<18.5$ & $<19.6$ & $<19.5$ & $<19.3$ & $<19.2$ & $<19.0$ & $<18.7$ \\
\hline Nitrite & $<29.8$ & $<31.6$ & $<31.4$ & $<31.1$ & $<31.0$ & $<30.7$ & $<30.2$ \\
\hline Sulfate & $<44.8$ & [55.6] & [49.0] & $<46.6$ & $<46.6$ & $<46.1$ & $<45.2$ \\
\hline Nitrate & 90,725 & 86,614 & 84,861 & 82,667 & 94,381 & 77,370 & 85,648 \\
\hline Phosphate & [101] & [69.5] & [55.9] & [41.6] & {$[47.2]$} & {$[51.6]$} & {$[37.4]$} \\
\hline
\end{tabular}


Table L.3 (Contd)




Table L.3 (Contd)

\begin{tabular}{|c|c|c|c|c|c|c|c|}
\hline \multirow[b]{2}{*}{ Analyte } & \multicolumn{7}{|c|}{$\begin{array}{l}\text { Analyte Concentration and Density at Given Time After Cooling to Ambient }\left(\sim 21^{\circ} \mathrm{C}\right) \\
\text { Temperature; } \mathrm{g} / \mathrm{mL} \text { for Density; } \mu \mathrm{g} / \mathrm{mL} \text { for Metals and Anions; } \mu \mathrm{Ci} / \mathrm{mL} \text { for Radionuclides }\end{array}$} \\
\hline & o hr & $1 \mathrm{hr}$ & $2 \mathrm{hr}$ & $4 \mathrm{hr}$ & $8 \mathrm{hr}$ & $24 \mathrm{hr}$ & $48 \mathrm{hr}$ \\
\hline $\mathrm{Fe}$ & $<0.328$ & 21.1 & 22.8 & 26.4 & 27.0 & 27.6 & 30.7 \\
\hline Mn & $<0.069$ & 5.73 & 2.78 & {$[1.04]$} & {$[0.668]$} & {$[0.139]$} & $<0.036$ \\
\hline $\mathrm{Na}$ & 256,562 & 256,449 & 252,711 & 249,604 & 249,237 & 239,733 & 256,702 \\
\hline $\mathrm{Ni}$ & $<0.715$ & $<0.681$ & $<0.680$ & $<0.659$ & $<0.688$ & [1.97] & {$[1.13]$} \\
\hline $\mathrm{P}$ & $<14.9$ & [21.7] & $<14.2$ & [16.2] & [22.3] & $<13.9$ & $<7.826$ \\
\hline$S$ & $<21.5$ & {$[23.0]$} & $<20.4$ & $<19.8$ & $<20.6$ & $<20.0$ & $<11.3$ \\
\hline $\mathrm{Si}$ & $<1.67$ & $<1.59$ & $<1.59$ & $<1.54$ & $<1.60$ & {$[2.80]$} & [3.76] \\
\hline $\mathrm{Sr}$ & $<0.017$ & {$[0.205]$} & {$[0.230]$} & {$[0.201]$} & {$[0.201]$} & {$[0.145]$} & [0.116] \\
\hline $\mathrm{U}$ & $<9.53$ & $<9.07$ & $<9.06$ & $<8.79$ & $<9.17$ & $<8.87$ & $<5.01$ \\
\hline $\mathrm{Zn}$ & $<0.834$ & 18.4 & 21.7 & 23.8 & 20.7 & 17.1 & 16.6 \\
\hline $\mathrm{Zr}$ & $<0.328$ & $<0.312$ & {$[0.409]$} & {$[0.488]$} & {$[0.382]$} & {$[0.431]$} & {$[0.313]$} \\
\hline Fluoride & $<16.8$ & $<19.2$ & $<20.5$ & NM & [41.7] & [36.3] & [60.3] \\
\hline Nitrite & $<27.2$ & $<31.0$ & $<33.1$ & NM & $<40.1$ & $<30.8$ & $<30.1$ \\
\hline Sulfate & $<40.7$ & $<46.6$ & $<49.7$ & NM & $<60.2$ & $<46.1$ & $<45.2$ \\
\hline Nitrate & 310,631 & 367,455 & 353,264 & NM & 361,130 & 339,539 & 373,756 \\
\hline Phosphate & {$[44.0]$} & [93.1] & [55.7] & NM & [144] & [86.1] & [90.4] \\
\hline${ }^{60} \mathrm{Co}$ & \multirow{5}{*}{\multicolumn{6}{|c|}{ Not Measured }} & $<4 \mathrm{E}-6$ \\
\hline${ }^{137} \mathrm{Cs}$ & & & & & & & $5.36 \mathrm{E}-2$ \\
\hline${ }^{154} \mathrm{Eu}$ & & & & & & & $<1 \mathrm{E}-5$ \\
\hline${ }^{155} \mathrm{Eu}$ & & & & & & & $<5 E-5$ \\
\hline${ }^{241} \mathrm{Am}$ & & & & & & & $<5 \mathrm{E}-5$ \\
\hline \multicolumn{8}{|c|}{ Opportunistic Analytes } \\
\hline $\mathrm{Ag}$ & $<0.626$ & $<0.595$ & $<0.595$ & $<0.577$ & $<0.602$ & $<0.582$ & $<0.329$ \\
\hline As & $<12.812$ & $<12.192$ & $<12.179$ & $<11.809$ & $<12.319$ & $<11.925$ & $<6.73$ \\
\hline $\mathrm{Ba}$ & $<0.048$ & 1.541 & 2.889 & 3.967 & 3.470 & 2.283 & 2.357 \\
\hline $\mathrm{Be}$ & $<0.015$ & $<0.015$ & $<0.015$ & $<0.014$ & $<0.015$ & $<0.014$ & $<0.008$ \\
\hline $\mathrm{Ca}$ & $<0.983$ & $<0.936$ & [1.227] & $<0.906$ & $<0.945$ & $<1.69$ & $<0.955$ \\
\hline $\mathrm{Ce}$ & $<2.98$ & $<2.84$ & $<2.83$ & $<2.75$ & $<2.86$ & $<2.77$ & $<1.57$ \\
\hline Co & $<0.715$ & $<0.681$ & $<0.680$ & $<0.659$ & $<0.688$ & [0.709] & $<0.376$ \\
\hline $\mathrm{Cu}$ & $<0.417$ & $<0.397$ & [0.629] & $<0.384$ & $<0.401$ & $<0.388$ & $<0.219$ \\
\hline Dy & $<0.864$ & $<0.822$ & $<0.821$ & $<0.796$ & $<0.831$ & $<0.804$ & $<0.454$ \\
\hline $\mathrm{Eu}$ & $<0.131$ & $<0.125$ & $<0.125$ & $<0.121$ & $<0.126$ & $<0.305$ & $<0.172$ \\
\hline $\mathrm{K}$ & $<5.959$ & 142 & 123 & 139 & 143 & 63.5 & 104 \\
\hline $\mathrm{La}$ & $<0.834$ & $<0.794$ & $<0.793$ & $<0.769$ & $<0.802$ & $<0.777$ & $<0.438$ \\
\hline $\mathrm{Li}$ & $<0.179$ & [0.693] & {$[0.346]$} & {$[0.610]$} & {$[0.350]$} & [0.339] & {$[1.06]$} \\
\hline $\mathrm{Mg}$ & $<0.417$ & $<0.397$ & $<0.397$ & $<0.384$ & $<0.401$ & $<0.638$ & $<0.360$ \\
\hline Mo & $<1.55$ & $<1.47$ & $<1.47$ & $<1.43$ & $<1.78$ & $<1.44$ & $<0.814$ \\
\hline $\mathrm{Nd}$ & $<1.61$ & {$[1.54]$} & $<1.53$ & $<1.48$ & {$[2.29]$} & $<1.50$ & $<0.845$ \\
\hline $\mathrm{Pb}$ & $<9.53$ & [30.2] & [30.2] & [30.2] & [24.5] & [25.3] & [34.4] \\
\hline $\mathrm{Pd}$ & $<1.88$ & {$[2.87]$} & $<1.78$ & $<1.73$ & $<1.80$ & $<1.75$ & $<0.99$ \\
\hline $\mathrm{Rh}$ & $<3.58$ & $<3.40$ & $<3.40$ & $<3.30$ & $<3.44$ & $<3.33$ & $<1.88$ \\
\hline $\mathrm{Ru}$ & $<2.53$ & $<2.41$ & $<2.41$ & $<2.33$ & $<2.44$ & $<2.36$ & $<1.33$ \\
\hline $\mathrm{Sb}$ & $<5.96$ & $<5.67$ & $<5.66$ & $<5.49$ & $<5.73$ & {$[16.0]$} & $<3.13$ \\
\hline Se & $<20.9$ & $<19.8$ & $<19.8$ & $<19.2$ & $<20.1$ & $<19.4$ & $<11.0$ \\
\hline
\end{tabular}


Table L.3 (Contd)

\begin{tabular}{|c|c|c|c|c|c|c|c|}
\hline \multirow[b]{2}{*}{ Analyte } & \multicolumn{7}{|c|}{$\begin{array}{l}\text { Analyte Concentration and Density at Given Time After Cooling to Ambient }\left(\sim 21^{\circ} \mathrm{C}\right) \\
\text { Temperature; } \mathrm{g} / \mathrm{mL} \text { for Density; } \mu \mathrm{g} / \mathrm{mL} \text { for Metals and Anions; } \mu \mathrm{Ci} / \mathrm{mL} \text { for Radionuclides }\end{array}$} \\
\hline & o hr & $1 \mathrm{hr}$ & $2 \mathrm{hr}$ & $4 \mathrm{hr}$ & $8 \mathrm{hr}$ & $24 \mathrm{hr}$ & $48 \mathrm{hr}$ \\
\hline Sn & $<8.04$ & {$[10.4]$} & $<7.65$ & $<7.41$ & $<7.73$ & $<7.49$ & $<4.23$ \\
\hline $\mathrm{Ta}$ & $<5.07$ & $<4.82$ & $<4.82$ & $<4.67$ & $<4.87$ & $<4.71$ & $<2.66$ \\
\hline $\mathrm{Te}$ & $<7.75$ & $<7.37$ & $<7.36$ & $<7.14$ & $<7.45$ & $<7.21$ & $<4.07$ \\
\hline Th & $<2.92$ & $<2.78$ & $<2.78$ & $<2.69$ & $<2.81$ & $<2.72$ & $<1.53$ \\
\hline $\mathrm{Ti}$ & $<0.128$ & $<0.122$ & $<0.122$ & {$[0.122]$} & $<0.123$ & {$[0.126]$} & $<0.067$ \\
\hline $\mathrm{Tl}$ & $<11.3$ & [11.3] & $<10.8$ & $<10.4$ & [17.2] & $<10.5$ & $<5.95$ \\
\hline $\mathrm{V}$ & $<0.220$ & $<0.210$ & $<0.210$ & $<<0.203$ & $<0.212$ & $<0.205$ & [0.344] \\
\hline $\mathrm{W}$ & $<5.66$ & $<5.39$ & {$[10.1]$} & $<5.22$ & $<5.44$ & $<5.27$ & $<2.97$ \\
\hline $\mathrm{Y}$ & $<0.095$ & $<0.091$ & $<0.091$ & $<0.088$ & $<0.092$ & $<0.122$ & $<0.069$ \\
\hline \multicolumn{8}{|l|}{$5 \mathrm{M} \mathrm{NaOH}$} \\
\hline Density & 1.15 & 1.18 & 1.22 & 1.21 & 1.21 & 1.20 & 1.23 \\
\hline $\mathrm{Al}$ & 122 & 3,294 & 3,435 & 3,407 & 3,499 & 3,324 & 3,534 \\
\hline $\mathrm{B}$ & $<0.820$ & $<0.830$ & $<0.870$ & $<0.864$ & $<0.860$ & $<0.844$ & [1.060] \\
\hline $\mathrm{Bi}$ & [6.15] & [11.41] & [12.3] & [14.4] & [16.5] & [12.3] & [15.5] \\
\hline $\mathrm{Cd}$ & $<0.581$ & $<0.588$ & $<0.616$ & $<0.612$ & $<0.609$ & $<0.598$ & $<0.601$ \\
\hline $\mathrm{Cr}$ & {$[1.26]$} & 8.16 & 10.91 & 12.6 & 14.3 & 15.1 & 16.3 \\
\hline $\mathrm{Fe}$ & [1.98] & 15.5 & 18.7 & 20.5 & 22.6 & 22.8 & 25.0 \\
\hline $\mathrm{Mn}$ & 0.803 & 1.74 & {$[0.725]$} & [0.317] & {$[0.143]$} & $<0.040$ & $<0.041$ \\
\hline $\mathrm{Na}$ & 134,242 & 137,241 & 142,040 & 140,825 & 145,558 & 136,495 & 145,600 \\
\hline $\mathrm{Ni}$ & {$[0.991]$} & [1.037] & [1.051] & {$[1.044]$} & [0.968] & {$[0.704]$} & [1.17] \\
\hline $\mathrm{P}$ & [9.91] & [16.6] & $<9.06$ & {$[10.80]$} & $<8.96$ & [9.15] & [14.14] \\
\hline$S$ & $<12.3$ & $<12.4$ & $<13.0$ & $<13.0$ & $<12.9$ & $<12.7$ & $<12.7$ \\
\hline $\mathrm{Si}$ & $<0.956$ & 37.0 & 40.6 & 41.8 & 43.4 & 41.5 & 44.9 \\
\hline $\mathrm{Sr}$ & {$[0.044]$} & {$[0.090]$} & {$[0.091]$} & {$[0.104]$} & {$[0.111]$} & {$[0.091]$} & {$[0.106]$} \\
\hline $\mathrm{U}$ & {$[5.81]$} & [14.9] & {$[18.5]$} & [19.4] & {$[15.4]$} & [13.7] & [13.8] \\
\hline $\mathrm{Zn}$ & [3.07] & 9.06 & 10.47 & 9.51 & 10.76 & 9.78 & 10.39 \\
\hline $\mathrm{Zr}$ & $<0.188$ & [0.228] & {$[0.243]$} & $<0.198$ & {$[0.237]$} & $<0.193$ & $<0.194$ \\
\hline Fluoride & [2.27] & $<1.128$ & $<1.119$ & $<1.16$ & {$[4.90]$} & $<1.124$ & $<1.126$ \\
\hline Nitrite & $<1.72$ & $<1.76$ & $<1.75$ & $<1.82$ & $<1.70$ & $<1.76$ & $<1.76$ \\
\hline Sulfate & $<2.55$ & $<2.61$ & $<2.59$ & $<2.69$ & $<2.52$ & $<2.60$ & $<2.60$ \\
\hline Nitrate & 118 & 142 & 143 & 148 & 141 & 144 & 158 \\
\hline Phosphate & 36.9 & 35.1 & 33.5 & 33.8 & 32.9 & 32.8 & 33.6 \\
\hline${ }^{60} \mathrm{Co}$ & \multirow{5}{*}{\multicolumn{6}{|c|}{ Not Measured }} & $2 \mathrm{E}-6$ \\
\hline${ }^{137} \mathrm{Cs}$ & & & & & & & $8.14 \mathrm{E}-2$ \\
\hline${ }^{154} \mathrm{Eu}$ & & & & & & & $<7 \mathrm{E}-6$ \\
\hline${ }^{155} \mathrm{Eu}$ & & & & & & & $<5 \mathrm{E}-5$ \\
\hline${ }^{241} \mathrm{Am}$ & & & & & & & $<2 \mathrm{E}-4$ \\
\hline \multicolumn{8}{|c|}{ Opportunistic Analytes } \\
\hline $\mathrm{Ag}$ & $<0.359$ & $<0.363$ & $<0.380$ & $<0.378$ & $<0.376$ & $<0.369$ & $<0.371$ \\
\hline As & $<7.34$ & $<7.43$ & $<7.79$ & $<7.74$ & $<7.71$ & $<7.56$ & $<7.60$ \\
\hline $\mathrm{Ba}$ & {$[0.376]$} & [0.553] & {$[0.337]$} & {$[0.396]$} & 0.986 & {$[0.493]$} & [0.304] \\
\hline $\mathrm{Be}$ & $<0.009$ & $<0.009$ & $<0.009$ & $<0.009$ & $<0.009$ & {$[0.009]$} & $<0.009$ \\
\hline $\mathrm{Ca}$ & {$[4.78]$} & [2.420] & {$[7.97]$} & {$[6.84]$} & {$[5.02]$} & [3.87] & {$[5.65]$} \\
\hline $\mathrm{Ce}$ & $<1.71$ & $<1.73$ & $<1.81$ & $<1.80$ & $<1.79$ & $<1.76$ & $<1.77$ \\
\hline
\end{tabular}


Table L.3 (Contd)

\begin{tabular}{|c|c|c|c|c|c|c|c|}
\hline \multirow[b]{2}{*}{ Analyte } & \multicolumn{7}{|c|}{$\begin{array}{l}\text { Analyte Concentration and Density at Given Time After Cooling to Ambient }\left(\sim 21^{\circ} \mathrm{C}\right) \\
\text { Temperature; } \mathrm{g} / \mathrm{mL} \text { for Density; } \mu \mathrm{g} / \mathrm{mL} \text { for Metals and Anions; } \mu \mathrm{Ci} / \mathrm{mL} \text { for Radionuclides }\end{array}$} \\
\hline & o hr & $1 \mathrm{hr}$ & $2 \mathrm{hr}$ & $4 \mathrm{hr}$ & $8 \mathrm{hr}$ & $24 \mathrm{hr}$ & $48 \mathrm{hr}$ \\
\hline Co & {$[0.478]$} & $<0.415$ & {$[0.507]$} & $<0.432$ & $<0.430$ & [0.563] & $<0.424$ \\
\hline $\mathrm{Cu}$ & $<0.239$ & [0.339] & {$[0.257]$} & {$[0.432]$} & $<0.251$ & {$[0.317]$} & [1.131] \\
\hline Dy & $<0.495$ & $<0.501$ & $<0.525$ & $<0.522$ & $<0.520$ & $<0.510$ & $<0.512$ \\
\hline $\mathrm{Eu}$ & $<0.188$ & $<0.190$ & $<0.199$ & $<0.198$ & $<0.197$ & $<0.193$ & $<0.194$ \\
\hline $\mathrm{K}$ & 59.4 & 62.6 & 66.7 & 72.4 & 82.8 & 78.1 & 79.2 \\
\hline $\mathrm{La}$ & $<0.478$ & $<0.484$ & $<0.507$ & $<0.504$ & $<0.502$ & $<0.493$ & $<0.495$ \\
\hline $\mathrm{Li}$ & $<0.102$ & [0.553] & {$[0.761]$} & [0.684] & [0.789] & [0.739] & {$[0.601]$} \\
\hline $\mathrm{Mg}$ & $<0.393$ & $<0.398$ & $<0.417$ & $<0.414$ & $<0.412$ & $<0.405$ & $<0.406$ \\
\hline Mo & $<0.888$ & $<0.899$ & $<0.942$ & $<0.936$ & $<0.932$ & $<0.915$ & $<0.919$ \\
\hline $\mathrm{Nd}$ & $<0.922$ & $<0.933$ & $<0.978$ & $<0.972$ & $<0.968$ & $<0.950$ & $<<0.954$ \\
\hline $\mathrm{Pb}$ & [6.83] & [21.4] & {$[22.8]$} & [25.6] & [21.9] & [26.0] & [27.9] \\
\hline $\mathrm{Pd}$ & $<1.076$ & $<1.089$ & $<1.141$ & $<1.135$ & $<1.129$ & $<1.108$ & $<1.113$ \\
\hline $\mathrm{Rh}$ & $<2.05$ & $<2.07$ & $<2.17$ & $<2.16$ & $<2.15$ & $<2.11$ & $<2.12$ \\
\hline $\mathrm{Ru}$ & $<1.45$ & $<1.47$ & $<1.54$ & $<1.53$ & $<1.52$ & $<1.50$ & $<1.50$ \\
\hline $\mathrm{Sb}$ & $<3.42$ & [7.61] & $<3.62$ & [9.00] & [6.81] & [7.74] & $<3.53$ \\
\hline Se & $<12.0$ & $<12.1$ & $<12.7$ & $<12.6$ & $<12.5$ & $<12.3$ & $<12.4$ \\
\hline Sn & $<4.61$ & $<4.67$ & $<4.89$ & $<4.86$ & $<4.84$ & $<4.75$ & $<4.77$ \\
\hline $\mathrm{Ta}$ & $<2.90$ & $<2.94$ & $<3.08$ & $<3.06$ & $<3.05$ & $<2.99$ & $<3.00$ \\
\hline $\mathrm{Te}$ & $<4.44$ & $<4.49$ & $<4.71$ & $<4.68$ & $<<4.66$ & $<4.57$ & $<4.59$ \\
\hline Th & $<1.67$ & $<1.69$ & $<1.78$ & $<1.76$ & $<1.76$ & $<1.72$ & $<1.73$ \\
\hline $\mathrm{Ti}$ & $<0.073$ & $<0.074$ & $<0.078$ & $<0.077$ & $<0.077$ & $<0.076$ & $<0.076$ \\
\hline $\mathrm{Tl}$ & $<6.49$ & $<6.57$ & $<6.88$ & $<6.84$ & $<6.81$ & $<<6.68$ & $<6.71$ \\
\hline $\mathrm{V}$ & {$[0.304]$} & {$[0.235]$} & $<0.134$ & {$[0.277]$} & {$[0.298]$} & {$[0.236]$} & {$[0.254]$} \\
\hline W & $<3.25$ & $<3.28$ & $<3.44$ & $<3.42$ & $<3.41$ & $<3.34$ & $<3.36$ \\
\hline $\mathrm{Y}$ & $<0.075$ & $<0.076$ & $<0.080$ & $<0.079$ & $<0.079$ & $<0.077$ & $<0.078$ \\
\hline
\end{tabular}


Table L.4. Analyte Concentrations as a Function of Time for Leaching at $80^{\circ} \mathrm{C}$, in $\mathrm{M}$

\begin{tabular}{|c|c|c|c|c|c|c|c|}
\hline \multirow[b]{2}{*}{ Analyte } & \multicolumn{7}{|c|}{$\begin{array}{l}\text { Analyte Concentration and Density at Given Time After Cooling to Ambient }\left(\sim 21^{\circ} \mathrm{C}\right) \\
\text { Temperature; } \mathrm{g} / \mathrm{mL} \text { for Density; } \mathrm{M} \text { for Metals and Anions }\end{array}$} \\
\hline & $0 \mathrm{hr}$ & $1 \mathrm{hr}$ & $2 \mathrm{hr}$ & $4 \mathrm{hr}$ & $8 \mathrm{hr}$ & $24 \mathrm{hr}$ & $48 \mathrm{hr}$ \\
\hline \multicolumn{8}{|l|}{$1 \mathrm{M} \mathrm{NaOH}$} \\
\hline Density & 1.06 & 1.06 & 1.06 & 1.07 & 1.07 & 1.07 & 1.08 \\
\hline $\mathrm{Al}$ & 4.162E-03 & 8.73E-02 & 1.09E-01 & $1.27 \mathrm{E}-01$ & $1.27 \mathrm{E}-01$ & $1.25 \mathrm{E}-01$ & $1.27 \mathrm{E}-01$ \\
\hline B & $<1.40 \mathrm{E}-05$ & $<<1.41 \mathrm{E}-05$ & $<<1.39 \mathrm{E}-05$ & $<1.37 \mathrm{E}-05$ & $<1.41 \mathrm{E}-05$ & $<<1.40 \mathrm{E}-05$ & $<1.37 \mathrm{E}-05$ \\
\hline $\mathrm{Bi}$ & $<4.52 \mathrm{E}-06$ & [1.51E-05] & [1.65E-05] & [1.92E-05] & [1.98E-05] & [2.11E-05] & [1.92E-05] \\
\hline $\mathrm{Cd}$ & $<9.51 \mathrm{E}-07$ & $<<9.57 \mathrm{E}-07$ & $<<9.46 \mathrm{E}-07$ & $<<9.36 \mathrm{E}-07$ & $<<9.63 \mathrm{E}-07$ & $<<9.54 \mathrm{E}-07$ & $<<9.33 \mathrm{E}-07$ \\
\hline $\mathrm{Cr}$ & [9.98E-06] & 7.06E-05 & $9.32 \mathrm{E}-05$ & $1.26 \mathrm{E}-04$ & $1.58 \mathrm{E}-04$ & 2.03E-04 & 2.31E-04 \\
\hline $\mathrm{Fe}$ & [7.88E-06] & 3.70E-05 & 4.04E-05 & $4.50 \mathrm{E}-05$ & 4.44E-05 & 4.02E-05 & 3.38E-05 \\
\hline $\mathrm{Mn}$ & 3.621E-06 & $2.70 \mathrm{E}-06$ & [1.82E-06] & [1.52E-06] & [9.85E-07] & [6.89E-07] & [6.18E-07] \\
\hline $\mathrm{Na}$ & 1.11 & 1.14 & 1.12 & 1.16 & 1.15 & 1.13 & 1.14 \\
\hline $\mathrm{Ni}$ & $<1.29 \mathrm{E}-06$ & $<1.29 \mathrm{E}-06$ & $<1.28 \mathrm{E}-06$ & $<1.26 \mathrm{E}-06$ & $<1.30 \mathrm{E}-06$ & $<1.29 \mathrm{E}-06$ & $<1.26 \mathrm{E}-06$ \\
\hline $\mathrm{P}$ & [3.00E-04] & [4.09E-04] & [3.43E-04] & [3.20E-04] & [3.80E-04] & [3.36E-04] & [3.49E-04] \\
\hline$S$ & $<7.06 \mathrm{E}-05$ & $<7.11 \mathrm{E}-05$ & $<7.02 \mathrm{E}-05$ & $<6.95 \mathrm{E}-05$ & $<7.15 \mathrm{E}-05$ & $<7.09 \mathrm{E}-05$ & $<6.93 \mathrm{E}-05$ \\
\hline $\mathrm{Si}$ & 1.052E-04 & 7.99E-04 & $8.24 \mathrm{E}-04$ & 8.63E-04 & 9.02E-04 & $8.25 \mathrm{E}-04$ & 8.29E-04 \\
\hline $\mathrm{Sr}$ & [8.79E-08] & [1.05E-07] & [5.71E-08] & [2.01E-07] & [1.02E-07] & [7.92E-08] & [7.04E-08] \\
\hline $\mathrm{U}$ & $<4.23 \mathrm{E}-06$ & [2.13E-05] & [2.10E-05] & [2.99E-05] & [3.21E-05] & [3.31E-05] & [3.37E-05] \\
\hline $\mathrm{Zn}$ & 2.408E-05 & $9.20 \mathrm{E}-05$ & $1.12 \mathrm{E}-04$ & $2.26 \mathrm{E}-04$ & $1.25 \mathrm{E}-04$ & $1.24 \mathrm{E}-04$ & $1.26 \mathrm{E}-04$ \\
\hline $\mathrm{Zr}$ & [4.83E-07] & [4.51E-07] & $<3.77 \mathrm{E}-07$ & [5.43E-07] & [5.24E-07] & [8.65E-07] & [7.10E-07] \\
\hline Fluoride & [1.61E-04] & [1.08E-04] & [9.58E-05] & [8.44E-05] & [8.53E-05] & [7.65E-05] & [7.59E-05] \\
\hline Nitrite & $<3.40 \mathrm{E}-05$ & [4.06E-05] & [4.50E-05] & [4.42E-05] & [4.33E-05] & [4.35E-05] & [4.44E-05] \\
\hline Sulfate & $<2.41 \mathrm{E}-05$ & $<2.32 \mathrm{E}-05$ & $<2.42 \mathrm{E}-05$ & $<2.37 \mathrm{E}-05$ & [2.53E-05] & $<2.33 \mathrm{E}-05$ & $<2.31 \mathrm{E}-05$ \\
\hline Nitrate & $1.65 \mathrm{E}-03$ & $1.77 \mathrm{E}-03$ & $1.83 \mathrm{E}-03$ & 1.92E-03 & $1.84 \mathrm{E}-03$ & 1.83E-03 & 1.83E-03 \\
\hline Phosphate & $3.06 \mathrm{E}-04$ & $3.06 \mathrm{E}-04$ & 3.13E-04 & $3.00 \mathrm{E}-04$ & $2.89 \mathrm{E}-04$ & $2.88 \mathrm{E}-04$ & $2.88 \mathrm{E}-04$ \\
\hline \multicolumn{8}{|c|}{$3 \mathrm{M}$ NaOH, Trial a } \\
\hline Density & 1.14 & 1.17 & 1.16 & 1.13 & 1.14 & 1.14 & 1.18 \\
\hline $\mathrm{Al}$ & 5.67E-03 & $1.256 \mathrm{E}-01$ & $1.30 \mathrm{E}-01$ & 1.36E-01 & $1.32 \mathrm{E}-01$ & 1.29E-01 & 1.37E-01 \\
\hline $\mathrm{B}$ & $<6.70 \mathrm{E}-05$ & [3.61E-04] & [2.40E-04] & [2.21E-04] & [1.52E-04] & [2.02E-04] & [2.62E-04] \\
\hline $\mathrm{Bi}$ & $<2.17 \mathrm{E}-05$ & [5.23E-05] & [4.00E-05] & [4.72E-05] & [5.03E-05] & [5.30E-05] & [6.56E-05] \\
\hline $\mathrm{Cd}$ & $<4.57 \mathrm{E}-06$ & $<4.72 \mathrm{E}-06$ & $<4.68 \mathrm{E}-06$ & $<4.81 \mathrm{E}-06$ & $<4.68 \mathrm{E}-06$ & $<4.65 \mathrm{E}-06$ & $<4.71 \mathrm{E}-06$ \\
\hline $\mathrm{Cr}$ & [2.96E-05] & $1.38 \mathrm{E}-04$ & $1.69 \mathrm{E}-04$ & $2.24 \mathrm{E}-04$ & $2.36 \mathrm{E}-04$ & 2.77E-04 & 3.04E-04 \\
\hline $\mathrm{Fe}$ & [4.60E-05] & $1.56 \mathrm{E}-04$ & $1.72 \mathrm{E}-04$ & $1.99 \mathrm{E}-04$ & $2.07 \mathrm{E}-04$ & $2.10 \mathrm{E}-04$ & $2.12 \mathrm{E}-04$ \\
\hline $\mathrm{Mn}$ & [9.89E-06] & [9.38E-06] & [3.66E-06] & [2.55E-06] & $<6.48 \mathrm{E}-07$ & $<6.43 \mathrm{E}-07$ & $<6.53 \mathrm{E}-07$ \\
\hline $\mathrm{Na}$ & 3.43 & 3.44 & 3.38 & 3.42 & 3.31 & 3.30 & 3.46 \\
\hline $\mathrm{Ni}$ & $<6.17 \mathrm{E}-06$ & [7.72E-06] & $<6.32 \mathrm{E}-06$ & [8.67E-06] & $<6.32 \mathrm{E}-06$ & [7.33E-06] & $<6.37 \mathrm{E}-06$ \\
\hline $\mathrm{P}$ & $<2.44 \mathrm{E}-04$ & [2.92E-04] & {$[2.80 \mathrm{E}-04]$} & $<2.57 \mathrm{E}-04$ & [3.60E-04] & [2.78E-04] & $<2.52 \mathrm{E}-04$ \\
\hline$S$ & $<3.39 \mathrm{E}-04$ & [7.60E-04] & $<3.47 \mathrm{E}-04$ & $<3.57 \mathrm{E}-04$ & [3.57E-04] & [7.57E-04] & [3.60E-04] \\
\hline $\mathrm{Si}$ & [2.80E-04] & $1.324 \mathrm{E}-03$ & $1.41 \mathrm{E}-03$ & $1.54 \mathrm{E}-03$ & $1.59 \mathrm{E}-03$ & $1.66 \mathrm{E}-03$ & $1.81 \mathrm{E}-03$ \\
\hline $\mathrm{Sr}$ & [4.82E-07] & [5.17E-07] & [4.94E-07] & [6.90E-07] & [6.00E-07] & [6.31E-07] & [6.05E-07] \\
\hline $\mathrm{U}$ & [2.16E-05] & [4.00E-05] & [3.38E-05] & [5.88E-05] & [5.72E-05] & [6.97E-05] & [7.07E-05] \\
\hline $\mathrm{Zn}$ & [3.97E-05] & $1.519 \mathrm{E}-04$ & $1.56 \mathrm{E}-04$ & $<1.73 \mathrm{E}-04$ & $1.65 \mathrm{E}-04$ & $1.56 \mathrm{E}-04$ & $1.67 \mathrm{E}-04$ \\
\hline $\mathrm{Zr}$ & $<1.82 \mathrm{E}-06$ & [2.31E-06] & $<1.86 \mathrm{E}-06$ & $<1.92 \mathrm{E}-06$ & [2.14E-06] & [2.49E-06] & [3.76E-06] \\
\hline Fluoride & [2.32E-04] & $<2.53 \mathrm{E}-05$ & $<2.42 \mathrm{E}-05$ & $<2.43 \mathrm{E}-05$ & $<2.43 \mathrm{E}-05$ & $<2.47 \mathrm{E}-05$ & $<2.48 \mathrm{E}-05$ \\
\hline Nitrite & $<1.64 \mathrm{E}-05$ & $<1.74 \mathrm{E}-05$ & $<1.66 \mathrm{E}-05$ & $<1.67 \mathrm{E}-05$ & $<1.67 \mathrm{E}-05$ & $<1.70 \mathrm{E}-05$ & $<1.70 \mathrm{E}-05$ \\
\hline Sulfate & $<1.15 \mathrm{E}-05$ & $<1.22 \mathrm{E}-05$ & $<1.16 \mathrm{E}-05$ & $<1.17 \mathrm{E}-05$ & $<1.17 \mathrm{E}-05$ & $<1.19 \mathrm{E}-05$ & $<1.19 \mathrm{E}-05$ \\
\hline
\end{tabular}


Table L.4 (Contd)

\begin{tabular}{|c|c|c|c|c|c|c|c|}
\hline \multirow[b]{2}{*}{ Analyte } & \multicolumn{7}{|c|}{$\begin{array}{l}\text { Analyte Concentration and Density at Given Time After Cooling to Ambient }\left(\sim 21^{\circ} \mathrm{C}\right) \\
\text { Temperature; } \mathrm{g} / \mathrm{mL} \text { for Density; } \mathrm{M} \text { for Metals and Anions }\end{array}$} \\
\hline & $0 \mathrm{hr}$ & $1 \mathrm{hr}$ & $2 \mathrm{hr}$ & $4 \mathrm{hr}$ & $8 \mathrm{hr}$ & $24 \mathrm{hr}$ & $48 \mathrm{hr}$ \\
\hline Nitrate & $1.62 \mathrm{E}-03$ & $2.01 \mathrm{E}-03$ & $2.01 \mathrm{E}-03$ & $2.01 \mathrm{E}-03$ & $2.08 \mathrm{E}-03$ & $1.10 \mathrm{E}-02$ & 2.19E-03 \\
\hline Phosphate & 2.97E-04 & 3.07E-04 & 2.94E-04 & $2.74 \mathrm{E}-04$ & $2.74 \mathrm{E}-04$ & $1.40 \mathrm{E}-03$ & $2.71 \mathrm{E}-04$ \\
\hline \multicolumn{8}{|c|}{$3 \mathrm{M}$ NaOH, Trial b } \\
\hline Density & 1.13 & 1.15 & 1.14 & 1.14 & 1.14 & 1.13 & 1.16 \\
\hline $\mathrm{Al}$ & 4.26E-03 & 1.13E-01 & $1.25 \mathrm{E}-01$ & $1.27 \mathrm{E}-01$ & $1.25 \mathrm{E}-01$ & 1.31E-01 & $1.32 \mathrm{E}-01$ \\
\hline $\mathrm{B}$ & [1.62E-04] & [1.16E-04] & [1.72E-04] & $<6.93 \mathrm{E}-05$ & $<6.91 \mathrm{E}-05$ & $<7.09 \mathrm{E}-05$ & $<6.92 \mathrm{E}-05$ \\
\hline $\mathrm{Bi}$ & $<2.20 \mathrm{E}-05$ & [5.37E-05] & [4.52E-05] & [3.29E-05] & [5.36E-05] & [4.28E-05] & [4.17E-05] \\
\hline $\mathrm{Cd}$ & $<4.64 \mathrm{E}-06$ & $<4.85 \mathrm{E}-06$ & $<4.61 \mathrm{E}-06$ & $<4.72 \mathrm{E}-06$ & [6.37E-06] & $<4.83 \mathrm{E}-06$ & $<4.71 \mathrm{E}-06$ \\
\hline $\mathrm{Cr}$ & [2.83E-05] & $1.26 \mathrm{E}-04$ & $1.62 \mathrm{E}-04$ & 1.95E-04 & $2.25 \mathrm{E}-04$ & 2.73E-04 & 2.93E-04 \\
\hline $\mathrm{Fe}$ & [2.91E-05] & $1.45 \mathrm{E}-04$ & $1.69 \mathrm{E}-04$ & 1.95E-04 & 2.03E-04 & $2.11 \mathrm{E}-04$ & $2.05 \mathrm{E}-04$ \\
\hline $\mathrm{Mn}$ & [9.49E-06] & [9.93E-06] & [4.66E-06] & [3.92E-06] & [3.29E-06] & {$[2.50 \mathrm{E}-06]$} & [2.21E-06] \\
\hline $\mathrm{Na}$ & 3.23 & 3.34 & 3.22 & 3.34 & 3.30 & 3.38 & 3.36 \\
\hline $\mathrm{Ni}$ & $<6.27 \mathrm{E}-06$ & $<6.56 \mathrm{E}-06$ & $<6.23 \mathrm{E}-06$ & $<6.38 \mathrm{E}-06$ & $<6.37 \mathrm{E}-06$ & $<6.53 \mathrm{E}-06$ & $<6.37 \mathrm{E}-06$ \\
\hline $\mathrm{P}$ & [2.87E-04] & $<2.59 \mathrm{E}-04$ & $<2.46 \mathrm{E}-04$ & [4.03E-04] & [4.32E-04] & [4.33E-04] & [3.62E-04] \\
\hline$S$ & $<3.44 \mathrm{E}-04$ & [3.80E-04] & $<3.42 \mathrm{E}-04$ & $<3.51 \mathrm{E}-04$ & $<3.50 \mathrm{E}-04$ & [1.10E-03] & $<3.50 \mathrm{E}-04$ \\
\hline $\mathrm{Si}$ & [2.40E-04] & $1.23 \mathrm{E}-03$ & 1.33E-03 & 1.33E-03 & $1.41 \mathrm{E}-03$ & 1.62E-03 & $1.58 \mathrm{E}-03$ \\
\hline $\mathrm{Sr}$ & [3.85E-07] & [5.86E-07] & [6.95E-07] & [4.63E-07] & [5.69E-07] & [7.29E-07] & [3.91E-07] \\
\hline $\mathrm{U}$ & $<2.06 \mathrm{E}-05$ & [5.53E-05] & [5.50E-05] & [3.80E-05] & [4.97E-05] & [4.16E-05] & [5.50E-05] \\
\hline $\mathrm{Zn}$ & [4.22E-05] & $1.44 \mathrm{E}-04$ & $1.51 \mathrm{E}-04$ & $1.51 \mathrm{E}-04$ & 1.49E-04 & 1.69E-04 & $1.61 \mathrm{E}-04$ \\
\hline $\mathrm{Zr}$ & [2.96E-06] & $<1.93 \mathrm{E}-06$ & [2.74E-06] & [2.16E-06] & [1.88E-06] & $<1.93 \mathrm{E}-06$ & [2.56E-06] \\
\hline Fluoride & [2.09E-04] & $<2.55 \mathrm{E}-05$ & $<2.44 \mathrm{E}-05$ & [6.60E-05] & [6.03E-05] & [6.15E-05] & [5.26E-05] \\
\hline Nitrite & $<1.65 \mathrm{E}-05$ & $<1.75 \mathrm{E}-05$ & $<1.68 \mathrm{E}-05$ & $<3.24 \mathrm{E}-05$ & [4.72E-05] & $<3.34 \mathrm{E}-05$ & $<3.20 \mathrm{E}-05$ \\
\hline Sulfate & $<1.16 \mathrm{E}-05$ & $<1.23 \mathrm{E}-05$ & $<1.18 \mathrm{E}-05$ & [4.04E-05] & [1.69E-04] & $<2.37 \mathrm{E}-05$ & $<2.27 \mathrm{E}-05$ \\
\hline Nitrate & $1.67 \mathrm{E}-03$ & 2.19E-03 & $2.06 \mathrm{E}-03$ & $2.01 \mathrm{E}-03$ & $2.00 \mathrm{E}-03$ & $2.05 \mathrm{E}-03$ & 1.95E-03 \\
\hline Phosphate & 3.12E-04 & $3.01 \mathrm{E}-04$ & $2.58 \mathrm{E}-04$ & 6.15E-04 & 4.05E-04 & $3.74 \mathrm{E}-04$ & $3.45 \mathrm{E}-04$ \\
\hline \multicolumn{8}{|c|}{$3 \mathrm{M}$ NaOH, Trial c } \\
\hline Density & 1.14 & 1.13 & 1.12 & 1.15 & 1.13 & 1.13 & 1.16 \\
\hline $\mathrm{Al}$ & 3.68E-03 & 1.09E-01 & 1.38E-01 & 1.30E-01 & 1.30E-01 & 1.29E-01 & 1.32E-01 \\
\hline $\mathrm{B}$ & $<6.98 \mathrm{E}-05$ & $<6.88 \mathrm{E}-05$ & $<7.21 \mathrm{E}-05$ & $<6.70 \mathrm{E}-05$ & $<6.72 \mathrm{E}-05$ & $<7.02 \mathrm{E}-05$ & $<6.93 \mathrm{E}-05$ \\
\hline $\mathrm{Bi}$ & $<2.26 \mathrm{E}-05$ & [2.67E-05] & [3.89E-05] & [4.33E-05] & [4.78E-05] & [4.84E-05] & [4.93E-05] \\
\hline $\mathrm{Cd}$ & $<4.75 \mathrm{E}-06$ & $<4.69 \mathrm{E}-06$ & $<4.91 \mathrm{E}-06$ & $<4.56 \mathrm{E}-06$ & $<4.57 \mathrm{E}-06$ & $<4.78 \mathrm{E}-06$ & $<4.72 \mathrm{E}-06$ \\
\hline $\mathrm{Cr}$ & [2.05E-05] & 1.19E-04 & 1.72E-04 & 1.94E-04 & $2.25 \mathrm{E}-04$ & $2.70 \mathrm{E}-04$ & 3.03E-04 \\
\hline $\mathrm{Fe}$ & [3.15E-05] & $1.35 \mathrm{E}-04$ & 1.79E-04 & $1.83 \mathrm{E}-04$ & $1.99 \mathrm{E}-04$ & $2.09 \mathrm{E}-04$ & $2.16 \mathrm{E}-04$ \\
\hline $\mathrm{Mn}$ & [1.32E-05] & [1.24E-05] & [7.10E-06] & [4.34E-06] & [3.25E-06] & [2.24E-06] & [1.71E-06] \\
\hline $\mathrm{Na}$ & 3.23 & 3.26 & 3.55 & 3.23 & 3.28 & 3.30 & 3.40 \\
\hline $\mathrm{Ni}$ & $<6.42 \mathrm{E}-06$ & $<6.34 \mathrm{E}-06$ & $<6.64 \mathrm{E}-06$ & $<6.17 \mathrm{E}-06$ & $<6.18 \mathrm{E}-06$ & $<6.46 \mathrm{E}-06$ & $<6.38 \mathrm{E}-06$ \\
\hline $\mathrm{P}$ & [5.38E-04] & [4.60E-04] & [5.87E-04] & [5.36E-04] & [4.88E-04] & [6.94E-04] & [3.02E-04] \\
\hline $\mathrm{S}$ & [7.45E-04] & $<3.48 \mathrm{E}-04$ & $<3.65 \mathrm{E}-04$ & [9.41E-04] & $<3.40 \mathrm{E}-04$ & $<3.55 \mathrm{E}-04$ & $<3.51 \mathrm{E}-04$ \\
\hline $\mathrm{Si}$ & [1.23E-04] & $1.14 \mathrm{E}-03$ & $1.52 \mathrm{E}-03$ & $1.38 \mathrm{E}-03$ & $1.46 \mathrm{E}-03$ & $1.51 \mathrm{E}-03$ & $1.61 \mathrm{E}-03$ \\
\hline $\mathrm{Sr}$ & [2.08E-07] & [4.25E-07] & [4.82E-07] & [4.82E-07] & [4.49E-07] & [5.05E-07] & [4.63E-07] \\
\hline $\mathrm{U}$ & $<2.11 \mathrm{E}-05$ & $<2.08 \mathrm{E}-05$ & [4.37E-05] & [5.07E-05] & [4.96E-05] & [3.85E-05] & [3.15E-05] \\
\hline $\mathrm{Zn}$ & 3.94E-05 & $1.46 \mathrm{E}-04$ & 1.56E-04 & 1.58E-04 & $1.54 \mathrm{E}-04$ & $1.47 \mathrm{E}-04$ & $1.61 \mathrm{E}-04$ \\
\hline $\mathrm{Zr}$ & $<1.89 \mathrm{E}-06$ & $<1.87 \mathrm{E}-06$ & $<1.96 \mathrm{E}-06$ & $<1.82 \mathrm{E}-06$ & $<1.82 \mathrm{E}-06$ & $<1.91 \mathrm{E}-06$ & [3.77E-06] \\
\hline Fluoride & [1.52E-04] & [6.87E-05] & [4.85E-05] & [6.27E-05] & [5.61E-05] & [6.64E-05] & [7.57E-05] \\
\hline
\end{tabular}


Table L.4 (Contd)

\begin{tabular}{|c|c|c|c|c|c|c|c|}
\hline \multirow[b]{2}{*}{ Analyte } & \multicolumn{7}{|c|}{$\begin{array}{l}\text { Analyte Concentration and Density at Given Time After Cooling to Ambient }\left(\sim 21^{\circ} \mathrm{C}\right) \\
\text { Temperature; } \mathrm{g} / \mathrm{mL} \text { for Density; } \mathrm{M} \text { for Metals and Anions }\end{array}$} \\
\hline & O hr & $1 \mathrm{hr}$ & $2 \mathrm{hr}$ & $4 \mathrm{hr}$ & $8 \mathrm{hr}$ & $24 \mathrm{hr}$ & $48 \mathrm{hr}$ \\
\hline Nitrite & [3.21E-05] & $<2.96 \mathrm{E}-05$ & $<3.13 \mathrm{E}-05$ & [4.40E-05] & $<3.22 \mathrm{E}-05$ & [4.57E-05] & [4.56E-05] \\
\hline Sulfate & $<2.28 \mathrm{E}-05$ & $<2.10 \mathrm{E}-05$ & $<2.22 \mathrm{E}-05$ & $<2.29 \mathrm{E}-05$ & $<2.28 \mathrm{E}-05$ & [2.82E-05] & $<2.31 \mathrm{E}-05$ \\
\hline Nitrate & $1.59 \mathrm{E}-03$ & $1.71 \mathrm{E}-03$ & $2.02 \mathrm{E}-03$ & $1.90 \mathrm{E}-03$ & 1.92E-03 & $2.01 \mathrm{E}-03$ & $2.01 \mathrm{E}-03$ \\
\hline Phosphate & $3.25 \mathrm{E}-04$ & 3.39E-04 & $3.45 \mathrm{E}-04$ & $3.22 \mathrm{E}-04$ & 3.17E-04 & 3.70E-04 & 3.33E-04 \\
\hline \multicolumn{8}{|c|}{$3 \mathrm{M} \mathrm{NaOH}$, with $1 \mathrm{M} \mathrm{NaNO}_{3}$} \\
\hline Density & 1.18 & 1.20 & 1.19 & 1.20 & 1.20 & 1.17 & 1.21 \\
\hline $\mathrm{Al}$ & $1.02 \mathrm{E}-02$ & $1.18 \mathrm{E}-01$ & $1.22 \mathrm{E}-01$ & $1.23 \mathrm{E}-01$ & $1.25 \mathrm{E}-01$ & $1.14 \mathrm{E}-01$ & $1.25 \mathrm{E}-01$ \\
\hline B & $<6.68 \mathrm{E}-05$ & $<7.04 \mathrm{E}-05$ & $<7.02 \mathrm{E}-05$ & $<6.97 \mathrm{E}-05$ & $<7.01 \mathrm{E}-05$ & $<6.82 \mathrm{E}-05$ & $<6.95 \mathrm{E}-05$ \\
\hline $\mathrm{Bi}$ & $<2.16 \mathrm{E}-05$ & [3.34E-05] & [4.99E-05] & [4.20E-05] & [4.68E-05] & [4.55E-05] & [4.64E-05] \\
\hline $\mathrm{Cd}$ & $<4.55 \mathrm{E}-06$ & $<4.80 \mathrm{E}-06$ & $<4.78 \mathrm{E}-06$ & $<4.75 \mathrm{E}-06$ & $<4.77 \mathrm{E}-06$ & $<4.64 \mathrm{E}-06$ & $<4.73 \mathrm{E}-06$ \\
\hline $\mathrm{Cr}$ & [3.01E-05] & $1.31 \mathrm{E}-04$ & $1.67 \mathrm{E}-04$ & 2.05E-04 & 2.36E-04 & $2.50 \mathrm{E}-04$ & 2.93E-04 \\
\hline $\mathrm{Fe}$ & [5.12E-05] & $1.52 \mathrm{E}-04$ & 1.73E-04 & $1.94 \mathrm{E}-04$ & 2.17E-04 & $1.88 \mathrm{E}-04$ & $2.10 \mathrm{E}-04$ \\
\hline $\mathrm{Mn}$ & $1.76 \mathrm{E}-05$ & [1.15E-05] & [6.91E-06] & [4.68E-06] & [3.50E-06] & [2.51E-06] & [2.51E-06] \\
\hline $\mathrm{Na}$ & 4.28 & 4.44 & 4.32 & 4.44 & 4.41 & 3.97 & 4.41 \\
\hline $\mathrm{Ni}$ & $<6.15 \mathrm{E}-06$ & $<6.48 \mathrm{E}-06$ & $<6.47 \mathrm{E}-06$ & $<6.42 \mathrm{E}-06$ & $<6.45 \mathrm{E}-06$ & $<6.28 \mathrm{E}-06$ & $<6.40 \mathrm{E}-06$ \\
\hline $\mathrm{P}$ & [4.47E-04] & [5.53E-04] & [5.11E-04] & [8.11E-04] & [2.95E-04] & $<2.48 \mathrm{E}-04$ & [3.64E-04] \\
\hline$S$ & $<3.38 \mathrm{E}-04$ & [9.79E-04] & [9.87E-04] & $<3.52 \mathrm{E}-04$ & [4.73E-04] & [1.15E-03] & $<3.52 \mathrm{E}-04$ \\
\hline $\mathrm{Si}$ & $<3.00 \mathrm{E}-05$ & [1.47E-04] & [1.58E-04] & [1.79E-04] & [2.47E-04] & [1.97E-04] & [2.23E-04] \\
\hline $\mathrm{Sr}$ & [4.46E-07] & [5.43E-07] & [7.94E-07] & [4.30E-07] & [7.92E-07] & [7.01E-07] & [6.79E-07] \\
\hline $\mathrm{U}$ & $<2.02 \mathrm{E}-05$ & [2.13E-05] & $<2.13 \mathrm{E}-05$ & [3.82E-05] & [5.97E-05] & [4.64E-05] & [3.68E-05] \\
\hline Zn & [5.06E-05] & $1.55 \mathrm{E}-04$ & $1.58 \mathrm{E}-04$ & $1.51 \mathrm{E}-04$ & 1.52E-04 & $1.45 \mathrm{E}-04$ & $1.64 \mathrm{E}-04$ \\
\hline $\mathrm{Zr}$ & $<1.81 \mathrm{E}-06$ & $<1.91 \mathrm{E}-06$ & $<1.91 \mathrm{E}-06$ & $<1.89 \mathrm{E}-06$ & [2.63E-06] & [2.15E-06] & [3.05E-06] \\
\hline Fluoride & $<9.74 \mathrm{E}-04$ & $<1.03 \mathrm{E}-03$ & $<1.03 \mathrm{E}-03$ & $<1.01 \mathrm{E}-03$ & $<1.01 \mathrm{E}-03$ & $<1.00 \mathrm{E}-03$ & $<9.84 \mathrm{E}-04$ \\
\hline Nitrite & $<6.49 \mathrm{E}-04$ & $<6.87 \mathrm{E}-04$ & $<6.83 \mathrm{E}-04$ & $<6.76 \mathrm{E}-04$ & $<6.75 \mathrm{E}-04$ & $<66.67 \mathrm{E}-04$ & $<6.56 \mathrm{E}-04$ \\
\hline Sulfate & $<4.66 \mathrm{E}-04$ & [5.79E-04] & [5.10E-04] & $<4.85 \mathrm{E}-04$ & $<4.85 \mathrm{E}-04$ & $<4.79 \mathrm{E}-04$ & $<4.71 \mathrm{E}-04$ \\
\hline Nitrate & 1.46 & 1.40 & 1.37 & 1.33 & 1.52 & 1.25 & 1.38 \\
\hline Phosphate & [1.07E-03] & [7.32E-04] & [5.89E-04] & [4.39E-04] & [4.97E-04] & [5.43E-04] & [3.94E-04] \\
\hline \multicolumn{8}{|c|}{$3 \mathrm{M} \mathrm{NaOH}$, with $5 \mathrm{M} \mathrm{NaNO}_{3}$} \\
\hline Density & 1.49 & 1.54 & 1.47 & 1.50 & 1.50 & 1.50 & 1.53 \\
\hline $\mathrm{Al}$ & $<6.63 \mathrm{E}-05$ & $1.37 \mathrm{E}-01$ & 1.33E-01 & $1.30 \mathrm{E}-01$ & $1.31 \mathrm{E}-01$ & 1.22E-01 & $1.33 \mathrm{E}-01$ \\
\hline B & $<1.32 \mathrm{E}-04$ & $<1.26 \mathrm{E}-04$ & $<1.26 \mathrm{E}-04$ & $<1.22 \mathrm{E}-04$ & $<1.27 \mathrm{E}-04$ & [1.51E-04] & [1.36E-04] \\
\hline $\mathrm{Bi}$ & $<4.28 \mathrm{E}-05$ & [8.59E-05] & [6.02E-05] & [8.91E-05] & [6.85E-05] & [7.23E-05] & [9.59E-05] \\
\hline $\mathrm{Cd}$ & $<9.01 \mathrm{E}-06$ & $<8.58 \mathrm{E}-06$ & $<8.57 \mathrm{E}-06$ & $<8.31 \mathrm{E}-06$ & $<8.66 \mathrm{E}-06$ & $<8.39 \mathrm{E}-06$ & $<4.73 \mathrm{E}-06$ \\
\hline $\mathrm{Cr}$ & $<9.74 \mathrm{E}-06$ & 1.70E-04 & 2.11E-04 & 2.55E-04 & 2.79E-04 & 2.81E-04 & 3.03E-04 \\
\hline $\mathrm{Fe}$ & $<5.87 \mathrm{E}-06$ & $3.77 \mathrm{E}-04$ & 4.07E-04 & $4.72 \mathrm{E}-04$ & $4.83 \mathrm{E}-04$ & 4.95E-04 & $5.50 \mathrm{E}-04$ \\
\hline $\mathrm{Mn}$ & $<1.25 \mathrm{E}-06$ & $1.04 \mathrm{E}-04$ & 5.05E-05 & [1.89E-05] & [1.22E-05] & [2.52E-06] & $<6.55 \mathrm{E}-07$ \\
\hline $\mathrm{Na}$ & 11.16 & 11.15 & 10.99 & 10.86 & 10.84 & 10.43 & 11.17 \\
\hline $\mathrm{Ni}$ & $<1.22 \mathrm{E}-05$ & $<1.16 \mathrm{E}-05$ & $<1.16 \mathrm{E}-05$ & $<1.12 \mathrm{E}-05$ & $<1.17 \mathrm{E}-05$ & [3.36E-05] & [1.92E-05] \\
\hline $\mathrm{P}$ & $<4.81 \mathrm{E}-04$ & [7.02E-04] & $<4.57 \mathrm{E}-04$ & [5.22E-04] & [7.19E-04] & $<4.48 \mathrm{E}-04$ & $<2.53 \mathrm{E}-04$ \\
\hline S & $<6.69 \mathrm{E}-04$ & [7.17E-04] & $<6.36 \mathrm{E}-04$ & $<6.17 \mathrm{E}-04$ & $<6.43 \mathrm{E}-04$ & $<6.23 \mathrm{E}-04$ & $<3.52 \mathrm{E}-04$ \\
\hline Si & $<5.94 \mathrm{E}-05$ & $<5.65 \mathrm{E}-05$ & $<5.65 \mathrm{E}-05$ & $<5.48 \mathrm{E}-05$ & $<5.71 \mathrm{E}-05$ & [9.98E-05] & [1.34E-04] \\
\hline $\mathrm{Sr}$ & $<1.94 \mathrm{E}-07$ & [2.34E-06] & [2.62E-06] & {$[2.30 \mathrm{E}-06]$} & [2.29E-06] & [1.65E-06] & [1.32E-06] \\
\hline $\mathrm{U}$ & $<4.01 \mathrm{E}-05$ & $<3.81 \mathrm{E}-05$ & $<3.81 \mathrm{E}-05$ & $<3.69 \mathrm{E}-05$ & $<3.85 \mathrm{E}-05$ & $<3.73 \mathrm{E}-05$ & $<2.10 \mathrm{E}-05$ \\
\hline $\mathrm{Zn}$ & $<1.28 \mathrm{E}-05$ & 2.81E-04 & 3.33E-04 & 3.65E-04 & 3.17E-04 & 2.62E-04 & $2.54 \mathrm{E}-04$ \\
\hline
\end{tabular}


Table L.4 (Contd)

\begin{tabular}{|c|c|c|c|c|c|c|c|}
\hline \multirow[b]{2}{*}{ Analyte } & \multicolumn{7}{|c|}{$\begin{array}{l}\text { Analyte Concentration and Density at Given Time After Cooling to Ambient }\left(\sim 21^{\circ} \mathrm{C}\right) \\
\text { Temperature; } \mathrm{g} / \mathrm{mL} \text { for Density; } \mathrm{M} \text { for Metals and Anions }\end{array}$} \\
\hline & $0 \mathrm{hr}$ & $1 \mathrm{hr}$ & $2 \mathrm{hr}$ & $4 \mathrm{hr}$ & $8 \mathrm{hr}$ & $24 \mathrm{hr}$ & $48 \mathrm{hr}$ \\
\hline $\mathrm{Zr}$ & $<3.59 \mathrm{E}-06$ & $<3.42 \mathrm{E}-06$ & [4.48E-06] & [5.35E-06] & [4.19E-06] & [4.73E-06] & [3.43E-06] \\
\hline Fluoride & $<8.86 \mathrm{E}-04$ & $<1.01 \mathrm{E}-03$ & $<1.08 \mathrm{E}-03$ & NM & [2.20E-03] & [1.91E-03] & [3.17E-03] \\
\hline Nitrite & $<5.90 \mathrm{E}-04$ & $<66.75 \mathrm{E}-04$ & $<7.20 \mathrm{E}-04$ & NM & $<<8.72 \mathrm{E}-04$ & $<<6.69 \mathrm{E}-04$ & $<6.55 \mathrm{E}-04$ \\
\hline Sulfate & $<4.24 \mathrm{E}-04$ & $<4.85 \mathrm{E}-04$ & $<5.17 \mathrm{E}-04$ & NM & $<6.27 \mathrm{E}-04$ & $<4.80 \mathrm{E}-04$ & $<4.71 \mathrm{E}-04$ \\
\hline Nitrate & 5.01 & 5.93 & 5.70 & NM & 5.82 & 5.48 & 6.03 \\
\hline Phosphate & [4.63E-04] & [9.80E-04] & [5.86E-04] & NM & [1.52E-03] & [9.07E-04] & [9.52E-04] \\
\hline \multicolumn{8}{|l|}{$5 \mathrm{M}$ NaOH } \\
\hline Density & 1.15 & 1.18 & 1.22 & 1.21 & 1.21 & 1.20 & 1.23 \\
\hline $\mathrm{Al}$ & 4.51E-03 & $1.22 \mathrm{E}-01$ & $1.27 \mathrm{E}-01$ & $1.26 \mathrm{E}-01$ & $1.30 \mathrm{E}-01$ & $1.23 \mathrm{E}-01$ & $1.31 \mathrm{E}-01$ \\
\hline B & $<7.58 \mathrm{E}-05$ & $<7.67 \mathrm{E}-05$ & $<8.04 \mathrm{E}-05$ & $<8.00 \mathrm{E}-05$ & $<7.96 \mathrm{E}-05$ & $<7.81 \mathrm{E}-05$ & [9.81E-05] \\
\hline $\mathrm{Bi}$ & [2.94E-05] & [5.46E-05] & [5.90E-05] & [6.89E-05] & [7.89E-05] & [5.89E-05] & [7.44E-05] \\
\hline $\mathrm{Cd}$ & $<5.17 \mathrm{E}-06$ & $<5.23 \mathrm{E}-06$ & $<$ <5.48E-06 & $<$ <5.45E-06 & $<$ <5.42E-06 & $<$ <5.32E-06 & $<5.34 \mathrm{E}-06$ \\
\hline $\mathrm{Cr}$ & [2.43E-05] & $1.57 \mathrm{E}-04$ & $2.10 \mathrm{E}-04$ & $2.42 \mathrm{E}-04$ & $2.76 \mathrm{E}-04$ & $2.90 \mathrm{E}-04$ & $3.14 \mathrm{E}-04$ \\
\hline $\mathrm{Fe}$ & [3.55E-05] & 2.77E-04 & 3.35E-04 & 3.67E-04 & 4.05E-04 & $4.09 \mathrm{E}-04$ & 4.47E-04 \\
\hline Mn & $1.46 \mathrm{E}-05$ & 3.17E-05 & [1.32E-05] & [5.77E-06] & [2.61E-06] & $<7.36 \mathrm{E}-07$ & $<7.40 \mathrm{E}-07$ \\
\hline $\mathrm{Na}$ & 5.84 & 5.97 & 6.18 & 6.13 & 6.33 & 5.94 & 6.33 \\
\hline $\mathrm{Ni}$ & [1.69E-05] & [1.77E-05] & [1.79E-05] & [1.78E-05] & [1.65E-05] & [1.20E-05] & [1.99E-05] \\
\hline $\mathrm{P}$ & [3.20E-04] & [5.36E-04] & $<2.92 \mathrm{E}-04$ & [3.49E-04] & $<2.89 \mathrm{E}-04$ & [2.95E-04] & [4.56E-04] \\
\hline $\mathrm{S}$ & $<3.84 \mathrm{E}-04$ & $<3.88 \mathrm{E}-04$ & $<4.07 \mathrm{E}-04$ & $<4.04 \mathrm{E}-04$ & $<4.03 \mathrm{E}-04$ & $<3.95 \mathrm{E}-04$ & $<3.97 \mathrm{E}-04$ \\
\hline $\mathrm{Si}$ & $<3.41 \mathrm{E}-05$ & $1.32 \mathrm{E}-03$ & $1.44 \mathrm{E}-03$ & $1.49 \mathrm{E}-03$ & $1.54 \mathrm{E}-03$ & $1.48 \mathrm{E}-03$ & $1.60 \mathrm{E}-03$ \\
\hline $\mathrm{Sr}$ & [5.07E-07] & [1.03E-06] & [1.03E-06] & [1.19E-06] & [1.27E-06] & [1.04E-06] & [1.21E-06] \\
\hline $\mathrm{U}$ & [2.44E-05] & [6.25E-05] & [7.76E-05] & [8.17E-05] & [6.48E-05] & [5.76E-05] & [5.79E-05] \\
\hline $\mathrm{Zn}$ & [4.70E-05] & $1.39 \mathrm{E}-04$ & $1.60 \mathrm{E}-04$ & $1.45 \mathrm{E}-04$ & $1.65 \mathrm{E}-04$ & $1.50 \mathrm{E}-04$ & $1.59 \mathrm{E}-04$ \\
\hline $\mathrm{Zr}$ & $<2.06 \mathrm{E}-06$ & {$[2.50 \mathrm{E}-06]$} & [2.66E-06] & $<2.17 \mathrm{E}-06$ & [2.59E-06] & $<2.12 \mathrm{E}-06$ & $<2.13 \mathrm{E}-06$ \\
\hline Fluoride & [1.20E-04] & $<5.94 \mathrm{E}-05$ & $<5.89 \mathrm{E}-05$ & $<6.13 \mathrm{E}-05$ & [2.58E-04] & $<5.92 \mathrm{E}-05$ & $<5.93 \mathrm{E}-05$ \\
\hline Nitrite & $<3.74 \mathrm{E}-05$ & $<3.83 \mathrm{E}-05$ & $<3.80 \mathrm{E}-05$ & $<3.95 \mathrm{E}-05$ & $<3.70 \mathrm{E}-05$ & $<3.82 \mathrm{E}-05$ & $<3.83 \mathrm{E}-05$ \\
\hline Sulfate & $<2.65 E-05$ & $<2.72 \mathrm{E}-05$ & $<2.69 \mathrm{E}-05$ & $<2.80 \mathrm{E}-05$ & $<2.62 \mathrm{E}-05$ & $<2.71 \mathrm{E}-05$ & $<2.71 \mathrm{E}-05$ \\
\hline Nitrate & $1.91 \mathrm{E}-03$ & $2.29 \mathrm{E}-03$ & 2.31E-03 & $2.38 \mathrm{E}-03$ & $2.27 \mathrm{E}-03$ & 2.32E-03 & 2.55E-03 \\
\hline Phosphate & 3.89E-04 & $3.70 \mathrm{E}-04$ & 3.53E-04 & 3.55E-04 & 3.55E-04 & $3.46 \mathrm{E}-04$ & $3.54 \mathrm{E}-04$ \\
\hline \multicolumn{8}{|c|}{$\begin{array}{l}\text { Analyte uncertainties were typically within } \pm 15 \%(2 \text {-s); results in brackets indicate that the analyte concentrations } \\
\text { were less than the minimum detection limit (MDL) and greater than the estimated quantitation limit (EQL), and } \\
\text { uncertainties were }>15 \% \text {. }\end{array}$} \\
\hline
\end{tabular}


Table L.5. Analyte Concentrations as a Function of Time for Leaching at $100^{\circ} \mathrm{C}$, in $\mu \mathrm{g} / \mathrm{mL}$

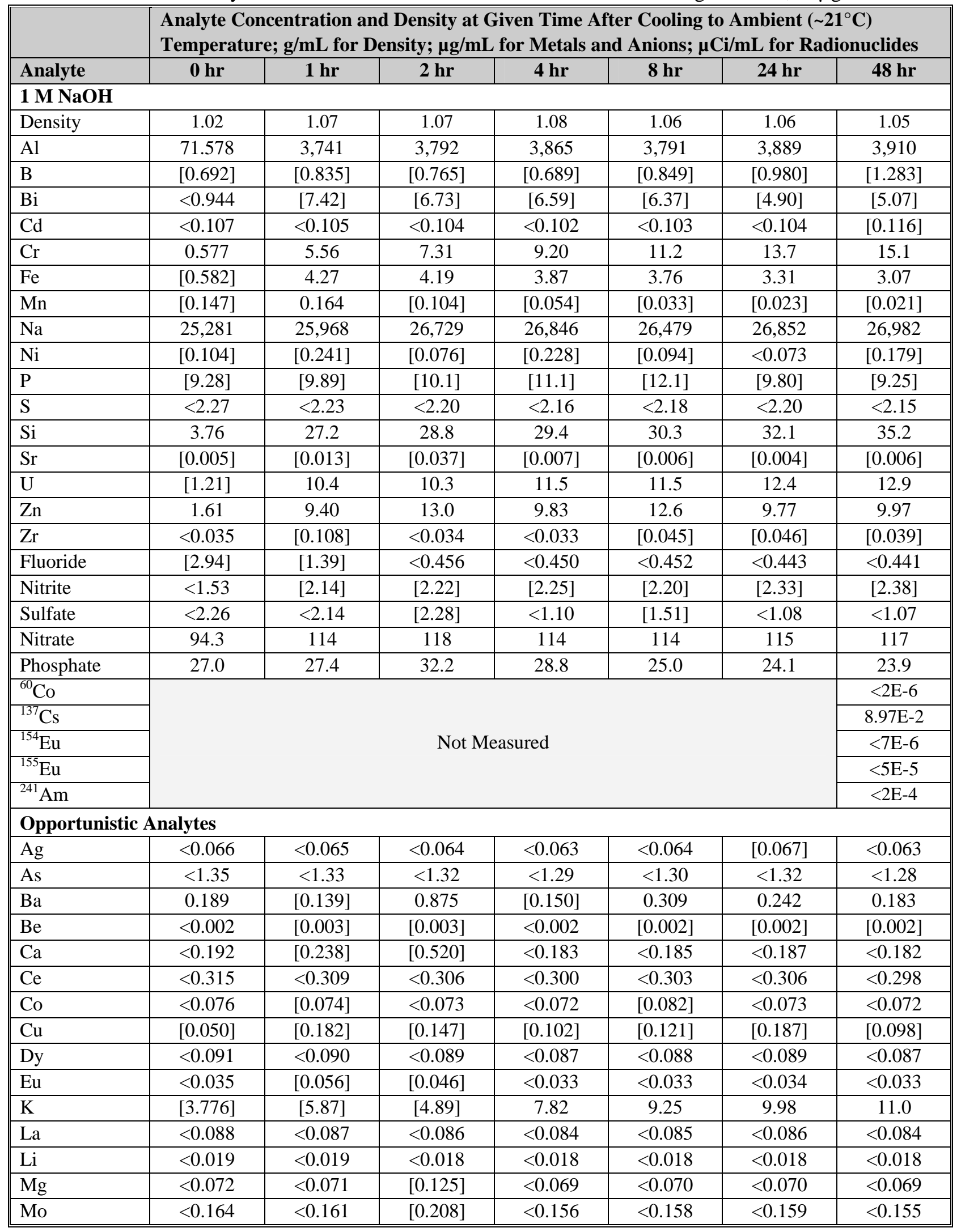


Table L.5 (Contd)

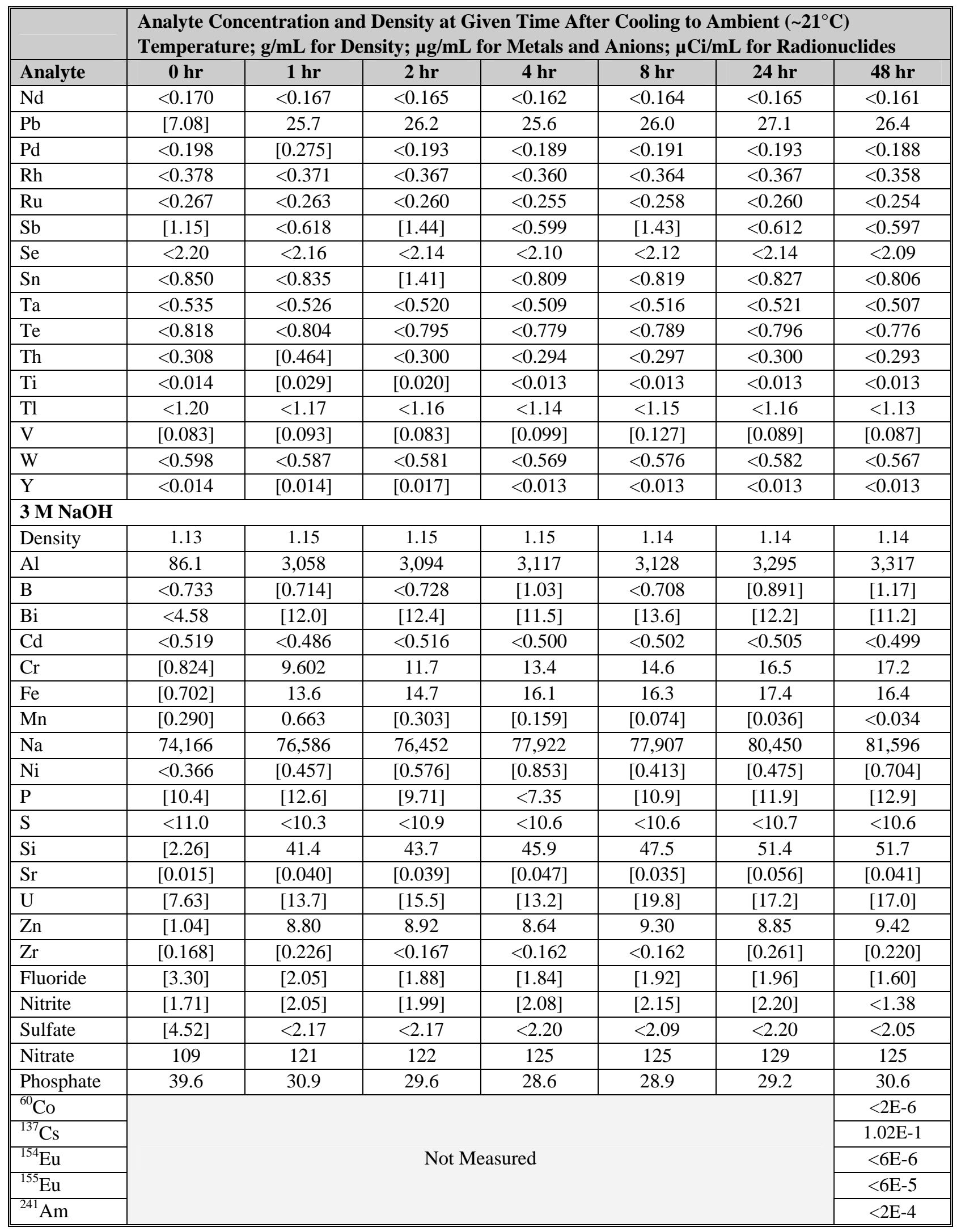


Table L.5 (Contd)

\begin{tabular}{|c|c|c|c|c|c|c|c|}
\hline \multirow[b]{2}{*}{ Analyte } & \multicolumn{7}{|c|}{$\begin{array}{l}\text { Analyte Concentration and Density at Given Time After Cooling to Ambient }\left(\sim 21^{\circ} \mathrm{C}\right) \\
\text { Temperature; } g / \mathrm{mL} \text { for Density; } \mu \mathrm{g} / \mathrm{mL} \text { for Metals and Anions; } \mu \mathrm{Ci} / \mathrm{mL} \text { for Radionuclides }\end{array}$} \\
\hline & O hr & $1 \mathrm{hr}$ & $2 \mathrm{hr}$ & $4 \mathrm{hr}$ & $8 \mathrm{hr}$ & $24 \mathrm{hr}$ & $48 \mathrm{hr}$ \\
\hline \multicolumn{8}{|c|}{ Opportunistic Analytes } \\
\hline $\mathrm{Ag}$ & $<0.320$ & $<0.300$ & $<0.319$ & $<0.309$ & $<0.310$ & $<0.312$ & $<0.308$ \\
\hline As & $<6.56$ & $<6.14$ & $<6.52$ & $<6.32$ & $<6.34$ & $<6.38$ & $<6.31$ \\
\hline $\mathrm{Ba}$ & {$[0.284]$} & {$[0.343]$} & {$[0.303]$} & {$[0.273]$} & {$[0.413]$} & {$[0.297]$} & {$[0.323]$} \\
\hline $\mathrm{Be}$ & $<0.008$ & $<0.007$ & {$[0.008]$} & $<0.008$ & $<0.008$ & $<0.008$ & [0.011] \\
\hline $\mathrm{Ca}$ & $<0.931$ & {$[2.51]$} & [2.31] & [5.29] & {$[5.31]$} & {$[1.87]$} & {$[2.76]$} \\
\hline $\mathrm{Ce}$ & $<1.53$ & $<1.43$ & $<1.52$ & $<1.47$ & $<1.48$ & $<1.48$ & $<1.47$ \\
\hline Co & $<0.366$ & $<0.343$ & $<0.364$ & $<0.353$ & $<0.354$ & [0.594] & $<0.352$ \\
\hline $\mathrm{Cu}$ & {$[0.259]$} & [0.429] & {$[0.455]$} & {$[0.647]$} & [0.531] & $<0.208$ & [0.279] \\
\hline Dy & $<0.443$ & $<0.414$ & $<0.440$ & $<0.426$ & $<0.428$ & $<0.430$ & $<0.426$ \\
\hline $\mathrm{Eu}$ & $<0.168$ & $<0.157$ & $<0.167$ & $<0.162$ & $<0.162$ & $<0.163$ & $<0.161$ \\
\hline K & 31.7 & [25.1] & 30.3 & 33.5 & [28.3] & [18.1] & [17.3] \\
\hline $\mathrm{La}$ & $<0.427$ & $<0.400$ & $<0.425$ & $<0.412$ & $<0.413$ & $<0.416$ & $<0.411$ \\
\hline $\mathrm{Li}$ & [0.366] & {$[0.543]$} & {$[0.576]$} & [0.794] & [0.443] & [0.475] & {$[0.352]$} \\
\hline $\mathrm{Mg}$ & $<0.351$ & $<0.329$ & $<0.349$ & $<0.338$ & $<0.339$ & $<0.341$ & $<0.338$ \\
\hline Mo & $<0.794$ & $<0.743$ & {$[0.819]$} & $<0.765$ & $<0.767$ & $<0.772$ & $<0.763$ \\
\hline $\mathrm{Nd}$ & $<0.824$ & $<0.772$ & $<0.819$ & $<0.794$ & $<0.797$ & $<0.802$ & $<0.792$ \\
\hline $\mathrm{Pb}$ & {$[5.80]$} & [26.9] & [21.8] & [20.0] & {$[23.6]$} & {$[25.2]$} & {$[27.0]$} \\
\hline $\mathrm{Pd}$ & $<0.961$ & $<0.900$ & $<0.956$ & $<0.926$ & $<0.930$ & $<0.935$ & $<0.925$ \\
\hline $\mathrm{Rh}$ & $<1.83$ & $<1.71$ & $<1.82$ & $<1.76$ & $<1.77$ & $<1.78$ & $<1.76$ \\
\hline $\mathrm{Ru}$ & $<1.30$ & $<1.21$ & $<1.29$ & $<1.25$ & $<1.25$ & $<1.26$ & $<1.25$ \\
\hline $\mathrm{Sb}$ & [7.33] & $<2.86$ & {$[5.16]$} & [7.94] & $<2.95$ & $<2.97$ & $<2.94$ \\
\hline Se & [16.2] & $<10.0$ & $<10.6$ & $<10.3$ & $<10.3$ & $<10.4$ & $<10.3$ \\
\hline Sn & $<4.12$ & $<3.86$ & $<4.10$ & $<3.97$ & {$[5.02]$} & $<4.01$ & $<3.96$ \\
\hline $\mathrm{Ta}$ & $<2.59$ & $<2.43$ & $<2.58$ & $<2.50$ & $<2.51$ & $<2.52$ & $<2.49$ \\
\hline $\mathrm{Te}$ & $<3.97$ & $<3.71$ & $<3.94$ & $<3.82$ & $<3.84$ & $<3.86$ & $<3.82$ \\
\hline Th & $<1.50$ & $<1.40$ & $<1.49$ & $<1.44$ & $<1.45$ & $<1.45$ & $<1.44$ \\
\hline $\mathrm{Ti}$ & $<0.066$ & $<0.061$ & $<0.065$ & $<0.063$ & $<0.063$ & $<0.064$ & $<0.063$ \\
\hline $\mathrm{Tl}$ & $<5.80$ & $<5.43$ & $<5.76$ & $<5.59$ & $<5.61$ & $<5.64$ & $<5.58$ \\
\hline $\mathrm{V}$ & $<0.113$ & {$[0.194]$} & $<0.112$ & [0.262] & [0.245] & [0.145] & {$[0.141]$} \\
\hline $\mathrm{W}$ & $<2.90$ & $<2.71$ & $<2.88$ & $<2.79$ & $<2.80$ & $<2.82$ & $<2.79$ \\
\hline $\mathrm{Y}$ & $<0.067$ & $<0.063$ & $<0.067$ & $<0.065$ & $<0.065$ & $<0.065$ & $<0.065$ \\
\hline \multicolumn{8}{|c|}{$5 \mathrm{M} \mathrm{NaOH}$} \\
\hline Density & 1.21 & 1.22 & 1.21 & 1.22 & 1.21 & 1.22 & 1.21 \\
\hline $\mathrm{Al}$ & 125 & 2,981 & 2,943 & 2,993 & 3,050 & 3,003 & 2,961 \\
\hline $\mathrm{B}$ & {$[0.868]$} & $<0.731$ & {$[0.854]$} & $<0.711$ & $<0.746$ & $<0.724$ & $<0.683$ \\
\hline $\mathrm{Bi}$ & [5.09] & [11.9] & [11.8] & [13.3] & [13.1] & [13.0] & [15.1] \\
\hline $\mathrm{Cd}$ & $<0.509$ & {$[0.640]$} & $<0.501$ & $<0.504$ & $<0.529$ & $<0.513$ & $<0.484$ \\
\hline $\mathrm{Cr}$ & [1.47] & 11.0 & 13.0 & 14.7 & 15.4 & 16.5 & 16.3 \\
\hline $\mathrm{Fe}$ & {$[2.87]$} & 23.2 & 25.0 & 27.6 & 28.9 & 29.6 & 29.3 \\
\hline $\mathrm{Mn}$ & 0.925 & 4.39 & 1.06 & [0.474] & [0.342] & {$[0.190]$} & {$[0.131]$} \\
\hline $\mathrm{Na}$ & 123,291 & 127,291 & 125,190 & 128,610 & 128,415 & 127,240 & 125,824 \\
\hline $\mathrm{Ni}$ & {$[0.748]$} & {$[0.700]$} & $<0.353$ & [0.859] & {$[0.560]$} & [0.513] & [0.683] \\
\hline
\end{tabular}


Table L.5 (Contd)

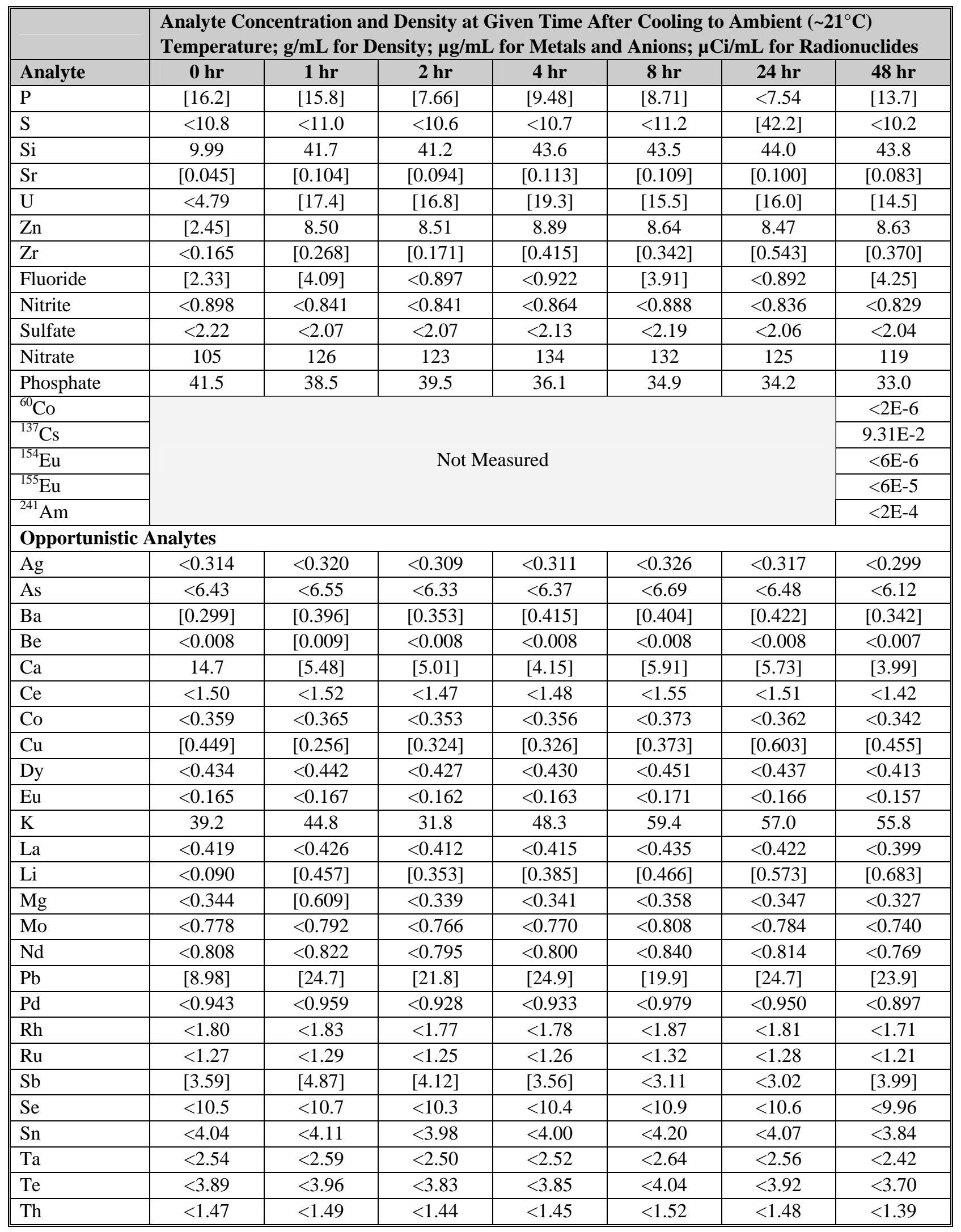


Table L.5 (Contd)

\begin{tabular}{|c|c|c|c|c|c|c|c|}
\hline \multirow[b]{2}{*}{ Analyte } & \multicolumn{7}{|c|}{$\begin{array}{l}\text { Analyte Concentration and Density at Given Time After Cooling to Ambient }\left(\sim 21^{\circ} \mathrm{C}\right) \\
\text { Temperature; } \mathrm{g} / \mathrm{mL} \text { for Density; } \boldsymbol{\mu g} / \mathrm{mL} \text { for Metals and Anions; } \mu \mathrm{Ci} / \mathrm{mL} \text { for Radionuclides }\end{array}$} \\
\hline & $0 \mathrm{hr}$ & $1 \mathrm{hr}$ & $2 \mathrm{hr}$ & $4 \mathrm{hr}$ & $8 \mathrm{hr}$ & $24 \mathrm{hr}$ & $48 \mathrm{hr}$ \\
\hline $\mathrm{Ti}$ & $<0.064$ & $<0.065$ & $<0.063$ & $<0.064$ & $<0.067$ & $<0.065$ & $<0.061$ \\
\hline $\mathrm{Tl}$ & $<5.69$ & $<5.79$ & $<5.60$ & $<5.63$ & $<5.91$ & $<5.73$ & $<5.41$ \\
\hline $\mathrm{V}$ & {$[0.224]$} & [0.158] & [0.295] & [0.255] & [0.277] & $<0.112$ & [0.185] \\
\hline $\mathrm{W}$ & $<2.84$ & $<2.89$ & $<2.80$ & $<2.82$ & $<2.95$ & $<2.86$ & $<2.70$ \\
\hline $\mathrm{Y}$ & $<0.066$ & $<0.067$ & $<0.065$ & $<0.065$ & $<0.068$ & $<0.066$ & $<0.063$ \\
\hline
\end{tabular}


Table L.6. Analyte Concentrations as a Function of Time for Leaching at $100^{\circ} \mathrm{C}$, in $\mathrm{M}$

\begin{tabular}{|c|c|c|c|c|c|c|c|}
\hline \multirow[b]{2}{*}{ Analyte } & \multicolumn{7}{|c|}{$\begin{array}{l}\text { Analyte Concentration and Density at Given Time After Cooling to Ambient }\left(\sim 21^{\circ} \mathrm{C}\right) \\
\text { Temperature; } \mathrm{g} / \mathrm{mL} \text { for Density; } \mathrm{M} \text { for Metals and Anions }\end{array}$} \\
\hline & o hr & $1 \mathrm{hr}$ & $2 \mathrm{hr}$ & $4 \mathrm{hr}$ & $8 \mathrm{hr}$ & $24 \mathrm{hr}$ & $48 \mathrm{hr}$ \\
\hline \multicolumn{8}{|l|}{$1 \mathrm{M} \mathrm{NaOH}$} \\
\hline Density & 1.02 & 1.07 & 1.07 & 1.08 & 1.06 & 1.06 & 1.05 \\
\hline$\overline{\mathrm{Al}}$ & $2.65 \mathrm{E}-03$ & 1.39E-01 & $1.41 \mathrm{E}-01$ & $1.43 \mathrm{E}-01$ & $1.41 \mathrm{E}-01$ & $1.44 \mathrm{E}-01$ & 1.45E-01 \\
\hline B & [6.40E-05] & [7.72E-05] & [7.07E-05] & [6.37E-05] & [7.86E-05] & [9.06E-05] & [1.19E-04] \\
\hline $\mathrm{Bi}$ & $<4.52 \mathrm{E}-06$ & [3.55E-05] & [3.22E-05] & [3.15E-05] & [3.05E-05] & [2.34E-05] & [2.43E-05] \\
\hline $\mathrm{Cd}$ & $<9.52 \mathrm{E}-07$ & $<9.35 \mathrm{E}-07$ & $<9.25 \mathrm{E}-07$ & $<9.06 \mathrm{E}-07$ & $<9.17 \mathrm{E}-07$ & $<9.26 \mathrm{E}-07$ & [1.04E-06] \\
\hline $\mathrm{Cr}$ & $1.11 \mathrm{E}-05$ & $1.07 \mathrm{E}-04$ & $1.41 \mathrm{E}-04$ & $1.77 \mathrm{E}-04$ & $2.15 \mathrm{E}-04$ & $2.64 \mathrm{E}-04$ & 2.90E-04 \\
\hline $\mathrm{Fe}$ & [1.04E-05] & 7.64E-05 & $7.50 \mathrm{E}-05$ & $6.92 \mathrm{E}-05$ & $6.73 \mathrm{E}-05$ & $5.92 \mathrm{E}-05$ & $5.50 \mathrm{E}-05$ \\
\hline $\mathrm{Mn}$ & [2.67E-06] & 2.99E-06 & [1.89E-06] & [9.82E-07] & [6.07E-07] & [4.18E-07] & [3.91E-07] \\
\hline $\mathrm{Na}$ & 1.10 & 1.13 & 1.16 & 1.17 & 1.15 & 1.17 & 1.17 \\
\hline $\mathrm{Ni}$ & [1.77E-06] & [4.11E-06] & [1.30E-06] & [3.88E-06] & [1.60E-06] & $<1.25 \mathrm{E}-06$ & [3.05E-06] \\
\hline $\mathrm{P}$ & [3.00E-04] & [3.19E-04] & [3.26E-04] & [3.58E-04] & [3.92E-04] & [3.16E-04] & [2.99E-04] \\
\hline$S$ & $<7.07 \mathrm{E}-05$ & $<6.94 \mathrm{E}-05$ & $<6.87 \mathrm{E}-05$ & $<6.73 \mathrm{E}-05$ & $<6.81 \mathrm{E}-05$ & $<6.88 \mathrm{E}-05$ & $<6.70 \mathrm{E}-05$ \\
\hline $\mathrm{Si}$ & $1.34 \mathrm{E}-04$ & 9.70E-04 & $1.03 \mathrm{E}-03$ & $1.05 \mathrm{E}-03$ & $1.08 \mathrm{E}-03$ & $1.14 \mathrm{E}-03$ & $1.25 \mathrm{E}-03$ \\
\hline $\mathrm{Sr}$ & [5.92E-08] & [1.52E-07] & [4.19E-07] & [8.55E-08] & [6.92E-08] & [4.19E-08] & [6.81E-08] \\
\hline $\mathrm{U}$ & [5.09E-06] & $4.36 \mathrm{E}-05$ & $4.34 \mathrm{E}-05$ & $4.83 \mathrm{E}-05$ & $4.82 \mathrm{E}-05$ & $5.22 \mathrm{E}-05$ & $5.41 \mathrm{E}-05$ \\
\hline $\mathrm{Zn}$ & $2.47 \mathrm{E}-05$ & $1.44 \mathrm{E}-04$ & 1.99E-04 & $1.50 \mathrm{E}-04$ & 1.93E-04 & $1.49 \mathrm{E}-04$ & $1.52 \mathrm{E}-04$ \\
\hline $\mathrm{Zr}$ & $<3.79 \mathrm{E}-07$ & [1.19E-06] & $<<3.69 \mathrm{E}-07$ & $<<3.61 \mathrm{E}-07$ & [4.99E-07] & [5.03E-07] & [4.25E-07] \\
\hline Fluoride & [1.55E-04] & [7.29E-05] & $<2.40 \mathrm{E}-05$ & $<2.37 \mathrm{E}-05$ & $<2.38 \mathrm{E}-05$ & $<2.33 \mathrm{E}-05$ & $<2.32 \mathrm{E}-05$ \\
\hline Nitrite & $<3.33 \mathrm{E}-05$ & [4.64E-05] & [4.83E-05] & [4.89E-05] & [4.79E-05] & [5.06E-05] & [5.17E-05] \\
\hline Sulfate & $<2.36 \mathrm{E}-05$ & $<2.22 \mathrm{E}-05$ & [2.37E-05] & $<1.14 \mathrm{E}-05$ & [1.57E-05] & $<1.12 \mathrm{E}-05$ & $<1.12 \mathrm{E}-05$ \\
\hline Nitrate & $1.52 \mathrm{E}-03$ & $1.84 \mathrm{E}-03$ & $1.90 \mathrm{E}-03$ & $1.84 \mathrm{E}-03$ & $1.84 \mathrm{E}-03$ & $1.85 \mathrm{E}-03$ & $1.88 \mathrm{E}-03$ \\
\hline Phosphate & 2.84E-04 & $2.88 \mathrm{E}-04$ & 3.39E-04 & 3.03E-04 & 2.63E-04 & 2.54E-04 & 2.52E-04 \\
\hline \multicolumn{8}{|l|}{$3 \mathrm{M} \mathrm{NaOH}$} \\
\hline Density & 1.13 & 1.15 & 1.15 & 1.15 & 1.14 & 1.14 & 1.14 \\
\hline$\overline{\mathrm{Al}}$ & 3.19E-03 & $1.13 \mathrm{E}-01$ & $1.15 \mathrm{E}-01$ & $1.16 \mathrm{E}-01$ & $1.16 \mathrm{E}-01$ & $1.22 \mathrm{E}-01$ & $1.23 \mathrm{E}-01$ \\
\hline B & $<6.78 \mathrm{E}-05$ & [6.61E-05] & $<6.74 \mathrm{E}-05$ & [9.52E-05] & $<6.55 \mathrm{E}-05$ & [8.24E-05] & [1.09E-04] \\
\hline $\mathrm{Bi}$ & $<2.19 \mathrm{E}-05$ & [5.74E-05] & [5.95E-05] & [5.49E-05] & [6.50E-05] & [5.82E-05] & [5.34E-05] \\
\hline $\mathrm{Cd}$ & $<4.62 \mathrm{E}-06$ & $<4.32 \mathrm{E}-06$ & $<4.59 \mathrm{E}-06$ & $<4.45 \mathrm{E}-06$ & $<4.46 \mathrm{E}-06$ & $<4.49 \mathrm{E}-06$ & $<4.44 \mathrm{E}-06$ \\
\hline $\mathrm{Cr}$ & [1.58E-05] & $1.85 \mathrm{E}-04$ & $2.25 \mathrm{E}-04$ & 2.57E-04 & 2.82E-04 & 3.17E-04 & 3.31E-04 \\
\hline $\mathrm{Fe}$ & [1.26E-05] & 2.43E-04 & 2.63E-04 & 2.87E-04 & 2.91E-04 & 3.11E-04 & 2.94E-04 \\
\hline Mn & [5.28E-06] & $1.21 \mathrm{E}-05$ & [5.52E-06] & [2.89E-06] & [1.34E-06] & [6.48E-07] & $<6.14 \mathrm{E}-07$ \\
\hline $\mathrm{Na}$ & 3.23 & 3.33 & 3.33 & 3.39 & 3.39 & 3.50 & {$[3.55]$} \\
\hline $\mathrm{Ni}$ & $<6.24 \mathrm{E}-06$ & [7.79E-06] & [9.82E-06] & [1.45E-05] & [7.04E-06] & [8.09E-06] & [1.20E-05] \\
\hline $\mathrm{P}$ & [3.35E-04] & [4.06E-04] & [3.13E-04] & $<2.37 \mathrm{E}-04$ & [3.53E-04] & [3.83E-04] & [4.17E-04] \\
\hline$S$ & $<3.43 \mathrm{E}-04$ & $<3.21 \mathrm{E}-04$ & $<3.41 \mathrm{E}-04$ & $<3.30 \mathrm{E}-04$ & $<3.31 \mathrm{E}-04$ & $<3.33 \mathrm{E}-04$ & $<3.30 \mathrm{E}-04$ \\
\hline $\mathrm{Si}$ & [8.04E-05] & $1.48 \mathrm{E}-03$ & 1.56E-03 & 1.63E-03 & 1.69E-03 & 1.83E-03 & $1.84 \mathrm{E}-03$ \\
\hline $\mathrm{Sr}$ & [1.71E-07] & [4.57E-07] & [4.50E-07] & [5.37E-07] & [4.04E-07] & [6.44E-07] & [4.69E-07] \\
\hline $\mathrm{U}$ & [3.21E-05] & [5.76E-05] & [6.50E-05] & [5.56E-05] & [8.31E-05] & [7.23E-05] & [7.15E-05] \\
\hline $\mathrm{Zn}$ & [1.59E-05] & $1.35 \mathrm{E}-04$ & $1.36 \mathrm{E}-04$ & 1.32E-04 & 1.42E-04 & $1.35 \mathrm{E}-04$ & $1.44 \mathrm{E}-04$ \\
\hline $\mathrm{Zr}$ & [1.84E-06] & [2.47E-06] & $<1.83 \mathrm{E}-06$ & $<1.77 \mathrm{E}-06$ & $<1.78 \mathrm{E}-06$ & [2.86E-06] & [2.41E-06] \\
\hline Fluoride & [1.74E-04] & [1.08E-04] & [9.88E-05] & [9.68E-05] & [1.01E-04] & [1.03E-04] & [8.44E-05] \\
\hline Nitrite & [3.72E-05] & [4.45E-05] & [4.33E-05] & [4.52E-05] & [4.67E-05] & [4.79E-05] & [3.00E-05] \\
\hline Sulfate & [4.70E-05] & $<2.25 \mathrm{E}-05$ & $<2.26 \mathrm{E}-05$ & $<2.29 \mathrm{E}-05$ & $<2.18 \mathrm{E}-05$ & $<2.29 \mathrm{E}-05$ & $<2.13 \mathrm{E}-05$ \\
\hline
\end{tabular}


Table L.6 (Contd)

\begin{tabular}{|c|c|c|c|c|c|c|c|}
\hline \multirow[b]{2}{*}{ Analyte } & \multicolumn{7}{|c|}{$\begin{array}{l}\text { Analyte Concentration and Density at Given Time After Cooling to Ambient }\left(\sim 21^{\circ} \mathrm{C}\right) \\
\text { Temperature; } \mathrm{g} / \mathrm{mL} \text { for Density; } \mathrm{M} \text { for Metals and Anions }\end{array}$} \\
\hline & $0 \mathrm{hr}$ & $1 \mathrm{hr}$ & $2 \mathrm{hr}$ & $4 \mathrm{hr}$ & $8 \mathrm{hr}$ & $24 \mathrm{hr}$ & $48 \mathrm{hr}$ \\
\hline Nitrate & $1.76 \mathrm{E}-03$ & 1.95E-03 & $1.97 \mathrm{E}-03$ & $2.02 \mathrm{E}-03$ & $2.02 \mathrm{E}-03$ & 2.07E-03 & $2.01 \mathrm{E}-03$ \\
\hline Phosphate & 4.17E-04 & $3.25 \mathrm{E}-04$ & 3.12E-04 & 3.01E-04 & $3.04 \mathrm{E}-04$ & $3.08 \mathrm{E}-04$ & $3.22 \mathrm{E}-04$ \\
\hline \multicolumn{8}{|l|}{$5 \mathrm{M} \mathrm{NaOH}$} \\
\hline Density & 1.21 & 1.22 & 1.21 & 1.22 & 1.21 & 1.22 & 1.21 \\
\hline $\mathrm{Al}$ & 4.65E-03 & 1.10E-01 & 1.09E-01 & $1.11 \mathrm{E}-01$ & 1.13E-01 & $1.11 \mathrm{E}-01$ & $1.10 \mathrm{E}-01$ \\
\hline B & [8.03E-05] & $<6.76 \mathrm{E}-05$ & [7.90E-05] & $<6.58 \mathrm{E}-05$ & $<6.90 \mathrm{E}-05$ & $<6.69 \mathrm{E}-05$ & $<6.32 \mathrm{E}-05$ \\
\hline $\mathrm{Bi}$ & [2.43E-05] & [5.68E-05] & [5.64E-05] & [6.38E-05] & [6.25E-05] & [6.20E-05] & [7.22E-05] \\
\hline $\mathrm{Cd}$ & $<4.53 \mathrm{E}-06$ & [5.69E-06] & $<4.45 \mathrm{E}-06$ & $<4.48 \mathrm{E}-06$ & $<4.70 \mathrm{E}-06$ & $<4.56 \mathrm{E}-06$ & $<4.31 \mathrm{E}-06$ \\
\hline $\mathrm{Cr}$ & [2.82E-05] & $2.11 \mathrm{E}-04$ & $2.50 \mathrm{E}-04$ & 2.83E-04 & 2.95E-04 & 3.17E-04 & 3.13E-04 \\
\hline $\mathrm{Fe}$ & [5.14E-05] & $4.15 \mathrm{E}-04$ & 4.48E-04 & 4.93E-04 & 5.17E-04 & 5.30E-04 & 5.25E-04 \\
\hline Mn & $1.68 \mathrm{E}-05$ & 7.98E-05 & 1.93E-05 & [8.63E-06] & [6.23E-06] & [3.46E-06] & [2.38E-06] \\
\hline $\mathrm{Na}$ & 5.36 & 5.54 & 5.45 & 5.59 & 5.59 & 5.53 & 5.47 \\
\hline $\mathrm{Ni}$ & [1.27E-05] & [1.19E-05] & $<6.02 \mathrm{E}-06$ & [1.46E-05] & [9.53E-06] & [8.73E-06] & [1.16E-05] \\
\hline $\mathrm{P}$ & [5.22E-04] & [5.11E-04] & [2.47E-04] & [3.06E-04] & [2.81E-04] & $<2.43 \mathrm{E}-04$ & [4.41E-04] \\
\hline$S$ & $<3.36 \mathrm{E}-04$ & $<3.42 \mathrm{E}-04$ & $<3.31 \mathrm{E}-04$ & $<3.33 \mathrm{E}-04$ & $<3.49 \mathrm{E}-04$ & $1.32 \mathrm{E}-03$ & $<3.20 \mathrm{E}-04$ \\
\hline $\mathrm{Si}$ & 3.56E-04 & $1.49 \mathrm{E}-03$ & 1.47E-03 & $1.55 \mathrm{E}-03$ & $1.55 \mathrm{E}-03$ & 1.57E-03 & $1.56 \mathrm{E}-03$ \\
\hline $\mathrm{Sr}$ & [5.12E-07] & [1.18E-06] & [1.08E-06] & [1.29E-06] & [1.24E-06] & [1.14E-06] & [9.42E-07] \\
\hline $\mathrm{U}$ & $<2.01 \mathrm{E}-05$ & [7.29E-05] & [7.05E-05] & [8.09E-05] & [6.53E-05] & [6.71E-05] & [6.10E-05] \\
\hline $\mathrm{Zn}$ & [3.75E-05] & $1.30 \mathrm{E}-04$ & 1.30E-04 & $1.36 \mathrm{E}-04$ & $1.32 \mathrm{E}-04$ & 1.30E-04 & $1.32 \mathrm{E}-04$ \\
\hline $\mathrm{Zr}$ & $<1.80 \mathrm{E}-06$ & [2.94E-06] & [1.87E-06] & [4.55E-06] & [3.75E-06] & [5.95E-06] & [4.06E-06] \\
\hline Fluoride & [1.23E-04] & [2.15E-04] & $<4.72 \mathrm{E}-05$ & $<4.85 \mathrm{E}-05$ & [2.06E-04] & $<4.70 \mathrm{E}-05$ & [2.24E-04] \\
\hline Nitrite & $<1.95 \mathrm{E}-05$ & $<1.83 \mathrm{E}-05$ & $<1.83 \mathrm{E}-05$ & $<1.88 \mathrm{E}-05$ & $<1.93 \mathrm{E}-05$ & $<1.82 \mathrm{E}-05$ & $<1.80 \mathrm{E}-05$ \\
\hline Sulfate & $<2.31 \mathrm{E}-05$ & $<2.16 \mathrm{E}-05$ & $<2.16 \mathrm{E}-05$ & $<2.22 \mathrm{E}-05$ & $<2.28 \mathrm{E}-05$ & $<2.15 \mathrm{E}-05$ & $<2.13 \mathrm{E}-05$ \\
\hline Nitrate & $1.70 \mathrm{E}-03$ & 2.03E-03 & $1.99 \mathrm{E}-03$ & $2.16 \mathrm{E}-03$ & $2.13 \mathrm{E}-03$ & 2.01E-03 & $1.92 \mathrm{E}-03$ \\
\hline Phosphate & 4.37E-04 & $4.05 \mathrm{E}-04$ & $4.15 \mathrm{E}-04$ & $3.80 \mathrm{E}-04$ & 3.67E-04 & 3.60E-04 & 3.47E-04 \\
\hline \multicolumn{8}{|c|}{$\begin{array}{l}\text { Analyte uncertainties were typically within } \pm 15 \% \text { ( } 2 \text {-s); results in brackets indicate that the analyte concentrations } \\
\text { were less than the minimum detection limit (MDL) and greater than the estimated quantitation limit (EQL), and } \\
\text { uncertainties were }>15 \% \text {. }\end{array}$} \\
\hline
\end{tabular}


Table L.7. Analyte Concentrations for Composite Wash Solution for Wash of Samples Leached at $80^{\circ} \mathrm{C}$ in $3 \mathrm{M} \mathrm{NaOH}$

\begin{tabular}{|c|c|c|c|}
\hline Analyte & $\begin{array}{c}\text { Concentration } \\
(\mu \mathrm{g} / \mathrm{mL})\end{array}$ & $\begin{array}{c}\text { Opportunistic } \\
\text { Analytes }\end{array}$ & $\begin{array}{c}\text { Concentration } \\
(\mu \mathrm{g} / \mathrm{mL})\end{array}$ \\
\hline $\mathrm{Al}$ & 180 & $\mathrm{Ag}$ & $<0.068$ \\
\hline B & [0.245] & As & $<1.387$ \\
\hline $\mathrm{Bi}$ & $<0.968$ & $\mathrm{Ba}$ & 0.247 \\
\hline $\mathrm{Cd}$ & $<0.110$ & $\mathrm{Be}$ & $<0.002$ \\
\hline $\mathrm{Cr}$ & 0.864 & $\mathrm{Ca}$ & [0.419] \\
\hline $\mathrm{Fe}$ & [0.235] & $\mathrm{Ce}$ & $<0.323$ \\
\hline $\mathrm{Mn}$ & $<0.007$ & Co & $<0.077$ \\
\hline $\mathrm{Na}$ & 4,129 & $\mathrm{Cu}$ & [0.355] \\
\hline $\mathrm{P}$ & $<1.61$ & Dy & $<0.094$ \\
\hline S & $<2.32$ & $\mathrm{Eu}$ & [0.045] \\
\hline $\mathrm{Si}$ & 3.74 & $\mathrm{~K}$ & [3.23] \\
\hline $\mathrm{Sr}$ & [0.004] & $\mathrm{La}$ & $<0.090$ \\
\hline $\mathrm{U}$ & [2.23] & $\mathrm{Li}$ & $<0.019$ \\
\hline $\mathrm{Zn}$ & 1.05 & $\mathrm{Mg}$ & $<0.074$ \\
\hline $\mathrm{Zr}$ & $<0.035$ & Mo & [0.213] \\
\hline Fluoride & $<0.956$ & $\mathrm{Nd}$ & $<0.174$ \\
\hline Nitrite & $<0.896$ & $\mathrm{Ni}$ & {$[0.126]$} \\
\hline Nitrate & 80.1 & $\mathrm{~Pb}$ & $<1.03$ \\
\hline Phosphate & $<1.79$ & $\mathrm{Pd}$ & $<0.203$ \\
\hline Sulfate & $<2.21$ & $\mathrm{Rh}$ & $<0.387$ \\
\hline & & $\mathrm{Ru}$ & $<0.274$ \\
\hline & & $\mathrm{Sb}$ & $<0.645$ \\
\hline & & Se & $<2.26$ \\
\hline & & Sn & $<0.871$ \\
\hline & & $\mathrm{Ta}$ & $<0.548$ \\
\hline & & $\mathrm{Te}$ & $<0.839$ \\
\hline & & Th & [0.452] \\
\hline & & $\mathrm{Ti}$ & $<0.014$ \\
\hline & & $\mathrm{Tl}$ & $<1.23$ \\
\hline & & $\mathrm{V}$ & {$[0.071]$} \\
\hline & & $\mathrm{W}$ & $<0.613$ \\
\hline & & $\mathrm{Y}$ & [0.017] \\
\hline
\end{tabular}



Appendix M

\section{Group 3 and 4 Reference and Concurrence Letters}

for Parametric Leaching 


\section{Appendix M}

\section{Group 3 and 4 Reference and Concurrence Letters for Parametric Leaching}

The following reference and concurrence letters are shown: the letter sent from PNNL to BNI giving the matrix and conditions for parametric testing of Group 3, the letter sent from BNI to PNNL giving concurrence to proceed with the parametric testing of Group 3, the letter sent from PNNL to BNI giving the matrix and conditions for parametric testing of Group 4, the letter sent from BNI to PNNL giving concurrence to proceed with the parametric testing of Group 4, and the letter sent from BNI to PNNL giving concurrence to proceed with the parametric testing of Group 4 with a change in two conditions. 
Letter Sent from PNNL to BNI Giving the Matrix and Conditions for Parametric Testing of Group 3:

\section{Pacific Northwest National Laboratory \\ Operated by Battelle for the U.S. Department of Energy}

January 7, 2008

Mr. Haukur R. Hazen

WTP/RPP-MOA-PNNL-00155

Bechtel National Inc.

2435 Stevens Center Place, MSIN: H4-02

Richland WA 99352

Dear Mr. Hazen:

Subcontract NO. 24590-QL-HC9-WA49-00001 - Project 53019 (WA\#2007-019)

Request for Approval of the Group 3 Caustic Leaching Test Matrix

Purpose:

The purpose of this document is to provide BNI with the necessary information to approve a test matrix for a leaching experiment to be performed with actual sludge samples from the Group 3 REDOX Cladding waste tanks.

Approval of the test matrix is required per Section 6.3.1.1 in Test Plan TP-RPP-WTP-467 Rev 0, Characterization and Small Scale Testing of Hanford Wastes to Support the Development and Demonstration of Leacbing and Ultrafiltration Pretreatment Processes.

\section{Requirements of the Test Plan:}

The test plan requires the following information to be provided for the caustic leaching process:

1) A statistically-designed parametric caustic leach test will be developed and submitted to the R\&T Issue Manager for review and written concurrence from BNI and ORP.

2) The test matrix will define:

a. The $w t \%$ UDS in the initial test aliquots

b. $\mathrm{NaOH}$ concentration, volume, and leach temperature

c. Proposed samples for follow-on characterization

d. Wash conditions for the leached solids that will be forwarded for follow-on characterization including the $\mathrm{NaOH}$ concentration and volume for the three wash steps.

902 Battelle Boulevard • P.O. Box 999 • Richland, WA 99352

Telephone (509) 375-4373 — Email gordon.beeman@pnl.gov — Fax (509) 375-2323 
Mr. Haukur R. Hazen

January 7,2008

Page 2

\section{Recommendations to $\mathrm{BNI}$ :}

\section{Caustic Leaching Tests for Group 3}

Group 3 composite waste is recommended for testing. It is a homogenized mixture of tank wastes from Hanford tanks C-103, C-104, C-105, BY-109, B-018, B-109, and is expected to be high in Gibbsite. Accordingly, this work addresses determination of gibbsite leaching kinetics as described in Section 6.3.1.1 of TP-RPP-WTP-467.

A sample consisting of approximately $14 \mathrm{~g}$ of water-insoluble solids from the Group 3 waste will be taken for this testing effort. All analyses will be performed as indicated in Table 1. Initial preparation of the solids for the leaching experiments will include washing the solids three times in $3 \mathrm{x}$ the volume of solids of $0.01 \mathrm{M} \mathrm{NaOH}$ to remove the water-soluble fraction.

The washed solids will be suspended in a minimum amount of deionized water. One slurry sample will be removed for characterization, and 13 slurry samples will be transferred to individual bottles for the leaching experiments. Each sample will contain $\sim 1 \mathrm{~g}$ of water-insoluble solids, and will be treated with $100 \mathrm{~mL}$ of $\mathrm{NaOH}$ solution (to reach a target of $1 \mathrm{wt} \%$ UDS) under the test conditions shown in Table 1.

Table 1. Group 3 Caustic Leach Testing Conditions

\begin{tabular}{|c|c|c|c|c|}
\hline & & \multicolumn{3}{|c|}{$\begin{array}{c}\text { Number of Samples at } \\
\text { Temperature, }{ }^{\circ} \mathrm{C}\end{array}$} \\
\hline$[\mathrm{NaOH}], \mathrm{M}$ & {$\left[\mathrm{NaNO}_{3}\right], \mathrm{M}$} & 60 & 80 & 100 \\
\hline 1 & 0 & 1 & 1 & 1 \\
\hline 3 & 0 & 1 & 3 & 1 \\
\hline 5 & 0 & 1 & 1 & 1 \\
\hline 3 & 1 & 0 & 1 & 0 \\
\hline 3 & 5 & 0 & 1 & 0 \\
\hline
\end{tabular}

All samples will be shaken for a period of 48 hours in an orbital shaker. One sample of the leachate solution for each condition will be taken at 1, 2, 4, 8, 24, and 48 hours.

After the final analytical samples are taken at 48 hours, samples will be removed from the leaching solutions for analysis.

The three samples digested with $3 \mathrm{M} \mathrm{NaOH}$ at $80^{\circ} \mathrm{C}$ will be processed for further characterization. A sample digested under these conditions is selected because this represents the median conditions examined. These leached solids will be washed three times with $1 \mathrm{x}$ the volume of solids of $0.01 \mathrm{M}$ $\mathrm{NaOH}$. This volume is chosen to remove the soluble components, so that the water-insoluble components can be studied. The combined wash solutions will be sampled for analysis.

The caustic leachate samples and washed solids samples will be submitted for analysis as shown in Table 2. 
Mr. Haukur R. Hazen

January 7, 2008

Page 3

Table 2. Group 3 Caustic Leach Testing Characterization Plan

\begin{tabular}{|c|c|c|c|}
\hline Process Step & Analyte & Solids & Supernatant \\
\hline Initial test aliquots & Wt $\%$ UDS & $\mathrm{X}$ & \\
\hline \multirow{2}{*}{$\begin{array}{l}\text { Caustic-leach time } \\
\text { test }\end{array}$} & ICP metals $(\mathrm{Cr}, \mathrm{P}, \mathrm{Al}, \mathrm{Si})$ & & $\mathrm{X}$ \\
\hline & $\begin{array}{l}\text { Anions (nitrate, sulfate, } \\
\text { phosphate) }\end{array}$ & & $\mathrm{X}$ \\
\hline \multirow{5}{*}{$\begin{array}{l}\text { Caustic-leached } \\
\text { slurry }\end{array}$} & Density & & $\mathrm{X}$ \\
\hline & ICP metals (Cr, $\mathrm{P}, \mathrm{Al}, \mathrm{Si})$ & & $\mathrm{X}$ \\
\hline & $\begin{array}{l}\text { Anions (nitrate, sulfate, } \\
\text { phosphate) }\end{array}$ & & $\mathrm{X}$ \\
\hline & Free hydroxide & & $\mathrm{X}$ \\
\hline & GEA & & $\mathrm{X}$ \\
\hline $\begin{array}{l}\text { Washes following } \\
\text { caustic leach }^{(x)}\end{array}$ & Density & & $\mathrm{X}$ \\
\hline \multirow{4}{*}{$\begin{array}{l}\text { Combined washes } \\
\text { following caustic }\end{array}$} & Density & & $\mathrm{X}$ \\
\hline & ICP metals $(\mathrm{Cr}, \mathrm{P}, \mathrm{Al}, \mathrm{Si})$ & & $\mathrm{X}$ \\
\hline & $\begin{array}{l}\text { Anions (nitrate, phosphate, } \\
\text { sulfate) }\end{array}$ & & $\mathrm{X}$ \\
\hline & TDS & & $\mathrm{X}$ \\
\hline \multirow{2}{*}{$\begin{array}{l}0.01 \mathrm{M} \mathrm{NaOH} \\
\text { rinse }^{(\mathrm{a})}\end{array}$} & Density & & $\mathrm{X}$ \\
\hline & $\operatorname{ICP}(\mathrm{Al})$ & & $\mathrm{X}$ \\
\hline \multirow{9}{*}{$\begin{array}{l}\text { Caustic-leached and } \\
\text { washed solids }{ }^{(2)}\end{array}$} & ICP metals $(\mathrm{Cr}, \mathrm{P}, \mathrm{Al}, \mathrm{Si})$ & $\mathrm{X}$ & \\
\hline & GEA & $\mathrm{X}$ & \\
\hline & Total alpha & $\mathrm{X}$ & \\
\hline & $\mathrm{Pu}$ & $\mathrm{X}$ & \\
\hline & $\mathrm{U} / \mathrm{KPA}$ & $\mathrm{X}$ & \\
\hline & ${ }^{90} \mathrm{Sr}$ & $\mathrm{X}$ & \\
\hline & Total beta & $\mathrm{X}$ & \\
\hline & XRD, SEM, TEM & $\mathrm{X}$ & \\
\hline & PSD, BET & $\mathrm{X}$ & \\
\hline
\end{tabular}


Mr. Haukur R. Hazen

January 7, 2008

Page 4

If you have any questions, please contact Reid Peterson on 376-5340.

Sincerely,

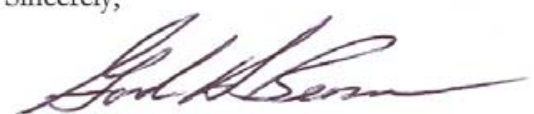

Gordon H. Beeman, Manager

RPP-WTP Support Program

GHB: $\mathrm{c}^{2}$

cc: $\quad$ SM Barnes (BNI)

RA Peterson (PNNL)

PS Sundar (BNI)

Project File/LB 


\section{Letter sent to PNNL from BNI giving concurrence to proceed with parametric testing of Group 3:}

From: Barnes, Steven M

Sent: Wednesday, January 16, 2008 10:20 AM

To: 'Peterson, Reid A'

Cc: Sundar, Parameshwaran S

Subject: RE: Group 3 Parametric Leach Test Matrix

Reid, this email is the follow-up to our verbal authorization to proceed with Group 3 as described in the subject test matrix. Steve

From: Sundar, Parameshwaran S

Sent: Wednesday, January 16, 2008 8:21 AM

To: Barnes, Steven M

Cc: 'Peterson, Reid A'

Subject: FW: Group 3 Parametric Leach Test Matrix

Importance: High

STEVE:

Just a reminder for you to send your concurrence to Reid Peterson on the Group 3 parametric leach test matrix.

SUNDAR

rom: Gilbert, Robert A (Rob) [mailto:Robert_A_Rob_Gilbert@RL.gov]

Sent: Thursday, January 10, 2008 8:45 AM

To: Sundar, Parameshwaran S

Cc: Barnes, Steven M; Peterson, Reid A; Bang, Ricky

Subject: RE: Group 3 Parametric Leach Test Matrix

Steve and Sundar

I have reviewed the proposed Gp. 3 Purex cladding waste sludge parameteric leach test matrix and concur. Please let me know if the project has substantive comments that could change the matrix.

Thanks

Rob Gilbert

From: Sundar, Parameshwaran S [mailto:pssundar@bechtel.com]

Sent: Wednesday, January 09, 2008 8:27 AM

To: Gilbert, Robert A (Rob)

Cc: Barnes, Steven; Peterson, Reid A

Subject: FW: Group 3 Parametric Leach Test Matrix

ROB:

I am forwarding the request from PNNL for approval of the test matrix for the parametric leaching tests with Group 3 waste. We would appreciate knowing of your comments or concurrence by COB January 11th. Please do let me know if you need more time or wish to discuss this.

Regards,

SUNDAR

From: Sundar, Parameshwaran S

Sent: Friday, January 04, 2008 8:01 AM

To: $\quad$ 'Gilbert, Robert A (Rob)'

Cc: 'Bang, Ricky'; 'Peterson, Reid A'; Barnes, Steven M

Subject: $\quad$ Group 3 Parametric Leach Test Matrix

ROB:

I am attaching the proposed test matrix plan draft from PNNL for Group 3 - Purex Cladding Waste parametric testing. This waste is predominantly gibbsite and the test plan is identical to that proposed and approved earlier for Group 4 - Redox Cladding

Waste. The temperature range from $60-100$ is proposed to obtain slower the kinetics of leaching reaction.

This is for your review and concurrence on the proposed test matrix, prior to BNI approval of it.

Regards,

SUNDAR

<<Group 3 Request for Approval - Parametric Test Matrix - Draft - 121907.doc >> 
Letter sent from PNNL to BNI giving the matrix and conditions for parametric testing of Group 4:

\section{Pacific Northwest National Laboratory \\ Operated by Battelle for the \\ U.S. Department of Energy}

January 7, 2008

Mr. Haukur R. Hazen

WTP/RPP-MOA-PNNL-00154

Bechtel National Inc.

2435 Stevens Center Place, MSIN: H4-02

Richland WA 99352

Dear Mr. Hazen:

Subcontract NO. 24590-QL-HC9-WA49-00001 - Project 53019 (WA\#2007-019)

Request for Approval of the Group 4 Caustic Leaching Test Matrix

Purpose:

The purpose of this document is to provide BNI with the necessary information to approve a test matrix for a leaching experiment to be performed with actual sludge samples from the Group 4 REDOX Cladding waste tanks.

Approval of the test matrix is required per Section 6.3.1.1 in Test Plan TP-RPP-WTP-467 Rev 0, Characterization and Small Scale Testing of Hanford Wastes to Support the Development and Demonstration of Leaching and Ultrafiltration Pretreatment Processes.

Requirements of the Test Plan:

The test plan requires the following information to be provided for the caustic leaching process:

1) A statistically-designed parametric caustic leach test will be developed and submitted to the R\&T Issue Manager for review and written concurrence from BNI and ORP.

2) The test matrix will define:

a. The $w t \%$ UDS in the initial test aliquots

b. $\mathrm{NaOH}$ concentration, volume, and leach temperature

c. Proposed samples for follow-on characterization

d. Wash conditions for the leached solids that will be forwarded for follow-on characterization including the $\mathrm{NaOH}$ concentration and volume for the three wash steps.

902 Battelle Boulevard • P.O. Box 999 • Richland, WA 99352

Telephone (509) 375-4373 Email gordon.beeman@pnl.gov $\mathbf{m}$ Fax (509) 375-2323 
Mr. Haukur R. Hazen

January 7, 2008

Page 2

\section{Recommendations to BNI:}

\section{Caustic Leaching Tests for Group 4}

Group 4 composite waste is recommended for testing. It is a homogenized mixture of tank wastes from Hanford tanks U-201, U-202, U-203, U-204, and U-105, and is expected to be high in Gibbsite. Accordingly, this work addresses determination of gibbsite leaching kinetics as described in Section 6.3.1.1 of TP-RPP-WTP-467.

A sample consisting of approximately $14 \mathrm{~g}$ of water-insoluble solids from the Group 4 waste will be taken for this testing effort. All analyses will be performed as indicated in Table 1. Initial preparation of the solids for the leaching experiments will include washing the solids three times in $3 \mathrm{x}$ the volume of solids of $0.01 \mathrm{M} \mathrm{NaOH}$ to remove the water-soluble fraction.

The washed solids will be suspended in a minimum amount of deionized water. One slurry sample will be removed for characterization, and 13 slurry samples will be transferred to individual bottles for the leaching experiments. Each sample will contain $\sim 1 \mathrm{~g}$ of water-insoluble solids, and will be treated with $100 \mathrm{~mL}$ of $\mathrm{NaOH}$ solution (to reach a target of $1 \mathrm{wt} \%$ UDS) under the test conditions shown in Table 1.

Table 1. Group 4 Caustic Leach Testing Conditions

\begin{tabular}{|c|c|c|c|c|}
\hline & & \multicolumn{4}{|c|}{$\begin{array}{c}\text { Number of Samples at } \\
\text { Temperature, }{ }^{\circ} \mathrm{C}\end{array}$} \\
\hline$[\mathrm{NaOH}], \mathrm{M}$ & {$\left[\mathrm{NaNO}_{3}\right], \mathrm{M}$} & 60 & 80 & 100 \\
\hline 1 & 0 & 1 & 1 & 1 \\
\hline 3 & 0 & 1 & 3 & 1 \\
\hline 5 & 0 & 1 & 1 & 1 \\
\hline 3 & 1 & 0 & 1 & 0 \\
\hline 3 & 5 & 0 & 1 & 0 \\
\hline
\end{tabular}

All samples will be shaken for a period of 48 hours in an orbital shaker. One sample of the leachate solution for each condition will be taken at $1,2,4,8,24$, and 48 hours.

After the final analytical samples are taken at 48 hours, samples will be removed from the leaching solutions for analysis.

The three samples digested with $3 \mathrm{M} \mathrm{NaOH}$ at $80^{\circ} \mathrm{C}$ will be processed for further characterization. A sample digested under these conditions is selected because this represents the median conditions examined. These leached solids will be washed three times with $1 \mathrm{x}$ the volume of solids of $0.01 \mathrm{M}$ $\mathrm{NaOH}$. This volume is chosen to remove the soluble components, so that the water-insoluble components can be studied. The combined wash solutions will be sampled for analysis.

Leachate from $80^{\circ} \mathrm{C}$ and $3 \mathrm{M} \mathrm{NaOH}$ test will have additional testing for $\mathrm{Al}$ stability: 
Mr. Haukur R. Hazen

January 7, 2008

Page 3

Leachate will be subdivided into 4 samples diluted with DI water in ratios of volume leachate:volume DI water of 1:0, 1:1,1:6, and 1:16. Solutions will be observed for evidence of precipitation at $1,3,5$, and 14 days. On each day, solution turbidity will be measured, and samples will be removed and filtered. Filtrates from one of the 4 samples will be analyzed for $\mathrm{Al}$ content. The rate of $\mathrm{Al}$ precipitation will be determined for the analyzed sample.

The caustic leachate samples, washed solids, and $\mathrm{Al}$ stability leachate samples will be submitted for analysis as shown in Table 2.

Table 2. Group 4 Caustic Leach Testing Characterization Plan

\begin{tabular}{|c|c|c|c|}
\hline Process Step & Analyte & Solids & Supernatant \\
\hline Initial test aliquots & Wt $\%$ UDS & $\mathrm{X}$ & \\
\hline \multirow{2}{*}{$\begin{array}{l}\text { Caustic-leach time } \\
\text { test }\end{array}$} & ICP metals (Cr, P, Al, Si) & & $\mathrm{X}$ \\
\hline & Anions (nitrate, sulfate, phosphate) & & $\mathrm{X}$ \\
\hline \multirow{5}{*}{$\begin{array}{l}\text { Caustic-leached } \\
\text { slurry }\end{array}$} & Density & & $\mathrm{X}$ \\
\hline & ICP metals $(\mathrm{Cr}, \mathrm{P}, \mathrm{Al}, \mathrm{Si})$ & & $\mathrm{X}$ \\
\hline & Anions (nitrate, sulfate, phosphate) & & $\mathrm{X}$ \\
\hline & Free hydroxide & & $\mathrm{X}$ \\
\hline & GEA & & $\mathrm{X}$ \\
\hline $\begin{array}{l}\text { Washes following } \\
\text { caustic leach }\end{array}$ & Density & & $\mathrm{X}$ \\
\hline \multirow{4}{*}{$\begin{array}{l}\text { Combined washes } \\
\text { following caustic } \\
\text { leach }\end{array}$} & Density & & $\mathrm{X}$ \\
\hline & ICP metals ( $\mathrm{Cr}, \mathrm{P}, \mathrm{Al}, \mathrm{Si})$ & & $\mathrm{X}$ \\
\hline & Anions (nitrate, phosphate, sulfate) & & $\mathrm{X}$ \\
\hline & TDS & & $\mathrm{X}$ \\
\hline \multirow{2}{*}{$\begin{array}{l}0.01 \mathrm{M} \mathrm{NaOH} \\
\text { rinse }^{(\mathrm{a})}\end{array}$} & Density & & $\mathrm{X}$ \\
\hline & $\mathrm{ICP}(\mathrm{Al})$ & & $\mathrm{X}$ \\
\hline \multirow{9}{*}{$\begin{array}{l}\text { Caustic-leached and } \\
\text { washed solids }{ }^{(2)}\end{array}$} & ICP metals (Cr, P, Al, Si) & $\mathrm{X}$ & \\
\hline & GEA & $\mathrm{X}$ & \\
\hline & Total alpha & $\mathrm{X}$ & \\
\hline & $\mathrm{Pu}$ & $\mathrm{X}$ & \\
\hline & $\mathrm{U} / \mathrm{KPA}$ & $\mathrm{X}$ & \\
\hline & ${ }^{90} \mathrm{Sr}$ & $\mathrm{X}$ & \\
\hline & Total beta & $\mathrm{X}$ & \\
\hline & XRD, SEM, TEM & $\mathrm{X}$ & \\
\hline & PSD, BET & $\mathrm{X}$ & \\
\hline \multirow[b]{2}{*}{ Al stability leachate } & Solution Turbidity & & $\mathrm{X}$ \\
\hline & $\operatorname{ICP}(\mathrm{Al})^{(\mathrm{B})}$ & & $\mathrm{X}$ \\
\hline \multicolumn{4}{|c|}{$\begin{array}{l}\text { (a) The solids washing and characterization will be conducted on selected samples as } \\
\text { defined in the test matrix. } \\
\text { (b) The ICP analysis for } \mathrm{Al} \text { during } \mathrm{Al} \text { stability testing will be conducted on one } \\
\text { selected sample as defined in the test matrix. }\end{array}$} \\
\hline
\end{tabular}


Mr. Haukur R. Hazen

January 7, 2008

Page 4

If you have any questions, please contact Reid Peterson on 376-5340.

Sincerely,



Gordon H. Beeman, Manager

RPP-WTP Support Program

GHB: ${ }^{2}$

cc: $\quad$ SM Barnes (BNI)

RA Peterson (PNNL)

PS Sundar (BNI)

Project File/LB 
Letter sent to PNNL from BNI giving concurrence to proceed with parametric testing of Group 4:

From: Sundar, Parameshwaran S

Sent: Wednesday, December 05, 2007 7:39 AM

To: Barnes, Steven M

Subject: FW: Group 4 Redox Cladding Waste Sludge Parametric Test Matrix

Importance: High

STEVE: We have concurrences from all reveiwers on the subject proposal for Group 4 parmetric tests. You may provide our approval to PNNL to proceed with the testing. SUNDAR

From: Gilbert, Robert A (Rob) [mailto:Robert_A_Rob_Gilbert@RL.gov]

Sent: Monday, December 03, 2007 2:42 PM

To: Sundar, Parameshwaran S

Cc: Peterson, Reid A; Barnes, Steven M; Lee, Ernest D (WTP); Peiffer, William; Huckaby, James; Bang, Ricky

Subject: RE: Group 4 Redox Cladding Waste Sludge Parametric Test Matrix

ORP concurs with the test matrix as proposed in the attached file. Please let me know if there are substantive comments within the project regarding the subject Group 4 test matrix.

Thanks

Rob Gilbert

From: Sundar, Parameshwaran S [mailto:pssundar@bechtel.com]

Sent: Tuesday, November 27, 2007 11:26 AM

To: Lee, Ernest; Peiffer, William; Gilbert, Robert A (Rob); Bang, Ricky; Huckaby, James

Cc: Peterson, Reid A; Barnes, Steven

Subject: RE: Group 4 Redox Cladding Waste Sludge Parametric Test Matrix

I mportance: High

\section{GENTS:}

I am attaching the draft letter from PNNL requesting approval of the test matrix for teh parametric testing with the Group 4 Redox Cladding Waste sludge sample.

Please note that we had discussed this at our meeting on November 20th. The proposed matrix conforms to the test plan. It is similar to that carried out for Group 5 Redox Sludge except in that the temperature range has been reduced $(60,80$ and $100 \mathrm{C})$ relative to that used with Group 5 (80, 90 and 100C). Group 5 was a predominantly boehmite waste where as the Group 4 sludge is predominantly gibbsite. The lower temperature range is to allow for a slower rate of dissolution.

Please let me have your comments, if any, or your concurrence no later than COB Thursday, November 29. Need less to say I am expecting your concurrence on this proposal.

Thanks,

SUNDAR

<<Group 4 Request for Approval of Parametric Test Matrix - 112607.doc>> 
Letter sent to PNNL from BNI giving concurrence to proceed with parametric testing of Group 4 with a change in test condition:

From: Barnes, Steven M

Sent: Thursday, December 13, 2007 4:11 PM

To: 'Peterson, Reid A'; Sundar, Parameshwaran S

Cc: Snow, Lanee A; Smith, Gary; Meier, Kirsten M; Lee, Ernest D (WTP); Reynolds, Jacob; Peiffer, William; Lowery, Patrick; Robert_A_Rob_Gilbert@orp.doe.gov; Ricky Bang

Subject: RE: Change in Group 4 test condition

Reid,

Please proceed with the remainder of the matrix as planned. We will discuss at the group meeting next week if this data point needs to be executed with new waste or to pick up during CUF testing.

Also, please proceed with the CAR for this event as we discussed.

Steve

From: Peterson, Reid A [mailto:reid.peterson@pnl.gov]

Sent: Thursday, December 13, 2007 3:24 PM

To: Sundar, Parameshwaran S

Cc: Barnes, Steven M; Snow, Lanee A; Smith, Gary; Meier, Kirsten M

Subject: Change in Group 4 test condition

Sundar,

Due to an experimental mix-up, we have changed one of the conditions in the Group 4 test matrix. 5 molar hydroxide was accidentally added to the $5 \mathrm{M} \mathrm{NaNO} 3$ sample - in place of the target $3 \mathrm{M} \mathrm{OH}$. I believe that we will still get an accurate measure of the nitrate impact on gibbsite dissolution kinetics. All of the $80 \mathrm{C}$ tests are either complete or underway. The 60 and $100 \mathrm{C}$ tests will be done next week. I propose that we proceed with the testing as is. Please let me know if you concur.

Reid.

Table 1. Group 4 Caustic Leach Testing Conditions

Number of Samples at Temperature, ${ }^{\circ} \mathrm{C}$

$[\mathrm{NaOH}], \mathrm{M} \quad[\mathrm{NaNO}], \mathrm{M} \quad 60 \quad 80 \quad 100$

$\begin{array}{lllll}1 & 0 & 1 & 1 & 1\end{array}$

$\begin{array}{lllll}3 & 0 & 1 & 3 & 1\end{array}$



$\begin{array}{lllll}3 & 1 & 0 & 1 & 0\end{array}$

$\begin{array}{lllll}3 \underline{5} & 5 & 0 & 1 & 0\end{array}$


PNNL-18054

WTP-RPT-167, Rev. 0

\section{Distribution}

No. of

Copies

OFFSITE
No. of

Copies

ONSITE

$17 \quad$ Pacific Northwest National Laboratory

L. A. Snow (2) P7-25

E. C. Buck

P7-27

A. J. Casella

P7-25

J. V. Crum

K6-24

R. C. Daniel

P7-22

K. Draper

K6-75

M. K. Edwards

P7-25

S. K. Fiskum

P7-25

L. K. Jagoda

K6-24

A. E. Kozelisky

P7-25

D. E. Kurath

P7-28

P. J. MacFarlan

P7-27

R. A. Peterson

P7-22

R. G. Swoboda

P7-22

Information Release

Project File

P8-55

K3-52

$4 \quad$ Bechtel National, Inc.

WTP R\&T Docs (2)

$\mathrm{H} 4-02$

P. S. Sundar

$\mathrm{H} 4-02$

S. Barnes

H4-02 